DESENVOLVIMENTO DE PRENSA PARA CONFORMAÇÃO SUPERPLÁSTICA COM SISTEMA DE CONTROLE IN SITU E TEMPO REAL DE PRESSÃO E DE TEMPERATURA E COM MÓDULO DE MONITORAMENTO DA DEFORMAÇÃO POR CORRELAÇÃO DIGITAL DE IMAGEM 


\section{DESENVOLVIMENTO DE PRENSA PARA CONFORMAÇÃO SUPERPLÁSTICA COM SISTEMA DE CONTROLE IN SITU E TEMPO REAL DE PRESSÃO E DE TEMPERATURA E COM MÓDULO DE MONITORAMENTO DA DEFORMAÇÃO POR CORRELAÇÃO DIGITAL DE IMAGEM}

\author{
Tese apresentada à Escola Politécnica da \\ Universidade de São Paulo para obtenção do \\ título de Doutor em Ciência.
}

Área de concentração: Engenharia Mecânica de Projeto e Fabricação

Orientador: Prof. Dr. Gilmar Ferreira Batalha

São Paulo 
Este exemplar foi revisado e alterado em relação à versão original, sob responsabilidade única do autor e com anuência de seu orientador.

São Paulo, de de

Assinatura do autor:

Assinatura do orientador:

Marinho, Erick Petta

DESENVOLVIMENTO DE PRENSA PARA CONFORMAÇÃO

SUPERPLÁSTICA COM SISTEMA DE CONTROLE IN SITU E TEMPO REAL DE PRESSÃO E DE TEMPERATURA E COM MÓDULO DE MONITORAMENTO DA DEFORMAÇÃO POR CORRELAÇÃO DIGITAL DE IMAGEM. / E. P. Marinho -- versão corr. -- São Paulo, 2016. $291 \mathrm{p}$.

Tese (Doutorado) - Escola Politécnica da Universidade de São Paulo. Departamento de Engenharia Mecatrônica e de Sistemas Mecânicos.

1.Prensas (Instrumentação; Controle) 2.Conformação mecânica 3.Ensaios dos materiais 4.Imagem Digital 5.Superplasticidade I.Universidade de São Paulo. Escola Politécnica. Departamento de Engenharia Mecatrônica e de Sistemas Mecânicos Il.t. 
DEDICATÓRIA

A minha esposa e amor da minha vida Aline, Minha fantástica mãe Margareth, meu Irmão e melhor amigo Renan e meu exemplo pai Marinho, pela compreensão de sempre e apoio irrestrito fundamentais para a conclusão desse trabalho. 


\section{AGRADECIMENTOS}

Ao professor Gilmar Ferreira Batalha, pela sempre dedicada e parceira orientação, como também pela amizade.

À empresa Embraer S/A, pela grande oportunidade que me foi concedida em desenvolver a tese com ajuda de uma excelente equipe e infraestrutura, agradecimento especial ao amigo Eng. Alberto Sakata.

Aos amigos Erika Fernanda Prados, Marcio Wagner e Felipe Toloczko pela grande ajuda e companheirismo durante toda a execução do projeto.

Ao professor Roberto Bortolussi pela positiva parceria entre a Escola Politécnica e a FEl.

Ao engenheiro Vicente Massaroti pela ajuda e confiança durante o desenvolvimento da tese.

Aos meus amigos da Poli, em especial aqueles que muito ajudaram ao longo do caminho da tese, Cesar, Agesinaldo, Fabio, Fred e Douglas.

Aos meus amigos de sempre, Jeizimayra, Alan e Bruno, cujo incentivo sempre foi presente.

Aos meus tios e primos, em especial ao Tio Zé e Tia Mary que sempre que precisei muito me apoiaram.

A Deus por me dar TUDO. 


\section{RESUMO}

Esta tese contempla o desenvolvimento de uma prensa para conformação biaxial superplástica com sistema de controle in situ e real time de pressão e de temperatura, como também um módulo de monitoramento de deformação através da técnica de correlação digital de imagem. A referida prensa é capaz de atingir durante a conformação ótimas condições superplásticas através da instrumentação e do controle dedicado dos parâmetros que caracterizam o processo de conformação fluidoestática biaxial, pressão, temperatura e taxa de deformação. São seis os principais temas abordados e desenvolvidos nessa tese: (a) técnicas, métodos e requisitos da superplasticidade da liga de titânio Ti6Al4V; (b) concepção e construção da prensa que atenda aos requisitos do projeto; (c) instrumentação do ferramental; (d) implementação do sistema de controle; (e) definição e aplicação de metodologia de ensaio superplástico para conformação fluidoestática biaxial e (f) fabricação da peça modelo. A aplicação e desenvolvimento do sistema de controle em expansão fluidoestática biaxial envolve desde a escolha das condições de conformação, determinação do ciclo de pressão, implementação de controles dedicados que atendam aos requisitos de conformação até os métodos de determinação dos coeficientes de interesse ( $m, n$ e K). Com tal instrumentação é possível determinar os coeficientes a partir de ensaios biaxiais, ao invés de simplesmente utilizar os coeficientes de ensaios de tração uniaxiais. Realizou-se um ensaio superplástico fluidoestático biaxial de chapas de liga de Ti6AL4V controlado em torno de sua condição ótima. Em suma sobre o controle, o sistema de controle térmico minimiza o intervalo de tempo de estabilização da temperatura, sem sobressinal, reduzindo o tempo de exposição do material superplástico a altas temperaturas; o sistema de controle de pressão aplica um ciclo de pressurização que é responsável por realizar a conformação de forma que resulte em uma taxa de deformação específica que represente a condição de maior índice de sensibilidade a taxa de deformação, assim se caracteriza como ponto ótimo do processo. Os principais resultados são o Ferramental instrumentado e controlado para realização de conformação superplástica em atmosfera controlada e os sistemas de controle de temperatura, pressão e deformação, validados e testados de forma integrada em ensaios de conformação superplástica

Palavras-chave: Superplasticidade. Conformação Superplástica. Instrumentação. Controle. Correlação digital de imagem. Controle in Situ. 


\section{ABSTRACT}

This thesis contemplates the full development of a superplastic biaxial forming Press which contains an in situ and real time pressure and temperature control systems, as well as a deformation monitoring module that applies digital image correlation technique. The Press can achieve optimum superplastic forming conditions supported by dedicated instrumentation and control of the parameters that characterize the superplastic forming process; these parameters are pressure, temperature and strain rate. Six main topics are discussed: (a) techniques, methods and Ti6Al4V alloy superplastic requirements; (b) design and construction of the press that meets the project requirements; (c) Press instrumentation; (d) control system implementation; (e) definition and implementation of a new superplastic test methodology for bulge test and (f) a part model manufacturing. The application and development of the control system in biaxial forming process involves the selection of forming conditions, pressure cycle determination, implementation of dedicated controls that meet the forming requirements, besides methods for calculating important coefficients $(\mathrm{m}$, $\mathrm{n} \mathrm{K}$ ). With the referred instrumentation, it is possible to determine these coefficients from biaxial tests, rather than simply using the uniaxial tensile tests coefficients. A Ti6Al4V alloy fluid static superplastic biaxial test was conducted, controlled around its optimum condition. Summarizing the control system, the thermal control system minimizes the stabilization temperature time, avoiding temperature overshooting, reducing the material time exposure at superplastic temperatures. The pressure control system applies a pressurization cycle, responsible for conducting the forming process, to achieve a specific strain rate. This represents the condition of maximum strain rate sensitivity, thus characterized as optimal process point. The main results are the instrumented and controlled superplastic biaxial forming Press efficient to conduct superplastic forming in a controlled atmosphere, and temperature, pressure and deformation control systems validated and tested in an integrated Superplastic forming tests.

Keywords: Superplasticity. Superplastic Forming. Instrumentation.Control. DIC (digital image correlation). In situ Control. 


\section{LISTA DE FIGURAS}

Figura 1.1. Desenho esquemático mostrando as vantagens e desvantagens do processo de Conformação Superplástica em ligas de Titânio e a metodologia proposta nesse trabalho .......................................................

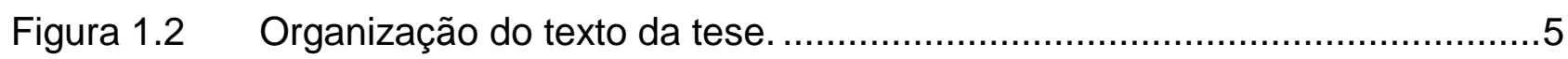

Figura 2.1 Corpo de prova da liga Bi-Sn submetido a uma deformação de 1950\% (PEARSON, 1934)

Figura 2.2 Recorde mundial de tração uniaxial conseguido por Higashi em uma liga de Cu-Al (ROBERT, 2009).

Figura 2.3. Alongamento uniforme alcançado para diferentes materiais ao longo dos anos (VULCAN, 2006)

Figura 2.4. Superplasticidade em um mais amplo espectro de materiais. (NIEH,2007). 10

Figura 2.5. Comparação do resultado de ensaio de tração isotérmico com o de ciclagem térmica. (BURKE, 1981)

Figura 2.6. Variáveis de controle para estudo da janela de Superplasticidade do processo de conformação (temperatura, índice de sensibilidade à taxa de deformação e taxa de deformação) (AKSENOV, 2012)

Figura 2.7. Análise da influência do índice de sensibilidade à taxa de deformação na taxa de redução da área de seção transversal

Figura 2.8. Dependência entre a tensão de escoamento (бe) e a taxa de deformação $(\varepsilon)$ para diferentes temperaturas de conformação. Material: Formall545 (VULCAN,2006).

Figura 2.9. Gráfico da dependência do $\log \sigma \times \log \varepsilon$ e $\mathrm{m} \times \log \varepsilon$ para material convencional (C1 e C1') e superplástico (C2 e C2'). Destaque para a região 2 na qual ocorre a superplasticidade. (BLANDIN, 1996)

Figura 2.11 Queda da tensão de escoamento devido aumento de temperatura para diversas taxas de conformação da liga Ti6Al4V. (JAIN,1991)

Figura 2.12 Deslocamento da região 2 devido aumento de temperatura para diversas taxas de deformação da liga Ti6Al4V. (AKSENOV, 2012)

Figura 2.13. Curvas $m$ versus $\dot{\varepsilon}$ para a liga de titânio Ti-6Al-4V com diferentes tamanhos de grão conformados a $927^{\circ} \mathrm{C}$. (GHOSH, 1982). 
Figura 2.14. Variação da ductilidade em função da taxa de deformação para a liga Ti-6Al-4V com diferentes tamanhos de grão a $775^{\circ} \mathrm{C}$ (a) e $875^{\circ} \mathrm{C}$ (b). (PANTAKAR, 2002)

Figura 2.15. Versão expandida da curva sigmoidal com foco nos mecanismos de deformação, explicita m e p para cada região. (GIULIANO,2011).

Figura 2.16. Desenho esquemático do mecanismo de escorregamento de grãos. (ASHBY, 1973) 28

Figura 2.17. Desenho esquemático mostrando o fluxo de difusão, em volume e nos contornos, durante a mudança de forma do grão no estágio intermediário. (ASHBY, 1973)

Figura 2.18. Relação entre os mecanismos de comutação dos grãos, fluência por discordâncias, e superplasticidade. (ASHBY, 1973)

Figura 2.19. Evolução da microestrutura e textura durante a deformação plástica. (CHANDRA,2000)

Figura 2.20. Evolução da microestrutura e textura durante a deformação superplástica. (CHANDRA,2000)

Figura 2.27. Desenho esquemático do procedimento para calcular o $\mathrm{m}$ a partir de curvas experimentais obtidas dos ensaios mecânicos. (a) tração a quente (b) fluência (GUANABARA, 2005).

Figura 2.28. Método para determinação do valor de m (VULCAN, 2006).

Figura 2.29. Curva do log tensão $x \log$ taxa de deformação para várias temperaturas utilizando diferentes corpos de prova (a) e curva tensão $x$ deformação utilizando o método dos saltos a $800^{\circ} \mathrm{C}$ (b). (GUANABARA, 2005)

Figura 2.30. Curva do log tensão $x \log$ taxa de deformação utilizando um único $\mathrm{CP}$ e diferentes CPDs a $800^{\circ} \mathrm{C}$ (a) e $900^{\circ} \mathrm{C}$ (b). (GUANABARA, 2005) 38

Figura 2.31. Gráfico que compara a amplitude dos resultados oriundos de ensaio de tração e de ensaio de expansão fluidoestática biaxial (KELLER, 2009).....39

Figura 2.32. Resumo das variáveis envolvidas na caracterização reológica utilizando ensaio de expansão fluidoestática biaxial.

Figura 2.33. (a) Diagrama esquemático de expansão fluidoestática biaxial que considera a distribuição de espessura uniforme e (b) esquema de tensões no elemento. (JOVANE, 1968)

Figura 2.34. Desenho de expansão fluidoestática biaxial de trabalho que considera a espessura função dos parâmetros geométricos H e D. (HOLT, 1970) ....41 
Figura 2.35. Esquemático do ensaio de expansão fluidoestática biaxial que considera o gradiente de pressão para justificar a variação de espessura. (GHOSH, 1982).

Figura 2.36. Diagrama esquemático do teste expansão livre (CHENG, 1996)

Figura 2.37. Procedimento para determinar os parâmetros do material através do teste de expansão livre (CHENG, 1996).

Figura 2.38. Desenho esquemático das etapas da expansão fluidoestática em uma matriz fêmea não simétrica. Adaptado (SIEGERT, 1994) 45

Figura 2.39. Desenho esquemático das etapas da expansão fluidoestática em uma matriz macho não simétrica. Adaptado (SIEGERT, 1994).

Figura 2.40. Conformação por sopro, blow forming (GHOSH, 2006).

Figura 2.41. Ferramental tipo prensa chapa para conformação por sopro, acesso do argônio pelo duto inferior.

Figura 2.42. Exemplos de métodos de termo conformação, em (a) conformação em uma matriz fêmea fixa com ajuda de uma matriz móvel macho, e em (b) "snap-back forming" conformação com reversão de pressão, com uma matriz macho que se move em direção ao material. (GHOSH, 2006)

Figura 2.43. Desenho esquemático das partes de uma ferramenta de estampagem profunda, punção-chapa-matriz. (DUTTA, 2005)

Figura 2.44. Fotos das amostras conformadas a 723K, (a) AA7075 não superplástica; (b) e (c) AA7075 superplástica, profundidade de $18.5 \mathrm{~mm}$ e $28.5 \mathrm{~mm}$ respectivamente. (DUTTA, 2005)

Figura 2.45. Desenho esquemático do ferramental com óleo em alta pressão. (ALNAIB, 1970) .52

Figura 2.46. Junção por difusão (PETER, 2003) .53

Figura 2.47. Conformação Superplástica combinada com junção por difusão (SPF/DB), o processo utiliza detalhes pré-alocado onde ocorrerá junção por difusão. (GHOSH, 2006) .

Figura 2.48. Conformação Superplástica combinada com junção por difusão (SPF/DB), o processo utiliza uma etapa de pré-conformação e duas chapas para obter o perfil desejado. (GHOSH, 2006)

Figura 2.49. Operações para juntar três ou mais chapas através dos processos combinado de Conformação Superplástica e junção por difusão. (PETER, 2003). 
Figura 2.50 Liga de titânio superplástica IMI550 (Ti-4AI-4Mo-2Sn-0.5Si) apresentado elevada elongação. (RIDLEY, 2011) 56

Figura 2.51 (a) Fratura superplástica na liga Ti6Al4V devido à instabilidade no escoamento plástico e (b) Falha por cavitação (AA 7575). Elongamento de $900 \%$. (RIDLEY, 1989) .

Figura 2.52 O "SR-71 Blackbird" foi o primeiro avião militar todo de titânio. Esta foto foi tirada no "Dryden Flight Research Center" em 1992, mostra o "SR71" decolando com "shock diamonds" na turbina de exaustão. (FANNING, 2008)

Figura 2.53. Evolução dos materiais utilizados na indústria aeronáutica. (SERRA, 2008).

Figura 2.54. Aumento do uso do titânio na aeronáutica. (HALE, 2010) ..... .58

Figura 2.55. O material certo para a aplicação certa, lema utilizado pelos engenheiros da Boeing na escolha dos materiais do 787. (HALE, 2010)

Figura 2.56. Tensão de escoamento em função da raiz quadrada da soma das impurezas para os quatro Graus de Ti CP. (ANIBAL, 2010)

Figura 2.57 Diagrama de fases binário para o Titânio com diferentes elementos de liga. (DOBRZAŃSKI, 2004)

Figura 2.58 Classificação das ligas de titânio com referência aos estabilizadores $\beta$ : $1-\alpha$ alloys, 2 - near $\alpha$ alloys, 3 - martensitic $\alpha+\beta$ alloys, $4-$ transition $\alpha+\beta$ alloys, $5-$ near $\beta$ alloys, $6-\beta$ alloys. (MOTYKA, 2012)

Figura 2.59

a) Ti - estabilizador- $\beta$ and b) Ti-6Al-4V. (MAY, 2009)

Figura 2.60

Seções isotérmicas do diagrama ternário para Ti-Al-V em $1100^{\circ} \mathrm{C}(\mathrm{a})$, $800^{\circ} \mathrm{C}$ (b) e $550^{\circ} \mathrm{C}$ (c), destaque da posição da liga Ti-6Al-4V (MAY, 2009)

Figura 2.61 Diagrama de fases 3D para classificar esquematicamente as ligas de titânio. (PETER,2003)

Figura 2.62 Ilustração esquemática mostrando o processo de nucleação e crescimento de $\alpha$ para formar um equilíbrio microestrutural $\alpha / \beta$ quando resfriado lentamente de uma temperatura acima de $\beta$-transus. (a) mostra um único grão de $\beta$ que existe acima da temperatura de $\beta$ transus, (b) mostra a nucleação de um grão a logo abaixo da $\beta$-transus, (c) mostra o contorno de grão completo $\alpha$, (d) mostra o crescimento de colônias de lamelas $\alpha$, e finalmente, (e) mostra a nucleação e o 
crescimento de lamelas a enquanto o resfriamento ocorrer. (CLINNING, 2012)

Figura 2.63 Rota do processo para microestrutura equiaxial de ligas de titânio $\alpha+\beta$ recristalizada em baixas temperaturas. (LÜTJERING, 2003)

Figura 2.64 Mecanismo de recristalização para obter microestrutura equiaxial a $800^{\circ} \mathrm{C}$, Ti-6Al-4V. (LÜTJERING, 2003)

Figura 2.65 Microestrutura equiaxial da liga de Ti-6Al-4V recristalizada a $800^{\circ} \mathrm{C}$. (LÜTJERING, 2003) 68

Figura 2.66 Os três tipos básicos de microestruturas da liga Ti-6Al-4V (a) Lamelar, (b) Bimodal e (c) Equiaxial. (MAY, 2009) .68

Figura 2.67 Microestrutura da liga Ti-6AL-4V antes (a) e depois (b) da deformação superplástica nas condições de $800^{\circ} \mathrm{C}$ e taxa de deformação 10-3 s-1. [SIENIAWSKI, 2007]

Figura 2.68 Comparação entre as variações máximas em função da taxa da deformação e temperatura para os casos de atmosfera protegida com argônio e não protegida. (THIRUVARUDCHELVAN, 2005)

Figura 2.69 Micrografia ótica da camada alfa (a) sem proteção de argônio e (b) com proteção de argônio. (THIRUVARUDCHELVAN, 2005)

Figura 2.70 Curvas tensão-deformação verdadeiras da liga Ti-6Al-4V testada em temperaturas entre 750 e $950^{\circ} \mathrm{C}$ e taxa de deformação de 5 x 10-4 s-1. (VANDERHASTEN, 2008)

Figura 2.71 Mapa de deformação da liga Ti-6Al-4V para temperaturas entre temperatura ambiente e $1000^{\circ} \mathrm{C}$ e taxas deformação entre $5 \times 10-4$ e 5 x 10-2 s-1. (DGG - crescimento de grão dinâmico, GBS escorregamento de grãos e DRX - recristalização dinâmica). (VANDERHASTEN, 2008)

Figura 2.72 a) Superfície de revolução de uma chapa deformada; b) Elementos da superfície; c) e d) Tensão atuante na superfície do elemento. (GIULIANO, 2011) .78

Figura 2.73 Tensão tangencial aplicada na calota esférica. (GIULIANO, 2011). .79

Figura 2.74 Fator de não uniformidade (Sb/Sp) durante o processo de conformação por expansão fluidoestática biaxial. (GIULIANO, 2011) 82

Figura 2.75 Parâmetros geométricos envolvidos na expansão fluidoestática biaxial. (GIULIANO, 2011) .82 
Figura 2.76 Parâmetros e teoria necessária para obtenção da curva tensão deformação

Figura 2.77 Comparação dos resultados da curva de pressão[bar] em função do tempo para a) MARC com 800 elementos com controle por taxa de deformação constante b) Abaqus com controle de pressão por tensão constante (linha preta) e por taxa de deformação constante (linha vermelha) (GONÇALVES, 2011)

Figura 2.78 Comparação dos resultados de espessura[mm] em função do tempo para a) MARC com 800 elementos com controle por taxa de deformação constante b) Abaqus com controle de pressão por tensão constante e dados experimentais (GONÇALVES, 2011).

Figura 3.1 Principais tópicos da tese e as devidas interligações entre cada tópico. .94

Figura 3.2 (a) Micrografia da secção transversal da amostra, microestrutura característica do material. (SANTOS,2015) (b) Micrografia da secção transversal da amostra.

Figura 3.3. Desenho esquemático mostrando as dimensões dos corpos de prova. (norma ASTM E2448)

Figura 3.4. Garras de INCONEL utilizadas nos ensaios de tração a quente em atmosfera de argônio.

Figura 3.5. Forno usado para aquecimento e encharcamento de atmosfera com argônio, acoplado a ferramenta de ensaio de tração.

Figura 3.6 Variação da tensão em função da taxa de deformação para 4 valores de temperatura para a liga Ti-6Al-4V.

Figura 3.8 Variação do $m$ em função do logaritmo da taxa de deformação para 4 valores de temperatura para a liga Ti-6Al-4V.

Figura 3.10 Variação da tensão (a) e sensibilidade à taxa de deformação (b) com a taxa de deformação e temperatura para a liga Ti-6Al-4V. Esses dados foram obtidos por tração (ensaio de saltos). (LEE, 1998).

Figura 3.11. Desenho esquemático mostrando os principais módulos de controle (temperatura, pressão e deformação) com destaque para o ferramental superplástico circulado.

Figura 3.12. Desenho da ferramenta - solução 1 .................................................104

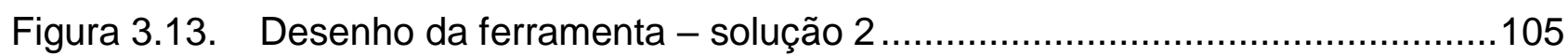

Figura 3.14. Desenho da ferramenta - solução 3 …….........................................106 
Figura 3.15. Simulação gráfica no CATIA de análise estática de esforços para as dimensões comerciais da ferramenta.

Figura 3.16. Dimensões dos flanges comerciais obtidas pela Valmec. 108

Figura 3.17. (a) Flange superior, (b) tubo de pressurização e (c) flange inferior. 108

Figura 3.18. Etapas da montagem do ferramental spf que vai ser colocado dentro do forno para que a conformação aconteça na temperatura superplástica...109

Figura 3.19. Aplicação de nitreto de boro cúbico nos parafusos. 110

Figura 3.20. Arranjo experimental da instrumentação do controle da ferramenta de expansão fluidoestática biaxial.

Figura 3.21. Sistema de projeção usado pela ARAMIS (HARTLEY, 2003) 115

Figura 3.22. Princípio de medição da fotogrametria. (TOMANEK, 2006) 116

Figura 3.23. Técnica de mapeamento do campo de deslocamento. (TOMANEK, 2006)

Figura 3.24. Faceta de 15X15 pixels com área de sobreposição de 2 pixels. (GOM, 2007)

Figura 3.25. Visualização da análise comparativa entre a posição inicial dos pixels (linha branca) e a posição dos pixels pós deformação (tracejado verde) Adaptado (GOM, 2007)

Figura 3.26. Exemplo da escolha de ponto inicial (GOM, 2007)

Figura 3.27. Esquema ilustrativo do cálculo computacional realizado com as facetas (GOM, 2007).

Figura 3.28. Setup experimental do módulo de controle de deformação 122

Figura 3.29. Sistema de dupla anilha para vedação. 125

Figura 3.30. Esquemático da instalação do sistema de alta pressão. 125

Figura 3.31. Espiga da conexão engate rápido....................................................126

Figura 3.32. Selante "SWAK Anaerobic Pipe Thread Sealant"................................126

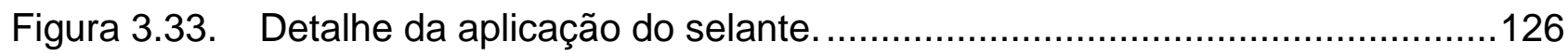

Figura 3.34. Instrumentação da atmosfera positiva de 150mmca de $\mathrm{H} 2 \mathrm{O}$...................127

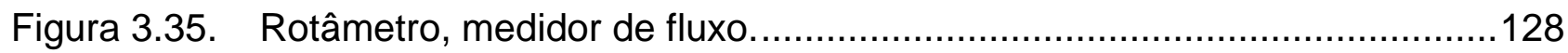

Figura 3.36. Bomba de vácuo, medidor de fluxo e chaves de linha, componentes do sistema de purga e atmosfera positiva .

Figura 3.37. Derivação na linha de alta pressão, para linha de pressão responsável pela atmosfera positiva de argônio dentro do forno

Figura 3.38. Válvula reguladora de pressão SENTRONICPLUS

Figura 3.37. Transdutor de pressão HBM 
Figura 3.40. - Regulador de pressão, série de aplicação especial, alta pressão de saída, simples estágio, latão niquelado.

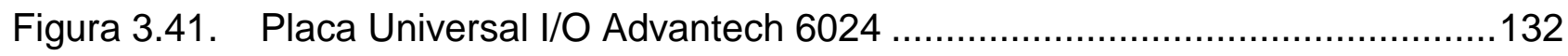

Figura 3.42. Instrumentação do módulo de controle da temperatura..........................133

Figura 3.43. Dados de temperatura do sistema supervisório ....................................134

Figura 3.44. Imagens do processo de fabricação do forno GRION, dimensões úteis: $500 \mathrm{~mm}(\mathrm{~A})$ X $600 \mathrm{~mm}(\mathrm{~L})$ X $600 \mathrm{~mm}(\mathrm{P})$ e dimensões externas: 880 $\mathrm{mm}$ (A) X $1000 \mathrm{~mm}$ (L) $1000 \mathrm{~mm}$

Figura 3.45. (a) Placas cerâmicas internas ao revestimento térmico por onde passaram as resistências de KANTHAL, (b) Imagem interna do forno com o ferramental de bulge posicionado para o ensaio, detalhe no isolamento térmico de fibra cerâmica e nas resistências de KANTHAL espiraladas.

Figura 3.46. Jaqueta de resfriamento 137

Figura 3.47. Visão explodida do esquema preme-gaxeta da jaqueta de resfriamento, como também o detalhe do rebaixo de posicionamento do anel $O$.

Figura 3.48. Serpentina utilizada para resfriamento do sistema de pressurização.......139

Figura 3.49. Localização do sensor do módulo de segurança térmico 139

Figura 3.50 Esquemático dos parâmetros fundamentais superplásticos através da abordagem de controle modularizado.

Figura 3.51. Caracterização da taxa de deformação ótima do processo; (a) ponto de inflexão do gráfico $\log \sigma \times \log \varepsilon$; (b) ponto máximo do gráfico $m \times \log \varepsilon$ (SNIPPE, 2010)

Figura 3.52. Diagrama de bloco dos módulos de controle implementados. 143

Figura 3.53. Diagrama de bloco de um sistema de feedback simples. 144

Figura 3.54. Entrada e saída de controladores ON-OFF. Cada figura mostra o input no eixo horizontal e a saída no eixo vertical. O ON-OFF ideal é mostrado na figura (a), com algumas modificações para zona morta (Dead zone) em (b) e com histerese em (c). (Astrom, 1995).

Figura 3.55. Simulação de um sistema de controle proporcional com realimentação. O diagrama superior mostra o set point $(\mathrm{ysp}=1)$ e a saída do processo (y) para diferentes valores de ganho proporcional $(\mathrm{K}) \mathrm{O}$ diagrama inferior mostra a variável de controle (u) para diferentes valores de ganho. (Astrom, 1995) 
Figura 3.56. Presença de offset e pouca oscilação para controlado proporcional com aumento do ganho.

Figura 3.57. Simulação de um sistema de controle proporcional-integral com realimentação. Considerando o ganho do controlador igual a 1 , o diagrama superior mostra o set point $(y s p=1)$ e a saída do processo (y) para diferentes valores de tempo de integração (Ti). O diagrama inferior mostra a variável de controle $(u)$ para diferentes valores de tempo de integração (Ti). (Astrom, 1995) ...

Figura 3.58. Simulação de um sistema de controle proporcional-integral-derivativo com realimentação. Considerando o ganho $(\mathrm{K})$ do controlador igual a 3 o e o tempo de integração (ti) igual 2, o diagrama superior mostra o set point ( $y s p=1)$ e a saída do processo (y) para diferentes valores de tempo derivativo $(\mathrm{Td})$. O diagrama inferior mostra a variável de controle (u) para diferentes valores de tempo derivativo (Td). (Åström, 1995)

Figura 3.59. Diagrama de blocos do sistema de controle de pressurização da prensa de Conformação Superplástica desenvolvida na tese.

Figura 3.60. Ação do controlador PID. No tempo t, o termo proporcional depende do valor instantâneo do erro. A porção integral do feedback baseia-se na integral do erro até o tempo $t$ (área sombreada). $O$ termo derivativo estima o crescimento ou o decaimento do erro ao longo do tempo, através da taxa de variação do erro. (Åström, 2008)

Figura 3.61. Exemplos de resposta em degrau. (Åström, 1995) .................................153

Figura 3.62. Resposta em degrau do sistema de pressurização de estudo da tese.....153

Figura 3.63. Determinação gráfica de um modelo de dois parâmetros para a resposta em degrau de um sistema estável. (Åström, 1995)..

Figura 3.64. Determinação gráfica de um modelo de três parâmetros para a resposta em degrau de um sistema estável. (Åström, 1995)

Figura 3.65. Determinação gráfica dos parâmetros do modelo de três parâmetros para a resposta em degrau do sistema de pressurização da tese.

Figura 3.66. Determinação gráfica dos parâmetros do modelo de três parâmetros para a resposta em degrau do sistema de pressurização da tese.

Figura 3.67. Sistema de controle PID em malha fechado. 159

Figura 3.68. Sistema de controle PID em malha fechado representado no domínio do tempo 
Figura 3.69. Simulação da reposta em degrau do sistema com controlador proporcional com parâmetros de Ziegler-Nichols

Figura 3.70. Simulação da reposta em degrau do sistema com controlador proporcional-integral com parâmetros de Ziegler-Nichols

Figura 3.71. Simulação da reposta em degrau do sistema com controlador proporcional-integral-derivativo com parâmetros de Ziegler-Nichols.

Figura 3.72. Calibração do controle de pressurização da peça modelo como controlador proporcional -integral sem ajuste dos parâmetros

Figura 3.73. Ação do controlador PI no controle da pressurização da peça modelo com parâmetros de Ziegler Nichols ajustados.

Figura 3.74. Simulação da reposta em degrau do sistema com controlador proporcional-integral com ajuste dos parâmetros de Ziegler-Nichols .......162

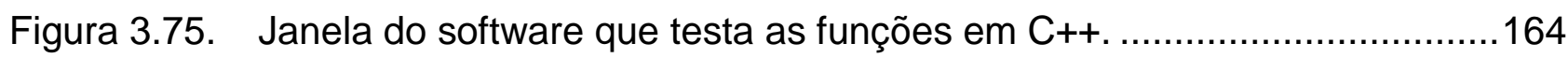

Figura 3.76. Janela de comando do software APAX...............................................165

Figura 3.77. Janela de eventos do sistema de aquisição. .......................................166

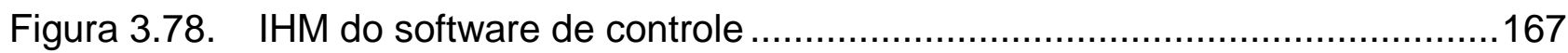

Figura 3.79. Esquema de ligações para o transdutor de pressão H8AP da HBM de ponte completa.

Figura 3.80. Representação da saída "programming Interface" e do conector M12 ....171

Figura 3.81. Resultado do controle da válvula sem alterações nas configurações de fábrica referentes a fundo de escala.

Figura 3.82. Conceito de sensibilidade em controle.

Figura 3.83. Janela de parâmetros relacionados ao "Setpoint" da válvula. 173

Figura 3.84. Sinal medido no teste de pressurização linear de 0-5 Bar.

Figura 3.85. Janela do Data Acquisition Software e janela dos parâmetros relacionados às variáveis de controle.

Figura 3.86. Curva de pressão por tempo após alterações no controle. 176

Figura 3.87. Melhor resultado de Curva de pressão por tempo obtido para curva de pressurização da Superplasticidade do PbSn.

Figura 3.88. Melhoria do controle de pressão devido a mudanças nos parâmetros de controle do controlador PID da válvula.

Figura 3.89 Exemplo da utilização do ARAMIS durante o início da expansão fluidoestática à temperatura ambiente utilizando o material PbSn60.

Figura 3.90 Exemplo da utilização do ARAMIS nos estágios finais da expansão fluidoestática à temperatura ambiente utilizando o material PbSn60. 
Figura 3.91 Estágio 9 de 122 de ensaio de verificação do acompanhamento do pixel durante a conformação.

Figura 3.92 Estágio 40 de 122 de ensaio de verificação do acompanhamento do pixel durante a conformação.

Figura 3.93 Estágio 103 de 122 de ensaio de verificação do acompanhamento do pixel durante a conformação.

Figura 3.94 Estágio 121 de 122 de ensaio de verificação do acompanhamento do pixel durante a conformação.

Figura 3.95 Instrumentação da ARAMIS para ensaio com sistema de medição ótica com a calibração definida e melhoria dos resultados pós-calibração. ......180

Figura 3.96 Exemplo da utilização do ARAMIS durante o início da expansão fluidoestática à temperatura ambiente utilizando o material PbSn60 com a calibração definida.

Figura 3.97 Exemplo da utilização do ARAMIS durante o final da expansão fluidoestática à temperatura ambiente utilizando o material PbSn60 com a calibração definida.

Figura 3.98 Montagem experimental e posicionamento do sistema de correlação de imagem digital nos ensaios de superplasticidade da liga de PbSn.

Figura 3.99 Faceta de lado 4 com pontos adjacentes 184

Figura 3.100 Tintas ULFALUX® utilizadas para produzir o padrão estocástico característica da medição do sistema de correlação digital de imagem ARAMIS.

Figura 3.101 Luminosidade resultante do aquecimento do titânio na temperatura de $925^{\circ} \mathrm{C}$ observado pela janela do forno.

Figura 3.102 Cristalinidade da janela de vidro do forno a $930^{\circ} \mathrm{C}$. 186

Figura 3.103 Curvas dos sinais de temperatura do termopar em contato com a peça (temperatura controlada, $820^{\circ} \mathrm{C}$, curva inferior flat) e do termopar junto ao meio próximo a uma das paredes do forno (curva superior oscilando $\left.\mathrm{em}+/-0.5^{\circ} \mathrm{C}\right)$.

Figura 3.104 Diagrama de fases do sistema PbSn. (FRANCHITTI, 2006) ... 188

Figura 3.105 Liga PbSn60 fundida e laminada. A seta indica a direção laminação e a vareta tem dimensões $25 \times 60 \times 8 \mathrm{~mm}$

Figura 3.106 Fotografia da ferramenta utilizada no ensaio de expansão fluidoestática biaxial da liga PbSn60. 
Figura 3.107 Setup dos primeiros ensaios de bulge à pressão de 0,5 Bar. Detalhe das câmeras e sua iluminação dedicada.

Figura 3.108 Curva de pressão exemplo utilizada para avaliar o ensaio a taxa de deformação constante.

Figura 3.109 Importância da caracterização reológica

Figura 3.110 Estratégia de ensaio de caracterização dos materiais utilizado por AOURA. Adaptado (AOURA, 2004).

Figura 3.111 Esquema de ensaio de expansão fluidoestática biaxial para uma peça fina. (AOURA, 2004).

Figura 3.112 Representação esquemática do estado plano de tensão Biaxial usado pelo ARAMIS (GOM,2000)

Figura 3.113 Esquemático descritivo da nova proposta de caracterização reológica de expansão fluidoestática biaxial livre.

Figura 4.1 Curvas tensão versus taxa de deformação (a) e índice de sensibilidade à taxa de deformação $(\mathrm{m})$ versus taxa de deformação de chapas de Ti$6 \mathrm{Al}-4 \mathrm{~V}$ de $2 \mathrm{~mm}$.

Figura 4.2 Curvas índice de sensibilidade à taxa de deformação $(m)$ versus log da taxa de deformação de chapas de Ti-6Al-4V de $2 \mathrm{~mm}$ a $850^{\circ} \mathrm{C}$ e dados da literatura obtidos nessa mesma condição (Lee et al., 1998).

Figura 4.3 Curvas $\sigma \times \varepsilon$ e $\log \dot{\varepsilon} \times \log \sigma$ a $800^{\circ} \mathrm{C}$. As curvas em vermelho correspondem ao segundo ensaio realizado.

Figura 4.4 Curvas $\sigma \times \varepsilon$ e $\log \dot{\varepsilon} \times \log \sigma$ a $850^{\circ} \mathrm{C}$. As curvas em vermelho correspondem ao segundo ensaio realizado.

Figura 4.5 Curvas $\sigma \times \varepsilon$ e $\log \dot{\varepsilon} \times \log \sigma$ a $900^{\circ} \mathrm{C}$. As curvas em vermelho correspondem ao segundo ensaio realizado.

Figura 4.6 Curvas $\sigma \times \varepsilon$ e $\log \dot{\varepsilon} \times \log \sigma$ a $900^{\circ} \mathrm{C}$. As curvas em vermelho correspondem ao segundo ensaio realizado.

Figura 4.7 Diagrama limite de conformação para a última imagem antes da ruptura.

Figura 4.8 Variação de espessura percentual não uniforme monitorada nos estágios 310 (a), 470 (b), 750(c) e 820(d).

Figura 4.9 Monitoramento da falha nas últimas 260 imagens, imagem 1100 (a), 1303 (b), 1351(c) e 1360(d).

Figura 4.10 Curva de pressurização do bulge test de PbSn. (a) Resultado do controle de pressão, (b) curva pressurizada no ensaio de bulge a taxa 
constante e (c) resultado do controle da válvula reguladora de pressão proporcional.

Figura 4.11 Resultado fornecido pelo sistema ARAMIS que afere o ensaio de Conformação Superplástica à taxa constante de 2x10-4 [s-1]

Figura 4.12 Monitoramento da região de deformação não uniforme de espessura nas imagens 200, 400 e na última imagem (1040) antes da ruptura.

Figura 4.13 (a) Altura em função da coordenada da seção transversal (b) Altura em função do tempo (número de imagens = 1 imagem por segundo) para o ponto mais alto do bulge e (c) a análise da altura das duas seções transversais do bulge e indicação da localização do ponto escolhido (Stage point) no bulge.

Figura 4.14 Comparação entre as medições experimentais da redução da espessura do domo e duas abordagens analíticas, equações (168) e (169)

Figura 4.15 Comparação entre as medições experimentais e a medição direta destrutiva por contato da redução da espessura de nove pontos ao longo da seção transversal (section 1) do bulge de PbSn.

Figura 4.16 Exemplos dos diagramas limites de conformação para ilustrar a evolução temporal da trajetória de deformação.

Figura 4.17 Tinta e corpo de prova de titânio pintado com o padrão estocástico característico do sistema de correlação digital de imagem ARAMIS.

Figura 4.18. Sequência de montagem do ferramental para ensaio de bulge 219

Figura 4.19. Sequência de posicionamento do ferramental para ensaio de expansão fluido estático biaxial.

Figura 4.20. Posicionamento do termopar em contato com a chapa de titânio. 220

Figura 4.21. Tubo de pressurização vedado na jaqueta de resfriamento através do sistema de gaxeta.

Figura 4.22. Atuação do sistema de controle térmico. 222

Figura 4.23. Detalhe do momento da quebra do vidro. 223

Figura 4.24. Detalhe do contato entre o parafuso e o vidro. .223

Figura 4.25. (a) Curva de entrada do sistema de controle de pressão, (b) Curva do sinal de pressão do ensaio aquisitado pelo transdutor de pressão. 224

Figura 4.26. Resultado do vazamento do cobre da interface de vedação do bulge......225

Figura 4.27. Blank conformado de titânio (Ti6Al4V) resultado do primeiro ensaio........225

Figura 4.28. Usinagem do raio de $6 \mathrm{~mm}$ no local indicado. 
Figura 4.29. Etapas de retrabalho da matriz inferior.

Figura 4.30. Etapas de soldagem da solução para vedação da concepção 2 de ferramental.

Figura 4.31. Detalhe de construção da redução do canal de pressurização.

Figura 4.32. Posicionamento do conjunto soldado (tubo+chapa de sacrifício $+\mathrm{CP}$ de titânio) na matriz inferior e visualização da saida do tubo de titânio onde será conectado o sistema de pressurização.

Figura 4.33. Procedimento de montagem da concepção dois do ferramental.

Figura 4.34. (a) Calibração da ARAMIS através do quartzo ao se utilizar o modelo icônico, (b) Modelo Icônico nas mesmas dimensões da janela do forno e (c) Parâmetros de calibração.

Figura 4.35. Montagem das placas de aço inox $304 \mathrm{com}$ janelas quadradas de área de visualização de $100 \mathrm{~mm} \times 100 \mathrm{~mm}$ com gaxetas de fibra cerâmica e quartzo.

Figura 4.36. Detalhe da quebra do quartzo durante o aquecimento na temperatura interna do forno de $670^{\circ} \mathrm{C}$, com a ferramenta a $550^{\circ} \mathrm{C}$

Figura 4.37. Curva de controle do módulo de pressurização.

Figura 4.38. (a) Detalhe da ruptura, (b) vista superior e (c) lateral do bulge superplástico de Ti6Al4V.

Figura 4.39. Concepção de ferramental para peça aeronáutica. .238

Figura 4.40. Peça modelo aeronáutica para ser conformada superplásticamente com a liga de Ti6Al4V.

Figura 4.41. Matriz superior para conformação da peça aeronáutica superplástica de Ti6Al4V.

Figura 4.42. Evolução do sistema de controle devido alteração dos parâmetros do controlador do sistema de pressurização de alta pressão.

Figura 4.43. Curva de controle do módulo de pressurização após tuning do controlador proporcional integral com parâmetros de Ziegler-Nichols

Figura 4.44. (a), (b) Vista em perspectiva da peça conformada, (c) vista superior.

Figura 4.45. Evolução do módulo de monitoramento da deformação.

Figura 4.46. (a) Detalhe da proteção térmica do módulo antigo (b) detalhe do aumento da proteção térmica do módulo final.

Figura 4.47. ARAMIS realizando a medição de deformação durante a Conformação Superplástica através do módulo de monitoramento de deformação.......243

Figura 4.48. Detalhe do número de pontos de fixação. 
Figura 4.49. Detalhe do quartzo utilizado no módulo de monitoramento de deformação.

Figura 4.50. Módulo de monitoramento de deformação durante Conformação Superplástica na temperatura de $927^{\circ} \mathrm{C}$

Figura 4.51. Exemplo de medição de deformação através do módulo de monitoramento de deformação, os pontos amarelos representam os pixeis que foram mapeados e acompanhados ao longo da deformação.

Figura 4.52. Bulge conformado superplásticamente no ensaio de validação do módulo de monitoramento de deformação.

Figura 8.1. Translação (u) e deformação de um elemento de linha .272

Figura 8.2 Deformação sofrida e representada pelo tensor $U$ 274

Figura 8.3 Definição de ângulo de cisalhamento .274

Figura 8.4 Definição do sistema de coordenadas, utilizando a deformação de uma área unitária (GOM, ARAMIS User Manual - Software - ARAMIS v6.1 and higher, 2007)

Figura 8.5 Análise da vizinhança para cálculo da deformação 2D (GOM, 2007) ......277

Figura 8.6 Definição do sistema 3D de coordenada de deformação da superfície local não deformada (GOM, ARAMIS User Manual - Software ARAMIS v6. 1 and higher, 2007)

Figura 8.7 Definição do sistema 3D de coordenada de deformação da superfície local (GOM, ARAMIS User Manual - Software - ARAMIS v6.1 and higher, 2007)

Figura 8.8 Etapas de cálculos necessários para cálculo das deformações ...............281

Figura 8.9 Faceta de lado 4 com pontos adjacentes .281 


\section{LISTA DE TABELAS}

Tabela 2.1. Expoente de Encruamento $n$ e Sensibilidade à taxa de deformação $m$ do material Alumínio para diferentes temperaturas (Vulcan, 2006).

Tabela 2.2. Alguns modelos de superplasticidade propostos baseados no princípio de GBS. (Adaptado de Nieh, 2007)

Tabela 2.3. Diferenças microestruturais e mecânicas em materiais convencionais e superplásticos.. .33

Tabela 2.4. Exemplos de sistema de medição classificados por variável e método .......43

Tabela 2.5. Vantagens e desvantagens na utilização de matrizes macho e fêmea........47

Tabela 2.6. Limite de escoamento, Densidade e Resistência específica de materiais aplicados na indústria aeronáutica. Em destaque a liga Ti-6Al-4V.

Tabela 2.7. Fases observadas em ligas de Titânio. .62

Tabela 2.8. Ligas de titânio com comportamento superplástico. Adaptado (BLANDIN, 1996), (BECK, 2003), (CHOKSHI, 1993), (OLLIVIER, 2003).

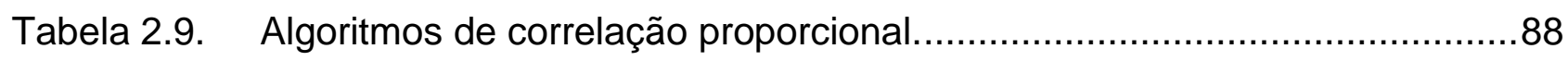

Tabela 2.10. Tabela de correção da pressão dado ymax............................................90

Tabela 3.1. Composição química da liga Ti6AI4V utilizada na tese..............................95

Tabela 3.2. Parâmetros de ensaio de tração uniaxial a quente para determinar a janela superplástica.

Tabela 3.4. Dados de Resistência a Tração em diferentes temperaturas dos aços ABNT 304 e 310

Tabela 3.5. Comparativo entre métodos de cálculo para modelo de deformação (GOM, 2007).

Tabela 3.6. Índice de vazamento do sistema de pressurização a temperatura ambiente

Tabela 3.7. Regra de Ziegler-Nichols baseada na resposta ao degrau da planta. 158

Tabela 3.8. Estimativa de parâmetros de Ziegler-Nichols para sintonia de controle PID. 


\section{LISTA DE ABREVIATURAS}

\begin{tabular}{ll} 
SPF & Superplastic Forming (Conformação Superplástica) \\
MEF & Método de elementos finitos \\
GBS & Grain boundary sliding (deslizamento de contornos de grão) \\
SPF/DB & Superplastic Forming/Diffusion Bonding (Soldagem por difusão) \\
SGG & Static Grain Grown (Crescimento estático de grão) \\
DEGG & Deformation-Enhanced Dynamic Grain Grown (Crescimento \\
& dinâmico dos grãos auxiliado pela deformação) \\
MBD & Mukherjee-Bird-Dorn \\
MS & Martensitic Start Temperature \\
DGG & Dynamic Grain Grown (Crescimento dinâmico de grão) \\
DRX & Dynamic Recrystalization (Recristalização dinâmica) \\
HC & Hexagonal Compacta \\
CCC & Cúbica de corpo centrado \\
FSS & Fine Structure Superplasticity \\
ISS & Internal-stress Superplasticity \\
IHM & Interface Homem Máquina \\
DFA & Design For Assembly \\
DAS & Data Acquisition Software \\
DFD & Design For Disassembly \\
PID & Proporcional Integral Derivativo \\
\hline
\end{tabular}




\section{LISTA DE SÍMBOLOS}

A Seção transversal do corpo de prova $\left[\mathrm{m}^{2}\right]$

a Raio da cavidade da chapa expandida por conformação biaxial [m]

$\begin{array}{lll}a_{0} & \text { Semieixo menor inicial da peça elíptica } & \text { [m] }\end{array}$

$b \quad$ Vetor de Burgers $\quad[\mu \mathrm{m}]$

$b_{0} \quad$ Semi-eixo maior inicial da peça elíptica $\quad$ [m]

Cm Constante adimensional que incorpora todos os parâmetros estruturais, menos o tamanho de grão. Chamada de constante de microestrutura e de dependência do mecanismo de deformação

$C_{1} \quad$ Constante

$C_{2} \quad$ Constante

$D_{V} \quad$ Coeficiente de autodifusão volumétrica

$D_{g b 0} \quad$ Fator Pré-exponencial

D Coeficiente de difusão

$D_{g s} \quad$ Coeficiente de difusão dos contornos

d Diâmetro de grão

$d_{0} \quad$ Tamanho de grão inicial $\quad[\mu \mathrm{m}]$

$d_{s} \quad$ Tamanho de grão após certo tempo t $\quad[\mu \mathrm{m}]$

$\begin{array}{lll}e_{0} & \text { Espessura inicial da peça } & \text { [m] }\end{array}$

$\begin{array}{lll}e_{l} & \text { Elongamento total } & \text { [\%] }\end{array}$

e Erro do controle

E Módulo de Young

$F_{g b} \quad$ Contribuição de tensão gerada pelo GBS 
$f \quad$ Contribuição de tensão gerada pelo empilhamento

$f_{0} \quad$ Fração de volume de cavidades em deformação zero

F Força

G Módulo de cisalhamento

$h \quad$ Altura total da peça conformada

$h_{p} \quad$ Altura do domo da calota

$h_{n} \quad$ Coeficientes de Fourier relativos à forma da fronteira

k Constante de Boltzmann

$K \quad$ Constante do material

$K_{p} \quad$ Ganho proporcional

$K_{i} \quad$ Ganho integral

I Comprimento da área útil do corpo de prova

lo Comprimento inicial da área útil do corpo de prova

$m$ Sensibilidade à taxa de deformação da equação de Norton-Hoff

$n \quad$ Expoente de encruamento da equação de Norton-Hoff

$p \quad$ Expoente de crescimento de grão

$P \quad$ Pressão de aplicada na expansão fluidoestática biaxial

$Q_{c} \quad$ Energia de ativação para processo de fluência

Q $\quad$ Energia de ativação

$q \quad$ Expoente de tamanho de grão

$R_{0} \quad$ Raio inicial da peça a ser conformada

$R_{c} \quad$ Raio de curvatura da peça conforma 
$R \quad$ Constante real dos gases

[J. $\left.\mathrm{mol}^{-1} \cdot \mathrm{K}^{-1}\right]$

S Espessura do blank

$\left[\mathrm{m}^{2}\right]$

$T_{H} \quad$ Temperatura homóloga

$T \quad$ Temperatura absoluta de ensaio

$T_{i} \quad$ Tempo de integração

$T_{d} \quad$ Tempo de derivativo

$t \quad$ Tempo

u Variável de controle

y Variável de processo

$y_{s p} \quad$ Set point da variável de processo

$\dot{\bar{U}} \quad$ Taxa de deslizamento de controle difusional

$\alpha_{0} \quad$ Ângulo inicial no topo do domo cônico para identificar a simetria $\left.{ }^{\circ}\right]$

$\beta \quad$ Coeficiente de cavitação dependente do material

$\bar{\beta} \quad$ Função de condição de tensão

ع́ Taxa de deformação

$\varepsilon \quad$ Deformação

$\varepsilon_{l} \quad$ Deformação na direção de tração, eixo z

$\varepsilon_{b} \quad$ Deformação na direção perpendicular a tração, eixo x

$\varepsilon_{S} \quad$ Deformação na direção perpendicular a tração, eixo y

$\varepsilon_{v} \quad$ Deformação verdadeira

$\dot{\varepsilon}_{e q} \quad$ Taxa de deformação equivalente tridimensional

ÉGS Taxa de escorregamento de grãos

$\varepsilon_{\ominus} \quad$ Taxa de deformação tangencial

$\dot{\varepsilon}_{\varphi} \quad$ Taxa de deformação circunferencial

$\delta \quad$ Largura de contorno de grão 
$\lambda \quad$ Comprimento de onda $\quad[\mathrm{nm}]$

v $\quad$ Fração de raio/cavidade do Bulge

$\gamma \quad$ Energia de superfície de contorno de grão

$\varphi \quad$ Ângulo da peça conformada $\left.\quad{ }^{\circ}\right]$

$\rho \quad$ Raio de curvatura da peça conformada na análise analítica $\quad[\mathrm{nm}]$

$\rho_{0} \quad$ Distância inicial do centro do Bulge $\quad[\mathrm{nm}]$

$\Omega \quad$ Volume atômico $\quad\left[\mathrm{nm}^{3}\right]$

$\xi \quad$ Coeficiente da taxa de deformação

$\sigma_{e q} \quad$ Tensão equivalente aplicada no polo [MPa]

$\sigma \quad$ Tensão equivalente uniaxial $\quad$ [MPa]

$\sigma_{a}(\dot{\varepsilon}) \quad$ Tensão por Fluência por discordâncias; $\quad$ [MPa]

$\sigma_{b}(\dot{\varepsilon})$ Tensão para GBS $\quad$ [MPa]

$\sigma_{e} \quad$ Tensão de escoamento $\quad$ [MPa]

$\sigma_{e q} \quad$ Tensão equivalente aplicada no polo $\quad$ [MPa]

$\sigma_{m} \quad$ Tensão média $\quad$ [MPa]

$\sigma_{\theta}$ e $\sigma_{\varphi} \quad$ Tensões tangenciais do estado plano de tensões [MPa]

$\sigma_{t} \quad$ Tensão transversal $\quad$ [MPa]

$\sigma_{0} \quad$ Limite de elasticidade $\quad$ [MPa]

$\sigma_{u} \quad$ Limite de resistência mecânica $\quad$ [MPa]

$\tau_{b}$ Tensão de cisalhamento para GBS [MPa] 


\section{ÍNDICE}

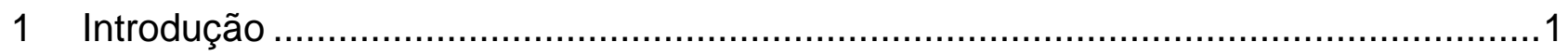

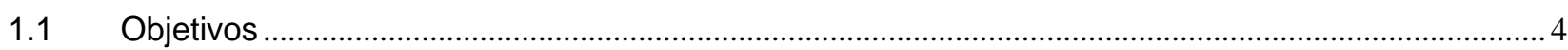

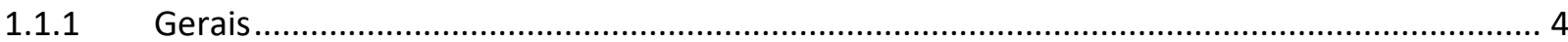

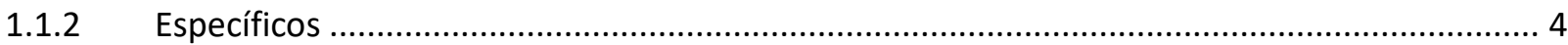

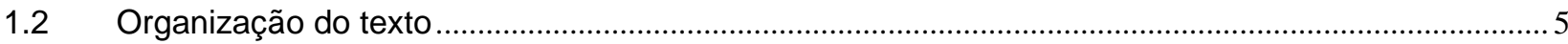

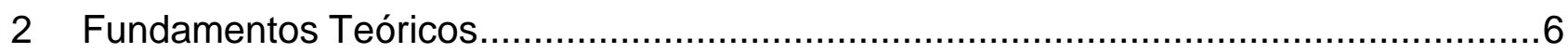

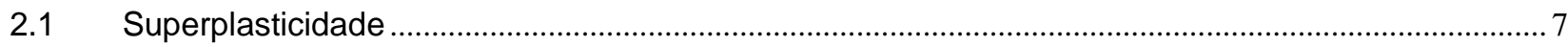

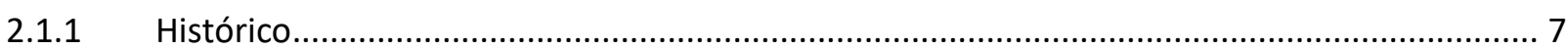

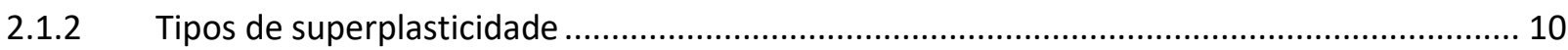

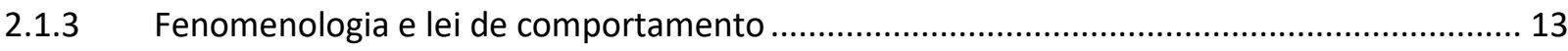

2.1.4 Mecanismo de deformação superplástica ............................................................................. 26

2.1.5 Métodos de Caracterização Reológica ..................................................................................... 35

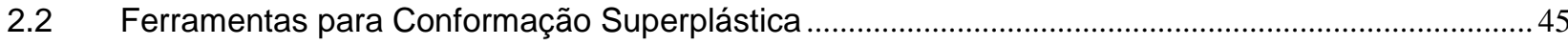

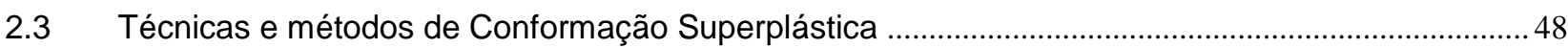

2.3.1 Moldagem por sopro e moldagem a vácuo...................................................................... 48

2.3.2 Termoconformacão - "Thermo Forming” .................................................................................. 50

2.3.3 Estampagem Profunda superplástica - "Deep Drawing SPF" .............................................. 51

2.3.4 Conformação Superplástica e Junção por Difusão ................................................................... 53

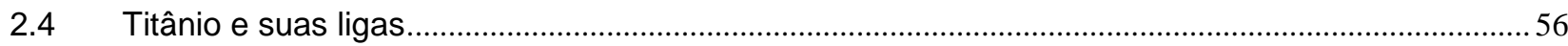

2.4.1 Ligas de Titânio e a indústria aeronáutica .......................................................................... 57

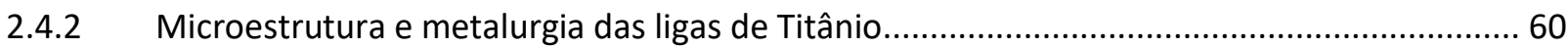

2.4.3 Formação da camada Alfa fragilizante (Alfa-case) ................................................................ 71

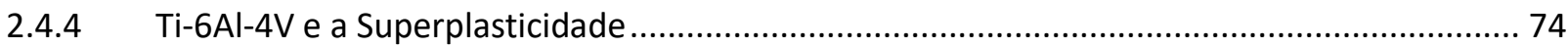

2.5 Modelagem Matemática do processo de Conformação Superplástica de chapas metálicas............76

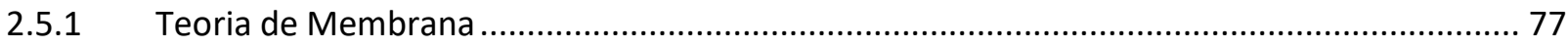

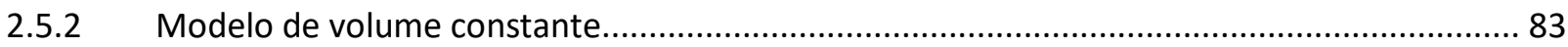

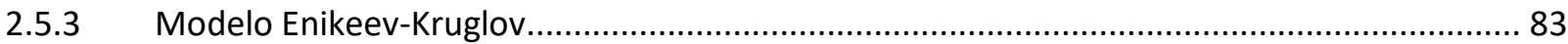

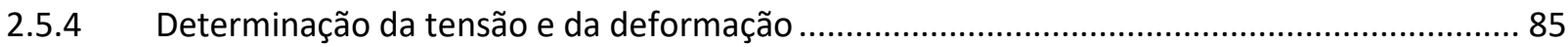

2.6 Modelos de controle de pressão SPF nos métodos de elementos finitos ........................................... 86

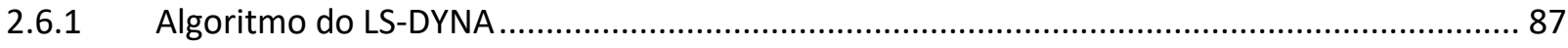

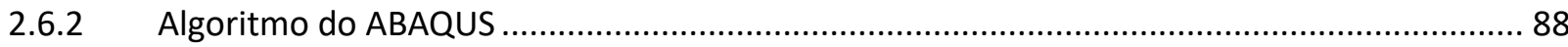

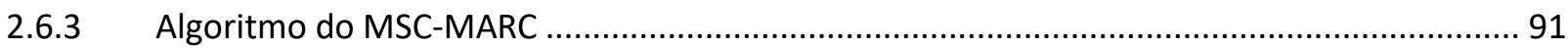

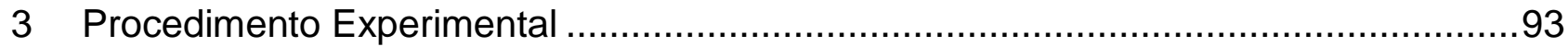

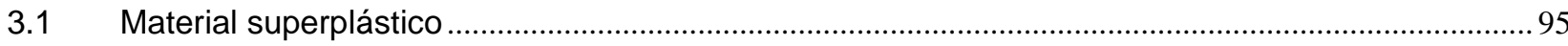

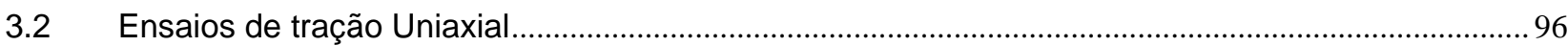


3.3 Ferramenta para o Ensaio de Expansão Fluidoestática Biaxial ........................................................ 101

3.3.1 Descrição da concepção inicial do ferramental superplástico ............................................ 101

3.3.2 Especificações do prensa-chapa ........................................................................................ 102

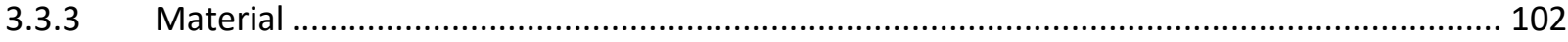

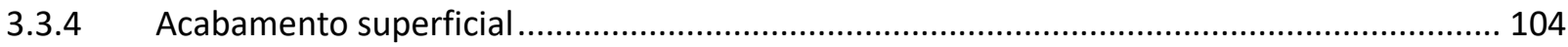

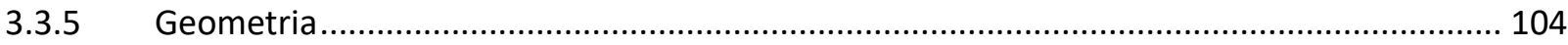

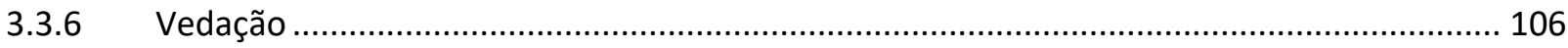

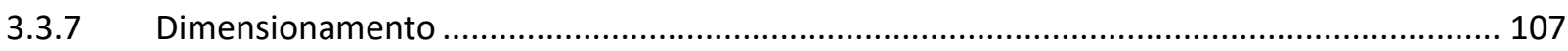

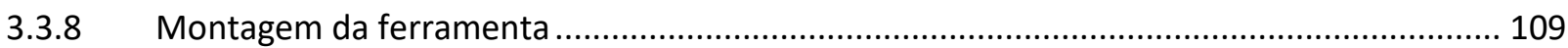

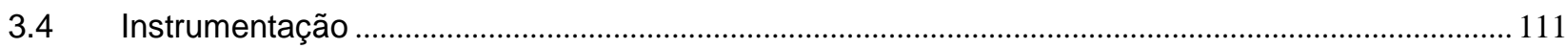

3.4.1 Módulo de controle da deformação..................................................................................... 112

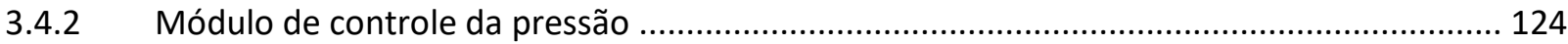

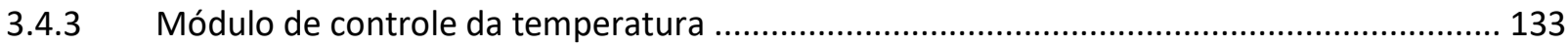

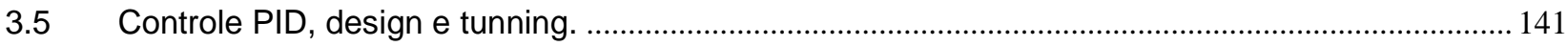

3.5.1 Resumo da abordagem de controle da tese...................................................................... 141

3.5.2 Controle PID - ação proporcional, integral e derivativa ................................................... 144

3.5.3 Ajuste de parâmetros de controladores PID (Tuning- Step response method) .................... 152

3.6 Integração, testes e calibração

3.6.1 Módulo do Sistema de aquisição e atuação .................................................................... 163

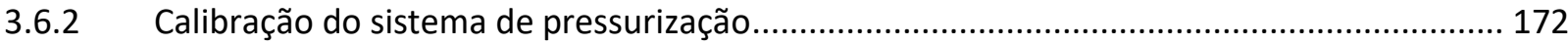

3.6.3 Calibração do sistema de correlação digital de imagem ......................................................... 178

3.6.4 Calibração do sistema de controle térmico..................................................................... 187

3.7 Validação da instrumentação a frio: Superplasticidade da liga PbSn ................................................ 188

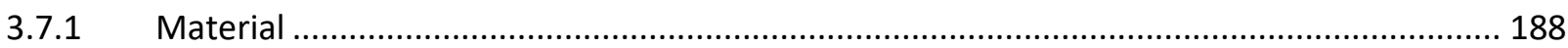

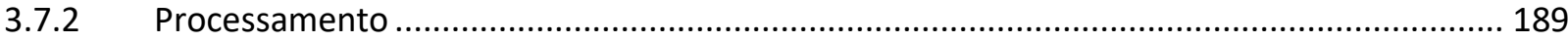

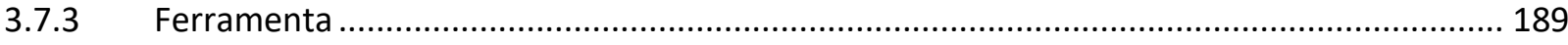

3.7.4 Ensaios de ajuste da medição óptica............................................................................... 190

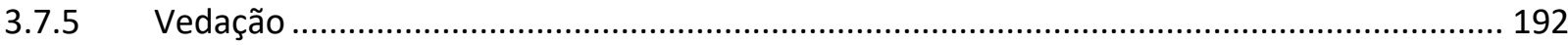

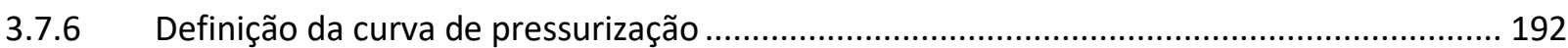

3.8 Caracterização reológica em Conformação Superplástica .................................................................... 193

3.8.1 Expansão fluidoestática biaxial à pressão constante .......................................................... 195

3.8.2 Expansão fluidoestática biaxial à velocidade de deformação constante.............................. 195

3.8.3 Expansão fluidoestática biaxial à tensão constante.......................................................... 196

3.9 Proposta de estratégia de caracterização de expansão fluidoestática biaxial .................................... 198

3.9.1 Modelo analítico de expansão fluidoestática biaxial livre .................................................. 198

3.9.2 Descrição do ensaio de caracterização reológica................................................................. 201

3.9.3 Método de determinação do coeficiente m...................................................................... 202 
3.9.4 Método de determinação do coeficiente $n$.

3.9.5 Método de determinação da constante do material K...................................................... 204

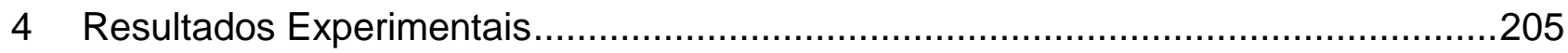

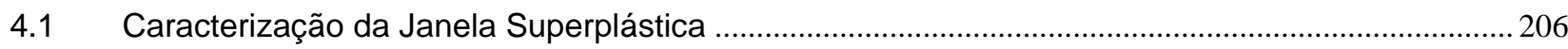

4.2 Resultados da validação do sistema de medição ótica para grandes deformações ........................ 209

4.3 Resultado dos testes de Integração dos sistemas de pressão e de deformação realizado com a liga $\mathrm{PbSn}$.

4.4 Resultados do primeiro ensaio de expansão fluidoestática biaxial superplástico ............................2217

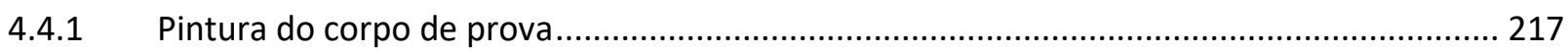

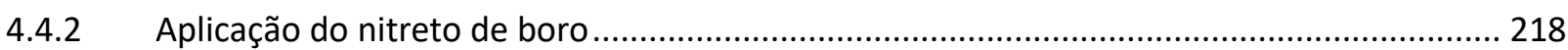

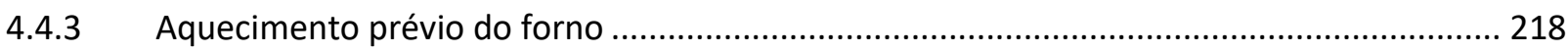

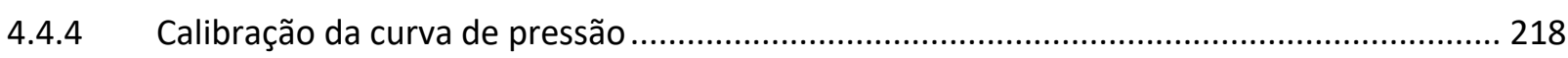

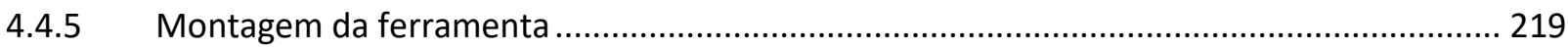

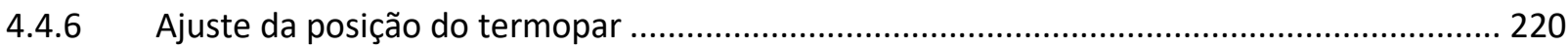

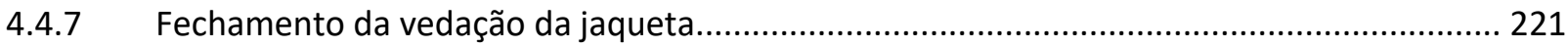

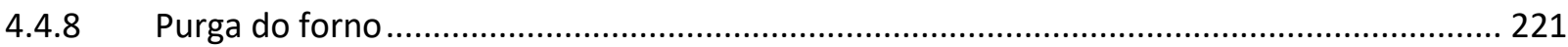

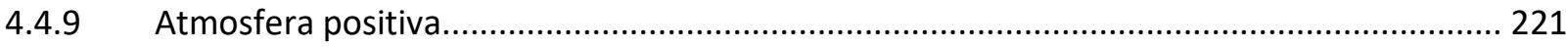

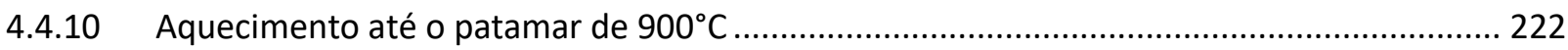

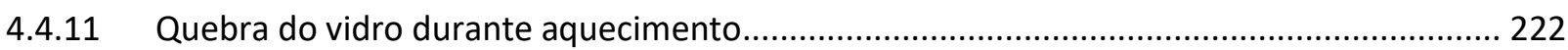

4.4.12 Pressurização da curva resultado da análise por elementos finitos .................................... 223

4.4.13 Vazamento no ferramental da primeira concepção........................................................... 224

4.5 Retrabalho do ferramental superplástico ............................................................................................226

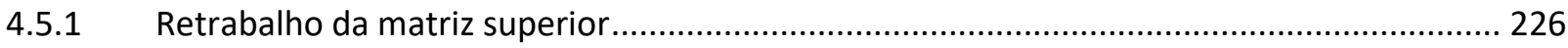

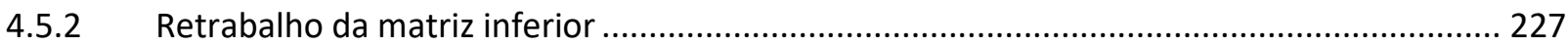

4.6 Alteração no procedimento de montagem do ferramental ............................................................230

4.7 Expansão fluidoestática biaxial cega da chapa de Ti6Al4V superplástico. .........................................2236

4.8 Conformação Superplástica da peça modelo de Ti6Al4V ...............................................................238

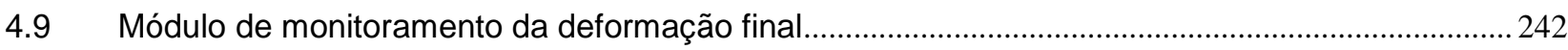

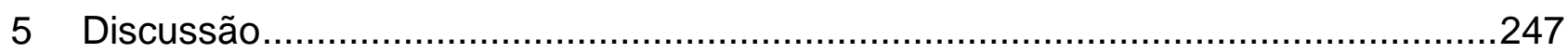

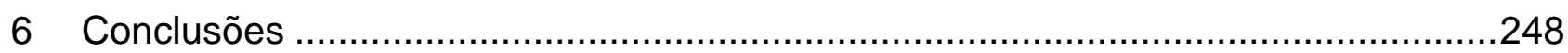

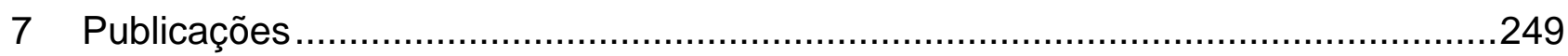

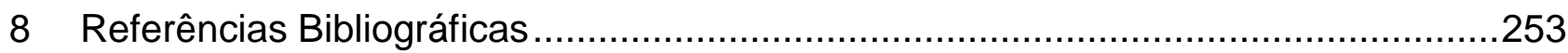

9 ANEXO

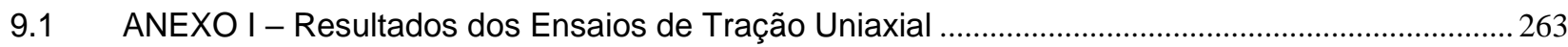

9.2 ANEXO II - As bases da deformação utilizada no ARAMIS...............................................................2 271

9.2.1 Conceito básicos do cálculo de deformação 2D .............................................................. 271

9.2.2 Cálculo do tensor gradiente de deformação utilizando o campo de deslocamento 2D ....... 277

9.2.3 Definições dos valores de deformação X-y e das direções de deformação em 3D................ 278 
9.3 ANEXO III - Resumo das funcionalidades da biblioteca do drive da ADAM 6024

9.4 ANEXO IV - Programa de geração de curva teste de pressurização ..................................................284

9.5 ANEXO V - Script em VBA do sistema de atuação/aquisição ........................................................286

9.6 ANEXO VII - itens utilizados na montagem da linha de alta pressão...............................................2 290 


\section{Introdução}

O aquecimento global e o consequente aumento da consciência ambiental chamaram a atenção da comunidade científica para o desenvolvimento de meios de transporte mais leves que representam economia de matéria prima e energia. Assim, novos materiais e técnicas de conformação para aplicação na indústria automobilista e aeronáutica têm sido objeto de estudo desde o início da década de 80 (GEIGER, 2007). É conhecido que os materiais leves como ligas de $\mathrm{Al}, \mathrm{Mg}$ e Ti possuem baixa conformabilidade em relação aos aços, entretanto esses materiais podem exibir ductilidade muito elevada em condições específicas de temperatura, taxa de deformação e tamanho de grão, fenômeno conhecido como superplasticidade. Essa característica levou ao desenvolvimento da técnica de Conformação Superplástica - Superplastic Forming (SPF) - que se destaca principalmente pela possibilidade de produzir peças de formas complexas em uma única operação (ABUFARHA, 2008). A superplasticidade ocorre acima da temperatura de recristalização e, diferente da deformação convencional, está relacionada ao mecanismo de escorregamento de contornos, do inglês - Grain Boundary sliding (GBS) (CHANDRA, 2000). As condições necessárias para ativação desse mecanismo de deformação são: (i) granulometria fina $(<10 \mu \mathrm{m})$ e estável em altas temperaturas; (ii) baixas taxas de deformação $\left(<10^{-3} \mathrm{~s}^{-1}\right)$; (iii) $\mathrm{T}_{\mathrm{H}}$ (temperatura homóloga) > 0,5; e (iv) alta sensibilidade à taxa de deformação. Assim, a Conformação Superplástica deve ser conduzida em temperaturas elevadas e baixas taxas de deformação, o que implica em tempos longos de processamento. Esse é o principal inconveniente da técnica que limita sua aplicação em larga escala.

Por outro lado, a Conformação Superplástica permite a fabricação de peças complexas em uma única operação, ou seja, dispensa processos de soldagem e usinagem e a fabricação de uma série de matrizes para conformação. Adicionalmente, produz peças inteiras (sem emendas) de alta qualidade. Isso torna o processo viável e interessante para a indústria. Entre os materiais que podem apresentar características superplásticas, o Ti e suas ligas têm grande potencial de aplicação na indústria aeronáutica devido à elevada relação entre resistência mecânica e peso, alta temperatura de uso e elevada resistência à corrosão (BOYER, 1996). Esses benefícios superam o alto custo da matéria prima (Ti com granulometria fina).

O comportamento superplástico é descrito por equações constitutivas que são utilizadas para obter a melhor curva pressão versus tempo na conformação de uma peça. Nesse sentido uma série de modelos foi desenvolvida nos últimos 20 anos, entre eles: 
(CAPPETTI, 2010), (VULCAN, 2006), (AOURA, 2004), (CHANDRA, 2000), (BAUDELET, 1995), (SATO, 1993), (DUTTA, 1992). Apesar de apresentarem resultados bastante coerentes com o experimental, os parâmetros dessas equações constitutivas são geralmente obtidos de ensaios de tração uniaxial.

Durante o processo uma chapa é submetida à pressão de gás que a faz "fluir" dentro da matriz na forma desejada (CHEN, 2001). A taxa de deformação é controlada pela pressão aplicada ao longo do tempo. Alguns modelos de ensaios de expansão fluidoestática biaxial foram desenvolvidos para corrigir esses parâmetros, porém nenhum deles é capaz de medi-los diretamente, como é feito no ensaio de tração uniaxial. Assim, para verificar se determinado modelo reproduz um ensaio real é necessário o desenvolvimento de um ensaio biaxial instrumentado, no qual seja possível obter os parâmetros superplásticos diretamente do ensaio.

Historicamente, o fenômeno da superplasticidade foi descoberto e sistematicamente estudado por metalúrgicos e engenheiros. Metalúrgicos focaram o estudo no entendimento das propriedades físicas e metalúrgicas dos materiais superplásticos, muitas vezes não se considerou condições práticas de ensaio. Em paralelo, engenheiros trabalharam em aplicações práticas dessa tecnologia através de abordagens empíricas e modelos criativo, e muitas vezes não se considerou características metalúrgicas importantes nos testes. Nesse contexto, o objetivo principal dessa tese é desenvolver uma prensa superplástica instrumentada e controlada capaz de realizar ensaios de conformação fluidoestática biaxial da liga Ti6Al4V que considere, além dos requisitos metalúrgicos, os requisitos de maior peso prático, que possibilite produzir peças aeronáuticas para avaliação prática do fenômeno sem desconsiderar a preocupação de cumprir com requisitos metalúrgicos.

A Figura 1.1 apresenta um diagrama esquemático no qual são mostradas as vantagens e limitações do processo de Conformação Superplástica em ligas de Titânio, contextualizado nos pilares temáticos abordados nesta tese:

(a) Análise das técnicas, métodos e requisitos da superplasticidade de titânio;

(b) Concepção e construção da prensa que atenda aos requisitos do projeto;

(c) Instrumentação do ferramental;

(d) Implementação do sistema de controle dedicado aos parâmetros de influência na Conformação Superplástica.

(e) Definição e aplicação de nova metodologia de ensaio de superplasticidade para bulge teste;

(f) Conformação da peça modelo aeronáutica. 


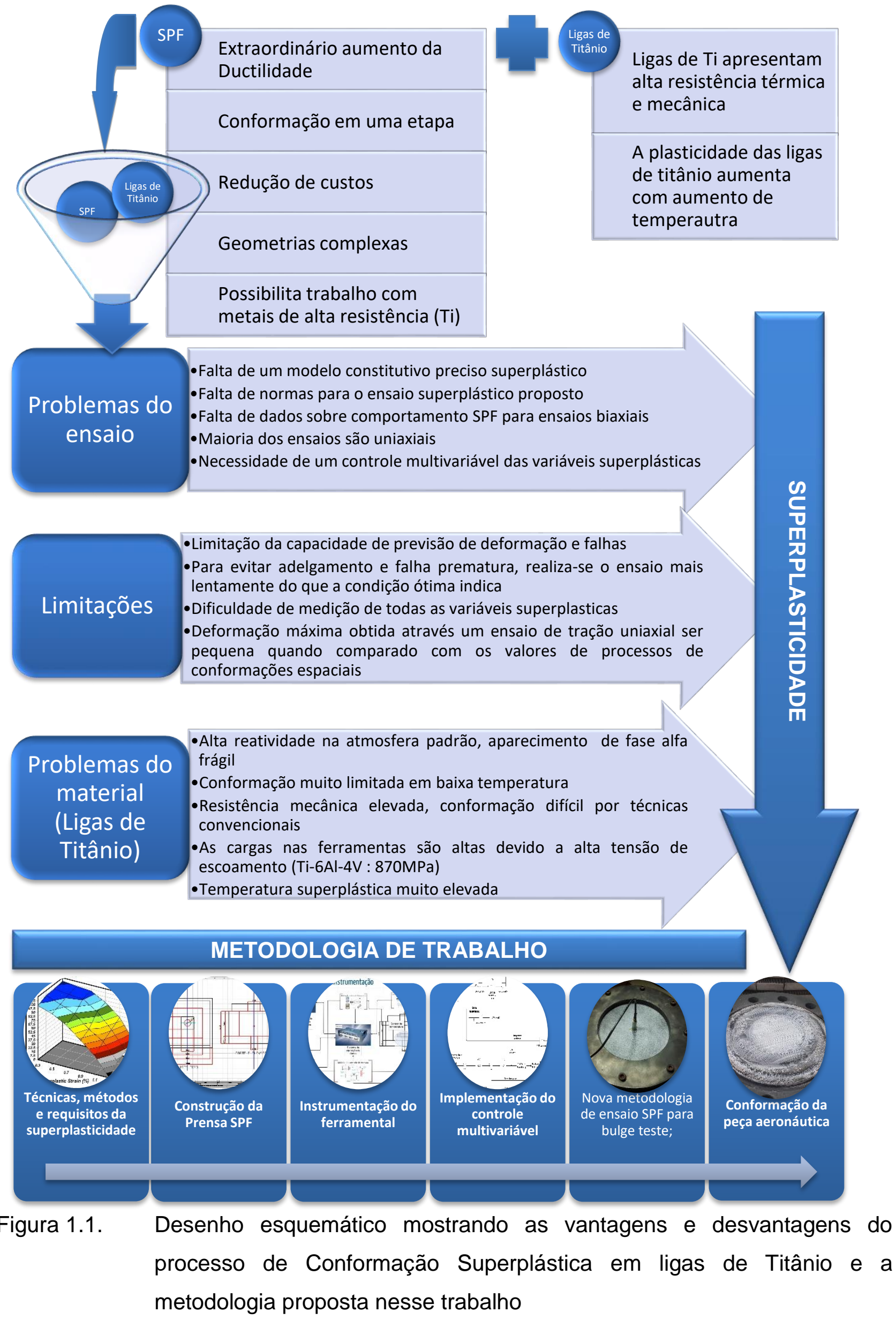




\subsection{Objetivos}

\subsubsection{Gerais}

Os objetivos gerais da referida tese são:

- Desenvolver um ferramental instrumentado e controlado para realização de Conformação Superplástica em atmosfera controlada da liga de titânio Ti6Al4V através de expansão fluidoestática biaxial;

- Desenvolver, implementar e integrar os sistemas de controle dos parâmetros do processo de expansão fluidoestática biaxial. Entenda-se tal controle dos parâmetros como necessários à ocorrência do fenômeno de superplasticidade. Em suma, para cada variável de controle (temperatura, pressão e deformação) objetiva-se projetar e desenvolver um sistema de controle dedicado.

\subsubsection{Específicos}

Os objetivos específicos buscados durante o desenvolvimento da tese serviram de alicerce para que fosse alcançado o objetivo geral, a complexidade do projeto da tese se desenhava a cada projeto das arquiteturas de controle necessárias para atendimento dos requisitos necessários à Conformação Superplástica. Para cumprir com tal desafio, foi necessário traçar objetivos secundários e subdividir etapas para garantir a entrega primária do objetivo geral. Destacam-se alguns dos objetivos secundários (específicos) e as próprias motivações e consequências:

- Validar o processo de medição por correlação digital imagem.

- Ajuste dos parâmetros de controle proporcional-integral-derivativo (PID) pelo método de resposta em degrau com Ziegler Nichols para curva de pressurização durante a conformação superplástica.

- Conformar superplasticamente uma peça aeronáutica em chapa de Ti6Al4V. 


\subsection{Organização do texto}

A Figura 1.2 descreve a organização do texto comentado com os principais pontos por capítulo, pretende-se com esse mindmap construir os alicerces tanto da metodologia quanto dos fundamentos necessários para a melhor apresentação do conteúdo da referida tese.
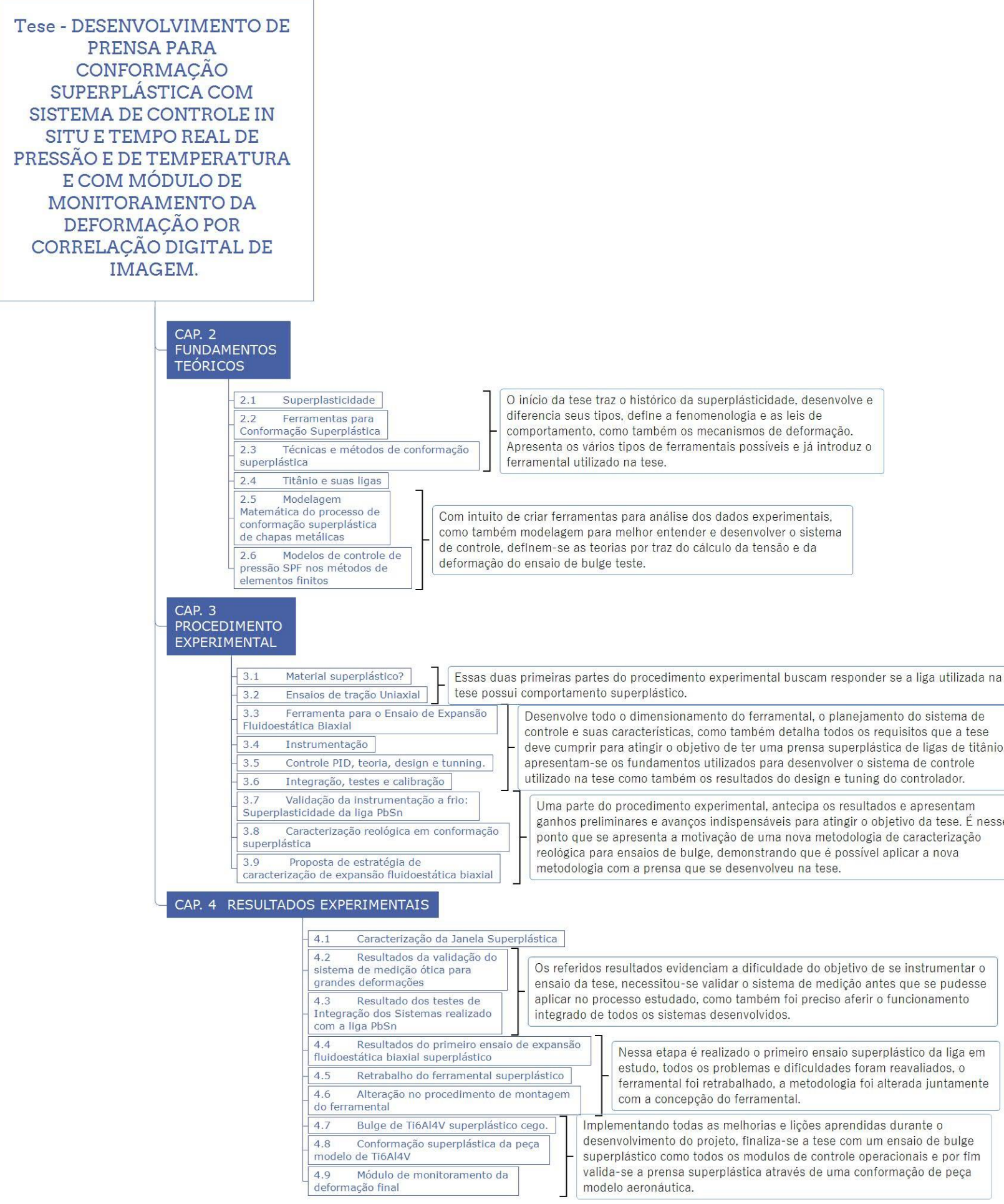

Figura 1.2 Organização do texto da tese. 


\section{Fundamentos Teóricos}

Nesse capítulo serão abordados os principais conceitos relacionados à Conformação Superplástica em ligas de Titânio. Inicialmente - capítulo 2.1 - será apresentado o histórico da superplasticidade, desde a aplicação em metais e suas ligas sem interesse industrial, até a aplicação em peças chaves da indústria aeronáutica, como também será discutido o amplo espectro da presença desse fenômeno ao dividir a superplasticidade em seus principais tipos. Em seguida serão apresentadas as variáveis que dominam seu comportamento reológico e por fim os métodos de caracterização utilizados para localizar a janela superplástica - ensaios uniaxiais e ensaios biaxiais.

No Capítulo 2.2 será feita uma breve discussão dos fatores que influenciam a escolha das matrizes utilizadas para a Conformação Superplástica.

No capítulo 2.3, descrevem-se as principais técnicas utilizadas para a conformação de material em regime superplástico, moldagem por sopro - "Blow Forming", moldagem a Vácuo - "Vacuum Forming", Termoconformacão - "Thermo Forming", estampagem Profunda - "Deep Drawing" e processo combinado entre Conformação Superplástica e junção por difusão - SPF/DB - Diffusion Bonding. O blow forming será a técnica utilizada para no desenvolvimento do ferramental superplástico controlado.

Essa tese utiliza a liga de titânio Ti6Al4V e no capítulo 2.4 serão traçadas relações entre a importância da liga e a sua dificuldade de processamento, como também a sua importância na indústria aeronáutica. Trata-se também das características micro e macroestruturais que definem a janela de superplasticidade da mesma.

Utilizando todo o sistema de controle e instrumentação detalhado nessa tese, será realizado um ensaio de expansão livre fluidoestática biaxial, conhecido como "Bulge teste", nesse ensaio, a abordagem matemática utilizada para avaliar as variáveis superplásticas de interesse baseia-se na teoria da membrana, detalhada no capítulo 2.5.

Ao final desse capítulo, pretende-se que toda a teoria necessária ao entendimento do procedimento experimental utilizado para estudar a superplasticidade da liga de titânio Ti6Al4V tenha sido apresentada e discutida. 


\subsection{Superplasticidade}

\subsubsection{Histórico}

Materiais superplásticos são aqueles que têm a habilidade de exibir altíssima ductilidade, (>200\%). Esse fenômeno foi observado pela primeira vez em 1912 por Rosenhain em uma liga de Zinco-cobre-alumínio (ROSENHAIN, 1912). O fenômeno superplástico foi também estudado nos trabalhos de Bengough nesse mesmo ano (BENGOUGH, 1912) e Jenkin em 1928 (JENKINS, 1928). Entretanto a primeira deformação superplástica experimentalmente obtida é atribuída ao trabalho de Pearson em 1934 (PEARSON, 1934). Esse trabalho foi conduzido em uma liga de $\mathrm{Bi}-\mathrm{Sn}$ e foi observado um alongamento de 1950\%. A Figura 2.1 apresenta o corpo de prova utilizado nesse estudo após deformação. É importante lembrar que esse material, fora das condições superplásticas, apresenta $5 \%$ de alongamento antes da ruptura, sendo classificado como frágil.

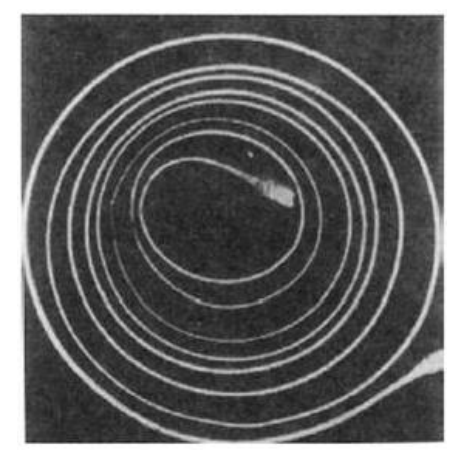

Figura 2.1 Corpo de prova da liga Bi-Sn submetido a uma deformação de $1950 \%$ (PEARSON, 1934)

Baseado nos estudos de Pearson, Bochvar (BOCHVAR, 1946), a quem é atribuído o termo superplasticidade, desenvolveu suas pesquisas no tema durante a década de 40 . Após esse período, as pesquisas só foram retomadas no ocidente, em 1962 com a publicação de uma revisão dos trabalhos soviéticos feita por Underwood (UNDERWOOD, 1962).

A princípio, antes de 1964, o principal alvo das pesquisas era obter o máximo alongamento através de ensaios de tração uniaxiais a quente. Assim, a pesquisa 
tecnológica teve início somente após os trabalhos pioneiros de Backofen (BACKOFEN, 1964), onde o expoente $m$ (sensibilidade à taxa de deformação) foi relacionado ao comportamento superplástico. A partir daí, começou-se a estudar o mecanismo de deformação responsável por esse comportamento e teorias a esse respeito foram propostas. Nesse mesmo ano, os autores publicaram o seu artigo mais conhecido e pela primeira vez, uma chapa de AIZn superplástica foi conformada como uma bolha. Este evento marca o surgimento de uma nova tecnologia: a da Conformação Superplástica.

Coautor de vários trabalhos com Backofen, Stuart Davis Fields recebeu seu doutorado em 1957, no departamento de metalurgia do MIT. Enquanto Backofen publicava em 1964, o Dr. Fields trabalhava no escritório do departamento de produtos da IBM, em Lexington, Kentucky. Em abril de 1965, Fields publicou a primeira patente com aplicação de Conformação Superplástica no mundo, para uma grande variedade de chapas e tubos. Todo este trabalho que havia sido desenvolvido nos EUA não demoraria a ser observado pela comunidade científica mundial.

O "Electricity Council Research Center", Capenhurst, Inglaterra, foi a primeira indústria com laboratórios para o estudo dessa nova tecnologia. Em 1969, aconteceu a primeira conferência sobre SPF, realizada em Capenhurst. A participação de alguns grupos, como Hinxton Hall, Cambridge, Divisão de Pesquisa da British Aluminium e Press Steel Fisher Division of British Leyland, foi notável. (BARNES, 2007)

Em 1971, a ISC Alloys Ltd., Avonmouth Bristol, Reino Unido, foi fundada como a primeira empresa comercial de Conformação Superplástica no mundo, a motivação foi a produção de formas complexas usando a liga eutetóide de $\mathrm{ZnAl}$ com baixos custos de ferramental e tempos de conformação. Até os dias de hoje, o maior alongamento uniforme de tensão uniaxial foi de aproximadamente $8000 \%$ (Figura 2.2) alcançado com bronze comercial. Os valores de alongamento uniforme em diferentes ligas superplásticas, em função dos anos, podem ser observados na Figura 2.3, houve um aumento de $3000 \%$ entre os anos de 1970 e 1990.

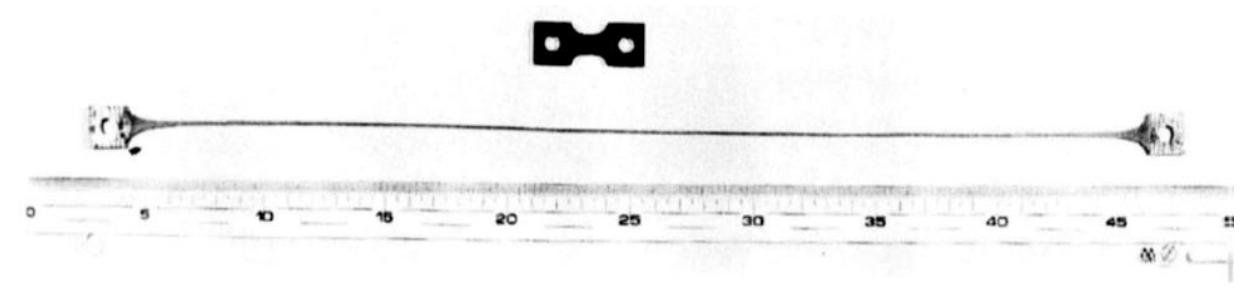

Figura 2.2 Recorde mundial de tração uniaxial conseguido por Higashi em uma liga de Cu-Al (ROBERT, 2009) 
No início dos anos 70, outro avanço ocorreu na indústria aeroespacial, foi a Conformação Superplástica em liga de titânio e o novo conceito, hoje conhecido como SPF / DB, resultado de dois processos combinados, o Superplastic forming (SPF) e o Diffusion Bonding (DB). Esta tecnologia avançou consideravelmente ao longo dos anos 70 e início dos 80 .

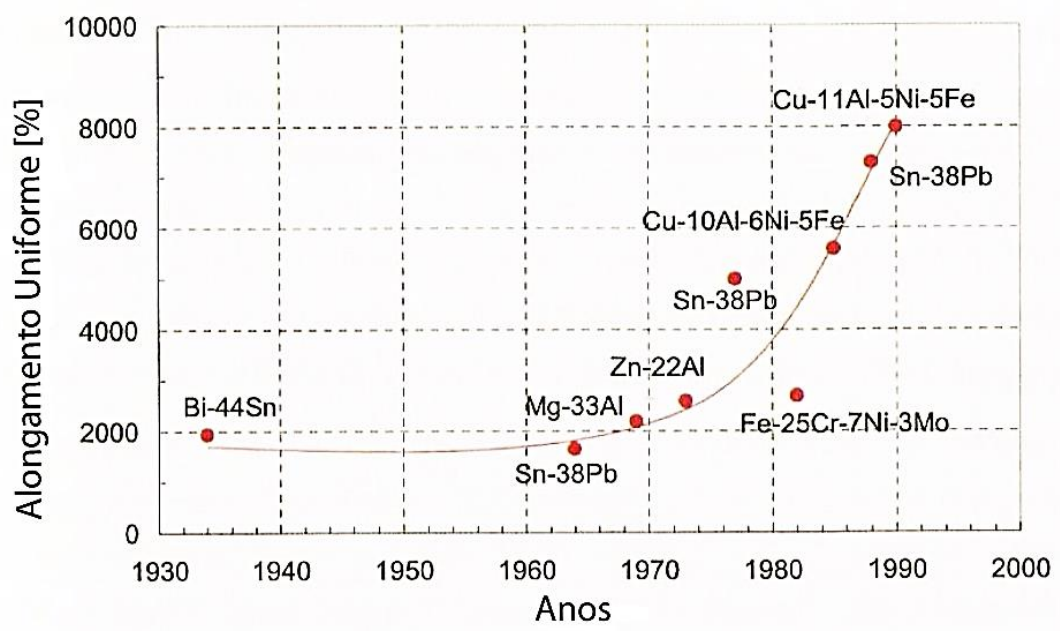

Figura 2.3. Alongamento uniforme alcançado para diferentes materiais ao longo dos anos (VULCAN, 2006)

A primeira aplicação comercial de titânio SPF foi em 1981, 13 anos depois que Johnson havia demonstrado pela primeira vez o comportamento em uma liga de titânio. A primeira aplicação comercial foi parte da asa da aeronave Airbus A310. (BARNES, 2007)

Em 1982, devido ao aumento do interesse pela superplasticidade ter crescido, a primeira conferência internacional em superplasticidade em materiais estruturais ocorreu em San Diego, editado por Paton e Hamilton. A segunda e terceira ocorreram respectivamente em 1985 - Grenoble e 1988 - Washington State. Essas três conferências ficaram conhecidas como ICSAM (International Conference of Superplasticity in Advanced Materials). Essa conferência ocorre até hoje, Osaka (1991), Moscou (1994), Bangalore (1997), Orlando (2000), Oxford (2003), Chengdu (2006), Seatle (2009), Albi (2012) e Tóquio (2015); como uma das contribuições dessa tese, o sistema de controle de deformação que utiliza correlação digital de imagem na Conformação Superplástica foi apresentado na conferência em Albi e foi publicado na edição especial do "Materials Science Forum Journal".

Em 1989 NATO/AGARD - North Atlantic Treaty Organization / Advisory Group for Aerospace Research and Development - escolheu a superplasticidade como uma das series de palestras (SHERBY, 1989). 


\subsubsection{Tipos de superplasticidade}

Para um material apresentar comportamento superplástico deve ser capaz de ser processado e apresentar como microestrutura grão fino equiaxial que permaneça estável na temperatura de deformação superplástica.

Há dois tipos de comportamento superplástico de sólidos policristalinos bem conhecidos: superplasticidade de estrutura fina (FSS - Fine Structure Superplasticity) e superplasticidade de tensão interna (ISS - Internal-Stress Superplasticity).

Com o objetivo de localizar os vários tipos de superplasticidade rapidamente citados nessa tese, e mais uma vez observar a potencialidade de se obter superplasticidade em altas taxas para caso de refino de grão cada vez mais acentuado, segue a Figura 2.4 abrangendo um amplo espectro de materiais superplásticos.

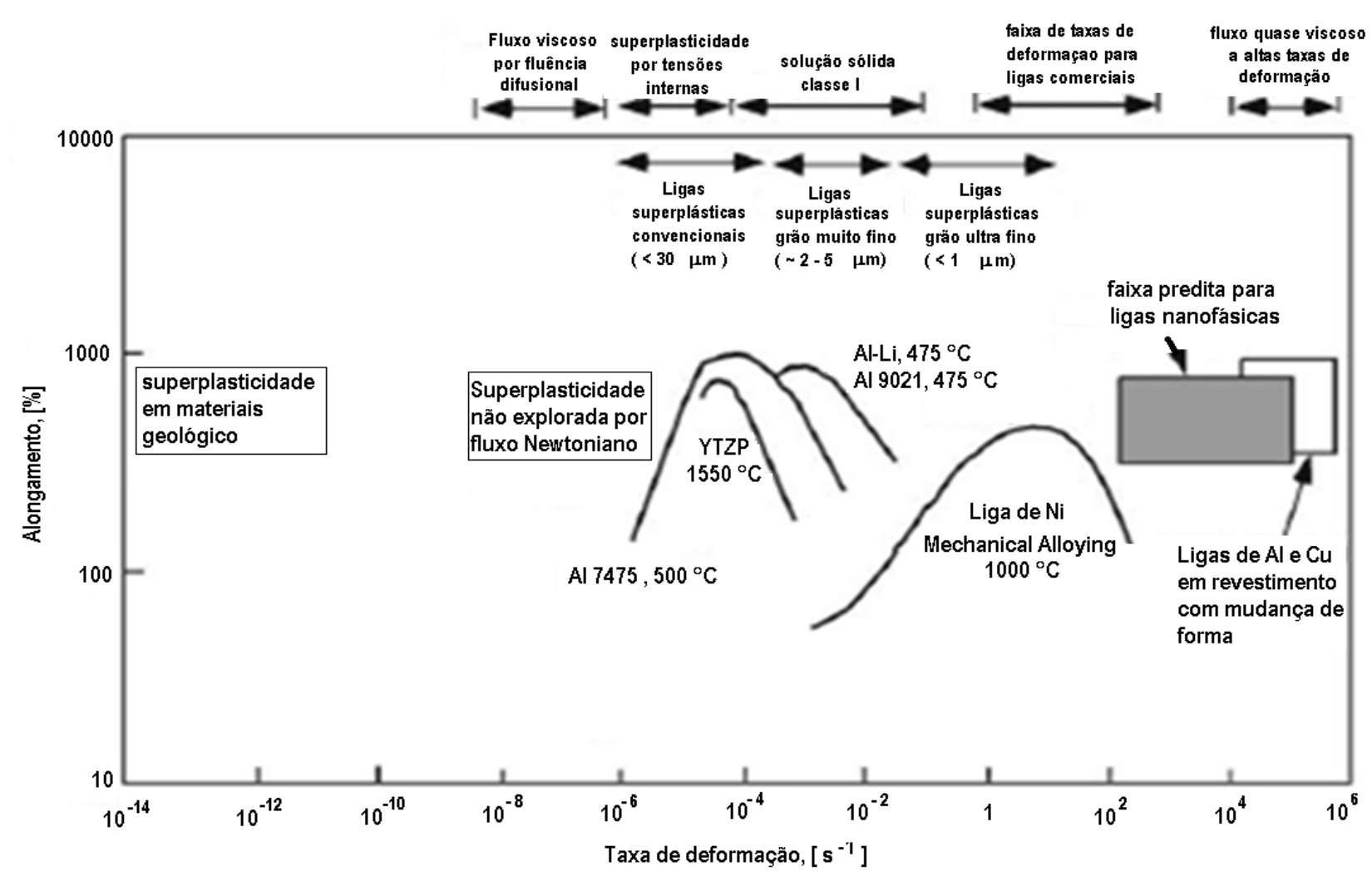

Figura 2.4. Superplasticidade em um mais amplo espectro de materiais. (NIEH,2007)

Os materiais que apresentam ISS (Superplasticidade por tensões internas) caracterizam-se pelo índice de sensibilidade a taxa de deformação ser próximo à unidade, podem assim possuir comportamento viscoso newtoniano ideal. Há muitas maneiras nas quais tensões internas podem ser geradas, tais como, ciclo térmico de materiais compostos, cujos constituintes apresentam coeficientes de expansão térmico diferentes; ciclo térmico 
de metais puros policristalinos ou ligas monofásicas que apresentem coeficientes de expansão térmico anisotrópico e ciclo térmico através de mudança de fase, como também mudanças de fase induzidas por pressão tem sido citadas como uma possível fonte de escoamento superplástico em materiais geológicos. Por exemplo, há uma transformação de fase no manto superior da terra, devido à pressão, a Olivina ${ }^{1}$ na fase ortorrômbica se transforma na fase espinela a uma profundidade de aproximadamente $400 \mathrm{Km}$ abaixo da superfície terrestre. (NIEH, 2007)

Nessas capas de Olivina, Paterson (PATERSON, 1990) apresentou evidências do fenômeno superplástico em baixíssimas taxas de deformação, da ordem de $10^{-14} \mathrm{~s}^{-1}$. Essa baixíssima velocidade seria capaz de operar o fenômeno superplástico em materiais de grão grossos, e não somente em grãos finos como se apresentam as condições superplásticas. O mesmo autor propõe que o movimento das geleiras deve ser atribuído a deformações superplásticas das camadas inferiores de gelo.

ISS pode ser observado através do a-urânio, Urânio ciclado termicamente exibe o índice de sensibilidade a taxa de deformação igual a unidade. Segue Figura 2.5 que compara as deformações resultantes entre os casos isotérmico e de ciclagem térmica.

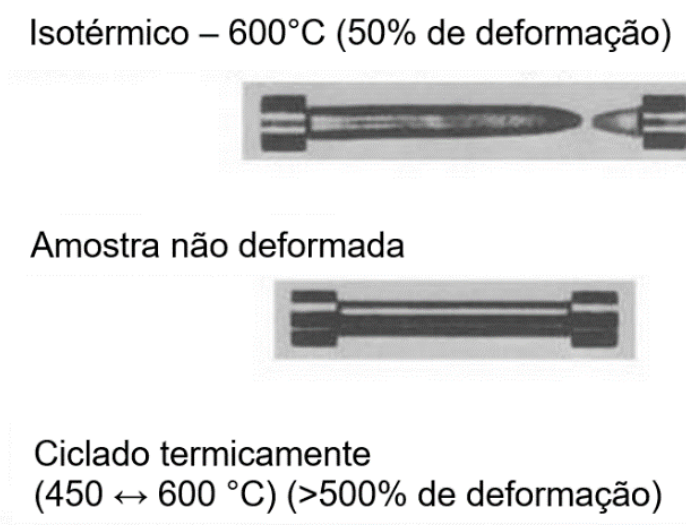

Figura 2.5. Comparação do resultado de ensaio de tração isotérmico com o de ciclagem térmica. (BURKE, 1981)

O mais conhecido e estudado tipo de comportamento superplástico é o FSS. Os prérequisitos estruturais para desenvolvimento de materiais superplásticos estão bem estabelecidos para materiais metálicos. Entretanto não estão claramente desenvolvidos para intermetálicos, cerâmicos e compósitos. (NIEH, 2007)

\footnotetext{
${ }^{1}$ A olivina é um silicato de ferro e de magnésio pertencente à família dos peridotipos. A proporção de ferro e de magnésio é variável, sendo que nos casos extremos de existência de apenas ferro ou de apenas magnésio,
} 
Os pré-requisitos de desenvolvimento de materiais FSS estão listados abaixo:

- Tamanho de grão pequeno: Para que o mecanismo de GBS - melhor explicado no capítulo 2.1.4 - domine durante a deformação, o tamanho do grão deve ser pequeno, tipicamente para metais deve ser menor que $10 \mu \mathrm{m}$ e para cerâmicos menor que $1 \mu \mathrm{m}$.

- Segundas fases: na maioria dos casos é difícil observar superplasticidade em materiais monofásicos mesmo com grão finos, pois o crescimento do grão é muito rápido nas temperaturas que ocorre o fenômeno GBS. A fim de manter o tamanho do grão a presença ou de uma segunda fase no material ou partículas nos contornos de grão é requerida.

- Resistência da segunda fase: como uma das razões de ocorrência da superplasticidade da liga de titânio (Ti-6Al-4V) atribui-se a resistência ao crescimento de grão imposta pela segunda fase da liga - a descrição micro estrutural da liga está no cap. 2.4.2.

- Tamanho, morfologia e distribuição da segunda fase: Maehara (MAEHARA, 1987) investigou um grande número de aços inoxidáveis e concluiu que a condição superplástica ótima é atingida quando uma distribuição fina de uma fase $\sigma$ dura está contida na matriz austenítica. Ele considera que esse comportamento ótimo ocorre quando há recristalização na parte macia da matriz durante a deformação.

- Natureza da estrutura do contorno de grão: Monzen (MONZEN, 1993) atesta que quanto maior a desordem do arranjo atômico do contorno, menor a resistência do contorno em deslizar, como também demonstrou que a presença de precipitados no contorno de grão pode reduzir a mobilidade de deslizamento do contorno.

- Textura e forma do grão: A forma do grão deve ser equiaxial e a textura resulta em um comportamento não superplástico.

- Mobilidade do contorno de grão: $O$ fato de que o grão mantém equixialidade mesmo após longas deformações é evidência indireta de que a migração do contorno de grão está ocorrendo.

Após as características do FSS, superplasticidade da liga de Ti-6AI-4V que será foco dessa tese, é interessante salientar a existência de mais um tipo de superplasticidade, a Superplasticidade de alta taxa de deformação (HSRS - High Strain Rate Superplasticity). 
A superplasticidade em alta taxa de deformação é definida pela associação de padrões japonesa (JSA - Japanese Standards Association) como a superplasticidade que ocorre em taxa de $10^{-2} \mathrm{~s}^{-1}$ ou superiores. (RIDLEY, 2011)

\subsubsection{Fenomenologia e lei de comportamento}

\subsubsection{Fenomenologia da conformação}

Com o objetivo de enumerar os principais aspectos da reologia do comportamento superplástico, inicia-se a discussão com observações experimentais comparativas entre a deformação plástica e superplástica.

\section{- Deformação plástica}

- Durante um ensaio de tração uniaxial, encontram-se geralmente três fases sucessivas:

- Uma deformação elástica linear reversível, muito mais marcante em uma conformação a quente do que a frio.

- Uma deformação plástica com encruamento. Quando a temperatura é elevada, a tensão pode diminuir quando a deformação plástica aumenta, devido ao amolecimento do material.

- Uma deformação plástica em regime estacionário na qual a tensão não depende da taxa de deformação. Nessa etapa ocorre o aparecimento da instabilidade geométrica.

- Na deformação plástica a tensão sofre uma fraca influência da taxa de deformação, o encruamento tem uma influência preponderante sobre o comportamento reológico.

\section{- Deformação superplástica}

- Um ensaio de tração uniaxial superplástico mostra que:

- O domínio elástico é muito reduzido e o limite de elasticidade pode ser negligenciado.

- O encruamento e o amolecimento são inexistentes ou negligenciáveis.

- A tensão de escoamento é muito sensível à taxa de deformação. 
Essa sensibilidade à taxa de deformação é a característica fundamental dos materiais superplásticos, tal fato dificulta o aparecimento da instabilidade geométrica.

\subsubsection{Lei de comportamento}

\section{- Deformação plástica}

O comportamento do escoamento plástico e viscoplástico de um material em tração uniaxial é comumente representado por uma equação da forma:

$$
\sigma=\sigma_{0}+f(\varepsilon, \dot{\varepsilon}, T)
$$

Onde em cada instante de um ensaio:

$\sigma=$ Tensão equivalente unidimensional;

$\sigma_{0}=$ Tensão limite de elasticidade;

$\varepsilon=\ln \left(\frac{l(t)}{l_{0}}\right)=$ Deformação verdadeira;

$\dot{\varepsilon}=$ Taxa de deformação equivalente;

$\mathrm{T}=$ Temperatura absoluta do material;

No âmbito da teoria das grandes deformações plásticas dos materiais metálicos, utiliza-se a seguinte lei:

$$
\sigma=\sigma_{0}+K \cdot \varepsilon^{n} \dot{\varepsilon}^{m}
$$

Em (2) aparecem os três coeficientes que caracterizam o comportamento reológico do material na deformação plástica.

$K=$ Coeficiente de resistência do material;

$n=$ Coeficiente de encruamento;

$m$ = Coeficiente de sensibilidade à taxa de deformação;

Quando os coeficientes m e n são nulos, o comportamento é rígido plástico perfeito, para $\sigma<\sigma_{0}$ não há escoamento. Quando $\sigma=\sigma_{0}$ a deformação existe mais é indeterminada.

Quando $\mathrm{m}=1$ e $\mathrm{n}=0$ e $\sigma_{0}=0$ o comportamento é o de um fluido Newtoniano.

Para $\mathrm{n}=0$ e $\sigma_{0}=0$, e $\mathrm{m}$ compreendido entre 0 e 1 caracteriza o comportamento viscoplástico de Norton. (BOUDE, 1994) 


\section{- Deformação superplástica}

A equação geral (2) é simplificada para representar a deformação superplástica, uma vez que de acordo com os resultados experimentais, o domínio elástico é reduzido e o limite de elasticidade é negligenciado, como também o encruamento é baixíssimo e seu coeficiente $\mathrm{n}$ também é negligenciado.

Uma boa aproximação da lei de comportamento superplástico é obtida por uma lei de potência, escoamento viscoplástico de Norton:

$$
\sigma=K \cdot \dot{\varepsilon}^{m}
$$

A generalização do caso tridimensional é feita por Hoff na forma:

$$
\sigma_{e q}=K \cdot \varepsilon_{e q}^{m}
$$

$\sigma_{e q}=$ Tensão equivalente de Von Mises;

$\varepsilon_{e q}=$ Taxa de deformação equivalente;

A superplasticidade é caracterizada pela influência de três parâmetros:

- Taxa de deformação - $\dot{\varepsilon}$

- Temperatura-T.

- Tamanho de grão - TG.

A busca pela janela superplástica envolve o controle das três variáveis mostradas na Figura 2.6. Existe um compromisso entre essas variáveis, quando uma delas não respeita as exigências não ocorre o fenômeno. De maneira resumida tem-se que as exigências microestruturas e condições de deformação abaixo são limitantes do processo.

- Taxa de deformação: $\dot{\varepsilon} \sim 10^{-4} s^{-1} ; 10^{-6} \geq \dot{\varepsilon} \geq 10^{-2} s^{-1}$;

- Temperatura homóloga $T_{H} \geq 0,5$ sendo que, $T_{H}=\frac{T}{T_{m}}$ e $T_{m}$ é Ponto de fusão;

- Granulação fina $(\mathrm{d} \leq 10 \mu \mathrm{m})$; 


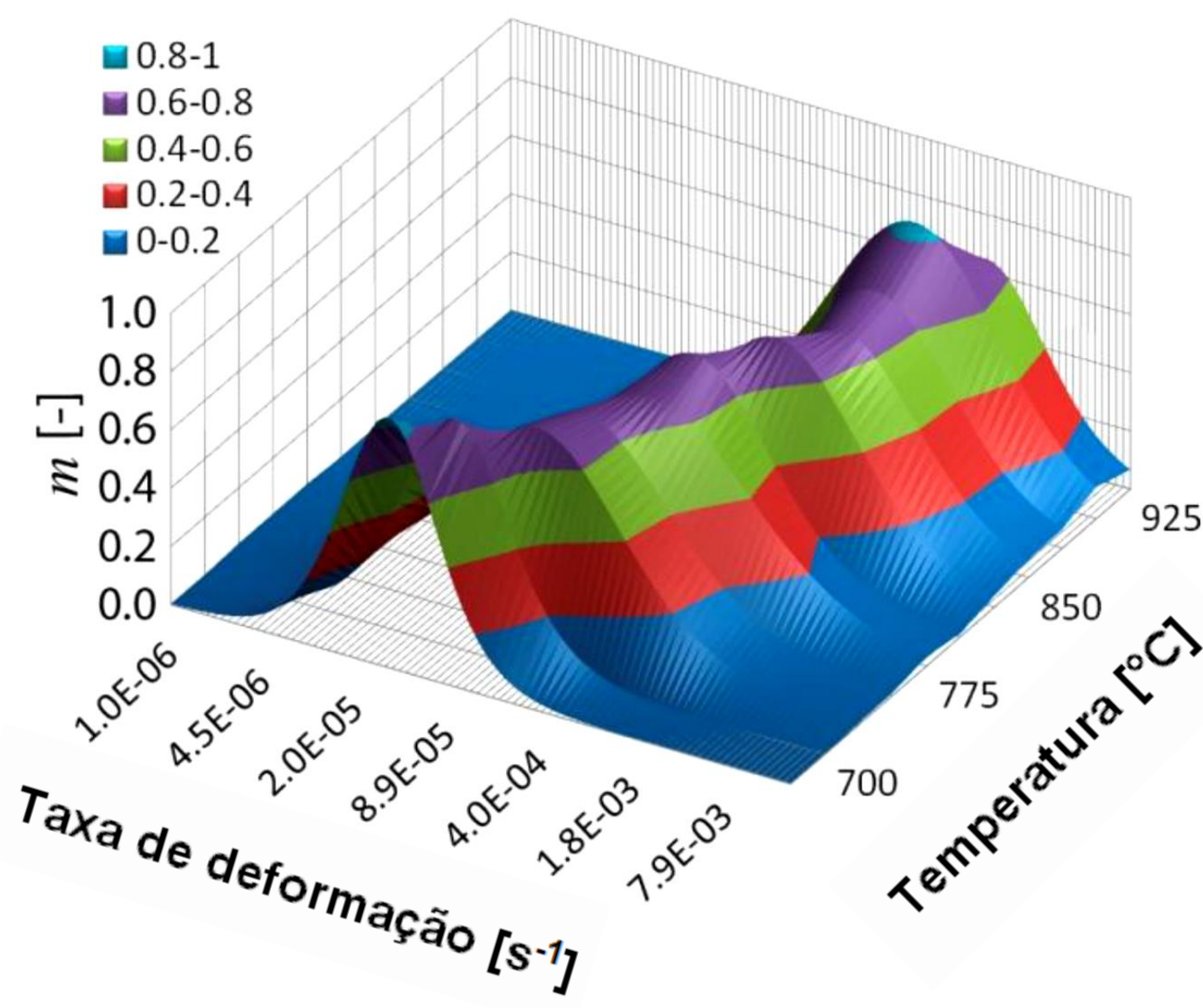

Figura 2.6. Variáveis de controle para estudo da janela de Superplasticidade do processo de conformação (temperatura, índice de sensibilidade à taxa de deformação e taxa de deformação) (AKSENOV, 2012)

A seguir será discutido separadamente o efeito de cada uma dessas variáveis no comportamento superplástico.

\subsubsection{Taxa de deformação e sensibilidade à taxa de deformação $(m)$}

Para um material superplástico, a tensão de escoamento é fortemente dependente da taxa de deformação. Dentro de uma faixa de taxa de deformação, característica de cada material é observada uma relação linear entre a taxa de deformação e a tensão de escoamento, em uma escala bi logarítmica. 


\subsection{Taxa de deformação}

Para a superplasticidade, a equação mais geral é a de Norton-Hoff, dada por:

$$
\sigma_{e}=K \cdot \varepsilon^{n} \dot{\varepsilon}^{m}
$$

Desconsiderando então o termo de encruamento, $\mathrm{n}=0$, característica de uma Conformação Superplástica, equação (5) resultará na equação (6) com boa aproximação.

$$
\sigma_{e}=K \cdot \dot{\varepsilon}^{m}
$$

Como também:

$$
\sigma_{e}=\frac{F}{A}
$$

Para corpos de prova de secção transversal retangular submetidos à tração, têm-se, três diferentes deformações:

$$
\begin{aligned}
& \varepsilon_{l}=\ln \frac{l}{l_{0}} \\
& \varepsilon_{b}=\ln \frac{b}{b_{0}} \\
& \varepsilon_{s}=\ln \frac{s}{s_{0}}
\end{aligned}
$$

Assumindo a conservação do volume:

$$
\begin{gathered}
A_{0} l_{0}=A_{1} l_{1} \\
l_{0} b_{0} s_{0}=l_{1} b_{1} s_{1} \\
\frac{l_{0} b_{0} s_{0}}{l_{1} b_{1} s_{1}}=1
\end{gathered}
$$


Logo:

$$
\sum_{i=1}^{3} \varepsilon_{i}=0
$$

A deformação que permeia todo o desenvolvimento da superplasticidade é a maior das três deformações:

$$
\varepsilon=\left\{\left|\varepsilon_{l}\right|,\left|\varepsilon_{b}\right|,\left|\varepsilon_{s}\right|\right\}_{\text {max }}
$$

Logo a taxa de deformação ou velocidade de deformação ao longo do tempo é:

$$
\dot{\varepsilon}=\frac{d \varepsilon}{d t}
$$

A superplasticidade ocorre em dependência do material e dentro dos valores limites de temperatura de deformação e velocidade de deformação. A conformação de chapas metálicas caracteriza-se por um alto alongamento uniforme e por um baixo valor de taxa de deformação durante a sua conformação.

\subsection{Sensibilidade à taxa de deformação}

A tensão de escoamento é definida pelas seguintes grandezas:

$$
\sigma_{e}=f(\text { Material }, \varepsilon, \dot{\varepsilon}, T)
$$

A ductilidade está relacionada à homogeneidade de deformação e ao alongamento, que são controlados pelo encruamento e sensibilidade à taxa de deformação. A descrição dos fenômenos de endurecimento e sensibilidade à taxa de deformação a partir das curvas tensão - deformação é realizada por expressões empíricas.

Pelas equações (6) e (7) tem-se:

$$
\frac{F}{A}=K \cdot \dot{\varepsilon}^{m}
$$

Como:

$$
\dot{\varepsilon}=\frac{1}{l} \frac{d l}{d t}=\frac{1}{A} \frac{d A}{d t}
$$


De (18) e (19) tem-se que a taxa de redução da área da seção transversal é:

$$
-\frac{d A}{d t}=\left(\frac{F}{K}\right)^{\frac{1}{m}} \cdot \frac{1}{A \frac{(1-m)}{m}}
$$

Observa-se que a taxa de redução da seção transversal é inversamente proporcional à seção transversal e muito sensível ao índice sensibilidade à taxa de deformação m. $\mathrm{O}$ aumento do valor de $\mathrm{m}$ favorece ao não aparecimento da instabilidade geométrica responsável pela ruptura. Pela análise da função, quando $m$ se aproxima da unidade, a taxa de redução da área da seção transversal converge a um valor ilustrado na Figura 2.7, assim como quando $m=1$, a taxa de redução da seção transversal se torna independente da área, dessa forma, um corpo de prova irregular manteria sua irregularidade durante a deformação, não haveria concentração de tensão local, o que resultaria em grandes deformações.

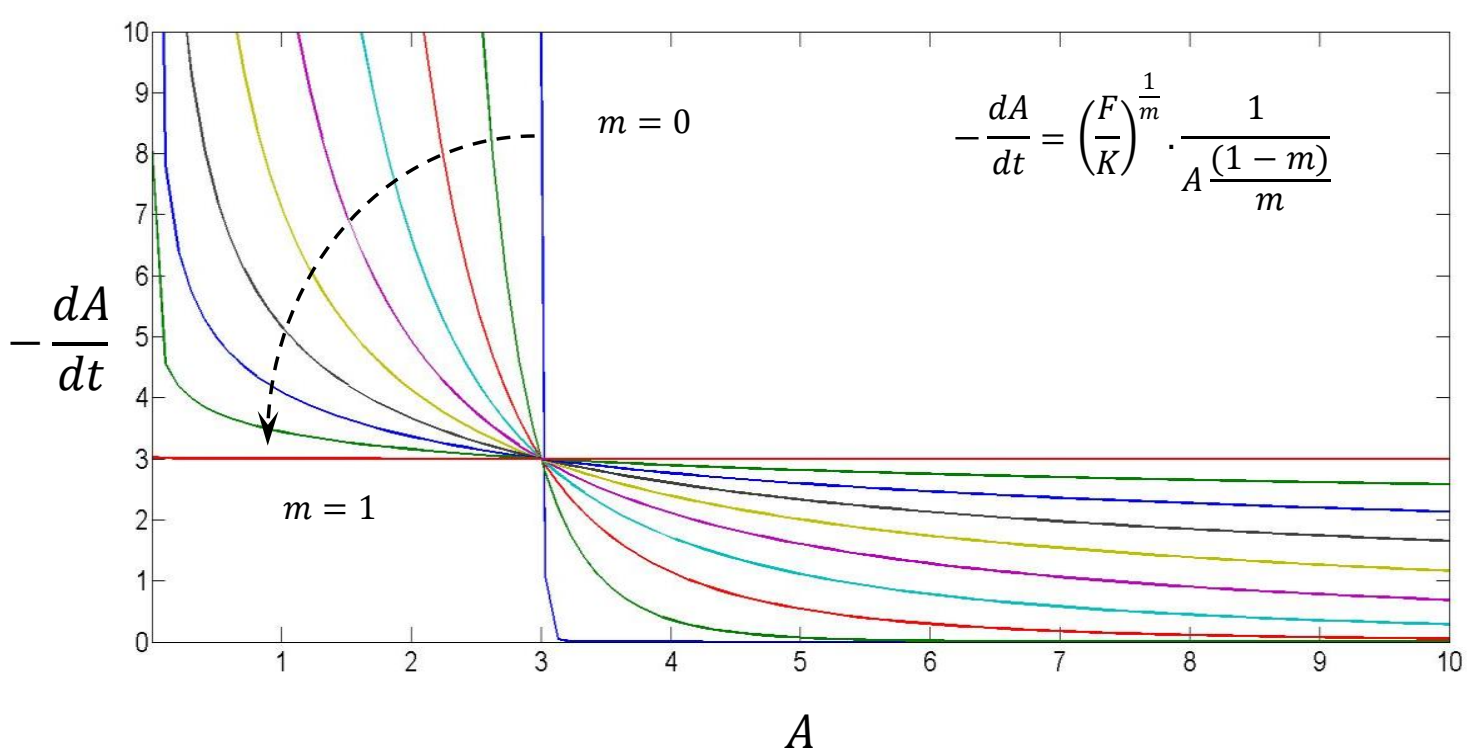

Figura 2.7. Análise da influência do índice de sensibilidade à taxa de deformação na taxa de redução da área de seção transversal. 
A relação entre a sensibilidade à taxa de deformação e o elongamento total pode ser obtido pela integração da equação (19). (RIDLEY,1989)

$$
e l=e l_{0}+100\left(\left[1-\alpha^{\frac{1}{m}}\right]^{-m}-1\right)
$$

Como essa relação depende da amplitude da janela superplástica, a mesma deve ser considerada do ponto de vista qualitativo e não quantitativo, evidencia assim a forte dependência do $\mathrm{m}$ no elongamento total $(\mathrm{el})$.

A equação mostra que para "m", coeficiente de sensibilidade à taxa de deformação, igual à unidade, dA/dt é independente da seção transversal e a taxa de formação do pescoço é constante durante o alongamento. Para "m" próximo de 10 material resiste à formação do pescoço, o que implica em grandes deformações, é o caso dos materiais que apresentam superplasticidade. Para ilustrar a dependência da tensão de escoamento com relação à sensibilidade a taxa de deformação $(\mathrm{m})$ e o expoente de encruamento $(\mathrm{n})$, observe a Tabela 2.1 .

Tabela 2.1. Expoente de Encruamento $\mathrm{n}$ e Sensibilidade à taxa de deformação $\mathrm{m}$ do material Alumínio para diferentes temperaturas (Vulcan, 2006)

\begin{tabular}{|l|c|c|}
\hline Comportamento da conformação & $\mathbf{n}$ & $\mathbf{~ m}$ \\
\hline Conformação a frio & $0,1-0,3$ & $0,01-0,1$ \\
\hline Forjamento a quente & $0,1-0,2$ & $0,15-0,2$ \\
\hline Conformação a quente & $0,01-0,1$ & $0,2-0,3$ \\
\hline Conformação Superplástica & $n \ll 0,1$ & $m \gg 0,4-0,8$ \\
\hline
\end{tabular}

A dependência entre a tensão de escoamento $\sigma_{\mathrm{e}}$ e a taxa de deformação $(\dot{\varepsilon})$ pode ser observada na Figura 2.8. (VULCAN,2006). 


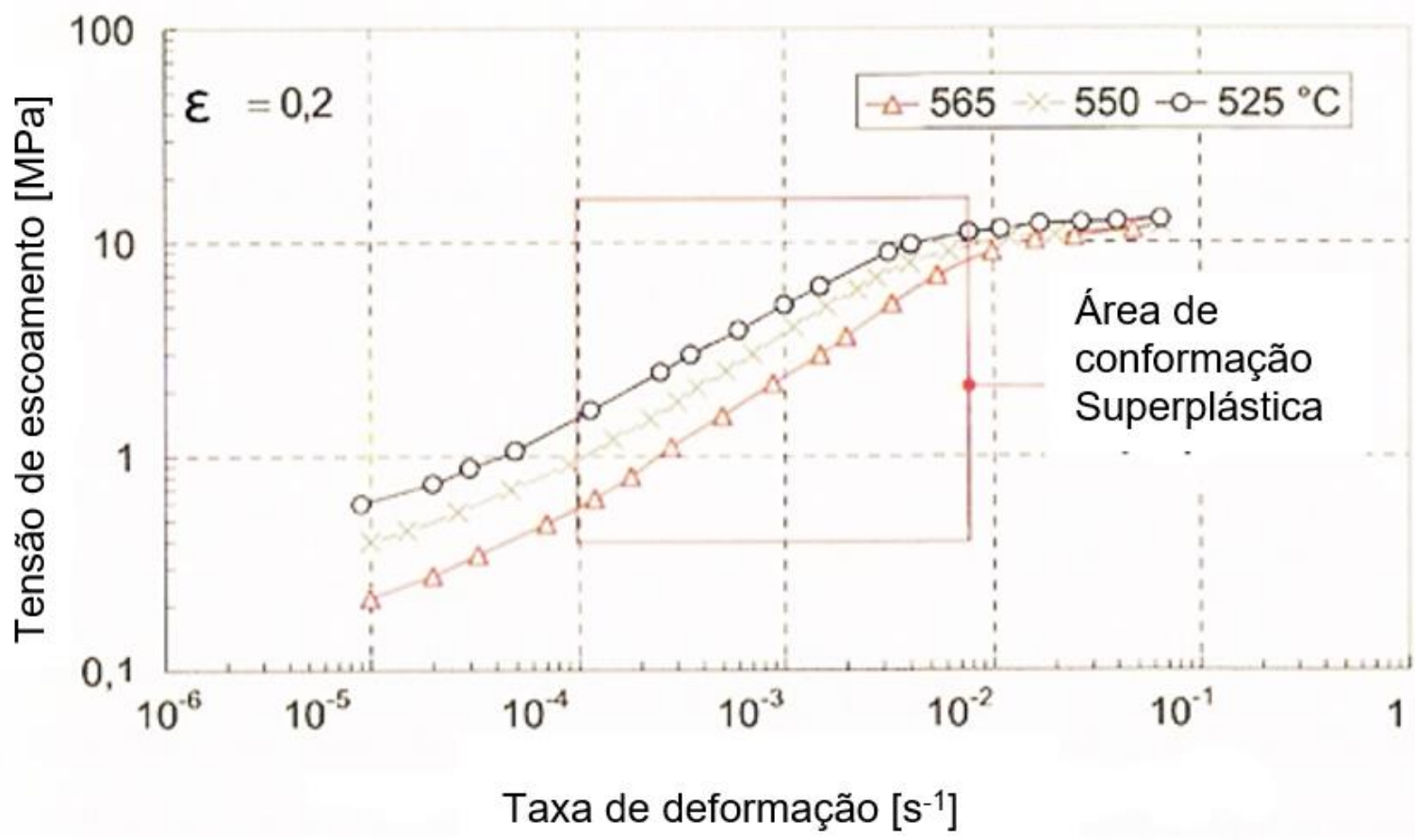

Figura 2.8. Dependência entre a tensão de escoamento $\left(\sigma_{e}\right)$ e a taxa de deformação $(\dot{\varepsilon})$ para diferentes temperaturas de conformação. Material: Formall545 (VULCAN,2006)

Em resumo os materiais que apresentam comportamento superplástico são caracterizados por baixo endurecimento por deformação e elevada sensibilidade à taxa de deformação. A Figura 2.9 apresenta um gráfico da dependência do log $\sigma$ e m com o log $\dot{\varepsilon}$ para material convencional $\left(\mathrm{C}_{1}\right.$ e $\left.\mathrm{C}_{1}^{\prime}\right)$ e superplástico $\left(\mathrm{C}_{2}\right.$ e $\left.\mathrm{C}_{2}^{\prime}\right)$. Observa-se que o material convencional não apresenta sensibilidade à taxa de deformação em nenhuma região sendo m constante e próximo de 0 .

A superplasticidade está relacionada à região $\mathrm{II}, \mathrm{m}>0,5$. Mais adiante no item 2.1.5 serão discutidos os métodos de obtenção desses parâmetros através de diferentes tipos de ensaios mecânicos.

O comportamento e caracterização das regiões são dados pela equação (22):

$$
\log \sigma_{e}=K+m \log \dot{\varepsilon}
$$

Denominadas de Região 1, Região 2 e Região 3, cada uma apresenta diferenças em suas características microestruturais. (SAMEKTO, 2005)

A caracterização da tendência Sigmoidal em termos destas três regiões é baseada principalmente no valor do coeficiente de encruamento, $n$ (caso dos ensaios de fluência) ou 
expoente de sensibilidade à taxa de deformação, $m$ (caso dos ensaios de tração a quente, foco desse trabalho) onde temperatura, T e tamanho de grão, $d$ são constantes.

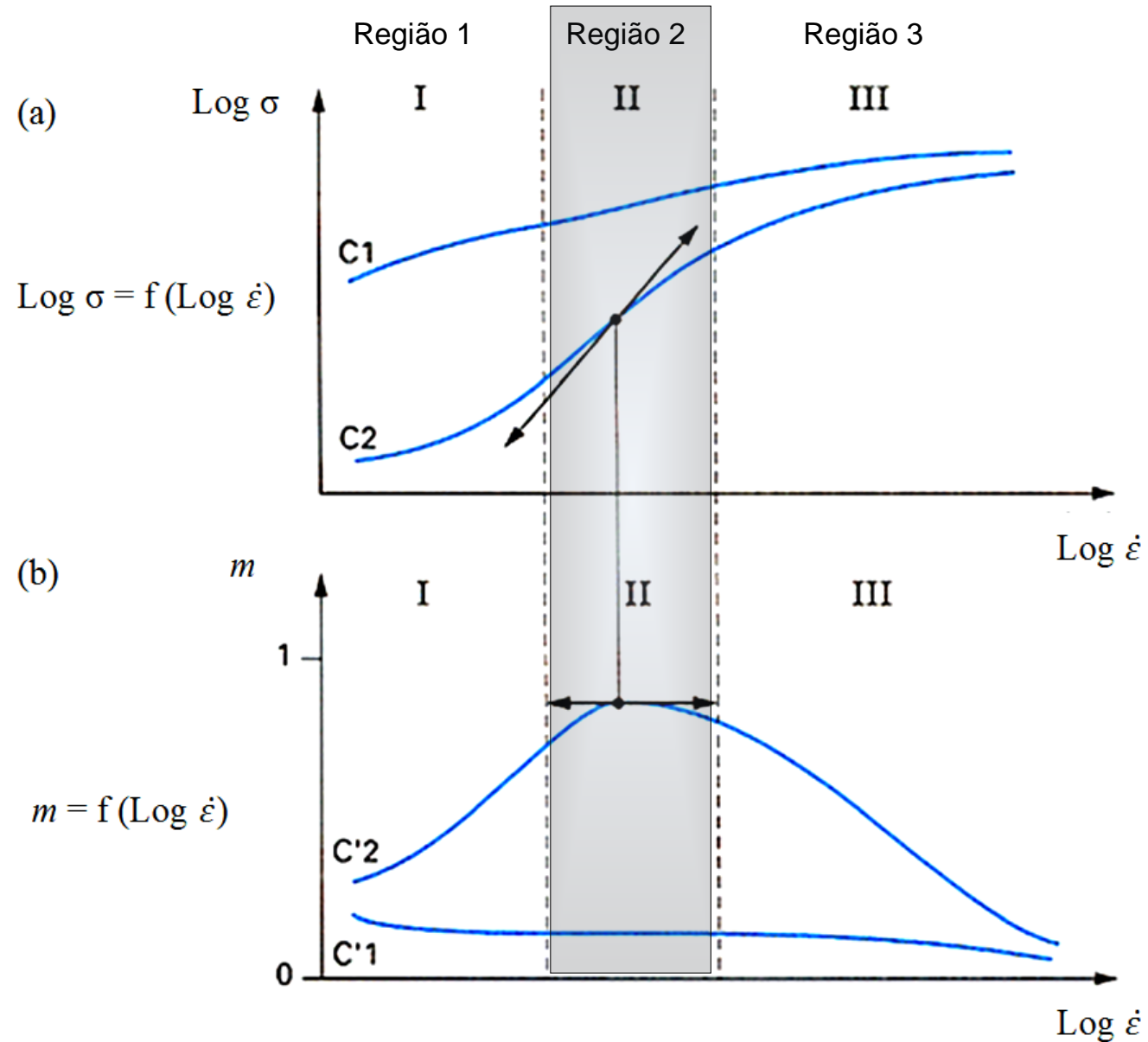

Figura 2.9. Gráfico da dependência do $\log \sigma \mathrm{X} \log \dot{\varepsilon}$ e $\mathrm{m} \times \log \dot{\varepsilon}$ para material convencional (C1 e C1') e superplástico (C2 e C2'). Destaque para a região 2 na qual ocorre a superplasticidade. (BLANDIN, 1996)

Na região 1, a influência da velocidade no mecanismo de deformação é muito baixa, e a exata indicação do porque ainda não é bem entendida. Os resultados nessa região são frequentemente limitados e inconsistentes. (SAMEKTO, 2005);

Na região 3, ocorrem grandes deformações em grãos individuais, devido a múltiplos deslizamentos. Nessa região o coeficiente de sensibilidade $\mathrm{m}$ assume geralmente valores próximos a 0,2. O mecanismo predominante de deformação é a movimentação de discordâncias. (SAMEKTO, 2005)

Na região 2, a existência de uma região estacionária é conhecida, na qual a velocidade de deformação é constante. É comumente aceito que a existência do estado 
estacionário é o resultado de um equilíbrio entre encruamento e um processo de recuperação de amolecimento. $O$ Valor de $m$ é máximo e deveria ser igual ou maior que 0,5. O fenômeno de superplasticidade ocorre nessa região.

\subsubsection{Temperatura}

As técnicas de conformação que envolvem temperatura podem ser divididas em dois grupos:

- Conformação a morno - abaixo da temperatura de recristalização.

- Conformação a quente - acima da temperatura de recristalização.

A influência da temperatura na relação tensão - taxa de deformação foi documentada para uma série de materiais.

O aumento da temperatura de deformação implica nas seguintes mudanças:

- A tensão de escoamento diminui, conforme exemplificado pela Figura 2.10; é importante ressaltar que a dependência desse parâmetro com a temperatura é muito maior nos materiais que apresentam comportamento superplástico que nos materiais convencionais (de grãos grosseiros).

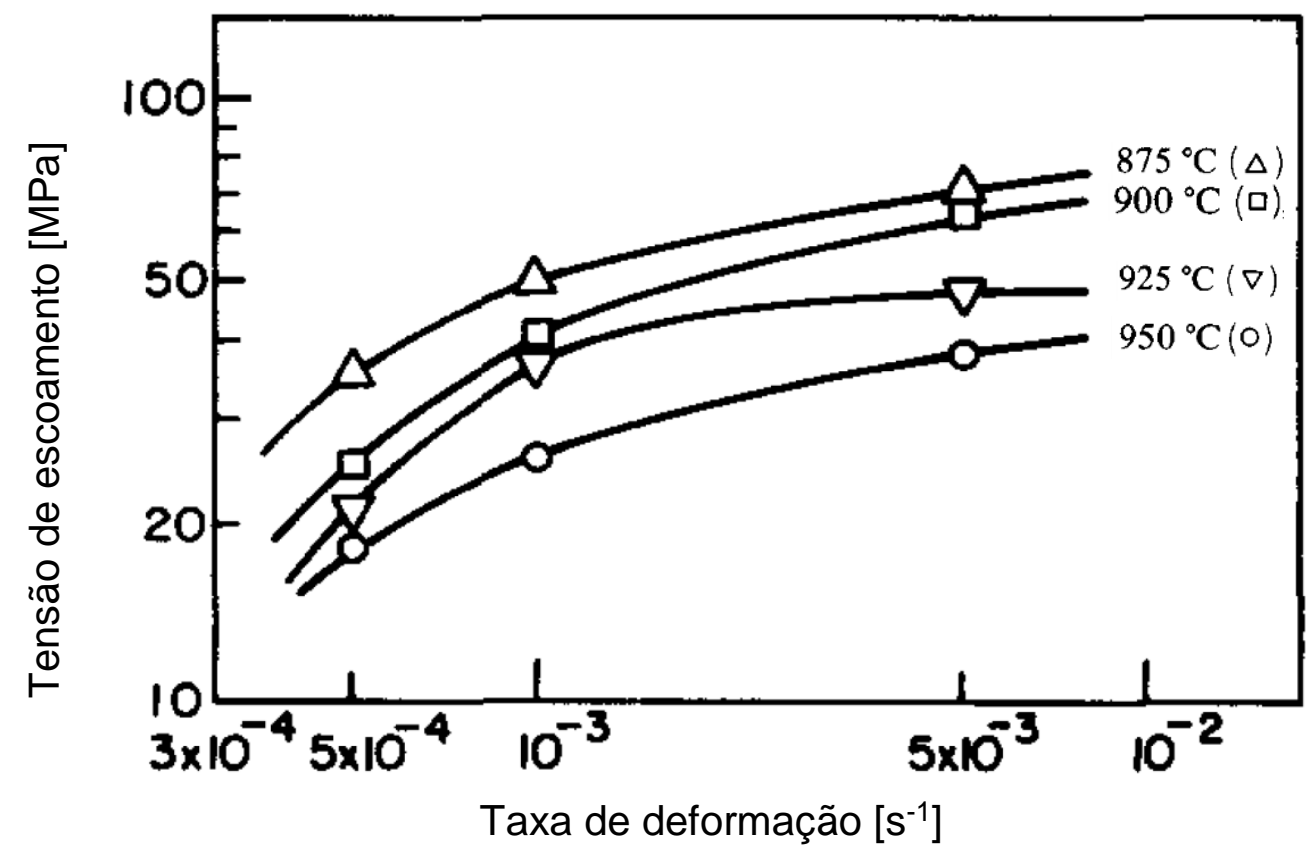

Figura 2.10 Queda da tensão de escoamento devido aumento de temperatura para diversas taxas de conformação da liga Ti6Al4V. (JAIN,1991) 
- O valor máximo, como também ótimo do ponto de vista de controle, de $\mathrm{m}$ aumenta e é deslocado para taxas de deformação maiores.

- A região II na Figura 2.9, é deslocada para taxas de deformação maiores.
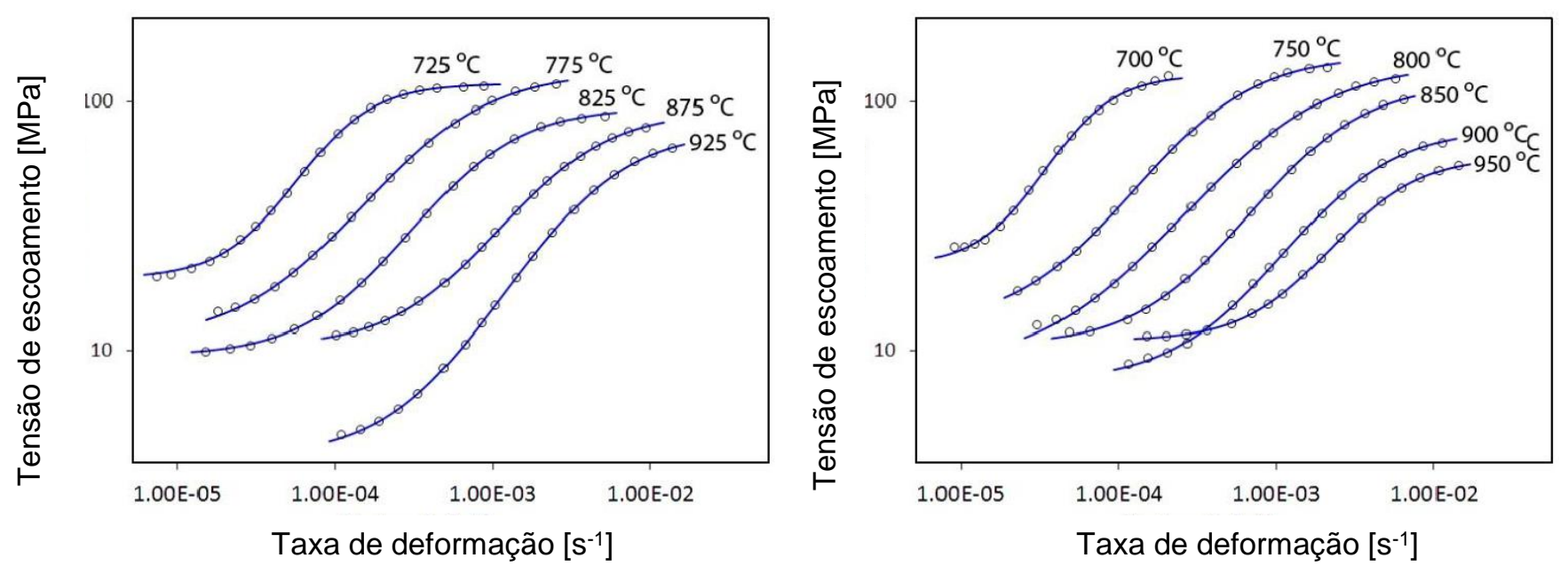

Figura 2.11 Deslocamento da região 2 devido aumento de temperatura para diversas taxas de deformação da liga Ti6AI4V. (AKSENOV, 2012) 


\subsubsection{Tamanho de grão}

A taxa de deformação para superplasticidade é inversamente proporcional ao crescimento de grão quando GBS é o processo controlador da taxa de deformação. (SHERBY, 1984)

$$
\dot{\varepsilon} \propto d^{-p}
$$

Geralmente a taxa de deformação é inversamente proporcional ao crescimento de grão na segunda ou terceira potência, dessa forma $p=2$ ou $p=3$. Do ponto de vista da tensão de escoamento, para uma dada taxa de deformação, a tensão de escoamento diminui quando o tamanho de grão diminui, diminuem-se dessa forma as forças aplicadas durante um processo de Conformação Superplástica.

O comportamento superplástico é apenas observado em materiais com grãos pequenos, geralmente $<10 \mu \mathrm{m}$. Abaixo desse valor, a diminuição do tamanho de grão implica em mudanças similares àquelas observadas com o aumento da temperatura. A Figura 2.12 mostra a relação do tamanho de grão com o índice de sensibilidade a taxa de deformação para a liga Ti-6Al-4V. É possível observar que o comportamento superplástico não ocorre em tamanhos de grão maiores que $20 \mu \mathrm{m}$.

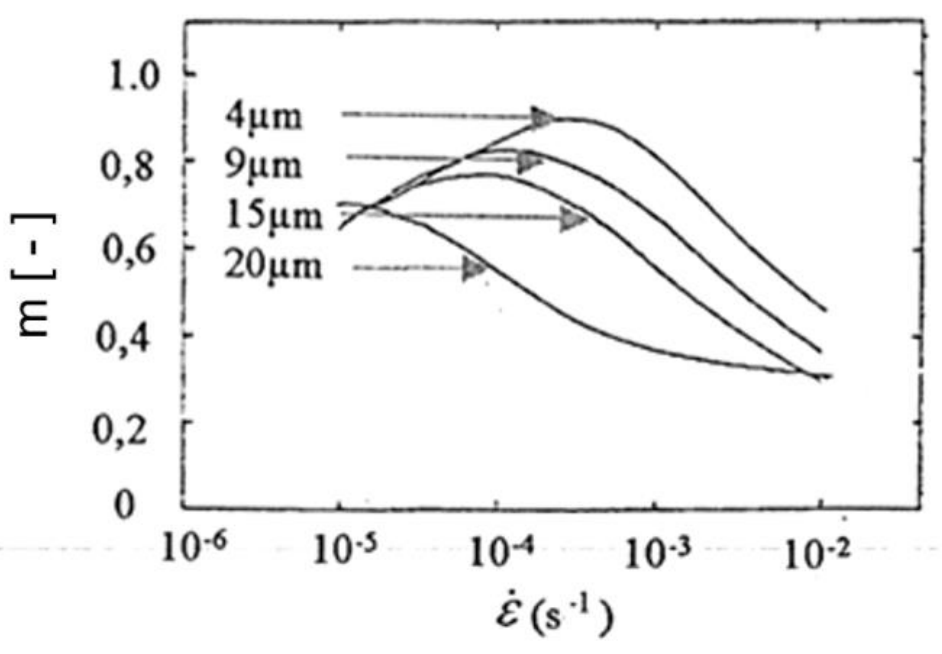

Figura 2.12. Curvas $\mathrm{m}$ versus $\dot{\varepsilon}$ para a liga de titânio Ti-6Al-4V com diferentes tamanhos de grão conformados a $927^{\circ} \mathrm{C}$. (GHOSH, 1982).

Ainda para a liga Ti-6Al-4V, a Figura 2.13 compara o alongamento para dois tamanhos de grão diferentes, 3 e $0,3 \mu \mathrm{m}$, a 775 e $875^{\circ} \mathrm{C}$ e taxas variando de $10^{-4}$ a $10^{-1} \mathrm{~s}^{-1}$. 


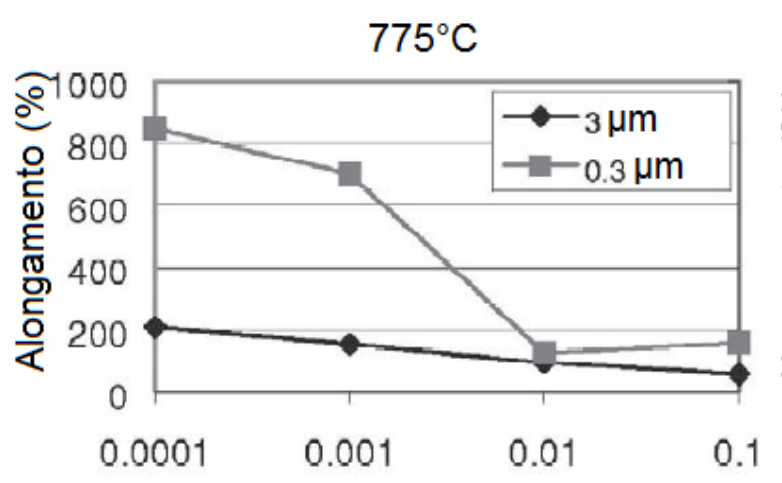

Taxa de deformação [ $\left.\mathbf{s}^{-1}\right]$ $875^{\circ} \mathrm{C}$

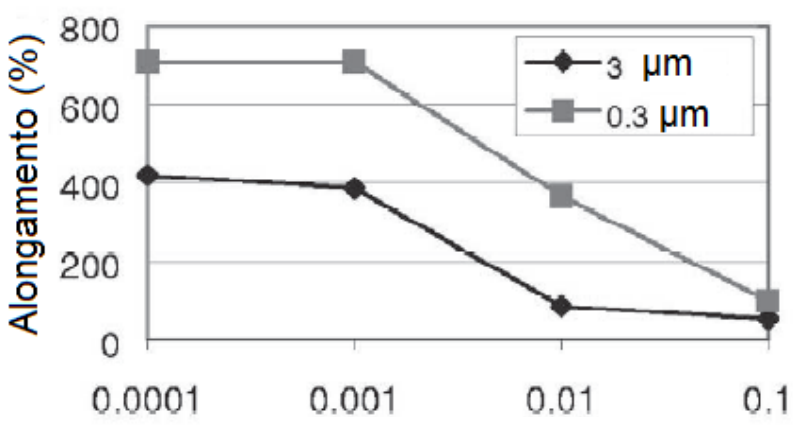

Taxa de deformação $\left[\mathbf{s}^{-1}\right]$

Figura 2.13. Variação da ductilidade em função da taxa de deformação para a liga Ti6Al-4V com diferentes tamanhos de grão a $775^{\circ} \mathrm{C}$ (a) e $875^{\circ} \mathrm{C}$ (b). (PANTAKAR, 2002)

Da Figura 2.13 observa-se que o alongamento aumenta com a diminuição do tamanho de grão em todas as condições e que esse comportamento é mais acentuado com a diminuição da temperatura e taxa de deformação.

\subsubsection{Mecanismo de deformação superplástica}

Para dar um enfoque de mecanismo nas três regiões da Figura 2.9, utiliza-se a versão expandida da curva sigmoidal característica da superplasticidade - Figura 2.14, e divide-se novamente nas três regiões anteriormente analisadas.

Na região 1 a forma da curva logarítmica pode mudar, para muitas ligas "m" é baixo ( $m=0.2$ ) e a interpretação desse fenômeno evidencia a existência de uma tensão limite de elasticidade (threshold stress) baixa para superplasticidade. Contudo, propõe-se que a existência da região 1 está relacionada com a segregação dos átomos de impurezas para o contorno de grão, onde eles interagem com o movimento das discordâncias do contorno que contribuem para o GBS. O maior problema dessa região deve-se ao fato que devido à lenta taxa, há a grande influência do crescimento de grão, afetando a tensão de escoamento e complicando a interpretação dessa região. (GIULIANO,2011)

$\mathrm{Na}$ região 3 acredita-se que o empilhamento de discordâncias é o processo de controle da taxa de deformação. Ocorre alta densidade de discordâncias nos grãos, a textura cristalográfica aumenta e ocorre significativo elongamento dos grãos. (GIULIANO,2011) 


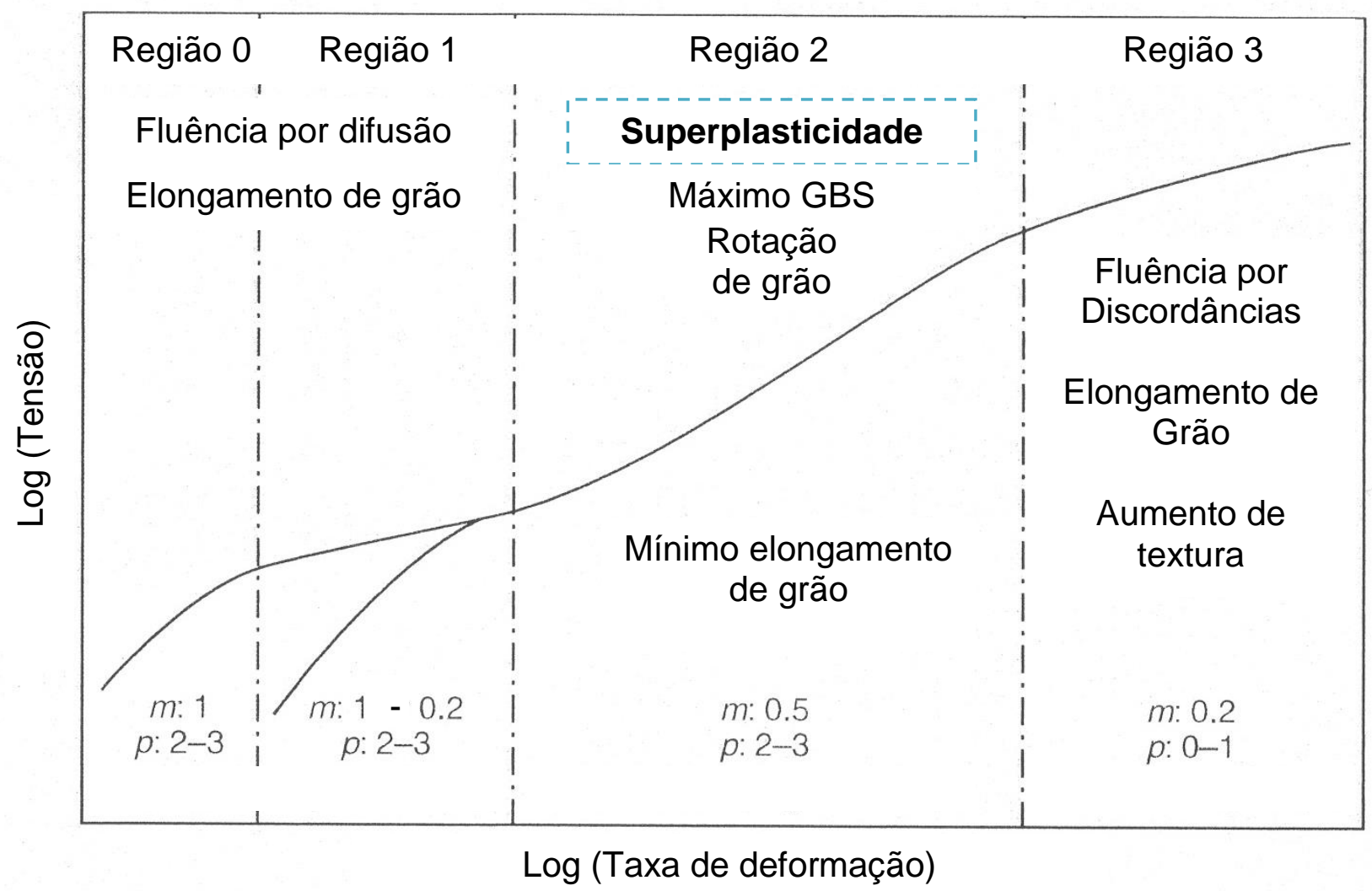

Figura 2.14. Versão expandida da curva sigmoidal com foco nos mecanismos de deformação, explicita m e p para cada região. (GIULIANO,2011)

Na região 2, região superplástica, vários trabalhos em superplasticidade sustentam a ideia do GBS como processo dominante superplástico, frequentemente referem-se ao trabalho de Rachinger (RACHINGER, 1952). Se o GBS ocorre em um sistema completamente rígido, então vazios deveriam aparecer na microestrutura. Contudo, como nem todos os materiais cavitam durante o escoamento superplástico, deve ocorrer acomodação nos deslizamentos do contorno. Entenda-se por acomodação movimento de discordâncias e/ou processos de difusão. (GIULIANO,2011)

A deformação superplástica está relacionada ao mecanismo de escorregamento dos grãos uns sobre os outros, do inglês "Grain boundaries sliding" (GBS) e, como ocorre na fluência ${ }^{2}$, a acomodação da deformação pode resultar de processos difusionais e/ou movimentação de discordâncias. Existe uma série de modelos baseados nesse princípio sendo uns dos mais conhecidos o proposto por Ashby e Verral (ASHBY, 1973) que é descrito a seguir.

Os processos difusionais na superplasticidade são análogos à fluência de NabarroHerring e Coble que resultam do gradiente de concentração de vacâncias no grão sob

\footnotetext{
${ }^{2}$ A fluência é uma deformação ao longo do tempo de um material submetido a uma carga ou tensão constante.
} 
tensão. No entanto, na fluência de Nabarro-Herring o transporte de massa ocorre por difusão volumétrica e na fluência de Coble ocorre ao longo dos contornos de grão (COURTNEY, 2000). Como proposto originalmente por Ashby e Verral (ASHBY, 1973), no mecanismo de escorregamento dos grãos a forma deste é preservada. A Figura 2.15 apresenta uma configuração bidimensional de quatro grãos antes Figura 2.15(a), depois Figura 2.15(c), e em um estágio intermediário do processo de escorregamento de grãos, Figura 2.15(b).

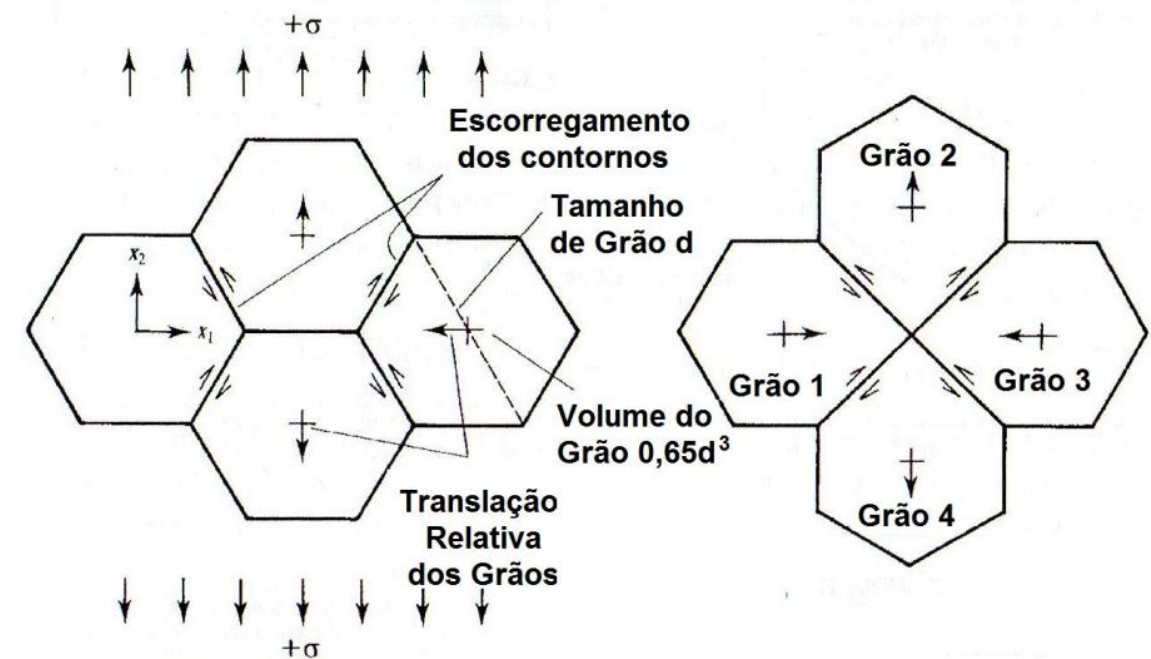

(a) Estado Inicial

(b) Estado Intermediário

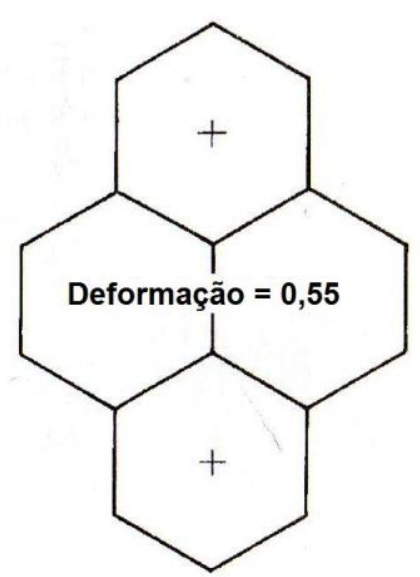

(c) Estado Final

Figura 2.15. Desenho esquemático do mecanismo de escorregamento de grãos. (ASHBY, 1973)

Da Figura 2.15 observa-se que no estágio intermediário, há um aumento na área de contornos de grão em relação aos estágios final e inicial, ou seja, a tensão aplicada deve superar o trabalho associado com a formação e aumento na área de contornos de grão. $O$ processo difusional é responsável pela acomodação da forma nesse estágio como mostrado na Figura 2.16.

Desde que a tensão supere àquela necessária para atingir o estágio intermediário, a taxa de deformação para o mecanismo de GBS é maior se comparado ao mecanismo de fluência convencional, o que está relacionado à geometria do primeiro mecanismo. Comparando os dois mecanismos é importante ressaltar que o volume de material que deve ser transportado para gerar uma determinada deformação no mecanismo de GBS é aproximadamente $1 / 7$ do necessário para produzir a mesma deformação via fluência. Adicionalmente, a distância de difusão nesse é reduzida por um fator de aproximadamente 3 em relação à fluência. Isso resulta em uma taxa de deformação uma ordem de grandeza maior que por fluência. Ashby e Verral (ASHBY, 1973), considerando o transporte de massa 
em volume e em contornos desenvolveram a equação (24) para descrever a taxa de escorregamento dos grãos, conhecida como "The constitutive equation for diffusionaccommodated flow".

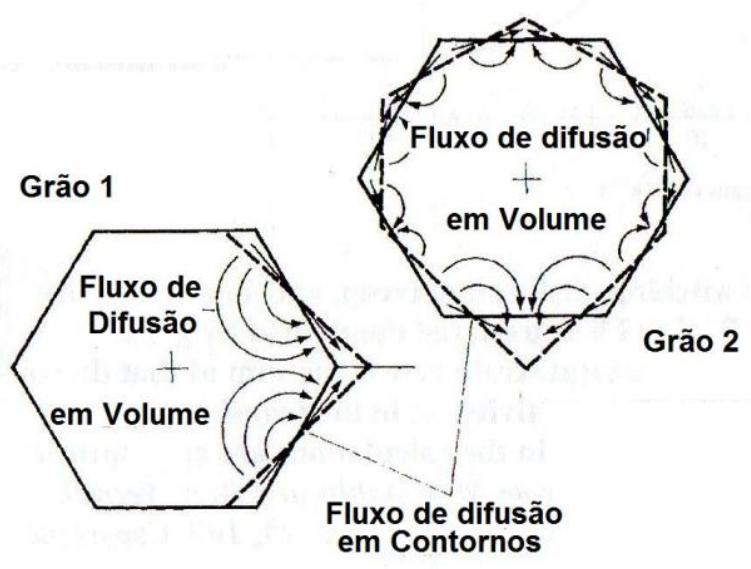

Figura 2.16. Desenho esquemático mostrando o fluxo de difusão, em volume e nos contornos, durante a mudança de forma do grão no estágio intermediário. (ASHBY, 1973)

$$
\dot{\varepsilon}_{\mathrm{GS}} \cong \frac{100 \Omega}{\mathrm{kTd}^{2}}\left(\sigma-0,72 \frac{\gamma}{\mathrm{d}}\right) \mathrm{D}_{\mathrm{v}}\left(1+\frac{3,3 \delta^{\prime} \mathrm{D}_{\mathrm{GB}}}{\mathrm{dD}_{\mathrm{L}}}\right)
$$

$\dot{\varepsilon}_{\mathrm{GS}}=$ Taxa de deformação do escorregamento de grãos; $\sigma=$ Tensão de deformação; $\Omega=$ Volume atômico; $d$ = Diâmetro de grão; $\gamma=$ Energia de superfície de contorno de grão; $D_{v}=$ Coeficiente de difusão volumétrica; $D_{G B}=$ Coeficiente de difusão dos contornos; $\delta^{\prime}=$ Largura do contorno de grão; $\mathrm{T}$ = Temperatura absoluta; $\mathrm{k}$ = Constante de Boltzmann.

O termo 0,72 y/d representa a tensão necessária para atingir o estágio intermediário. Se somente o transporte de massa pelos contornos é importante, logo $3,3 \delta^{\prime} \mathrm{D}_{\mathrm{GB}}>>\mathrm{dD}_{v}$, a equação se reduz para:

$$
\dot{\varepsilon}_{\mathrm{GS}} \cong \frac{330 \Omega}{\mathrm{kT}} \frac{\delta^{\prime} \mathrm{D}_{\mathrm{GB}}}{\mathrm{d}^{3}}\left(\sigma-0,72 \frac{\gamma}{\mathrm{d}}\right)
$$

e o mecanismo de GBS poder ser considerado competitivo com a fluência de Coble, e a domina quando a tensão é maior que 0,72 y/d.

Além de processos difusivos, o mecanismo de GBS compete com o mecanismo de fluência por discordâncias, sendo o último dominante em altos níveis de tensão. Como os 
processos difusivos e por discordâncias operam em paralelo, a taxa de deformação é resultado da soma da contribuição de cada processo individualmente. A Figura 2.17 apresenta a relação entre os mecanismos de GBS, fluência por discordâncias, e superplasticidade proposto por Ashby e Verral (ASHBY, 1973). A região a esquerda (azul) é dominante para GBS e a região a direita (vermelha) para fluência por discordâncias. A região de transição é caracterizada por um rápido aumento na tensão com a taxa de deformação que caracteriza o comportamento superplástico, evidencia-se assim a contribuição de ambos os mecanismos (azul e vermelho).

Os mecanismos de superplasticidade baseados no movimento de discordâncias estão associados a um tamanho de grão fino. Dessa forma, as discordâncias são emitidas e capturadas pelos contornos de grão e raramente são observadas no interior destes em materiais deformados no regime superplástico. A maioria dos modelos de superplasticidade baseados em discordâncias chega a equações constitutivas da seguinte forma:

$$
\dot{\varepsilon}_{\mathrm{DS}}=\mathrm{CD}\left(\frac{\sigma \Omega}{\mathrm{kT}}\right)\left(\frac{\sigma}{\mathrm{G}}\right)\left(\frac{\mathrm{b}}{\mathrm{d}}\right)^{2}
$$

onde C é uma constante que depende do modelo, e D é o coeficiente de difusão nos contornos.

Em comum com o modelo de Ashby e Verral, os modelos de discordâncias para a superplasticidade consideram, na Figura 2.17, a região vermelha a direita controlada por fluência por discordância. Em contraste, a Região de transição apresenta um mecanismo independente de superplasticidade e não um estágio de transição.(COURTNEY, 2000).

Em uma recente revisão, Guanabara e Batalha (Guanabara e Batalha, 2009) apresentaram um resumo de alguns modelos de superplasticidade. Extraída desse trabalho, a Tabela 2.2 apresenta alguns modelos propostos para superplasticidade baseados no princípio de GBS acomodado por movimento de discordâncias. É importante ressaltar que apesar de apresentar mecanismo de deformação similar à fluência, a superplasticidade necessita de condições microestruturais específicas para ocorrer, a mais importante é o tamanho de grão fino, <10 $10 \mathrm{~m}$, separado por contornos de alto ângulo ${ }^{3} \mathrm{e}$ estável em altas temperaturas. Assim, apenas um número pequeno de ligas comerciais irá apresentar comportamento superplástico sob conformação.

\footnotetext{
${ }^{3}$ Quando o desalinhamento entre os grãos vizinhos é grande (maior que $\sim 15^{\circ}$ ), o contorno formado é chamado contorno de grão de alto ângulo. Se o desalinhamento é pequeno (em geral, menor que $5^{\circ}$ ), o contorno é chamado contorno de pequeno ângulo, e as regiões que tem essas pequenas diferenças de orientação são chamadas de subgrãos.
} 


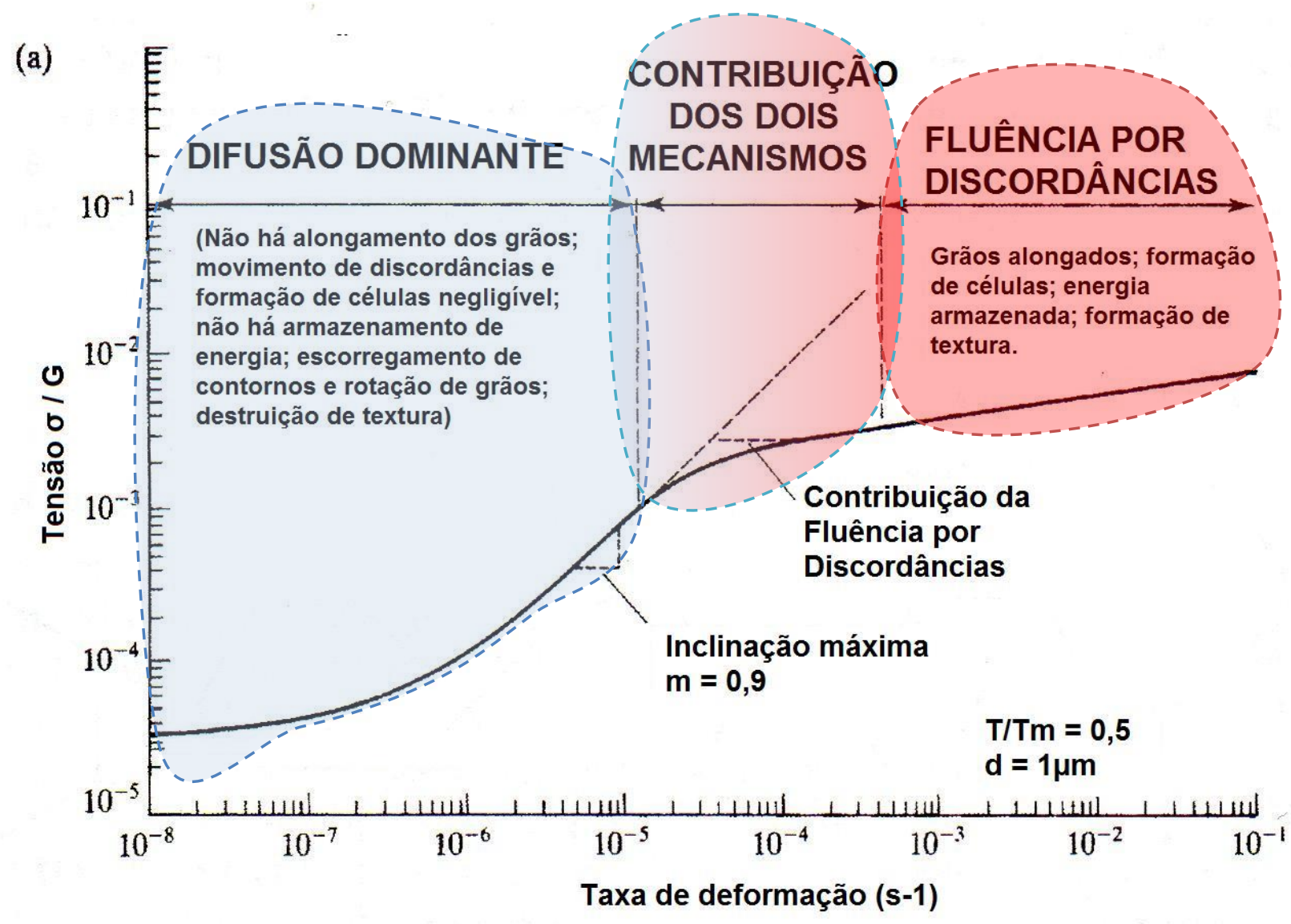

(b)

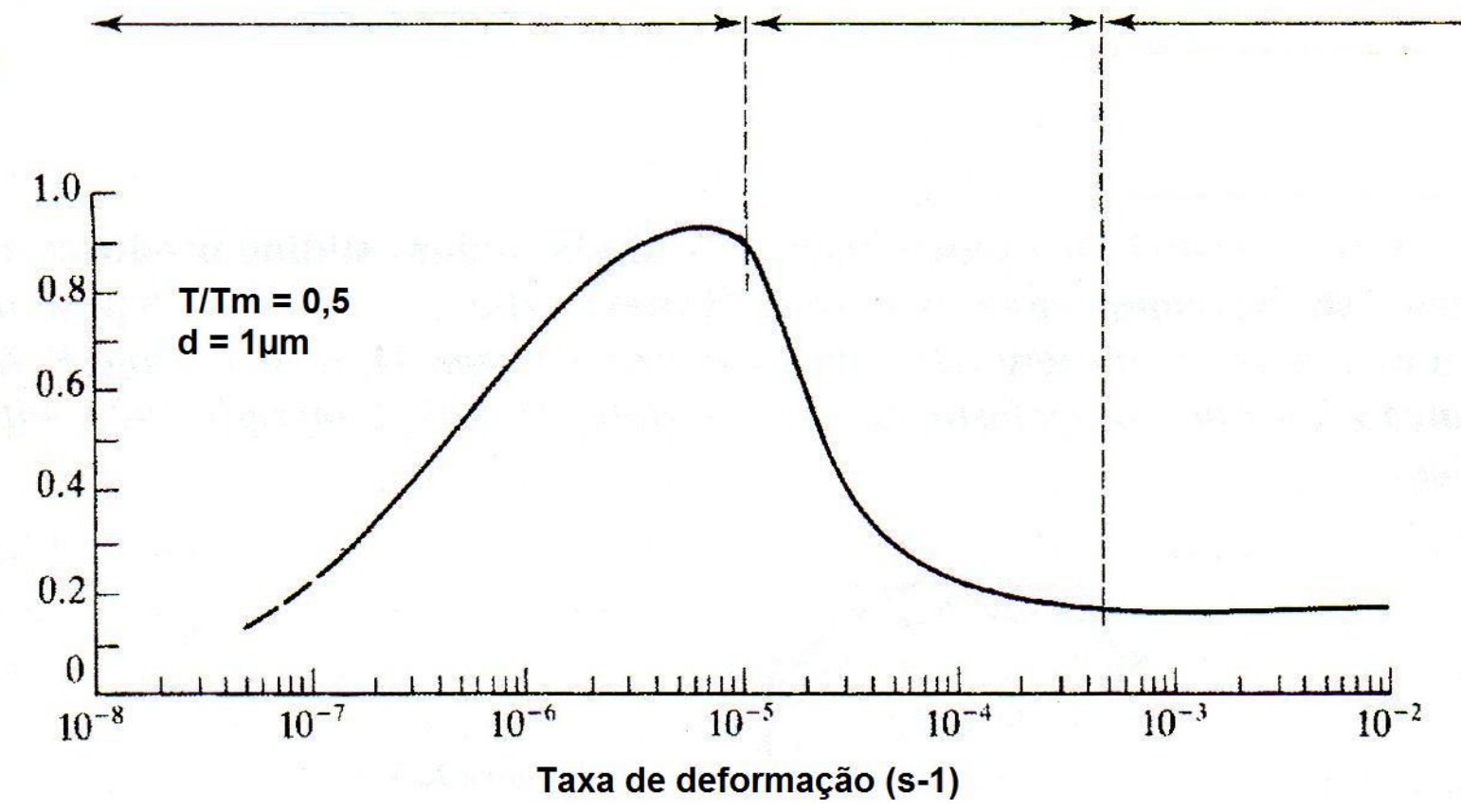

Figura 2.17. Relação entre os mecanismos de comutação dos grãos, fluência por discordâncias, e superplasticidade. (ASHBY, 1973) 
Tabela 2.2. Alguns modelos de superplasticidade propostos baseados no princípio de GBS. (Adaptado de Nieh, 2007)

\begin{tabular}{|c|c|c|}
\hline Autor & Aspectos Importantes & Equação Constitutiva \\
\hline $\begin{array}{l}\text { Ball e Hutchson } \\
\text { (1969) }\end{array}$ & $\begin{array}{l}\text { Mostraram que os grãos se } \\
\text { movimentam em grupos circundados } \\
\text { por grãos orientados de forma } \\
\text { desfavorável à deformação. A } \\
\text { relaxação da tensão ocorre com o } \\
\text { movimento de discordâncias nesses } \\
\text { grãos. }\end{array}$ & $\begin{array}{r}\dot{\varepsilon}=k_{1}\left(\frac{b}{d}\right)^{2} D_{g b}\left(\frac{\sigma}{E}\right)^{2} \\
(27)\end{array}$ \\
\hline Muhkerjee (1971) & 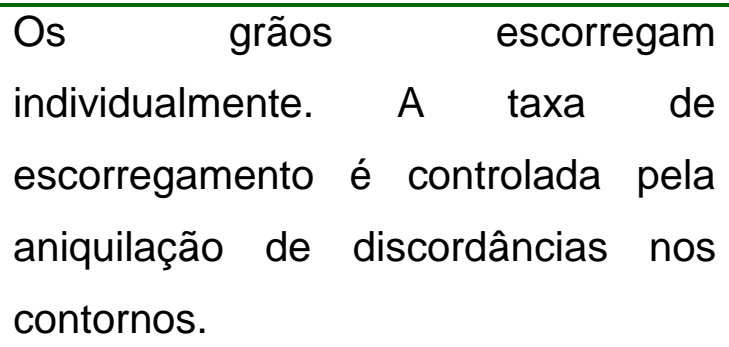 & $\begin{array}{r}\dot{\varepsilon}=\mathrm{k}_{2}\left(\frac{\mathrm{b}}{\mathrm{d}}\right)^{2} \mathrm{D}_{\mathrm{gb}}\left(\frac{\sigma}{\mathrm{E}}\right)^{2} \\
(\mathbf{2 8})\end{array}$ \\
\hline Langdon (1970) & $\begin{array}{l}\text { O GBS ocorre pelo movimento de } \\
\text { discordâncias ao longo dos contornos } \\
\text { de grão pela combinação de } \\
\text { escorregamento e escalagem. }\end{array}$ & $\dot{\varepsilon}=k_{3}\left(\frac{b}{d}\right)^{2} D_{L}\left(\frac{\sigma}{E}\right)^{2}$ \\
\hline Gifkins (1976) & $\begin{array}{l}\text { GBS se dá pelo movimento de } \\
\text { discordâncias nos contornos de grão } \\
\text { que se acumulam nas junções triplas. }\end{array}$ & $\begin{array}{r}\dot{\varepsilon}=\mathrm{k}_{4}\left(\frac{\mathrm{b}}{\mathrm{d}}\right)^{2} \mathrm{D}_{\mathrm{gb}}\left(\frac{\sigma}{\mathrm{E}}\right)^{2} \\
(30)\end{array}$ \\
\hline $\begin{array}{l}\text { Perevezentsev } \\
\text { et al (1992) }\end{array}$ & $\begin{array}{l}\text { O comportamento superplástico está } \\
\text { relacionado à modificação da } \\
\text { natureza dos contornos de grão que } \\
\text { passam a exibir um estado excitado, o } \\
\text { que facilita o processo de GBS. }\end{array}$ & $\dot{\varepsilon}=k_{5}\left(\frac{b}{d}\right)^{2} D_{g b}\left(\frac{\sigma}{E}\right)^{2}$ \\
\hline
\end{tabular}

A Tabela 2.3 apresenta algumas diferenças microestruturais e mecânicas em materiais convencionais e superplásticos. 
Tabela 2.3. Diferenças microestruturais e mecânicas em materiais convencionais e superplásticos

\begin{tabular}{ccc}
\hline Parâmetro & Materiais & Materiais \\
\hline Sensibilidade à taxa & Superplásticos & Convencionais \\
de deformação & Alta $(\mathrm{m}>0,5)$ & Baixa $(\mathrm{m} \rightarrow 0)$ \\
\hline Endurecimento por & Baixo $(\mathrm{n} \rightarrow 0)$ & Alto \\
deformação & & Movimento de \\
\hline Mecanismo de & GBS & discordâncias \\
deformação & & Aumenta \\
\hline Textura & Diminui & Aumenta \\
\hline Anisotropia & Diminui & \\
\hline
\end{tabular}

Para ilustrar a diferença de comportamento da microestrutura entre um processo de conformação clássico e um processo superplástico, destaca-se a Figura 2.18, com a evolução da microestrutura e da textura de uma conformação plástica, e a Figura $2.19 \mathrm{com}$ o mesmo esquemático para a superplasticidade. 


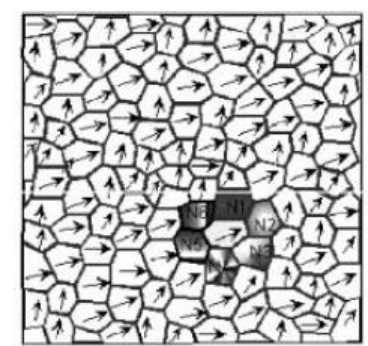

Microestrutura inicial

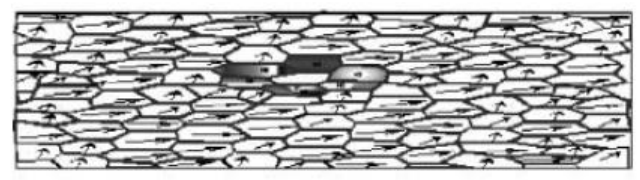

Microestrutura intermediária
Posição da vizinhança do grão - (inalterada)
Direção de aplicação de tensão
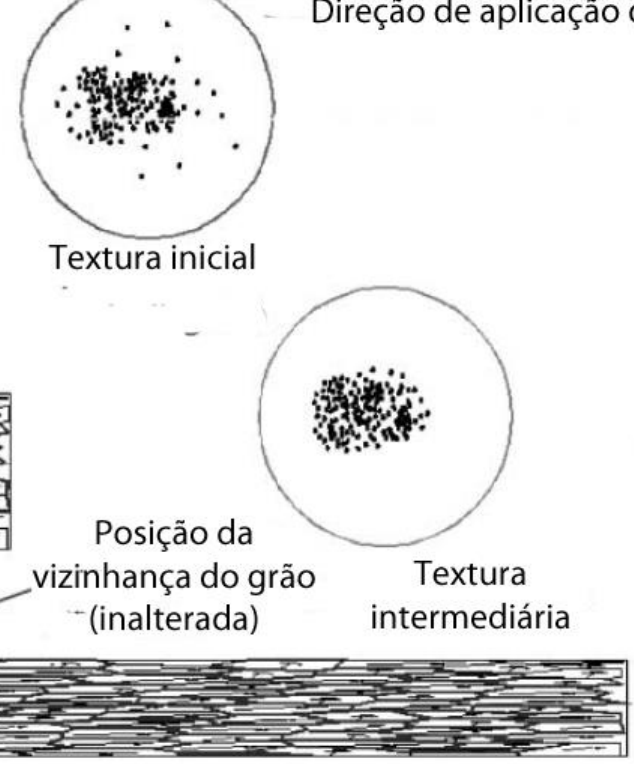

Microestrutura final
Aumento do nível de deformação plástica

Figura 2.18. Evolução da microestrutura e textura durante a deformação plástica. (CHANDRA,2000)

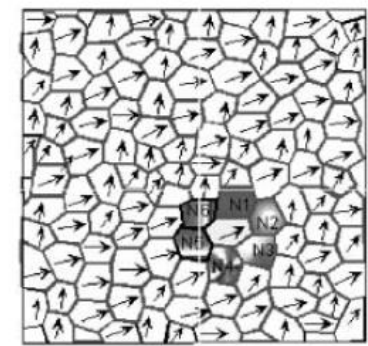

Microestrutura inicial

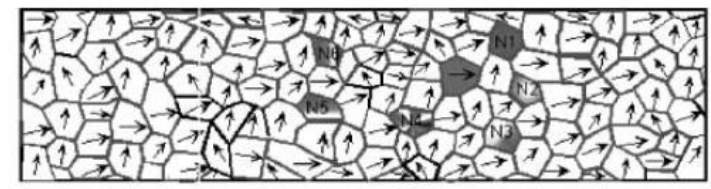

Microestrutura intermediária
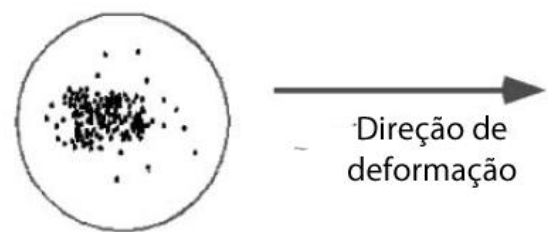

Textura Inicial

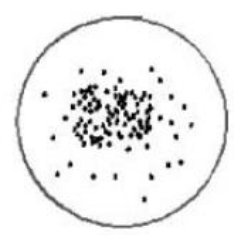

- Textura intermediária
Aumento da deformação superplásica

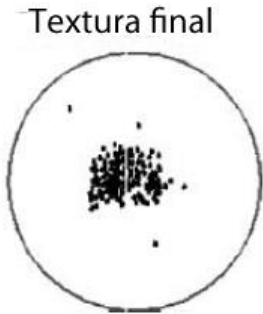

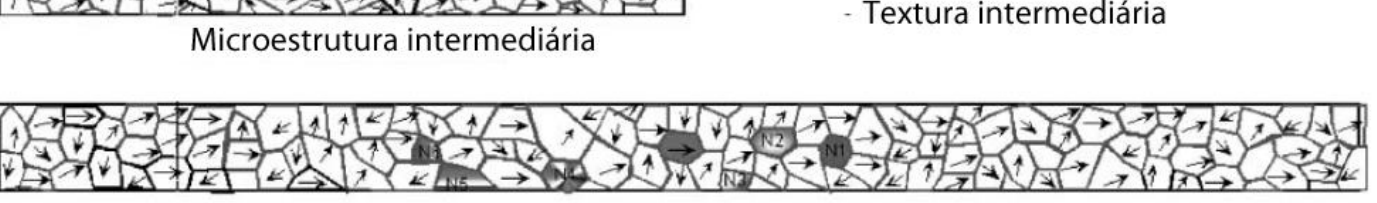

Microestrutura final

Figura 2.19. Evolução da microestrutura e textura durante a deformação superplástica. (CHANDRA,2000) 


\subsubsection{Métodos de Caracterização Reológica}

Os ensaios de tração, pela simplicidade e facilidade de realização, são os mais utilizados para levantar os parâmetros reológicos dos materiais ( $m, n$ e K) no que cerne a superplasticidade, por mais que não sejam ensaios que traduzam os requisitos reais de conformação em alguns aspectos. Por exemplo, as tensões aplicadas nos ensaios de tração comuns são unidimensionais enquanto que numa expansão fluidoestática biaxial a tensão considerada é sempre bidimensional.

\subsubsection{Ensaios uniaxiais}

Como a superplasticidade ocorre em alta temperatura o "m" pode ser determinado por ensaios de tração a quente convencional, utilizando a equação (32), ou em máquinas de fluência, ou seja, com carga constante. No segundo caso, a taxa de deformação é medida em função da tensão aplicada através da seguinte relação:

$$
\dot{\varepsilon}=A(\sigma)^{\frac{1}{m}}
$$

A Figura 2.20 apresenta um desenho esquemático do procedimento para calcular o m a partir de curvas experimentais obtidas dos ensaios mecânicos.
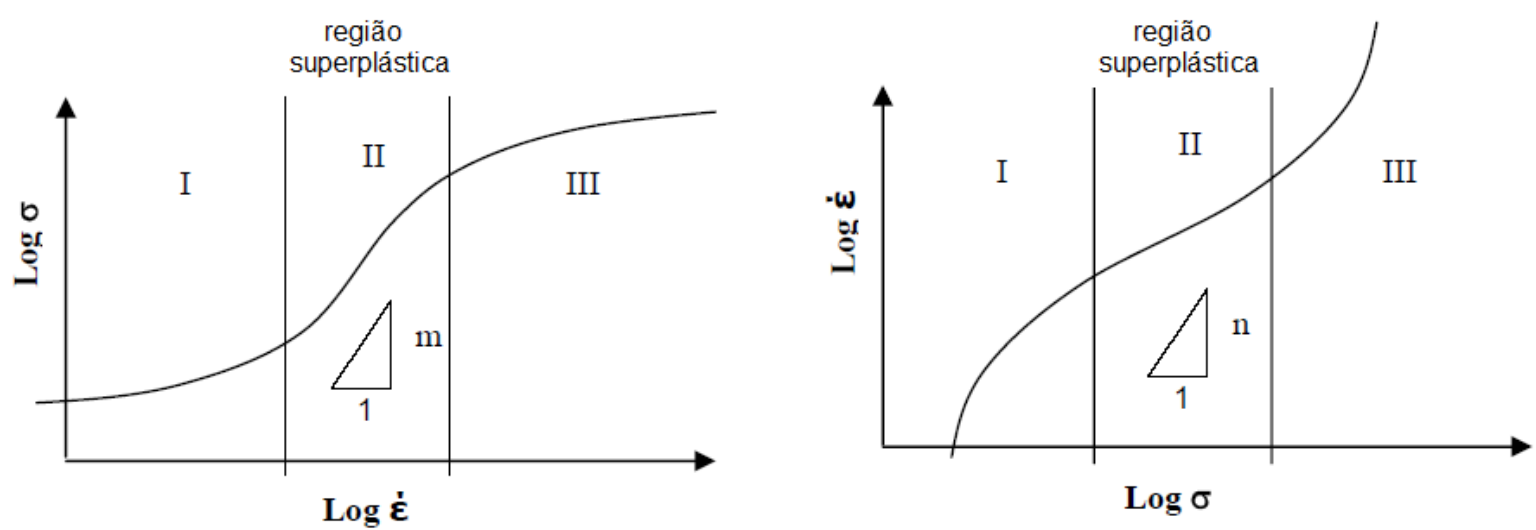

Figura 2.20. Desenho esquemático do procedimento para calcular o $\mathrm{m}$ a partir de curvas experimentais obtidas dos ensaios mecânicos. (a) tração a quente (b) fluência (GUANABARA, 2005). 
Por outro lado, é possível realizar ensaios de tração a quente com taxa constante para diferentes taxas de deformação. A deformação verdadeira está relacionada com o comprimento da área útil do corpo de prova (I) da seguinte maneira:

$$
\varepsilon_{v}=\ln \left(\frac{l}{l_{0}}\right)
$$

Assim, o ensaio de tração com taxa de deformação constante pode ser realizado controlando a velocidade do travessão mantendo a relação (CHENG, 1996):

$$
\frac{\Delta l}{\Delta t}=l \cdot \dot{\varepsilon} \cdot e^{(\dot{\varepsilon} t)}
$$

Ainda em relação aos ensaios de tração a quente, é possível utilizar um único teste com velocidade variável conhecido como método de saltos. Quando o material atinge a tensão máxima, a velocidade do travessão aumenta, que por sua vez modifica a taxa de deformação e assim sucessivamente. 0 referido ensaio foi utilizado para levantar as características reológicas da liga usada na tese, TI-6Al-4V; para realizar os ensaios de tração a quente, construiu-se um forno resistivo tubular para aquecer a amostra durante o ensaio de saltos.

O mais conhecido método de determinação do expoente de velocidade $m$ é o método de saltos de velocidade de Backofen. Este método calcula o valor de $m$ através de saltos de velocidade.

Observa-se que há duas possibilidades de cálculo para determinar o $m$, baseandose em dois métodos abaixo descritos.

Método 1

$$
m=\frac{\ln \left(\frac{F_{E}}{F_{D}}\right)}{\ln \left(\frac{V_{2}}{V_{1}}\right)}
$$

Método 2

$$
m=\frac{\ln \left(\frac{F_{F}}{F_{D}}\right)}{\ln \left(\frac{V_{2}}{V_{1}}\right)}
$$

Confirma-se o sucesso do método 2 quando se compara com um teste de tração, são obtidos valores menores e mais precisos. 


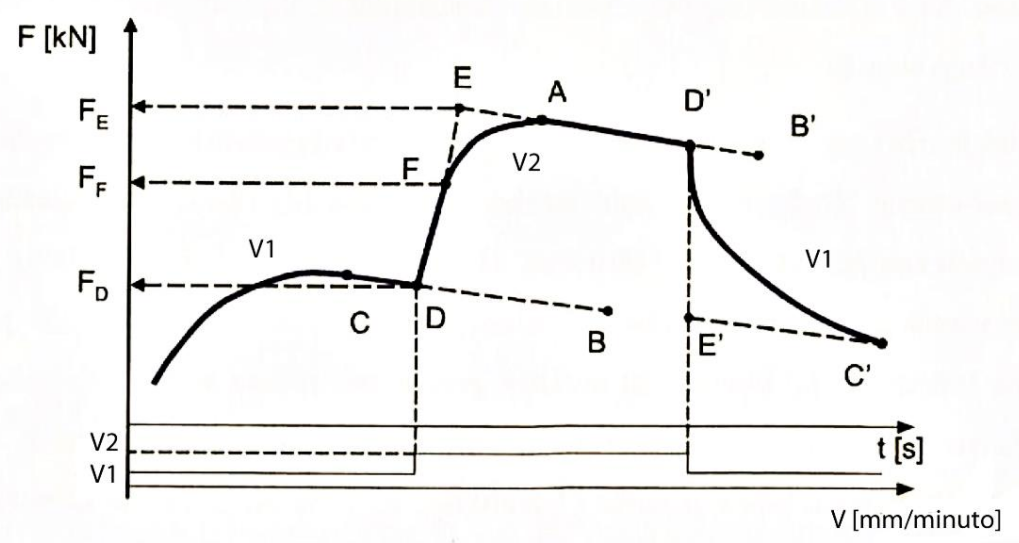

Figura 2.21. Método para determinação do valor de m (VULCAN, 2006)

Em um estudo com o aço inoxidável Fe-Mn-Al foi feita uma comparação entre o valor de $\mathrm{m}$ calculado pelo método de saltos e por tração a quente com velocidade constante (GUANABARA, 2010). A Figura 2.22 mostra as curvas obtidas dos ensaios de tração utilizando ambos os métodos e a Figura 2.23 mostra o valor de m obtido pelas duas técnicas onde é possível observar ótima concordância entre elas. Em tais resultados observa-se uma grande vantagem do ensaio de saltos, quando comparado ao ensaio de tração convencional, no ensaio de saltos utiliza-se um único corpo de prova para data condição de temperatura.
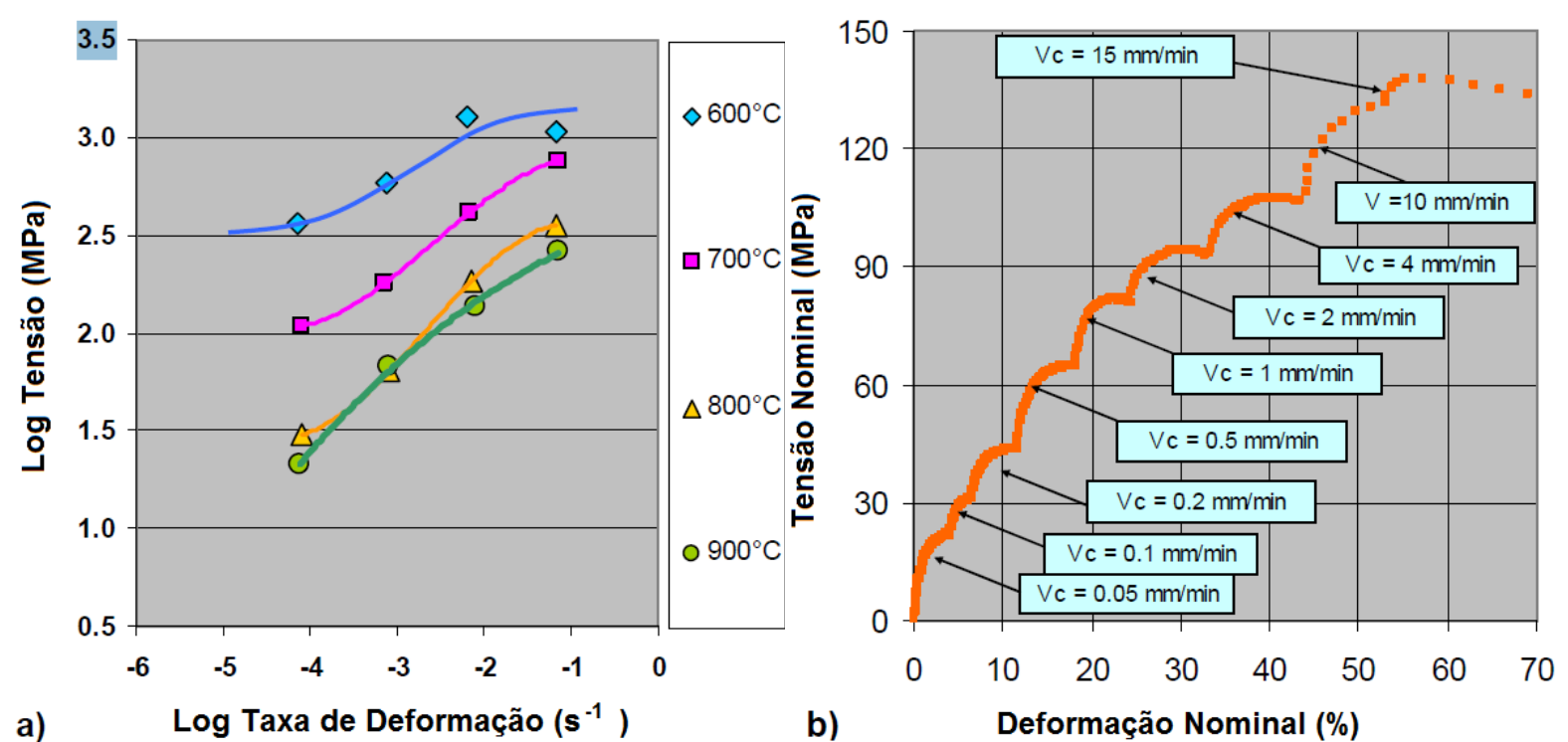

Figura 2.22. Curva do log tensão $x \log$ taxa de deformação para várias temperaturas utilizando diferentes corpos de prova (a) e curva tensão $x$ deformação utilizando o método dos saltos a $800^{\circ} \mathrm{C}$ (b). (GUANABARA, 2005) 


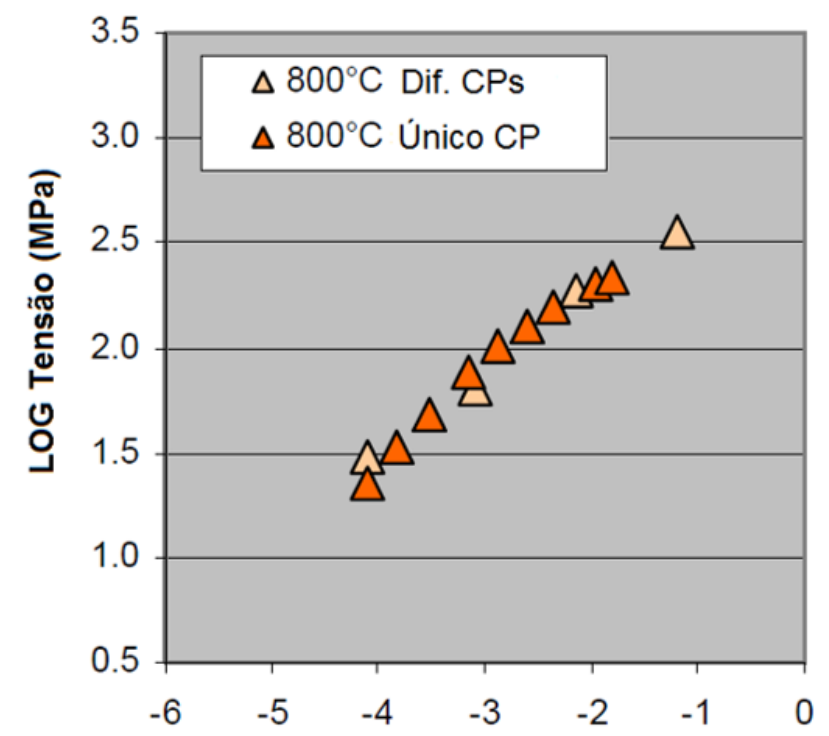

a) LOG Taxa de Deformação $\left(\mathbf{s}^{-1}\right)$

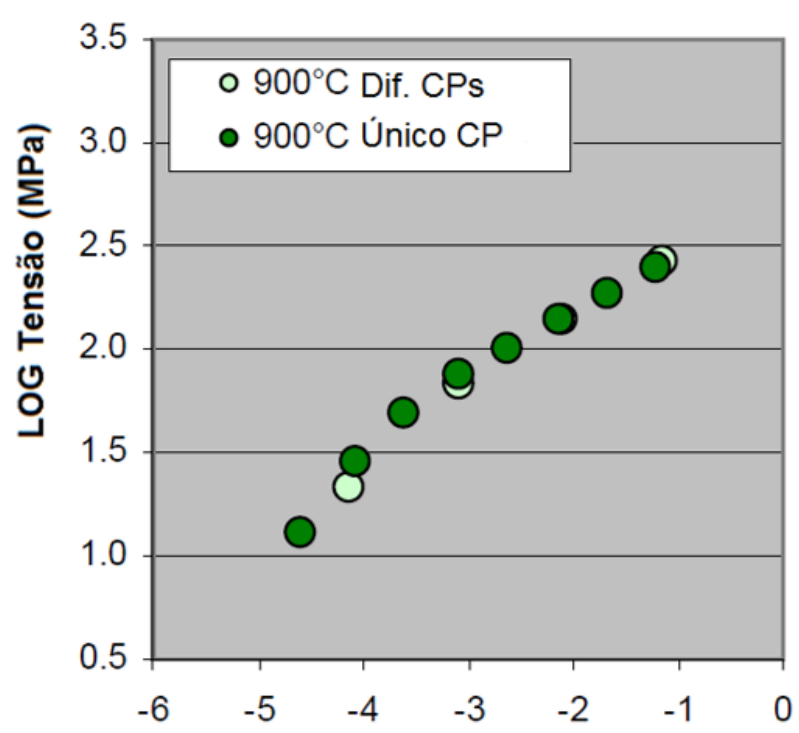

b)

LOG Taxa de Deformação $\left(\mathbf{s}^{-1}\right)$

Figura 2.23. Curva do log tensão x log taxa de deformação utilizando um único CP e diferentes CPDs a $800^{\circ} \mathrm{C}$ (a) e $900^{\circ} \mathrm{C}$ (b). (GUANABARA, 2005)

Todos os procedimentos discutidos até agora são baseados em ensaios de tração uniaxiais. No entanto, a Conformação Superplástica do ponto de vista industrial é geralmente feita em chapas, ou seja, em um estado biaxial de tensões. A necessidade de realizar ensaios e levantar propriedades mecânicas mais próximas da realidade praticada na indústria, foi a motivação que levou ao desenvolvimento de novas técnicas de caracterização do comportamento superplástico. 


\subsubsection{Ensaios biaxiais - expansão fluidoestática biaxial}

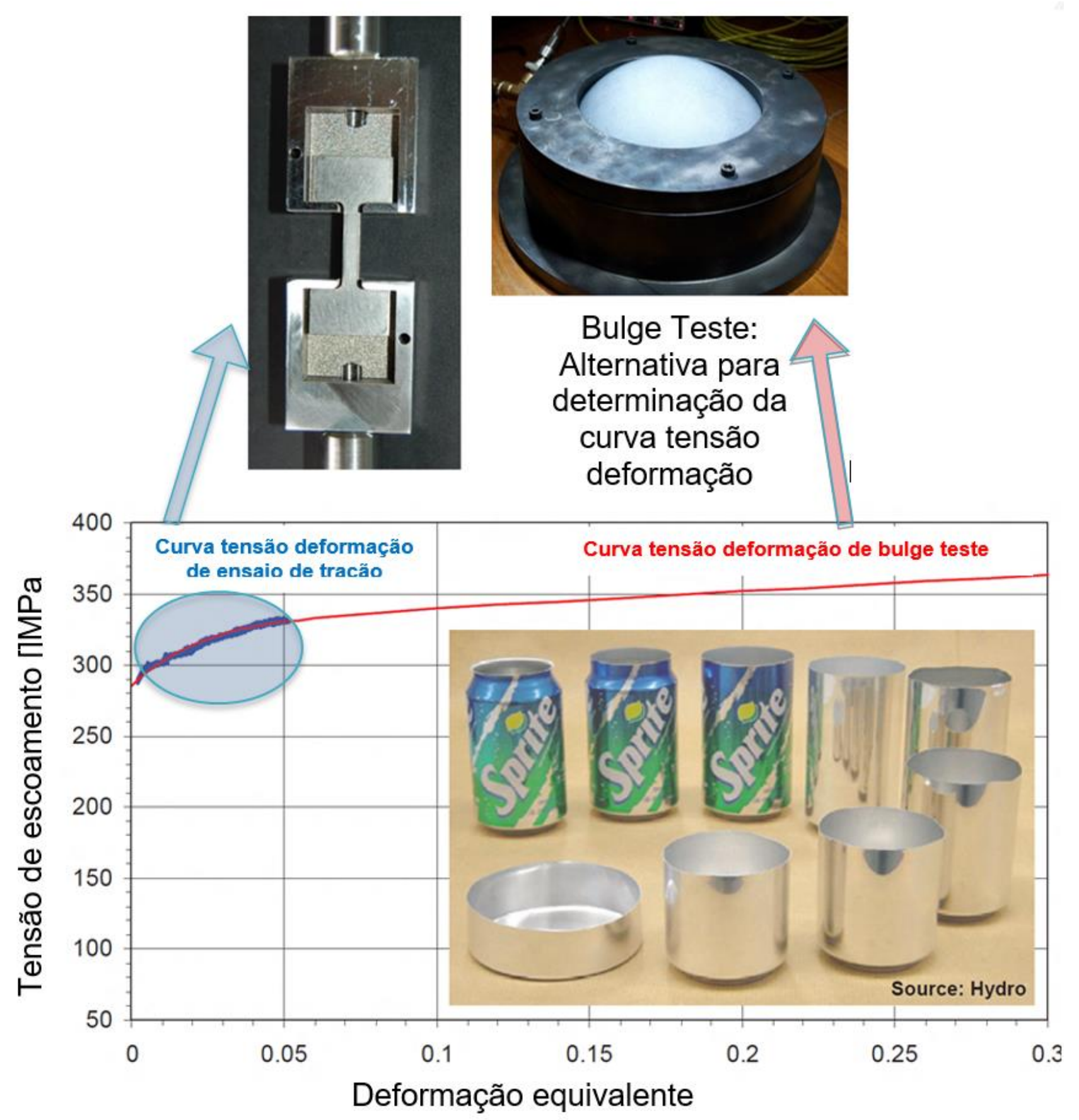

Figura 2.24. Gráfico que compara a amplitude dos resultados oriundos de ensaio de tração e de ensaio de expansão fluidoestática biaxial (KELLER, 2009).

Inicialmente é interessante destacar quais são as características reológicas objetivos desses ensaios. No caso da expansão fluidoestática biaxial são m (índice de sensibilidade à taxa de deformação), n (Expoente de encruamento) e $K$ (constante do material). 
À caracterização reológica do material utiliza-se o ensaio de bulge pela possibilidade de conhecer o comportamento do material em valores de deformação equivalente maiores do que seria possível com a caracterização através do ensaio de tração.

A Figura 2.25 resume a abordagem analítica utilizada na tese para o cálculo da tensão e da deformação através do ensaio de bulge teste, assim como a relação entre cada variável medida e sua utilização nessa abordagem, observa-se que a espessura se evidencia como a variável mais importante, pois se relaciona tanto ao cálculo da tensão quanto ao da deformação.

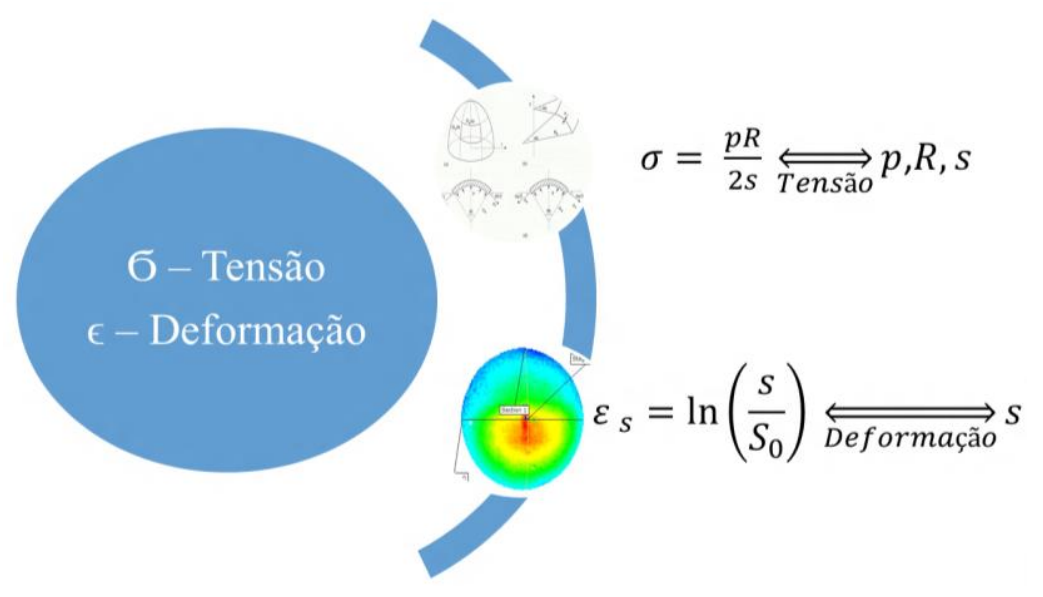

Figura 2.25. Resumo das variáveis envolvidas na caracterização reológica utilizando ensaio de expansão fluidoestática biaxial.

Nos anos 60 ensaios de tração eram utilizados para levantar as características reológicas de expansão fluidoestática biaxial. Jovane propôs o primeiro modelo analítico para estudar a expansão fluidoestática biaxial hemisférica em 1962, mostrado na Figura 2.26. (JOVANE, 1968)
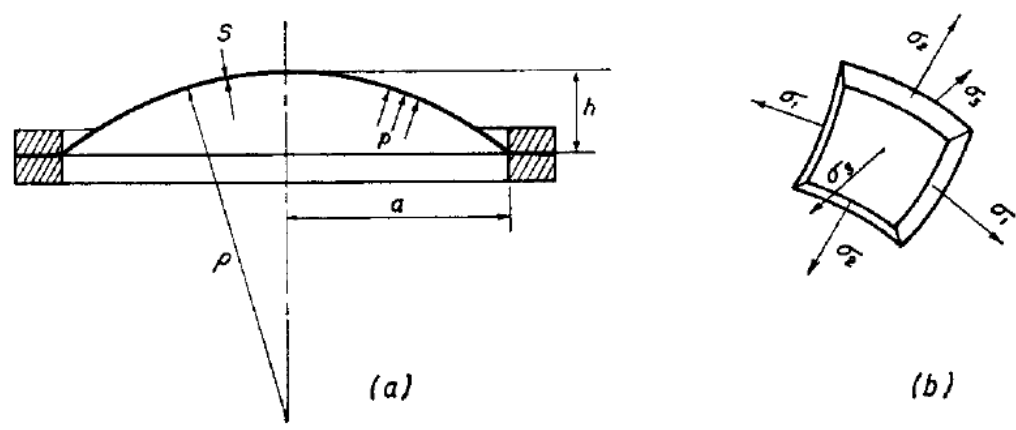

Figura 2.26. (a) Diagrama esquemático de expansão fluidoestática biaxial que considera a distribuição de espessura uniforme e (b) esquema de tensões no elemento. (JOVANE, 1968) 
Em seguida, estudos experimentais e analíticos mostraram que a distribuição de espessura ao longo do corpo de prova depende do índice de sensibilidade a taxa de deformação, conforme mostra Figura 2.27. (HOLT, 1970)

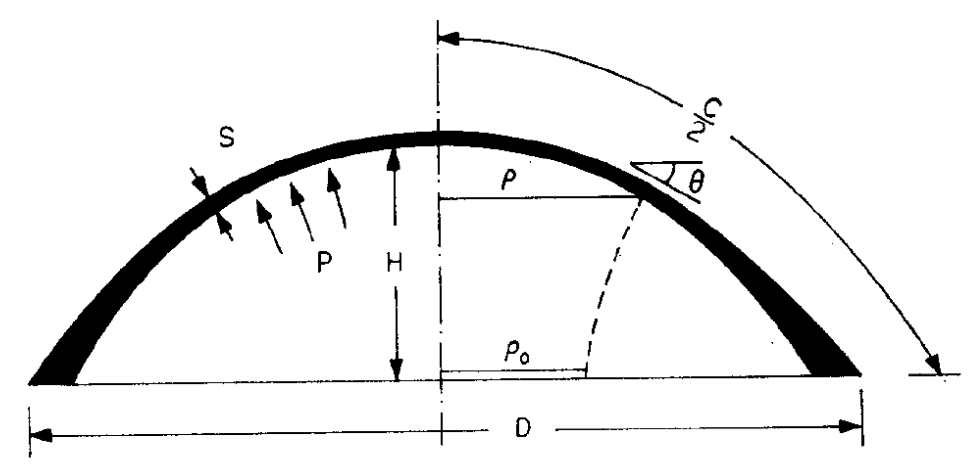

Figura 2.27. Desenho de expansão fluidoestática biaxial de trabalho que considera a espessura função dos parâmetros geométricos H e D. (HOLT, 1970)

Outros trabalhos analíticos mostraram que a redução de espessura (thinning) da peça era mais importante que o coeficiente de distribuição não uniforme da mesma. Essa redução de espessura é devido a um gradiente de tensão entre o polo e a base do domo deformado, o esquemático do modelamento da Figura 2.28. (GHOSH, 1982)

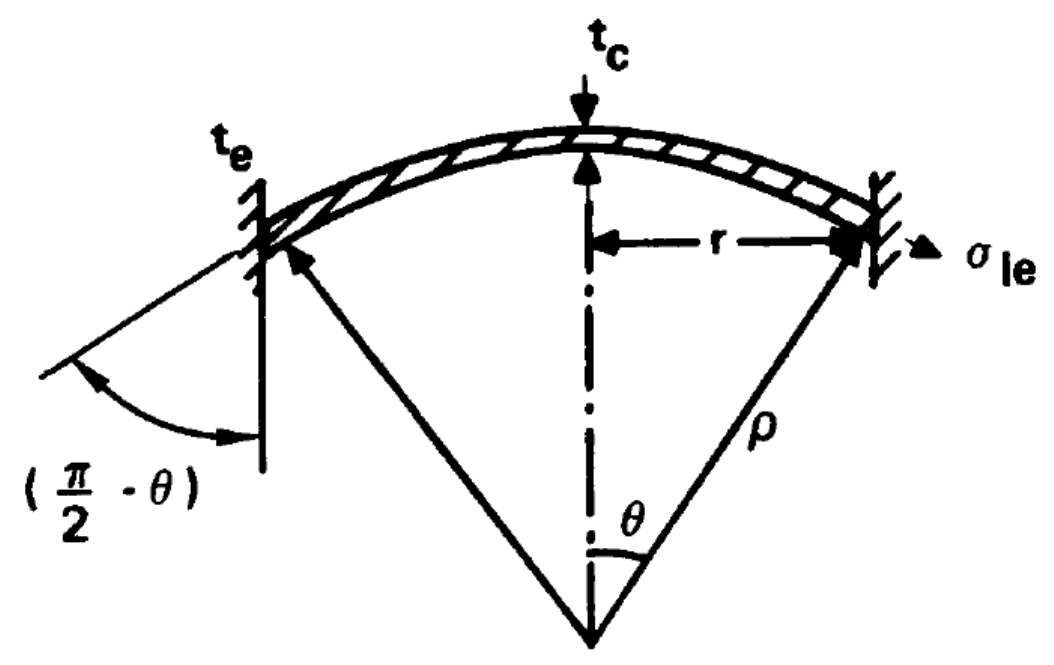

Figura 2.28. Esquemático do ensaio de expansão fluidoestática biaxial que considera o gradiente de pressão para justificar a variação de espessura. (GHOSH, 1982) 
A caracterização do processo também foi estudada para a superfície cônica, conforme trabalho de Holt. (HOLT, 1970)

O procedimento apresentado por Jung-Hu (CHENG, 1996) é um dos primeiros estudos a propor uma metodologia de caracterização reológica a partir de ensaios de expansão fluidoestática biaxial livre. No entanto a identificação dos parâmetros reológicos teve como hipóteses a distribuição uniforme da espessura, conforme mostrado na Figura 2.29, e a utilização de ensaios a pressão constante, que também limitava o campo de aplicação desse procedimento.

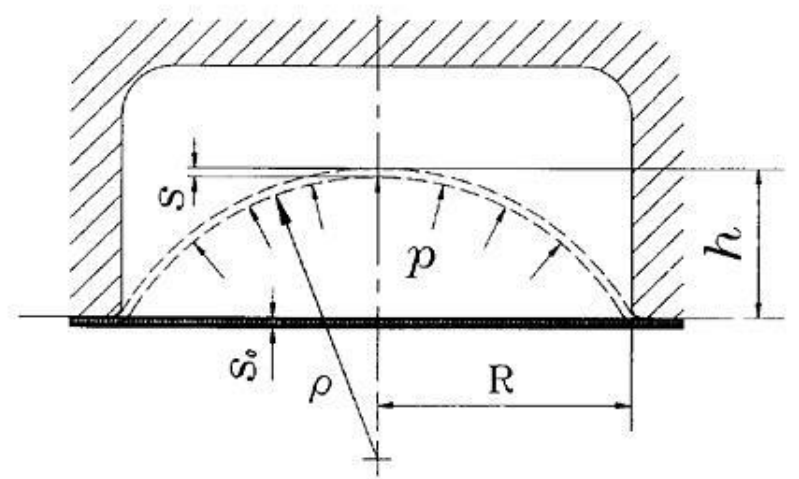

Figura 2.29. Diagrama esquemático do teste expansão livre (CHENG, 1996)

Para obter a curva tensão deformação através do teste de expansão livre seria necessário medir essas variáveis em cada instante em todos os pontos. Porém, é medida a altura da semiesfera, $h$, utilizando um dispositivo LVDT em função do tempo e através das relações geométricas e da relação entre a pressão com a tensão esperada são obtidas as curvas tensão - taxa de deformação. A Figura 2.30 apresenta o procedimento para determinar os parâmetros do material através do teste de expansão livre proposto por Cheng (CHENG, 1996).

Aoura (AOURA, 2004) realizou em 2004 também uma proposta de caracterização de ligas por ensaio biaxial. Ele realiza ensaio a tensão constante, uma vantagem de sua modelagem é que a variação da espessura ao longo de um meridiano não é uniforme, como também ele realiza um estudo com a matriz cônica e uma matriz de geometria variável.

O método de caracterização reológico proposto por Aoura (AOURA, 2004) é confrontado à nova proposta de caracterização reológica de ensaios de expansão fluidoestática biaxial dessa tese de doutorado. Com o objetivo de escolher o melhor método/sensor para instrumentar o ensaio de bulge teste superplástico desenvolvido na tese, busca-se comparar alternativas dentre os métodos de medição usados nas conformações plásticas convencionais. 
A Tabela 2.4 exemplifica alguns métodos de medição de espessura e raio de curvatura, tanto métodos de medição direta e indireta.

Para cumprir com requisitos de ensaio da liga de Ti-6Al-4V, desenvolveu-se o ferramental superplástico com sistema de controle de deformação baseado no método de medição indireta que corresponde a um sistema de correlação digital de imagem chamado GOM-ARAMIS. Detalhes desse sistema de medição estão no capítulo 3.4.1 - Módulo de controle da deformação.

O modelo analítico utilizado na tese é discutido no capítulo 3.9.1.

Após a escolha do método de medição indireto, foi necessária a validação da utilização de métodos indiretos tanto para medição de raio de curvatura (Relação analítica) quanto para medição de espessura (ARAMIS). Detalhes sobre essa validação estão no capítulo 3.7 - Validação da instrumentação a frio: Superplasticidade da liga PbSn.

Tabela 2.4. Exemplos de sistema de medição classificados por variável e método

$\begin{array}{lll}\text { Sistema de } & \begin{array}{l}\text { Variável de } \\ \text { interesse }\end{array} & \text { Método }\end{array}$

Direto

Espessura

Espessura do polo por ultrasson

Raio de curvatura

Medição através de correlação

digital de imagem (DIC) (ARAMIS)

Indireto

Espessura

Cálculo baseado em relações analíticas

Medição baseada na teoria de conservação de volume e através da medição da superfície com DIC $\left(\varepsilon_{1}+\varepsilon_{2}\right)$ (ARAMIS)

Raio de curvatura

Cálculo baseado em relações analíticas e considerações de esfericidade.

Utilização de interpolação e aproximação por esferas, hipérboles e parábolas. 

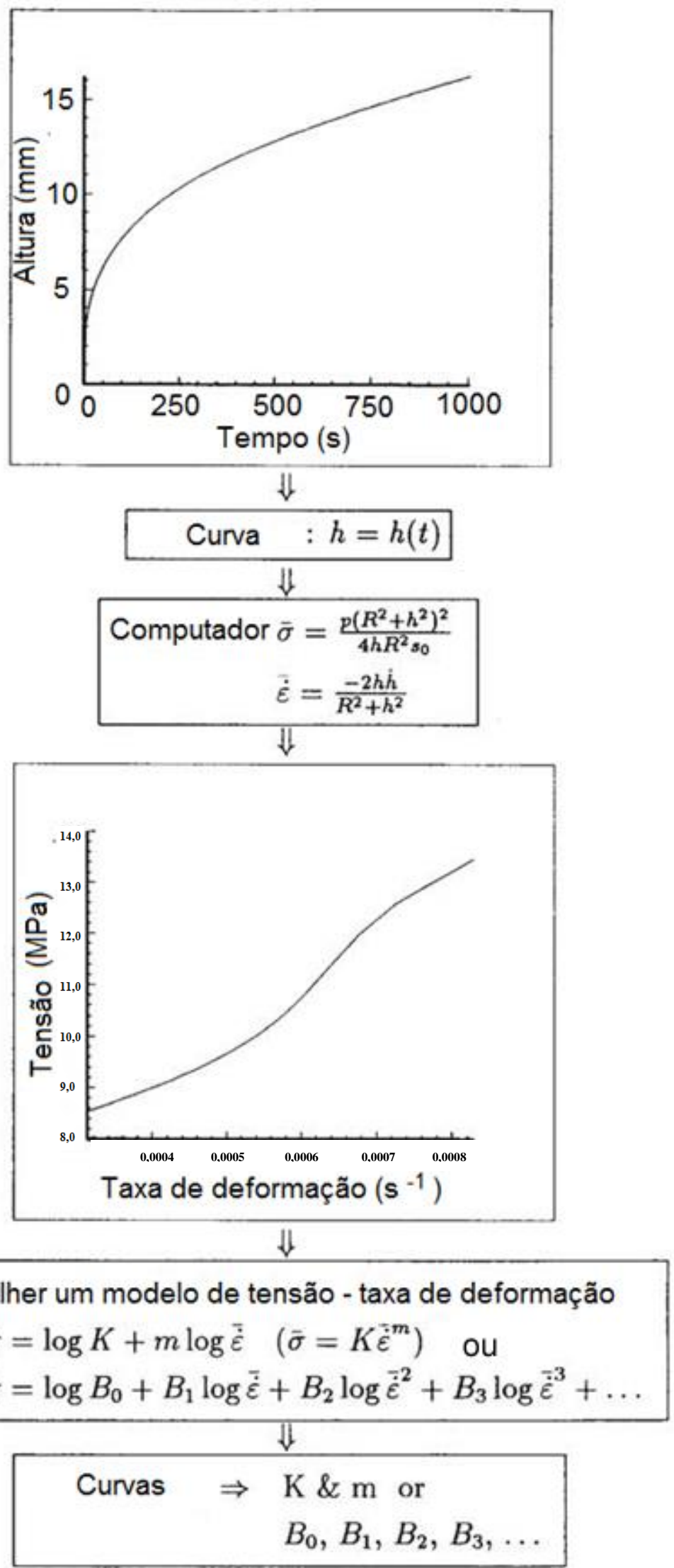

Figura 2.30. Procedimento para determinar os parâmetros do material através do teste de expansão livre (CHENG, 1996) 


\subsection{Ferramentas para Conformação Superplástica}

Uma das definições inicias da tese foi a escolha da melhor matriz/ferramental que atendesse a necessidade tanto de realizar um ensaio de expansão fluido estático biaxial superplástico quanto de conformar uma peça modelo. Segue discussão a respeito dos tipos de matrizes utilizadas na fabricação de peças por Conformação Superplástica, são três os tipos de matrizes que são frequentemente utilizadas:

- Matriz Fêmea;

- Matriz Macho;

- Matriz Membrana;

Na conformação por matriz fêmea utiliza-se uma matriz com forma côncava. A Figura 2.31 mostra o desenho esquemático das etapas da expansão fluidoestática biaxial em uma matriz fêmea não simétrica.
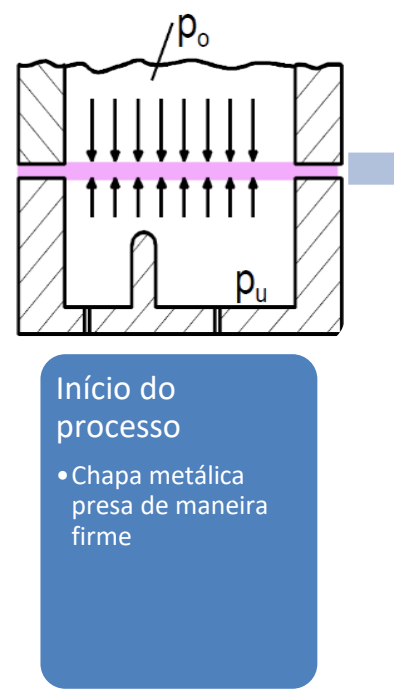
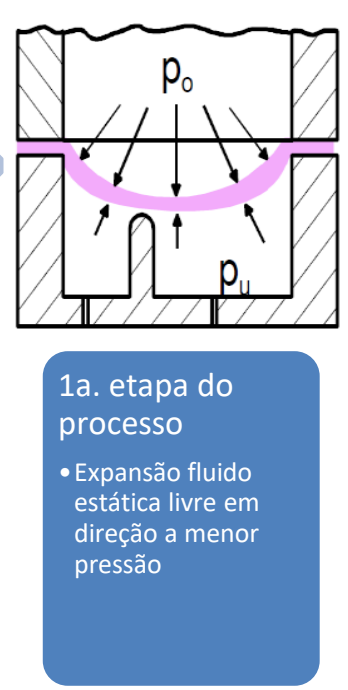

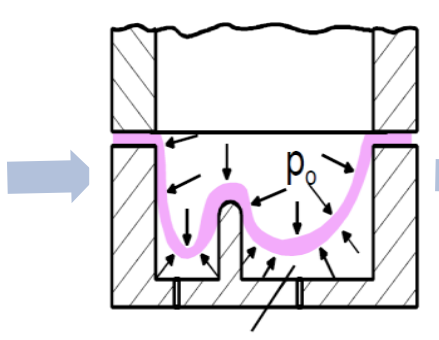

2a. etapa do processo

- Início do contato entre a

ferramenta e a chapa

- Divisão da membrana gasosa em duas sub-membranas

- Mudanças nas condições de

tensão de escoamento do

material

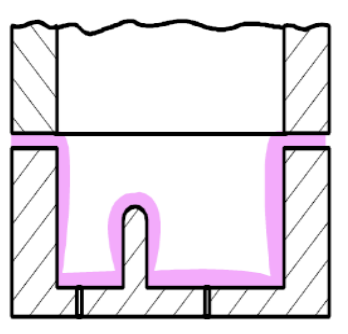

Etapa final

- Variações nas

condições de atrito

resultam em uma

desfavorável

variação na

destribuição de

espessura

Figura 2.31. Desenho esquemático das etapas da expansão fluidoestática em uma matriz fêmea não simétrica. Adaptado (SIEGERT, 1994)

O processo de conformação com matriz macho trabalha com formas convexas. A Figura 2.32 apresenta um desenho esquemático das etapas da expansão fluidoestática em uma matriz macho não simétrica. 

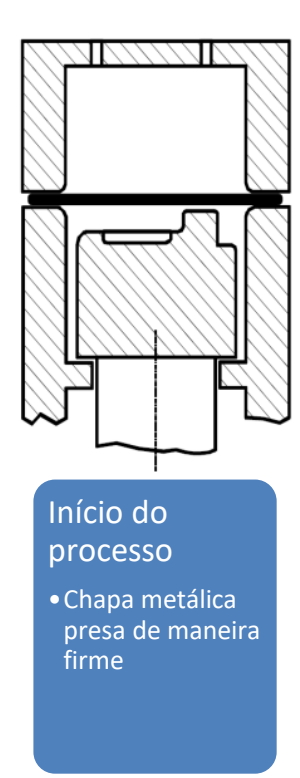

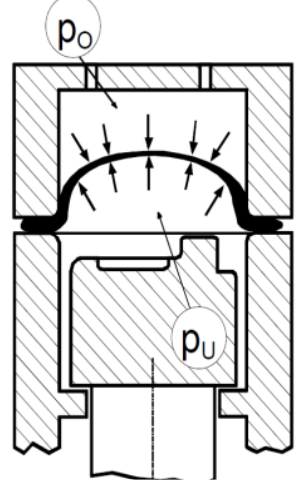

1a. etapa do processo

• Expansão fluido

estática livre em

direção a menor pressão

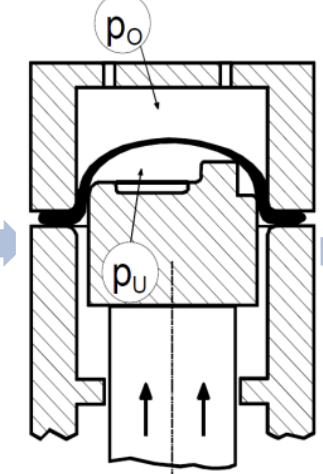

2a. etapa do processo

-Apos a conformaçõa livre, no

momento em que o domo é

suficientemente grande, a matriz com forma convexa se move, causa assim

uma mudança na forma da chapa

devido a mudança na direção de

pressão.

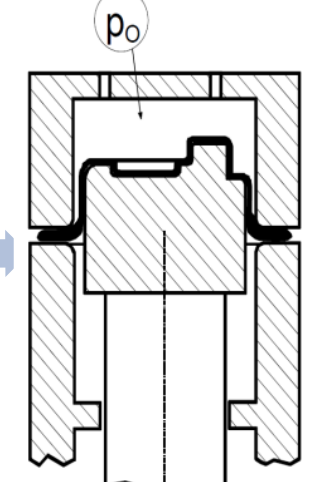

Etapa final

• Variações nas condições de atrito resultam em uma desfavorável variação na

destribuiç̧ão de espessura,

porém melhor quando

comparado ao processo

com matriz fêmea

Figura 2.32. Desenho esquemático das etapas da expansão fluidoestática em uma matriz macho não simétrica. Adaptado (SIEGERT, 1994)

Vale ressaltar que durante a conformação com matriz macho, o atrito do contato ferramenta-chapa ocorre muito mais tarde quando comparado ao processo com matriz fêmea, isso resulta em uma distribuição de espessura mais favorável. Adicionalmente, o processo com matriz macho permite uma réplica mais precisa dos contornos internos. Devido a diferenças locais no escoamento do material, o contorno externo não conforma exatamente como a geometria requerida. (SIEGERT, 1994)

A Tabela 2.5 resume as principais vantagens e desvantagens na utilização de matrizes macho e fêmea.

Nessa tese, será utilizada uma matriz fêmea para conformação da peça modelo, a principal característica que definiu essa escolha foi a intenção de obter a forma exata da superfície externa da chapa conformada. O retrabalho no ferramental de bulge test necessário para que possibilitasse a conformação da peça modelo era menor no caso da matriz fêmea. Detalhes desse retrabalho estão descritos do capítulo 4.5.1. 
Tabela 2.5. Vantagens e desvantagens na utilização de matrizes macho e fêmea

Obtém a réplica exato do contorno interno
da peça conformada




\subsection{Técnicas e métodos de Conformação Superplástica}

Essa tese tem como objetivo principal desenvolver uma prensa de Conformação Superplástica instrumentada e controlada para realizar ensaios de expansão fluido estático biaxial, técnica conhecida como "Blow Forming". Há diferentes técnicas e métodos utilizados para a conformação de material em regime superplástico, segue lista dos principais:

- Moldagem por sopro - "Blow Forming";

- Moldagem a Vácuo - "Vacuum Forming";

- Termoconformacão - "Thermo Forming";

- Estampagem Profunda - "Deep Drawing";

- Processo combinado entre Conformação Superplástica e junção por difusão - SPF/DB;

\subsubsection{Moldagem por sopro e moldagem a vácuo}

A conformação por sopro é o método mais empregado devido ao baixo nível de tensão necessário. Neste método, a lâmina (chapa) é fixada entre o molde e a tampa e, após aquecer até a temperatura superplástica, o gás é injetado e a chapa adquire a forma do molde, ou expande livremente.

A moldagem por sopro e a moldagem a vácuo são basicamente o mesmo processo, algumas vezes chamado de Deformação por estiramento "Stretch Forming", no qual um diferencial de pressão é imposto na matriz superplástica, exigindo a estanqueidade da matriz, deformando a chapa metálica até a configuração do molde. A diferença consiste que a conformação a vácuo, a pressão aplicada é limitada a pressão atmosférica, dessa forma a taxa de deformação e a capacidade de elongamento uniforme são limitadas. (GHOSH, 2006)

O método the blow forming com matriz fêmea está ilustrado na Figura 2.33. 


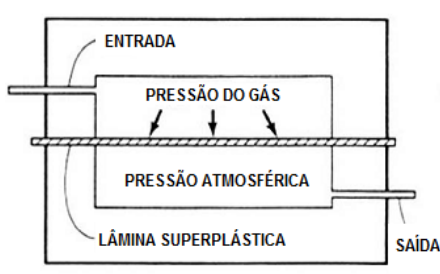

PASSO 1

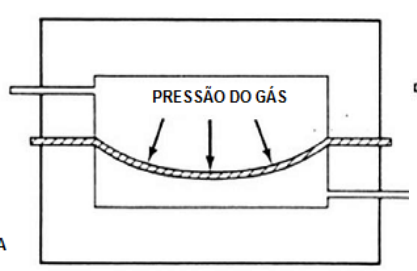

PASSO 2

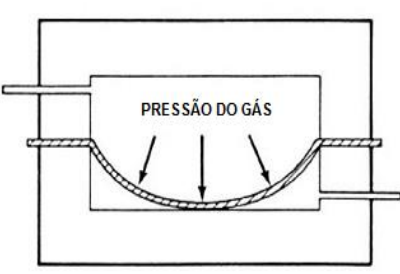

PASSO 3

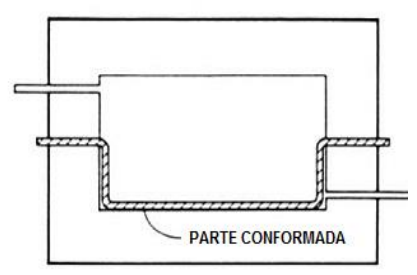

PASSO 4

Figura 2.33. Conformação por sopro, blow forming (GHOSH, 2006)

A parte inferior da câmara de conformação se comporta dependendo do tipo de material que está sendo usado, em alguns casos pode ser deixada em aberto, quando se realiza uma expansão fluidoestática biaxial livre, ou atmosfera de pressão controlada, dessa forma aplica-se uma contrapressão para trabalhar com a pressão relativa e controlar a cavitação, como no caso de ligas de alumínio; a parte oposta a aplicação da pressão muitas vezes recebe um gás inerte para evitar a oxidação durante a conformação, como no caso das ligas de Titânio. O gás utilizado pode ser o ar, caso não ocorra oxidação ou contaminação da liga. Com materiais reativos, como as ligas de titânio, um gás inerte, como o argônio, é recomendável. Utiliza-se argônio na instrumentação da prensa utilizada nessa tese.

A conformação por sopro foi usada nessa tese devido ao acesso livre de um dos lados da chapa conformada, um dos requisitos do desenvolvimento da prensa superplástica é ter acesso visual a uma das superfícies de conformação, para que através de correlação digital de imagem possa ser medido a espessura ao longo da conformação. Segue Figura 2.34 com esquemático representativo da concepção do ferramental, cujo detalhamento está no capítulo 3.3.

Acesso inferior para argônio utilizado para aplicar a curva de pressurização.

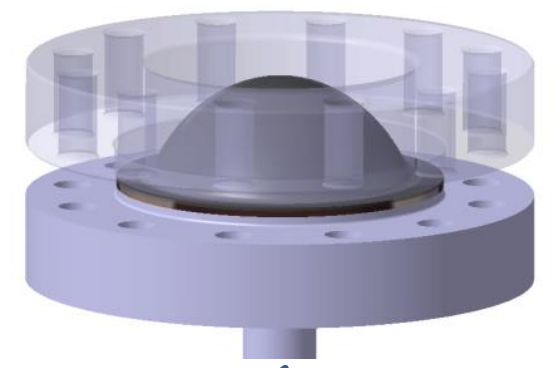

Matriz superior vazada para permitir acesso do sistema de correlação digital de imagem.

Figura 2.34. Ferramental tipo prensa chapa para conformação por sopro, acesso do argônio pelo duto inferior. 


\subsubsection{Termoconformacão - "Thermo Forming"}

Essa técnica usa uma das partes da matriz de maneira móvel ou ajustável, a moldagem pode ocorrer com pressão gasosa ou vácuo, a moldagem térmica é um método comumente utilizado para conformações plásticas.

A Figura 2.35 mostra dois exemplos de moldagem térmica, em (a) uma matriz móvel macho é usada para estirar a chapa em uma primeira etapa, seguido pela aplicação da pressão gasosa que será responsável pela conformação da chapa na matriz superior fixa, e obtém-se a forma desejada. Em (b) como primeira etapa realiza-se uma expansão fluidoestática livre, afastando a chapa da ferramenta, a ferramenta macho é então movida na direção da chapa pré-conformada, na etapa 3 a pressão é revertida e a chapa ganha a forma da matriz móvel macho.

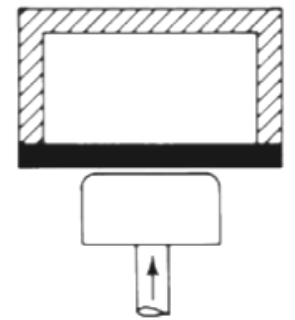

Etapa 1

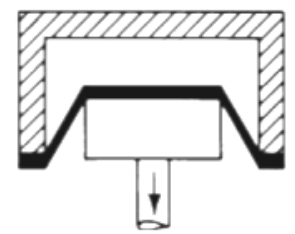

Etapa 2

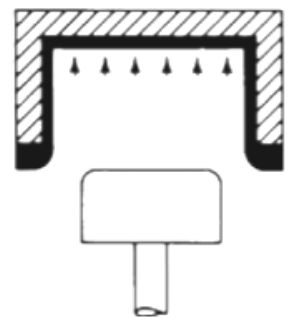

Etapa 3

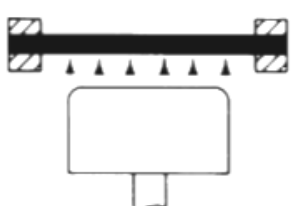

Etapa 1

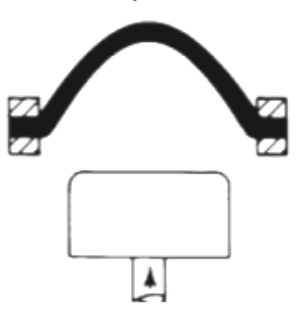

Etapa 2

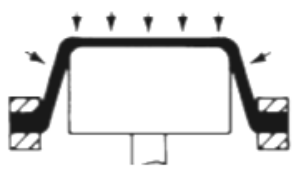

Etapa 3

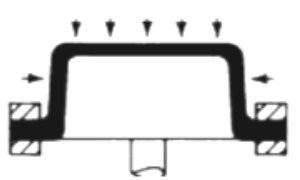

Etapa 4

(b)

Figura 2.35. Exemplos de métodos de termo conformação, em (a) conformação em uma matriz fêmea fixa com ajuda de uma matriz móvel macho, e em (b) "snap-back forming" conformação com reversão de pressão, com uma matriz macho que se move em direção ao material. (GHOSH, 2006) 


\subsubsection{Estampagem Profunda superplástica - "Deep Drawing SPF”}

É importante destacar que a possibilidade de trabalhar com ligas superplásticas através de moldagem por sopro, moldagem a Vácuo e moldagem térmica representa uma vantagem do ponto de vista de ferramental, esses processos necessitam de uma matriz simples, ao contrário da estampagem profunda.

Na estampagem profunda, um disco metálico (blank) é colocado sobre uma matriz e é comprimido para o seu interior com ajuda de uma punção, geralmente de forma cilíndrica. O objetivo da análise da estampagem profunda é determinar as relações geométricas entre o máximo diâmetro do disco e o mínimo diâmetro do punção possível para se conformar um copo cilíndrico sem que ocorra ruptura ou falhas superficiais. (KALPAKJIAN, 2006)

$\mathrm{Na}$ conformação, à medida que o punção avança sobre o blank, o metal em contato com o punção, acomoda-se em torno do seu perfil, reduzindo a espessura da chapa. A força total do punção para a deformação completa do copo corresponde á somatória de todos os esforços envolvidos na deformação da peça, inclusive o atrito. $O$ esforço para deformação ideal aumenta continuamente devido ao efeito do encruamento na conformação plástica. É exatamente por esse motivo que essa técnica é pouco utilizada para Conformação Superplástica, que apresenta encruamento próximo de zero. Em outras palavras, para prevenir o afinamento e a consequente ruptura, a estampagem profunda conta com o encruamento por deformação, e esse encruamento não se pronuncia nos materiais durante a Conformação Superplástica. (GHOSH, 2006)

Para algumas ligas, zinco, alumínio, entre outras, tentou-se através da diferença de temperatura entre a chapa e o punção obter um melhor resultado para estampagem, estudou-se a influência de algumas variáveis como carga de fechamento da matriz, diâmetro da chapa conformada e velocidade de estampagem, no resultado da estampagem profunda com materiais superplásticos. Corpos de prova obtidos por essa técnica mantiveram suas características superplásticas. (HAWKINS,1976).

A Figura 2.36 apresenta um exemplo de ferramental de estampagem profunda.
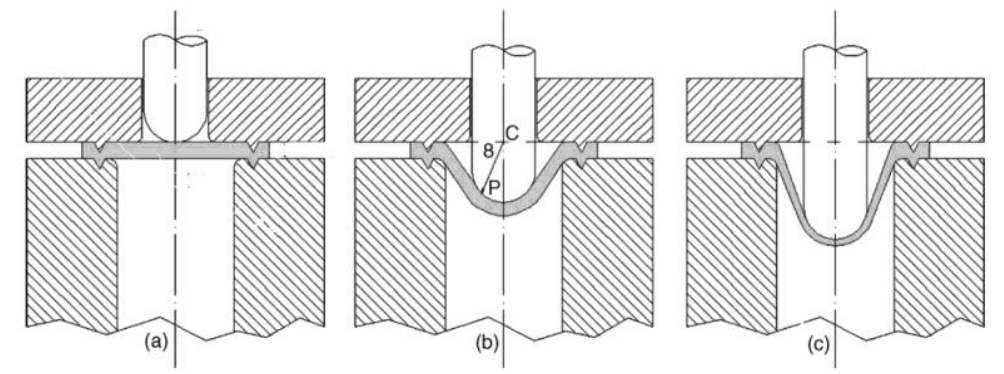

Figura 2.36. Desenho esquemático das partes de uma ferramenta de estampagem profunda, punção-chapa-matriz. (DUTTA, 2005) 
Alguns trabalhos realizados em baixas taxas de deformação - $10^{-3} \mathrm{~s}^{-1}(723 \mathrm{~K})$ - ligas de $7075 \mathrm{Al}$, apresentaram problemas de uniformidade de espessura, conforme pode ser observado na Figura 2.37. (DUTTA, 2005).

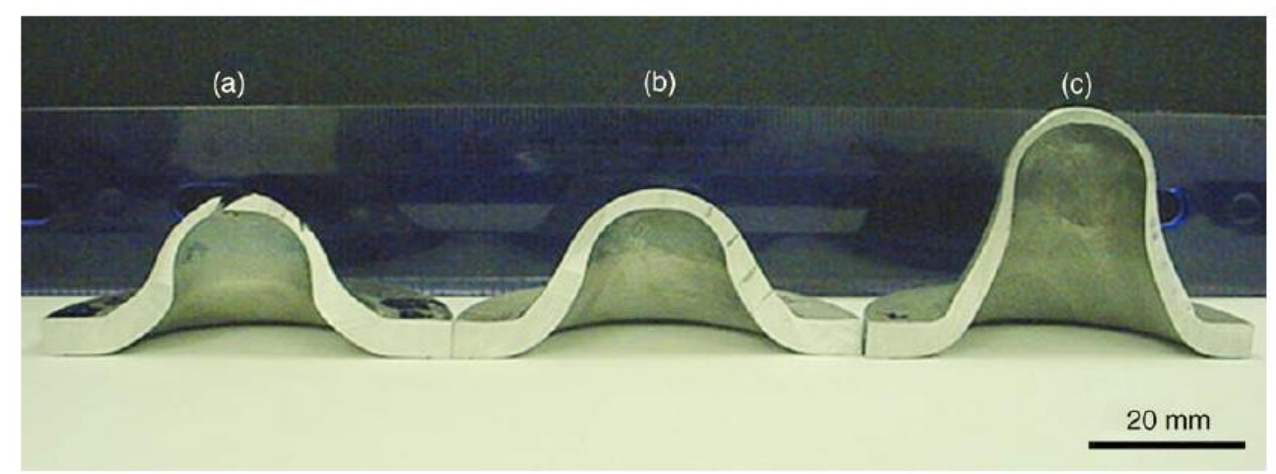

Figura 2.37. Fotos das amostras conformadas a 723K, (a) AA7075 não superplástica; (b) e (c) AA7075 superplástica, profundidade de $18.5 \mathrm{~mm}$ e $28.5 \mathrm{~mm}$ respectivamente. (DUTTA, 2005)

Em outro método de estampagem profunda, óleo em alta pressão ao redor da periferia da chapa foi utilizado durante a conformação para ajudar a estampagem. Bom controle sobre a espessura foi obtido nesse trabalho, porém somente com ligas que possuam características superplásticas à temperatura ambiente. A Figura 2.38 apresenta o desenho esquemático do ferramental utilizado nesse trabalho. (AL-NAIB, 1970).

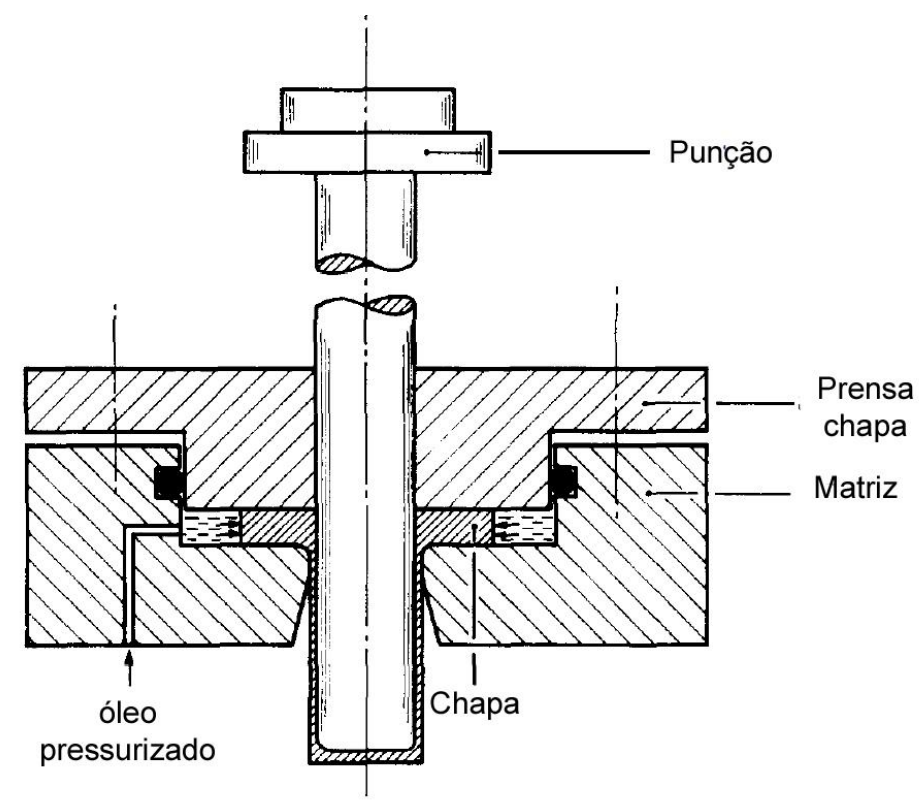

Figura 2.38. Desenho esquemático do ferramental com óleo em alta pressão. (ALNAIB, 1970) 


\subsubsection{Conformação Superplástica e Junção por Difusão}

A combinação de Conformação Superplástica (SPF) e Junção por Difusão (DB Diffusion Bonding) evoluiu devido à similaridade entre os requisitos térmicos para ambos os processos (PETER, 2003). Por exemplo, no caso da liga de Ti-6Al-4V, os requisitos térmicos para SPF são:

$$
\begin{aligned}
& T_{S P F} \cong 700{ }^{\circ} \mathrm{C} \text { até } 1000{ }^{\circ} \mathrm{C} \\
& \dot{\varepsilon} \cong 1.3 \times 10^{-4} \text { até } 10^{-3} \\
& \sigma \cong 2 \text { até } 20 \mathrm{MPa}
\end{aligned}
$$

E para DB:

$$
\begin{aligned}
& T_{D B} \cong 920^{\circ} \mathrm{C} \text { até } 950^{\circ} \mathrm{C} \\
& t_{D B} \cong 1.3 \times 10^{-4} \text { até } 10^{-3} \\
& P_{D B} \cong 20 \text { até } 60 \mathrm{bar}
\end{aligned}
$$

Embora junção por difusão não seja um processo de conformação de chapas, ele complementa e acrescenta ao SPF várias possibilidades que justificam seu uso combinado como será comentado a seguir.

A Figura 2.39 mostra em etapas o processo de difusão.
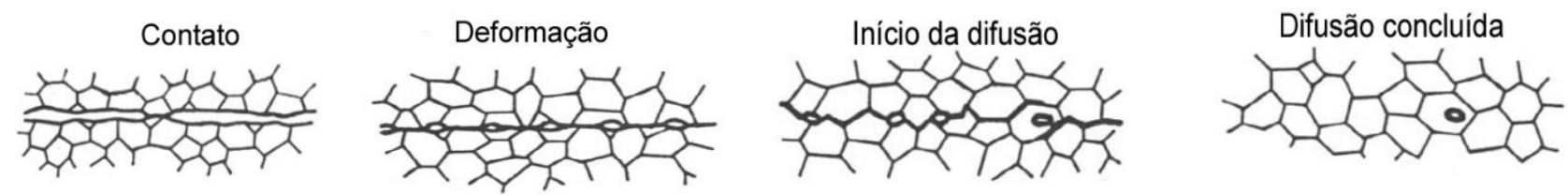

Figura 2.39. Junção por difusão (PETER, 2003)

O processo combinado de SPF/DB possui as seguintes variações: (i) conformação de uma chapa simples em detalhes pré-alocados do mesmo material para que ocorra a difusão (Figura 2.40); (ii) DB em duas chapas em lugares escolhidos, seguido da conformação de uma ou das duas chapas em uma matriz (Figura 2.41) e (iii) DB de três ou 
mais chapas em locais selecionados, seguido de uma expansão fluidoestática interno que conforma o resultado da difusão em uma matriz (Figura 2.42).

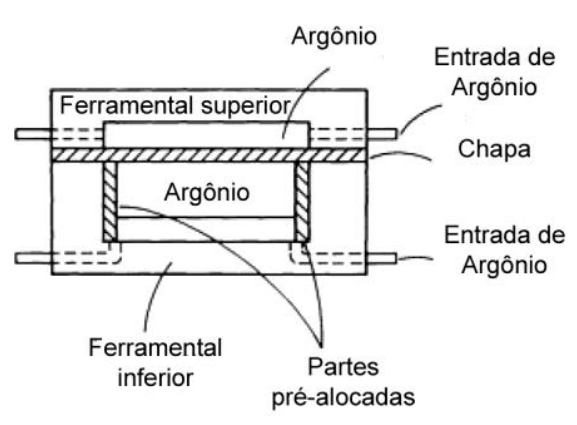

Ferramental Superior

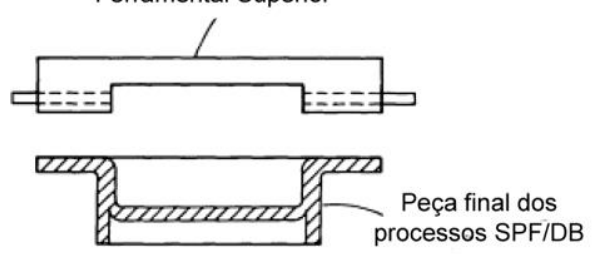

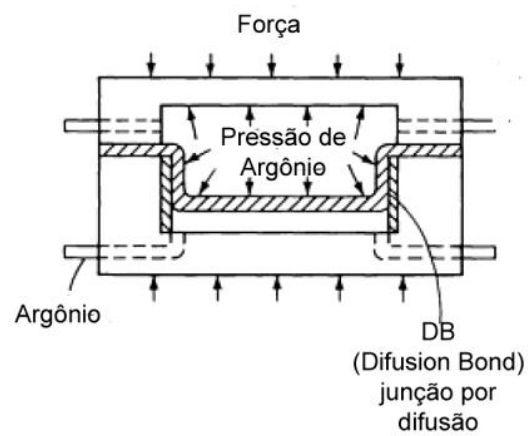

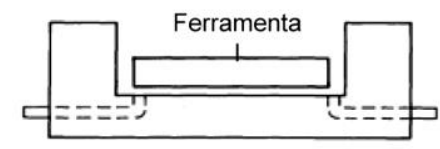

Figura 2.40. Conformação Superplástica combinada com junção por difusão (SPF/DB), o processo utiliza detalhes pré-alocado onde ocorrerá junção por difusão. (GHOSH, 2006)

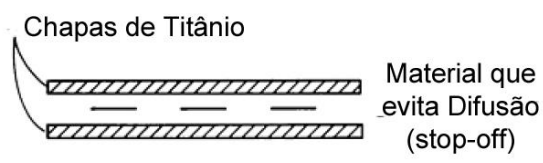

Passo 1
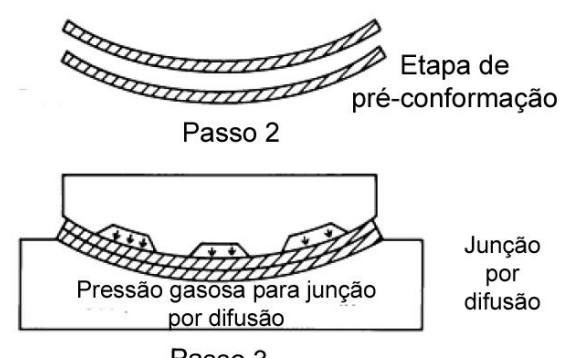

Passo 3

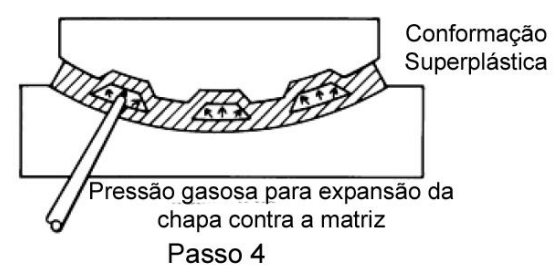

Figura 2.41. Conformação Superplástica combinada com junção por difusão (SPF/DB), o processo utiliza uma etapa de pré-conformação e duas chapas para obter o perfil desejado. (GHOSH, 2006) 
3 chapas
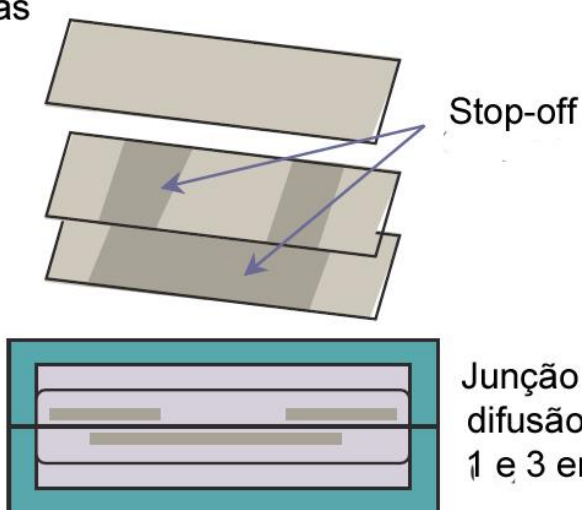

Junção por difusão de

1 e 3 em 2

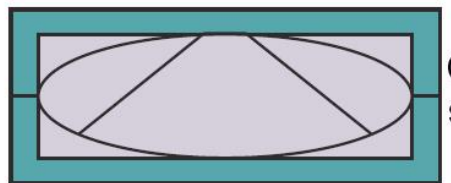

Conformação superplástica

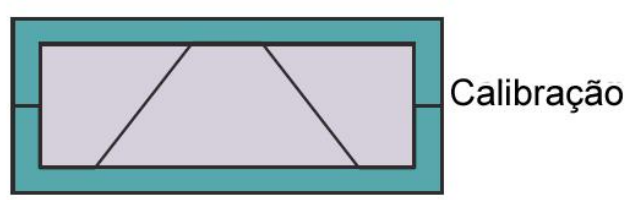

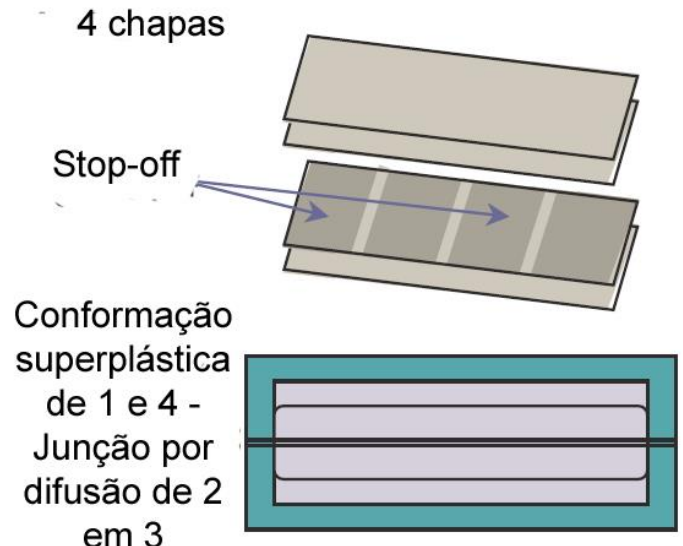

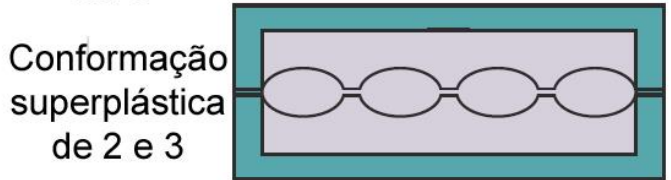

Junção por difusão de 2 em 1 e 2 . Junção por difusão de 3

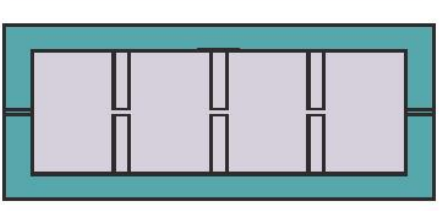
em 3 e 4

Figura 2.42. Operações para juntar três ou mais chapas através dos processos combinado de Conformação Superplástica e junção por difusão. (PETER, 2003). 


\subsection{Titânio e suas ligas}

Típicas deformações de ensaios uniaxiais superplásticos estão ilustradas na Figura 2.43 .

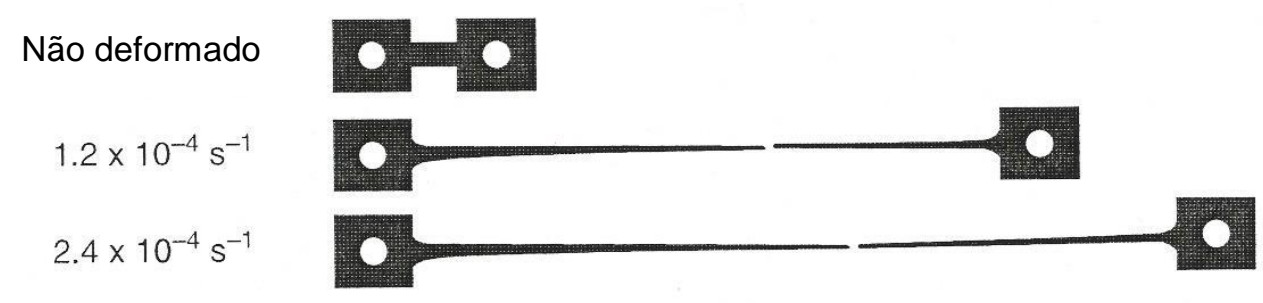

Figura 2.43 Liga de titânio superplástica IMI550 (Ti-4AI-4Mo-2Sn-0.5Si) apresentado elevada elongação. (RIDLEY, 2011)

Nas ligas de titânio a falha superplástica característica ocorre como resultado da instabilidade plástica do escoamento, reflete a área de secção transversal negligenciável. Por outro lado, a falha superplástica pode ocorrer devido a um fenômeno muito recorrente na superplasticidade das ligas de alumínio, a cavitação.

(a)

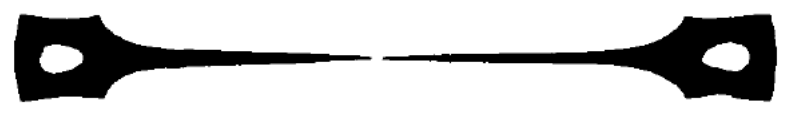

(b)

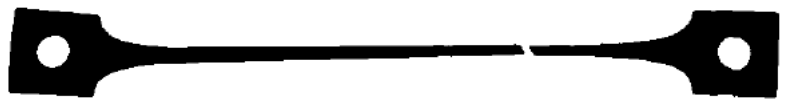

Figura 2.44 (a) Fratura superplástica na liga Ti6Al4V devido à instabilidade no escoamento plástico e (b) Falha por cavitação (AA 7575). Elongamento de 900\%. (RIDLEY, 1989) 


\subsubsection{Ligas de Titânio e a indústria aeronáutica}

O titânio foi isolado em 1825, alcançando status comercial somente em meados do século $X X$; sua baixa densidade $\left(\mathrm{d}=4,7 \mathrm{Mg} / \mathrm{m}^{3}\right)$ e excelente resistência mecânica e à corrosão, além da ótima relação buy-to-fly ${ }^{4}$ o confirmaram como importante material estrutural nas indústrias química, petroquímica e aeroespacial. (BECK, 2003). Nessa última, tem sido usado desde 1950 no avião experimental “Douglas Aircraft X-3 Stiletto”. Em aviões militares o percentual de titânio aumentou progressivamente com avanços tecnológicos, nos anos 60, o "Phantom F-4 possuía 9 \% em peso de titânio, atualmente o F-22 supera os 39\%. O "SR-71 Blackbird" militar, embora não esteja mais em produção, ostenta os recordes de velocidade e altitude sendo $90 \%$ feito com ligas de titânio. A Figura 2.45 apresenta uma foto desse avião. (AIT, 2007).

A Figura 2.46 apresenta a evolução de alguns materiais utilizados na indústria aeronáutica ao longo dos anos, onde é possível observar que a aplicação das ligas de titânico cresceu aproximadamente $300 \%$ nos últimos 50 anos.

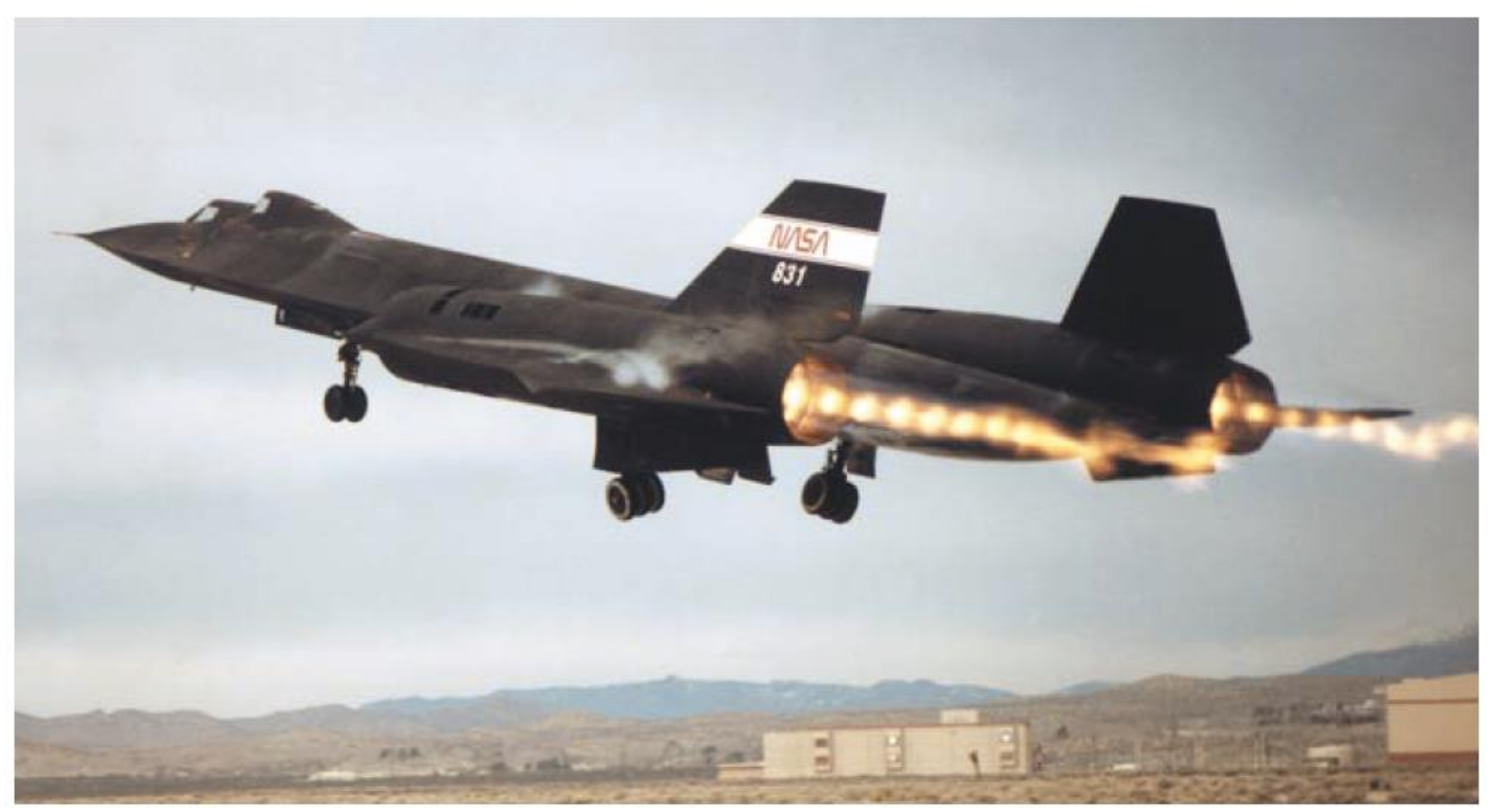

Figura 2.45 O "SR-71 Blackbird" foi o primeiro avião militar todo de titânio. Esta foto foi tirada no "Dryden Flight Research Center" em 1992, mostra o "SR-71" decolando com "shock diamonds" na turbina de exaustão. (FANNING, 2008)

\footnotetext{
${ }^{4}$ É a razão entre a quantidade de massa necessária para a produção da peça e a quantidade de massa que resulta na peça final.
} 


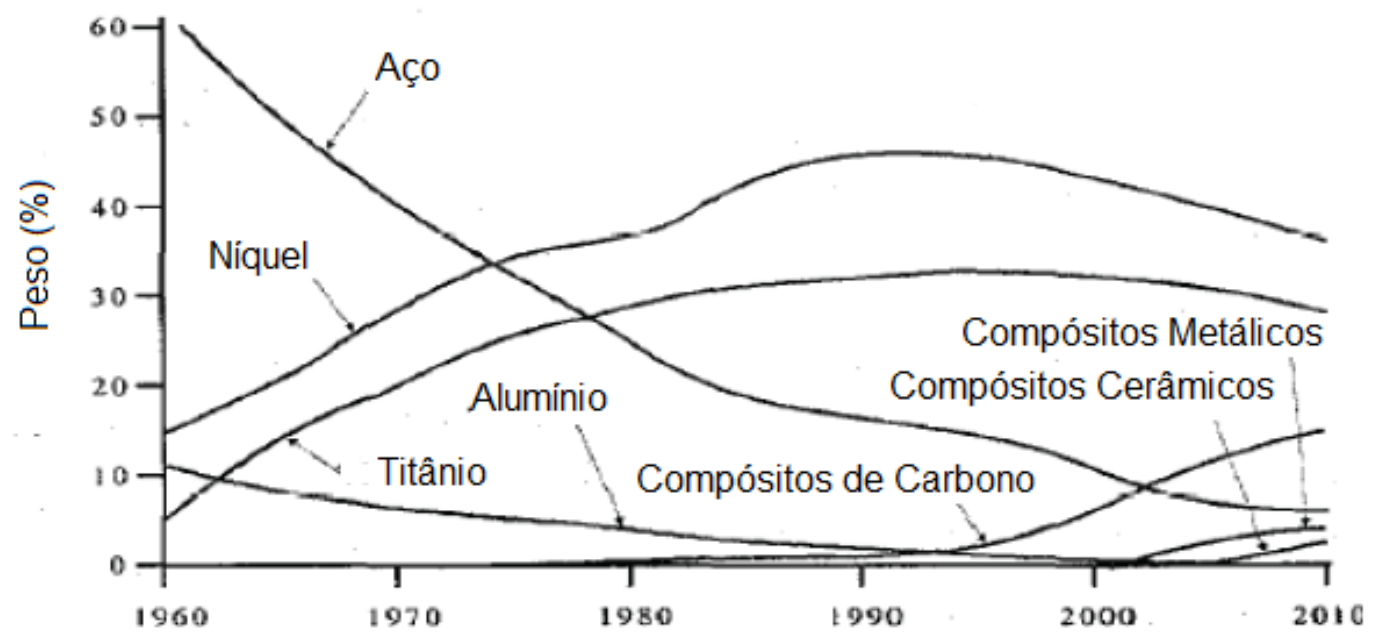

Figura 2.46. Evolução dos materiais utilizados na indústria aeronáutica. (SERRA, 2008).

No estudo apresentado por Hale (HALE, 2010) foi mostrado o aumento do uso do titânio na aeronáutica, e uma perspectiva da aplicação até 2020. Segundo o autor, um dos motivos que levaram a esse crescimento foi a mudança na maneira de selecionar os materiais, abandonando ideias já definidas e buscando relacionar as características dos materiais com àquelas requeridas para determinada aplicação. A Figura 2.47 apresenta os resultados obtidos desse estudo.

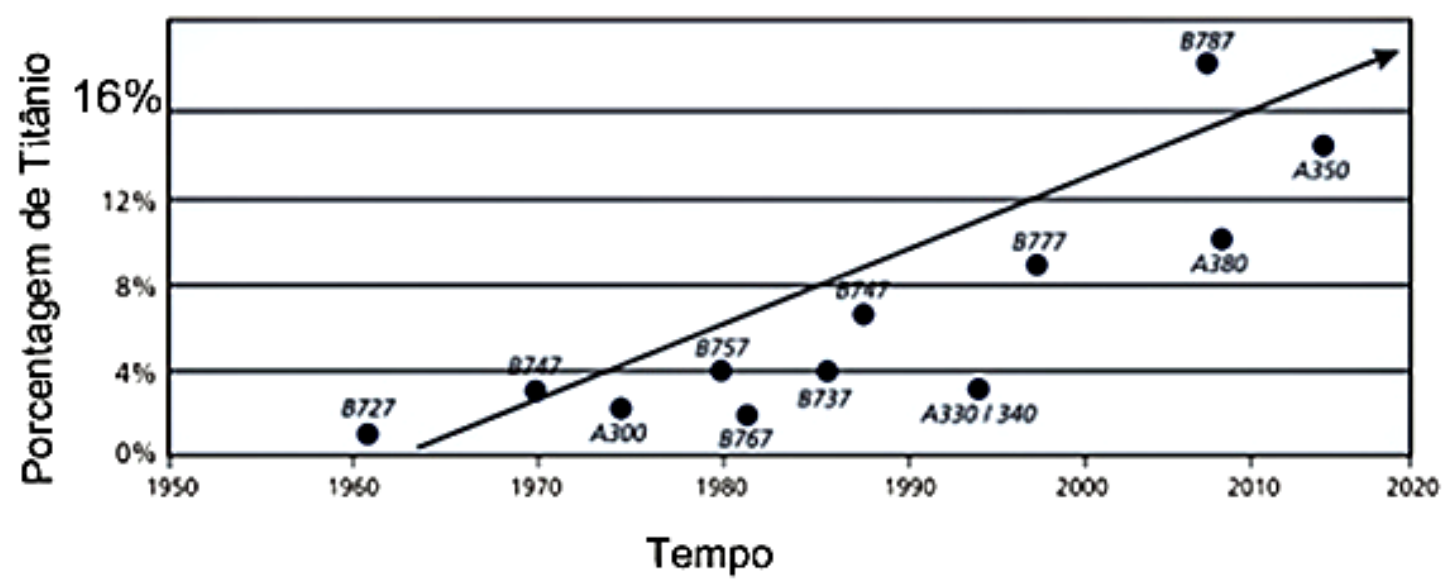

Figura 2.47. Aumento do uso do titânio na aeronáutica. (HALE, 2010) 
Da Figura 2.47, observa-se crescimento linear da aplicação do Titânio nos aviões da Boeing. Adicionalmente, esse crescimento acompanha o global como mostrado na Figura 2.46. Ainda em relação ao trabalho do Hale (HALE, 2010), a Figura 2.48 mostra a distribuição de materiais utilizados no Boeing seguindo o lema "material certo para a aplicação certa”.

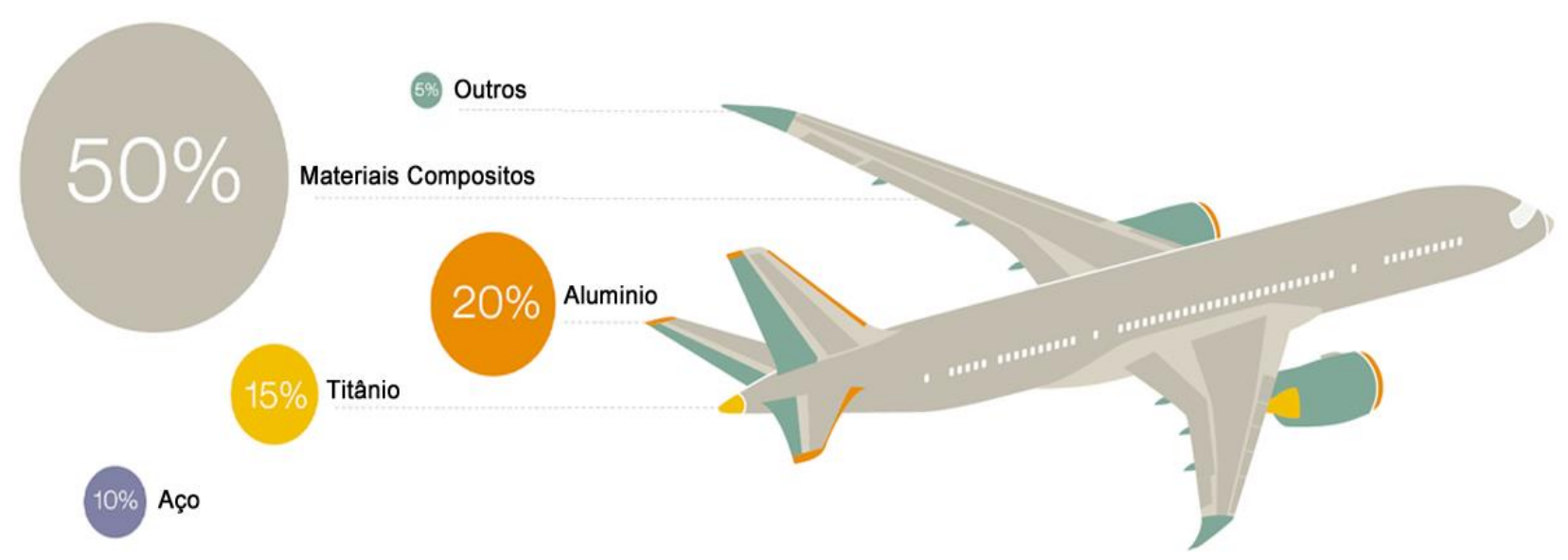

Figura 2.48. O material certo para a aplicação certa, lema utilizado pelos engenheiros da Boeing na escolha dos materiais do 787. (HALE, 2010)

O Titânio é aplicado principalmente na fabricação dos seguintes componentes: motores a jato, pás das turbinas, nos compressores, discos e componentes rotativos críticos.

A Tabela 2.6 apresenta algumas propriedades da liga de interesse da tese, Ti-6AL$4 \mathrm{~V}$ em comparação a outros materiais também utilizados na indústria aeronáutica.

A produção de titânio SPF cresceu na década de 1980. Apenas 10 anos depois, em 1991, no setor aeroespacial, Rohr Industries, trabalhava com 10 linhas full-time de produção e produzia mais de 400 peças diferentes, em uma produção anual de mais de 20.000 peças de titânio superplástico. (BARNES, 2007) 
Tabela 2.6. Limite de escoamento, Densidade e Resistência específica de materiais aplicados na indústria aeronáutica. Em destaque a liga Ti-6Al-4V.

\begin{tabular}{|c|c|c|c|}
\hline Material & $\begin{array}{c}\text { Limite de } \\
\text { escoamento } \\
(\mathbf{M P a})\end{array}$ & $\begin{array}{c}\text { Densidade } \\
\left(\mathbf{K g} / \mathbf{m}^{\mathbf{3}}\right)\end{array}$ & $\begin{array}{c}\text { Resistência Mecânica } \\
\text { Específica } \\
\left(\mathbf{M P a}^{\mathbf{3}} \cdot \mathbf{k g}^{-1}\right)\end{array}$ \\
\hline Aço (1020) & 300 & 7800 & 0,038 \\
\hline $\begin{array}{c}\text { Aço 1080 } \\
\text { (Temperado - revenido) }\end{array}$ & 900 & 7800 & 0,115 \\
\hline $\begin{array}{c}\text { Aço Ferramenta } \\
\text { (AISI H14) }\end{array}$ & 1100 & 7900 & 0,139 \\
\hline $\begin{array}{c}\text { Liga de Alumínio } \\
\text { (AA 7075) }\end{array}$ & 400 & 2800 & 0,143 \\
\hline $\begin{array}{c}\text { Liga de Alumínio } \\
\text { (AA 6061) }\end{array}$ & 220 & 2800 & 0,079 \\
\hline $\begin{array}{c}\text { Titânio } \\
\text { (Ti6Al-4V) }\end{array}$ & 900 & $\mathbf{4 4 3 0}$ & $\mathbf{0 , 2 0 3}$ \\
\hline
\end{tabular}

\subsubsection{Microestrutura e metalurgia das ligas de Titânio}

O Titânio comercial consiste em uma liga complexa que contém elementos que modificam a temperatura de transformação polimórfica que passa a ocorrer em uma faixa de temperaturas onde as fases coexistem. O Titânio é extremamente sensível à presença de impurezas advindas do processo Kroll, no qual o $\mathrm{TiCl}_{4}$ é reduzido a titânio metálico pelo magnésio, produzindo $\mathrm{Ti}+2 \mathrm{MgCl}_{2}$ (ROUVER, 1971). Os principais elementos presentes no Titânio comercial são: Fe, C, Ni, O e H.

A influência das impurezas no $\mathrm{Ti}$ é de tal modo acentuado, que o metal comercialmente puro é classificado em classes, graus de um a quatro. A Figura 2.49 mostra uma relação linear entre a raiz quadrada da concentração de átomos de soluto e a tensão de escoamento para os quatro graus existentes. O Ferro, por exemplo, aumenta a resistência mecânica, mas reduz a ductilidade e a resistência à fluência. É importante ressaltar a acentuada fragilidade causada por absorção de $\mathrm{O}$ e $\mathrm{N}$ em operações de soldagem, ou introduzidos na produção e refino. 


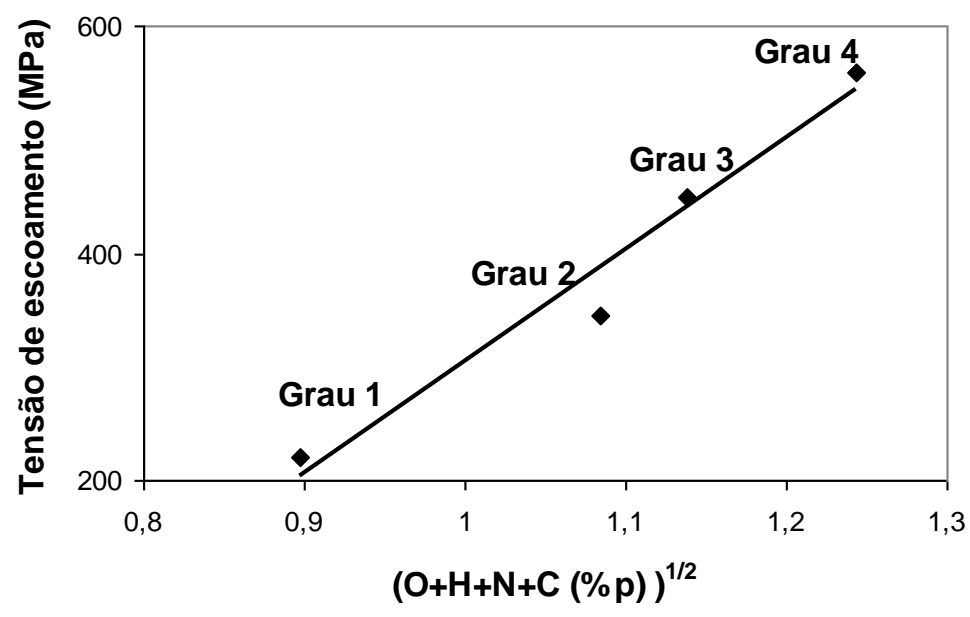

Figura 2.49. Tensão de escoamento em função da raiz quadrada da soma das impurezas para os quatro Graus de Ti CP. (ANIBAL, 2010)

Os elementos de liga para o titânio classificam-se como estabilizadores de $\alpha$ ou estabilizadores de $\beta$. Dentre os primeiros o principal é o Al, seguido em eficácia pelo $\mathrm{Sn}$ e $Z$ r. Os estabilizadores de $\beta$ dividem-se por sua vez em estabilizadores de $\beta$ isomorfo (Mo, $\mathrm{V}, \mathrm{Ta}, \mathrm{Nb}$ ) e de $\beta$ eutetóide (Mn, $\mathrm{Fe}, \mathrm{Cr}, \mathrm{Co}, \mathrm{Ni}, \mathrm{Cu}, \mathrm{Si}$ ). A Figura 2.50 apresenta alguns diagramas de fase binários desses sistemas.

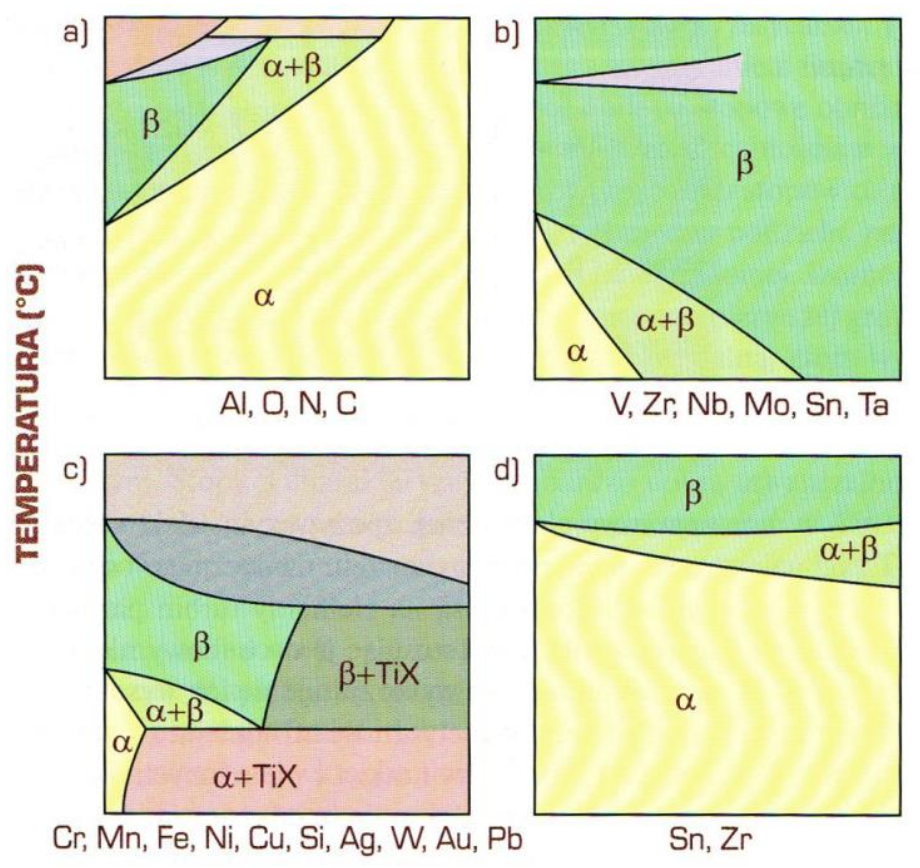

Figura 2.50 Diagrama de fases binário para o Titânio com diferentes elementos de liga. (DOBRZAŃSKI, 2004) 
As ligas de Titânio podem ainda apresentar uma grande variedade de microestruturas, que depende da composição química, processamento e tratamento térmico da liga. A Tabela 2.7 apresenta os símbolos e as definições das várias fases que podem estar presentes nesse sistema.

Tabela 2.7. Fases observadas em ligas de Titânio

\begin{tabular}{|c|l|}
\hline Símbolo & \multicolumn{1}{|c|}{ Descrição } \\
\hline$\alpha$ & $\begin{array}{l}\text { Forma alotrópica do Titânio em baixa temperatura com estrutura } \\
\text { cristalina Hexagonal Compacta (HC) }\end{array}$ \\
\hline$\beta$ & $\begin{array}{l}\text { Forma alotrópica do Titânio em alta temperatura com estrutura } \\
\text { cristalina Cúbica de corpo centrado (CCC). Pode existir em baixas } \\
\text { temperaturas nas condições metaestável e estável em ligas } \\
\text { altamente enriquecidas }\end{array}$ \\
\hline$\beta_{2}$ (segunda fase) & $\begin{array}{l}\text { Tỉ3Al existe em várias ligas que contém Al. } \\
\text { Fase CCC com estrutura típica do Ti2AINb, é uma versão ordenada } \\
\text { da forma alotrópica CCC estável em alta temperatura. Pode } \\
\text { aparecer em baixas temperaturas na condição metaestável. }\end{array}$ \\
\hline
\end{tabular}

Baseado nos elementos de liga e nas fases presentes na microestrutura, as ligas de Titânio são classificadas em:

- Ligas Alfa $(\alpha)$ : apresentam uma única fase e são endurecidas por solução sólida adicionando elementos de liga neutros. São estáveis e possuem boas propriedades em altas temperaturas.

- Ligas próximas de $\alpha$ : contém uma pequena porcentagem de elementos de liga estabilizadores de $\beta$ (1 a 2 \%). A microestrutura consiste de fase a com pouca quantidade de $\beta$ retida.

- Ligas $\alpha+\beta$ : contém maiores quantidades de elementos de liga estabilizadores de $\beta$ (4 a $6 \%$ ). Essas ligas podem ser tratadas termicamente para produzir diferentes microestruturas. A liga mais conhecida dessa classe é a Ti6Al4V, objeto de estudo do presente trabalho. 
- Ligas $\beta$ Metaestável: Possuem elementos de liga estabilizadores de $\beta$ entre 10 e $15 \%$, a fase $\beta$ é retida à temperatura ambiente em condição metaestável. Essas ligas contêm pequena quantidade de elementos de liga estabilizadores de a como agente endurecedor. Apresentam elevada resistência mecânica.

- Ligas $\beta$ : Possuem elevada quantidade de estabilizadores de $\beta, 30 \%$, sendo essa a fase estável à temperatura ambiente. As ligas $\beta$ são metais refratários e possuem alta densidade e baixa ductilidade. São utilizadas em ambientes altamente corrosivos.

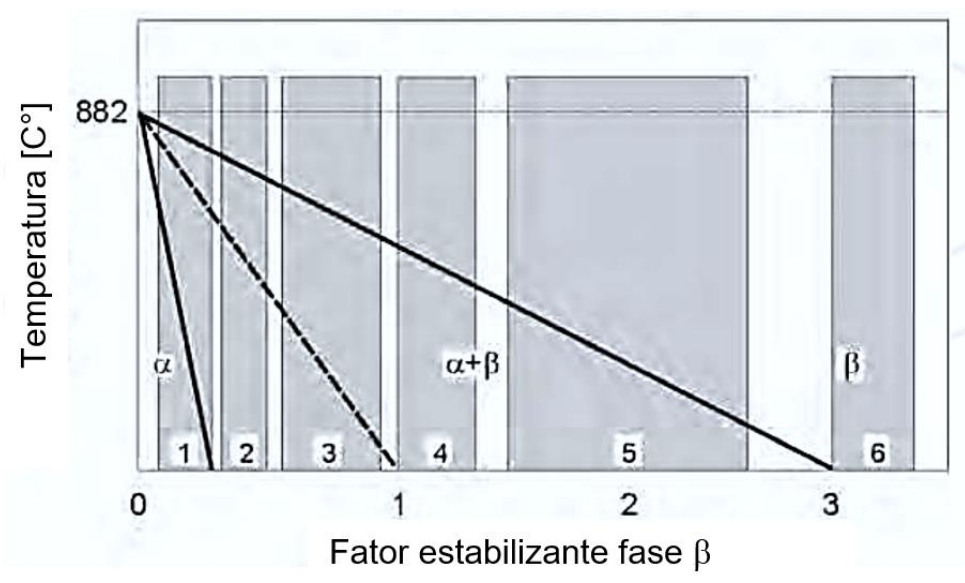

Figura 2.51 Classificação das ligas de titânio com referência aos estabilizadores $\beta$ : $1-\alpha$ alloys, 2 - near $\alpha$ alloys, 3 - martensitic $\alpha+\beta$ alloys, 4 - transition $\alpha+\beta$ alloys, 5 - near $\beta$ alloys, $6-\beta$ alloys. (MOTYKA, 2012)

Para melhor ilustrar a divisão de grupos das ligas de titânio que contem estabilizadores fase $\beta$, segue Figura 2.52 que relaciona a concentração desses estabilizadores em função da temperatura.

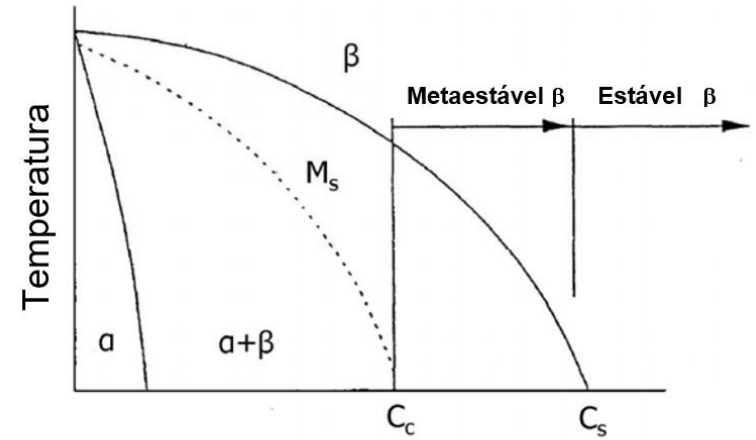

a) Concentração estabilizador- $\beta$

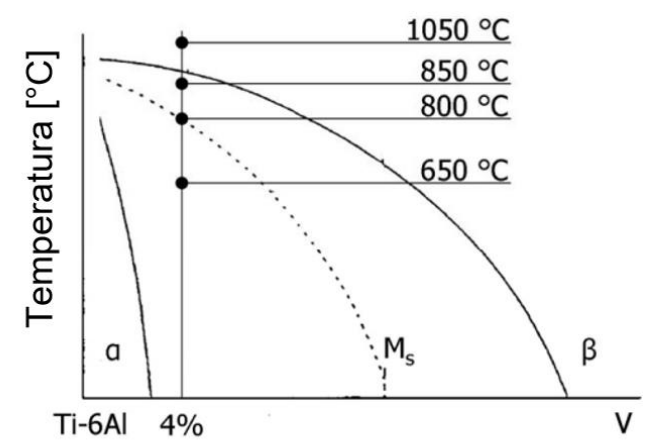

b)

Figura 2.52 a) Ti-estabilizador- $\beta$ and b) Ti-6Al-4V. (MAY, 2009) 
Ligas de titânio $\alpha$ e próximas de $\alpha$ exibem alta resistência a corrosão e baixa resistência a temperatura ambiente. Ligas $(\alpha+\beta)$ apresentam maior resistência mecânica devido a presença de ambas fases, tais ligas tem suas propriedades mecânicas dependentes da composição, da quantidade de fase $\alpha$ e fase $\beta$, tratamento térmico e tratamento termomecânico. Ligas $\beta$ (metaestáveis e estáveis) exibem elevada resistência, boa conformabilidade e baixo coeficiente de elasticidade. Ligas $\beta$ metaestáveis variam desde críticas $(\mathrm{Cc})$ até estáveis (Cs), Figura 2.52, são capazes de precipitar uma segunda fase quando envelhecidas. Em ligas $\beta$ estáveis não há precipitação, mesmo em longas exposições térmicas. (MAY,2009)

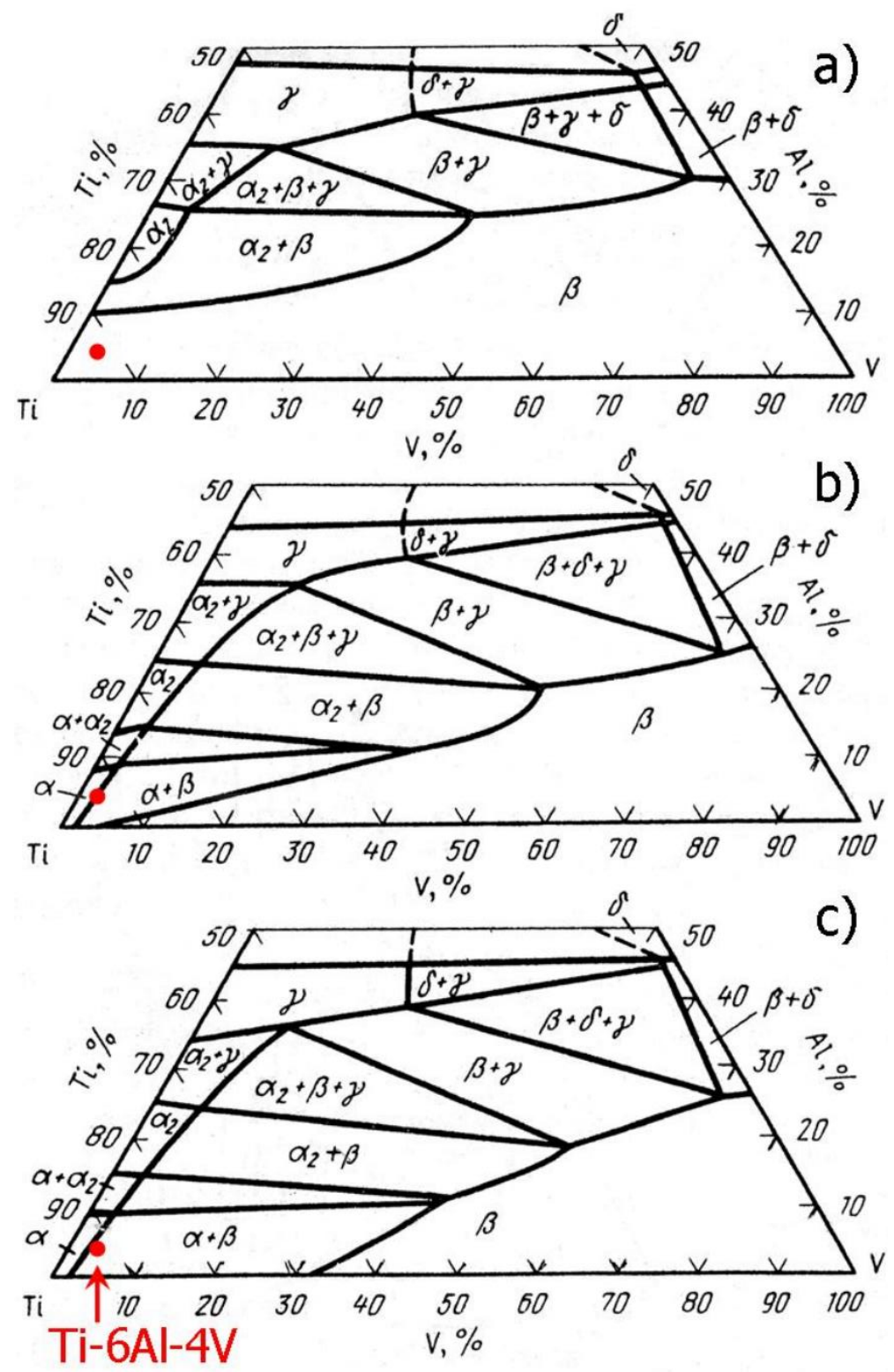

Figura 2.53 Seções isotérmicas do diagrama ternário para Ti-Al-V em $1100^{\circ} \mathrm{C}(\mathrm{a}), 800^{\circ} \mathrm{C}$ (b) e $550^{\circ} \mathrm{C}$ (c), destaque da posição da liga Ti-6Al-4V (MAY, 2009) 
A liga utilizada na tese, Ti-6Al-4V pertence ao tipo $(\alpha+\beta)$ e seu diagrama de fase quase-estático binário com 4\% de Vanádio está representado pela Figura 2.52 (b), como também segue seu diagrama ternário para temperaturas de $1100^{\circ} \mathrm{C}, 800^{\circ} \mathrm{C}$ e $550^{\circ} \mathrm{C}$ representado na Figura 2.53, com destaque para a posição da liga. (MAY,2009)

Essa classificação da liga de titânio quanto às fases está esquematicamente representada na Figura 2.54.

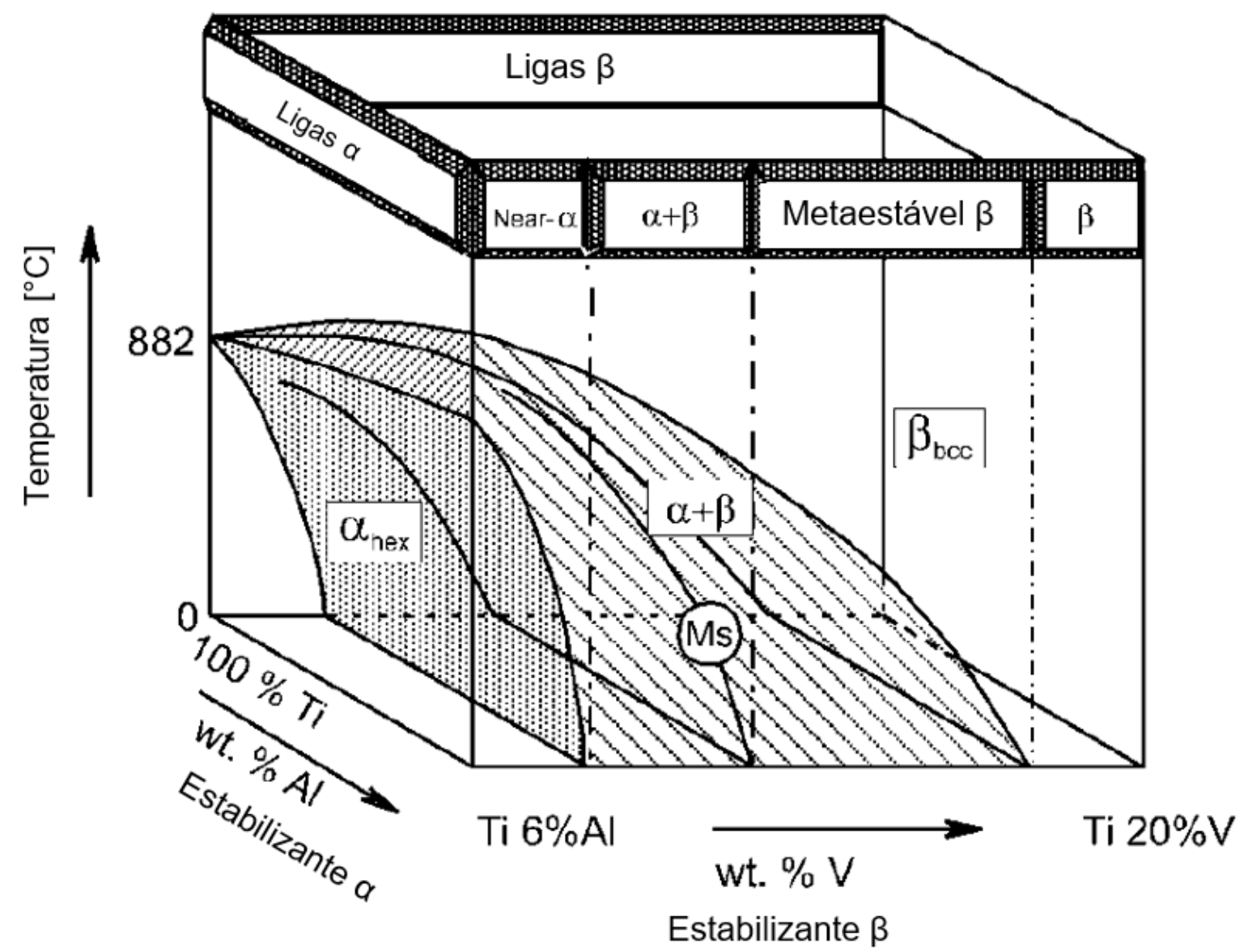

Figura 2.54 Diagrama de fases 3D para classificar esquematicamente as ligas de titânio. (PETER,2003)

Os dois casos extremos desse arranjo de fases são a microestrutura lamelar, que é geralmente obtida através de um processo de resfriamento na área da fase $\beta$, e a microestrutura equiaxial, que é resultado de um processo de recristalização.

A temperatura de transição da fase $\beta$ ( $\beta$-transus) da liga comercial de Ti-6Al-4V é geralmente próximo a $1000^{\circ} \mathrm{C}$, quando ocorre um aquecimento desde a temperatura ambiente até acima da $\beta$-transus, haverá inteiramente fase $\beta$ na liga, quando houver um resfriamento, sob certas condições de equilíbrio, a transformação reversa $\beta \rightarrow \alpha$ ocorrerá. 
Quando for resfriado de uma temperatura superior a temperatura metaestável (MS Temperature) e a taxa de resfriamento for rápida o suficiente para permitir a transformação difusional, ocorrerá a formação da fase martensítica. (CLINNING, 2012)

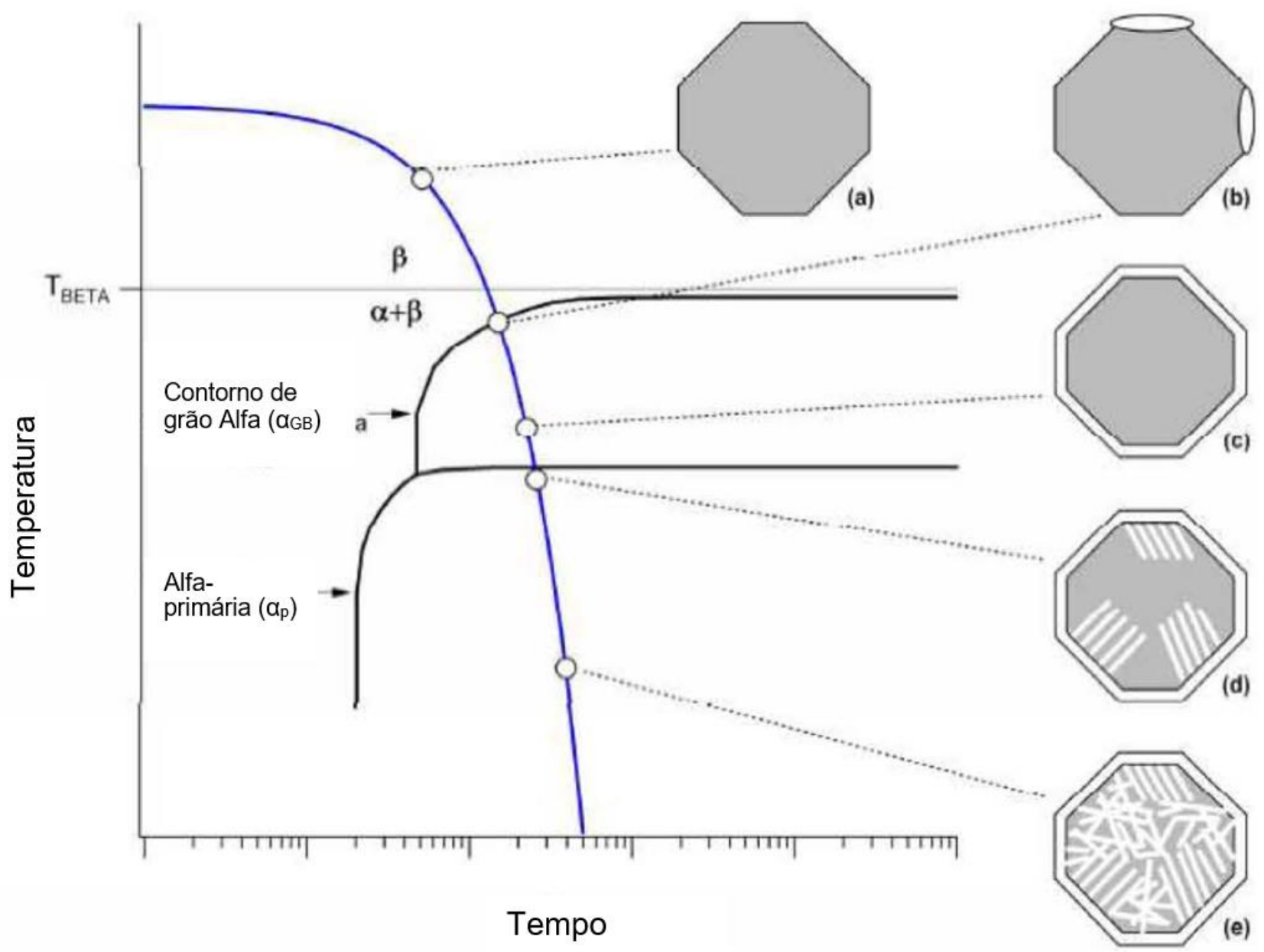

Figura 2.55 Ilustração esquemática mostrando o processo de nucleação e crescimento de $\alpha$ para formar um equilíbrio microestrutural $\alpha / \beta$ quando resfriado lentamente de uma temperatura acima de $\beta$-transus. (a) mostra um único grão de $\beta$ que existe acima da temperatura de $\beta$-transus, (b) mostra a nucleação de um grão a logo abaixo da $\beta$-transus, (c) mostra o contorno de grão completo $\alpha$, (d) mostra o crescimento de colônias de lamelas $\alpha$, e finalmente, (e) mostra a nucleação e o crescimento de lamelas a enquanto o resfriamento ocorrer. (CLINNING, 2012)

Já no caso da microestrutura equiaxial, ela é resultado de um processo de recristalização. Segue Figura $2.56 \mathrm{com}$ as etapas do processo para obter microestrutura equiaxial (LÜTJERING, 2003) 


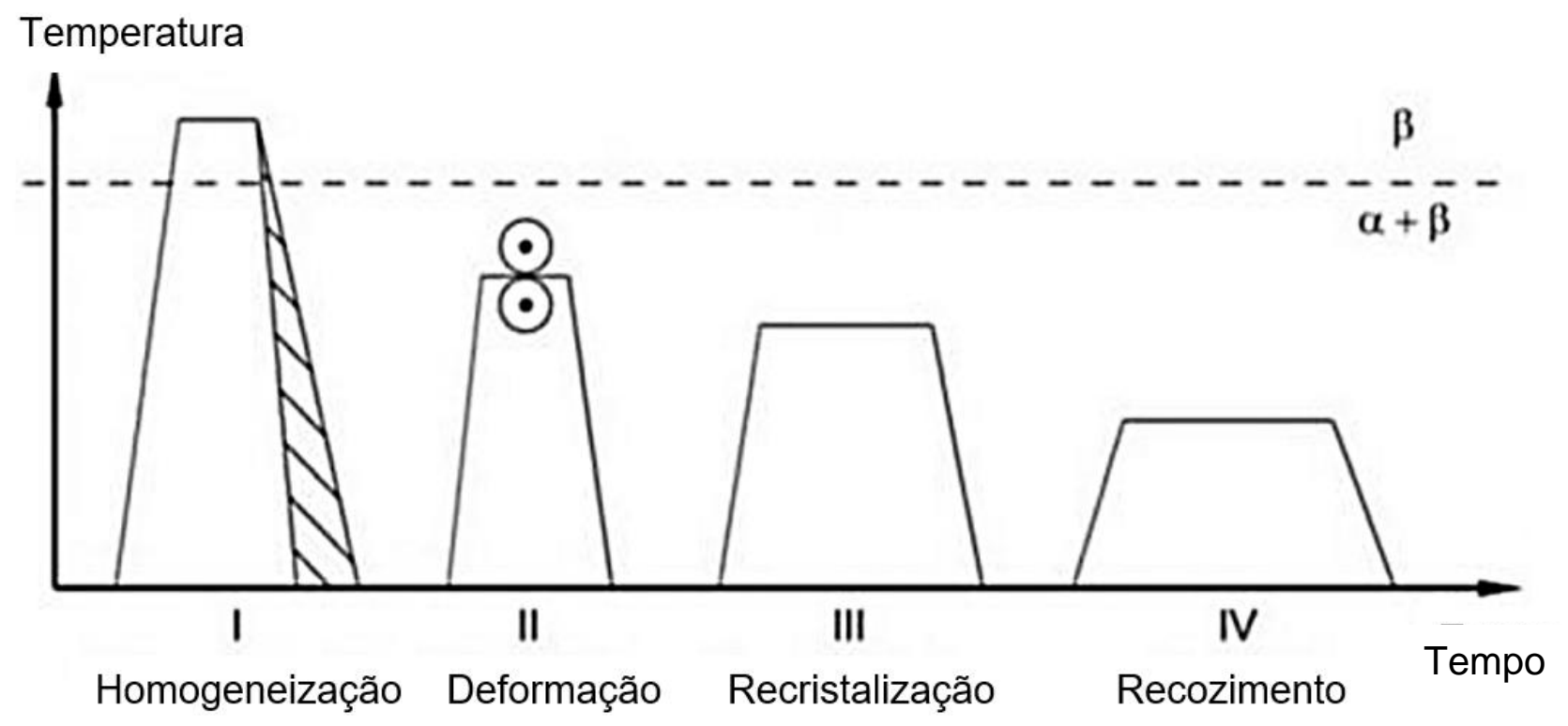

Figura 2.56 Rota do processo para microestrutura equiaxial de ligas de titânio $\alpha+\beta$ recristalizada em baixas temperaturas. (LÜTJERING, 2003)

O mecanismo que muda a estrutura inicial lamelar para equiaxial pode ser observado na Figura 2.57, a fase a penetra ao longo do contorno de grão da fase $\beta$, causando a separação do grão de $\beta$ na fase final. (LÜTJERING, 2003)

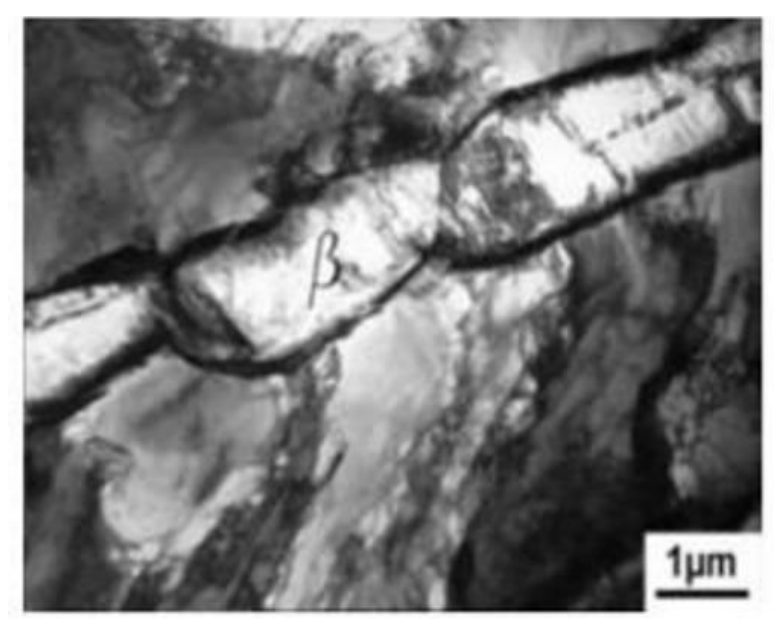

Figura 2.57 Mecanismo de recristalização para obter microestrutura equiaxial a $800^{\circ} \mathrm{C}$, Ti-6AI-4V. (LÜTJERING, 2003)

Segue imagem, da liga de Ti-6Al-4V obtida pela rota descrita para obtenção de microestrutura equiaxial. 


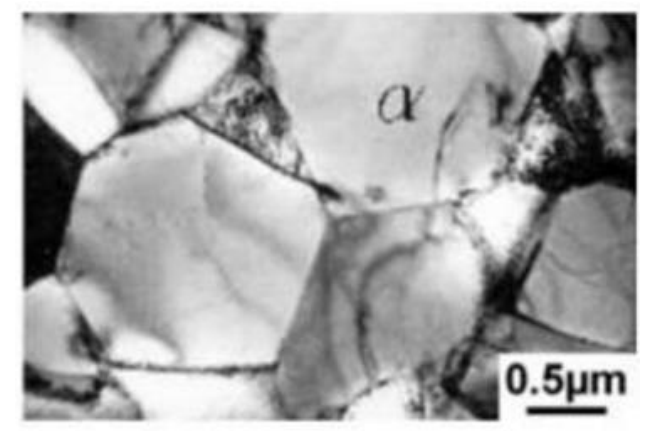

Figura 2.58 Microestrutura equiaxial da liga de Ti-6Al-4V recristalizada a $800^{\circ} \mathrm{C}$. (LÜTJERING, 2003)

Em resumo, em relação a liga utilizada na tese, há três tipos básicos de microestrutura, seguem tais tipos na Figura 2.59. Dentre elas a microestrutura equiaxial, Figura 2.59 (c), é a que melhor propicia o mecanismo da superplasticidade. Microestruturas equiaxiais apresentam frequentemente alta ductilidade, enquanto lamelar tem alta resistência a fratura e a falha por fadiga, já a bimodal combina as vantagens de ambas.
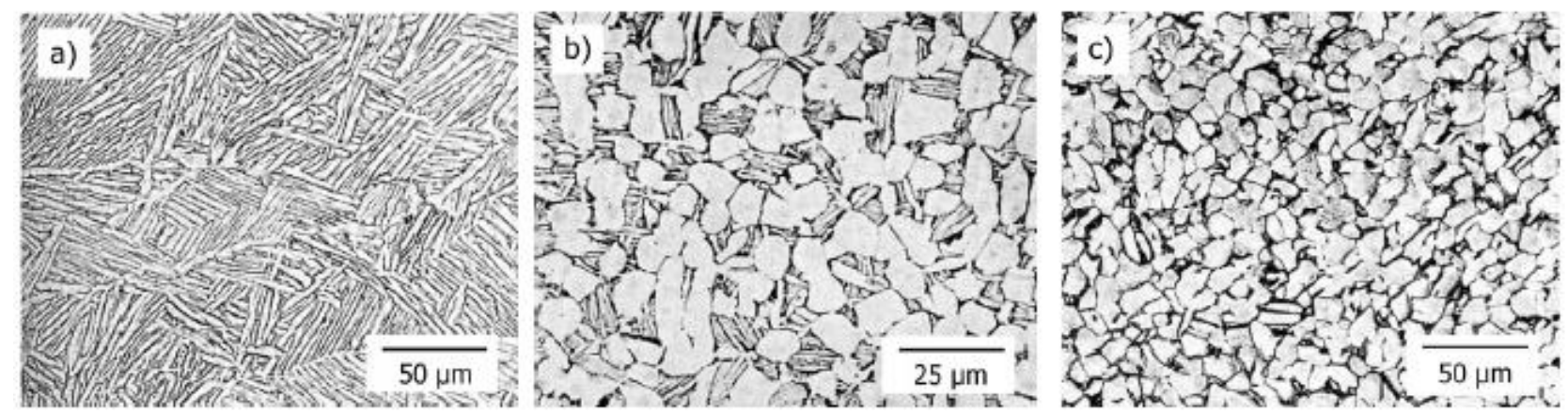

Figura 2.59 Os três tipos básicos de microestruturas da liga Ti-6Al-4V (a) Lamelar, (b) Bimodal e (c) Equiaxial. (MAY, 2009)

No capítulo 2.1.4 é enfatizado que a deformação superplástica não causa mudança no formato equiaxial dos grãos, contudo observa-se uma transformação gradual da textura, isso indica que o GBS é o mecanismo que domina a deformação superplástica. Nesse contexto, deve-se ressaltar que a condição microestrutural inicial de uma deformação superplástica pode ser diferente de equiaxial, segue exemplo de superplasticidade a alta taxa de deformação (high superplasticity) com microestrutura inicial composta de grãos com elevada elongação, entretanto, após a deformação superplástica ocorreram mudanças 
significativas referentes a morfologia das fases dos componentes da liga TI-6AL-4V, e a microestrutura tornou-se predominantemente equiaxial. Segue Figura 2.60 com a evolução microestrutural citada.

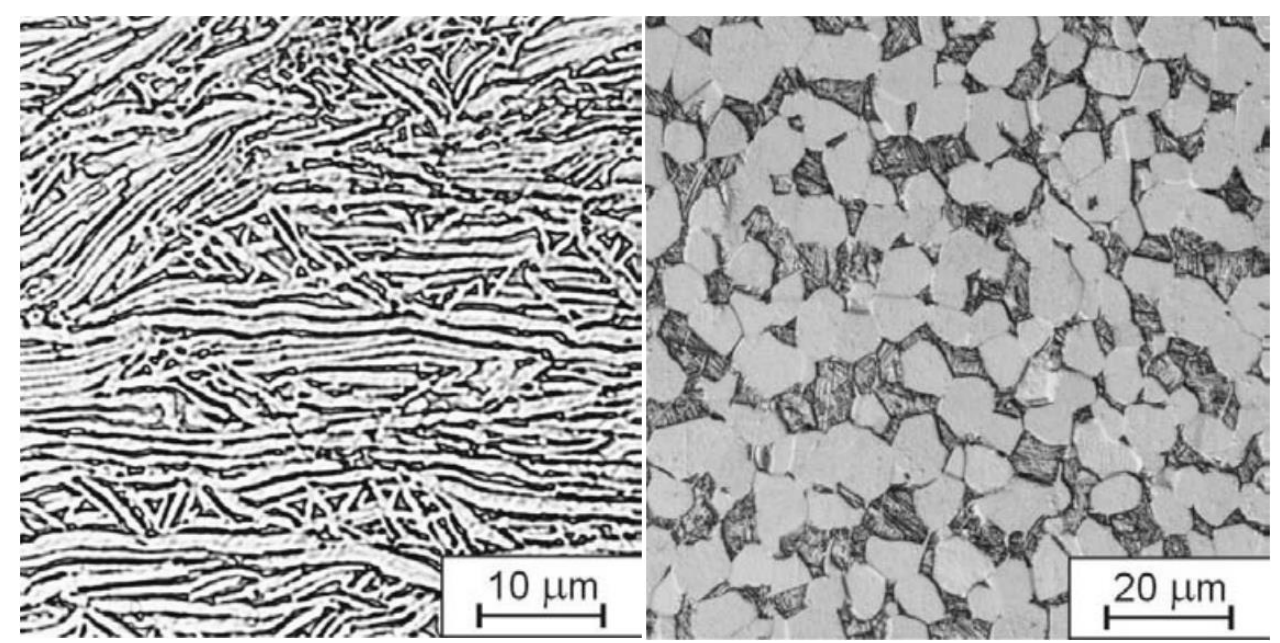

Figura 2.60 Microestrutura da liga Ti-6AL-4V antes (a) e depois (b) da deformação superplástica nas condições de $800^{\circ} \mathrm{C}$ e taxa de deformação $10^{-3} \mathrm{~s}^{-1}$. [SIENIAWSKI, 2007]

A microestrutura das ligas de titânio que apresentam comportamento superplástico geralmente é caracterizada por uma estrutura de tamanho de grão pequeno (fine-grain) equiaxial ou bimodal composta por $\alpha+\beta$ e tamanho de grão na ordem de 5 a $15 \mu \mathrm{m}$. Essa estrutura $\alpha+\beta$ impede o crescimento do grão durante a deformação, se caracterizando como o tipo de microestrutura mais estável durante o processo de conformação superplástico que ocorre a uma temperatura de $\approx 0,9$ da temperatura de transformação de $\beta$ (PETER, 2003).

A Tabela 2.8 apresenta as ligas de titânio que podem apresentar comportamento superplástico e as condições para que isso ocorra. É importante observar a variabilidade de valores entre as mesmas ligas, no caso da liga de interesse dessa tese, Ti-6Al-4V, para valores de temperatura de aplicação da superplasticidade, tem-se desde $840^{\circ} \mathrm{C}$ até $930^{\circ} \mathrm{C}$, para índices de sensibilidade a taxa de deformação, tem-se de 0,7 até 0,9. Essa variabilidade justifica a necessidade de realizar ensaios de saltos iniciais para localizar o ponto ótimo de superplasticidade para a liga da tese. 
Tabela 2.8. Ligas de titânio com comportamento superplástico. Adaptado (BLANDIN, 1996), (BECK, 2003), (CHOKSHI, 1993), (OLLIVIER, 2003).

\begin{tabular}{|c|c|c|c|c|}
\hline Ligas & $\begin{array}{c}\text { Temperatura } \\
{\left[{ }^{\circ} \mathbf{C}\right]}\end{array}$ & $\begin{array}{c}\text { Taxa de } \\
\text { deformação } \\
{\left[\mathbf{s}^{-1}\right]}\end{array}$ & $\mathbf{m}[-]$ & $\begin{array}{c}\text { Deformação } \\
\text { [\%] }\end{array}$ \\
\hline Ti-6Al-4V & 880 & $2.10^{-4}$ & 0,8 & 1000 \\
\hline Ti-6Al-4V & 930 & $10^{-4}$ & 0,9 & 800 \\
\hline Ti-6Al-4V & $840-900$ & $10^{-4}$ a $10^{-3}$ & 0,7 a 0,8 & $700-12000$ \\
\hline Ti-6Al-4V & $840-870$ & $1,3.10^{-4}$ a $10^{-3}$ & 0,75 & \\
\hline Ti-6Al-5V & 850 & $8.10^{-4}$ & 0,7 & 1100 \\
\hline Ti-6Al-5V & 850 & $8.10^{-4}$ & 0,5 & \\
\hline Ti-6Al-2Sn-4Zr-2MoV & 900 & $2.10^{-4}$ & 0,7 & 600 \\
\hline Ti-6Al-2Sn-4Zr-2Mo & 900 & $2.10^{-4}$ & 0,67 & \\
\hline Ti-4Al-4Mo-2Sn-0,5Si & 850 a 900 & $10^{-4}$ a $10^{-3}$ & 0,7 & 1230 \\
\hline Ti-4,5Al-5Mo-1,5SCr & 870 & $2.10^{-4}$ & $0,63-0,81$ & \\
\hline Ti-6Al-4V-1Co & 835 & $10^{-4}$ & & 1090 \\
\hline Ti-6Al-4V-2Ni & 815 & 2. $10^{-4}$ & 0,8 & 700 \\
\hline Ti-6Al-4V-2Co & 815 & 2. $10^{-4}$ & 0,5 & 700 \\
\hline Ti-6Al-4V-2Fe & 815 & 2. $10^{-4}$ & 0,5 & 700 \\
\hline Ti-6Al-4V-1Fe-1Co & 815 & 2. $10^{-4}$ & 0,5 & 500 \\
\hline Ti-6Al-4V-1Fe-1Ni & 815 & 2. $10^{-4}$ & 0,7 & 500 \\
\hline Ti-6Al-4V-1Co-1Ni & 815 & 2. $10^{-4}$ & 0,7 & 550 \\
\hline Ti-6Al-4V-2Ni & 815 & 2. $10^{-4}$ & 0,85 & \\
\hline Ti-6Al-4V-2Co & 815 & 2. $10^{-4}$ & 0,53 & \\
\hline Ti-6Al-4V-2Fe & 815 & 2. $10^{-4}$ & 0,54 & \\
\hline Ti-5Al-2,5Sn & 1000 & $2.10^{-4}$ & 0,49 & \\
\hline Ti-15V-3Cr-3Sn-3Al & 815 & $2.10^{-4}$ & 0,5 & \\
\hline SP700 & 775 & $1,3.10^{-5}$ a $1,3.10^{-3}$ & $0,59-0,38$ & \\
\hline Ti-5Al-2Sn-4Zr-4Mo-2Cr-1Fe & 700 a 775 & $10^{-4}$ a $10^{-3}$ & $0,4-0,5$ & 1000 \\
\hline Ti-3,9Al-3,7V-3Mo-1Fe & 750 & - & - & 2000 \\
\hline Ti-25Al-13Nb & 950 & $2.10^{-4}$ & 0,87 & 742 \\
\hline Ti-25Al-10Nb & 950 & $2.10^{-4}$ & 0,72 & 633 \\
\hline
\end{tabular}




\subsubsection{Formação da camada Alfa fragilizante (Alfa-case)}

Essa característica das ligas de titânio transforma uma simples conformação mecânica em um grande desafio; torna-se necessário ter controle da atmosfera de conformação devido ao fato de que Titânio em solução sólida se combina com carbono, nitrogênio e especialmente com oxigênio formando a camada alfa.

A tese desenvolveu o sistema de controle para cumprir com requisito de ter a atmosfera de conformação controlada e preenchida por um gás inerte, utilizou-se o argônio. No capítulo 3.4.2 há o detalhamento do sistema de proteção contra aparecimento da camada alfa durante a deformação a quente, em resumo, foi realizada uma purga no forno de conformação seguido de preenchimento de argônio, dessa forma, o oxigênio foi substituído pelo argônio antes da conformação.

A camada alfa é a fase enriquecida de oxigênio que ocorre no titânio e suas ligas quando expostas em altas temperaturas e atmosferas oxidantes, ocorre pela difusão através da solução sólida intersticial do oxigênio no titânio ou em alguns casos podendo ser carbono e nitrogênio. Formada pelo $\mathrm{TiO}_{2}$, a camada alfa é considerada dura e frágil pela literatura. (ZIMMER, 2001)

Para destacar a relevância da preocupação do efeito da oxidação na ductilidade da liga de Ti-6Al-4V durante a Conformação Superplástica, seguem resultados, na Figura 2.61, da pesquisa de Thiruvarudchelvan que investiga essa influência através de ensaios de tração uniaxiais nas temperaturas de $800^{\circ} \mathrm{C}, 850^{\circ} \mathrm{C}$ e $900^{\circ} \mathrm{C}$.

A variação da deformação máxima como função da taxa de deformação indica claramente que os corpos de prova que tiveram atmosfera protegida/controlada com argônio obtiveram deformações máximas maiores, esse sintoma aponta que a oxidação degrada a ductilidade da liga de Ti-6Al-4V. (THIRUVARUDCHELVAN, 2005)

Segue Figura 2.62 da seção transversal de uma amostra que foi exposta ao ar a $900^{\circ} \mathrm{C}$ por 1 hora, observa-se as camadas do óxido (alfa case) na figura (a) sem proteção de argônio. 

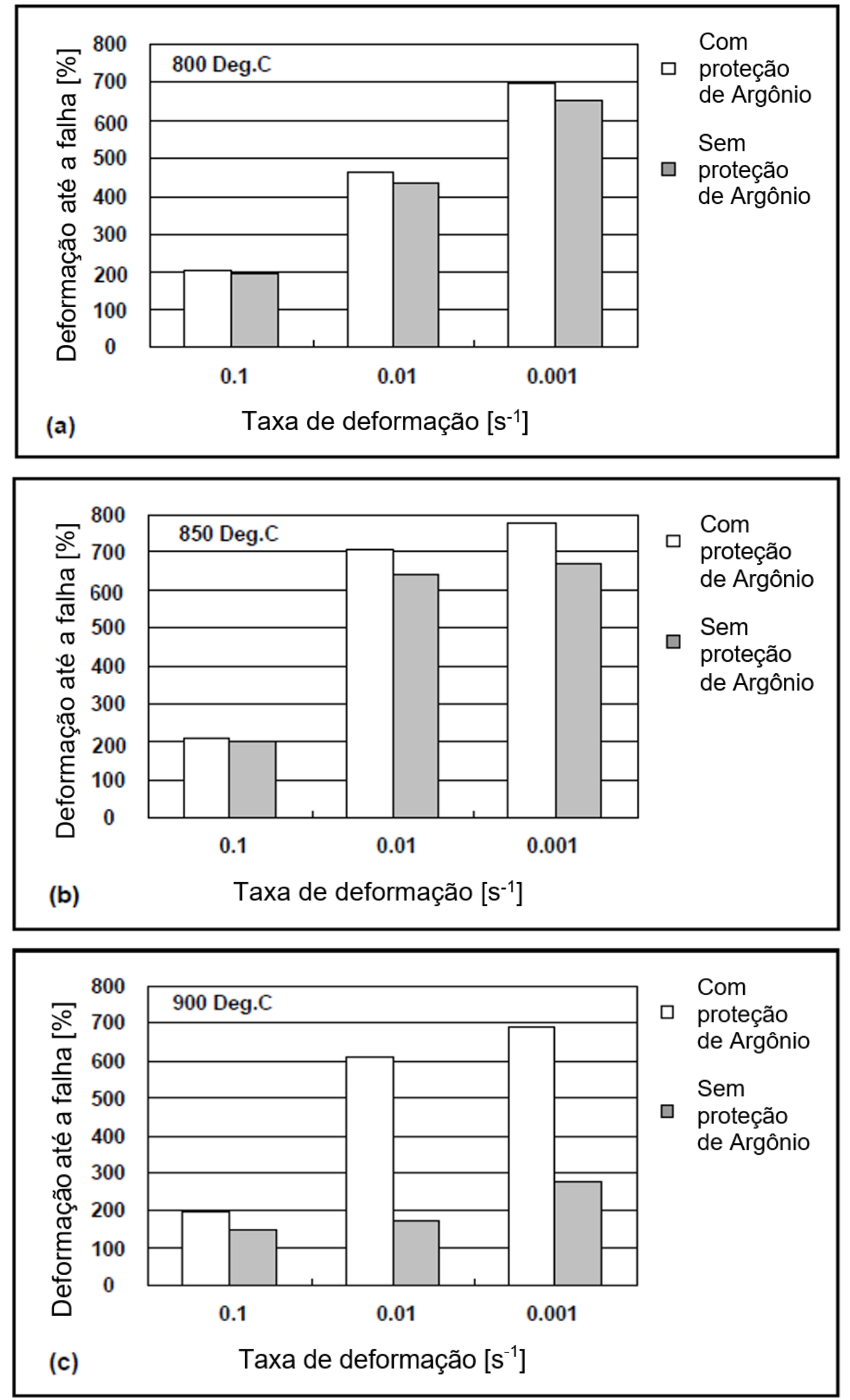

Figura 2.61 Comparação entre as variações máximas em função da taxa da deformação e temperatura para os casos de atmosfera protegida com argônio e não protegida. (THIRUVARUDCHELVAN, 2005) 

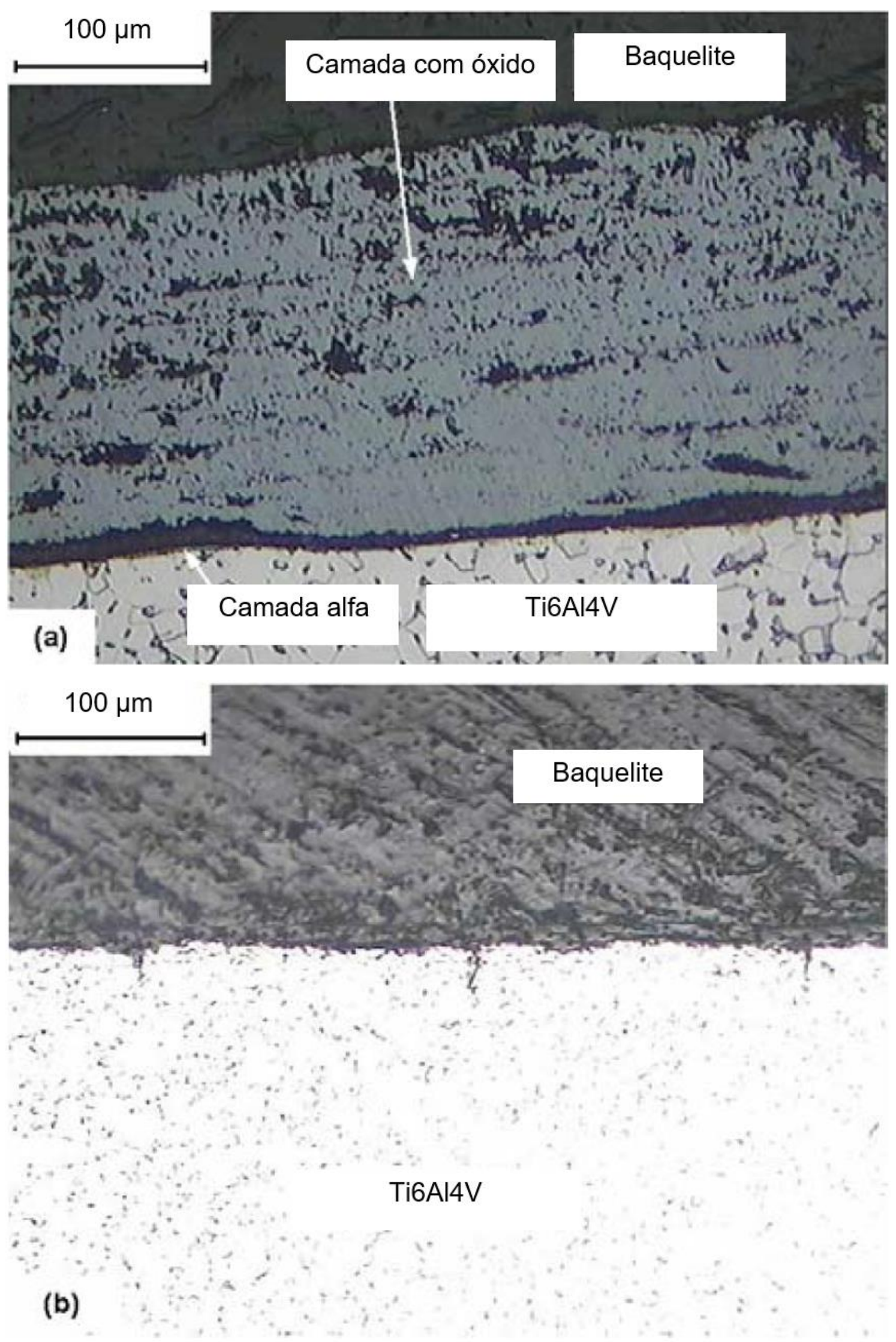

Figura 2.62 Micrografia ótica da camada alfa (a) sem proteção de argônio e (b) com proteção de argônio. (THIRUVARUDCHELVAN, 2005) 


\subsubsection{Ti-6Al-4V e a Superplasticidade}

A liga Ti-6Al-4V é uma das ligas de Titânio mais utilizadas na indústria aeronáutica por suas ótimas propriedades mecânicas em alta temperatura, resistência à corrosão e principalmente, a capacidade de exibir comportamento superplástico. A superplasticidade ocorre em condições específicas de temperatura e taxa de deformação conhecida como janela superplástica, que vai depender basicamente da microestrutura da liga (tamanho de grão e fases presentes, por exemplo).

Para a liga Ti-6Al-4V em estudo nessa tese, foram realizados ensaios de salto para determinação da janela superplástica, toda a metodologia e os resultados detalhados estão discutidos no capítulo 3.2.

Em outro estudo (VANDERHASTEN, 2008) foi utilizada a liga TIMETAL 6-4 Titanium Aero na forma de chapas de $1 \mathrm{~mm}$ de espessura e tamanho de grão de $8 \mu \mathrm{m}$. Ensaios de tração a quente com taxa de deformação constante mostraram que a janela superplástica ocorre entre 800 e $850^{\circ} \mathrm{C}$ e taxa de $5 \times 10^{-4} \mathrm{~s}^{-1}$, similar ao encontrado por Lee (LEE, 1998).

A Figura 2.63 mostra curvas tensão-deformação obtidas desse estudo para uma taxa de $5 \times 10^{-4} \mathrm{~s}^{-1}$ e temperaturas variando de 750 a $950^{\circ} \mathrm{C}$.

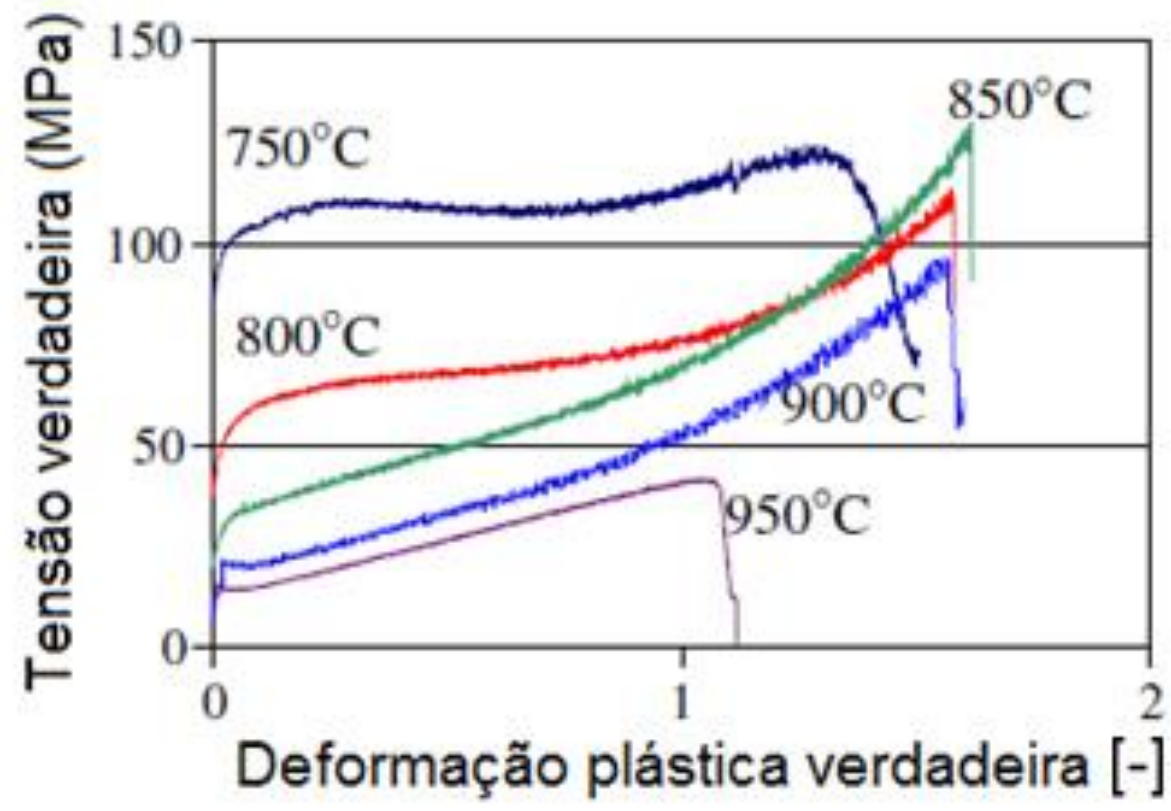

Figura 2.63 Curvas tensão-deformação verdadeiras da liga Ti-6Al-4V testada em temperaturas entre 750 e $950^{\circ} \mathrm{C}$ e taxa de deformação de $5 \times 10^{-4} \mathrm{~s}^{-1}$. (VANDERHASTEN, 2008) 
Ainda em relação ao trabalho do Vanderhasten, considerando resultados obtidos de ensaios de tração eles mapearam os mecanismos de deformação ativos para a liga Ti-6Al4V em quatro domínios principais. Esses domínios são apresentados na Figura 2.64. Como discutido no item 2.1.4, a superplasticidade ocorre no pequeno domínio correspondente ao mecanismo de escorregamento de contornos (GBS) + crescimento de grão dinâmico (DGG).

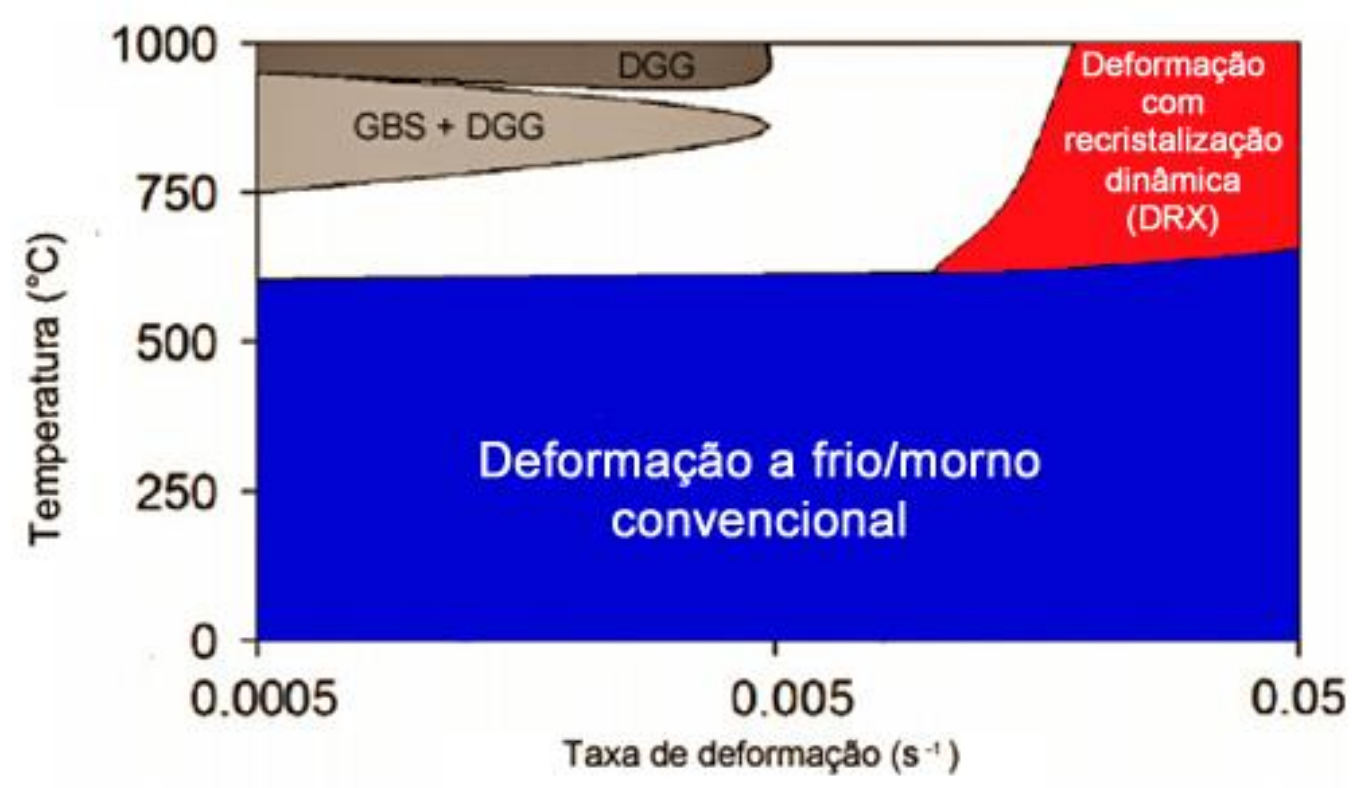

Figura 2.64 Mapa de deformação da liga Ti-6Al-4V para temperaturas entre temperatura ambiente e $1000^{\circ} \mathrm{C}$ e taxas deformação entre $5 \times 10^{-4}$ e $5 \times 10^{-2} \mathrm{~s}^{-1}$. (DGG crescimento de grão dinâmico, GBS - escorregamento de grãos e DRX recristalização dinâmica). (VANDERHASTEN, 2008) 


\subsection{Modelagem Matemática do processo de Conformação Superplástica de chapas metálicas}

Sabe-se que os metais superplásticos apresentam o comportamento profundamente relacionado com a temperatura e a taxa de deformação. De fato, a superplasticidade aparece em um reduzido espectro de valores de temperatura e taxa. Dessa forma, uma análise precisa e um planejamento da abordagem matemática da conformação são indispensáveis.

Através do desenvolvimento de modelos analíticos aproximados, ainda que para uma estrutura de geometria simples, é possível predizer a distribuição de espessura, calcular o ciclo de pressurização e examinar a influência das constantes do material nos parâmetros do processo e na geometria da peça conformada.

A modelagem matemática analítica superplástica assume as seguintes hipóteses:

- A deformação plástica notável obtida durante o processo de conformação superplástico torna negligenciável a deformação elástica.

- Como as taxas de deformação usuais à superplasticidade são da ordem de $10^{-5}$ $10^{-3} \mathrm{~s}^{-1}$, nas equações de movimento do continuum, as forças de inércia podem ser desprezadas. Dessa forma só equações de equilíbrio devem ser consideradas.

- O processo de Conformação Superplástica ocorre a uma determinada temperatura, cerca de $50 \%$ da temperatura de fusão em Kelvin. Portanto, o processo é considerado isotérmico durante a modelagem.

- O efeito do crescimento do tamanho de grão e a interligação de vazios nucleados internamente são desconsiderados.

- Assume-se que o material é isotrópico e incompressível.

- A espessura do corpo de prova é pequena quando comparada com o diâmetro do mesmo corpo de prova, dessa forma os efeitos de flexão e cisalhamento podem ser desconsiderados, característica essa que torna possível usar a teoria da membrana para descrever o estado de tensão da peça conformada. (GIULIANO, 2011). 


\subsubsection{Teoria de Membrana}

A determinação da curva tensão deformação para ensaios de expansão fluidoestática biaxial exige o equacionamento dos valores de curvatura e espessura a partir da teoria de membrana. O tratamento matemático exposto a seguir também estabelece os parâmetros para o ciclo de pressurização, responsável por manter a taxa de deformação constante.

A teoria de membrana é elaborada com base em três simplificações principais:

- As forças inerciais podem ser desprezadas;

- A tensão de espessura é desprezada por ser muito menor do que a tangencial e circunferencial;

- As tensões tangencial e circunferencial são uniformemente distribuídas ao longo da superfície;

Considerando a superfície de revolução mostrada na Figura 2.65 e adotando as três simplificações, a equação do equilíbrio pode ser escrita:

$$
2 \sigma_{\varphi} \operatorname{sen}\left(\frac{d \varphi}{2}\right) s R_{\theta} d \theta+2 \sigma_{\theta} \operatorname{sen}\left(\frac{d \theta}{2}\right) s R_{\varphi} d \varphi=p R_{\varphi} d \varphi R_{\theta} d \theta
$$

onde $s$ é a espessura do bulge, p é a pressão interna aplicada à superfície e $\mathrm{R}_{\varphi}$ e $\mathrm{R}_{\theta}$ são os dois raios de curvatura do bulge.

Como o ângulo $\alpha$ é pequeno, a aproximação $\sin \frac{\mathrm{d} \alpha}{2}=\frac{\mathrm{d} \alpha}{2}$ é válida e a equação de equilíbrio pode ser reescrita:

$$
\frac{\sigma_{\varphi}}{R_{\varphi}}+\frac{\sigma_{\theta}}{R_{\theta}}=\frac{p}{s}
$$




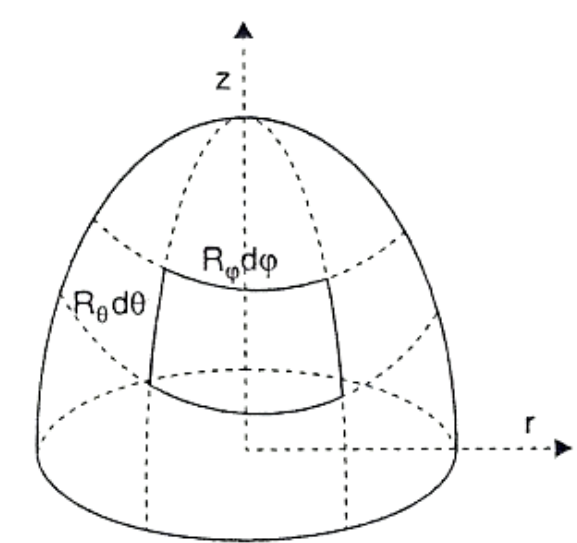

(a)

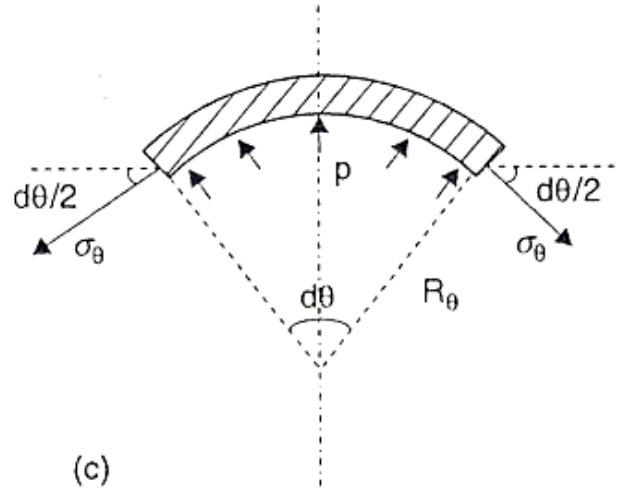

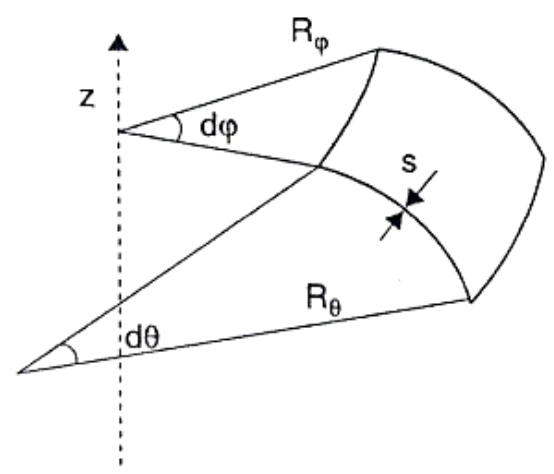

(b)

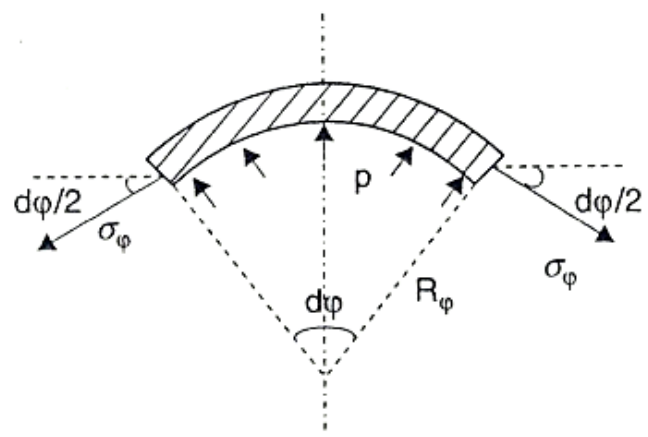

(d)

Figura 2.65 a) Superfície de revolução de uma chapa deformada; b) Elementos da superfície; c) e d) Tensão atuante na superfície do elemento. (GIULIANO, 2011)

A partir da Figura 2.65, a tensão tangencial $\sigma_{\theta}$ pode ser expressa da seguinte forma:

$$
\begin{aligned}
& \frac{\sigma_{\varphi}}{R_{\varphi}}+\frac{\sigma_{\theta}}{R_{\theta}}=\frac{p}{s} \\
& \sigma_{\theta} \operatorname{sen} \varphi \cdot 2 \pi r s=p \pi r^{2} \\
& r=R_{\varphi} \operatorname{sen} \varphi \\
& \sigma_{\theta}=\frac{p R_{\varphi}}{2 s}
\end{aligned}
$$

Substituindo (48) em (45), tem-se:

$$
\sigma_{\varphi}=\frac{p R_{\varphi}}{2 s}\left(2-\frac{R_{\varphi}}{R_{\theta}}\right)
$$


As equações (48) e (49) são as principais equações da teoria da membrana. Depois de estabelecidas $\sigma_{\theta}$ e $\sigma_{\varphi}$, pode-se também determinar o estado de tensão na casca através do critério de Von Mises de tensão equivalente para o caso de estado plano de tensão.

$$
\bar{\sigma}=\sqrt{\sigma_{\varphi}^{2}+\sigma_{\theta}^{2}-\sigma_{\varphi} \sigma_{\theta}}=\frac{p R_{\varphi}}{2 s} \sqrt{\left(\frac{R_{\varphi}}{R_{\theta}}\right)^{2}-3 \frac{R_{\varphi}}{R_{\theta}}+3}
$$

Como os ensaios serão realizados em chapas circulares, assume-se que a superfície formada corresponde a uma calota esférica - Figura 2.66. Sob essa condição, $R_{\theta}=R_{\varphi} e$ as tensões tangencial e circunferencial são equivalentes.

$$
\sigma_{\varphi}=\sigma_{\theta}=\frac{p R}{2 s}
$$
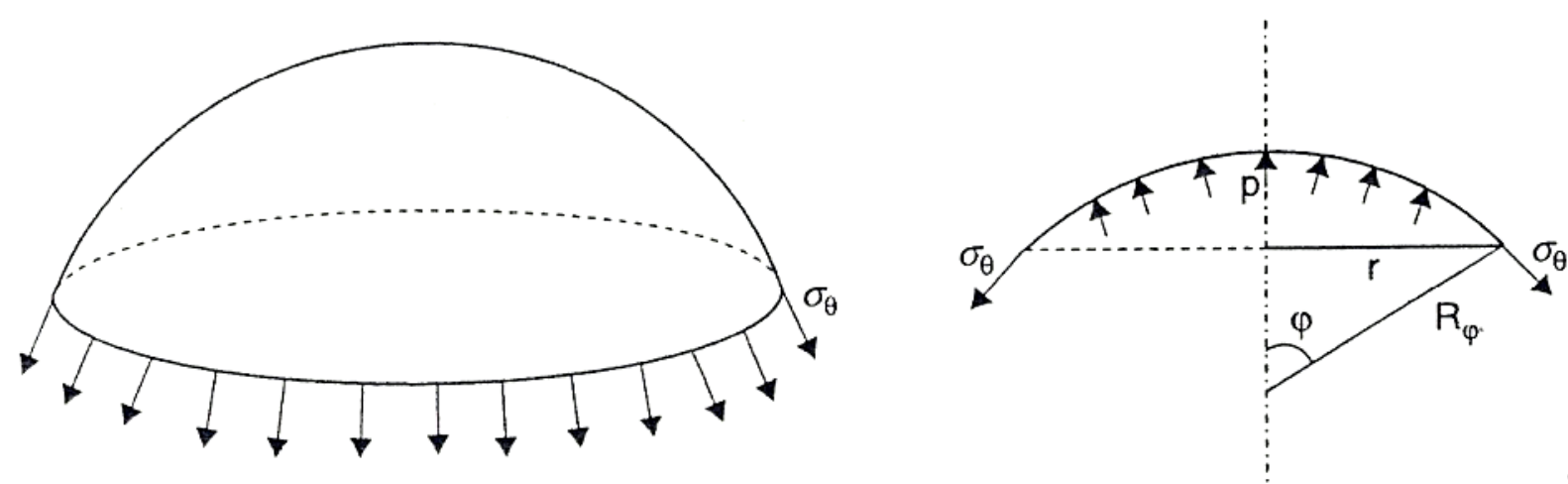

Figura 2.66 Tensão tangencial aplicada na calota esférica. (GIULIANO, 2011)

Estabelecidas as relações necessárias para a tensão, ainda é preciso encontrar equações que definam a taxa de deformação $\dot{\bar{\varepsilon}}$. Para tanto, emprega-se a lei de fluxo de Von Mises, que descreve as taxas de deformação tangencial $\left(\dot{\varepsilon}_{\theta}\right)$, circunferencial $\left(\dot{\varepsilon}_{\varphi}\right)$ e de espessura $\left(\dot{\varepsilon}_{t}\right)$ em função das componentes da tensão.

$$
\begin{aligned}
& \dot{\varepsilon}_{\theta}=\frac{\dot{\bar{\varepsilon}}}{\overline{\bar{\sigma}}}\left[\sigma_{\theta}-\frac{1}{2}\left(\sigma_{\varphi}+\sigma_{t}\right)\right] \\
& \dot{\varepsilon}_{\varphi}=\frac{\dot{\bar{\varepsilon}}}{\bar{\sigma}}\left[\sigma_{\varphi}-\frac{1}{2}\left(\sigma_{\theta}+\sigma_{t}\right)\right] \\
& \dot{\varepsilon}_{t}=\frac{\dot{\bar{\varepsilon}}}{\overline{\bar{\sigma}}}\left[\sigma_{t}-\frac{1}{2}\left(\sigma_{\varphi}+\sigma_{\theta}\right)\right]
\end{aligned}
$$


Adotando a simplificação da calota esférica e o critério de Von Mises $\left(\dot{\varepsilon}_{\theta}+\dot{\varepsilon}_{\varphi}+\dot{\varepsilon}_{\mathrm{t}}=\right.$ 0), é válida a seguinte relação.

$$
\dot{\bar{\varepsilon}}=-\dot{\varepsilon}_{\mathrm{t}}=2 \dot{\varepsilon}_{\theta}=2 \dot{\varepsilon}_{\varphi}
$$

No modelo de Jovane (JOVANE, 1968) não se considera a não uniformidade da variação da espessura, hipótese evidenciada por diversos trabalhos (CORNFIELD,1970) (HOLT,1970). De fato, próximo a periferia da chapa, a deformação circunferencial $\left(\dot{\varepsilon}_{\varphi}\right)$ é negligenciada. Em contraste com as equações da teoria da membrana (53), ao assumir $\dot{\varepsilon}_{\varphi}=0$, resulta em:

$$
\sigma_{\theta}=2 \sigma_{\varphi}
$$

Essa discrepância é resultado de que próximo da periferia da chapa a deformação por cisalhamento não poderia ter sido desconsiderada no equacionamento. (GIULIANO, 2011).

Dessa forma o estado plano de tensão determinado na borda da chapa se caracteriza pelas seguintes equações:

$$
\begin{gathered}
\sigma_{\theta}=\frac{p R}{2 s} \\
\sigma_{\varphi}=\frac{\sigma_{\theta}}{2} \\
\bar{\sigma}=\sqrt{3} \sigma_{\varphi}=\sqrt{3} \frac{\sigma_{\theta}}{2} \\
\dot{\varepsilon}_{\theta}=0 \\
\dot{\varepsilon}_{\theta}=-\dot{\varepsilon}_{\mathrm{t}} \\
\dot{\bar{\varepsilon}}=\frac{2}{\sqrt{3}} \dot{\varepsilon}_{\varphi}=-\frac{2}{\sqrt{3}} \dot{\varepsilon}_{\mathrm{t}}
\end{gathered}
$$

Portanto, ao utilizar a equação (48) e os índices "p" para polo e "b" para base, temse:

$$
\sigma_{\theta p} s_{p}=\sigma_{\theta b} s_{b}
$$




$$
\overline{\sigma_{p}} s_{p}=\frac{2}{\sqrt{3}} \overline{\sigma_{b}} s_{b}
$$

Substituindo (55), (60), (61), (62) e o clássico modelo de lei de potência $\left(\bar{\sigma}=K \dot{\bar{\varepsilon}}^{m}\right)$ na equação (64) obtém-se:

$$
\frac{s_{b}}{s_{p}}=\left(\frac{2}{\sqrt{3}}\right)^{1+\mathrm{m}}\left(\frac{\dot{\varepsilon}_{\mathrm{t}_{\mathrm{p}}}}{\dot{\varepsilon}_{\mathrm{t}_{\mathrm{b}}}}\right)^{\mathrm{m}}
$$

A taxa de deformação de espessura $\left(\dot{\varepsilon}_{t}\right)$ ainda pode ser expressa em função da

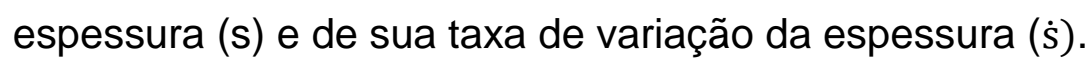

$$
\dot{\varepsilon}_{t}=\frac{\dot{s}}{s}
$$

Durante o processo de deformação a espessura no domo do bulge se comporta com um adelgamento que segue:

$$
s_{p}=S(t) s_{0}
$$

Com $\mathrm{s}_{0}=$ espessura inicial e $\mathrm{S}(\mathrm{t})<1$;

A Figura 2.67 mostra a espessura no domo do bulge é menor que a espessura na borda, tal não uniformidade é ampliada pela diminuição do índice de sensibilidade a taxa de deformação. Observa-se que a diferença também ocorrerá no caso ideal $(m=1)$, apesar de ser menor.

A tensão pode ser obtida a partir da medida do raio $R$, que pode ser expresso em função da altura do bulge e do raio inicial da chapa através de análise geométrica dos parâmetros da Figura 2.68.

$$
\mathrm{R}=\frac{\mathrm{a}^{2}+\mathrm{h}^{2}}{2 \mathrm{~h}}
$$




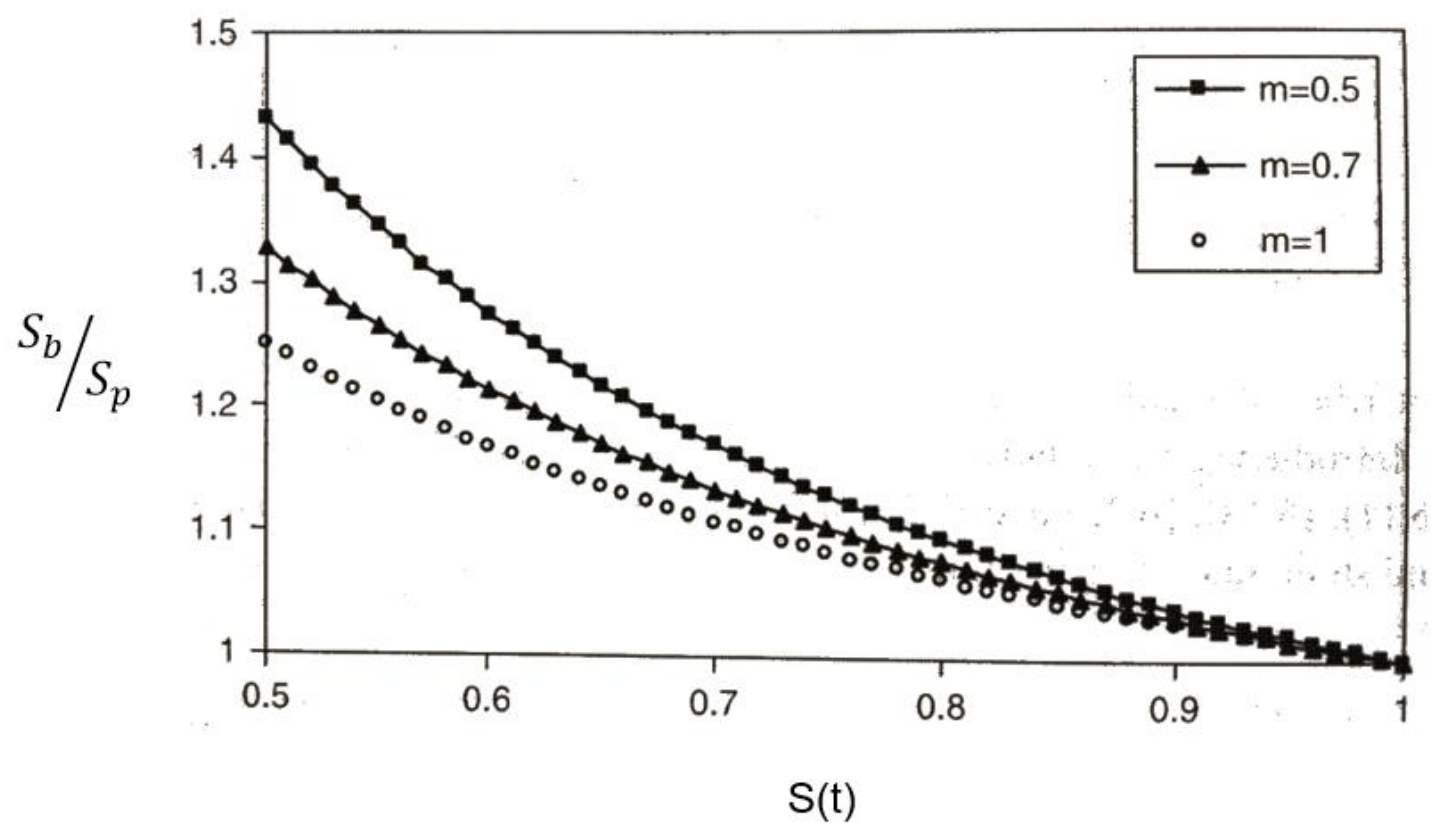

Figura 2.67 Fator de não uniformidade $\left(\mathrm{S}_{\mathrm{b}} / \mathrm{S}_{\mathrm{p}}\right)$ durante o processo de conformação por expansão fluidoestática biaxial. (GIULIANO, 2011)

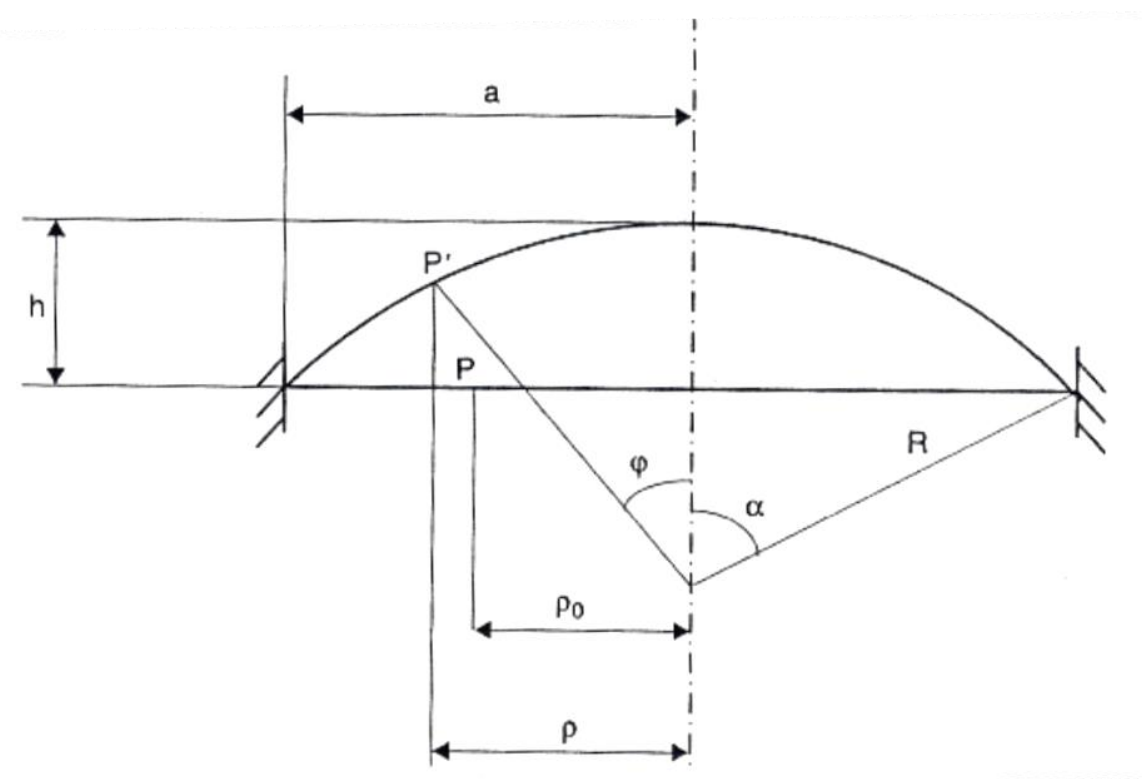

Figura 2.68 Parâmetros geométricos envolvidos na expansão fluidoestática biaxial. (GIULIANO, 2011)

A espessura no polo, entretanto, não pode ser determinada somente a partir de relações geométricas no bulge. Dentre os modelos encontrados na literatura, dois são comumente usados no estudo de ensaios de expansão fluidoestática biaxial, modelo de volume constante e modelo de Enikeev-Kruglov. Ambos modelos são usados na tese para validação dos sistemas de controle. 


\subsubsection{Modelo de volume constante}

O modelo proposto por Jovane (JOVANE, 1968) determina a espessura do polo com base na hipótese de que o volume se mantém constante durante o ensaio, que já foi validada experimentalmente (YANG, 1992). Dessa forma, o produto da área pela espessura deve se manter constante, o que resulta na expressão seguinte.

$$
s_{p}=s_{0} \frac{a^{2}}{a^{2}+h^{2}}
$$

O equacionamento elaborado por Jovane é, entretanto, bastante questionado por considerar a espessura do bulge uniforme, hipótese que se provou falha por diversos resultados experimentais (DUTTA, 2004) (MARINHO, 2012). Ainda assim, para efeito de instrumentação de ensaios de expansão fluidoestática biaxial, o modelo é útil, pois as relações matemáticas desenvolvidas dependem somente da espessura no polo (SANTOS, 2010).

\subsubsection{Modelo Enikeev-Kruglov}

O modelo proposto por Enikeev e Kruglov (ENIKEEV, 1995) define a espessura de cada ponto em função de sua posição na superfície do bulge. É um tratamento mais elaborado, mas que ainda assim não exige cálculos complexos.

Assumindo-se que a taxa de deformação é constante durante o ensaio, pode-se determinar a espessura do polo a partir da equação (70).

$$
s_{p}(t)=s_{0} \exp \left(-\dot{\varepsilon}_{t} t\right)
$$

A espessura, entretanto, não é uniforme em todo o domo, como se verifica experimental e analiticamente pela equação (65).

Antes de se determinar a função proposta, é preciso encontrar uma expressão para espessura na periferia do bulge. Como a prensa chapa não se deforma durante o ensaio, a deformação circunferencial pode ser desprezada. A deformação tangencial, por outro lado, varia em função de $\frac{\alpha}{\sin \alpha}$, que resulta na seguinte expressão para espessura na periferia $s_{b} \cdot(E N I K E E V, 1994)$ 


$$
s_{b}=s_{0} \frac{\sin \alpha}{\alpha}
$$

Tomando-se um ponto $\mathrm{P}$ como mostrado na Figura 2.68 a sua distância inicial do centro do bulge, $\rho_{0}$, é expressa como uma fração $v$ do raio "a" da cavidade $\left(\rho_{0}=v a\right)$. Em um determinado instante $t>0$, esse ponto assume a posição $P^{\prime}$. Se $\varphi$ é o ângulo entre o eixo de simetria e o raio de curvatura traçado até P', a posição desse ponto é definida pelo valor de $\varphi$. Como $\mathrm{P}$ e $\mathrm{P}$ ' correspondem ao mesmo ponto material, estabelece-se uma relação entre $\varphi$ e a como segue. (ENIKEEV,1994)

$$
\varphi=v \alpha
$$

Um meridiano do bulge é alongado em função de $\frac{\sin \alpha}{\alpha}$, como definido para deformação tangencial, e a latitude passando por P' é alongada de $\frac{\rho}{\rho_{0}}$ vezes, onde $\rho$ é a distância do ponto P' ao eixo de simetria. Tomando essas duas deformações em consideração, a espessura no ponto considerada pode ser determinada. (ENIKEEV,1994)

$$
\frac{s}{s_{0}}=\left(\frac{\rho_{0}}{\rho}\right) \cdot\left(\frac{\sin \alpha}{\alpha}\right)
$$

Através de relações geométricas no bulge, observa-se que $\rho=\operatorname{Rsin} \phi$ e $\rho_{0}=$ va e pode-se reescrever a expressão anterior.

$$
s(\varphi, \alpha)=s_{0}\left[\frac{\sin (\alpha)}{\alpha}\right]^{2} \frac{\varphi}{\sin \varphi}
$$

Em particular, a equação (74) apresenta as condições limite de que $s(0, \alpha)=s_{p}$ e $s(\alpha, \alpha)=s_{b}$. Dessa forma, a espessura no polo do bulge pode ser expressa da seguinte forma. (ENIKEEV,1994)

$$
s_{p}=s_{0}\left[\frac{\sin (\alpha)}{\alpha}\right]^{2}
$$




\subsubsection{Determinação da tensão e da deformação}

De posse dos valores da espessura e do raio da calota esférica, encontra-se a tensão $\bar{\sigma}$ e a taxa de deformação $\dot{\bar{\varepsilon}}$. Para o modelo de volume constante em particular, as equações (55), (66), (68) e (69) determinam as seguintes expressões.

$$
\begin{gathered}
H=h / a \\
\bar{\sigma}=\frac{p a}{4 s_{0}} \frac{\left(1+H^{2}\right)^{2}}{H} \\
\dot{\bar{\varepsilon}}=\frac{2 H}{1+H^{2}} \dot{H}
\end{gathered}
$$

Essas duas variáveis ( $\bar{\sigma}$ e $\dot{\bar{\varepsilon}})$ definem a curva tensão deformação procurada no ensaio de tração biaxial.

A Figura 2.69 apresenta o encadeamento das variáveis de interesse que possibilita a análise da relação tensão-deformação no bulge teste.

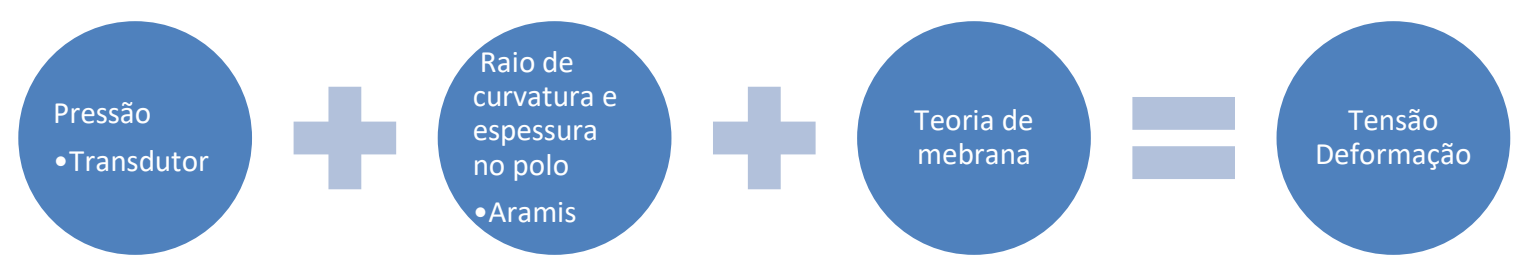

Figura 2.69 Parâmetros e teoria necessária para obtenção da curva tensão deformação 


\subsection{Modelos de controle de pressão SPF nos métodos de elementos finitos}

Essa sessão foca na escolha do modelo de pressurização, e consequentemente do software para gerar a curva de pressão que, do ponto de vista do sistema de controle, é o input do módulo de controle de pressão dedicado, para que a prensa de Conformação Superplástica, construída nessa tese, seja capaz de realizar a Conformação Superplástica em atmosfera controlada da liga de titânio Ti6Al4V através de expansão fluidoestática biaxial na condição ótima de máximo índice de sensibilidade a taxa de deformação.

Apresentam-se os modelos de pressurização para o LS-DYNA, ABAQUS e MARC. Um estudo comparativo entre MARC e ABAQUS é realizado e a maior diferença entre os modelos é que no MARC a pressão é variada para controlar diretamente a taxa de deformação e mantê-la próximo ao valor indicado como ótimo, entretanto no ABAQUS utiliza-se um modelo de controle indireto. Há resultados comparativos de simulações utilizando o MSC MARC e o ABAQUS, que justificam, além da disponibilidade do software, o porquê se usar o MSC MARC para gerar as curvas de input para o módulo de controle de pressão.

Em resumo, o algoritmo de controle de pressão do MSC MARC é aquele que mais se aproxima da abordagem experimental utilizada no desenvolvimento da prensa superplástica desenvolvida na tese, pois foca no controle da taxa de deformação.

Há dois tipos de métodos numéricos de determinação de curva de pressão de conformação, um deles usa um algoritmo em função da taxa de deformação durante a simulação, o outro usa um pós processamento do resultado preliminar da simulação. Toda a abordagem discutida nessa tese refere-se aos algoritmos em função da taxa de deformação.

Geralmente, algoritmos de simulação de Conformação Superplástica consideram variar a pressão de forma incremental para tentar manter a taxa de deformação próxima da ótima considerada. Em MEF a estratégia de controle usual baseia-se na proporção entre a taxa de deformação ótima e a máxima observada em alguns elementos. 


\subsubsection{Algoritmo do LS-DYNA}

LS-DYNA é um código de elementos finitos dinâmico explícito comercial. Para controlar a taxa de deformação, tal software calcula a diferença entre a taxa de deformação ótima esperada e a taxa de deformação máxima do modelo. (SAMEKTO, 2005)

$$
R=\frac{\dot{\varepsilon}_{o p}}{\dot{\varepsilon}_{\max }}
$$

Se R é menor que 1, a pressão deve ser diminuída, e se $\mathrm{R}$ é maior que 1 , a pressão deve ser aumentada. Durante a simulação numérica, a pressão pode ser ajustada usando um multiplicador, (pmult $=f(R)$ ), e a nova pressão aplicada no início do novo step de cálculo, é obtida através de: (SAMEKTO, 2003)

$$
p_{\text {new }}=p_{\text {old }} \cdot p_{\text {mult }}
$$

No início da simulação numérica, $p_{\text {mult }}$ é definido como 1. Durante os primeiros steps, a pressão pode seguir a equação (81) e alcançar $R=1$ rapidamente. $O$ Parâmetro $n$ pode ser substituído pelo índice de sensibilidade a taxa de deformação. Após $R$ atingir $1, n$ deveria ser reduzido para evitar um aumento maior que o desejado no $p_{\text {mult }}$. (SAMEKTO, 2005)

$$
p_{\text {new }}=p_{\text {old }} \cdot R^{n}
$$

Se após alguns steps, $p_{\text {new }}$ continua alto e $\mathrm{R}$ já for menor que 1, a pressão pode ser reduzida usando a equação (82), em que o W é o parâmetro de corte e ele é escolhido de tal forma a ser maior que 1.0 ou 1.2 .

$$
p_{\text {new }}=p_{\text {old }}+\frac{\left(p_{\text {new }}-p_{\text {old }}\right)}{W}
$$

Tal algoritmo usado por LS-DYNA é um exemplo de algoritmo de correlação proporcional; a correção da pressão de conformação é proporcional a máxima variação da taxa de deformação. A 
Tabela 2.9. Algoritmos de correlação proporcional.

\begin{tabular}{|l|l|}
\hline \multirow{2}{*}{ Doltsinis } & \multicolumn{1}{|c|}{ Algoritmos } \\
\hline & $\begin{array}{c}P_{n+1}=\frac{\dot{\varepsilon}^{\text {opt }}}{\dot{\varepsilon}_{n}^{\text {max }}} P_{n} \\
\text { É simples, entretanto, resulta em alta variação em torno do valor ótimo } \\
\text { desejado. (DOLTSINIS, 1987) }\end{array}$ \\
\hline Xiang & $\begin{array}{l}\text { Para utilizar esse algoritmo é necessária uma correlação numérico- } \\
\text { experimental. (XIANG, 2001) }\end{array}$ \\
\hline Hwang & $P_{n+1}=\left(1-\lambda \frac{\dot{\varepsilon}_{n}^{\text {max }}-\dot{\varepsilon}^{\text {opt }}}{\dot{\varepsilon}_{n}^{\text {max }}}\right) P_{n}$ \\
\hline Sorgente & $\begin{array}{l}\text { Esse algoritmo de controle de pressão previne oscilações e mudanças } \\
\text { rápidas na pressão de conformação. (HWANG, 2002) }\end{array}$ \\
\hline $\begin{array}{l}\text { O referido algoritmo propicia uma curva mais contínua e mantem } \\
\text { adequadamente a taxa de deformação constante em torno do valor } \\
\text { desejado. (SORGENTE, 2008) }\end{array}$
\end{tabular}

Tem-se: $P_{n}=$ Pressão de conformação no final do incremento n; $P_{n+1}=$ Pressão de conformação no próximo incremento; $\dot{\varepsilon}^{\text {opt }}=$ taxa de deformação ótima; $\dot{\varepsilon}_{n}^{\max }=$ Máxima taxa de deformação do incremento.

\subsubsection{Algoritmo do ABAQUS}

O módulo de análise implícita do ABAQUS, o ABAQUS/Standard usa o método de integração direta de Newmark. As equações de Newmark são dadas por:

$$
\begin{gathered}
\dot{d}_{i+1}=\dot{d}_{i}+(\Delta t)\left[(1-\gamma) \ddot{d}_{i}+\gamma \ddot{d}_{i+1}\right] \\
d_{i+1}=d_{i}+(\Delta t) \dot{d}+(\Delta t)^{2}\left[\left(\frac{1}{2}-\beta\right) \ddot{d}_{i}+\beta \ddot{d}_{i+1}\right]
\end{gathered}
$$


Onde $\beta$ e $\gamma$ são parâmetros escolhidos pelo usuário. Multiplicando a eq. (3.2) pela matriz de massa $[M]$ e substituindo na eq. (3.3), obtemos:

$$
K^{\prime d_{i+1}}=F^{\prime}{ }_{i+1}
$$

onde,

$$
\begin{gathered}
K^{\prime}=K+\frac{1}{\beta(\Delta t)^{2}} M \\
F^{\prime}{ }_{i+1}=F_{i+1}+\frac{M}{\beta(\Delta t)^{2}}\left[d_{i}+(\Delta t) \dot{d}+\left(\frac{1}{2}-\beta\right)(\Delta t)^{2} \ddot{d}_{i}\right]
\end{gathered}
$$

Usando as equações acima é possível determinar o valor de $d_{i+1}, \dot{d}_{i+1}$ e $\ddot{d}_{i+1}$. Devido à natureza iterativa da solução, a simulação necessita da satisfação do critério de convergência em cada incremento. Geralmente a velocidade de convergência é um problema e pode causar o término prematuro da análise.

Apesar de não parecer, o método explicito dinâmico é vantajoso em simulações de conformação de chapas metálicas onde o tempo real é alguns segundos, ele tem a característica de necessitar de menos memória e capacidade de processamento desde que não exista a necessidade de uma matriz de rigidez coerente.

Em um processo como o de Conformação Superplástica, esse método é incapaz de reduzir o tempo computacional devido aos requisitos de estabilidade no tamanho do incremento temporal. Além disso, quando materiais sensíveis à taxa de deformação estão envolvidos, resultados precisos são difíceis de serem obtidos sem que se utilize um grande número de incrementos temporais.

O algoritmo de pressão do ABAQUS é mais simples que aquele usado no LS-DYNA. A pressão $\mathrm{P}$ deve ser capaz de manter a taxa de deformação $(\dot{\varepsilon})$ em um valor predeterminado $\dot{\varepsilon}_{o p t}$, que corresponde ao máximo índice de sensibilidade a taxa de deformação do material especificado. Segue a equação que condiciona o requisito buscado (LI,2004):

$$
g=\dot{\varepsilon}-\dot{\varepsilon}_{\text {opt }}
$$


Para satisfazer a equação de equilíbrio de forças globais não lineares que vem da discretização dos elementos finitos, o deslocamento nodal, $U(t)$, e a pressão externa aplicada devem seguir a equação (LI,2004):

$$
F^{i n t}(U(t))=F^{e x t}(P(t))
$$

As restrições externas são definidas como (LI,2004):

$$
g(U(t))=0
$$

Uma vez que a solução da equação não linear global é realizada na forma incremental, a forma discreta do equilíbrio acima mencionado é dada por (LI,2004):

$$
\begin{aligned}
F^{i n t}\left(U_{n+1}\right) & =F^{e x t}\left(P_{n+1}\right) \\
g\left(U_{n+1}\right) & =0
\end{aligned}
$$

ABAQUS calcula o valor de $\gamma_{\max }$ que expressa a razão entre a máxima taxa de deformação equivalente e a taxa ótima predeterminada para os pontos de integração em um conjunto específico de elementos $(L I, 2004)$. Segue a razão:

$$
\gamma_{\max }=\frac{\dot{\varepsilon}_{\max }}{\dot{\varepsilon}_{\text {opt }}}
$$

A Tabela 2.10 define as correções na pressão aplicada nas interações em função da razão $\gamma_{\max }$

Tabela 2.10. Tabela de correção da pressão dado $\gamma_{\max }$.

\begin{tabular}{|l|c|}
\hline Se & Então \\
\hline$\gamma_{\max }<0.2$ & $P_{n+1}=2.0 P_{n}$ \\
\hline $0.2 \leq \gamma_{\max }<0.5$ & $P_{n+1}=1.5 P_{n}$ \\
\hline $0.5 \leq \gamma_{\max }<0.8$ & $P_{n+1}=1.2 P_{n}$ \\
\hline $0.8 \leq \gamma_{\max }<1.5$ & $P_{n+1}=P_{n}$ \\
\hline $1.5 \leq \gamma_{\max }<3$ & $P_{n+1}=0.5 P_{n}$ \\
\hline $3 \leq \gamma_{\max }$ & $P_{n+1}=0.5 P_{n}$ \\
\hline
\end{tabular}




\subsubsection{Algoritmo do MSC-MARC}

No software MSC MARC, a pressão é variada na proporção direta da relação entre as taxas de deformação entre os steps. Há também um fator chamado CUTOFF, que varia de 0 até 1 , e indica a porcentagem do número de elementos que são selecionados para calcular a média da taxa de deformação máxima. O CUTOFF usualmente varia entre 0,7 e 0,9. Por exemplo, se for 0,9, significa que $10 \%$ dos elementos estão sendo usados para compor a média. Nesse contexto, quanto maior o fator CUTOFF, maior a oscilação de pressão e menor os limites de taxa de deformação.

A escolha do MSC-MARC para gerar as curvas de pressão da referida tese foi resultado da comparação dos gráficos de pressão no tempo gerados pelas simulações MEF, observa-se que o algoritmo de controle de pressão por taxa de deformação constante do Marc produziu um perfil de pressão com um desvio menor quando comparado ao algoritmo padrão do Abaqus que também controla a pressão para manter a taxa de deformação constante. (GONÇALVES, 2011)

Seguem as curvas comparativas entre os resultados da curva de pressão[bar] em função do tempo para o MARC com 800 elementos com controle por taxa de deformação constante e para o Abaqus com controle de pressão por tensão constante (linha preta) e por taxa de deformação constante (linha vermelha).
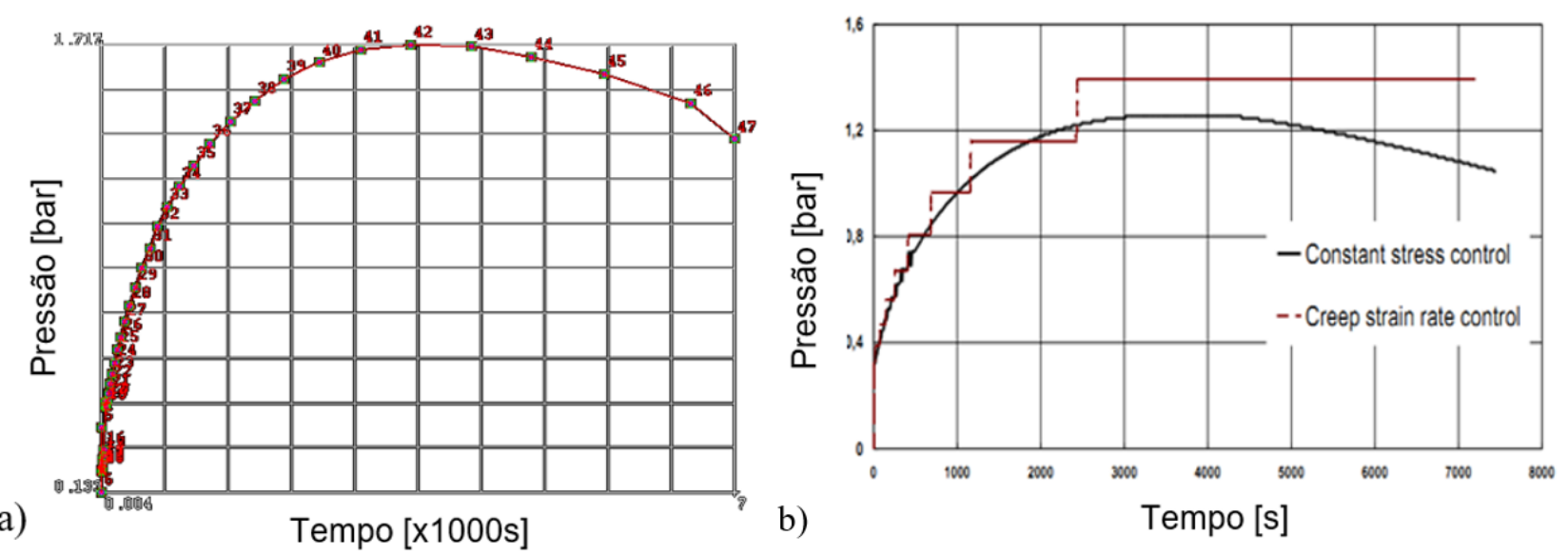

Figura 2.70 Comparação dos resultados da curva de pressão[bar] em função do tempo para a) MARC com 800 elementos com controle por taxa de deformação constante b) Abaqus com controle de pressão por tensão constante (linha preta) e por taxa de deformação constante (linha vermelha) (GONÇALVES, 2011) 
Verifica-se que o perfil de pressão do MARC para o algoritmo de controle por taxa de deformação constante é mais suave que o apresentado pelo ABAQUS quando também utiliza o algoritmo de controle de taxa de deformação constante.

Compara-se também o perfil de redução de espessura em função do deslocamento radial do bulge. A Figura 2.71 compara o resultado das simulações no MARC e o resultado da simulação com ABAQUS de espessura em [mm] em função do ângulo (diretamente proporcional ao comprimento de arco)
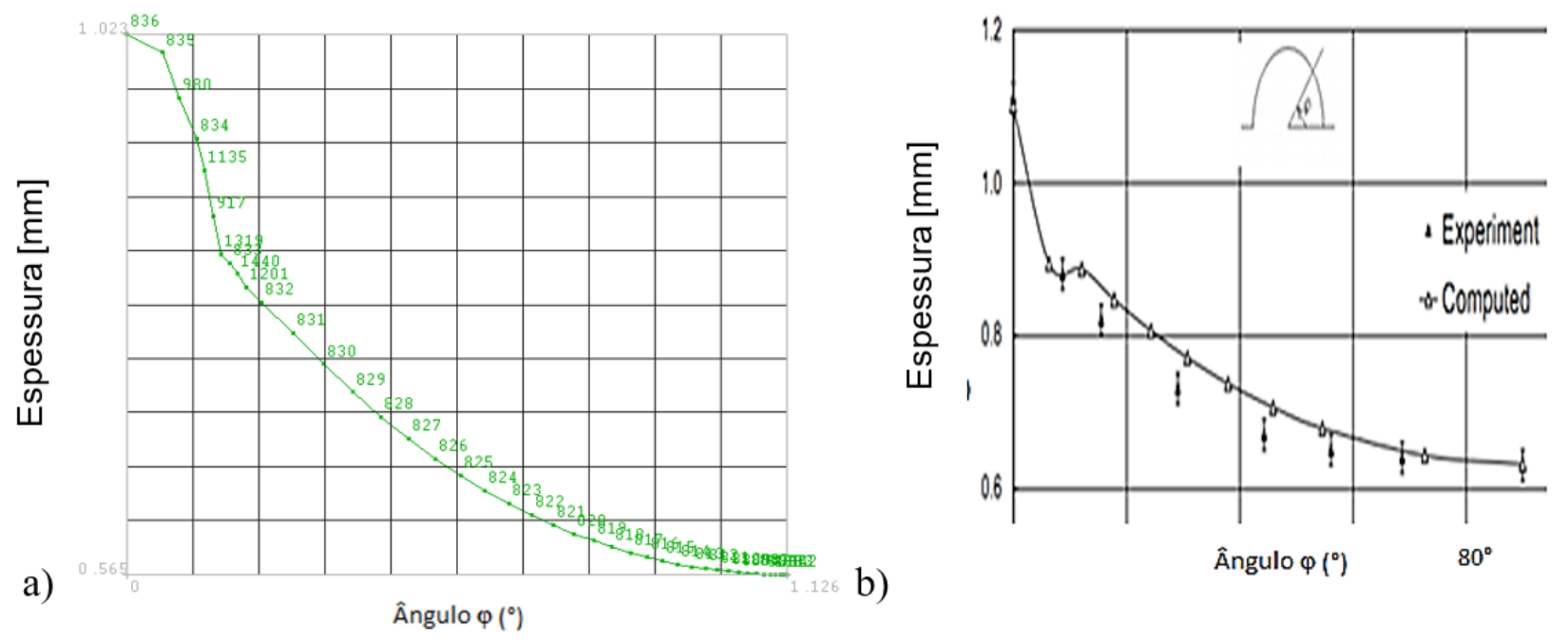

Figura 2.71 Comparação dos resultados de espessura[mm] em função do tempo para a) MARC com 800 elementos com controle por taxa de deformação constante b) Abaqus com controle de pressão por tensão constante e dados experimentais (GONÇALVES, 2011)

Observa-se que, a simulação de Aoura no Abaqus detectou uma curvatura da função espessura com um mínimo local no início do gráfico, comportamento que não foi detectado nas simulações do Marc, como também há melhoria dos resultados das curvas de pressão aumentando o número de elementos. (GONÇALVES,2011)

Dessa forma, valida-se a utilização do MARC para gerar as curvas de pressurização para serem utilizadas pelo sistema de controle de pressão como inputs. 


\section{Procedimento Experimental}

A tese tem como objetivo principal desenvolver um ferramental instrumentado e controlado para realização de Conformação Superplástica em atmosfera controlada da liga de titânio Ti6Al4V através de expansão fluidoestática biaxial. O procedimento experimental reflete a interdisciplinaridade da tese, algumas etapas ocorreram em paralelo devido a necessidade da interligação dos resultados, para localizar os principais pontos trabalhados e os tópicos envolvidos tem-se a Figura 3.1.

A seguir é apresentada a evolução do procedimento experimental referente a cada etapa do desenvolvimento do projeto base dessa tese.

Na Figura 3.1 observa-se a inter-relação de vários tópicos da tese. Agrupou-se esquematicamente cada tópico fazendo fronteira com os respectivos tópicos que possuem relação direta. É importante ressaltar que há várias fronteiras que não foram possíveis de serem representadas, devido ao elevado número de relações entre os tópicos.

As cores subdividem os tópicos em grupos por tema de desenvolvimento, conforme lista seguinte:

- Pressão;

- Deformação;

- Temperatura;

- Instrumentação e procedimentos;

- Fundamentos teóricos. 


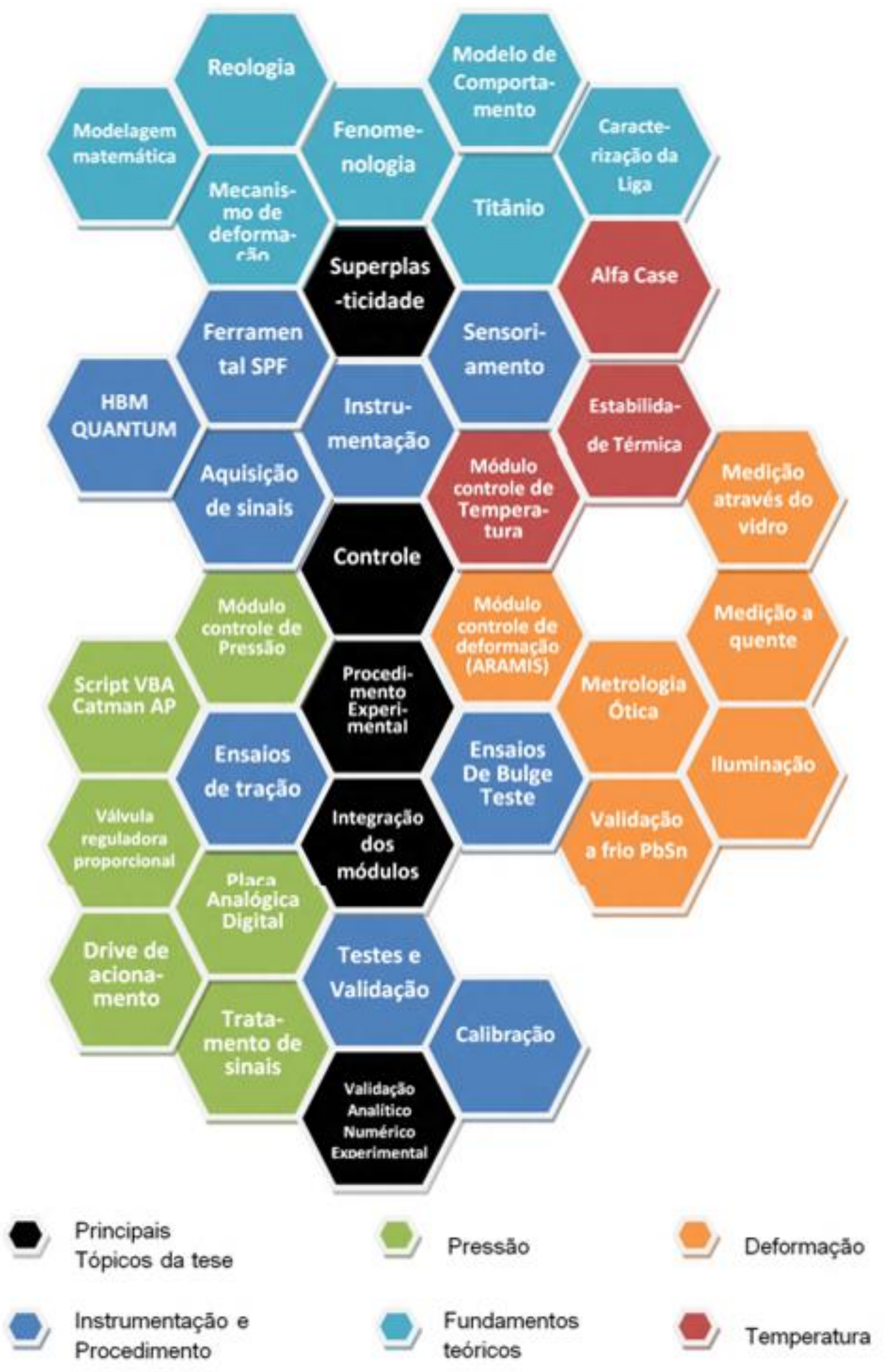

Figura 3.1 Principais tópicos da tese e as devidas interligações entre cada tópico. 


\subsection{Material superplástico}

Utilizou-se chapa da liga comercial Ti-6Al-4V 2mm de espessura, tamanho de grão e composição química especificada. $\mathrm{O}$ ataque usado foi $\mathrm{KROLL}$ (361 $\mathrm{ml} \mathrm{HNO}_{3}$, $602 \mathrm{ml} \mathrm{H} \mathrm{H}_{2} \mathrm{O}$ e $26 \mathrm{ml} \mathrm{HF}$. A composição química foi determinada através de espectrometria de Emissão Ótica e é apresentada na Tabela 3.1.

Tabela 3.1. Composição química da liga Ti6Al4V utilizada na tese.

\begin{tabular}{|c|c|c|}
\hline$\%$ & Especificado & Encontrado \\
\hline Al & $5,00-6,75$ & 6,73 \\
\hline $\mathbf{V}$ & $3,50-4,50$ & 3,59 \\
\hline Fe & Máx 0,30 & 0,16 \\
\hline $\mathbf{C}$ & Máx. 0,08 & 0,022 \\
\hline
\end{tabular}

O tamanho de grão foi especificado utilizando Microscópio ótico Heicherter - Polyvar - Software de imagens Buehler - Ominmet, o tamanho de grão medido no MEV é de 10 $\mu \mathrm{m}$, apresentado na Figura 3.2.

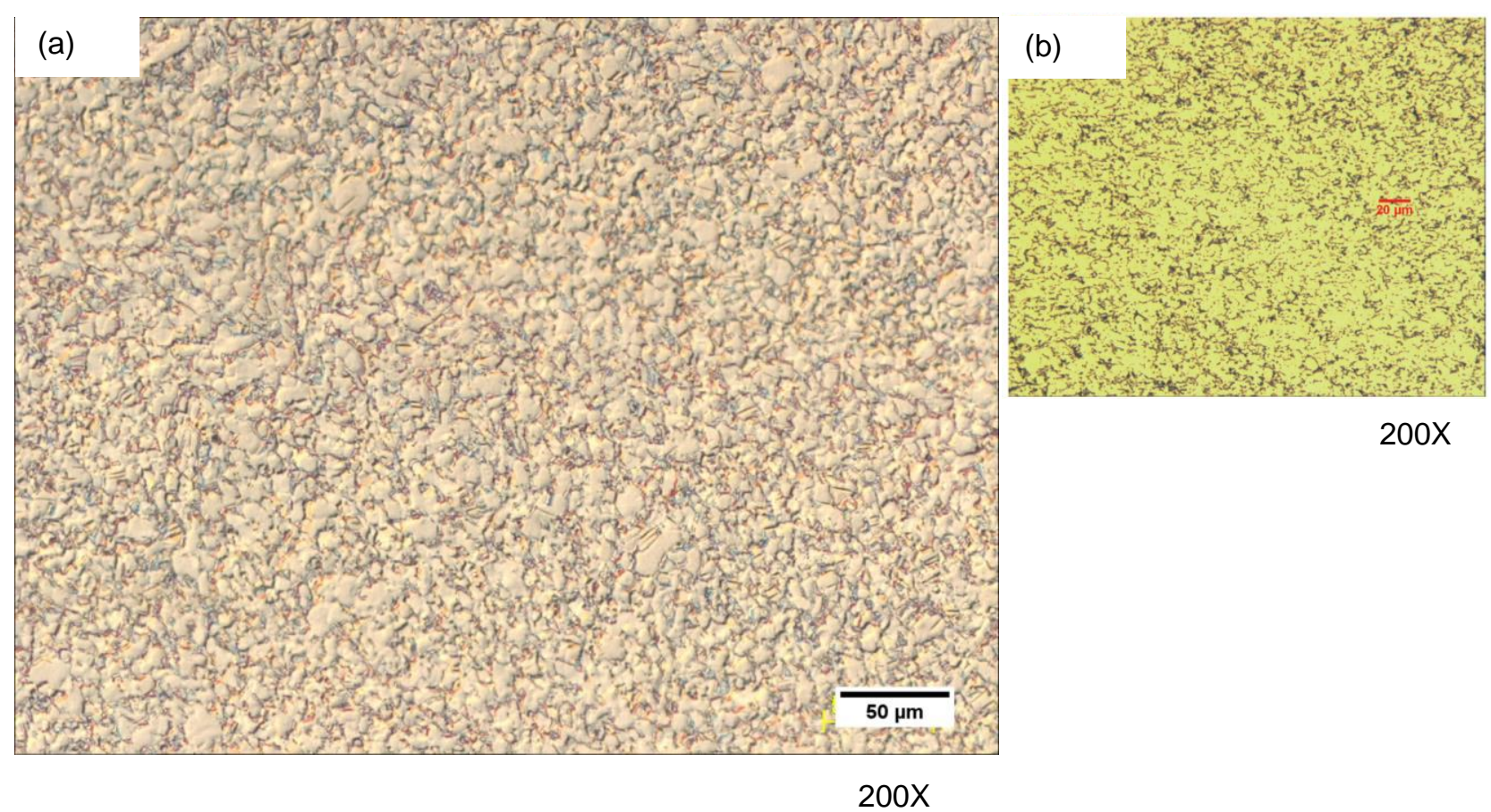

Figura 3.2 (a) Micrografia da secção transversal da amostra, microestrutura característica do material. (SANTOS,2015) (b) Micrografia da secção transversal da amostra. 


\subsection{Ensaios de tração Uniaxial}

O ensaio de tração uniaxial é usado para levantar relações entre tensão-deformação; assim como a expansão fluidoestática biaxial determina o estado de tensões biaxial.

Os ensaios de tração foram realizados em máquina de tração-compressão no Centro Universitário da $\mathrm{FEl}$, em corpos de prova do tipo gravata com comprimento útil e seção iguais a $25 \mathrm{~mm}$ e $6 \times$ ( 1 e 2) $\mathrm{mm}^{2}$, como especificado na norma de ensaios de tração uniaxial sugerida para determinar as propriedades superplásticas dos materiais, ASTM E2448 . A Figura 3.3 apresenta um desenho esquemático do corpo de prova com suas dimensões e a Figura 3.4 apresenta as garras feitas de inconel e um exemplo de corpo de prova.

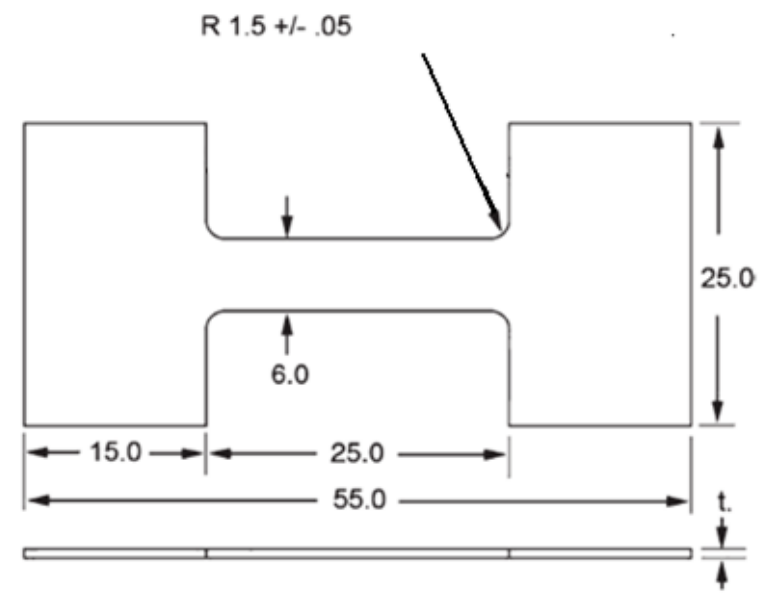

Figura 3.3. Desenho esquemático mostrando as dimensões dos corpos de prova. (norma ASTM E2448)

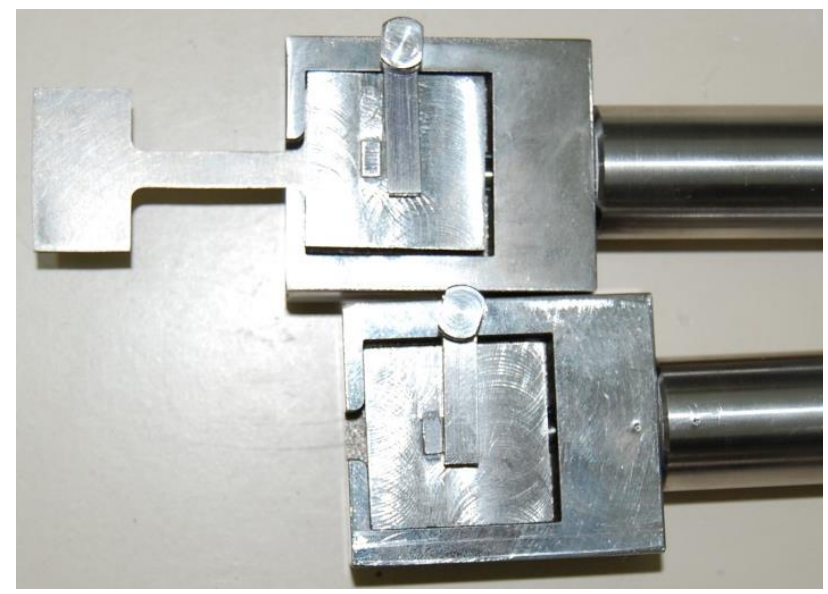

Figura 3.4. Garras de INCONEL utilizadas nos ensaios de tração a quente em atmosfera de argônio. 
Os ensaios foram conduzidos em atmosfera de argônio em duas etapas: (i) ensaio de saltos com taxa de deformação variando de $2,5 \times 10^{-5}$ a $1,0 \times 10^{-2} \mathrm{~s}^{-1}$ e temperaturas de $800^{\circ} \mathrm{C}, 850^{\circ} \mathrm{C}, 875^{\circ} \mathrm{C}, 900^{\circ} \mathrm{C}, 925^{\circ} \mathrm{C}$ e $950^{\circ} \mathrm{C}$, a fim de localizar a janela superplástica e; (ii) ensaios com taxa de deformação constante que foram realizados em 3 taxas e 3 temperaturas diferentes dentro da janela superplástica determinada na primeira etapa. Para cada condição foram ensaiados de dois a três corpos de prova. A Tabela 3.2 apresenta as condições de ensaio e a quantidade de corpos de prova necessários. Para realizar os ensaios em atmosfera de argônio foi desenvolvido um forno poço com fluxo de argônio constante e isolamento passante nas garras do corpo de prova, conforme pode ser observado na Figura 3.5.

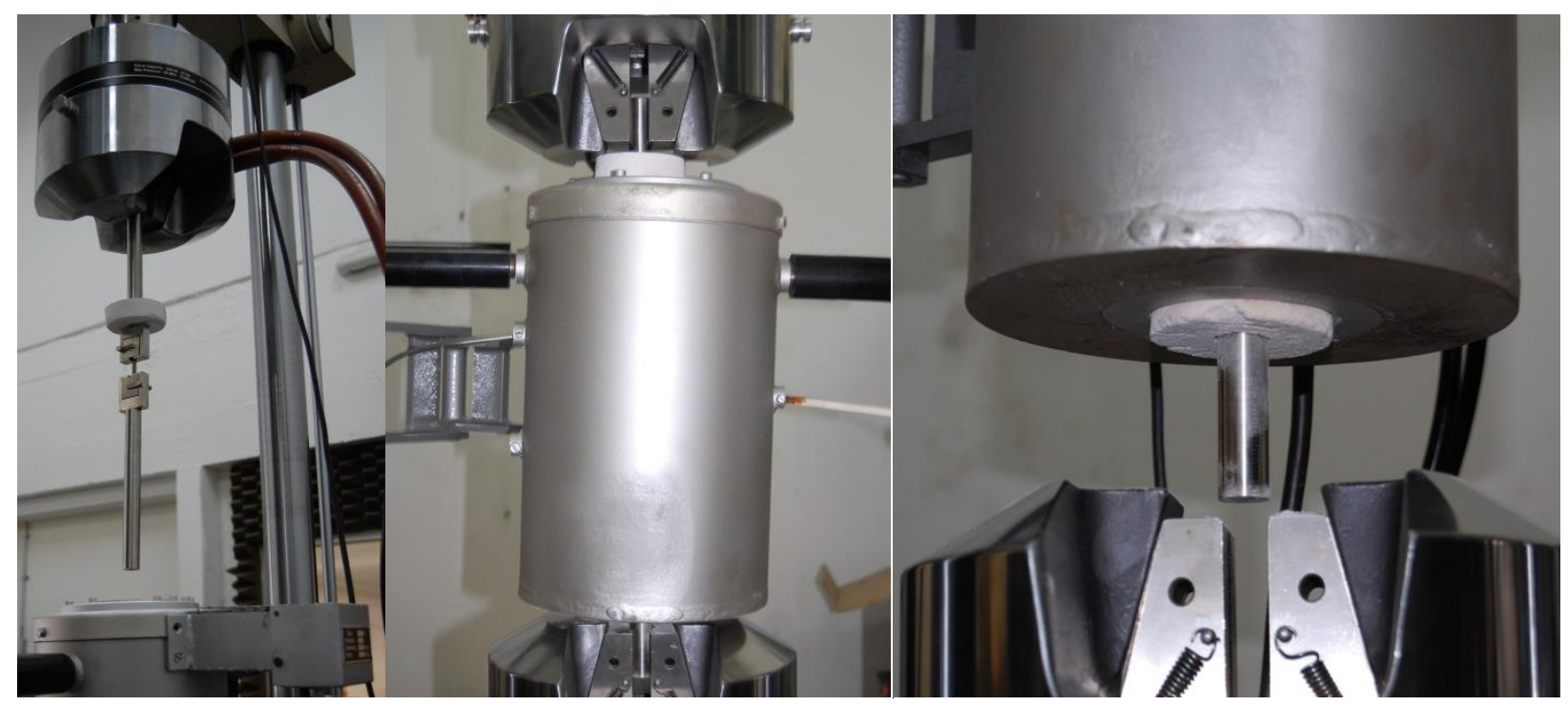

Figura 3.5. Forno usado para aquecimento e encharcamento de atmosfera com argônio, acoplado a ferramenta de ensaio de tração.

No Anexo 10.1 - seguem tabelas com a identificação de alguns ensaios propostos considerando três corpos de prova por condição ensaiada.

Desses ensaios foram obtidas as curvas $\sigma \times \dot{\varepsilon}$ e $\mathrm{m} \times \dot{\varepsilon}$ em todas as temperaturas. Entretanto, para evidenciar o comportamento superplástico apresentam-se os gráficos dos resultados das condições testadas nos ensaios de saltos. A Figura 3.6, conhecida por "S shape", apresenta a curva log da tensão versus log $\dot{\varepsilon}$, por sua vez a Figura 3.7, conhecida por "Peak shape", apresenta a curva da variação do índice de sensibilidade à taxa de deformação versus $\log \dot{\varepsilon}$. 
Tabela 3.2. Parâmetros de ensaio de tração uniaxial a quente para determinar a janela superplástica.

\begin{tabular}{|c|c|c|c|}
\hline Ensaio & $\begin{array}{c}\text { Temperatura } \\
\left({ }^{\circ} \mathbf{C}\right)\end{array}$ & $\begin{array}{c}\text { Taxa de deformação } \\
\left(\mathbf{s}^{-1}\right)\end{array}$ & $\begin{array}{c}\text { Corpos de } \\
\text { Prova }\end{array}$ \\
\hline & & $2.5 \times 10^{-5}$ & \\
& 800 & $5 \times 10^{-5}$ & \\
& 850 & $2.5 \times 10^{-4}$ & \\
Saltos & 875 & $5 \times 10^{-4}$ & \\
& 900 & $1 \times 10^{-3}$ & \\
& 925 & $2.5 \times 10^{-3}$ & \\
& 950 & $5 \times 10^{-3}$ & \\
& & $1 \times 10^{-2}$ & \\
\hline Taxa de & 875 & $2.5 \times 10^{-4}$ & \\
deformação & 900 & $5 \times 10^{-4}$ & \\
constante & 925 & $1 \times 10^{-3}$ & \\
\hline
\end{tabular}

Observam-se nesses resultados que a tensão de escoamento diminui e o índice de sensibilidade a taxa de deformação aumenta com o aumento da temperatura e que a condição ótima para o comportamento superplástico, da liga da tese, foi a $925^{\circ} \mathrm{C}$ e taxa de $2,5 \times 10^{-5} \mathrm{~s}^{-1}$. Esses valores foram usados como requisitos para o sistema de controle de temperatura e de pressão respectivamente. Detalhes do sistema de controle são apresentados no capítulo 3.4 .

No estudo do Lee (LEE, 1998) foi utilizada uma liga comercial de Ti-6Al-4V na forma de chapas de $6 \mathrm{~mm}$ de espessura. A liga foi submetida a um processo de refinamento de grão que resultou em um tamanho de grão final de $\approx 2.5 \mu \mathrm{m}$. A Figura 3.8 apresenta os resultados obtidos dos ensaios de tração a quente com taxa variável (ensaio de saltos), $A$ curva tensão versus $\log \dot{\varepsilon}$ é representada pela Figura 3.8(a) e sensibilidade à taxa de deformação versus log $\dot{\varepsilon}$ pela Figura 3.8(b). Observa-se o mesmo comportamento da liga da tese, a tensão de escoamento diminui e o índice de sensibilidade a taxa de deformação aumenta com o aumento da temperatura. No caso de Lee, a condição ótima para o comportamento superplástico foi a $900^{\circ} \mathrm{C}$ e taxa de $5 \times 10^{-5} \mathrm{~s}^{-1}$, representa a condição ensaiada com maior indice de sensibilidade a taxa de deformação. 


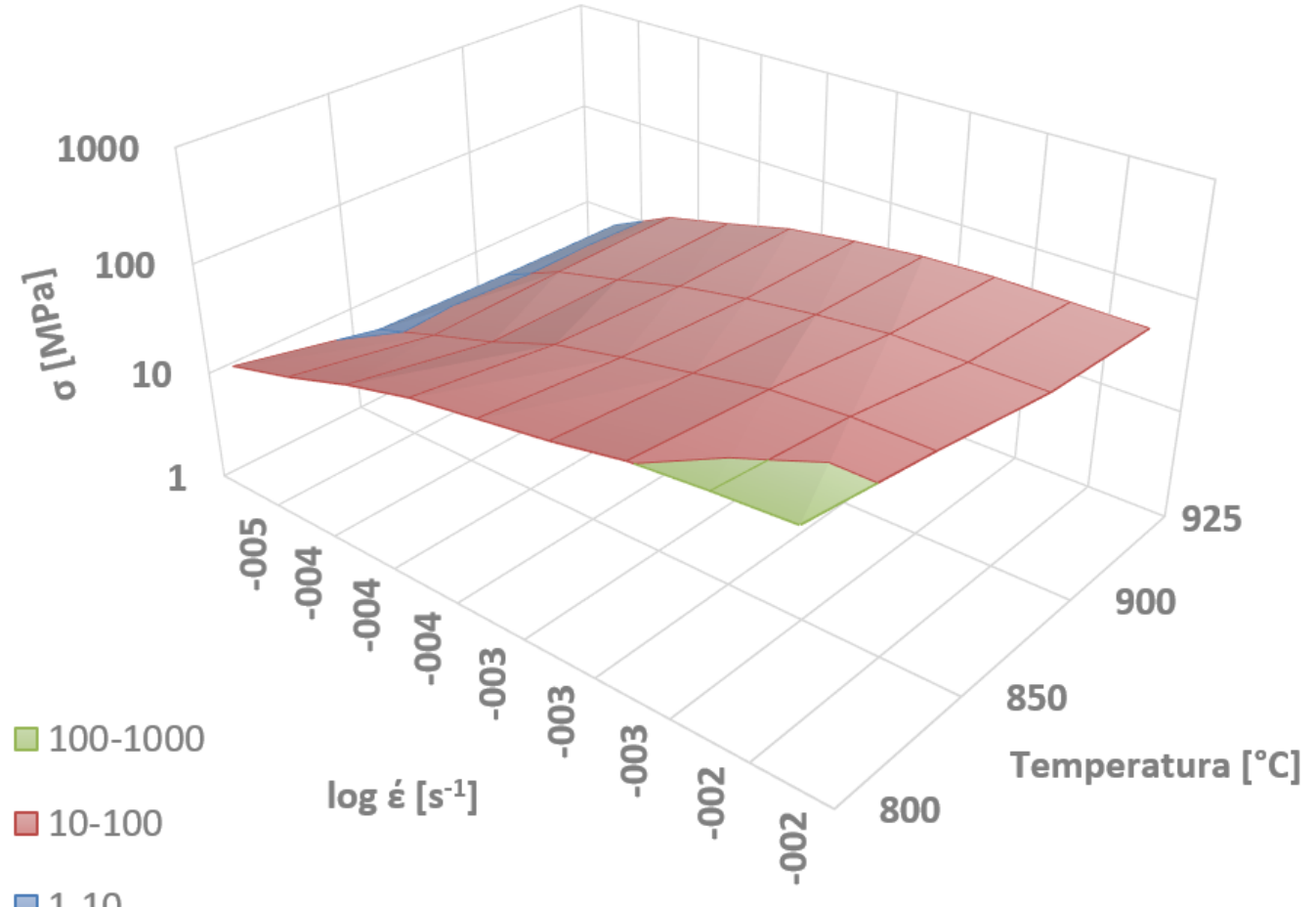

Figura 3.6 Variação da tensão em função da taxa de deformação para 4 valores de temperatura para a liga Ti-6Al-4V.

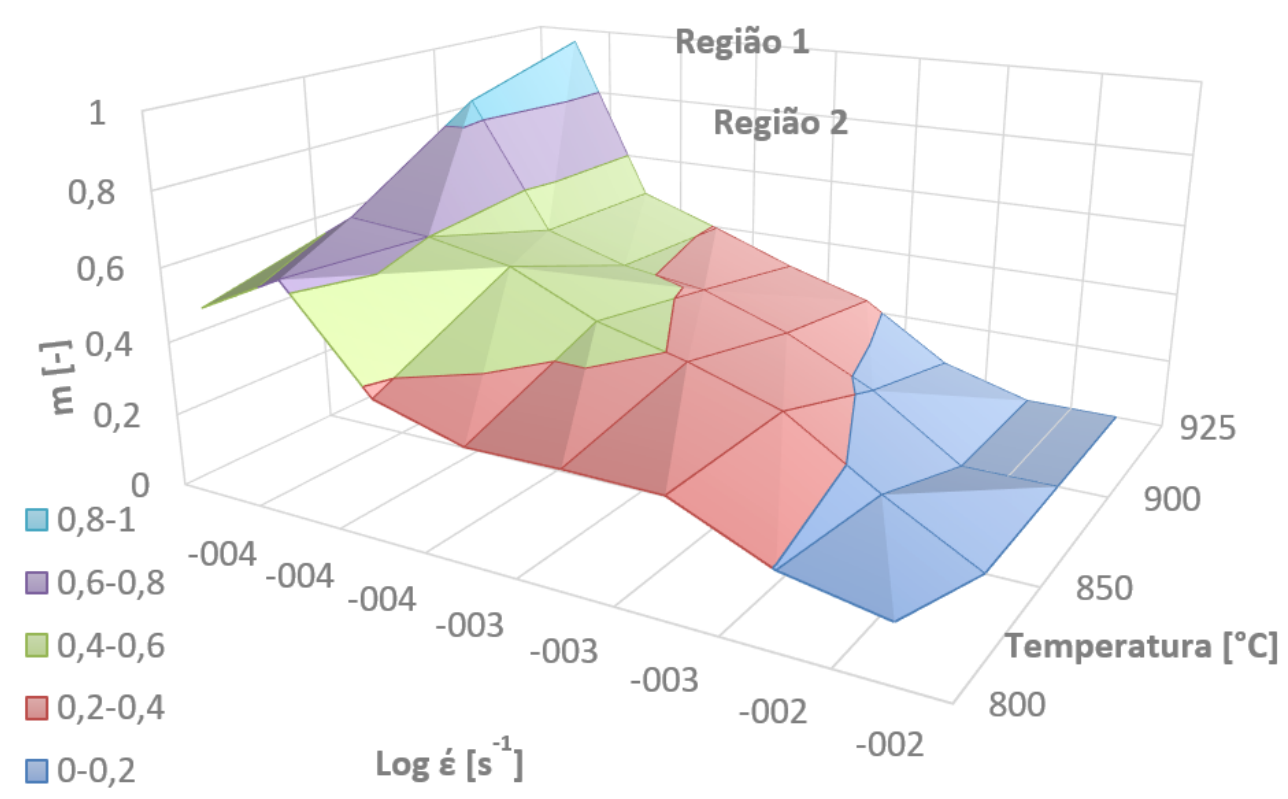

Figura 3.7 Variação do $m$ em função do logaritmo da taxa de deformação para 4 valores de temperatura para a liga Ti-6Al-4V.

$\mathrm{Na}$ Figura 3.7 observa-se que há duas regiões de valores de $m>0,6$, representados por região 1 e região 2, uma Conformação Superplástica convencional ocorre em qualquer ponto dessas duas regiões, o sistema de controle apresentado 
nessa tese é capaz de realizar a conformação sempre na região ótima do processo, entenda-se região 1 do referido gráfico.
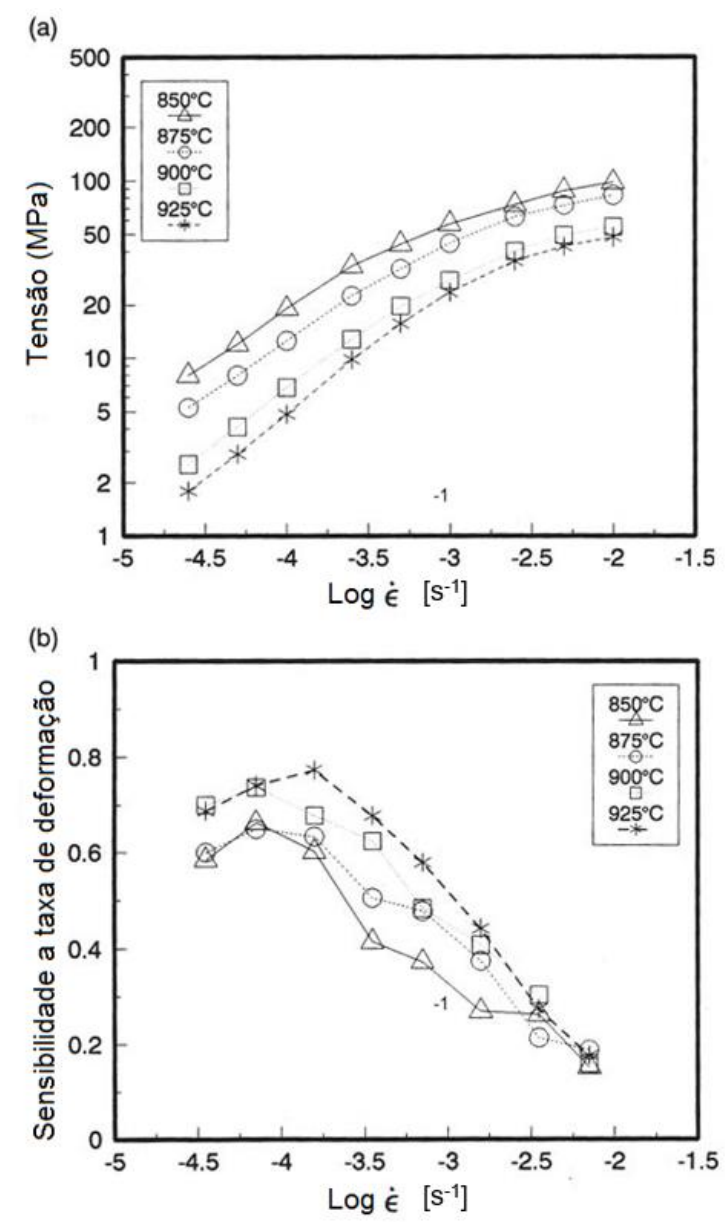

Figura 3.8 Variação da tensão (a) e sensibilidade à taxa de deformação (b) com a taxa de deformação e temperatura para a liga Ti-6Al-4V. Esses dados foram obtidos por tração (ensaio de saltos). (LEE, 1998)

O objetivo principal é gerar dados que sirvam de set point inicial para desenvolver o controle do ensaio de expansão fluidoestática biaxial, muitas vezes funcionando como valores limites, ou mesmo condições de contorno do comportamento superplástico da liga Ti-6Al-4V.

De maneira resumida, que antecipa o que será explicado no capítulo sobre implementação do controle, este comportamento tensão-deformação uniaxial, usado como dados de entrada do programa de elementos finitos MARC, através da análise numérica de uma expansão fluidoestática biaxial livre superplástica com taxa de deformação constante, gerará o perfil de pressurização que possibilitará que o ensaio biaxial se desenvolva de maneira controlada. 


\subsection{Ferramenta para o Ensaio de Expansão Fluidoestática Biaxial}

Inicialmente será descrita a primeira concepção da ferramenta, aquela utilizada para realização do primeiro ensaio de bulge superplástico. É importante antecipar e ressaltar que no capítulo 4.5 serão apresentadas as mudanças realizadas na ferramenta para ajuste de alguns parâmetros que foram observados durante o primeiro ensaio; tais mudanças ocorreram tanto na geometria do ferramental, quanto na concepção da montagem do ferramental para o ensaio.

\subsubsection{Descrição da concepção inicial do ferramental superplástico}

Este capítulo tem como objetivo o detalhamento do dimensionamento da parte do ferramental que ficará dentro do forno. As demais partes do ferramental, desde os parâmetros utilizados para escolha das mesmas até as dificuldades encontradas do ponto de vista da instrumentação serão discutidas individualmente no capítulo sobre instrumentação.

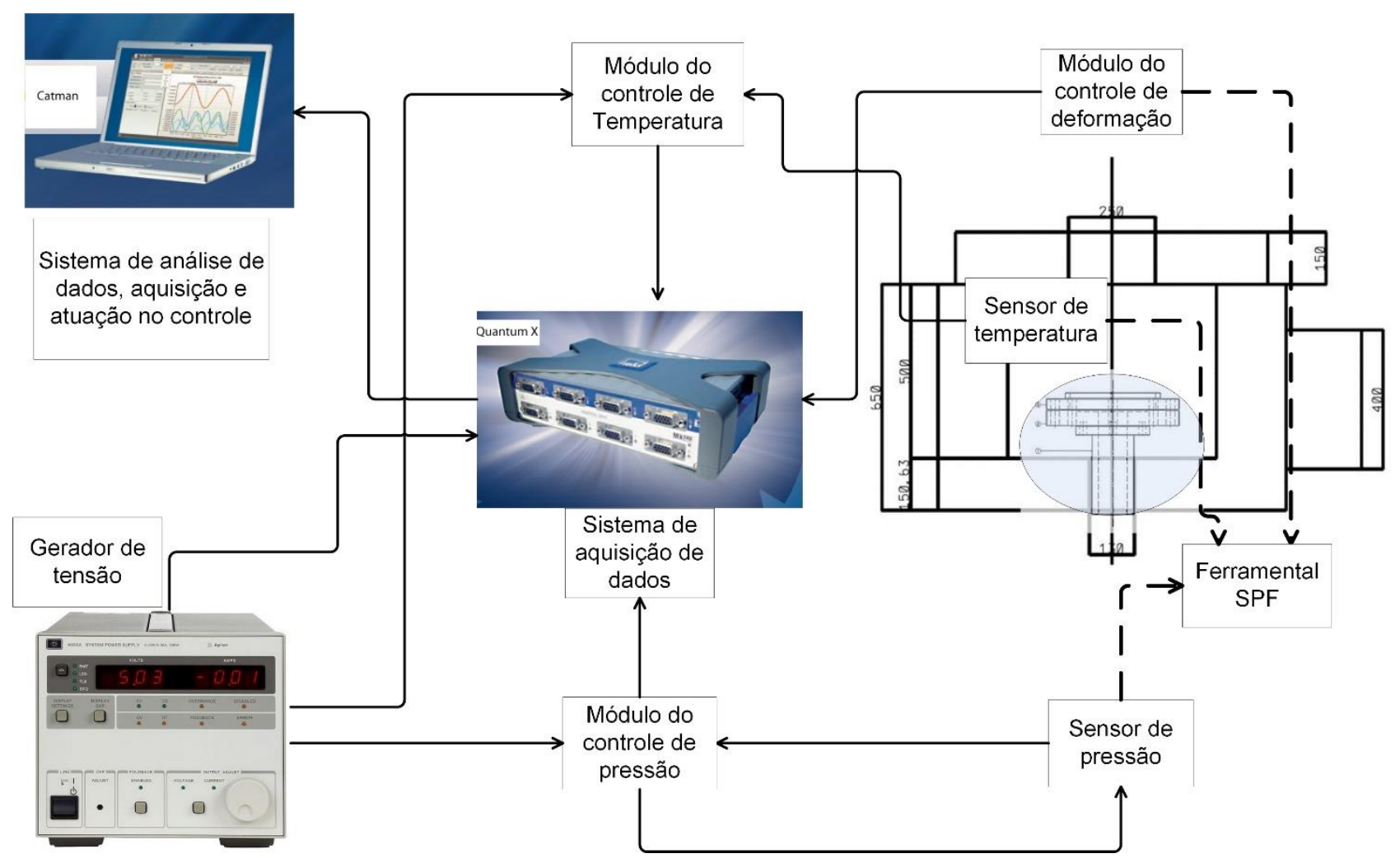

Figura 3.9. Desenho esquemático mostrando os principais módulos de controle (temperatura, pressão e deformação) com destaque para o ferramental superplástico circulado. 
A Figura 3.9 destaca o ferramental SPF dentro do forno, destaca a ligação do ferramental com os três sensores utilizados durante o ensaio (temperatura, pressão e deformação) e seus respectivos módulos interligados pelo sistema de aquisição e atuação.

A ferramenta dimensionada é a parte do prensa-chapa do ferramental. Sua funcionalidade é prender a chapa de Ti-6AI-4V de modo que a vedação seja mantida e o mesmo não escorregue, desse modo não será necessário um modelo para escorregamento com atrito. Na outra extremidade da ferramenta é acoplado o sistema de pressurização, logo após o módulo de resfriamento que garante que a temperatura de trabalho em regime estacionário esteja abaixo da temperatura máxima de trabalho do transdutor de pressão escolhido.

\subsubsection{Especificações do prensa-chapa}

A ferramenta é projetada para a liga Ti-Al6-4V cuja janela do processo está estimada em torno de $900^{\circ} \mathrm{C}$ e $1000^{\circ} \mathrm{C}$ com pressões de até 40 bar. Considerando a pior condição de trabalho, os cálculos serão feitos para $1000^{\circ} \mathrm{C}$ e 40 bar com um fator de segurança de no mínimo 2.

A chapa a ser conformada é circular de espessuras $1 \mathrm{~mm}$ e $2 \mathrm{~mm}$. O diâmetro não pode ultrapassar o tamanho da janela de vidro do forno, através dessa são aquisitados dados de deformação, assim sendo o diâmetro do prensa-chapa foi fixado em $250 \mathrm{~mm}$, para que se pudesse definir a instrumentação da ferramenta de conformação em paralelo ao desenvolvimento da matriz da ferramenta de expansão fluidoestática biaxial.

\subsubsection{Material}

Devido à elevada temperatura da janela superplástica do titânio, poucas possibilidades de material para a fabricação da ferramenta foram localizadas, cada uma com suas vantagens e desvantagens: inconel 625, AISI H13, ABNT 310, ABNT 304. A.

A primeira opção devido larga utilização para trabalhos a quente, o inconel 625 disponível nas dimensões do projeto exigiria importação, cujo o alto custo inviabilizou.

$\mathrm{O} \mathrm{H} 13$ apesar de manter a dureza em temperaturas próxima a $1000^{\circ} \mathrm{C}$ logo acima dessa temperatura ele perde suas características de tempera, por isso não é recomendado 
para trabalhos de longo tempo nessa faixa de temperatura. Além disso, também tem a desvantagem de ser um material caro e suas peças também seriam importadas.

O ABNT 304, quando comparado com o ABNT 310 na temperatura de trabalho $\left(1000^{\circ} \mathrm{C}\right)$ apresenta resistência à tração mais baixa, o que implicaria em paredes mais grossas e um ferramental mais pesado. O ABNT 310 é classificado como aço refratário, seria melhor o ABNT 310L, mas é uma liga pouco disponível comercialmente para compra de pequenos lotes. O ABNT 310 é recomendado para trabalhos na temperatura de no máximo $1150^{\circ} \mathrm{C}$, atendendo assim aos requisitos de projeto. Dessa forma escolhe-se o ABNT 310.

A Tabela 3.3 apresenta dados de resistência à tração para esses Aços a $1093^{\circ} \mathrm{C}$.

Tabela 3.3. Dados de Resistência a Tração em diferentes temperaturas dos aços ABNT 304 e 310

\begin{tabular}{|c|c|c|}
\hline Material & $\begin{array}{c}\text { Temperatura } \\
\left({ }^{\circ} \mathbf{C}\right)\end{array}$ & $\begin{array}{c}\text { Resistência à tração } \\
(\mathbf{M P a})\end{array}$ \\
\hline ABNT 304 & \multirow{2}{*}{1093} & 37,26 \\
\cline { 1 - 2 } ABNT 310 & & 93,16 \\
\hline
\end{tabular}




\subsubsection{Acabamento superficial}

O acabamento superficial é um ponto crítico da primeira concepção da ferramenta, haja vista que a vedação seria feita através do processo de "DB" - diffusion bonding, tratado no capítulo 2.3.4. Durante o aquecimento do forno até a temperatura superplástica de $927^{\circ} \mathrm{C}$, buscou-se por 90 minutos manter um patamar de $900^{\circ} \mathrm{C}$, temperatura característica da soldagem por difusão, após esse período, o segundo patamar na temperatura superplástica de $927^{\circ} \mathrm{C}$ foi alcançado e o ensaio foi realizado.

\subsubsection{Geometria}

A princípio existe uma geometria ideal da ferramenta: uma peça única usinada a partir de um tarugo de 254mm e um flange liso de 203,2mm nominal para fixar a chapa de titânio .A impossibilidade de usinagem invalida a solução, porém é a partir dela que as próximas ferramentas são sugeridas. A Figura 3.10 apresenta o desenho dessa ferramenta.

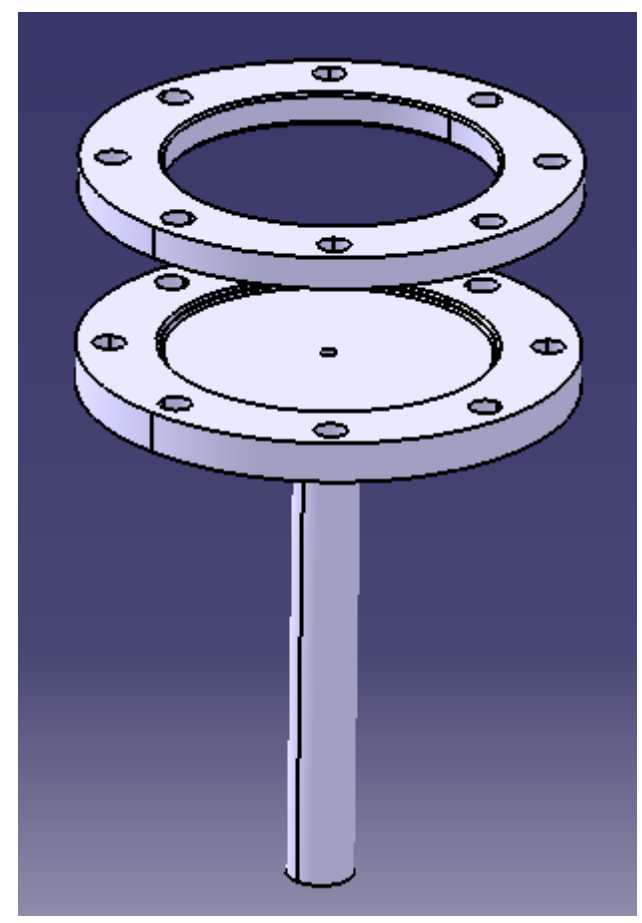

Figura 3.10. Desenho da ferramenta - solução 1

A ferramenta será dividida em três peças de modo que será necessária uma junção, que é crítica por causa da temperatura e pressão de trabalho. A solução imediata para essa junção seria a solda, porém como ela teria função estrutural, as chances de trincar e deixar 
escapar o ar pressurizado seriam grandes, impossibilitando o trabalho do controle do ciclo de pressão.

Para a solução apresentada a seguir, dividiu-se a ferramenta em um flange de $76,2 \mathrm{~mm}$ com pescoço, um flange cego usinado de $203,2 \mathrm{~mm}$ e um flange liso de $203,8 \mathrm{~mm}$. A junção seria feita com uma junta comercial da TEADIT a camprofile $®$ com micaflex®, que é feita com o núcleo de material igual ao material da ferramenta e um acabamento a partir de mica nominal, essa junta suporta até $1000^{\circ} \mathrm{C}$ e 50 bar. Surge o problema de se trabalhar no limite, com fator de segurança 1, mas não há uma junta que suporte condições de trabalho mais críticas. A ferramenta é apresentada na Figura 3.11.

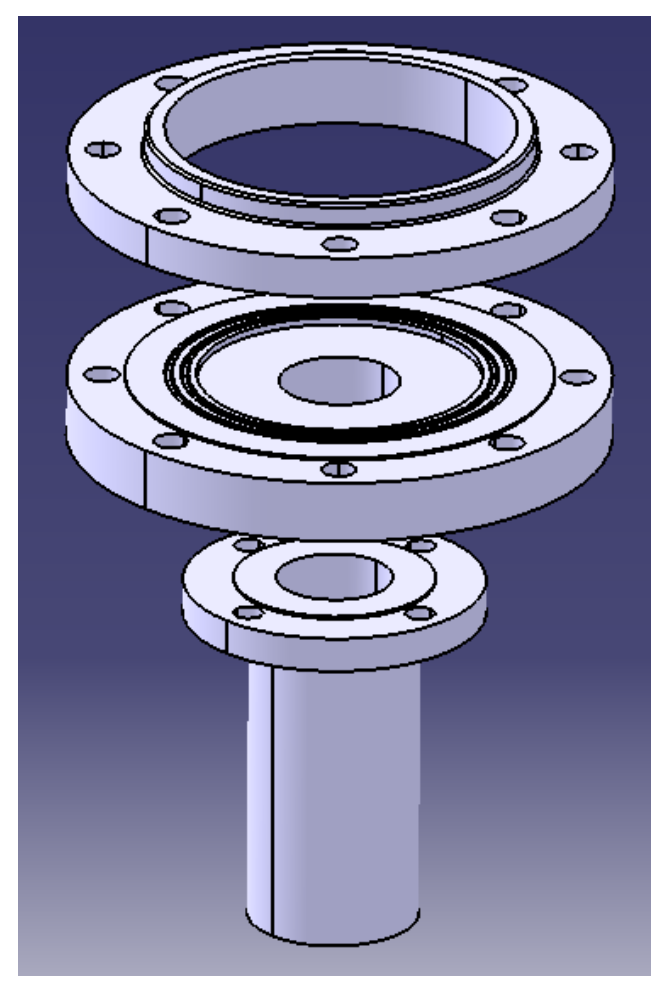

Figura 3.11. Desenho da ferramenta - solução 2

Para a terceira e última solução foi apresentada a ferramenta dividida em três partes, sendo um tubo nominal de 50,8mm, um flange cego usinado de 203,2mm e um flange liso de 203,2mm. Nessa solução a junção entre o flange cego e o tubo será feito por rosca e será usado um cordão de solda para fins de vedação e não estrutural. A grande vantagem dessa solução é o tamanho do furo que terá que ser feito no forno, haverá uma redução de $\phi 130 \mathrm{~mm}$ para $\$ 80 \mathrm{~mm}$. Além disso, a junção entre as peças é muito mais simples e as condições de trabalho não estarão no limite, Figura 3.12. 


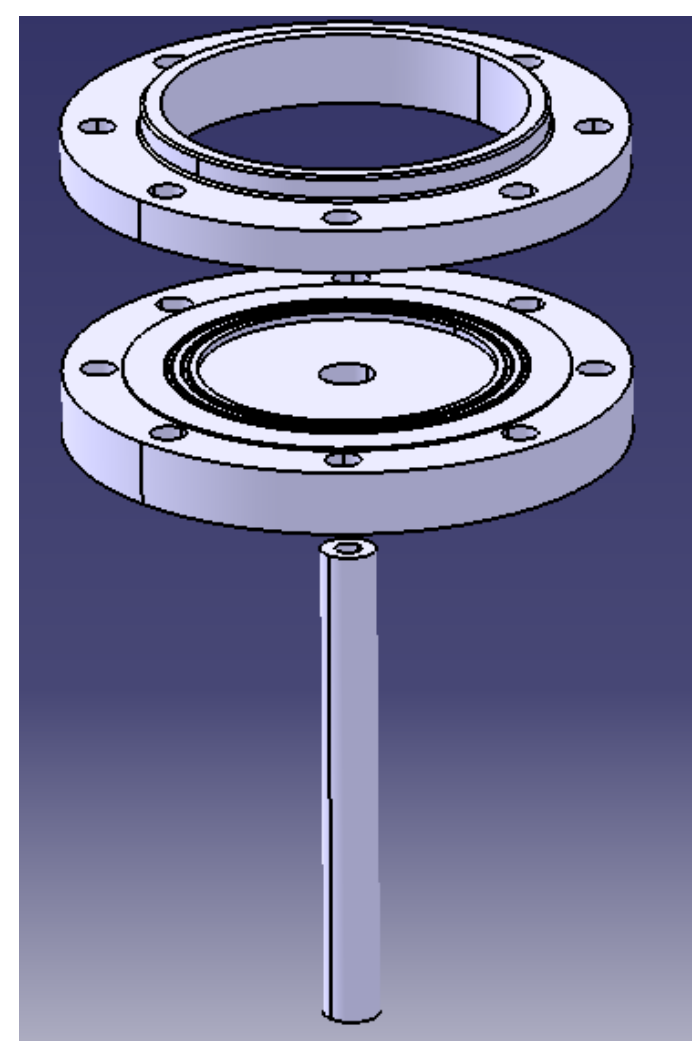

Figura 3.12. Desenho da ferramenta - solução 3

\subsubsection{Vedação}

Entenda-se vedação do prensa chapa como a necessidade de evitar que durante o processo de pressurização (limite de 40 Bar) e na temperatura superplástica $\left(927^{\circ} \mathrm{C}\right)$ não haja vazamento entre a matriz inferior e a chapa de titânio, porém busca-se também evitar a junção da chapa de titânio com a matriz superior do prensa chapa. A complexidade da solução do problema evidenciou, durante o ensaio do primeiro bulge, a necessidade de buscar uma nova solução/metodologia para realizar a conformação.

Para a vedação foram levantadas quatro soluções. A primeira é a mais simples, simplesmente colocar a chapa de titânio em contato com duas superfícies lisas do inox ABNT 310. Porém tal solução abre a possibilidade da chapa de titânio escorregar entre os dois flanges, nesse caso o atrito teria que ser considerado, com o escorregamento a vedação também não estaria garantida e poderia ser obtido resultados não esperados.

Outra possibilidade seria usinar perfis negativos em um flange e positivo no outro para deformar a borda da chapa por deformação forçada na etapa de montagem e fechamento da matriz para evitar o escorregamento e tentar manter a vedação. Porém, 
devido as propriedades mecânicas do titânio, haveria dificuldades de garantir a deformação forçada a frio da chapa de modo a preencher o perfil nos flanges e garantir a vedação.

A terceira solução seria a utilização dos anéis camprofile® entre o blank e o flange superior. Tais anéis funcionam por expansão, entretanto as superfícies dos flanges são lisas, necessitariam de retrabalho, essa solução também foi descartada.

A quarta e utilizada solução requer um anel de cobre entre a placa de titânio e o flange inferior. Com a temperatura e a pressão características da soldagem por difusão, seria forçada essa soldagem entre a chapa de titânio e a flange inferior garantindo assim a vedação e fixação.

A análise dessa possibilidade de solução para vedação, do ponto de vista de DFD Design for Disassembly - não apresenta o melhor resultado possível, entre cada ensaio seria necessária usinagem para retirada da solda (cobre+titânio) da ferramenta, entretanto, considerando as outras opções, a solução com anel de cobre foi a escolhida para o primeiro setup da prensa de Conformação Superplástica.

\subsubsection{Dimensionamento}

Escolhida a terceira solução para o dimensionamento do tubo, utilizou-se o modelo de vaso de pressão, equação (94) para cálculo das dimensões.

$$
\sigma_{1}=\frac{\mathrm{pr}}{\mathrm{t}}
$$

Sendo $\sigma_{1}$ a maior tensão no vaso de pressão, esta será a tensão crítica analisada. Para o ABNT 310 com fator de segurança 2 precisa-se de uma relação entre raio e espessura de 4,6. Comercialmente, o mais próximo é um tubo de diâmetro externo de $60,33 \mathrm{~mm}$ e parede de $8,71 \mathrm{~mm}$ (padrão 160-S) que possui relação entre raio e espessura de 4,9 .

Para o flange, trabalhando com uma pressão de 40 bar, realizou-se no CATIA uma análise estática para as dimensões comerciais, Figura 3.13, e foi concluído que as dimensões que garantem segurança para o projeto são da classe normatizada de 600 lbs (5,8 N), cujas dimensões estão ilustradas na Figura 3.14.

A ferramenta usinada na geometria da Figura 3.14 pode ser observada na Figura 3.15. 

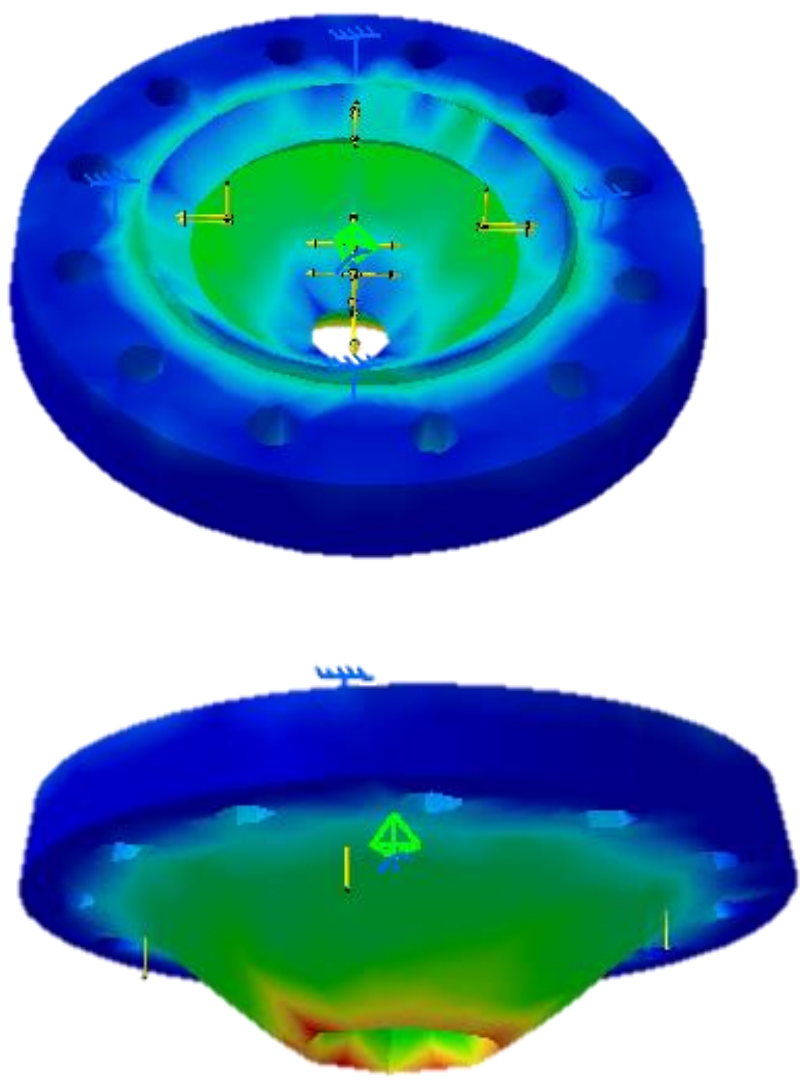
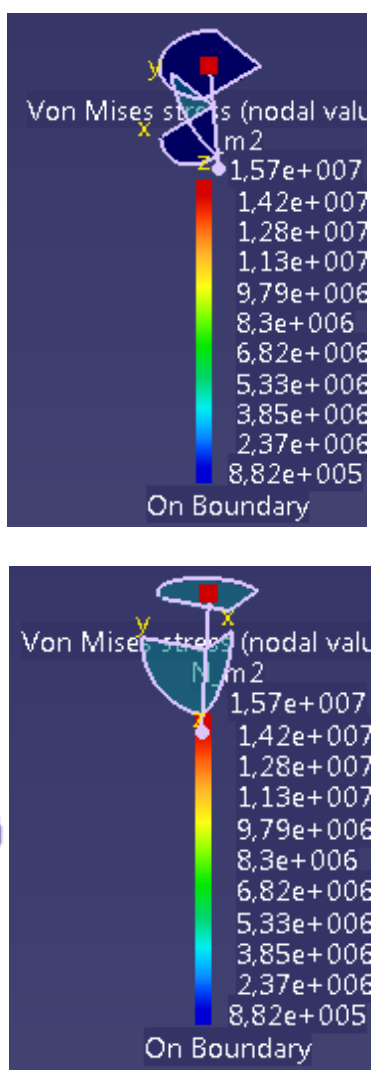

Figura 3.13. Simulação gráfica no CATIA de análise estática de esforços para as dimensões comerciais da ferramenta.
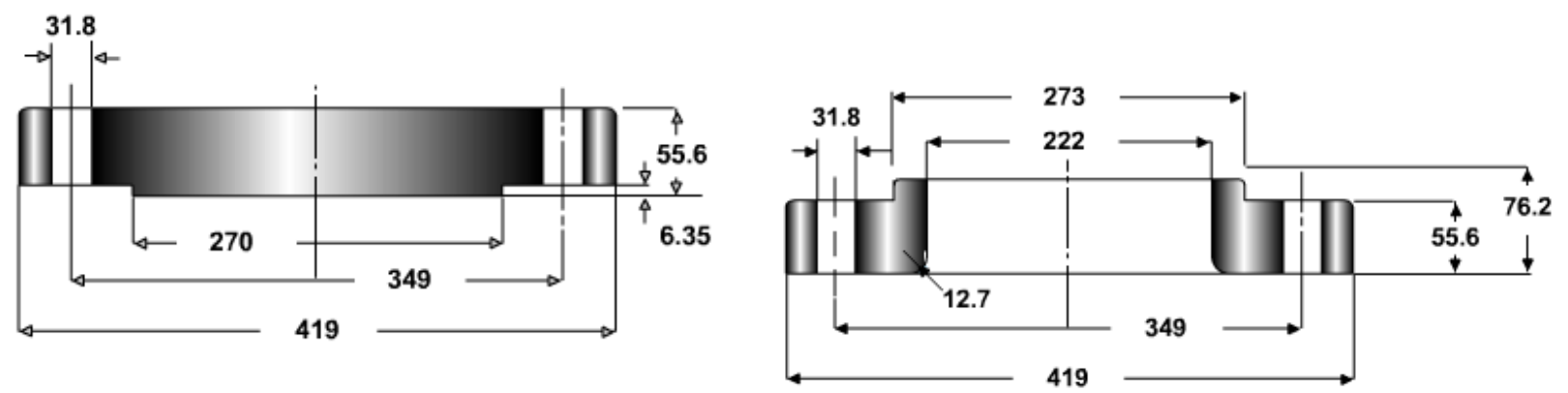

Figura 3.14. Dimensões dos flanges comerciais obtidas pela Valmec.

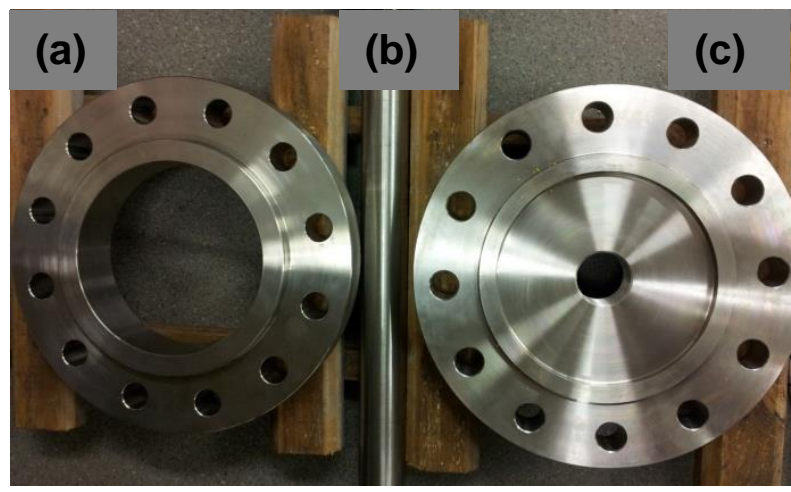

Figura 3.15. (a) Flange superior, (b) tubo de pressurização e (c) flange inferior. 


\subsubsection{Montagem da ferramenta}

Apresentam-se as etapas da montagem da ferramenta na sua primeira concepção na Figura 3.16.
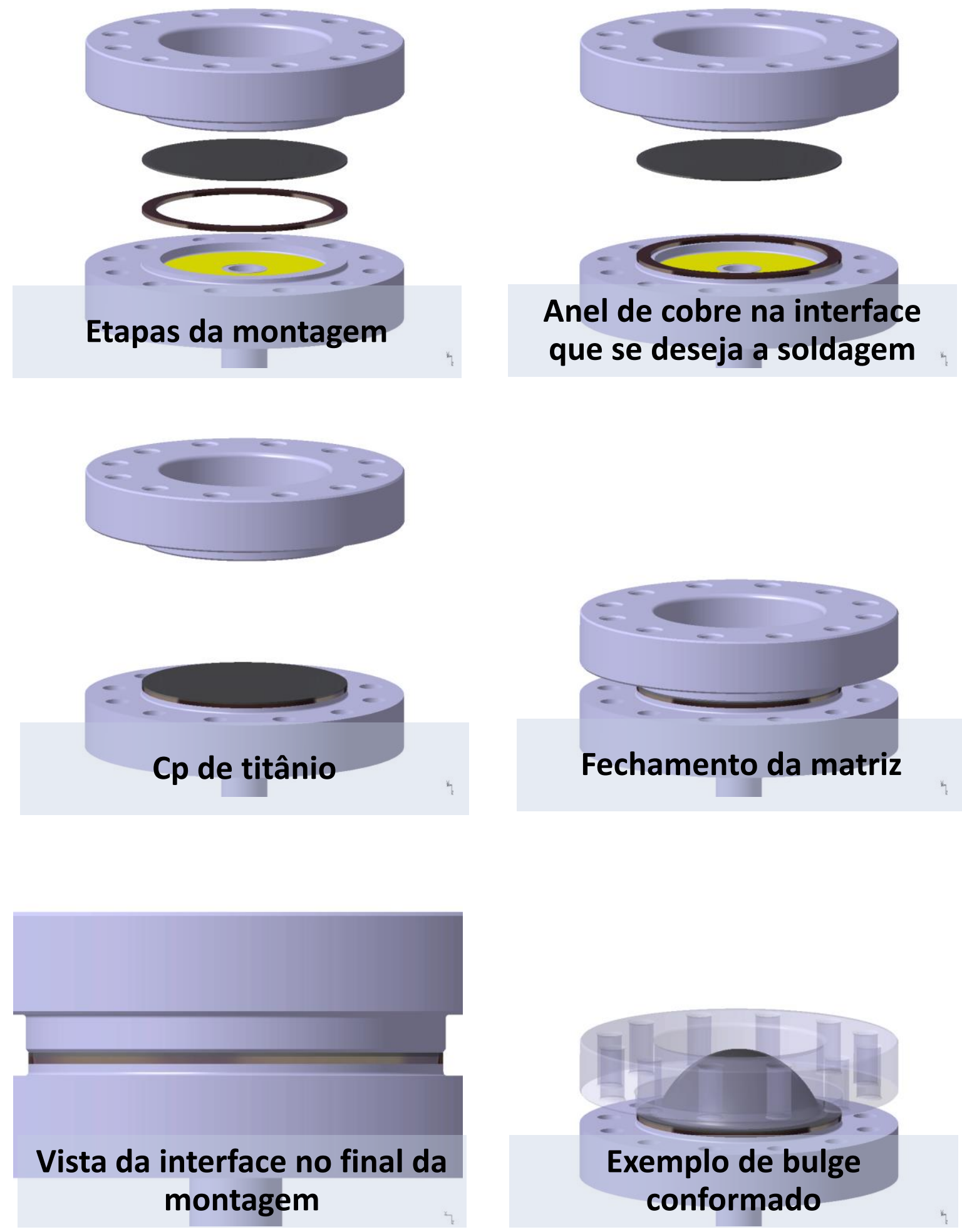

Fechamento da matriz

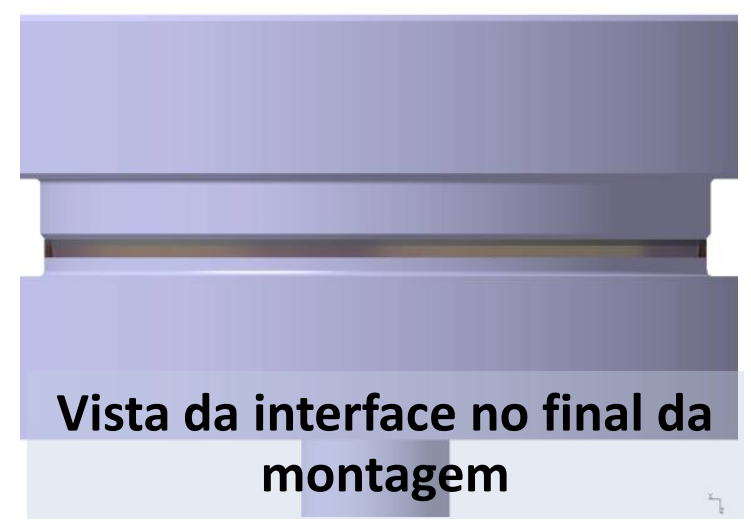

Figura 3.16. Etapas da montagem do ferramental spf que vai ser colocado dentro do forno para que a conformação aconteça na temperatura superplástica. 
A limpeza da ferramenta é uma etapa importante pois o polimento e a interface limpa são característica necessárias para que ocorra a soldagem por difusão. Utilizou-se álcool isopropílico nessa etapa.

Em razão da preocupação com a desmontagem, nitreto de boro cúbico foi pulverizado nos parafusos para evitar que eles soldassem e dificultasse a abertura da matriz no pós-ensaio. Observa-se o padrão de aplicação na Figura 3.17.

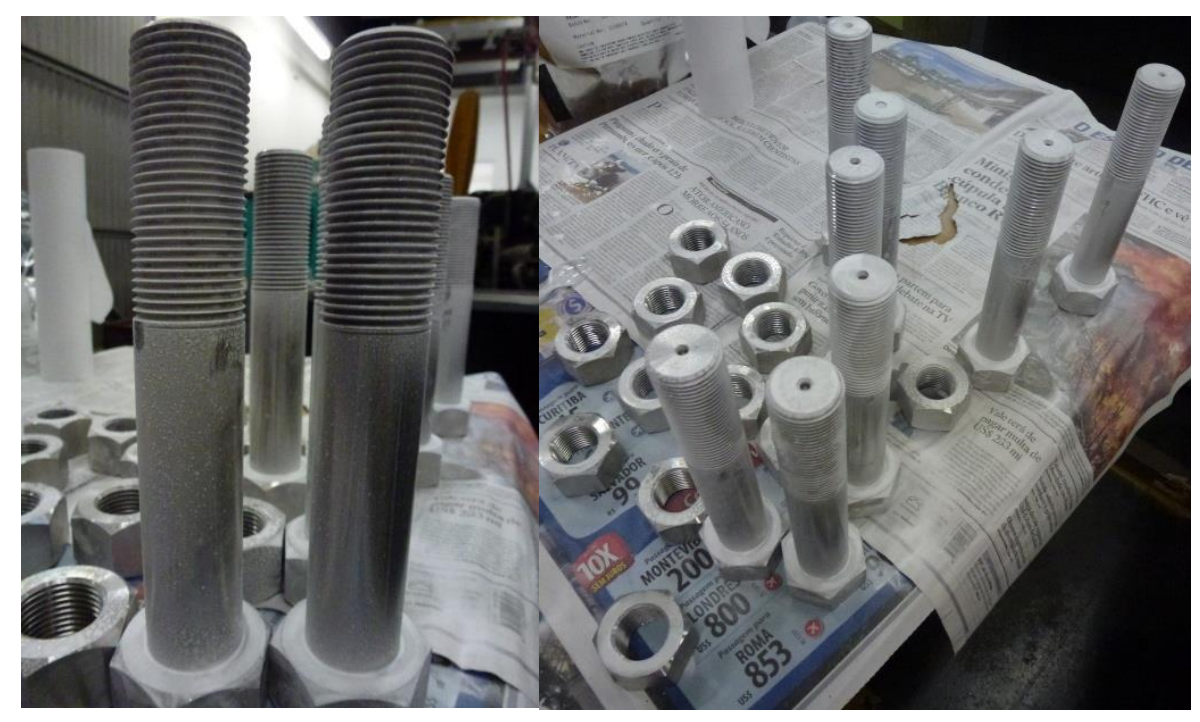

Figura 3.17. Aplicação de nitreto de boro cúbico nos parafusos.

O nitreto de boro também foi utilizado entre a matriz superior e o blank de titânio para que se evitasse a solda nos locais indesejados.

Após o detalhamento das características da ferramenta, em sua primeira concepção, a instrumentação de apoio ao ensaio superplástico será apresentada no capítulo seguinte. 


\subsection{Instrumentação}

A instrumentação desse projeto representa um desafio multidisciplinar e multitarefa, cada escolha está relacionada a algum requisito do projeto ou vinculado a alguma outra decisão de projeto. Com a intenção de facilitar o entendimento e a justificativa de cada decisão tomada, dividir-se-á essa etapa em sub-etapas:

- Instrumentação para medição de deformação;

- Instrumentação para medição da pressão e atuação na mesma;

- Instrumentação para medição da temperatura e atuação na mesma;

Para cada variável de monitoramento, entenda-se pressão, temperatura e deformação, foi proposto um sistema de medição e de controle, cujo sensor escolhido atenda as especificações do projeto do ferramental.

Um estudo da escolha dos sensores baseando-se nas restrições do projeto, como também uma proposta de controle para cada um dos sistemas (Sistema de medição de deformação, Sistema de medição de pressão e Sistema de medição de temperatura) foram resultados de Marinho no seu trabalho de formatura. (MARINHO,2010)

O presente capítulo foca em detalhar as estratégias de medição das variáveis de projeto, especificando as características de cada sistema de medição, desde sensores a placas conversoras.

A integração de cada parte do sistema de controle será detalhada no capítulo 3.6.

Pode-se resumir os principais componentes utilizados no controle do processo de maneira esquemática no setup experimental da Figura 3.18.

Segue lista dos itens de monitoramento e controle da Figura 3.18:

- Temperatura;

- Termopares 1, 2 e 3;

- Forno por aquecimento resistivo Grion;

- Jaqueta de resfriamento;

- Dois controladores de temperatura Therma-Grion;

- Sistema de monitoramento de temperatura;

- Software de análise de dados; 
- Pressão;

- Transdutor de pressão HBM;

- Válvula de pressão;

- Deformação;

- Sistema de medição ARAMIS;

- Software de tratamento de dados ARAMIS 3D;

- Tratamento e aquisição dos dados;

- Software Catman@Enterprise;

- Placa aquisitora de dados QuantumX;

Para cada um dos sensores (deformação, pressão e temperatura) foi necessário um teste de instalação dedicado, devido as severas condições de atuação dos mesmos. Cada um foi ligado ao seu sistema de aquisição, teve seu sinal aquisitado, calibrado e, caso necessário, filtrado. Somente após o aperfeiçoamento de cada módulo de controle, passouse para a etapa de integração dos módulos.

Nos próximos tópicos serão apresentados detalhes dos módulos de controle desenvolvidos na tese.

\subsubsection{Módulo de controle da deformação}

O sistema de medição utilizado para auxiliar no controle da deformação durante a Conformação Superplástica utiliza-se de um sistema ótico moderno de medição, ARAMIS da GOM (Brunswick, Alemanha). ARAMIS é um sistema para análise de deformação Ótica 3D, com alta resolução temporal e de medida, assim como alta exatidão, fornece como medidas as coordenadas 3D de posicionamento, velocidade e aceleração, assim como gráficos de tensão $x$ deformação e taxa de deformação. $O$ uso desse sistema preenche os requisitos necessários buscados pelo projeto. 


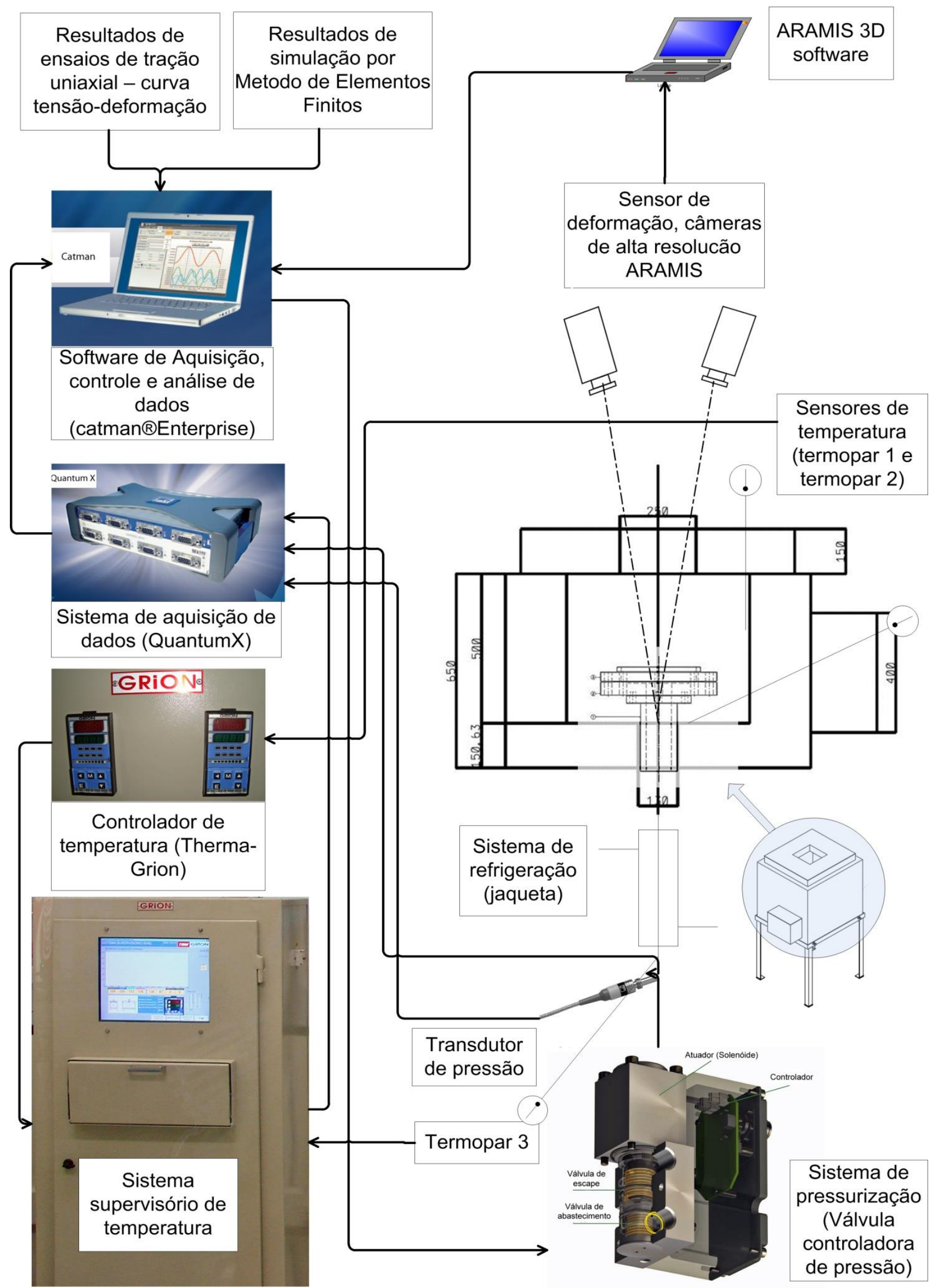

Figura 3.18. Arranjo experimental da instrumentação do controle da ferramenta de expansão fluidoestática biaxial. 
No detalhamento do novo modelo de caracterização reológica - Capítulo 3.9 proposto por Marinho evidencia-se a importância de aquisitar os valores de espessura do domo da peça conformada e da tensão do campo de tensão biaxial.

O software do sistema de medição ARAMIS, permite que até duas variáveis - duas deformações pontuais do processo, por exemplo - sejam utilizadas, em tempo real, em uma malha de controle que envolva a planta do processo.

No modelo de caracterização reológica, as duas variáveis de interesse escolhidas são espessura e tensão do campo de tensão biaxial, conforme definido no capítulo 2.5.4.

Do ponto de vista do posicionamento do sistema ARAMIS, é importante ressaltar alguns pontos do projeto, utilizar-se-á a janela de vidro do forno para a aquisição das imagens que podem ser utilizadas para levantamento dos dados relativos a deformação durante a conformação.

O sistema ARAMIS introduz alternativa no campo experimental de medições de deslocamento e deformação, possibilita o monitoramento e aquisição do mapa de deformação de uma superfície sobre tensão.

Inicialmente, nesse capítulo, será explorado o princípio teórico de medição, o setup do sistema de correlação digital de imagem e as etapas de aperfeiçoamento da utilização dessa técnica de medição. No capítulo 3.7 será explorada a utilização desse sistema de medição ótico, que uma vez integrado ao sistema de pressurização, possibilitou a validação da instrumentação proposta nessa tese à temperatura ambiente.

\subsubsection{Princípio teórico de medição - Fotogrametria}

O princípio que fundamenta a medição dos pontos superficiais utilizando coordenadas 3D é a fotogrametria. (TOMANEK, 2006)

O princípio fundamental desse método baseia-se na correspondência entre a distribuição de valores do nível de cinza de uma área retangular de pixels (faceta) não deformada com os valores da distribuição do nível de cinza da mesma área no estado deformado.

O sistema usa projeção central para a conexão funcional entre as coordenadas dos pixels das imagens das câmeras e as coordenadas do objeto medidas. Observe esquematicamente essa relação na Figura 3.19. 

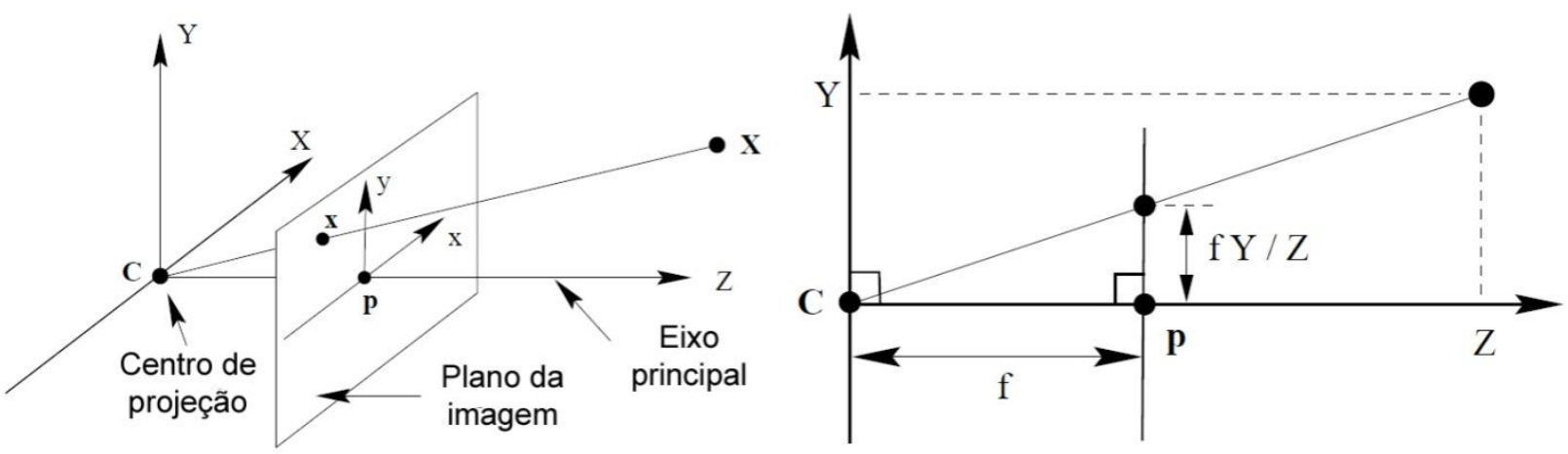

Figura 3.19. S Sistema de projeção usado pela ARAMIS (HARTLEY, 2003)

Tem-se o centro de projeção na origem e o plano da imagem é o plano $Z=f$; as coordenadas globais $(X, Y, Z) T$ são mapeadas pelas coordenadas $\left(\frac{f X}{Z}, \frac{f Y}{Z}, f\right)^{T}$ no espaço ou $\left(\frac{f X}{Z}, \frac{f Y}{Z}\right)$ no plano da imagem. (HARTLEY, 2003)

$$
(X, Y, Z)^{T} \rightarrow\left(\frac{f X}{Z}, \frac{f Y}{Z}\right)^{T}
$$

Após entender o tipo de projeção que está por trás da correlação de imagens 3D com as coordenadas dos pixels no plano 2D, explica-se o princípio de medição da fotogrametria.

As coordenadas do objeto 3D $(x, y, z)$ são determinadas pela intersecção das retas centrais que cada câmera possui, conforme Figura 3.20, os planos retangulares representam as câmeras. $\mathrm{O}_{1}$ e $\mathrm{O}_{2}$ são os centros de perspectiva. A representação do ponto $P$ em ambos os chips CMOS das câmeras são atribuídos respectivamente a $\mathrm{O}_{1}$ e $\mathrm{O}_{2},\left(x_{1}, y_{1}\right)$ e $\left(x_{2}, y_{2}\right)$. Se a posição das duas câmeras e dos dois pontos imagem homólogos são conhecidos, 0 ponto objeto correspondente $\mathrm{P}(x, y, z)$ pode ser calculado. Esse procedimento é conhecido como intersecção espacial. 


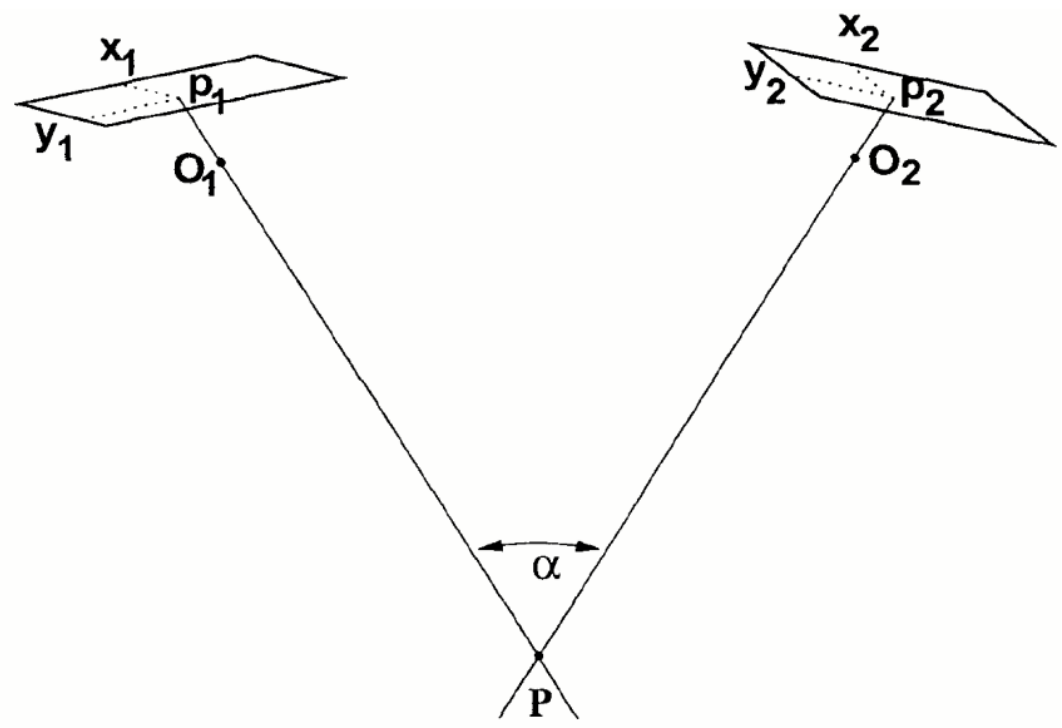

Figura 3.20. Princípio de medição da fotogrametria. (TOMANEK, 2006)

O princípio de mapeamento de deslocamento baseia-se em localizar e comparar as mudanças de movimento de cada faceta que sofreu alteração. Cada faceta é comparada na imagem atual com a imagem de referência (estado sem deformação) através dos dados aquisitados pelas duas câmeras. Essas alterações e comparações estão representadas no esquema abaixo da Figura 3.21.

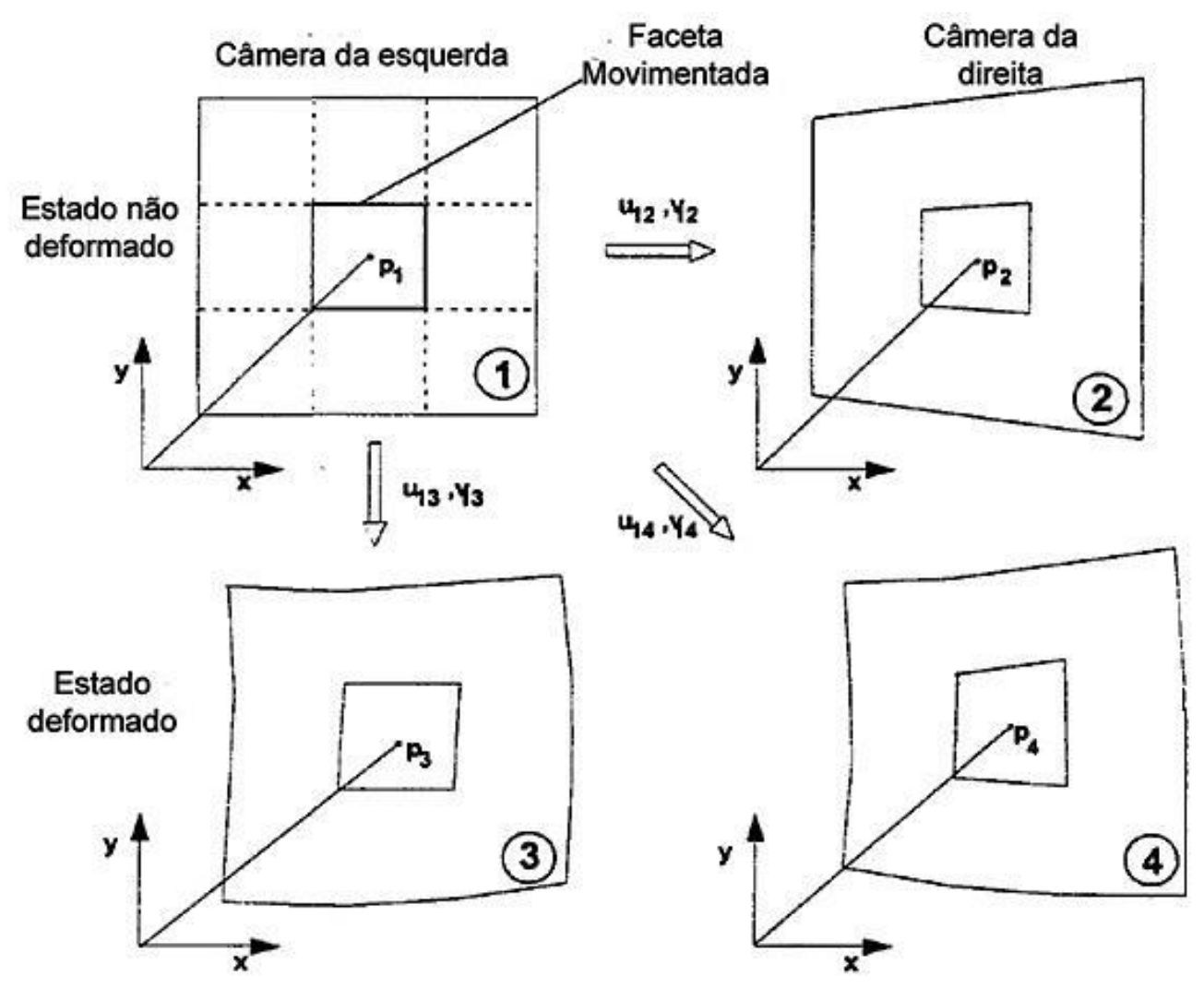

Figura 3.21. Técnica de mapeamento do campo de deslocamento. (TOMANEK, 2006) 


\subsubsection{Princípio da medição dos desvios}

Para um setup de medição 3D, utiliza-se duas câmeras anteriormente calibradas, o alvo de medição precisa estar dentro do espaço 3D calibrado. Depois de configurado o software de medição, imagens são gravadas (monocromáticas, câmera direita e esquerda) em vários estágios de deformação do alvo medido.

Após ser definida a área de medição desejada (máscara computacional) como também o ponto inicial, a medição é realizada.

Durante a medição, ARAMIS observa a deformação através das facetas. A Figura 3.22 mostra a representação da uma faceta de 15X15 pixels com uma área de sobreposição de dois pixels no estágio inicial de deformação.

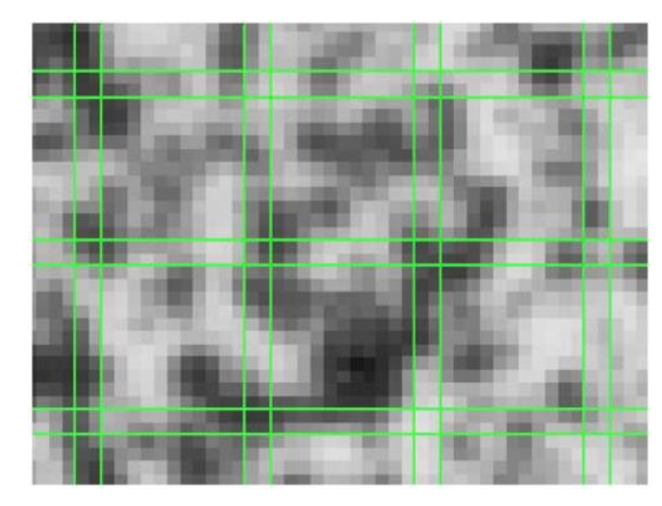

Figura 3.22. Faceta de 15X15 pixels com área de sobreposição de 2 pixels. (GOM, 2007)

O tamanho da faceta em pixels deve ser definido no software. Em diferentes estágios de deformação as facetas são identificadas e seguidas através do seu nível de cinza individual.

Observa-se, na Figura 3.23, a variação da posição dos pixels acompanhando o tracejado verde mudando de posição em comparação com a linha branca que representa o estado não deformado da faceta analisada.

O sistema determina as coordenadas 2D da facetas desde os cantos até a resultante central. Através de métodos fotogramétricos, as coordenadas 2D das facetas observada da câmera da esquerda e as coordenadas 2D das mesmas facetas observadas também pela câmera da direita, formam uma coordenada 3D comum.(GOM, 2007)

Após a aquisição de dados, há um tratamento de sinais que objetiva reduzir o ruído de medição, como também eliminar outras perturbações locais. O resultado da medição fica disponível finalmente em uma vista 3D. 

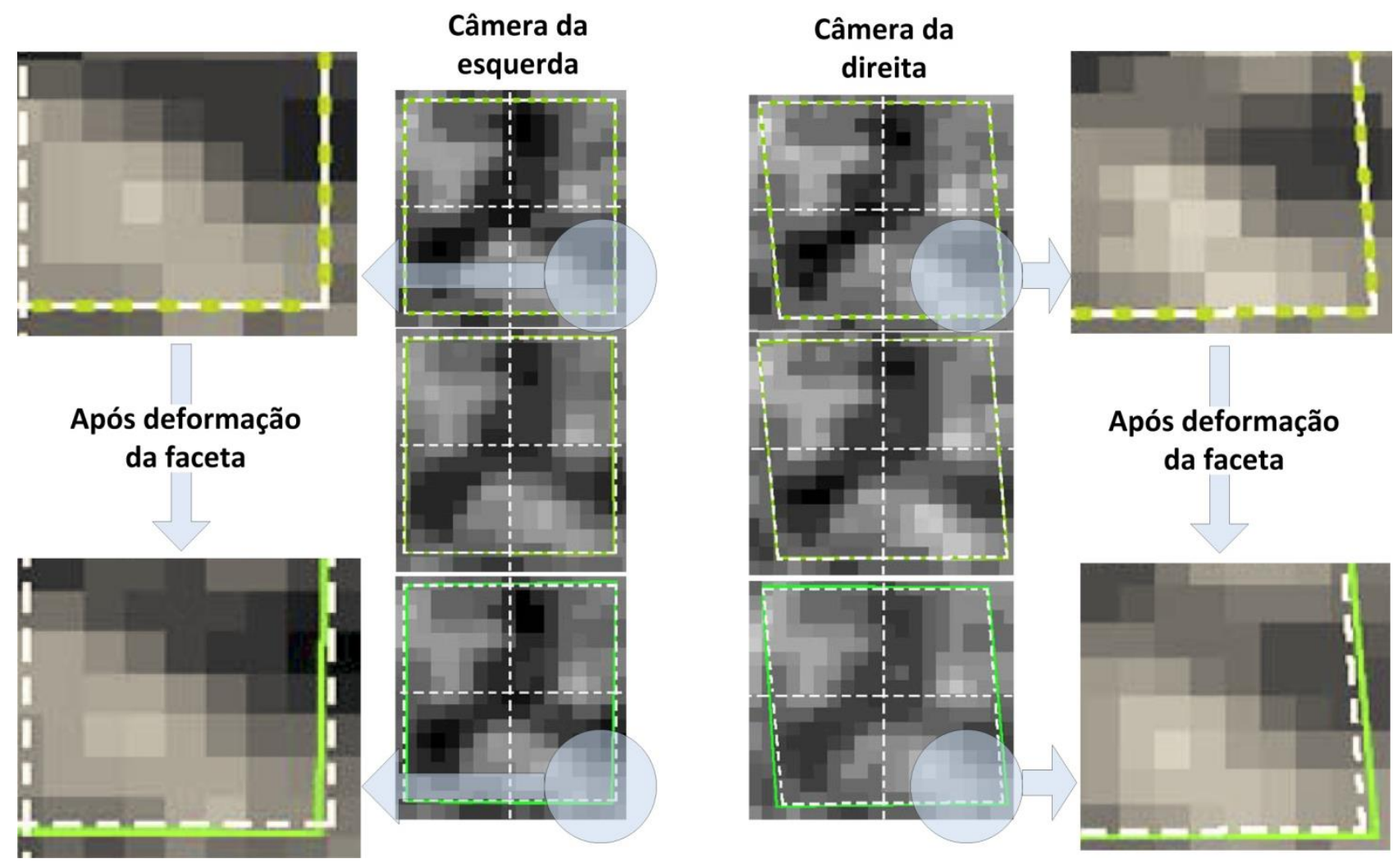

Figura 3.23. Visualização da análise comparativa entre a posição inicial dos pixels (linha branca) e a posição dos pixels pós deformação (tracejado verde) Adaptado (GOM, 2007)

\subsubsection{Computação facetada}

Utilizando uma faceta como exemplo, expõe-se o princípio computacional utilizado em um ponto 3D através de 21 estágios de deformação.

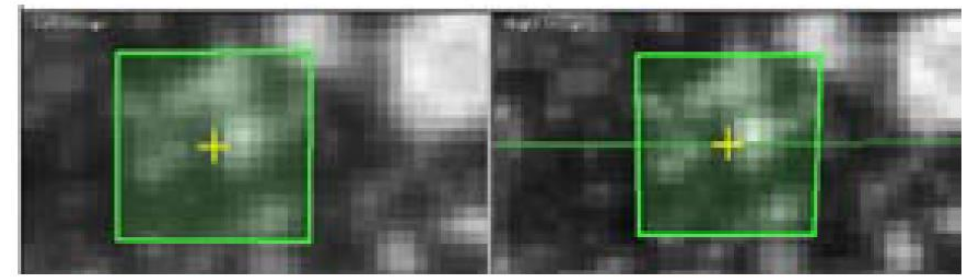

Figura 3.24. Exemplo da escolha de ponto inicial (GOM, 2007)

Seguem os passos do cálculo computacional do ponto de vista prático: 
- Inicialmente a computação facetada requer a definição, de maneira automática ou manual, do ponto inicial em todos os estágios, conforme exemplo ilustrativo na Figura 3.24.

- O tamanho da faceta verde depende da definição do campo facetado quando o projeto é criado.

- A cálculo computacional começa na imagem esquerda do estágio não deformado.

- $\quad$-..• : Devido a definição do ponto inicial, o software sabe em princípio a posição das facetas na imagem 2D. Pela identificação do padrão estocástico, resultado da aplicação do spray sobre o objeto a ser visualizado, da faceta na imagem esquerda e direita, a faceta retangular é otimizada. Do resultado das coordenadas da imagem 2D das facetas (ponto central da faceta) na imagem esquerda e direita, o software calcula a posição 3D da faceta;

automaticamente com o próximo estágio. Realizando novamente o cálculo da posição 3D da faceta no novo estágio de deformação;

- Em seguida realiza-se o cálculo da deformação, dado de saída buscado, resultado do deslocamento das posições dos pontos 3D entre os estágios. 
Vista Esquerda
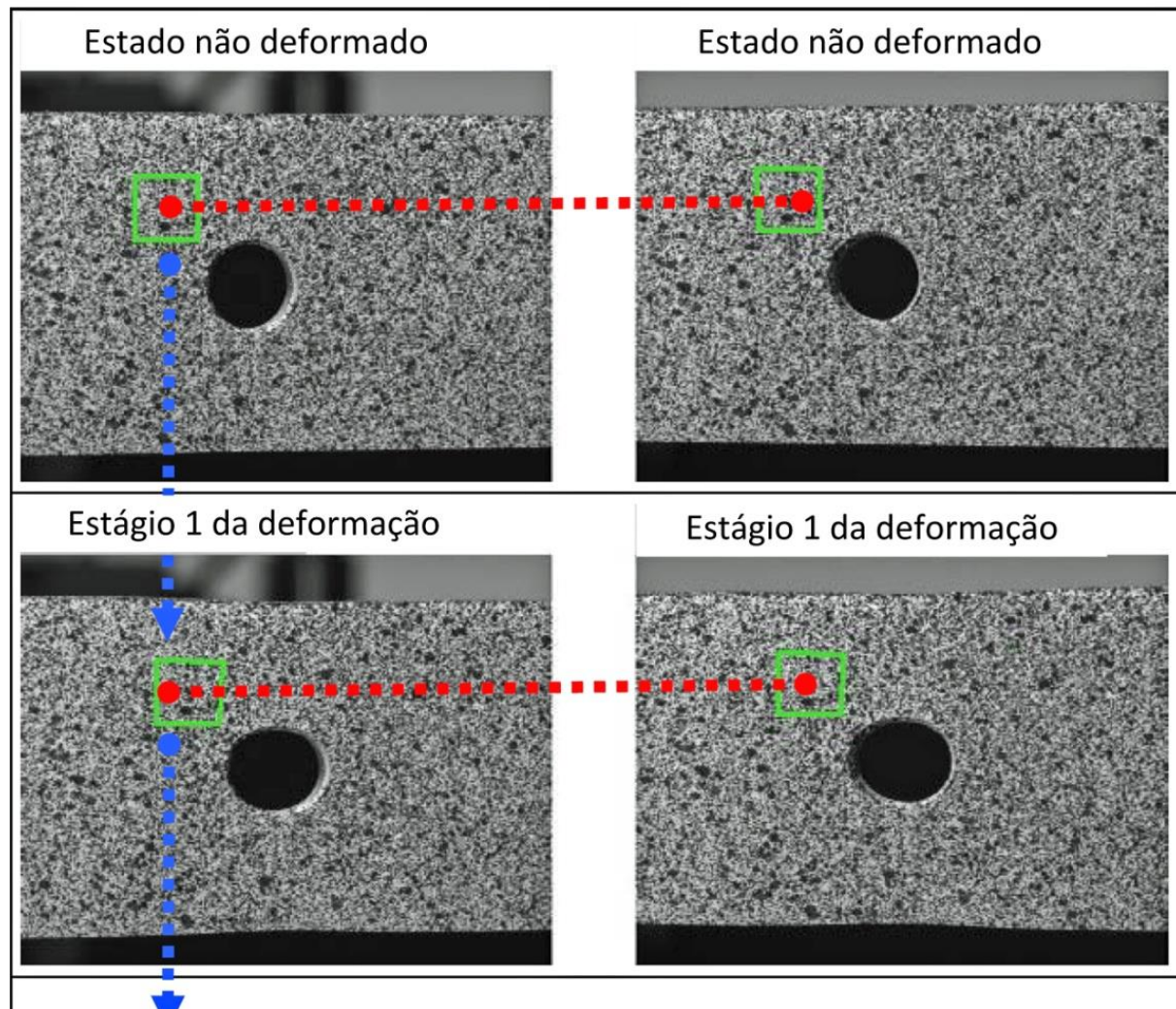

Estágio 2 ao 13 da deformação

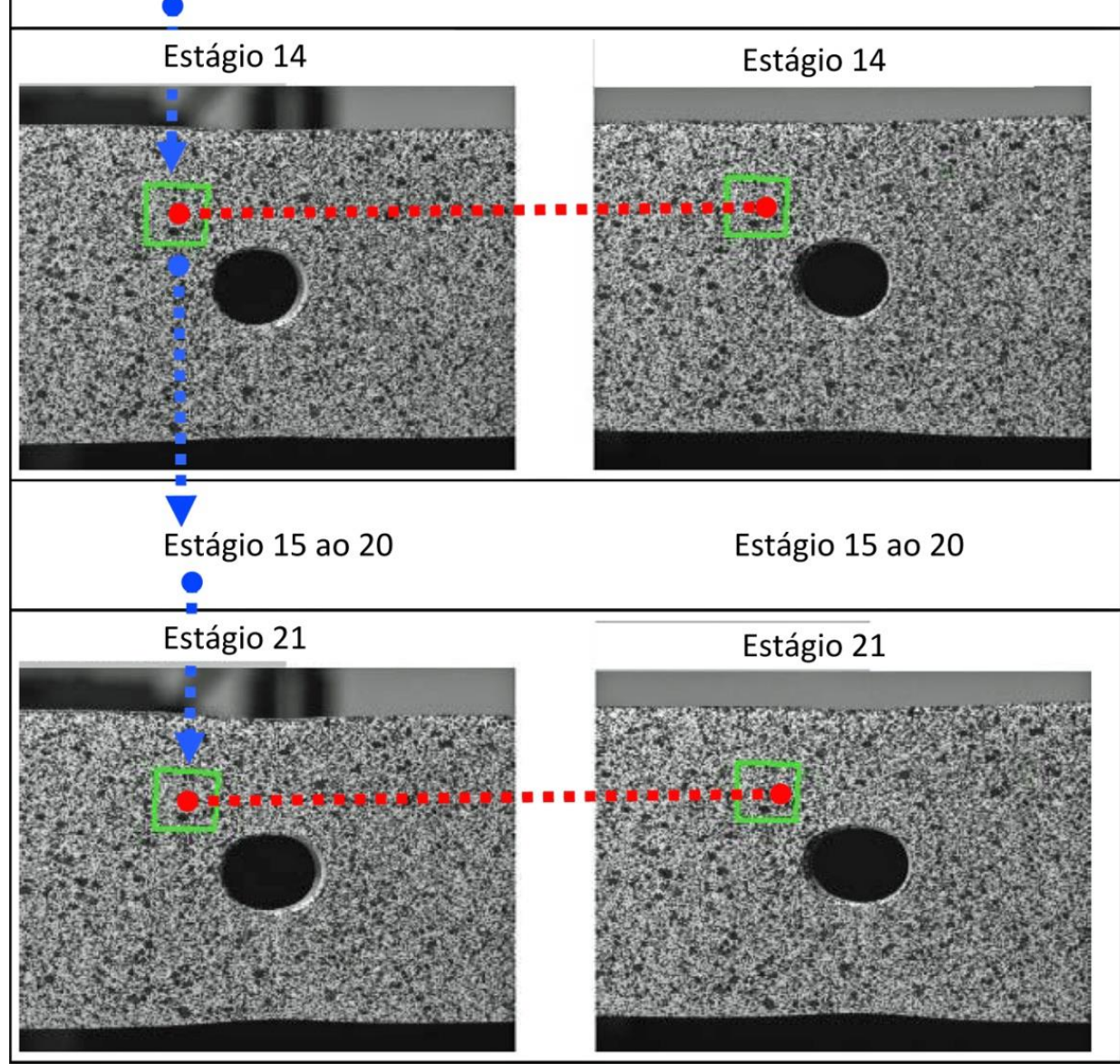

Figura 3.25. Esquema ilustrativo do cálculo computacional realizado com as facetas (GOM, 2007) 


\subsubsection{O cálculo da deformação}

Para o cálculo da deformação, a ARAMIS apresenta dois métodos, Deformação Linear e Deformação Spline, detalhes no capítulo 10.2 em anexo.

Normalmente nas medições com o ARAMIS utiliza-se o modelo de deformação Linear, porém, quando o objeto em análise possuir pequenos raios de curvatura, o modelo de deformação Spline é recomendado.

Segue uma tabela comparativa entre os modelos, com um resumo das vantagens e desvantagem de cada modelo.

Tabela 3.4. Comparativo entre métodos de cálculo para modelo de deformação (GOM, 2007).

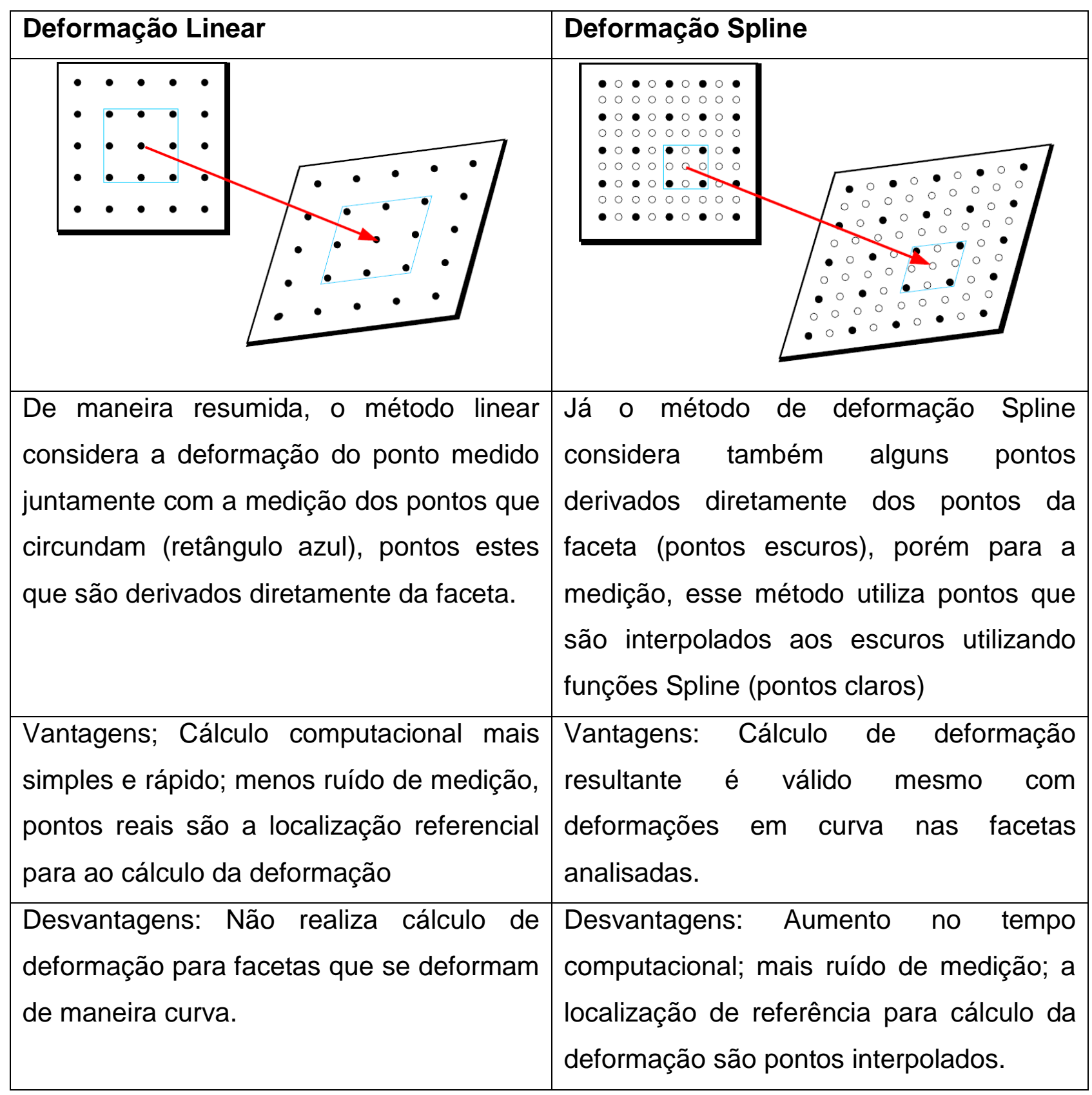




\subsubsection{Setup de medição e metodologia}

De maneira esquemática (Figura 3.26) mostra-se o setup de medição experimental que utiliza o sensor ARAMIS e é responsável por aquisitar os dados referentes à deformação e participar do controle do processo superplástico na chapa de titânio em estudo.

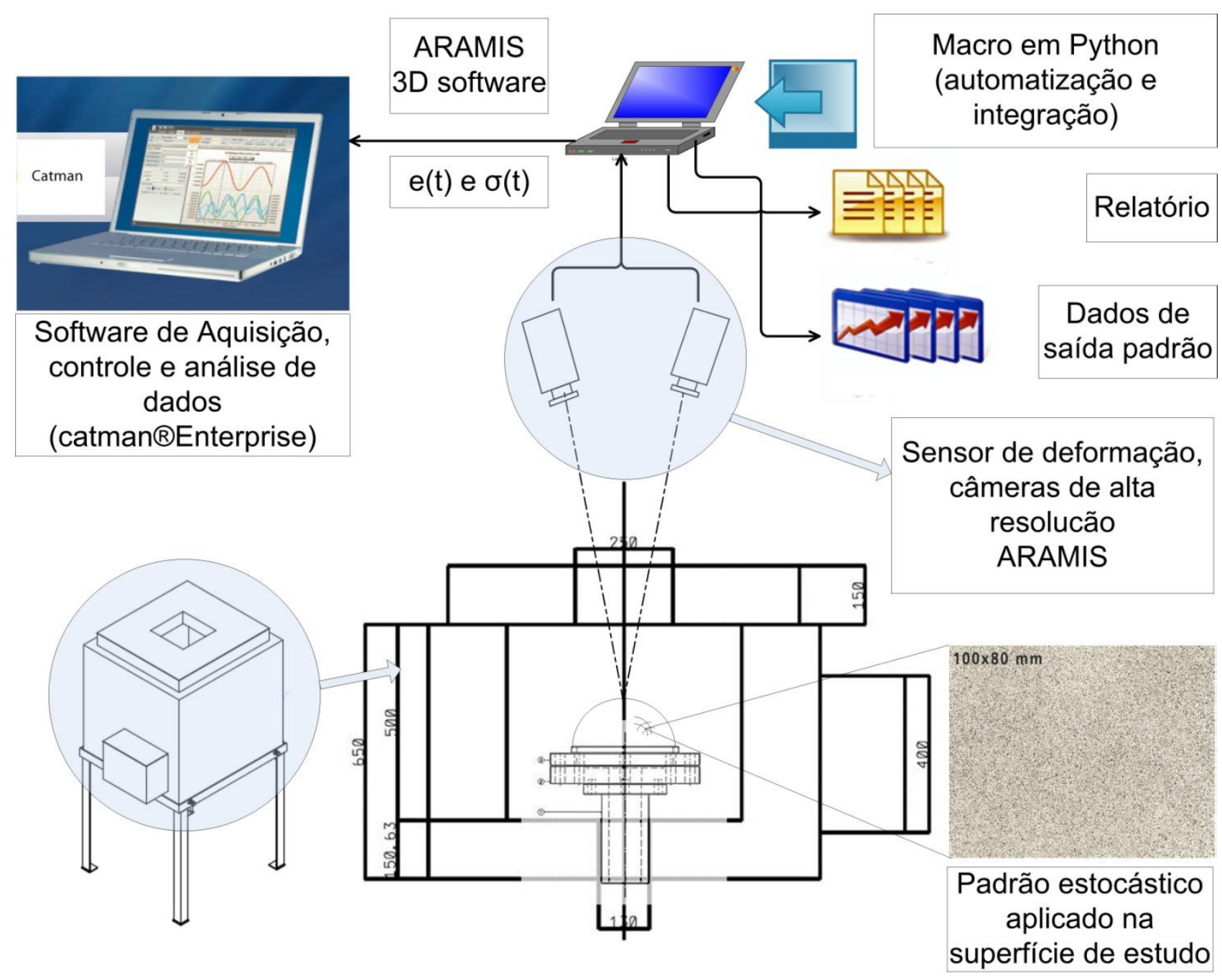

Figura 3.26. Setup experimental do módulo de controle de deformação

Os valores de espessura e tensão podem ser utilizados como valores de entrada do sistema de controle, que, por sua vez, poderia calcular uma curva de pressurização cuja responsabilidade é variar a taxa de deformação na busca do índice ótimo de sensibilidade a taxa de deformação. 
De posse da espessura em função do tempo e(t) e da tensão equivalente em função do tempo $\sigma(\mathrm{t})$, o ciclo de pressão que resulta em uma Conformação Superplástica está definido, $P=f(\mathrm{e}(\mathrm{t}) \sigma(\mathrm{t}))$.

Detalhes da metodologia dessa tese serão explicados no capítulo 3.9 - Proposta de estratégia de caracterização reológica.

\subsubsection{Metodologia de medição com a ARAMIS}

Em linhas gerais seguem passos padrões para realização de uma medição com o sistema ARAMIS (GOM, 2007):

- Determinação do volume de medição e preparação do objeto que será medido, através da aplicação do spray que fornece o padrão estocástico necessário para que o sistema realize a medição.

- No caso da medição em 3D, calibração do sistema;

- Criação de um novo projeto de medição no software ARAMIS (2D ou 3D), no caso dos objetivos desse plano de trabalho, cria-se um novo projeto 3D, como também é necessário definir os parâmetros de entrada do software (Tamanho das facetas, estágios, etc..)

- Ajuste do modo de gravação das imagens (medições simples ou rápidas);

- Gravação das imagens durante a medição;

- Definição do ponto inicial necessário para os cálculos computacionais;

- Realização dos cálculos computacionais;

- Escolha dos resultados que se pretende analisar;

- Pós-processamento dos dados para eliminar ruídos de medição e realizar a interpolação dos dados 3D que estiverem faltando.

- Definição dos elementos de análise (Seções, planos, pontos, etc.);

- Documentação dos resultados.

\subsubsection{Avanço na utilização da ARAMIS}

A proposta de utilização de correlação de imagem digital na determinação de parâmetros no teste de expansão fluidoestática biaxial superplástico apresentado em Albi - França, como resultado do grupo de pesquisa LEFA-POLI-USP, está sendo validada para se tornar a norma ISO/CD 16808 "Metallic materials -- Sheet and strip -- Determination of biaxial stress-strain curve by means of bulge test with optical measuring systems" para ensaios de bulge teste. 


\subsubsection{Módulo de controle da pressão}

Conforme será detalhada durante a metodologia descrita no capítulo 3.9 referente à estratégia de caracterização reológica proposta nessa tese, há dois modos de operação do módulo de sistema de controle de pressão.

- Módulo manual, que utiliza o regulador de pressão simples estágio LHS 1500;

- Módulo automático, que utiliza a válvula reguladora da pressão eletrônica de 3 vias SentronicPlus da empresa alemã Numatics.

No módulo manual é possível realizar ensaios de expansão fluidoestática biaxial à pressão constante, importante, a princípio, para validar os métodos de aquisição de dados através da comparação desses resultados com dados existentes da literatura, mais detalhes no capítulo 3.8.1.

Com o sistema de controle de pressão operacional a temperatura ambiente, notouse a necessidade de um melhor tratamento no quesito vazamento. Mesmo à temperatura ambiente, não se conseguiu tirar todos os pontos de vazamento. Quando o sistema foi testado e mantido à pressão constante, houve um padrão de vazamento observado que aumentava quando submetido a altas pressões, que pode ser observado na Tabela 3.5.

Tabela 3.5. I Índice de vazamento do sistema de pressurização a temperatura ambiente.

\begin{tabular}{cc}
\hline Pressão [Bar] & $\begin{array}{c}\text { Vazamento } \\
\text { [Bar/minuto] }\end{array}$ \\
\hline 1 & 0,005 \\
5 & 0,08 \\
10 & 0,1 \\
20 & 0,5 \\
\hline
\end{tabular}

Em razão do risco de vazamento quando o ensaio for realizado em alta temperatura, realizou-se a mudança de conexões antes de latão niquelado, para conexões de aço inox. Todos os pontos de rosca passíveis de substituição foram substituídos por sistema de duplo anilha, que foi responsável por acabar com o vazamento, Figura 3.27.

Durante montagem da conexão com projeto de geometria avançada, a anilha dianteira é pressionada contra o corpo da conexão e o tubo para criar a vedação primária, enquanto a anilha traseira articula para dentro para criar um forte cravamento no tubo. A geometria da anilha traseira permite melhor engenharia da ação de articulação-mandril, 
que transforma o movimento axial em ação de crimpagem radial no tubo, que opera contudo com Ponto Pivô uma baixa exigência de torque de montagem.
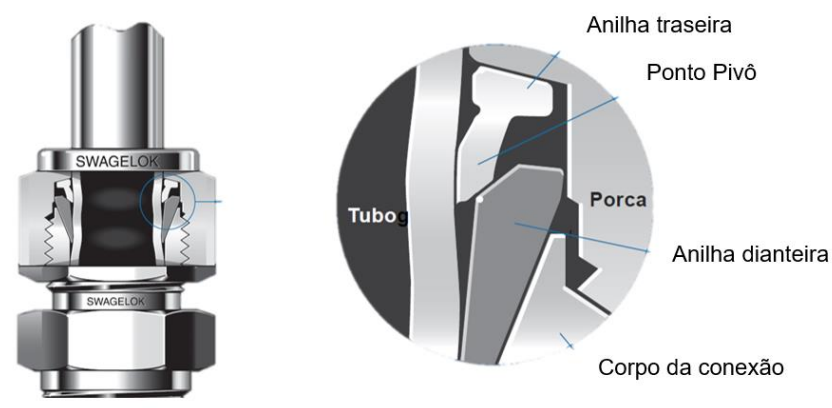

Figura 3.27. Sistema de dupla anilha para vedação.

\subsubsection{Instalação da linha de alta pressão}

O sistema de pressurização sofreu algumas mudanças em relação a primeira concepção, tanto no quesito segurança e vazamentos, quanto no quesito proteção térmica. O primeiro sistema de pressurização montado foi utilizado para desenvolvimento e calibração do ensaio a frio. Dessa forma não havia sido previsto alguns itens que servem de proteção térmica ao próprio sistema. Segue descrição resumida do atual sistema de pressurização de alta pressão instalado ao forno de Conformação Superplástica. Lista do material utilizado segue em anexo 10.6. A Figura 3.28 esquematiza a instalação do sistema de alta pressão.

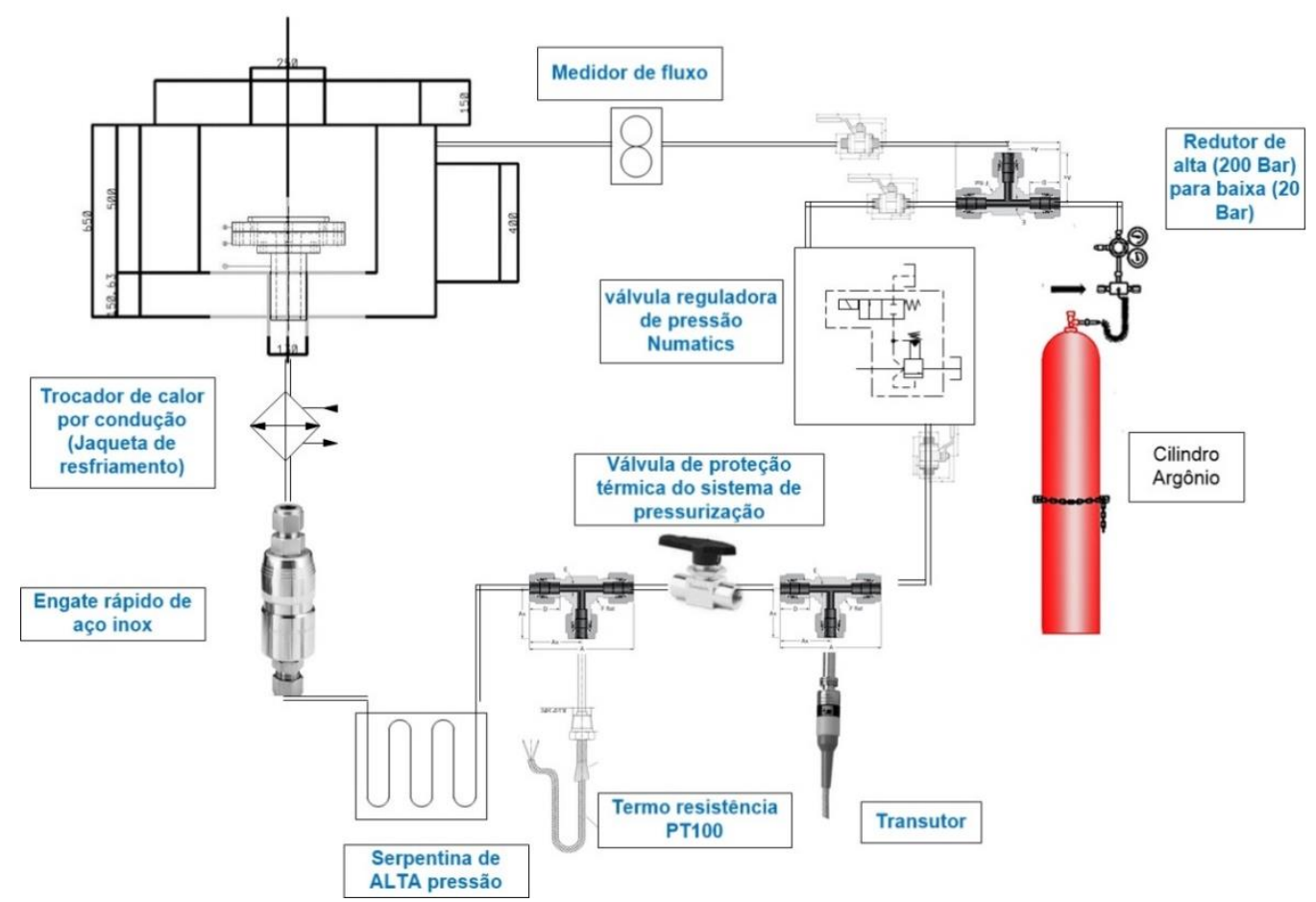

Figura 3.28. Esquemático da instalação do sistema de alta pressão. 


\subsubsection{Conexão com a ferramenta}

Utilizou-se um sistema de engate rápido como interface entre a linha de alta pressão e a ferramenta. A Figura 3.29 mostra a espiga da linha de pressurização. O motivo da escolha do engate rápido foi segurança, escolheu-se uma conexão que possibilitasse uma intervenção no sentido de proteger o sistema de pressurização, seria possível desconectar tal sistema com segurança de retenção do argônio quente.

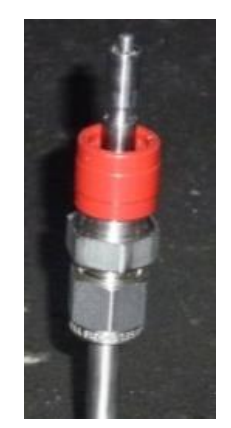

Figura 3.29. Espiga da conexão engate rápido.

Para conectar o corpo do engate rápido na ferramenta de Conformação Superplástica utilizou-se um selante "SWAK Anaerobic Pipe Thread Sealant" - Figura 3.30. Essa interface é considerada a de maior exigência térmica de toda a instrumentação.

\section{SWAKK}

Figura 3.30. Selante "SWAK Anaerobic Pipe Thread Sealant".

Detalhe do selante na saída da ferramenta de Conformação Superplástica pode ser observado na Figura 3.31.

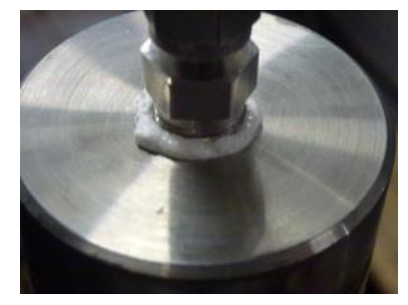

Figura 3.31. Detalhe da aplicação do selante. 


\subsubsection{Atmosfera positiva - evitar fragilização do Titânio pela fase $\alpha$}

No ferramental proposto de expansão fluidoestática, o fenômeno da cavitação não será analisado, caso o material de estudo fossem ligas de alumínio, por exemplo, seria preciso evitá-la com aplicação de contrapressão durante a conformação.

Entretanto a liga de Ti-6Al-4V estudada fragiliza quando conformada a quente em uma atmosfera com presença de oxigênio.

A criação de uma atmosfera positiva de argônio passa a ser de grande importância para evitar o aparecimento da fase $\alpha$, que fragiliza a liga em estudo.

Realiza-se a instrumentação - Figura 3.32 - que possibilite uma atmosfera positiva de 150mmca de $\mathrm{H}_{2} \mathrm{O}$; através da bomba de vácuo, realiza-se quatro purgas na atmosfera de controle do forno, em seguida, inicia-se o processo de pressurização do ambiente de dentro do forno com argônio até que atinja a pressão suficiente para que comece a escapar argônio de dentro do forno pela saída imersa em 150 mmca (visualização através de aborbulhamento de argônio). Um rotâmetro será utilizado para ter uma visualização da vazão durante o momento de pressurização, será importante para detectar problemas de vazamento.

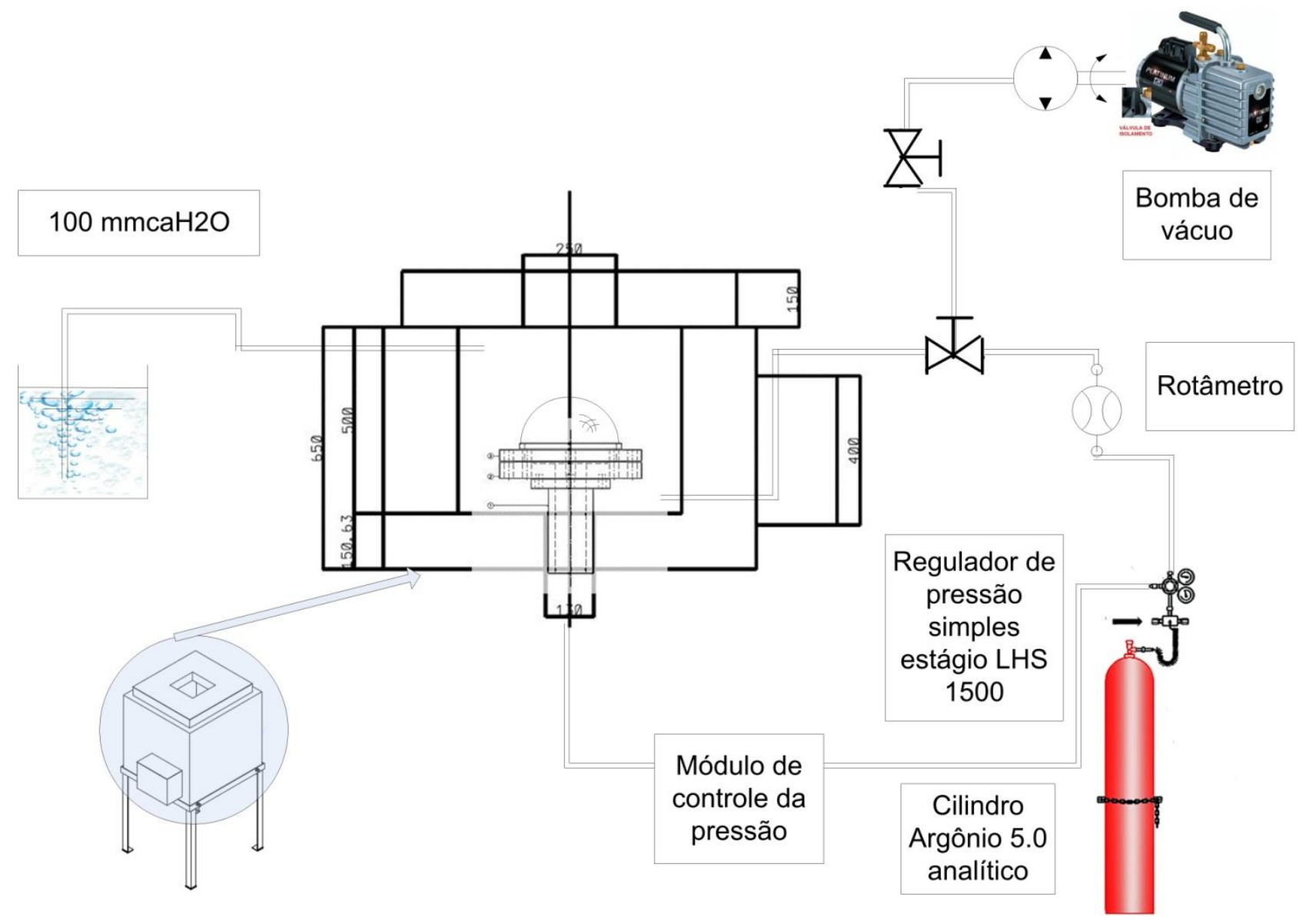

Figura 3.32. Instrumentação da atmosfera positiva de $150 \mathrm{mmca}$ de $\mathrm{H}_{2} \mathrm{O}$ 


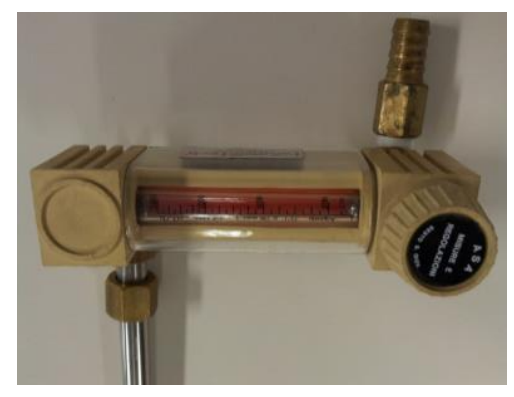

Figura 3.33. Rotâmetro, medidor de fluxo.

Um medidor de fluxo de área variável é o dispositivo escolhido para medir o fluxo de argônio que manterá a atmosfera positiva dentro do forno.

Para evitar a formação da camada alfa na liga de titânio $6 \mathrm{AL} 4 \mathrm{~V}$, é necessário primeiramente realizar quatro purgas ao forno. Para realizar a purga, instalou-se ao forno uma bomba de vácuo - Figura 3.34, que utiliza a mesma linha de derivação para criação da atmosfera positiva. Em um primeiro momento a chave de linha 1 estará fechada e a chave de linha 2 estará aberta, assim realiza-se a purga. Em um segundo momento, com a chave de linha 1 aberta e a chave de linha 2 fechada, através do controle de vazão da válvula manual no início da derivação de linha e do medido de fluxo - Figura 3.35, aplica-se ao forno a atmosfera positiva de argônio de proteção ao aparecimento da camada alfa.

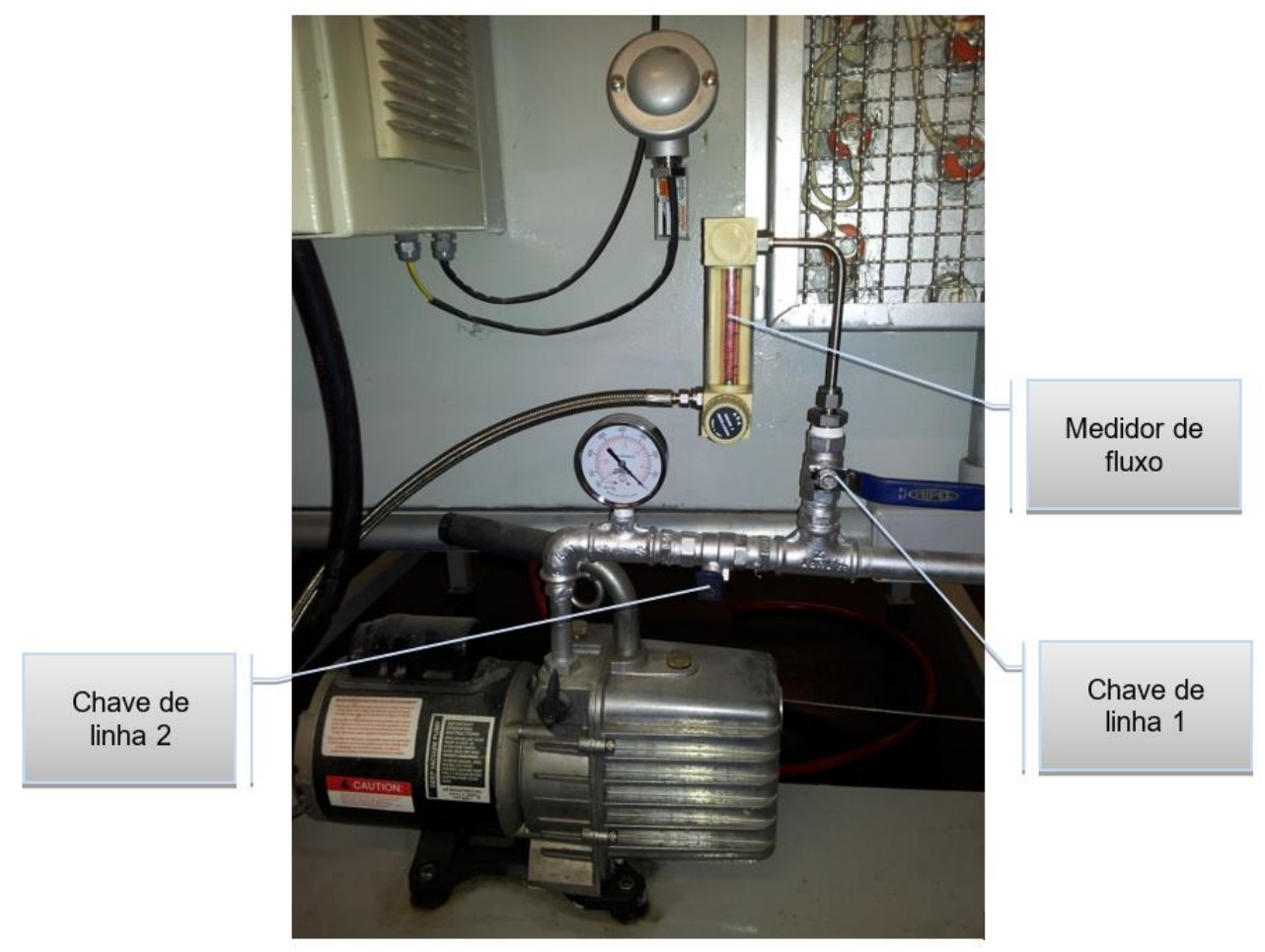

Figura 3.34. Bomba de vácuo, medidor de fluxo e chaves de linha, componentes do sistema de purga e atmosfera positiva 


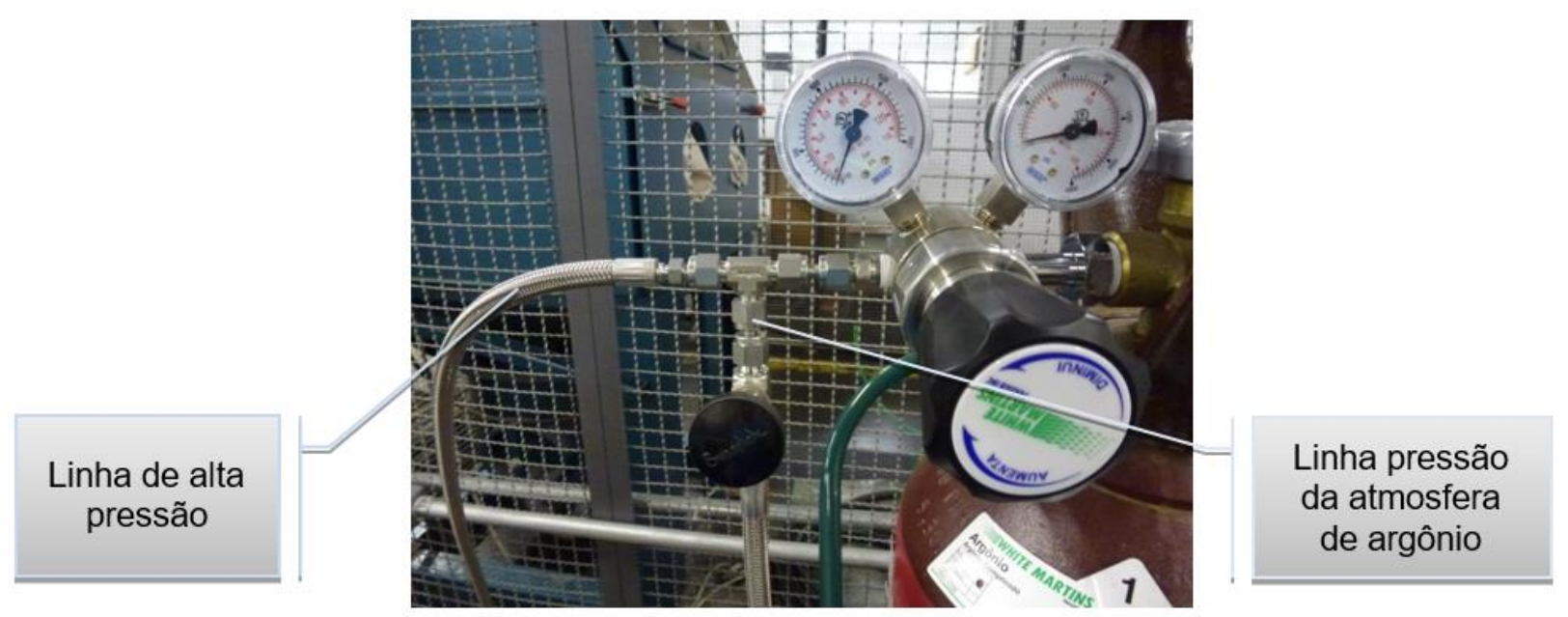

Figura 3.35. Derivação na linha de alta pressão, para linha de pressão responsável pela atmosfera positiva de argônio dentro do forno.

\subsubsection{Válvula reguladora de pressão}

Regulador de pressão eletrônico ASCO NUMATICS, 3 vias, corpo de latão, construção tipo pistão de ação direta, vedações em viton (modelo específico construído para aplicações em alta temperatura), conexão de G 1/4" DN6, sinal de comando de 0 a 10 volts, realimentação de saída de 0 a 10 volts, pressão de controle de 0 a $50 \mathrm{Bar}$, com sensor de saída.

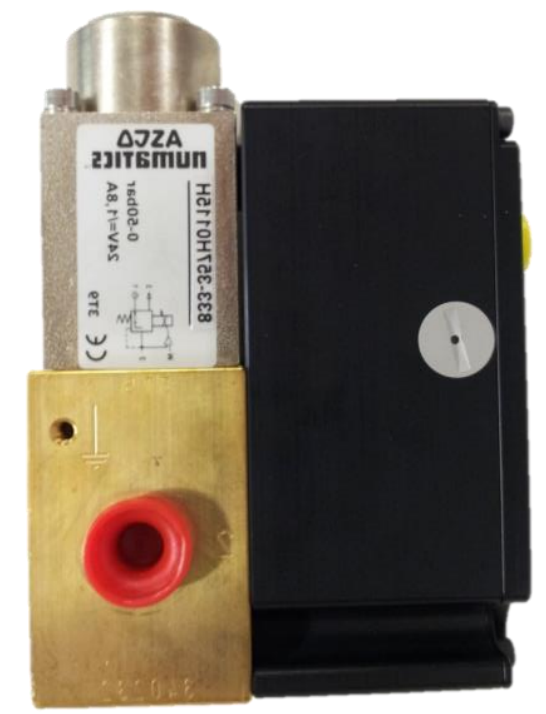

Figura 3.36. Válvula reguladora de pressão SENTRONICPLUS. 
A válvula reguladora de pressão eletrônica SentronicPlus - Figura 3.36, possui um software de aquisição de dados (DaS - Data Acquisition Software) que acessa a configuração dos parâmetros de controle da válvula através do canal RS232 do PC usado pelo sistema de aquisição de dados. Essa possibilidade de ajuste ótimo dos parâmetros de controle da válvula para cada aplicação específica foi um pré-requisito de projeto, e a necessidade foi estabelecida quando se observou limites de pressão de 0 a 30 Bar para um mesmo material com geometrias diferentes. Logo, seria necessário calibrar a válvula para o caso de pressurização da chapa de titânio de $1 \mathrm{~mm}$ e de $2 \mathrm{~mm}$ de espessura, isso varia os limites de pressão, que influenciam diretamente na calibração da válvula, ou seja, escolha dos parâmetros de controle.

Outra vantagem do acesso aos sinais internos é de que o sinal de comando, sinal de realimentação e parâmetros de controle podem ser vistos em tempo real, como também ajustados conforme a necessidade da aplicação.

A temperatura de trabalho da válvula, tanto do ambiente como do fluido, não deve superar $60^{\circ} \mathrm{C}$, fato esse que impossibilita a atuação da válvula imediatamente após a saída do ferramental do forno. Para contornar esse problema será utilizado um transdutor de pressão da HBM, produzido para trabalhos em alta temperatura, instalado logo após a jaqueta de resfriamento, esse transdutor será utilizado para gerar o sinal de pressão que será realimentado no controle da válvula.

\subsubsection{Transdutor de pressão HBM}

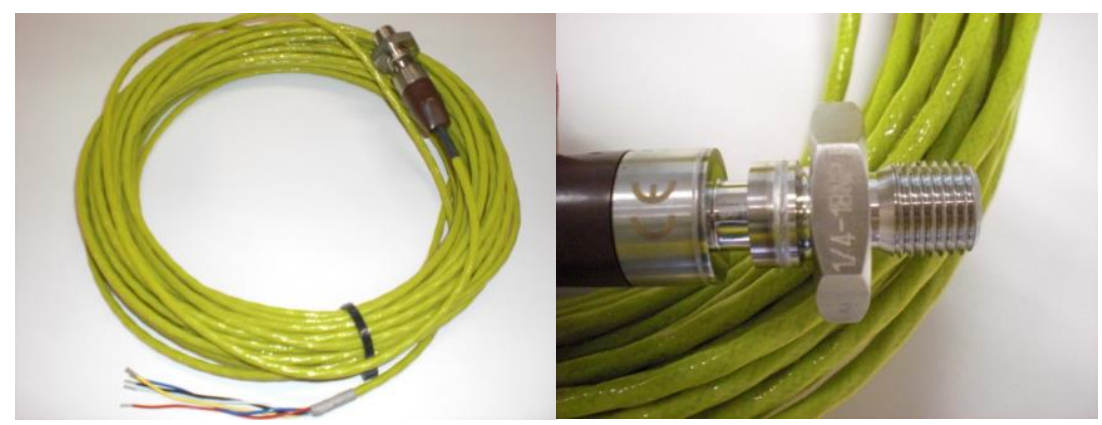

Figura 3.37. Transdutor de pressão HBM

O Transdutor de pressão apresentado na Figura 3.37, utilizado para aperfeiçoar o controle da pressão do processo. Foi dimensionado para uma faixa de pressão de 0 a 100 bar, que visa ser utilizado nos dois modos de operação do módulo de controle de pressão. Possui um sinal de saída de $2 \mathrm{mV} / \mathrm{V}$. 
É um modelo especial para trabalhos em alta temperatura, tem sua temperatura limite de trabalho em $140^{\circ} \mathrm{C}$, o que impõe uma restrição importante para o módulo do sistema de controle de temperatura, que é a temperatura de saída do argônio pressurizado dentro do ferramental que está dentro do forno, após sistema de resfriamento (jaqueta) e serpentina, ser inferior a temperatura de limite de trabalho do transdutor.

Observa-se na Figura 3.47 que a localização do transdutor de pressão está imediatamente antes da válvula de proteção do sistema, que tem sua temperatura aferida pela termoresistência logo ao lado.

\subsubsection{Regulador alta pressão de saída, simples estágio, LHS-1500.}

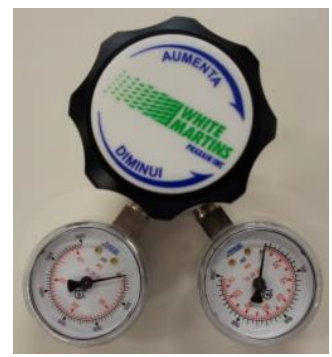

Figura 3.38. - Regulador de pressão, série de aplicação especial, alta pressão de saída, simples estágio, latão niquelado.

Os reguladores para Cilindro estão disponíveis em simples ou duplo estágio. Os reguladores de duplo estágio oferecem uma maior estabilidade de pressão de saída, o que evita os ajustes periódicos que devem ser feitos em um regulador de simples estágio à medida que a pressão do cilindro diminui. Como o modo manual de pressurização desse projeto, aquele que usará esse regulador, realiza-se através da pressurização de um pequeno volume de trabalho, não se justifica o investimento em um modelo de duplo estágio, dessa forma o regulador adquirido para o projeto é de simples estágio.

A seleção adequada do regulador de pressão é uma etapa crítica e de muita importância para a segurança e a eficiência dos sistemas operacionais. Segue abaixo, alguns itens críticos para a escolha apropriada de um regulador de Gases Especiais:

- Compatibilidade entre os materiais; os materiais utilizados para construir reguladores de pressão devem ser compatíveis com o gás a que se destinam. No caso do regulador desse projeto, foi necessário escolher um modelo de uma série especial para utilização com argônio, que utilize selo de viton.

- Faixa de pressão de entrada e saída; os reguladores devem ser especificados para suportar a pressão máxima do cilindro de gás, entenda-se para o projeto 200 bar, e a pressão de trabalho do equipamento/processo a que se aplica. 
- Toxicidade do gás utilizado; em função do gás utilizado, diversos acessórios devem ser incorporados ao regulador para manter a segurança da operação. Nesse projeto utilizar-se-á argônio, que é um gás não tóxico.

\subsubsection{Placa conversora digital analógica}

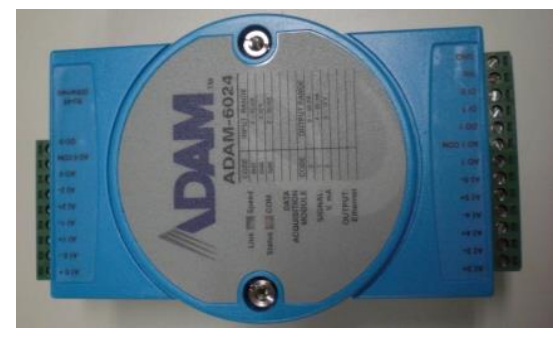

Figura 3.39. Placa Universal I/O Advantech 6024

Escolheu-se a empresa Advantech para a compra desse módulo de entrada e saída (I/O) universal - Figura 3.39 - pela necessidade de fornecer à válvula reguladora de pressão um sinal de 0-10 Volts que será enviado primeiramente para a placa $A D$, em forma de sinal digital, que sai do software de controle de pressão. Como também se verificou a existência por parte da empresa Spectris, representante da HBM no Brasil, a existência de drives de acionamento para a aplicação que se deseja realizar.

Por mais que não houvesse o driver exato para a placa A/D ADAM-6024, seria mais simples adaptar o drive de uma placa da mesma empresa.

\subsubsection{Pontos críticos da instrumentação do módulo de pressão}

A temperatura de trabalho dos componentes do módulo de controle da pressão é fator crítico na escolha dos componentes desse módulo, como também no desenvolvimento da estratégia de controle da pressão.

A válvula dimensionada para atuar no processo possui um transdutor próprio de saída, porém o posicionamento da válvula deverá ser tanto suficientemente afastado do processo de expansão que garanta que nem a temperatura do ambiente nem a temperatura do gás pressurizado atinjam a temperatura de $60^{\circ} \mathrm{C}$.

Dessa forma, será utilizado outro transdutor de pressão da HBM, que possui a característica de trabalho a altas temperaturas $-140^{\circ} \mathrm{C}-$, mais próximo do processo, que será capaz de eliminar a perda de carga de pressurização resultante da distância do atuador ao processo, aquisitando os dados de pressão e assim ajustar o set point de pressurização da válvula reguladora de pressão. 


\subsubsection{Módulo de controle da temperatura}

Através da utilização de 3 termopares - Figura 3.40 -, os sinais de temperatura são aquisitados e utilizados na malha de controle para possibilitar e garantir que a janela superplástica seja respeitada.

Os termopares 1 e 2 são utilizados para alimentar a malha de controle de temperatura, que através de dois PID cascateados realizará o aquecimento do forno da maneira mais rápida possível sem sobre sinal. $O$ termopar 3 é utilizado para garantir que 0 transdutor de pressão trabalhe abaixo da sua temperatura máxima de trabalho, $140^{\circ} \mathrm{C}$.

Esse módulo possui seu próprio sistema supervisório de temperatura, que mostrará durante todo o processo de ensaio as medidas dos 3 termopares, os sinais de ação dos controladores e os parâmetros utilizados no PIDs.

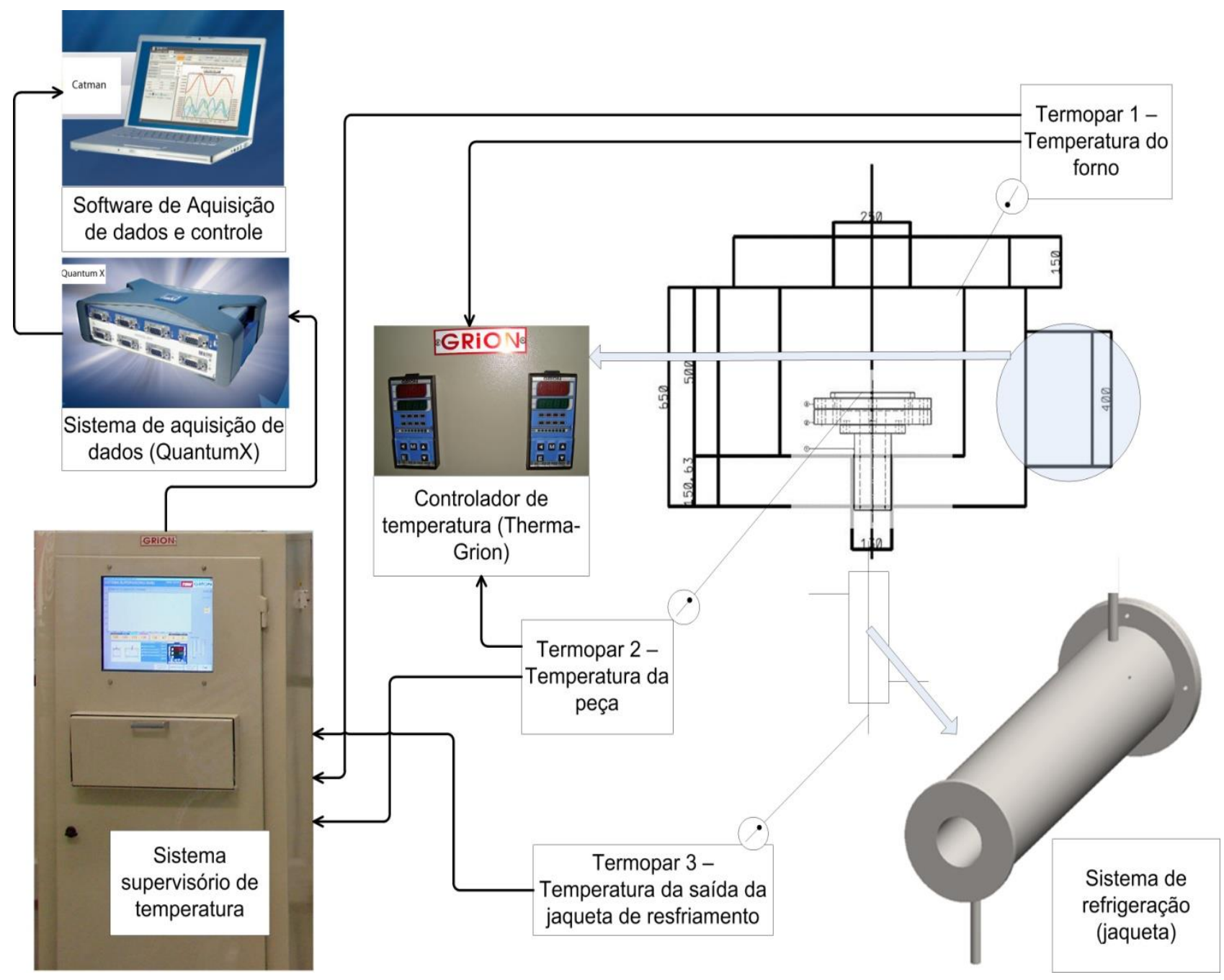

Figura 3.40. Instrumentação do módulo de controle da temperatura 


\subsubsection{Sistema supervisório de temperatura}

No sistema supervisório haverá a indicação de várias variáveis de interesse, destacam-se na Figura 3.41. O programa de aquecimento tem por padrão possuir dois patamares de temperatura, o primeiro objetiva manter a temperatura estável para que ocorra a soldagem por difusão, depois de um intervalo pré-determinado, no caso do primeiro ensaio $90 \mathrm{~min}$, a temperatura irá para o segundo patamar, a temperatura superplástica da liga.

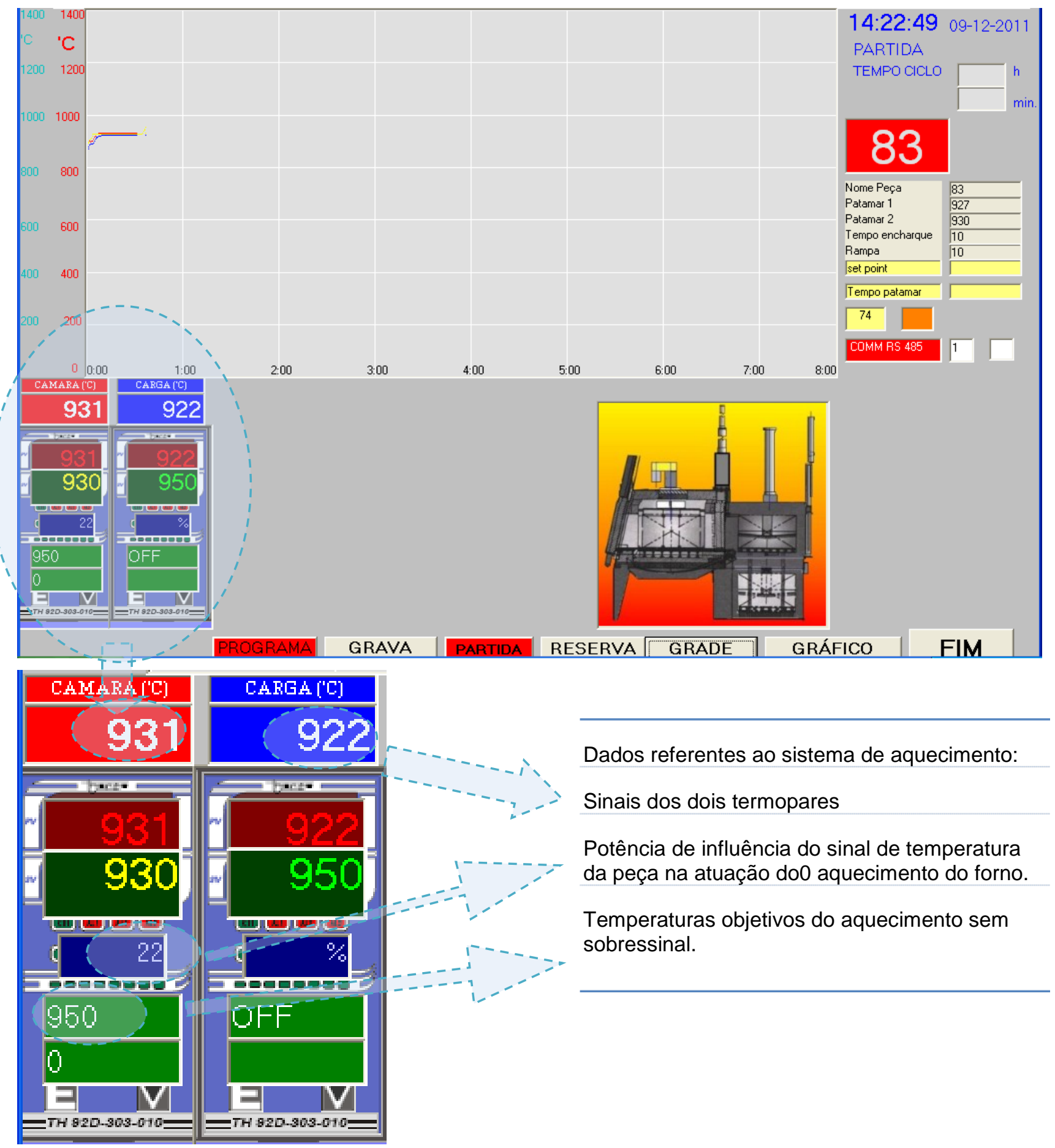

Figura 3.41. Dados de temperatura do sistema supervisório 


\subsubsection{Forno}
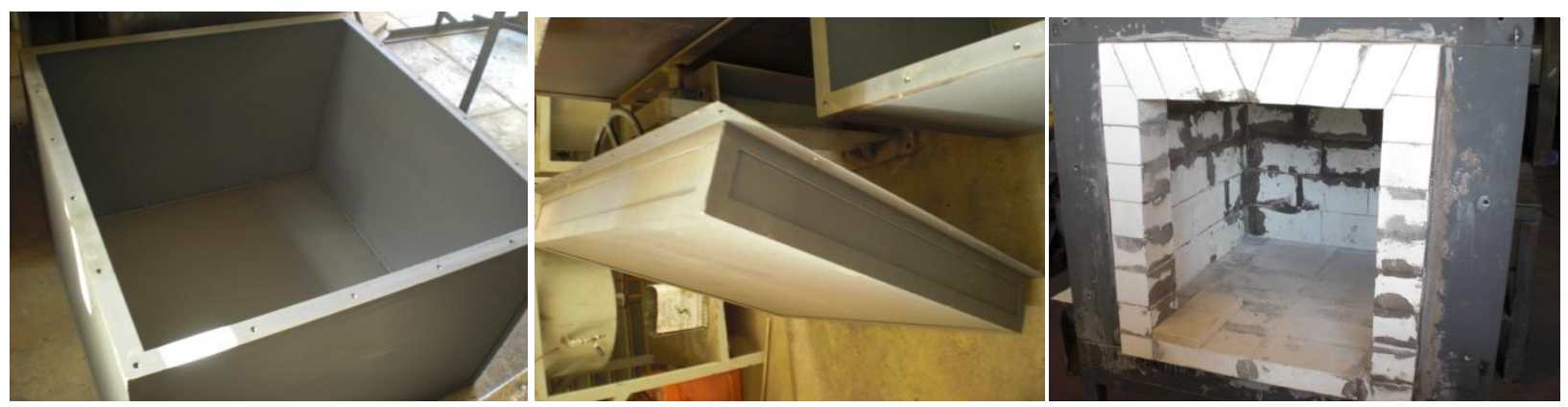

Figura 3.42. Imagens do processo de fabricação do forno GRION, dimensões úteis: $500 \mathrm{~mm}(\mathrm{~A}) \times 600 \mathrm{~mm}(\mathrm{~L}) \times 600 \mathrm{~mm}(\mathrm{P})$ e dimensões externas: $880 \mathrm{~mm}$ (A) $X 1000 \mathrm{~mm}(\mathrm{~L}) 1000 \mathrm{~mm}$

O forno destina-se ao aquecimento da chapa de titânio disposta horizontalmente na câmara aquecida, foi desenhado para que através de 2 acessos ao interior da câmera de aquecimento, o superior é um acesso por janela e o inferior um furo de diâmetro de 130 $\mathrm{mm}$, a fim de adaptar-se a instrumentação dos dois outros módulos de controle.

O acesso visual superior foi usado pelo módulo de controle de deformação, o sensor ARAMIS necessita de contato visual com a chapa de titânio para aquisitar o deslocamento de cada ponto da superfície de titânio.

O acesso inferior foi usado pelo módulo de controle da pressão, o sistema de pressurização aplica a pressão na matriz que está dentro da câmara de aquecimento através do acesso inferior. Seguem as especificações técnicas do forno:

- Temperatura de operação: $1200^{\circ} \mathrm{C}$

- Temperatura máxima: $1200^{\circ} \mathrm{C}$

- $20 \mathrm{KW}-380 \mathrm{~V}-220 \mathrm{~V}$ trifásico

- Patamar temporizado e rampa de aquecimento programável

- Aquecimento por resistências em liga KANTHAL dispostas nas paredes do forno

- Indicação digital e controle de temperatura do forno com Certificado de Aferição RBC/INMETRO

- Termopar tipo K para medição e controle com Certificado de Aferição pela RBC/INMETRO 
Dimensões úteis: $500 \mathrm{~mm}(\mathrm{~A}) \times 600 \mathrm{~mm}(\mathrm{~L}) \times 600 \mathrm{~mm}(\mathrm{P})$

Dimensões externas: $880 \mathrm{~mm}$ (A) X $1000 \mathrm{~mm}$ (L) $1000 \mathrm{~mm}$ (P)

O forno terá sua estrutura em chapas e perfilados de aço carbono. $\mathrm{Na}$ isolação do forno será aplicado isolamento térmico de fibra cerâmica - Figura 3.42, de modo que a temperatura exterior não ultrapasse $75^{\circ} \mathrm{C}$.

Todas as chapas e perfilados receberam fundo anticorrosivo e serão pintadas com tinta resistente à temperatura.

Foram utilizadas resistências elétricas de liga KANTHAL em formato de fio e dispostas em placas cerâmicas - Figura 3.43.

(a)

(b)

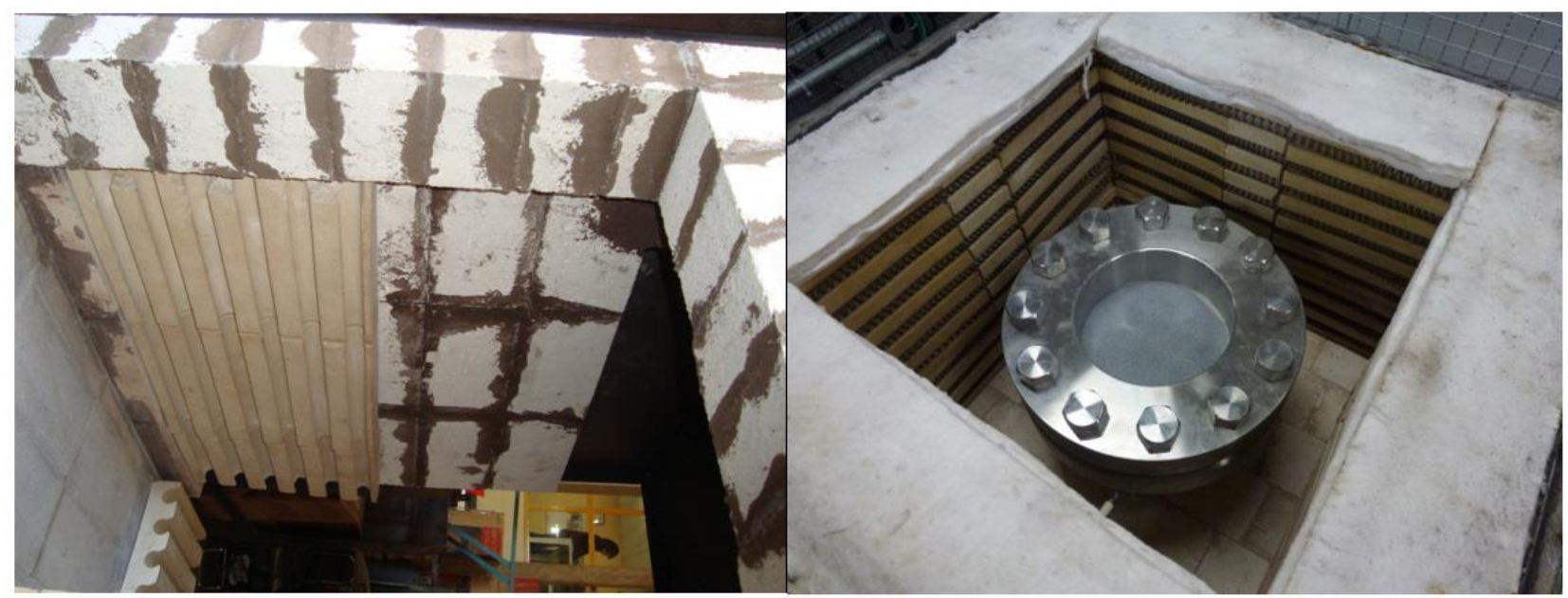

Figura 3.43. (a) Placas cerâmicas internas ao revestimento térmico por onde passaram as resistências de KANTHAL, (b) Imagem interna do forno com o ferramental de bulge posicionado para o ensaio, detalhe no isolamento térmico de fibra cerâmica e nas resistências de KANTHAL espiraladas.

O controlador eletrônico digital microprocessado permite a escolha da temperatura desejada. O sistema de controle é PID: proporcional, integral e derivativo, permitindo uma boa estabilização da temperatura. Contatores fazem a energização das resistências. Há um pirômetro de segurança para proteger o forno contra sobre temperatura.

O equipamento destina-se ao controle de processos de tratamento térmico. 200 programas de tratamento térmico podem ser instalados. 
Para a aplicação do primeiro ensaio de bulge, foi pré-definido que o programa recebesse de dados de entrada referentes a dois patamares, temperatura e tempo do patamar.

A CPU é um computador PC com interface USB dedicada ao sistema de aquisição de dados e com placa Ethernet para comunicação de rede interna, importante para integração dos sistemas de controle.

O controle da temperatura da câmara de aquecimento do forno contempla 2 malhas fechadas PID. Os 2 sinais de temperatura são de 2 termopares. O sinal de saída é de 4-20 mA ou pulso 3-32 VDC.

As 2 malhas de controle de temperatura são dependentes e estão em cascata, detalhes no capítulo sobre o controle, com isso há um controle cruzado, ou seja, pode-se controlar o grau de interferência (0-100\%) de uma malha sobre a outra. Busca-se dessa forma reduzir o tempo de encharcamento da matriz de conformação.

Um monitor LCD de 9" mostra os gráficos das curvas desejadas (setpoint), Temperatura $1 \mathrm{x}$ tempo e Temperatura $2 \mathrm{x}$ tempo.

\subsubsection{Jaqueta de resfriamento}

Para garantir que o transdutor de pressão trabalhe abaixo da sua temperatura limite de operação $\left(140^{\circ} \mathrm{C}\right)$, foi necessário adaptar ao forno, junto à saída da matriz de expansão fluidoestático biaxial, uma jaqueta de resfriamento - Figura 3.44.

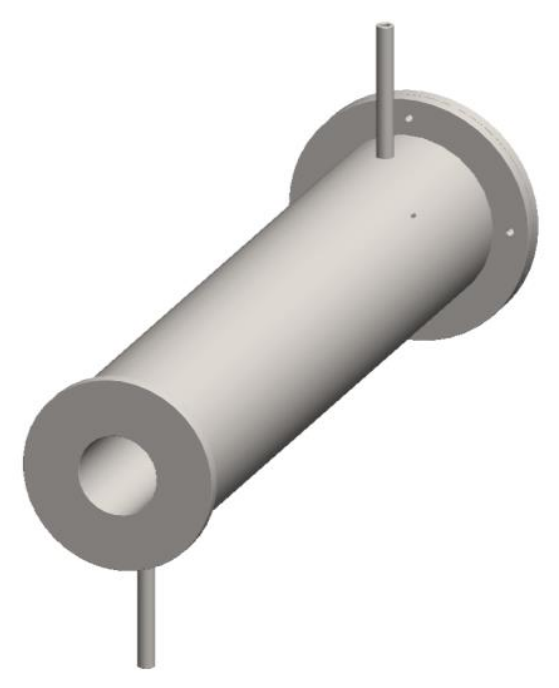

Figura 3.44. Jaqueta de resfriamento 
Trata-se de um sistema de jaqueta de água para resfriar o tubo inferior da matriz. Tubo responsável pela pressurização do processo de conformação. Feita em aço ASTM A36. Há uma entrada e uma saída de água $1 / 2$ " BSP. Usa-se conjuntamente com a jaqueta um sistema de vedação preme-gaxeta usinado em aço carbono cuja finalidade será vedar o eixo e permitir manter uma pressão positiva interna de $150 \mathrm{mmca}$ de argônio. Para essa vedação utiliza-se o esquema preme-gaxeta esquematizado em uma vista explodida na Figura 3.45 .
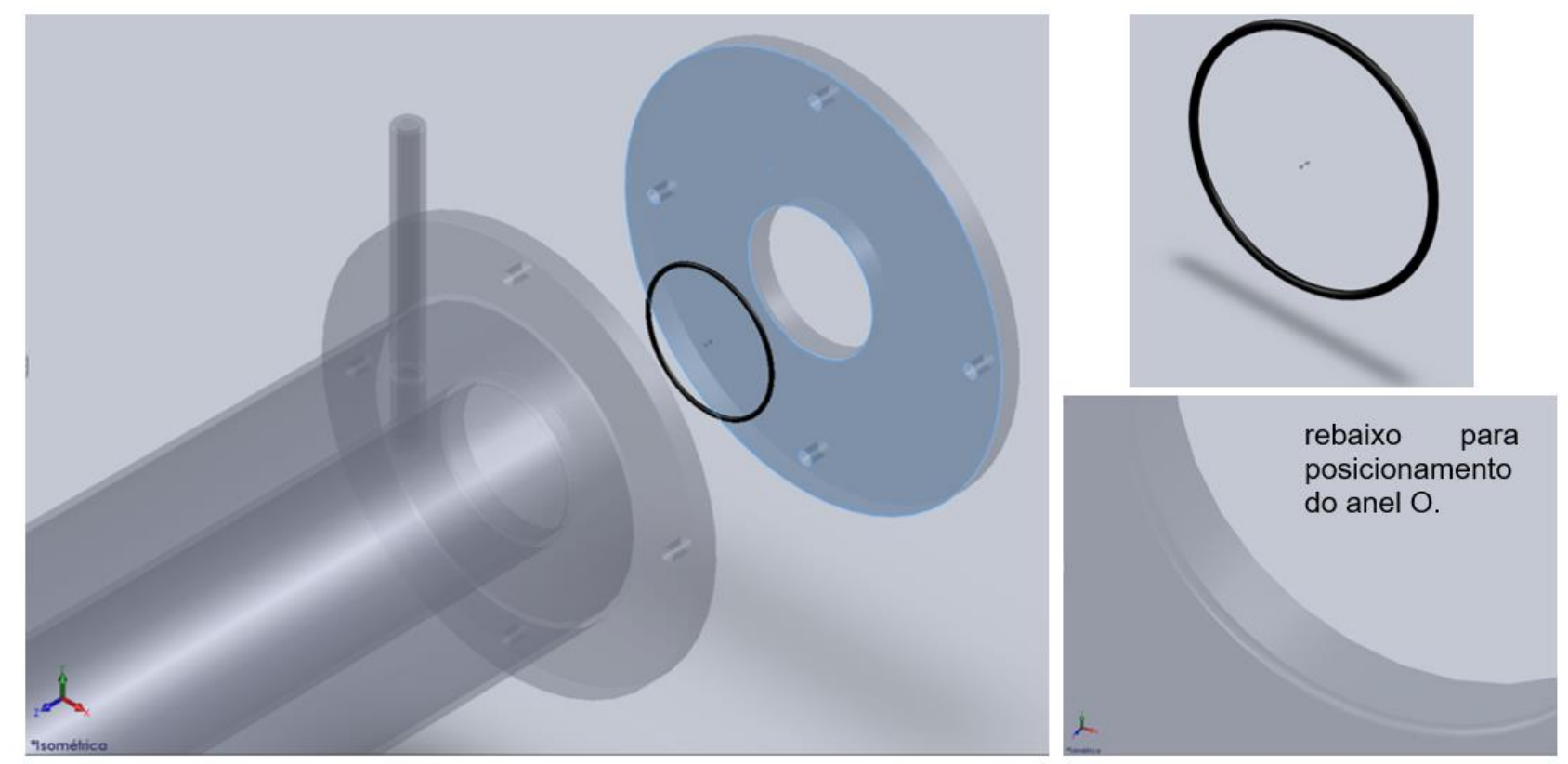

Figura 3.45. Visão explodida do esquema preme-gaxeta da jaqueta de resfriamento, como também o detalhe do rebaixo de posicionamento do anel $O$.

\subsubsection{Resfriamento com serpentina de aço inox}

Logo após a saída da ferramenta do forno, utilizou-se uma serpentina para contribuir com o sistema de resfriamento da linha de pressurização. O objetivo é que a temperatura do argônio durante todo o processo não ultrapasse $140^{\circ} \mathrm{C}$, que é a temperatura de trabalho do sistema de controle de pressão.

Segue na Figura 3.46 imagem da serpentina utilizada para contribuir ao resfriamento do argônio. 


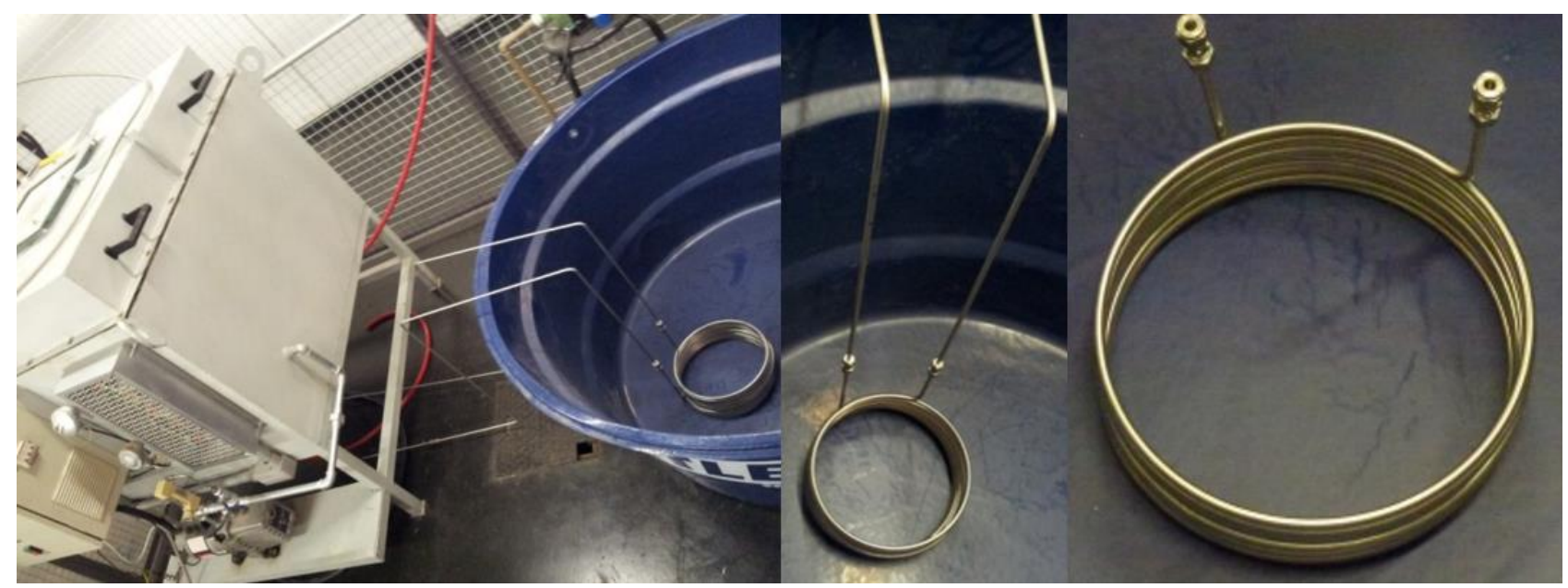

Figura 3.46. Serpentina utilizada para resfriamento do sistema de pressurização.

\subsubsection{Módulo de proteção térmica}

A primeira interface do sistema de medição e controle com o sistema de pressurização é o transdutor de pressão. Após o aquecimento do forno, deve-se verificar a temperatura do argônio na linha de pressão antes de abrir a válvula de acesso à ferramenta pelo sistema de pressurização.

Dessa forma colocou-se na linha de pressurização em série - Figura 3.47, no sentido válvula - ferramenta, o transdutor de pressão, uma válvula de segurança e uma termoresistência. Dessa forma é possível verificar a temperatura do processo mesmo que a válvula de segurança térmica esteja fechada.

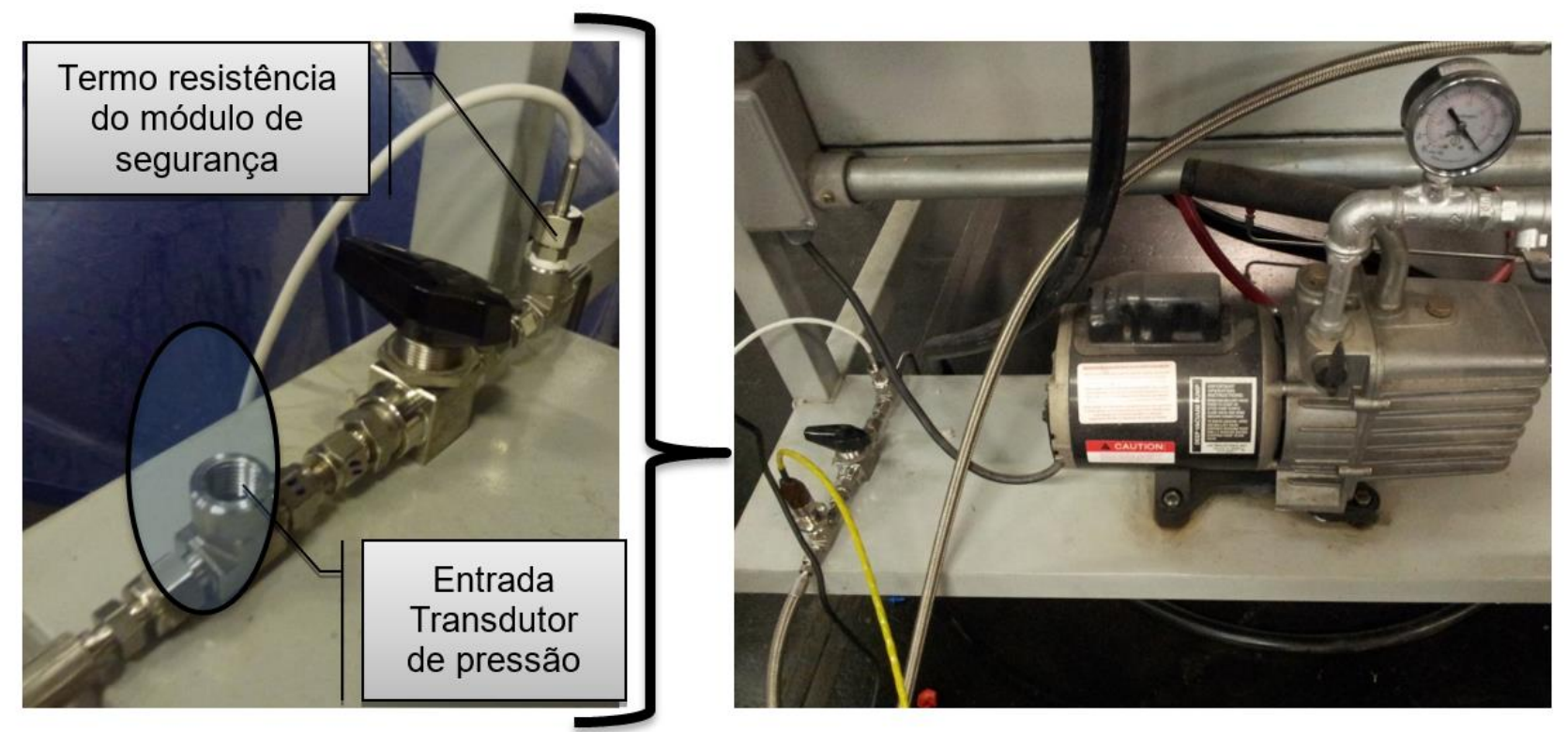

Figura 3.47. Localização do sensor do módulo de segurança térmico 


\subsubsection{Pontos críticos da instrumentação do módulo de temperatura}

Trabalhar com uma temperatura objetivo na média dos $1000^{\circ} \mathrm{C}$ representou dificuldades tanto no dimensionamento da ferramenta (matriz) de conformação, como também na instrumentação. A solução de resfriamento do tubo externo ao forno através da jaqueta de resfriamento foi imprescindível para possibilitar a medição da pressão junto ao processo de conformação, e não longe do processo junto a válvula. 


\subsection{Controle PID, design e tunning.}

\subsubsection{Resumo da abordagem de controle da tese}

O diagrama da Figura 3.48, evidencia a importância da modularização dos testes, pois para a análise dos parâmetros superplásticos, é necessário que as três malhas de controle estejam implementadas.

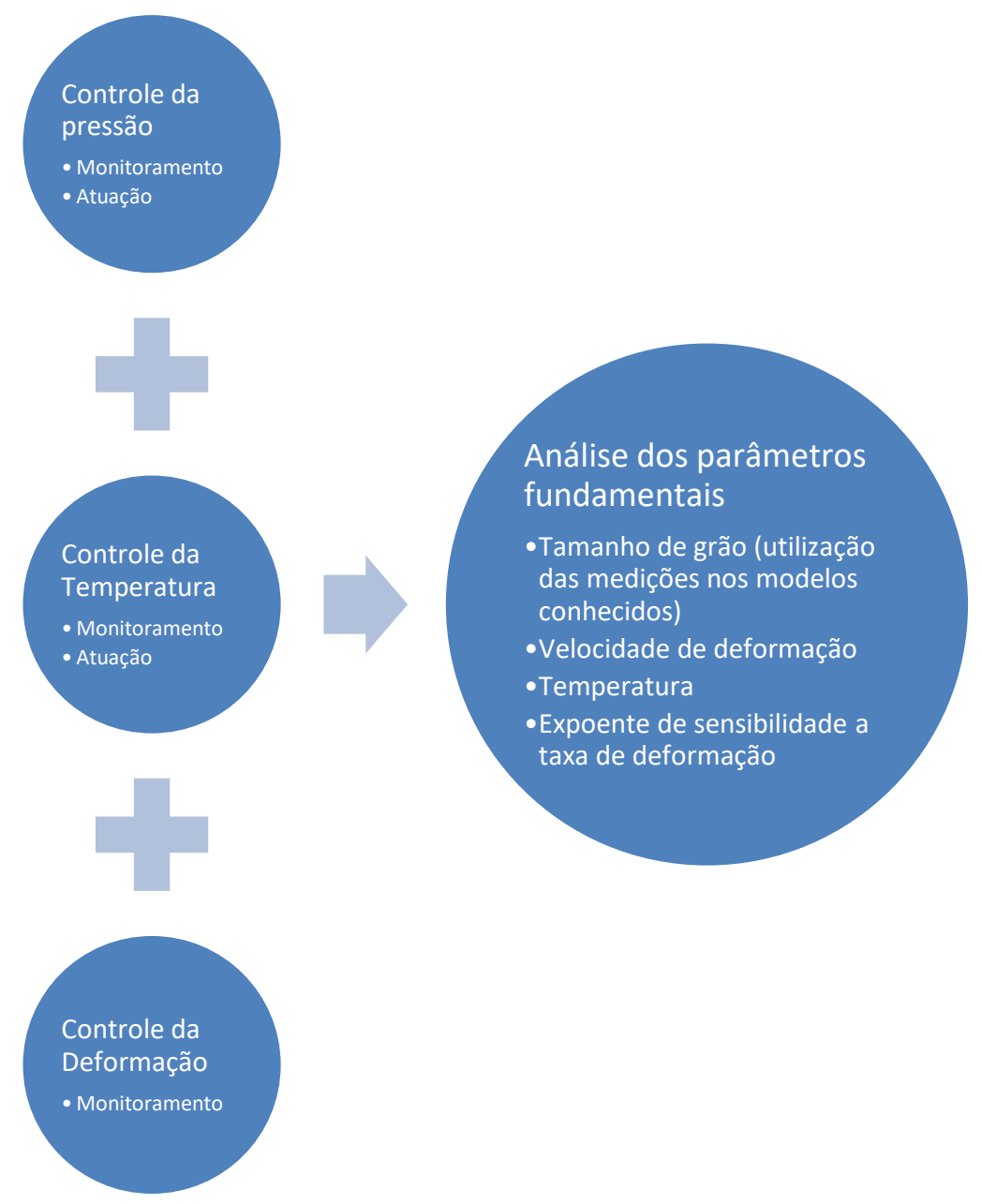

Figura 3.48 Esquemático dos parâmetros fundamentais superplásticos através da abordagem de controle modularizado.

Uma vez que o processo de conformação adotado no presente projeto será um dispositivo nos moldes de Termoconformacão/conformação por sopro (Blow Forming), a fim de aperfeiçoar os métodos de controle e monitoramento do processo, deve-se considerar durante a conformação os seguintes itens: 
- Temperatura ótima de conformação e de estabilidade da superplasticidade;

- Relacionada com a temperatura, está o melhor valor para a taxa de deformação;

- Espessura da chapa de titânio;

- Curva de pressão x tempo;

O objetivo básico da simulação do processo de conformação é permitir o controle trabalhar com um ótimo ciclo de pressão/tempo de conformação que produza uma taxa de deformação ótima, caracterizado pelo máximo índice de sensibilidade a taxa de deformação.

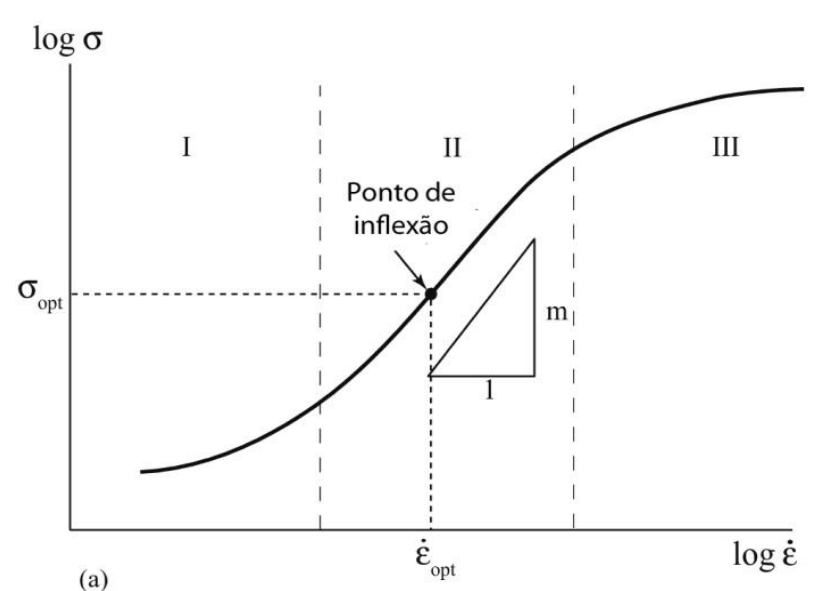

(a)

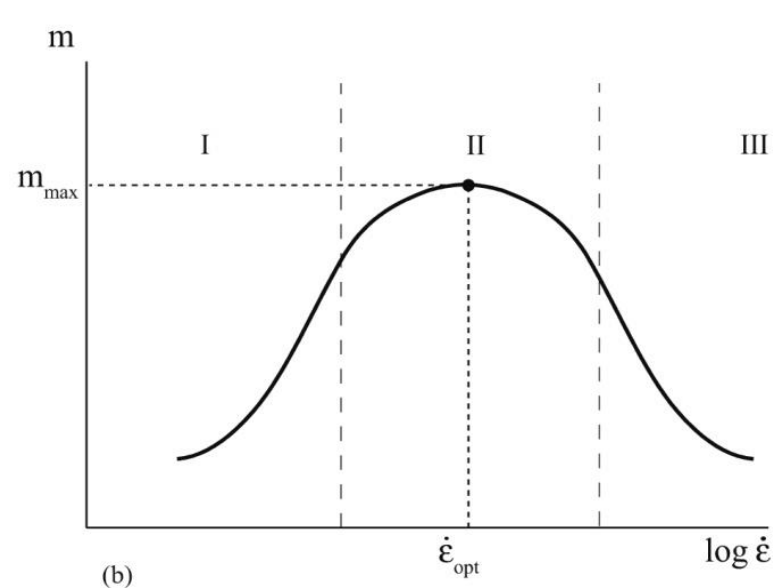

(b)

Figura 3.49. Caracterização da taxa de deformação ótima do processo; (a) ponto de inflexão do gráfico $\log \sigma \times \log \dot{\varepsilon}$; (b) ponto máximo do gráfico $m \times \log \dot{\varepsilon}$ (SNIPPE, 2010)

A abordagem por controles independentes foi implementada nessa tese. As variáveis são aquisitadas e tratadas por módulos individualizados, entretanto a inter-relação entre os parâmetros exige a integração de análise dos dados.

Do ponto de vista do controle, pela importância da estabilidade de cada módulo, foi pensado de caráter modular e independente a sua implementação. Pela complexidade de evolução conjunta dos módulos, a abordagem de integração, testes e calibração mostrouse necessária para validar métodos de medição, até então, ainda não há consenso no campo da Superplasticidade.

A Figura 3.50 resume a abordagem de controle aplicada no desenvolvimento do ensaio de expansão fluidoestática biaxial superplástica controlado da tese, são 3 malhas 
independentes, controle de pressão, deformação e temperatura, com um sistema de aquisição comum.

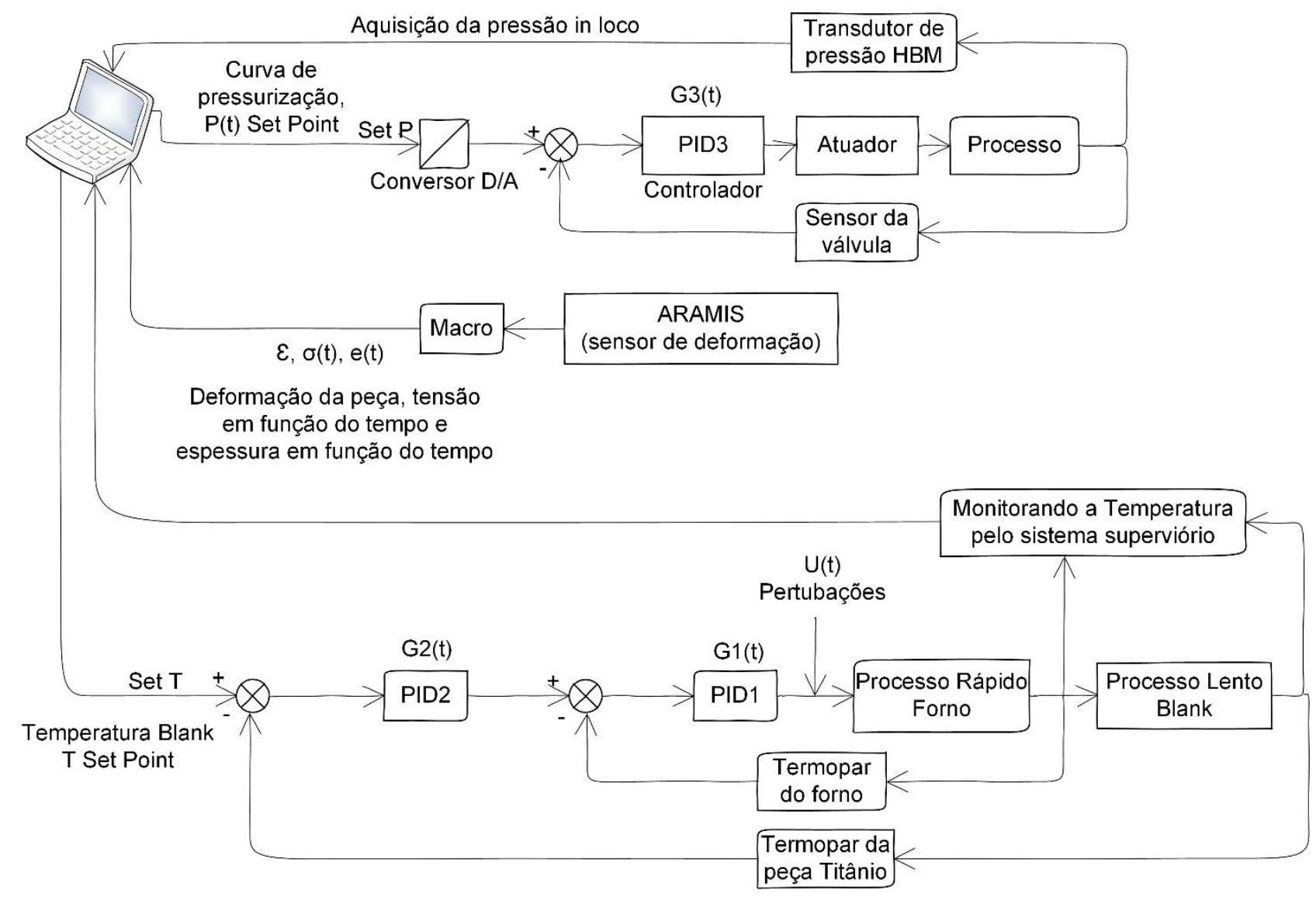

Figura 3.50. Diagrama de bloco dos módulos de controle implementados.

O design da malha de controle de pressão é detalhado nessa seção, entretanto incialmente destaca-se a malha de controle térmico, a proposta de controle de temperatura utilizando dois PIDs em cascata. Com essa abordagem consegue-se reduzir o tempo de atuação do sistema de aquecimento até que seja estabilizada a temperatura, levando para o menor valor possível o atraso térmico de aquecimento devido ao tempo de encharcamento da peça a ser conformada (Inércia térmica da matriz). Há dois processos em paralelo, um de resposta rápida, que consiste no aquecimento do forno e na medição de temperatura através do termopar do forno, e outro processo de resposta lenta, que consiste no aquecimento da peça conformada e na medição da temperatura real da peça através de outro termopar em contato com a chapa. 


\subsubsection{Controle PID - ação proporcional, integral e derivativa}

Para alinhar a nomenclatura e ilustrar os termos usados na argumentação da descrição do sistema de controle, segue Figura 3.51 com diagrama de bloco de um sistema de feedback simples.

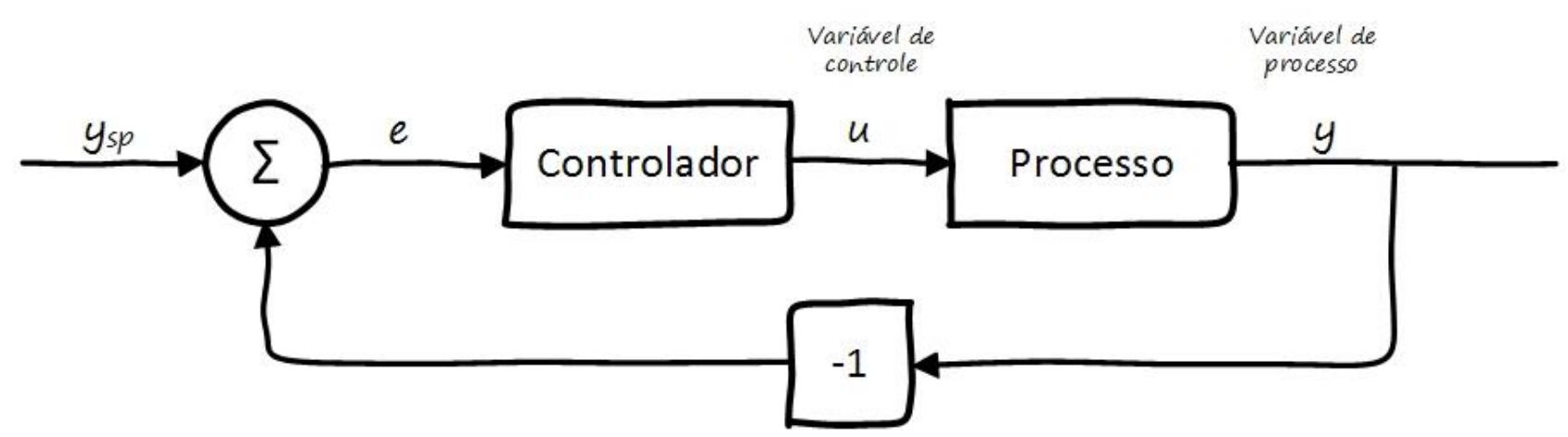

Figura 3.51. Diagrama de bloco de um sistema de feedback simples.

O sistema genérico da Figura 3.51 tem dois componentes principais, o processo e controlador, representados por blocos ligados com setas denotando a relação de causa entre as entradas e as saídas. O processo tem uma entrada, no caso do sistema pneumático, a variável de controle manipulada $(u)$ é a pressão. A saída é chamada de variável de processo $(y)$, cuja medida é responsabilidade do sensor. Define-se o set point (SP) como o valor desejável da variável de processo, a diferença entre o set point e a variável de processo é a definição de erro do controle (e). Em linhas gerais, o sistema de controle busca manter a variável de processo próximo do valor desejado, diminui assim ao máximo o erro.

Sobre o controlador, há diversas técnicas para ajustá-lo e diversas metodologias para escolher o melhor tipo. Outro termo importante é o tuning, que se define como o procedimento de descoberta dos parâmetros do controle, para realizar o tuning há duas principais maneiras, uma delas é escolher alguns parâmetros do controlador, observar o feedback e modificar os parâmetros até o comportamento desejado do sistema, outra maneira é desenvolver um modelo matemático que descreva o comportamento do processo, para então ser capaz de determinar os parâmetros do controlador através das técnica de designe do controle.

Mesmo tendo sido escolhido um modelo matemático no tópico 2.5, na tese os parâmetros do controle foram estabelecidos através da análise da resposta em 
degrau do sistema, detalhado nesse tópico. Tal abordagem foi utilizada devido a disponibilidade de toda a instrumentação para realização dos ensaios.

O controlador detecta o sinal do erro atuante $\left(e=y_{s p}-y\right)$, o qual é normalmente de muito baixa potência, e o amplifica, tal sinal alimenta o atuador, que no referido caso é uma válvula reguladora proporcional-integral-derivativa.

Pode-se classificar os controladores industriais de acordo com as suas ações de controle (OGATA, 2003)

1. Controladores ON-OFF:

2. Controladores proporcionais;

3. Controladores Integrais;

4. Controladores proporcional-integrais;

5. Controladores proporcional-derivativos;

6. Controladores proporcional-integral-derivativo (PID);

O feedback ON-OFF pode ser descrito conforme condições matemáticas abaixo:

$$
u(t)=\left\{\begin{array}{l}
u_{\max } \text { if } e>0 \\
u_{\min } \text { if } e<0
\end{array}\right.
$$

Esse tipo de controle implica em que toda ação do controlador aplica a máxima ação corretiva, observa-se a variável de controle na figura abaixo:

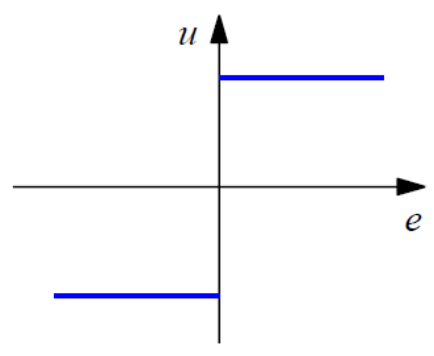

(a) On-off control

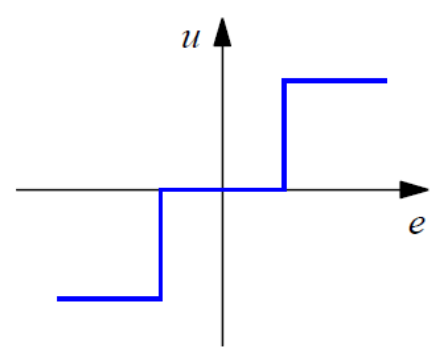

(b) Dead zone

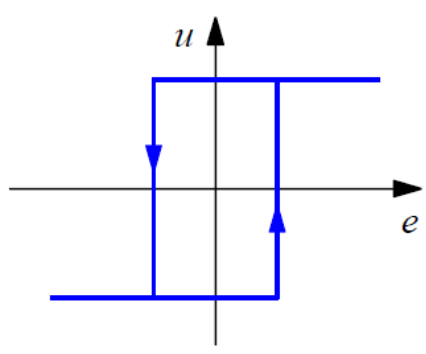

(c) Hysteresis

Figura 3.52. Entrada e saída de controladores ON-OFF. Cada figura mostra o input no eixo horizontal e a saída no eixo vertical. O ON-OFF ideal é mostrado na figura (a), com algumas modificações para zona morta (Dead zone) em (b) e com histerese em (c). (ASTROM, 1995)

Essa reação do sistema de controle para qualquer valor de erro pode resultar em um sistema oscilatório, para evitar esse efeito, adiciona-se ao controlador uma característica 
de proporcionalidade ao erro $\left(K_{p} \mathrm{e}\right)$ - Controlador Proporcional, conforme observa-se na formulação abaixo:

$$
u(t)=\left\{\begin{array}{c}
u_{\max } \text { if } e \geq e_{\max } \\
\boldsymbol{K}_{\boldsymbol{p}} \mathbf{e} \text { if } e_{\min }<e<e_{\max } \\
u_{\min } \text { if } e \leq e_{\min }
\end{array}\right.
$$

O intervalo $\left(e_{\min }, e_{\max }\right)$ é chamado de banda proporcional, e $\mathrm{K}_{\mathrm{p}}$ é chamado de ganho. Ainda que o controlador proporcional tenha uma larga vantagem em comparação ao ON-OFF, ele apresenta a desvantagem de frequentemente a variável de processo desviar do seu valor de referência, conforme Figura 3.53.
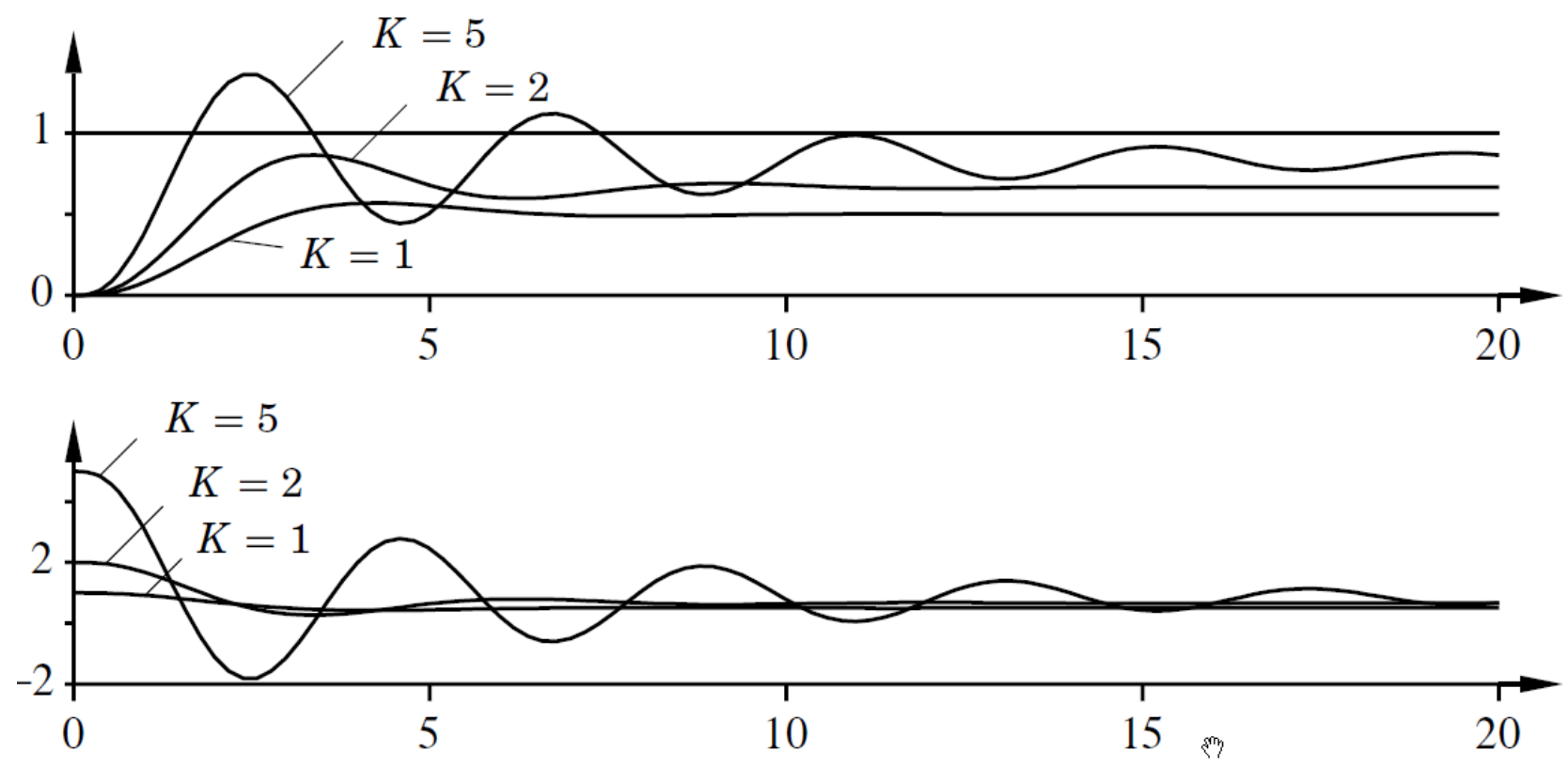

Figura 3.53. Simulação de um sistema de controle proporcional com realimentação. O diagrama superior mostra o set point $\left(y_{s p}=1\right)$ e a saída do processo $(y)$ para diferentes valores de ganho proporcional $(\mathrm{K}) \mathrm{O}$ diagrama inferior mostra a variável de controle (u) para diferentes valores de ganho. (ASTROM, 1995)

É importante destacar que com o aumento do ganho $\mathrm{K}$ do controlador proporcional, elimina-se a influência do distúrbio e maximiza-se, indesejavelmente, o erro de leitura, além de não retirar o erro em regime permanente. 
Em uma primeira tentativa de aplicar um controlador proporcional, observou-se a presença de um grande offset com aumento do ganho do controlador, como também uma baixa oscilação. Segue Figura 3.54 que exemplifica a limitação de um controlador somente proporcional, o ensaio de calibração representado pela Figura 3.54 objetivava calibrar a expansão do bulge teste da liga de Ti6Al4V.

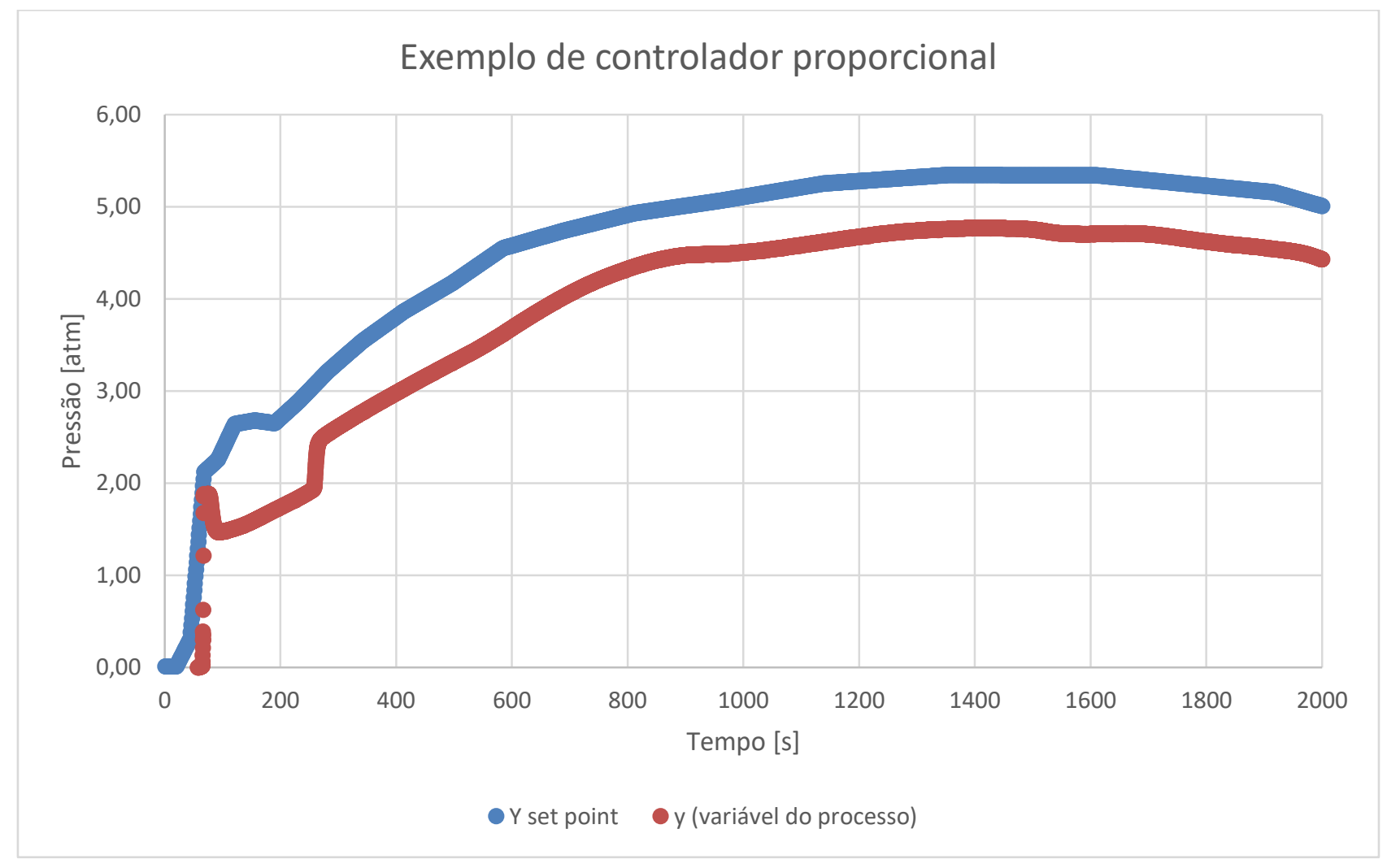

Figura 3.54. Presença de offset e pouca oscilação para controlado proporcional com aumento do ganho.

Para atingir um nível de controle que atenda ao requisito de buscar erro em regime estacionário igual a zero, $(\mathrm{e}=0)$, utiliza-se a ação do controle proporcional à integral do erro - controle integral, conforme observa-se na formulação abaixo:

$$
u(t)=\frac{1}{T_{i}} \int_{0}^{t} e(\tau) d \tau
$$

Define-se o ganho integral conforme igualdade:

$$
K_{i}=\frac{1}{T_{i}}
$$


Segue Figura 3.55 com a simulação de um sistema de controle proporcional-integral com realimentação para diferentes valores de tempo de integração.
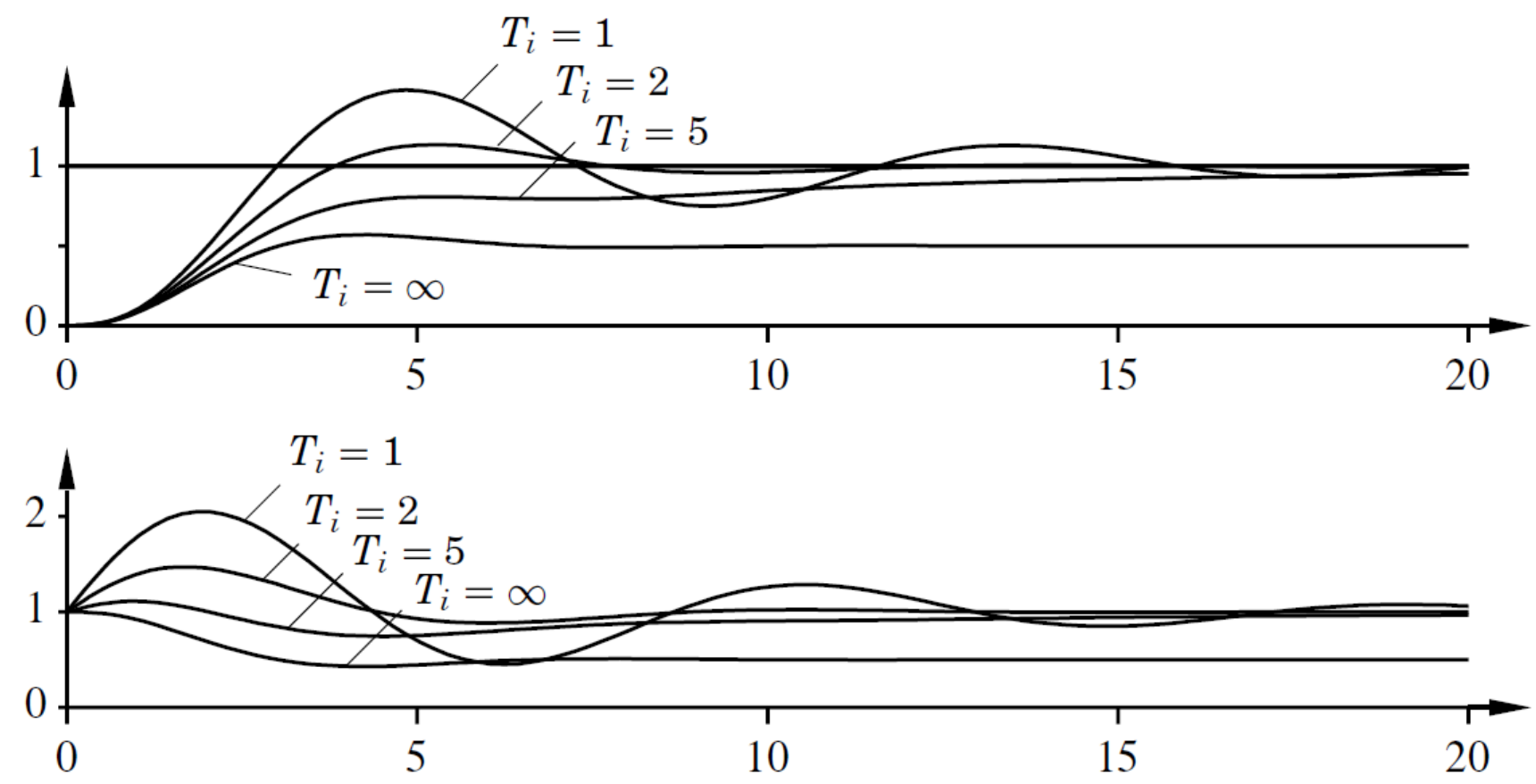

Figura 3.55. Simulação de um sistema de controle proporcional-integral com realimentação. Considerando o ganho do controlador igual a 1, o diagrama superior mostra o set point $\left(\mathrm{y}_{\mathrm{sp}}=1\right)$ e a saída do processo $(\mathrm{y})$ para diferentes valores de tempo de integração $\left(\mathrm{T}_{\mathrm{i}}\right)$. O diagrama inferior mostra a variável de controle $(\mathrm{u})$ para diferentes valores de tempo de integração $\left(T_{i}\right)$. (ASTROM, 1995)

O problema é que nem sempre o regime estacionário ocorre, como nos casos em que o sistema pode estar oscilatório, nesse cenário, um outro fator deve ser adicionado ao controle para aumentar a eficiência, o referido fator carrega habilidade preditiva, é chamado de parcela derivativa (controle derivativo), em resumo esse fator é a extrapolação linear do erro, e tem a função de aperfeiçoar a estabilidade do sistema em malha fechada.

$$
e\left(t+T_{d}\right) \approx e(t)+\boldsymbol{T}_{\boldsymbol{d}} \frac{\boldsymbol{d e}(\boldsymbol{t})}{\boldsymbol{d} \boldsymbol{t}}
$$



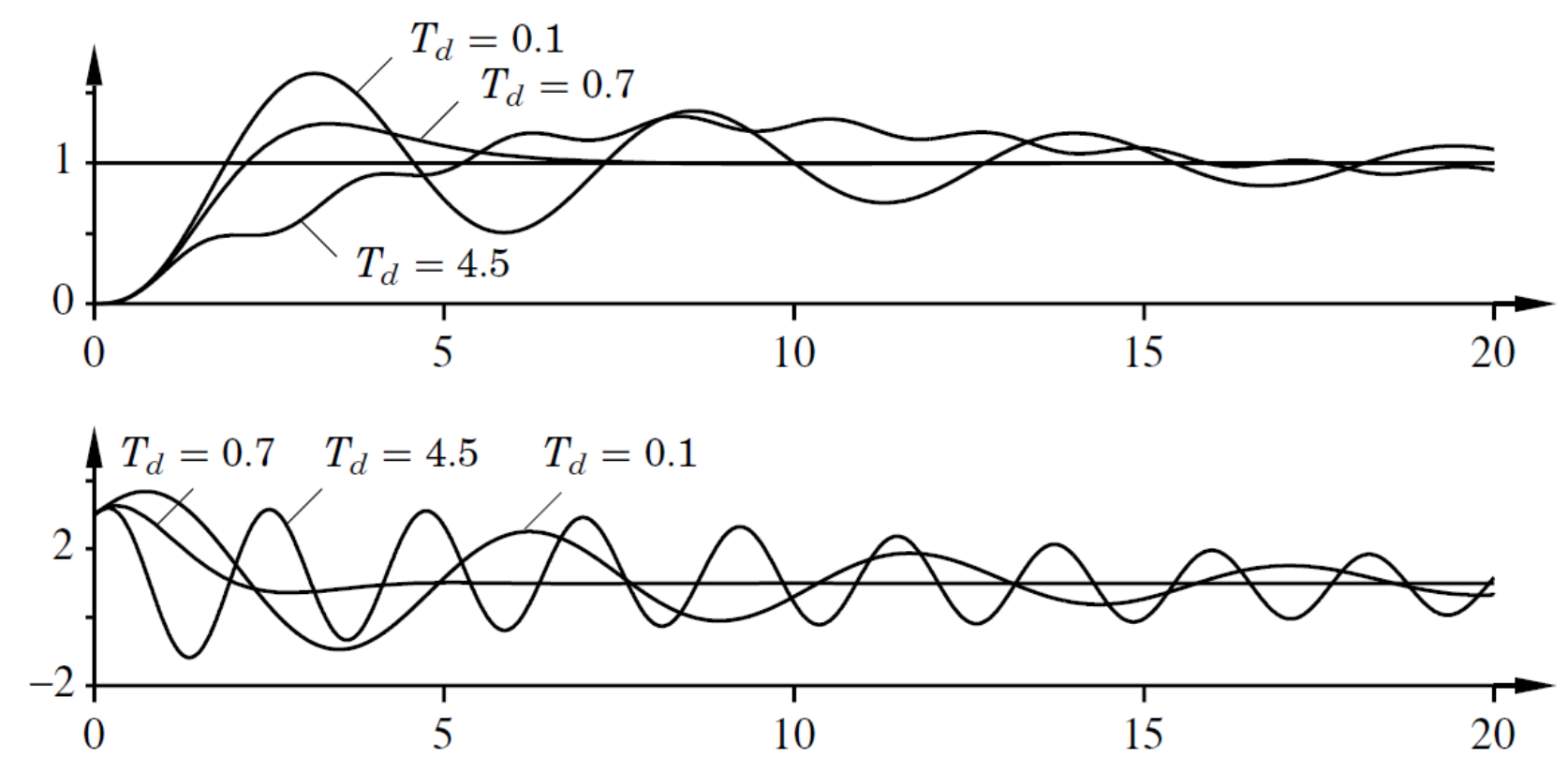

Figura 3.56. Simulação de um sistema de controle proporcional-integral-derivativo com realimentação. Considerando o ganho $(K)$ do controlador igual a 3 o e o tempo de integração $\left(\mathrm{t}_{\mathrm{i}}\right)$ igual 2, o diagrama superior mostra o set point $\left(y_{s p}=1\right)$ e a saída do processo $(y)$ para diferentes valores de tempo derivativo $\left(T_{d}\right)$. O diagrama inferior mostra a variável de controle $(u)$ para diferentes valores de tempo derivativo (Td). (ÅSTRÖM, 1995)

Pela necessidade do controle da taxa de deformação com o menor erro possível durante a conformação, para que seja possível realizar a conformação em torno da taxa de deformação ótima, inicialmente utilizou-se um controlador proporcional-integral-derivativo (PID) na análise, dessa forma foi possível analisar a combinação das ações de controle proporcional, de controle integral, e de controle derivativo.

$O$ algoritmo do PID é descrito:

$$
u(t)=K\left(e(t)+\frac{1}{T_{i}} \int_{0}^{t} e(\tau) d \tau+T_{d} \frac{d e(t)}{d t}\right)
$$


A variável de controle manipulada $(u(t))$ é resultado da soma de 3 termos, o termo $\mathrm{P}\left(\boldsymbol{K}_{p} \mathbf{e}(\mathbf{t})\right)$, que é proporcional ao erro, o termo I $\left(\boldsymbol{K}_{i} \int_{0}^{t} \boldsymbol{e}(\boldsymbol{\tau}) \boldsymbol{d} \tau\right)$, que é proporcional à integral do erro, e o termo $\mathrm{D}\left(\boldsymbol{T}_{d} \frac{d e(t)}{d t}\right)$, que é proporcional ao derivativo do erro.

Em termos de função de transferência tem-se o controlador PID representado pela equação (102) e a função em malha fechada pela equação (103) ambas representadas na Figura 3.57.

$$
\frac{U(S)}{E(S)}=K(s)=K_{p}\left(1+\frac{1}{T_{i} S}+T_{d} s\right)
$$

$$
\frac{C(S)}{R(S)}=\frac{K(s) G(s)}{1+K(s) G(s)}
$$

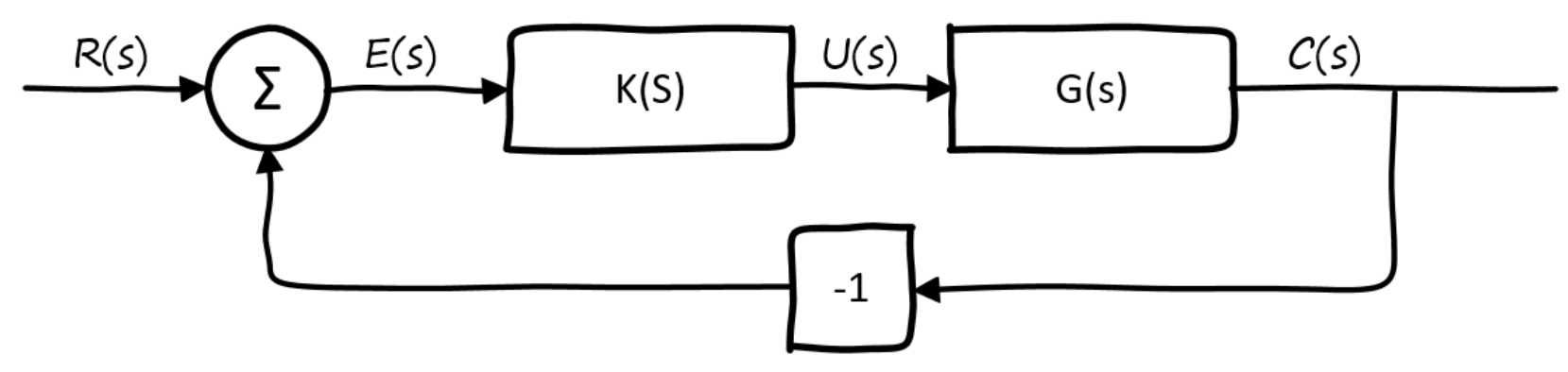

Figura 3.57. Diagrama de blocos do sistema de controle de pressurização da prensa de Conformação Superplástica desenvolvida na tese.

A ação de um controlador PID, em função do tempo, pode ser descrita da seguinte maneira, o passado é representado pela integral do erro, o presente é representado pelo termo proporcional direto ao erro, já o futuro é proporcional ao termo derivativo, extrapolação linear do erro. (ÅSTRÖM, 2008) 


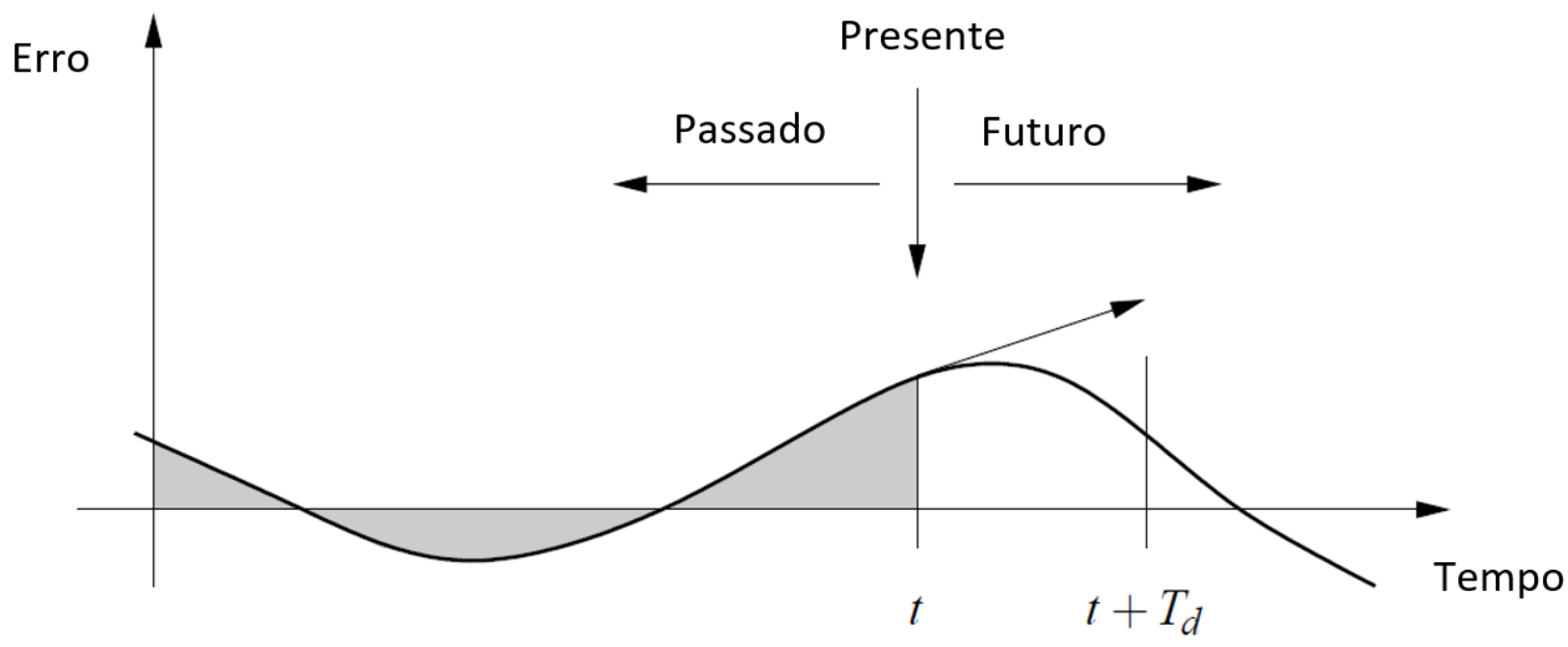

Figura 3.58. Ação do controlador PID. No tempo t, o termo proporcional depende do valor instantâneo do erro. A porção integral do feedback baseia-se na integral do erro até o tempo $t$ (área sombreada). $O$ termo derivativo estima o crescimento ou o decaimento do erro ao longo do tempo, através da taxa de variação do erro. (ÅSTRÖM, 2008) 


\subsubsection{Ajuste de parâmetros de controladores PID (Tuning- Step response method)}

A dinâmica do processo pode ser determinada pela resposta do processo a entradas de sinais típicos de teste, como degrau, rampa, parábola de aceleração, impulso, senoidais e outras. A tese utiliza a entrada em degrau para análise da planta do sistema de controle em malha fechada.

Para analisar corretamente a resposta transiente experimental a uma entrada padrão conhecida, o sistema precisa estar em completo repouso antes que o input seja aplicado, e que não haja erros de medição. Na prática, tais limitações definem que o escopo de aplicação do "Step response methods" são modelos simples, entretanto suficientes para ajustar os parâmetros de um controlador PID.

\subsubsection{Análise da resposta em degrau}

Coloca-se o controlador em modo manual, muda-se a variável de controle, grava-se a variável de processo e divide-se pela mudança da variável de controle. (ÅSTRÖM, 1995) Na Figura 3.59 há tipos de resposta em degrau, a referência A é a saída de um processo com variação monotônica para um novo valor estacionário, a referência $B$ a saída do processo que oscila em torno de um valor estacionário, bem incomum, ambos, $\mathrm{A}$ e $\mathrm{B}$, representam sistema estáveis, enquanto $C$ e $D$ representam sistemas instáveis. A figura $E$ apresenta um longo "dead time" (atraso na resposta), já a figura $F$ é um sistema de fase não mínima, no qual o sinal medido move-se no sentido errado inicialmente.

Em relação ao sistema da tese, temos a resposta em degrau, Figura 3.60, que representa um exemplo do tipo A, da Figura 3.59.

Há muitos métodos de obter modelos paramétricos da referida resposta em degrau, na tese apresentam-se dois tipos de modelos, modelo de dois parâmetros e modelo de três parâmetros. 
A

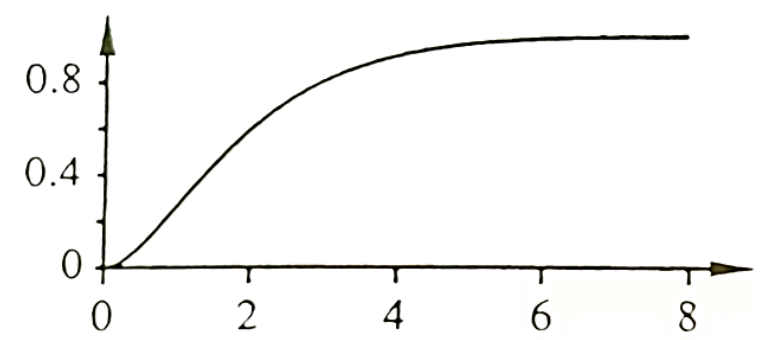

C

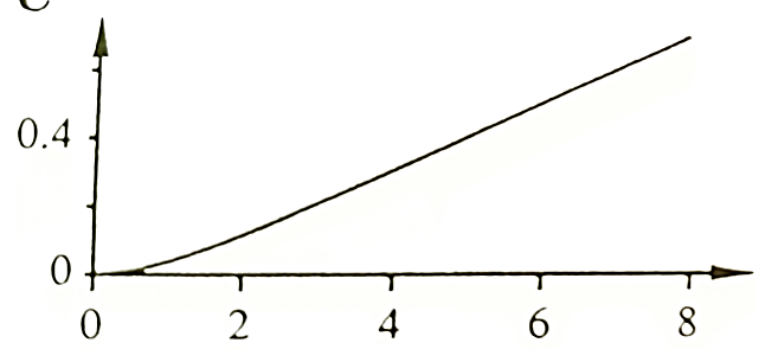

E

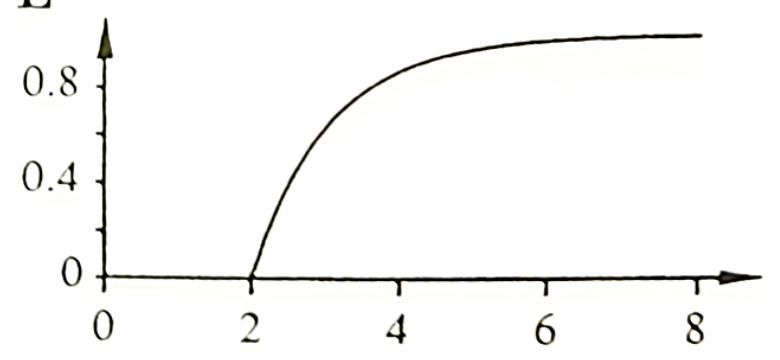

B

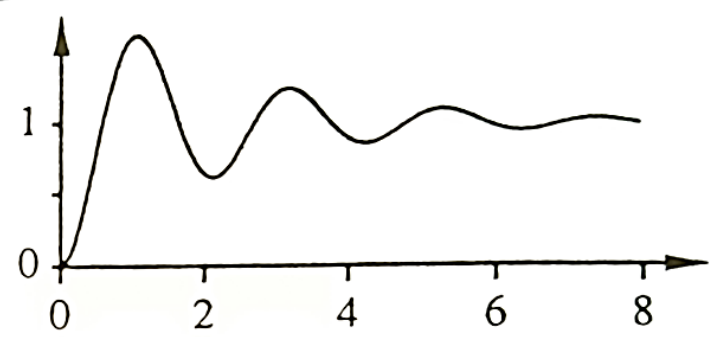

D

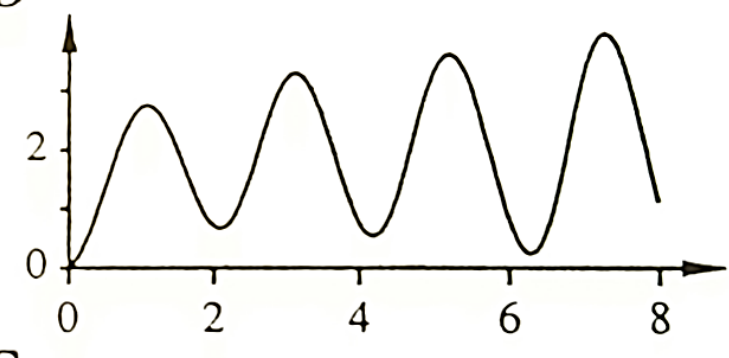

F

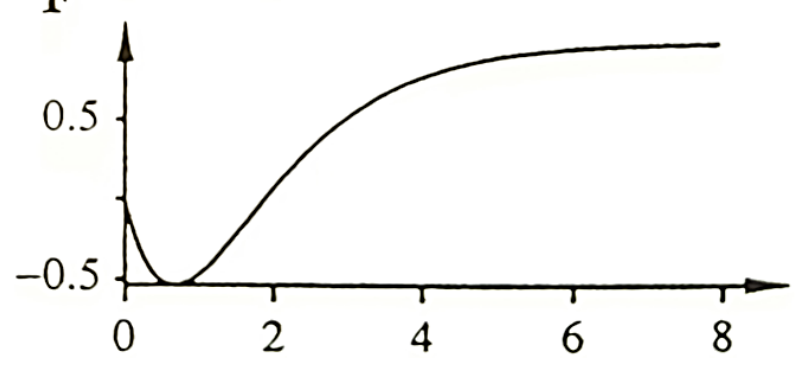

Figura 3.59. Exemplos de resposta em degrau. (ÅSTRÖM, 1995)

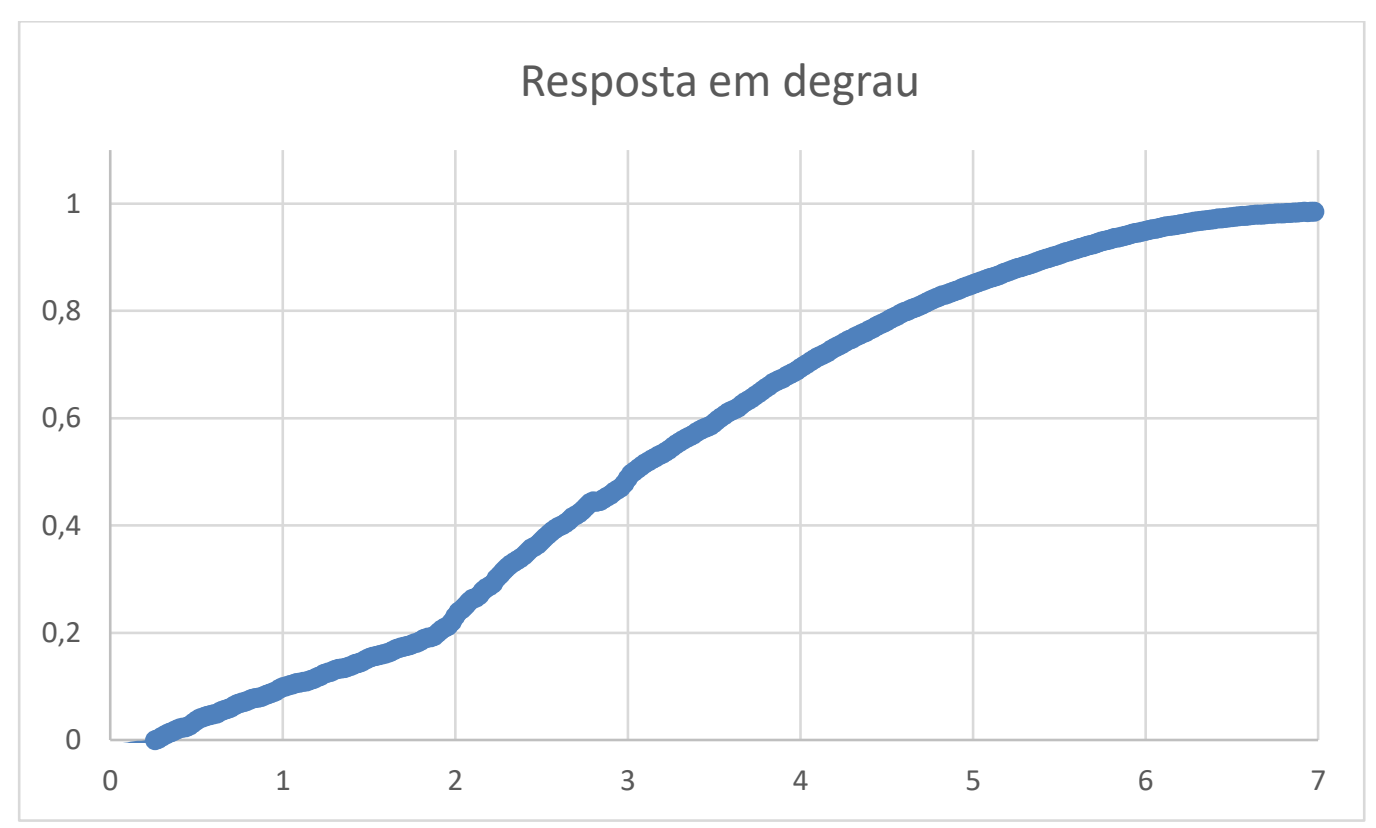

Figura 3.60. Resposta em degrau do sistema de pressurização de estudo da tese. 


\subsubsection{Modelo de dois parâmetros}

Esse é o modelo mais simples para representar a dinâmica de um processo, chamase bi paramétrico pois um termo captura o ganho e o outro o comportamento do tempo. Define-se $T_{a r}$ (average residence time) na equação (104), como uma medida grosseira do tempo que o sistema leva para acomodar a resposta em degrau. O $T_{a r}$ é a razão da área da Figura $3.61\left(A_{0}\right)$ e o ganho estático do processo $(K)$.

$$
\begin{gathered}
T_{a r}=\frac{A_{0}}{K} \\
A_{0}=\int_{0}^{\infty}(s(\infty)-s(t)) d t
\end{gathered}
$$

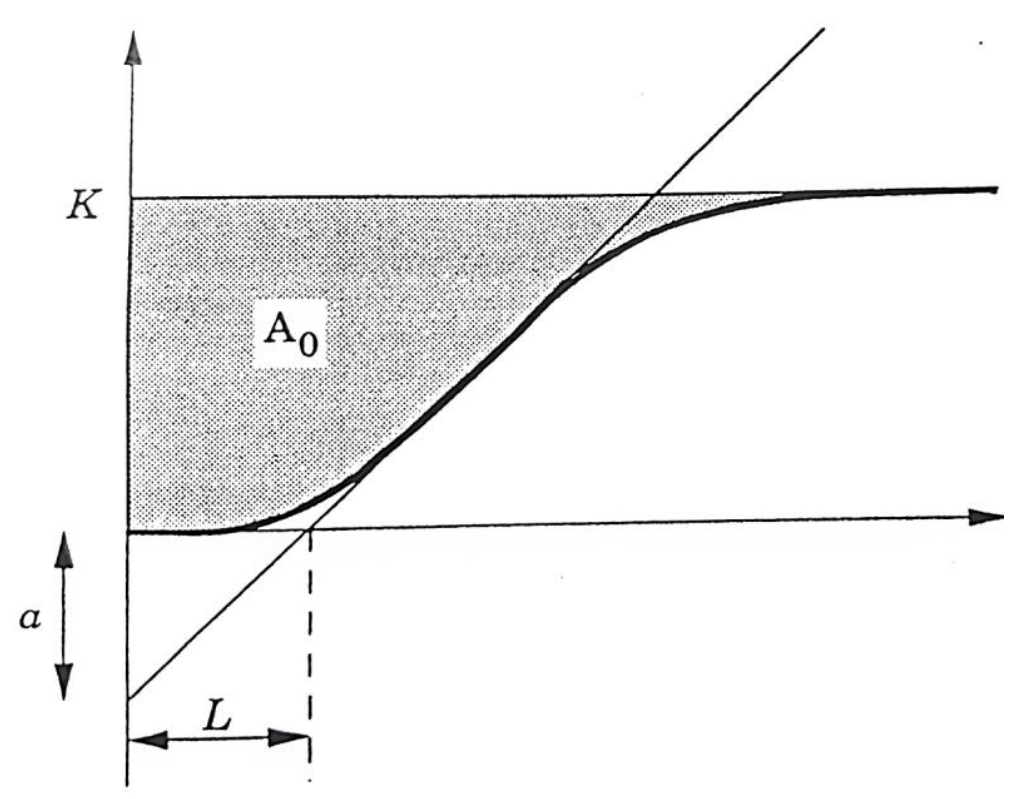

Figura 3.61. Determinação gráfica de um modelo de dois parâmetros para a resposta em degrau de um sistema estável. (ÅSTRÖM, 1995)

Com os parâmetros anteriormente definidos o processo pode ser aproximado pelo modelo representado pela equação (106), tal modelo chama-se "residence time approximation". (ÅSTRÖM, 1995)

$$
G_{2 a}(s)=\frac{K}{1+s T_{a r}}
$$


Outra aproximação bi paramétrica para a resposta em degrau é formada por um integrador com "dead time", representado pela função de transferência da equação (107), cujos parâmetros também estão graficamente determinados na Figura 3.61. (ÅSTRÖM, 1995)

$$
G_{2 b}(s)=\frac{a}{s L} e^{-s L}
$$

O modelo representado pela equação (107) é a base do processo de tuning conhecido por Ziegler Nichols. (ÅSTRÖM, 1995)

\subsubsection{Modelo de três parâmetros}

Em comparação ao modelo de dois parâmetros, o modelo de três resulta em uma melhor aproximação com a equação (108), na qual $K$ é o ganho estático, $T$ é a constante do tempo e $L$ é o dead time.

$$
G(s)=\frac{K}{1+s T} e^{-s L}
$$

A resposta em degrau do modelo em função do tempo é calculada com a equação (109)

$$
s(t)=K\left(1-e^{-\frac{(t-L)}{T}}\right)
$$

Para as equações (108) e (109), tem-se os parâmetros $K$ e $L$ graficamente representados na Figura 3.62, para calcular $T$ deve-se buscar o tempo B, que corresponde a $63 \%$ do valor do ganho, e diminuir de $L$, logo $T=B-A$. 


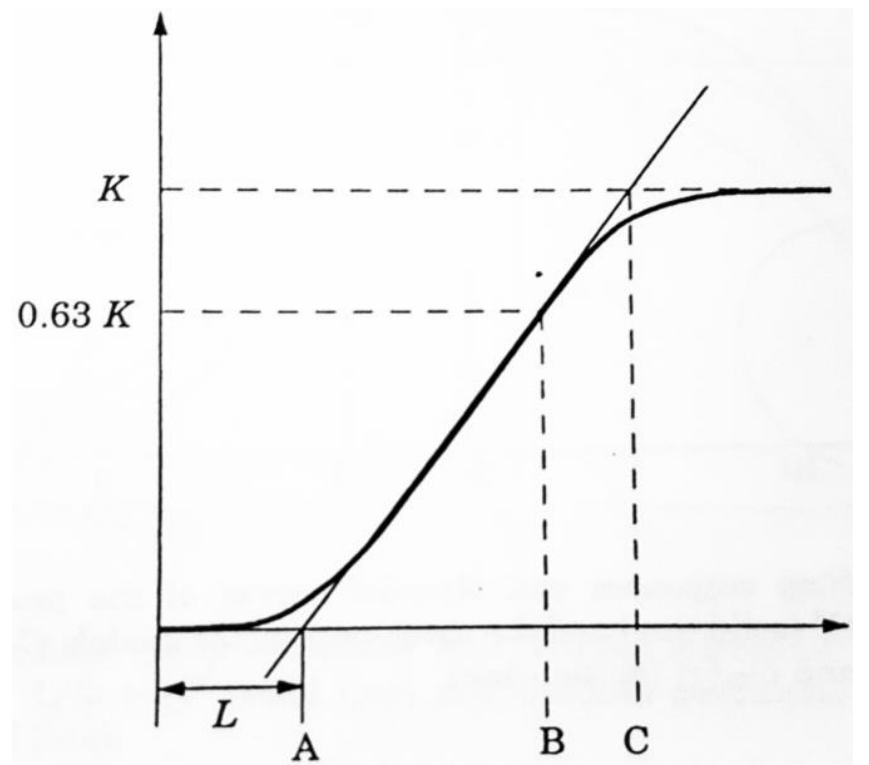

Figura 3.62. Determinação gráfica de um modelo de três parâmetros para a resposta em degrau de um sistema estável. (ÅSTRÖM, 1995)

Através da análise da resposta em degrau, a tese utiliza o modelo de 3 parâmetros para modelar o processo, conforme apresentado na Figura 3.63.

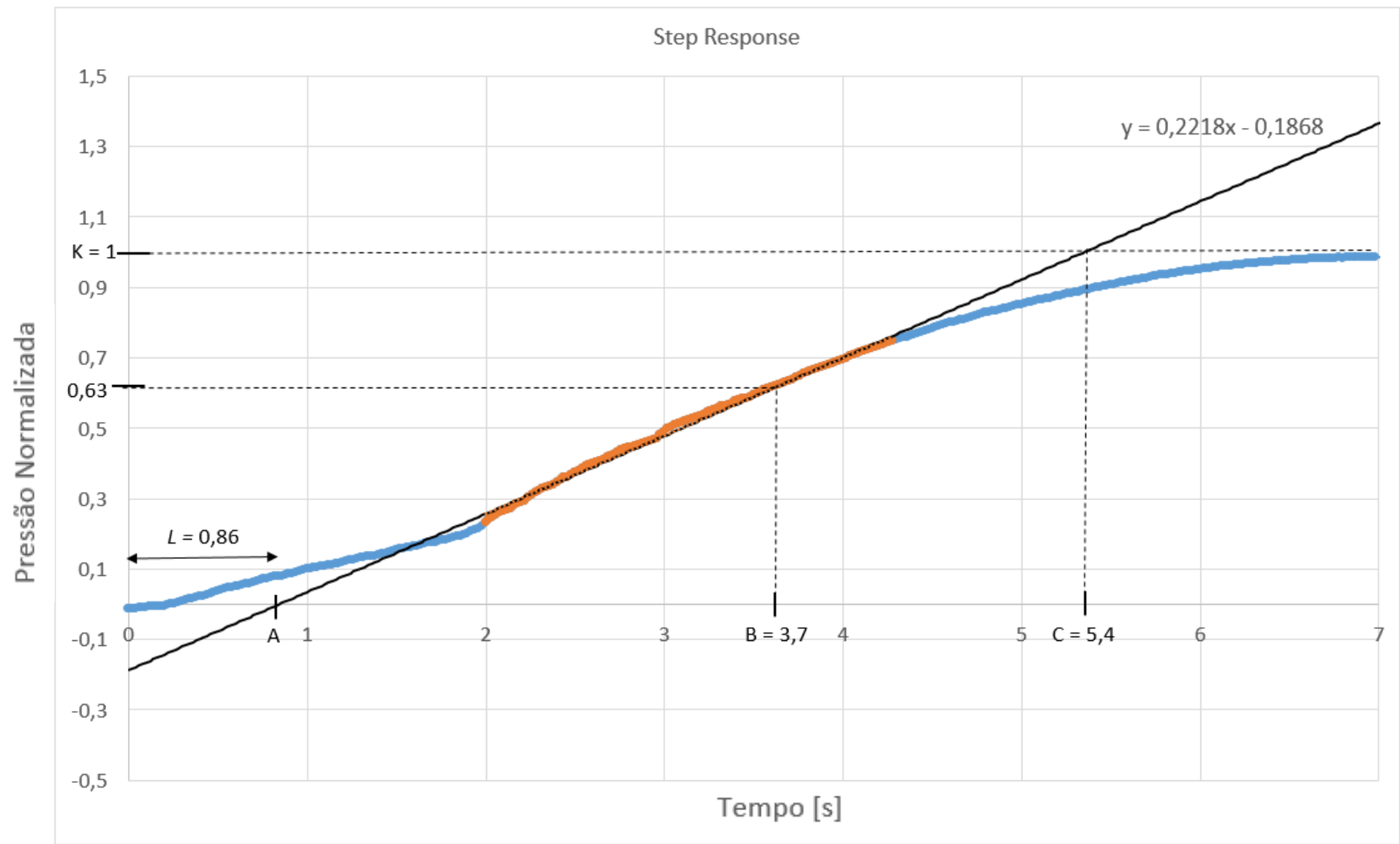

Figura 3.63. Determinação gráfica dos parâmetros do modelo de três parâmetros para a resposta em degrau do sistema de pressurização da tese. 
Para o processo de pressurização, tem-se os parâmetros do referido modelo, $\mathrm{A}=$ $0,86, \mathrm{~B}=3,7, \mathrm{C}=5,4, \mathrm{~L}=\mathrm{A}$ e $\mathrm{T}=\mathrm{B}-\mathrm{A}=2,84$.

A planta modelada pela resposta em degrau é calculada pela equação:

$$
G(s)=\frac{1}{1+s 2,84} e^{-s 0,86}
$$

Considerando a inversa de Laplace, a resposta em degrau do modelo de pressurização em função do tempo é calculada com a equação (111).

$$
s(t)=\left(1-e^{-\frac{(t-0,86)}{2,84}}\right)
$$

Segue a resposta em degrau do modelo de pressurização versus resposta em degrau experimental na Figura 3.64.

\section{Resposta em degrau experimental versus modelo de pressurização} com 3 parâmetros

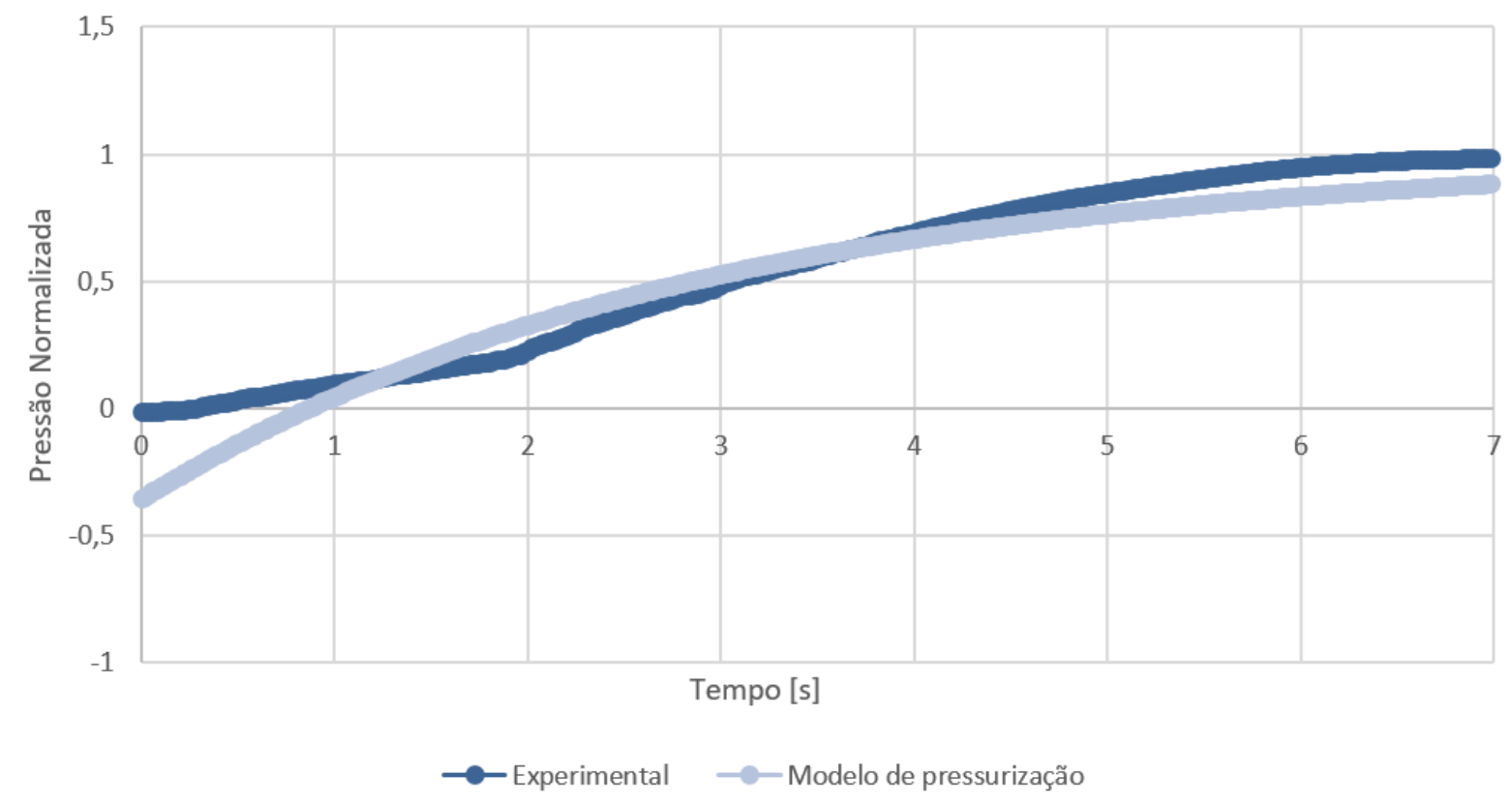

Figura 3.64. Determinação gráfica dos parâmetros do modelo de três parâmetros para a resposta em degrau do sistema de pressurização da tese.

Observa-se boa correlação com o modelo de 3 parâmetros e os dados experimentais. 


\subsubsection{Regras de Ziegler-Nichols para sintonia de controladores PID}

O processo de selecionar parâmetros do controlador que garantam uma dada especificação de desempenho é conhecido como sintonia do controlador. Ziegler e Nichols sugeriram regras para ajustar os valores de $K_{p}, T_{i} e T_{d}$, baseada na resposta experimental ao degrau.

Utilizam-se os parâmetros da função de transferência $\frac{C(s)}{U(s)}$, que pode ser aproximada por um sistema de primeira ordem com atraso de transporte $\frac{C(s)}{U(s)}=\frac{K}{1+s T} e^{-s L}$, como entrada na Tabela 3.6 de parâmetros definida pelo modelo de Ziegler Nichols:

Tabela 3.6. Regra de Ziegler-Nichols baseada na resposta ao degrau da planta.

\begin{tabular}{|l|c|c|c|}
\hline Tipo de controlador & $K_{p}$ & $T_{i}$ & $T_{d}$ \\
\hline $\mathrm{P}$ & $\frac{\mathrm{T}}{L}$ & $\infty$ & 0 \\
\hline $\mathrm{PI}$ & $0,9 \frac{\mathrm{T}}{\mathrm{L}}$ & $\frac{L}{0,3}$ & 0 \\
\hline $\mathrm{PID}$ & $1,2 \frac{\mathrm{T}}{\mathrm{L}}$ & $2 L$ & $0,5 L$ \\
\hline
\end{tabular}

Tem-se que a planta estudada aproximada pelo modelo de três parâmetros é $G(s)=$ $\frac{1}{1+s 2,84} e^{-s 0,86}$, logo para o processo de pressurização os parâmetros de entrada da metodologia de Ziegler-Nichols são $L=0,86$ e $\mathrm{T}=2,84$.

Seguem os parâmetros estimados através da formulação de Ziegler-Nichols:

Tabela 3.7. Estimativa de parâmetros de Ziegler-Nichols para sintonia de controle PID.

\begin{tabular}{|l|c|c|c|}
\hline Tipo de controlador & $K_{p}$ & $T_{i}$ & $T_{d}$ \\
\hline P & 3,3 & $\infty$ & 0 \\
\hline PI & 2,97 & 2,86 & 0 \\
\hline PID & 3,96 & 1,72 & 0,43 \\
\hline
\end{tabular}


Para escolher o melhor controlador, realiza-se uma análise preliminar dos controladores resultado da estimativa de Ziegler-Nichols, com essa finalidade observa-se 0 comportamento do sistema representado pela Figura 3.65 no domínio do tempo.

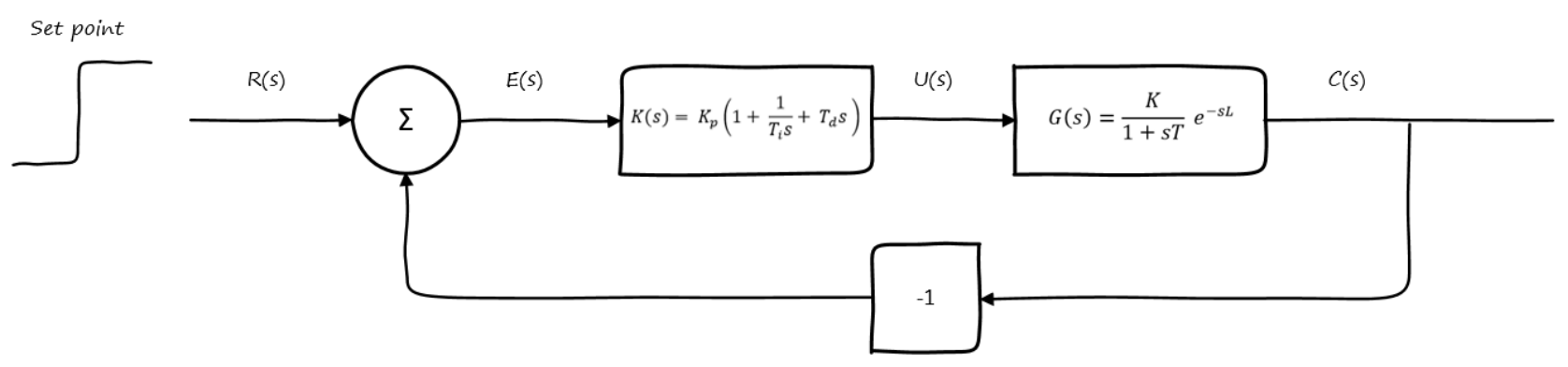

Figura 3.65. Sistema de controle PID em malha fechado.

Para cada controlador, aplicou-se a função de transferência em malha fechada $\frac{C(S)}{R(S)}=\frac{K(s) G(s)}{1+K(s) G(s)}$ cuja planta é aproximada pelo sistema de primeira ordem com atraso de transporte $G(s)=\frac{1}{1+s 2,84} e^{-s 0,86}$.

Durante o desenvolvimento da função de transferência $\frac{C(S)}{R(S)}$, utilizou-se a aproximação do tempo morto pela equação (112).

$$
e^{-L s}=\frac{1-\frac{L s}{2}+\frac{(L s)^{2}}{8}-\frac{(L s)^{3}}{48}+\cdots}{1+\frac{L s}{2}-\frac{(L s)^{2}}{8}+\frac{(L s)^{3}}{48}+\cdots}
$$

No Matlab a função "pade(dead Time,ordem do polinômio)" realiza a referida tarefa de aproximação, logo:

$$
e^{-0,86 s}=\frac{-1 s^{3}+13.9535 s^{2}-81.1249 s+188.6626}{s^{3}+13.9535 s^{2}+81.1249 s+188.6626}
$$

Seguem as Figura 3.67, Figura 3.68 e Figura 3.69 com o comportamento da variável de processo em resposta a entrada em degrau da função de transferência no domínio do tempo do sistema de controle representado na Figura 3.66. 
Set point

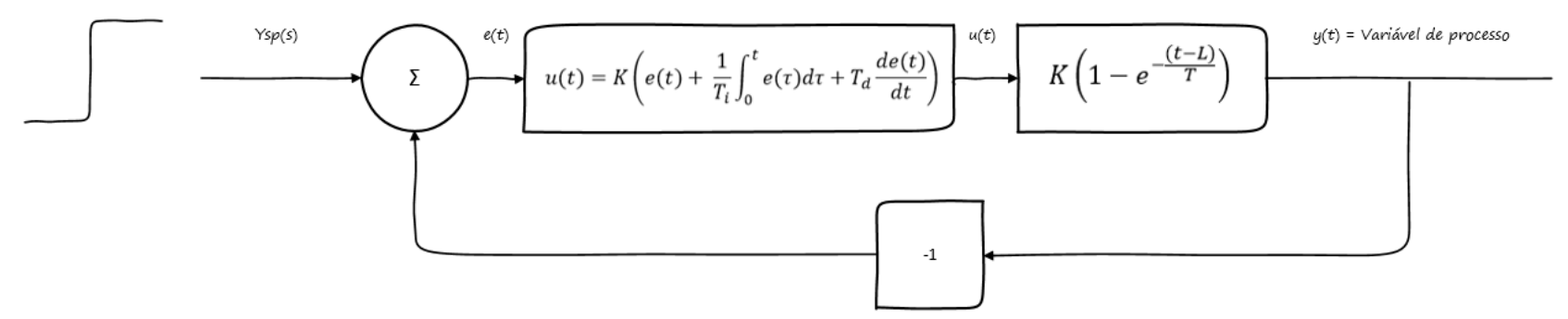

Figura 3.66. Sistema de controle PID em malha fechado representado no domínio do tempo.

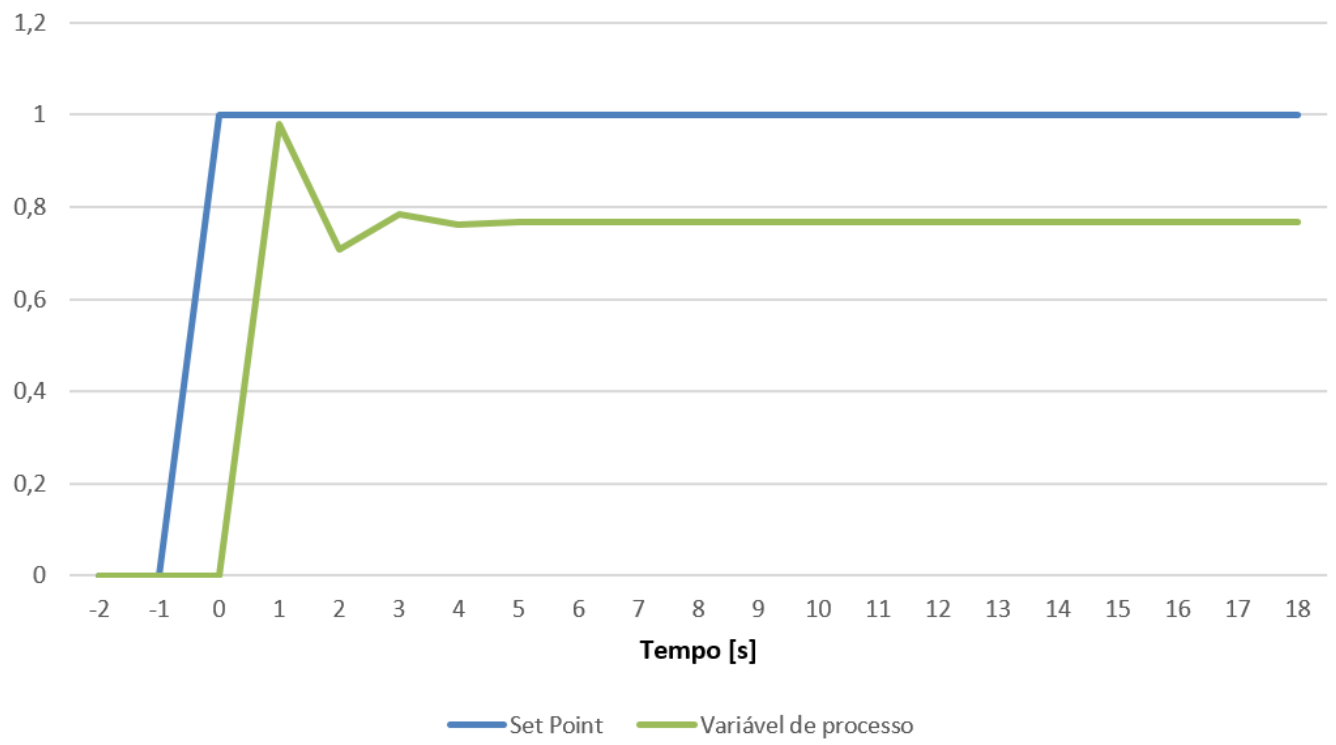

Figura 3.67. Simulação da reposta em degrau do sistema com controlador proporcional com parâmetros de Ziegler-Nichols

1,2

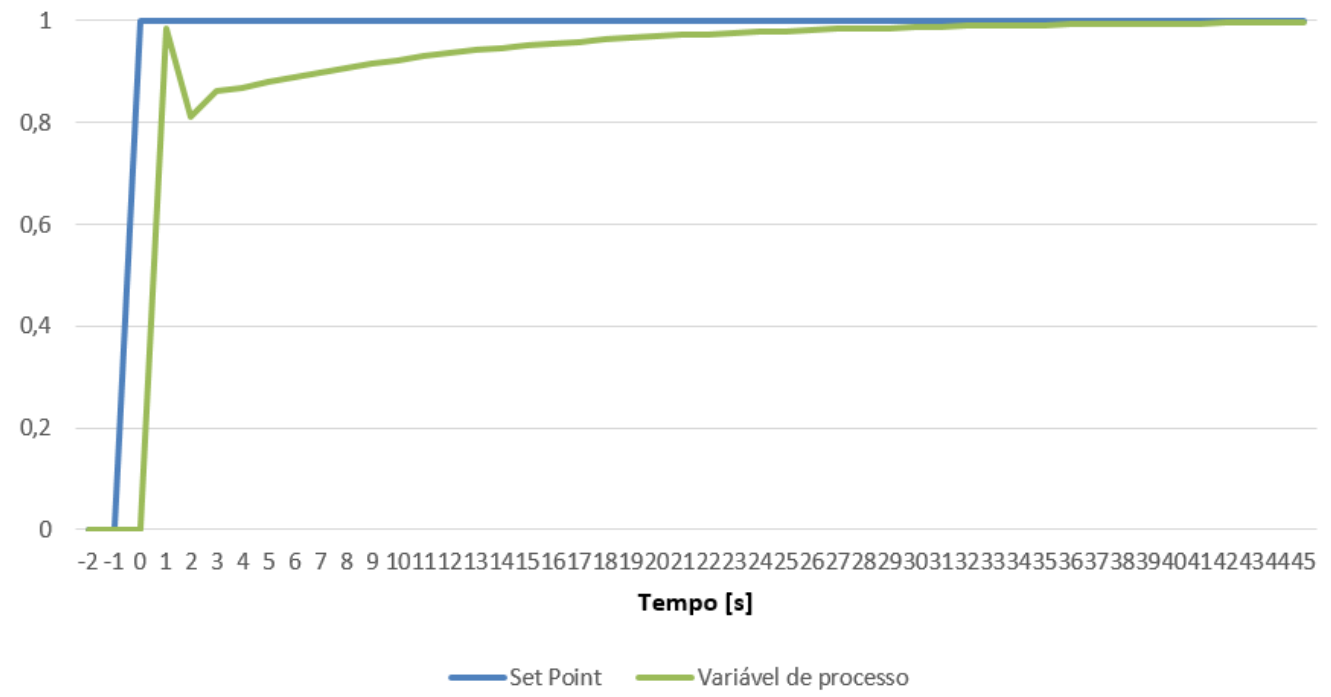

Figura 3.68. Simulação da reposta em degrau do sistema com controlador proporcional-integral com parâmetros de Ziegler-Nichols 


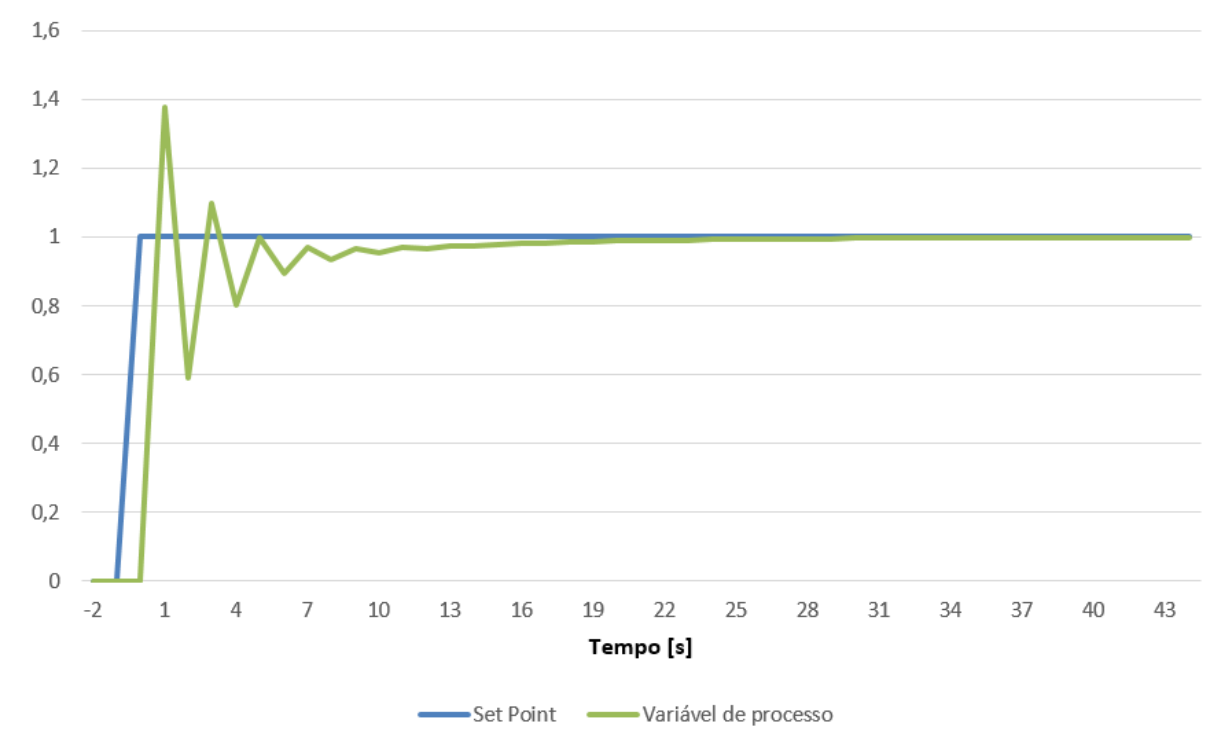

Figura 3.69. Simulação da reposta em degrau do sistema com controlador proporcional-integral-derivativo com parâmetros de Ziegler-Nichols

Pela análise preliminar dos controladores sintonizados pelo método de ZieglerNichols, escolhe-se o controlador proporcional-integrativo para ser utilizado nas conformações superplásticas da tese.

$\mathrm{Na}$ etapa de calibração do controle de pressurização da peça modelo, configurou-se o controlado proporcional-integral com os parâmetros de Ziegler-Nichols, segue Figura 3.70 com o resultado da pressurização com o controlador PID sintonizado.

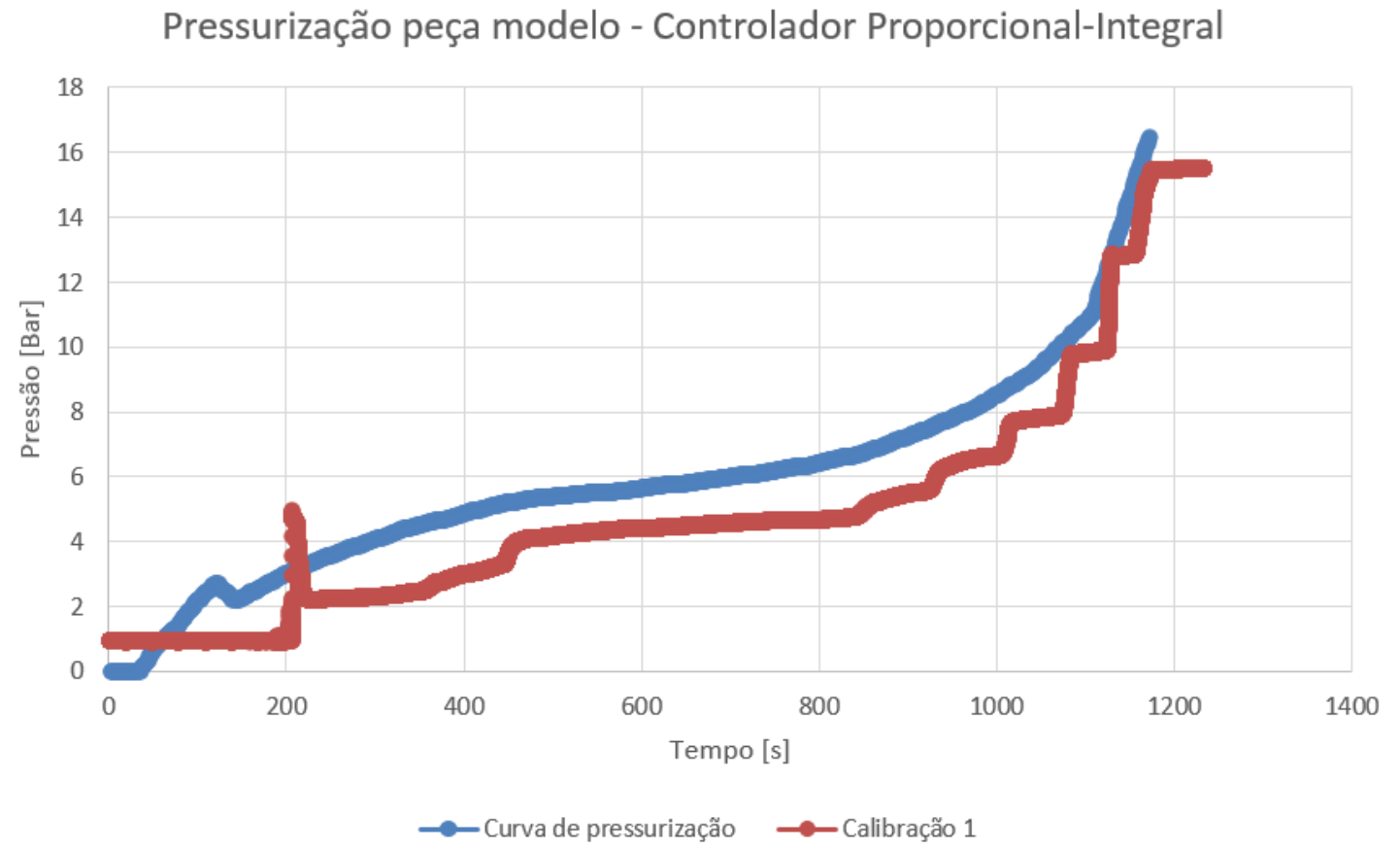

Figura 3.70. Calibração do controle de pressurização da peça modelo como controlador proporcional -integral sem ajuste dos parâmetros 
Segue Figura 3.71 exemplificando a ação do controlador PI aplicado na pressurização da peça modelo com sintoniza dos parâmetros ajustados de Ziegler-Nichols, cuja resposta em degrau dos referidos parâmetros está representado pela Figura 3.72.

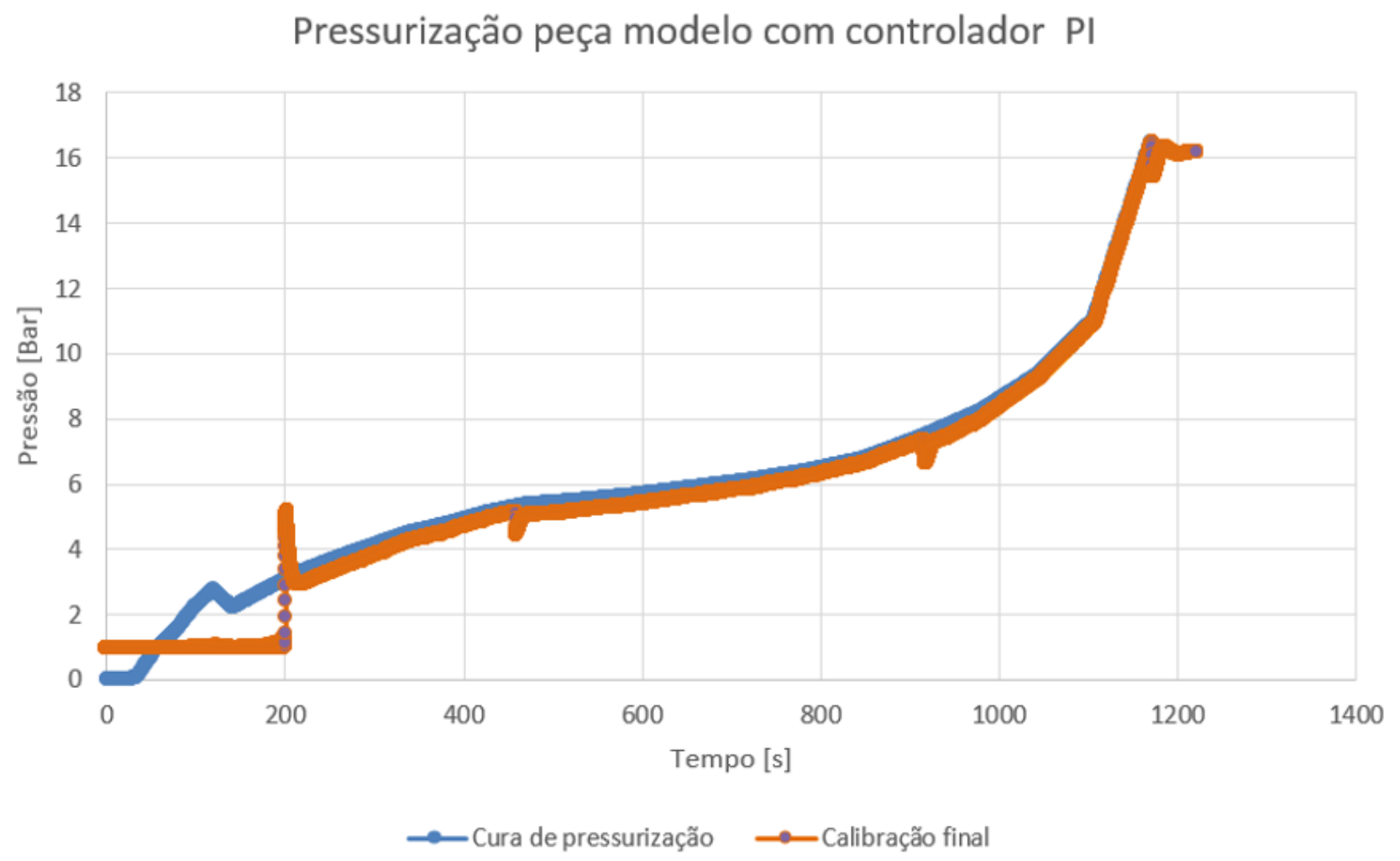

Figura 3.71. Ação do controlador PI no controle da pressurização da peça modelo com parâmetros de Ziegler Nichols ajustados.

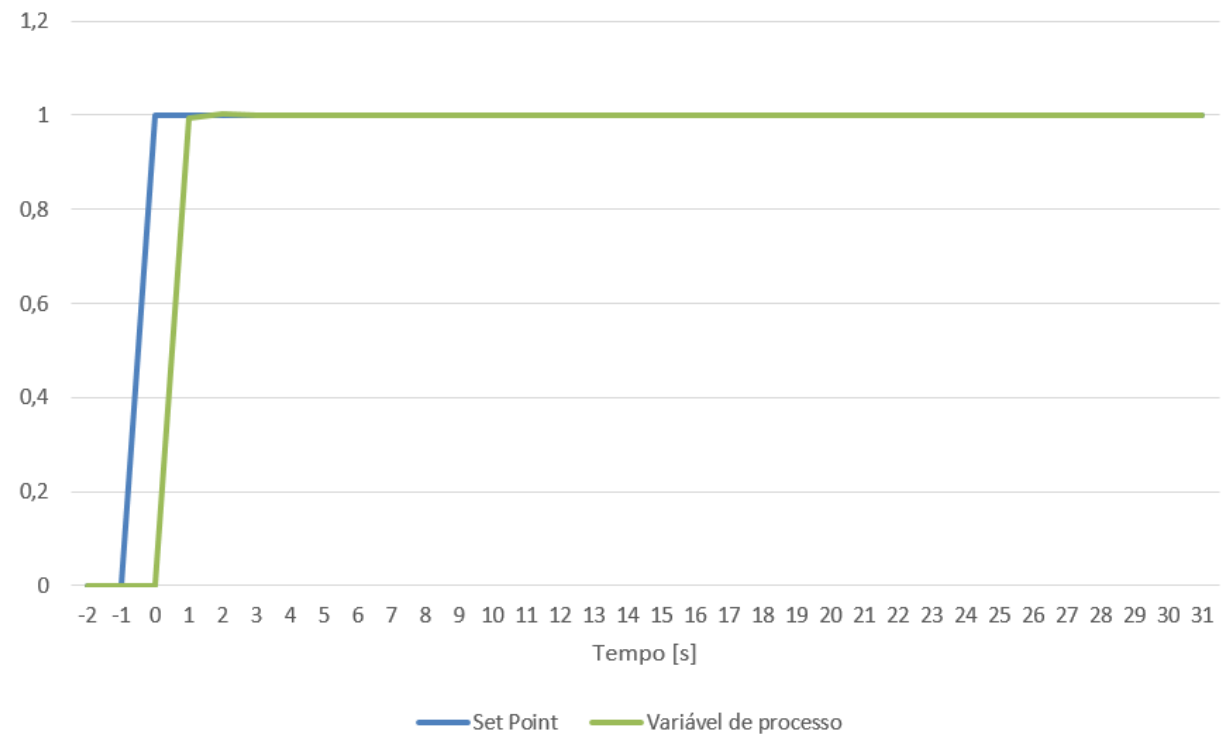

Figura 3.72. Simulação da reposta em degrau do sistema com controlador proporcional-integral com ajuste dos parâmetros de Ziegler-Nichols 


\subsection{Integração, testes e calibração}

Nesse capítulo, será aprofundado as etapas de desenvolvimento do módulo do sistema de aquisição e atuação, todos os testes de integração dos demais módulos, como também a calibração e aperfeiçoamento dos mesmos serão detalhados.

\subsubsection{Módulo do Sistema de aquisição e atuação}

De maneira resumida e esquemática antecipa-se a sequência das etapas desenvolvidas relacionadas ao sistema de aquisição de dados, cada item da lista apresentada será trabalhado nesse capítulo:

- Teste das funções do drive

- Programa APAX;

- Desenvolvimento de script em VBA, entenda-se a leitura dos dados pelo CATMAN que serão utilizados pelo sistema de pressurização, implementação das rotinas necessárias para acionamento da válvula, implementação da rotina de controle de pressão e o desenvolvimento do ambiente de monitoramento da pressão;

- Integração do sistema de aquisição com o transdutor de pressão;

- Testes de funcionamento da placa ADAM 6024;

- Integração da placa ADAM 6024 com a válvula reguladora de pressão proporcional;

- Integração da válvula reguladora de pressão proporcional com sistema de aquisição;

O sistema de aquisição vai concentrar as tarefas de aquisição e atuação. Em um primeiro momento, através do transdutor, o sinal de pressão é simplesmente armazenado e monitorado pelo sistema de aquisição, em um segundo momento, para cada sinal é realizada uma comparação entre o sinal objetivo (set point) e o sinal medido.

Uma biblioteca de funções em $C_{++}$(resumo das funções - Anexo 10.3) foi desenvolvida para ser chamada pelo Script em VBA que roda no CatmanEasy ${ }^{\circledR}$. As funções são chamadas pelo CatmanEasy e controlam a placa AD através do protocolo MODBUS. Dessa forma o sistema de aquisição passa a realizar a tarefa de atuação do sistema de controle. 


\subsubsection{Teste das funções do drive}

Para testar as funções em $\mathrm{C}++$ em nível lógico, desenvolveu-se um aplicativo que possibilita ler e escrever nas saídas analógicas e digital de uma Placa AD virtual. Simulando as possibilidades de chamada das funções em $\mathrm{C}_{++}$, antes de testar na placa AD. A Figura 3.73 mostram os canais possíveis de verificação.

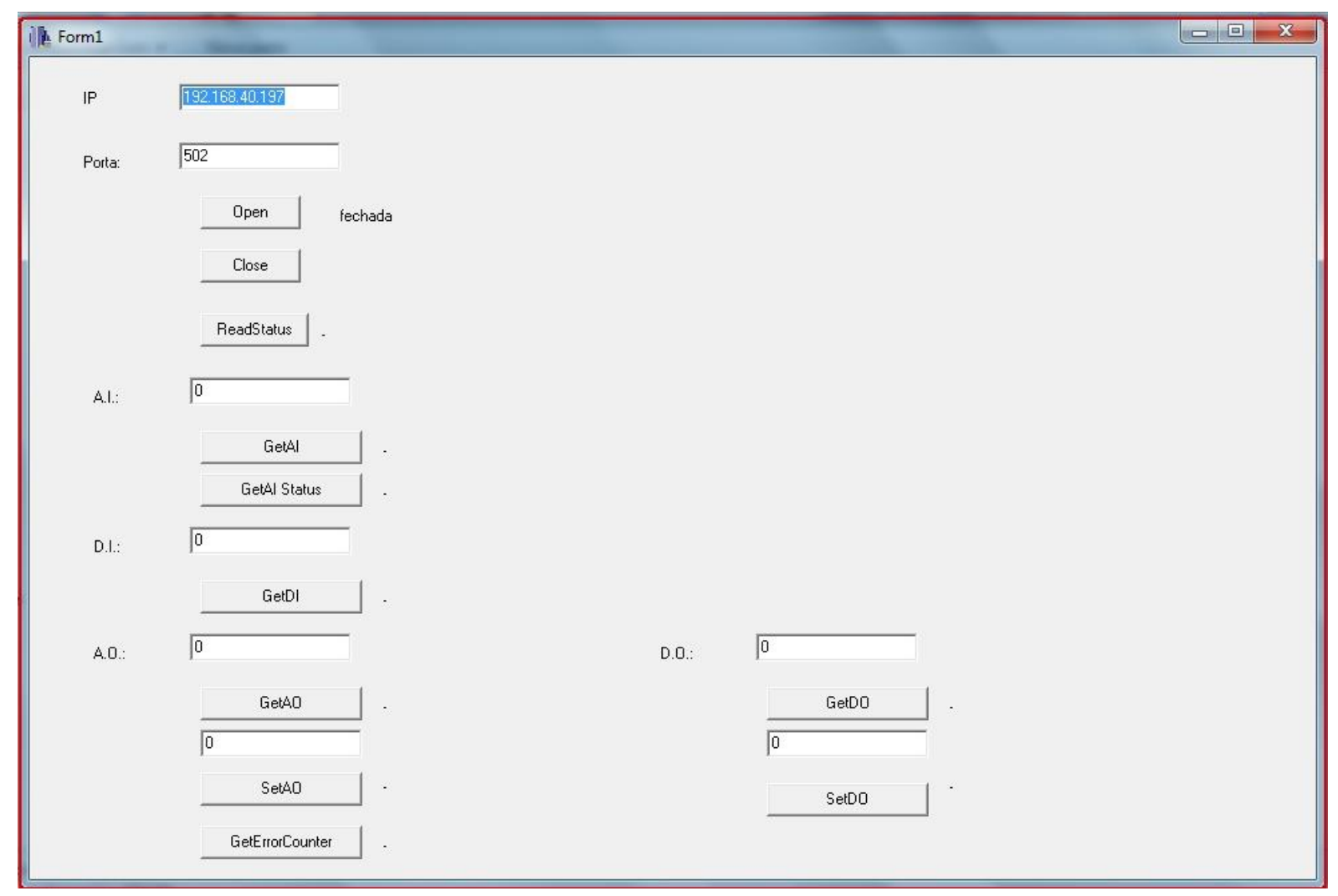

Figura 3.73. Janela do software que testa as funções em C++.

\subsubsection{Programa APAX}

O programa é utilizado para testar a conexão da placa $A D$, definindo IP na rede que não gere conflitos com o sistema de aquisição. O Programa mapeia a rede Ethernet e localiza o roteador, que por sua vez localiza a placa ADAM-6024.

O APAX realiza comandos básicos de acionamento da válvula através da placa ADAM-6024. Na Figura 3.74 podem-se observar duas abas, "input" e "output". Para atuação na válvula reguladora deve-se escolher a aba "output" e selecionar o canal 1 (Channel Index $=1$ ) e tensão de saída da placa (0-10 V) (Output range = 0-10 V). 
Manualmente é possível digitar no campo "Value to output" um valor em tensão e ao aplicar esse valor medir com o transdutor a pressão de trabalho.

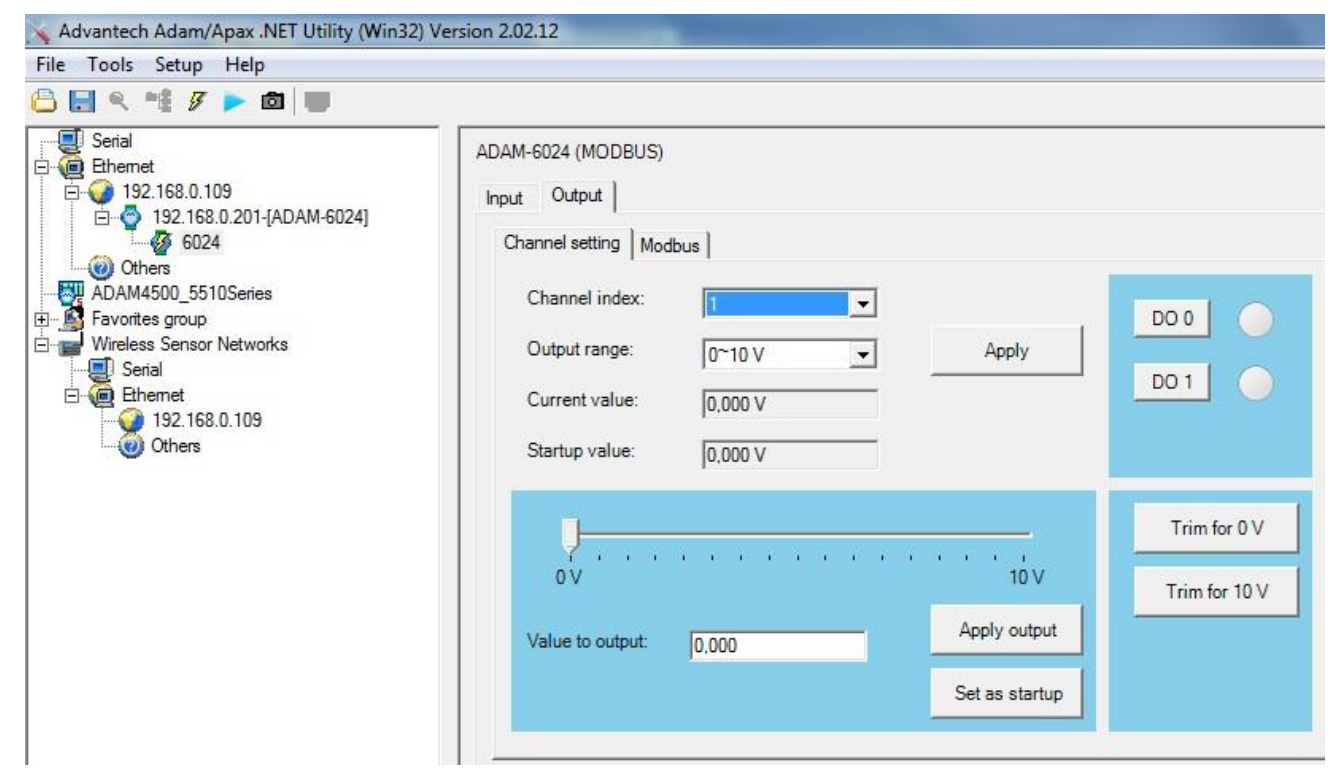

Figura 3.74. Janela de comando do software APAX.

A utilização do programa APAX foi importante para obter a curva de pressurização da válvula e localizar os pontos que não ocorre a linearidade que se espera de uma válvula proporcional.

\subsubsection{Desenvolvimento de script em VBA}

Para utilizar o sistema de aquisição foi necessário escrever um script - Anexo 10.5 -em VBA que através do macro do CatmanEasy ${ }^{\circledR}$ funcionasse como atuador do sistema de controle. As funções VBA estão comentadas no referido anexo. Inicialmente é importante entender a estrutura do programa e perceber que as funções serão executadas sempre antes, durante ou depois de um evento pré-determinado do sistema de aquisição. A Figura 3.75 mostra os eventos e as respectivas funções.

Para facilitar o entendimento, as funções do script foram criadas com os mesmos nomes dos eventos do sistema de medição:

- After DAQ (data acquisition) Stop;

- After Transfer Data Block;

- Before DAQ Start;

- Mostrar Mensagem de erro ADAM; 


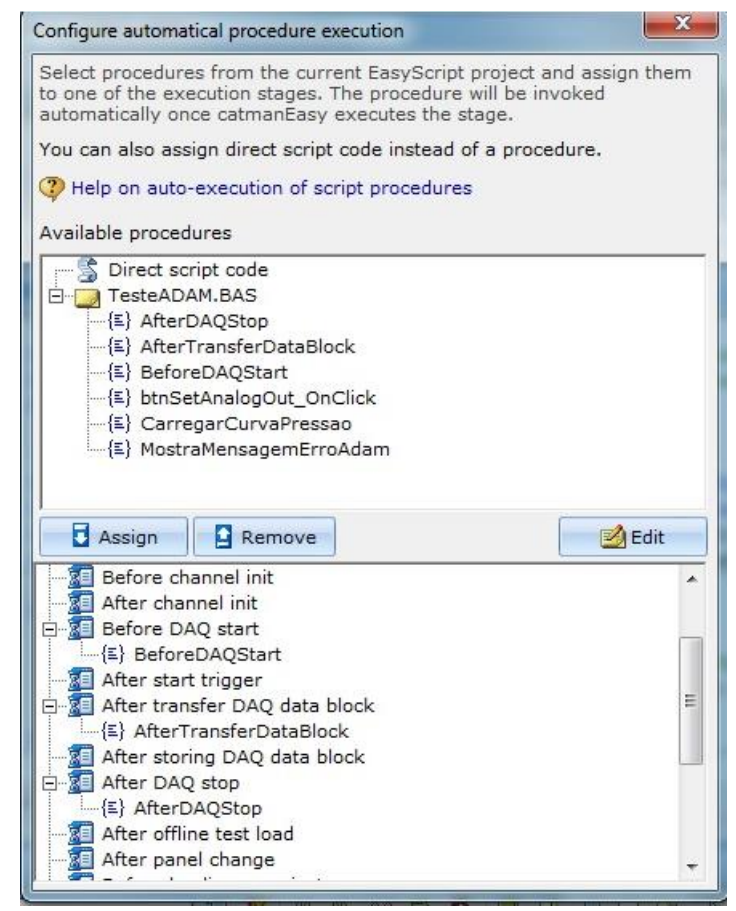

Figura 3.75. Janela de eventos do sistema de aquisição.

Outras funções foram criadas para automatizar o processo e são chamadas mediante alguma interação do usuário na interface homem máquina (IHM) do sistema de controle, sempre considerando a relevância da ação relacionada aos conceitos de clicabilidade, utilidade e usabilidade. Como por exemplo, a possibilidade de aplicar algum valor de tensão (0-10v) na válvula mesmo durante o processo de pressurização utilizando a função "Btn (button) Set Analog Out on Click".

A Figura 3.76 apresenta primeira versão da IHM (Interface Homem Máquina) do software de controle do processo de Conformação Superplástica. 
Curva de pressurização recebida

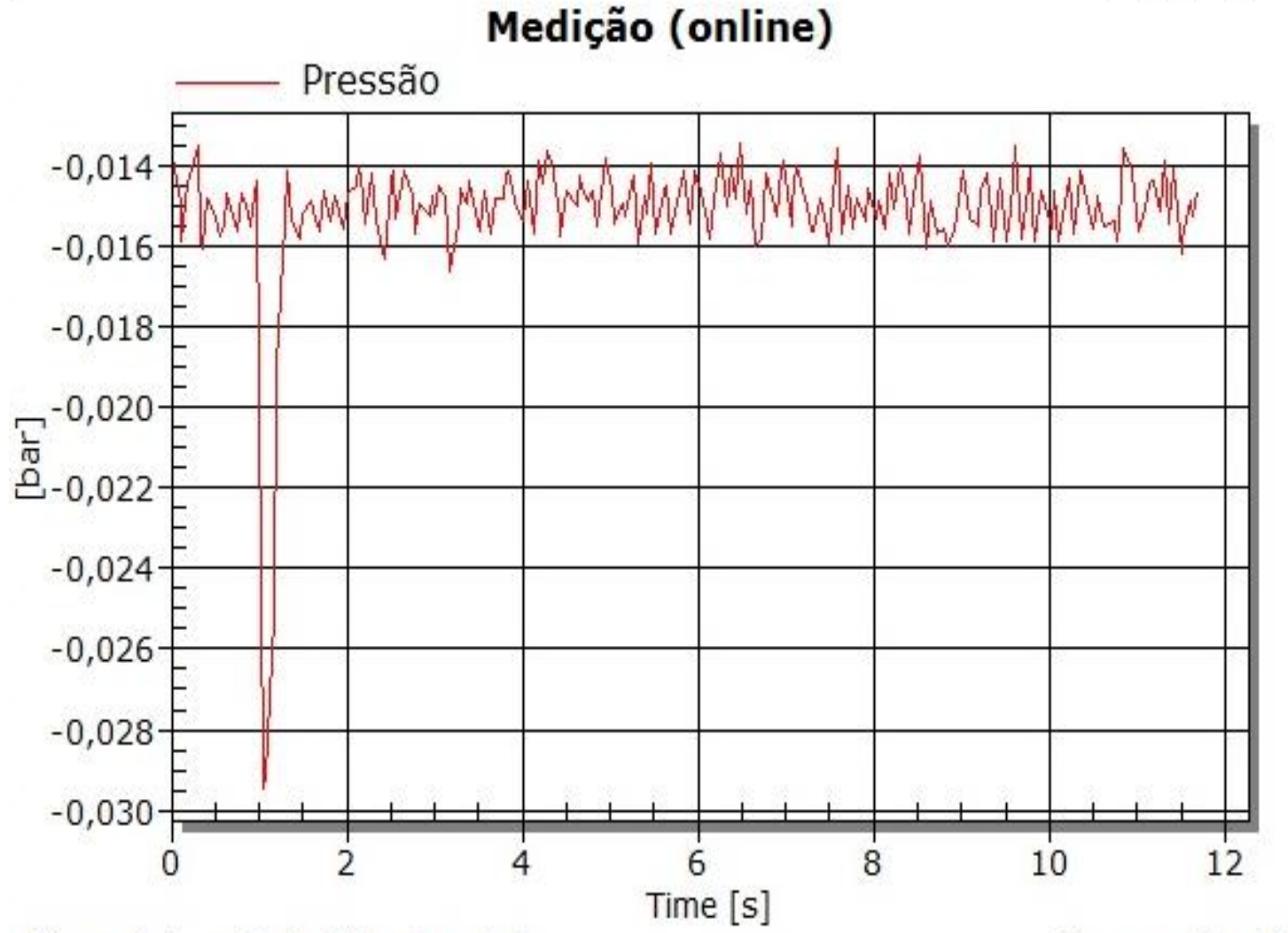

Time window: 2 min (Scroll mode)

Compression: $3 \mathrm{x}$

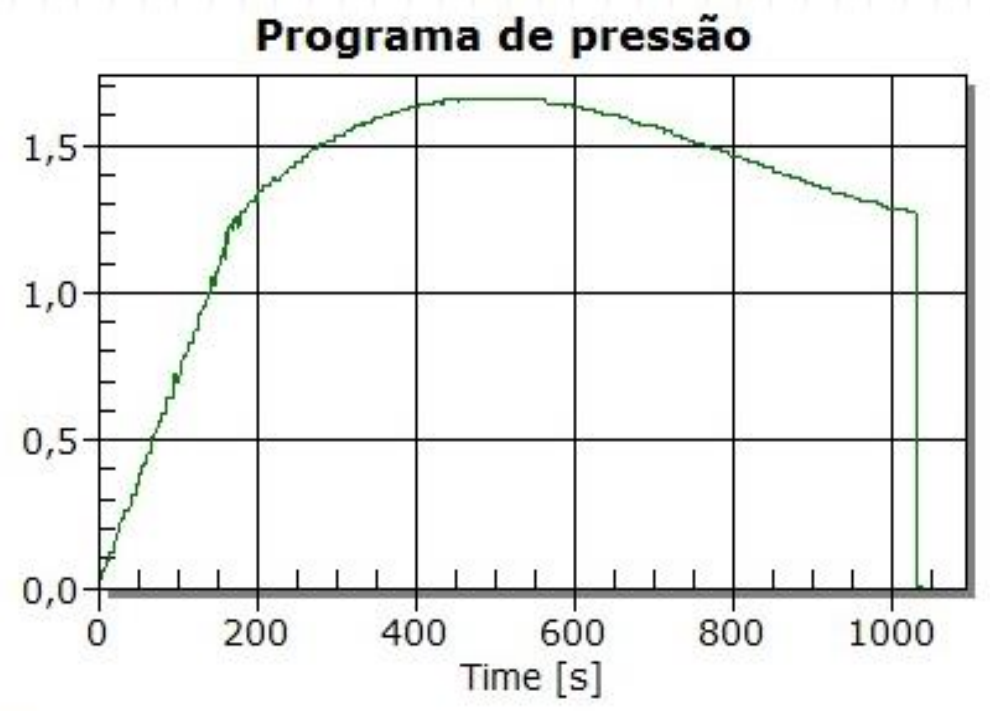

Voltagem Aplicada na Válvula controladora de Pressão

0,185592185592186

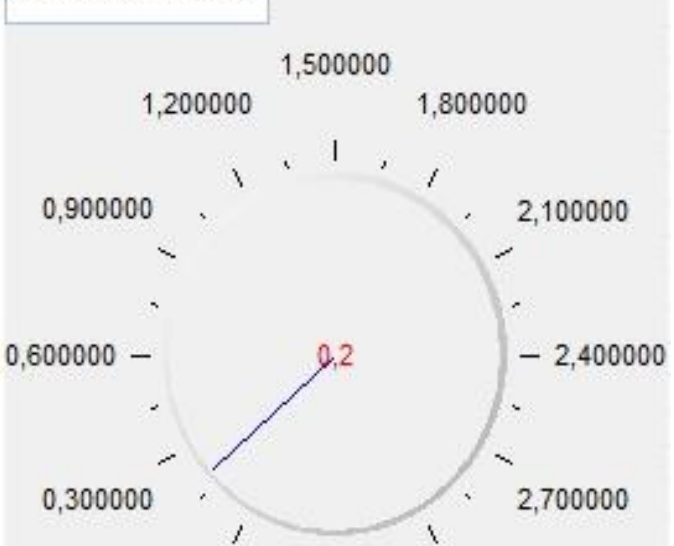

0,000000

3,000000

$0,000000-3,000000$

$76 \quad$ Escreve Saida Analogica 0 - 4095

0,09236 Pressao Buscada (bar)

\section{Pressão}

\section{$-0,015$ bar}

Figura 3.76. IHM do software de controle 
Da Figura 3.76:

- A janela "Programa de pressão" mostra a curva de pressão que é recebida pela válvula para realizar o controle de pressão do processo de conformação.

- A janela "Medição (online)" mostra a curva do sinal aquisitado pelo transdutor de pressão na frequência que o sistema de controle for definido. O sistema está configurado para utilizar $50 \mathrm{~Hz}$ default.

- O campo "Escreve na saída analógica" mostra o valor que a placa AD está recebendo do sistema de controle, é um valor entre 0-4095 (obedecendo a resolução da placa $A D$ que é 12 bits).

- Logo abaixo há o campo "Pressão buscada", mostra o valor em Bar da pressão que instantaneamente está sendo usada de setpoint do sistema de controle.

- Não menos importante é o monitoramento da voltagem que está sendo aplicada na válvula instantaneamente, há dois campos responsáveis, um mostrador analógico (que pode ser configurado para ter seu fundo de escala dentro da voltagem esperada, 0 - 3 Volts, por exemplo) e um campo que mostra o próprio valor da voltagem.

De maneira resumida, além de gerar a IHM apresentada, o script de controle do sistema de Conformação Superplástica realiza os seguintes procedimentos:

- Chamada das funções do ADAM, escritas em $\mathrm{C}++$, utilizadas pelo sistema de pressurização durante o acionamento da válvula; Adam6024Open, Adam6024Close, Adam6024SetAnalogOutput

Adam6024GetLastErrorMessage;

- Antes do início da aquisição, carrega a curva de pressão correspondente ao programa de pressurização que será recebido pela válvula; configura o IP da placa $A D$ e ativa a comunicação com a mesma; 
- Após o final da aquisição, apaga os dados em memória, ajusta a pressão para zero bar relativo e aguarda a queda da pressão para que a comunicação com a placa AD possa ser finalizada.

- Depois de cada medição, através da função AfterTransferDataBlock, depois que o pacote de medições for enviado ao sistema de controle, o sistema busca o novo valor de pressão que deve ser atualizado na válvula, caso esse valor seja o mesmo, o sistema só monitora, caso tenha mudado, um novo valor é escrito na porta analógica do PC, sinal esse que vai ser transmitido pela ADAM à válvula.

\subsubsection{Integração do sistema de aquisição com transdutor de pressão}

Através da tecnologia do TEDS (Transducer electronic data sheet), após a configuração e calibração do transdutor de pressão, esses dados são armazenados e serão responsáveis por tornar o procedimento de recalibração muito mais rápido. O processo se resume à atualização do "zero Balance" (ajusta o transdutor ao seu valor de referência) do transdutor. A pressão atmosfera servirá de valor zero para as medições. A apresenta um desenho esquemático das ligações para o transdutor de pressão H8AP da HBM de ponte completa. 

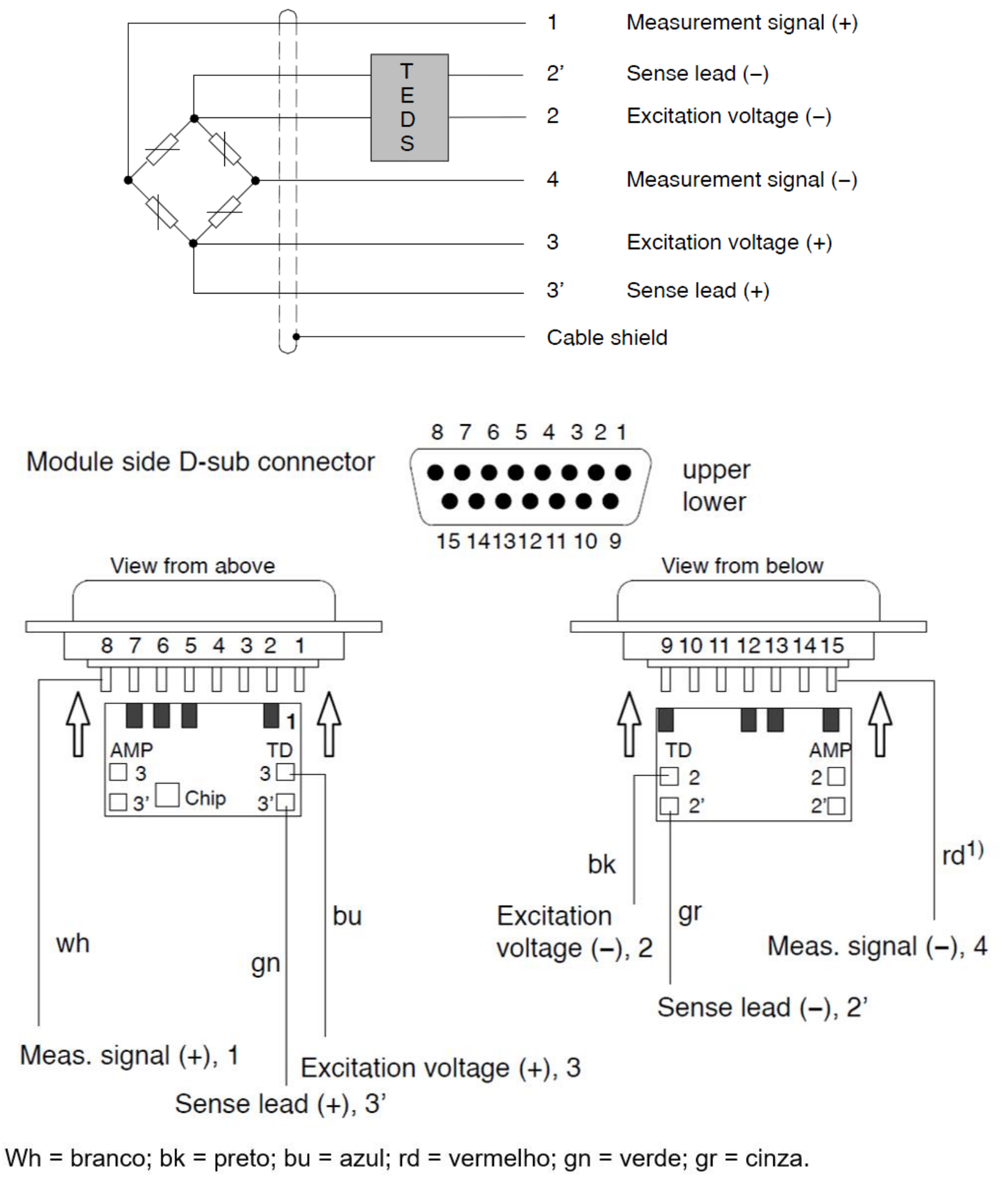

Figura 3.77. Esquema de ligações para o transdutor de pressão H8AP da HBM de ponte completa. 


\subsubsection{Testes de funcionamento da placa ADAM 6024;}

Através do programa APAX já apresentado, as funções da biblioteca de funções do drive da placa ADAM 6024 foram testadas.

\subsubsection{Integração da placa ADAM 6024 com a válvula reguladora de pressão proporcional;}

Para implementar os parâmetros de controle necessários para melhorar a atuação da válvula e para visualizar os sinais lidos pela válvula reguladora proporcional durante 0 processo, utilizou-se a saída "Programe Interface" da Válvula, conforme Figura 3.78.

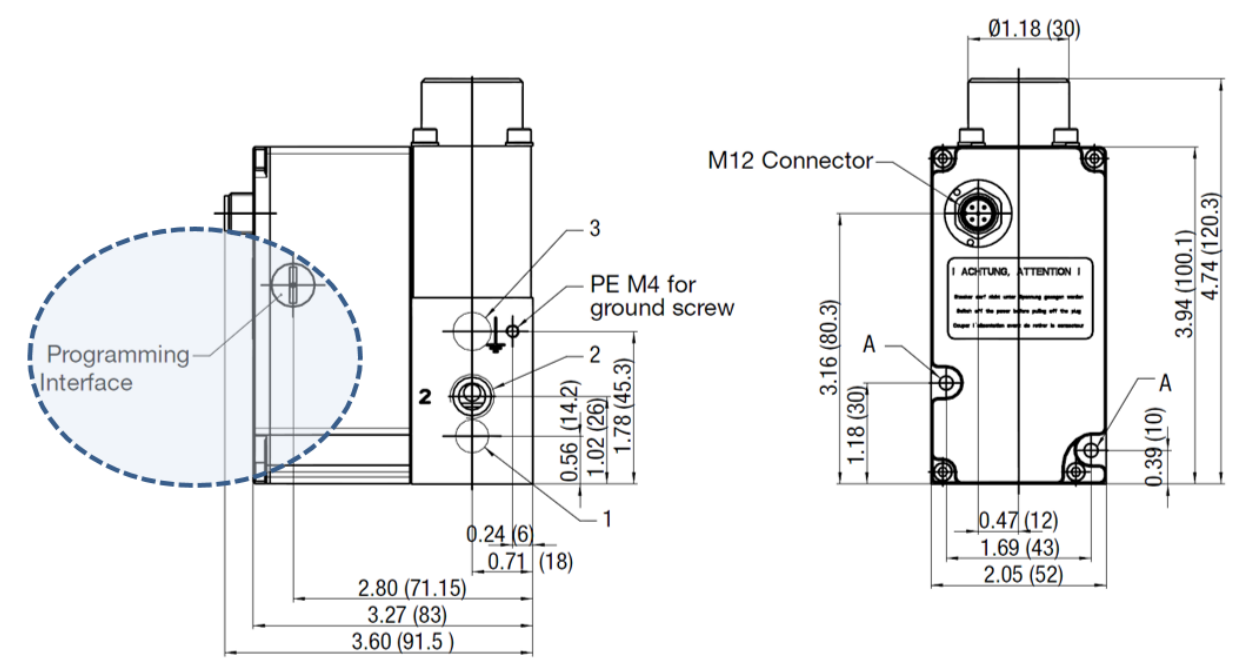

Figura 3.78. Representação da saída "programming Interface" e do conector M12.

Utilizou-se um cabo da própria Numatics, (9 pinos Sub-D conversor para RS 232) como a estação de trabalho dedicada a aquisição de dados não possuía a saída RS 232, foi necessário a utilização de um conversor USB-RS 232 e o drive do conversor.

\subsubsection{Integração da Válvula reguladora de pressão proporcional com o sistema de aquisição;}

A válvula recebe o sinal do sistema de aquisição, quando ele funciona como atuador do sistema de controle, que recebe a curva que servirá de programa de pressurização para Conformação Superplástica. 


\subsubsection{Calibração do sistema de pressurização}

Como metodologia de trabalho realizou-se uma sequência de testes para avaliar a necessidade de alteração dos parâmetros de controle da válvula. Os primeiros resultados obtidos não foram satisfatórios, Figura 3.79, aplicando uma curva de pressurização linear de 0 - 10 Bar. A sensibilidade da válvula na faixa de pressão de $0-3$ Bar estava baixa, dessa forma não seria possível realizar os testes com chumbo estanho, pois a pressão máxima de trabalho era aproximadamente 2 Bar. Para que se entenda o porquê da utilização do chumbo estanho, todo o detalhamento será apresentado no capítulo 3.7 Validação da instrumentação a frio: Superplasticidade da liga $\mathrm{PbSn}$, nesse momento da tese será focado que para utilizar a liga de chumbo estanho, que é superplástica a temperatura ambiente, são necessária pressões menores que na conformação do titânio, essa foi a motivação dos ajustes dos parâmetros de controle da válvula.

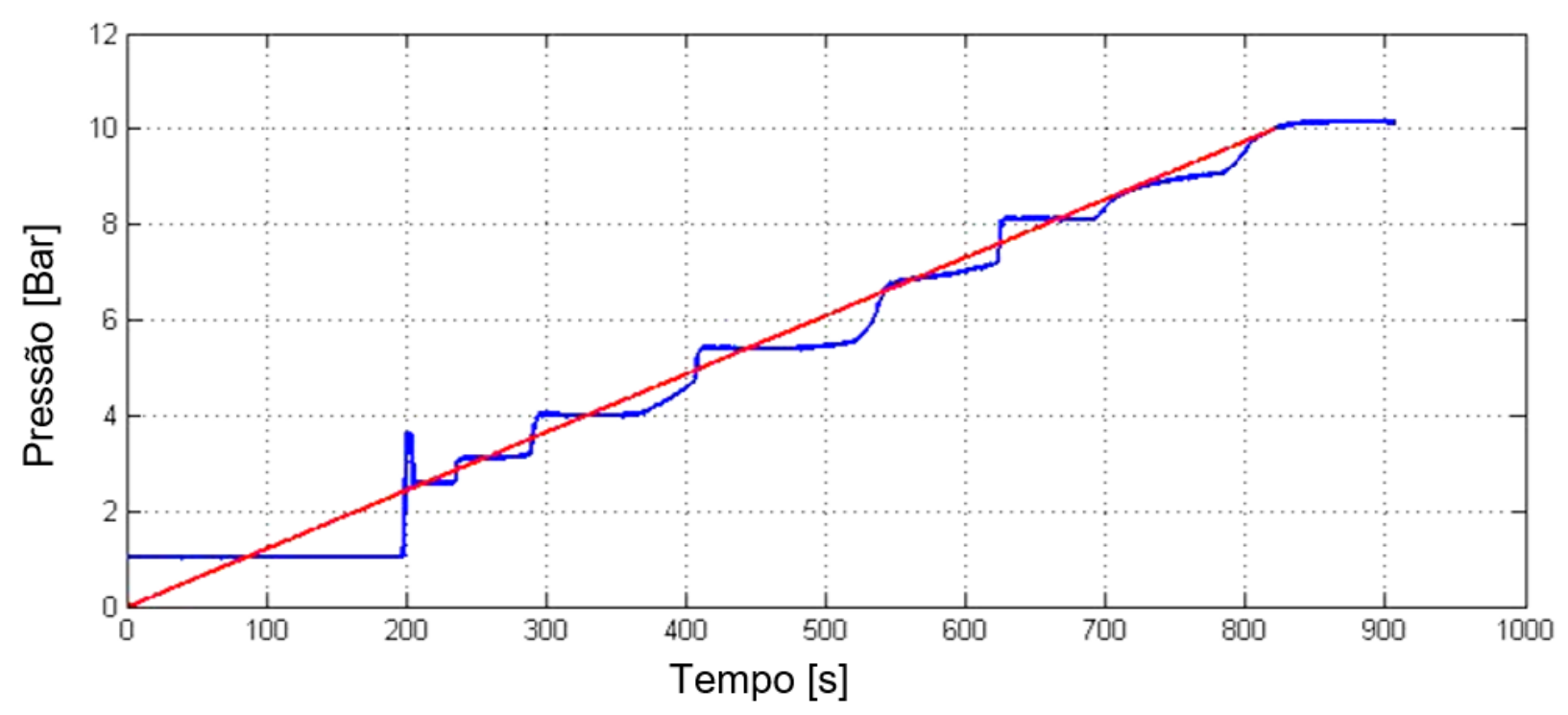

Figura 3.79. Resultado do controle da válvula sem alterações nas configurações de fábrica referentes a fundo de escala.

O conceito de sensibilidade da válvula está relacionado à menor mudança no sinal de comando que resulte em uma variação na pressão de saída da válvula. Normalmente é expressa em porcentagem da pressão máxima de saída. A Figura 3.80 representa a sensibilidade no sentido de controle. 


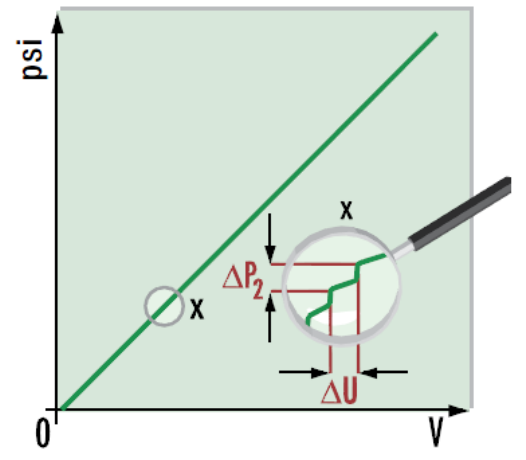

Figura 3.80. Conceito de sensibilidade em controle.

Uma das possibilidades de personalização dos parâmetros de funcionamento da válvula chama-se "Setpoint Span" cuja funcionalidade é alterar o fundo de escala de trabalho da válvula de 0-50Bar para 0-5Bar. Objetiva-se, portanto, obter uma menor sensibilidade. A Figura 3.81 apresenta a janela de parâmetros relacionados ao "Setpoint" da válvula.

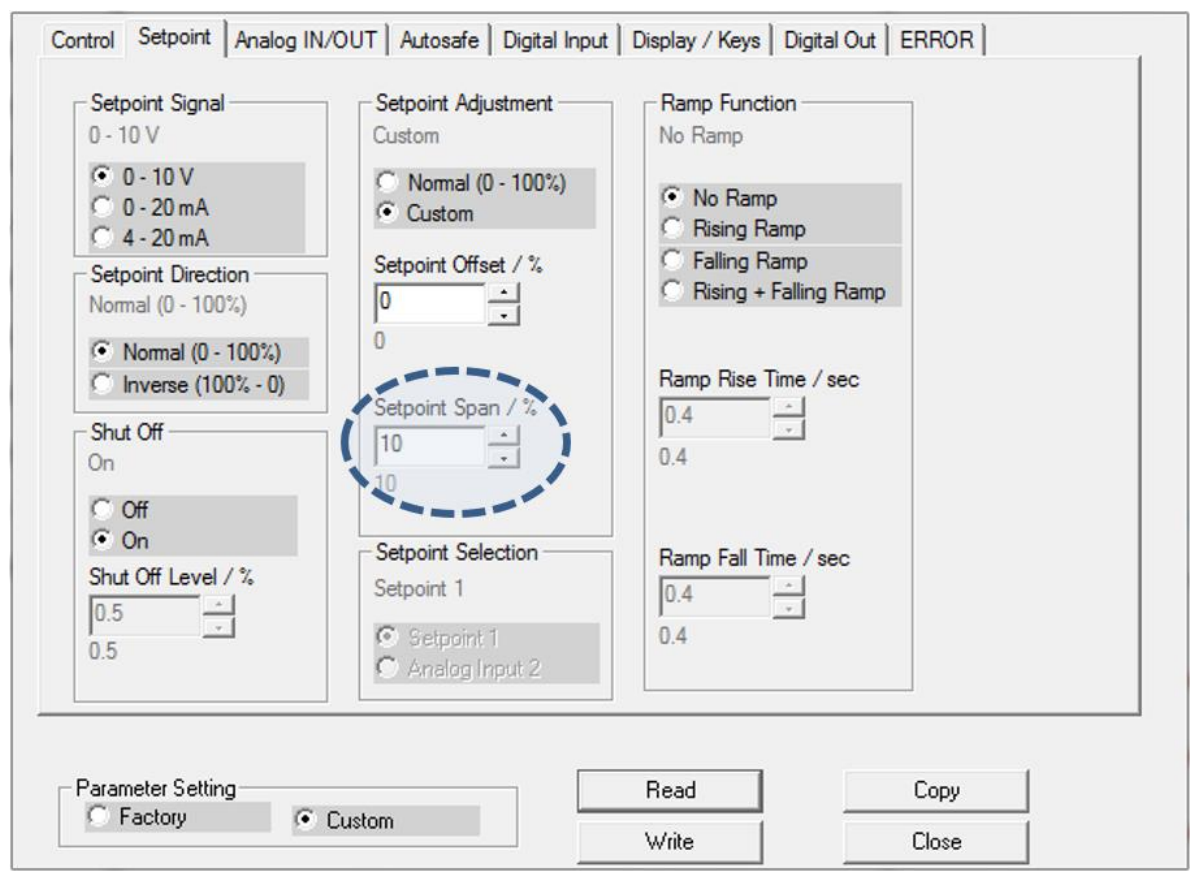

Figura 3.81. Janela de parâmetros relacionados ao "Setpoint" da válvula.

O ajuste de fundo de escala (Span Adjustment) relaciona a porcentagem da pressão máxima da válvula que será a pressão máxima de trabalho relacionada ao sinal de 
comando de $10 \mathrm{~V}$. Após alguns ajustes nos parâmetros de fábrica obteve-se a curva de pressurização da válvula de um programa de pressurização linear de 0-5Bar, Figura 3.82.

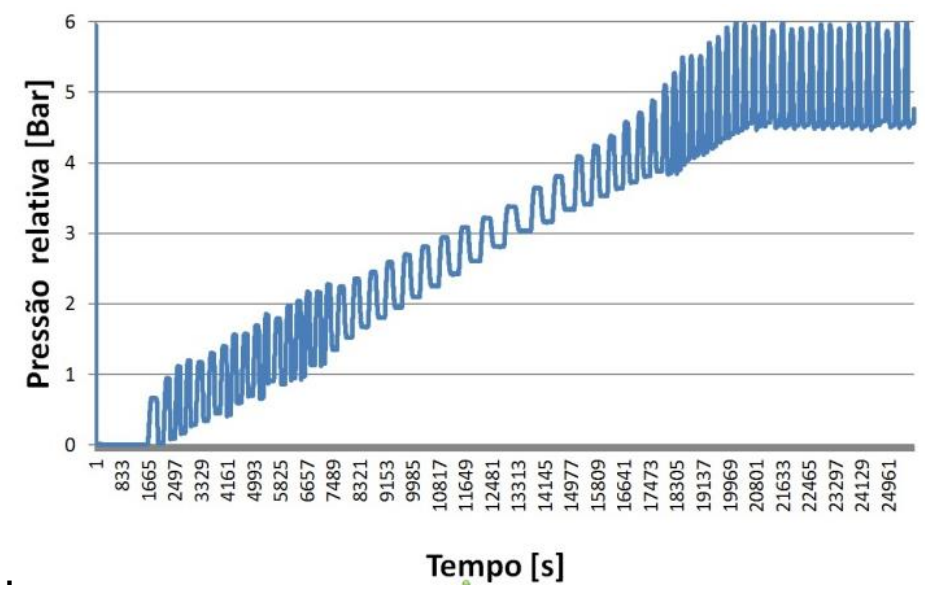

Figura 3.82. Sinal medido no teste de pressurização linear de 0-5 Bar.

Alterações foram realizadas nos parâmetros de controle da válvula, A Figura 3.81 ilustra o programa DAS (Data Acquisition Software) e a janela que contém as possibilidades de ajuste dos parâmetros de controle. Após alguns testes, o valor da constante de integração foi aumentado em 10 vezes, melhores resultados no que cerne a instabilidade e oscilação foram obtidos.

Futuros testes serão realizados objetivando diminuir o desvio do sinal do "Setpoint" com o sinal medido. Porém a mudança do "span" da válvula é um ajuste de caráter eletrônico, dessa forma a mecânica de construção da válvula não permite um ajuste tão fino quanto se deseja. Entretanto, para os ensaios de titânio, esperam-se pressões de trabalho maiores que as usadas no $\mathrm{PbSn}$. 

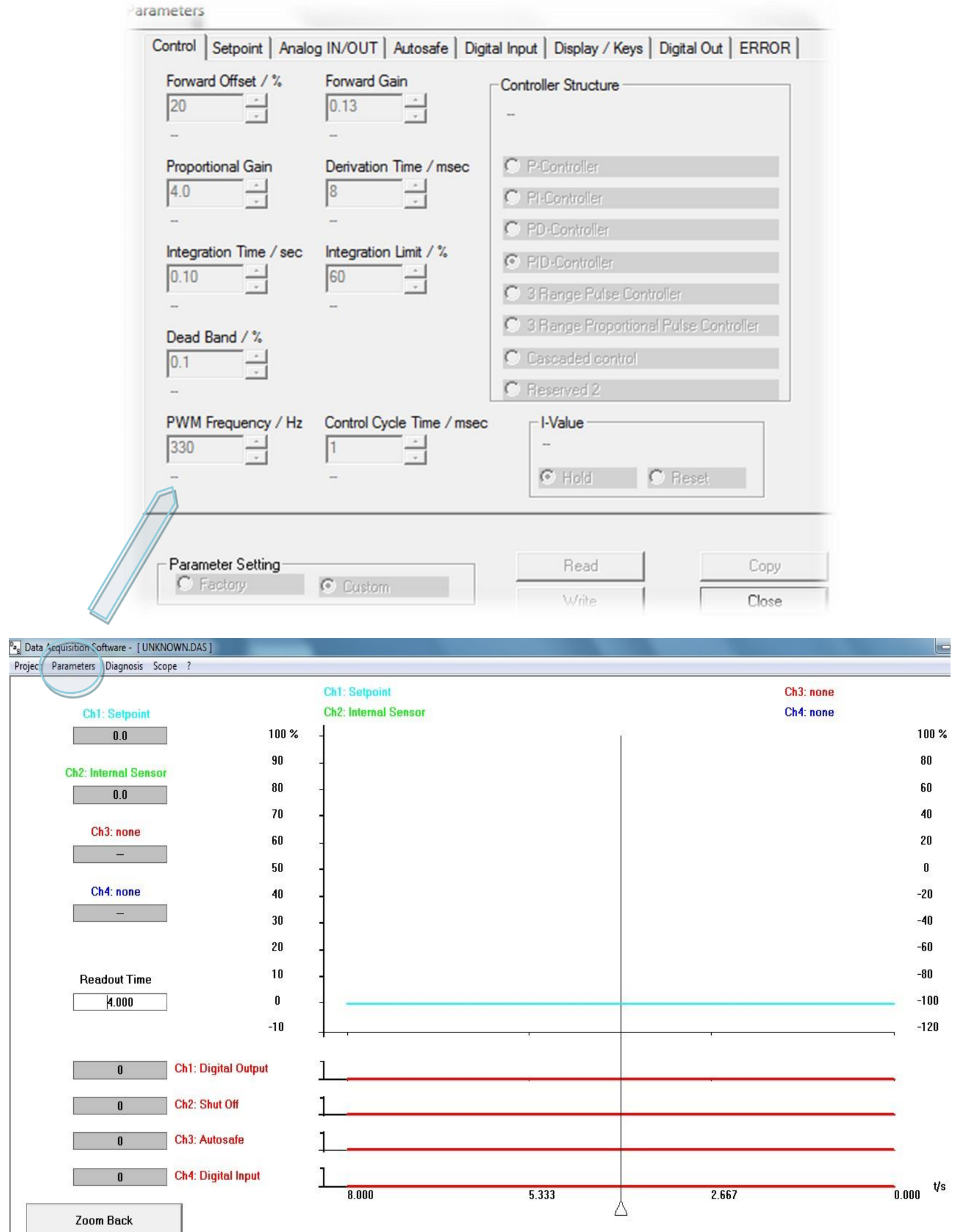

Figura 3.83. Janela do Data Acquisition Software e janela dos parâmetros relacionados às variáveis de controle. 
Após as alterações do ponto de configuração da válvula, a Figura 3.84 apresenta uma curva de pressão com um comportamento menos oscilante e sobressinal menor que o apresentado nas condições anteriores.

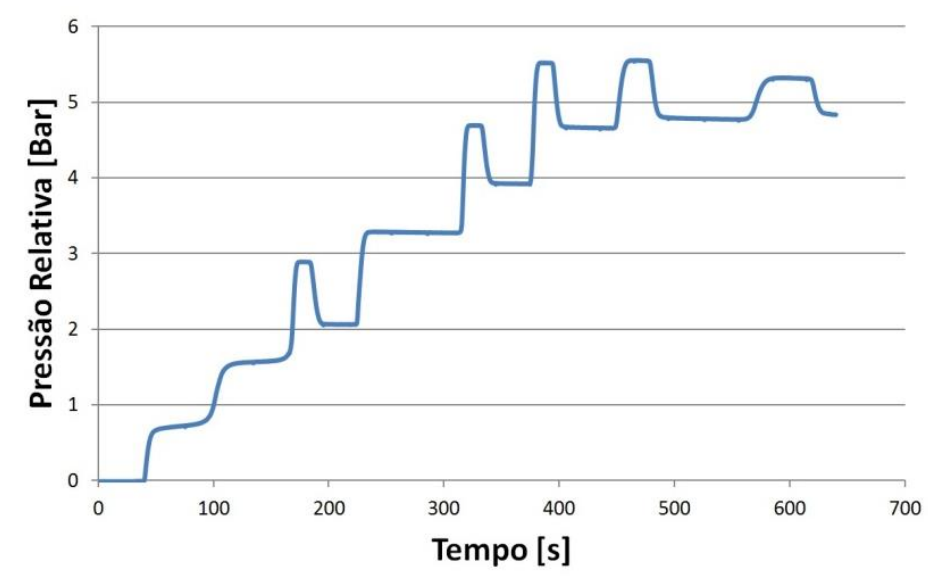

Figura 3.84. Curva de pressão por tempo após alterações no controle.

A Figura 3.85 apresenta o melhor resultado de controle da curva de pressurização aplicada em um exemplo de processo de Conformação Superplástica antes da sintonia do controlador PI com parâmetros de Ziegler-Nichols.

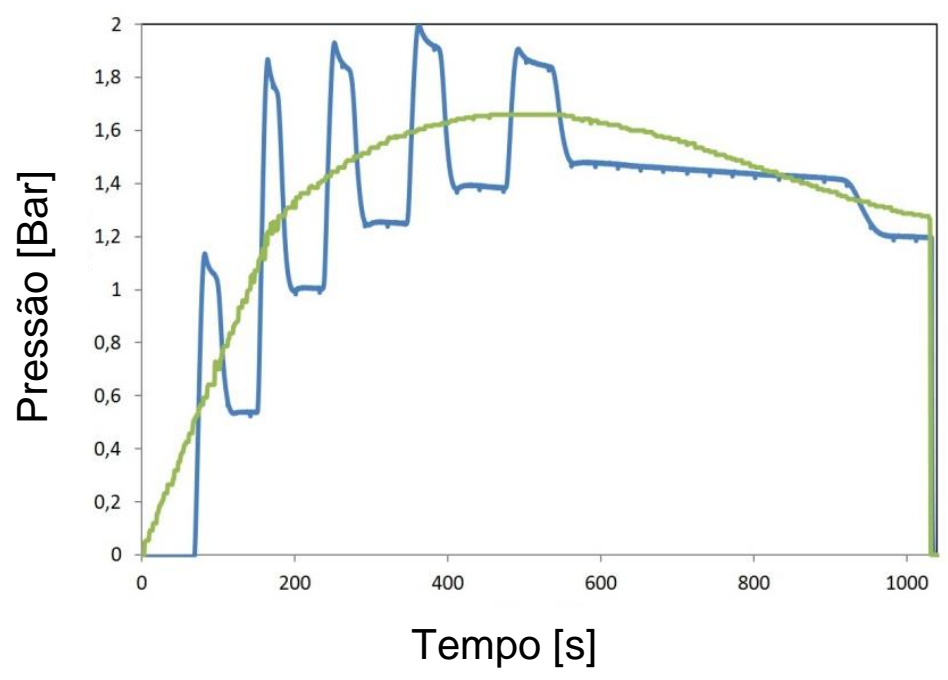

Figura 3.85. Melhor resultado de Curva de pressão por tempo obtido para curva de pressurização da Superplasticidade do PbSn.

Depois de realizados os testes com PbSn, foi necessário mudar alguns parâmetros da válvula para realizar a Conformação Superplástica da liga de Ti6Al4V. 
Com as curvas de titânio, buscou-se refinar o controle aplicando a estratégia de tuning com os parâmetros de Ziegler-Nichols, detalhado no capítulo 3.5 - Controle PID, design e tunning.

Do ponto de vista de parâmetros da válvula, a primeira alteração foi na mudança no Setpoint de 10\% do span (0 - 5 Bar) para 30\% (0 - 15 Bar); denomina-se span a faixa de atuação da válvula, nessa tese é de 50 Bar.
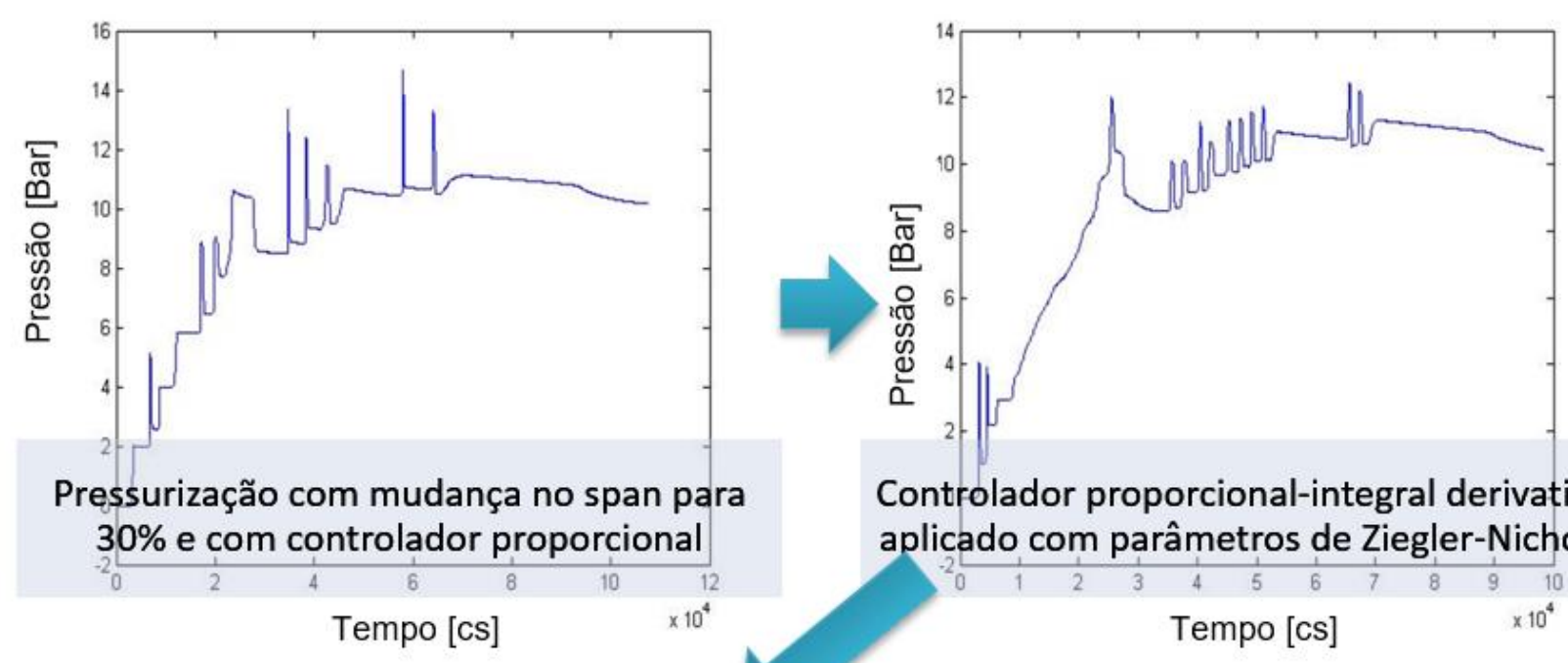

Controlador proporcional-integral derivativo aplicado com parâmetros de Ziegler-Nichols

Tempo [cs]

Tempo [cs]
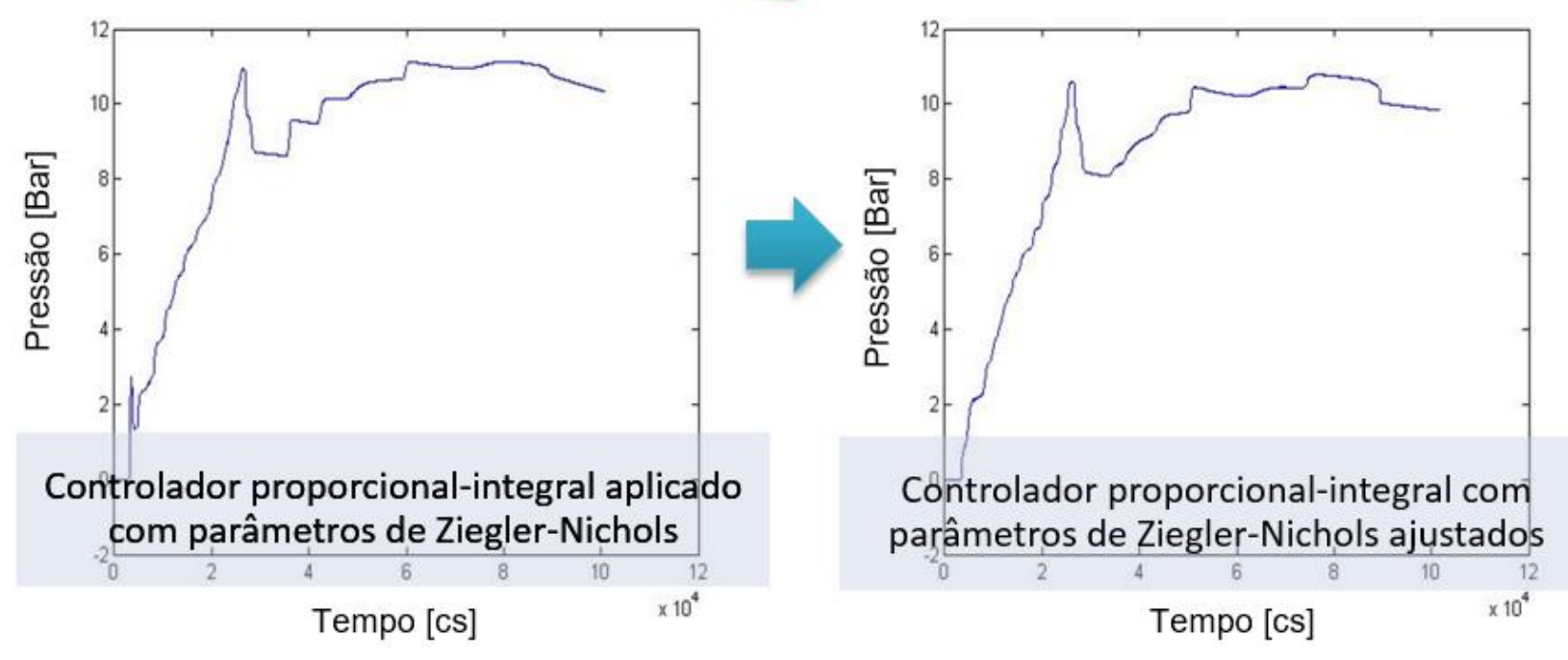

Figura 3.86. Melhoria do controle de pressão devido a mudanças nos parâmetros de controle do controlador PID da válvula.

A Figura 3.86 representa a evolução no controle da pressão aplicada no ensaio de expansão fluidoestática biaxial superplástico. 


\subsubsection{Calibração do sistema de correlação digital de imagem}

Conforme previsto para os resultados dos primeiros ensaios com aquisição de deformação utilizando o sistema ARAMIS, algumas dificuldades foram encontradas, assim como alguns resultados foram alcançados. A principal dificuldade, no que cerne o sistema de medição ótico, foi o ajuste da iluminação. Devido a percepção do reflexo de maneiras diferentes pelas duas câmeras do ARAMIS, notava-se uma falha de leitura em alguns pontos do bulge, conforme pode ser observado na Figura 3.87 e Figura 3.88. Essa dificuldade foi superada após a adaptação da calibração do sistema ARAMIS para a nossa aplicação. De modo objetivo, pode-se dizer que é necessário calibrar as câmeras com uma intensidade de luz acima no padrão e uma abertura de lente abaixo do indicado para a distância focal utilizada.

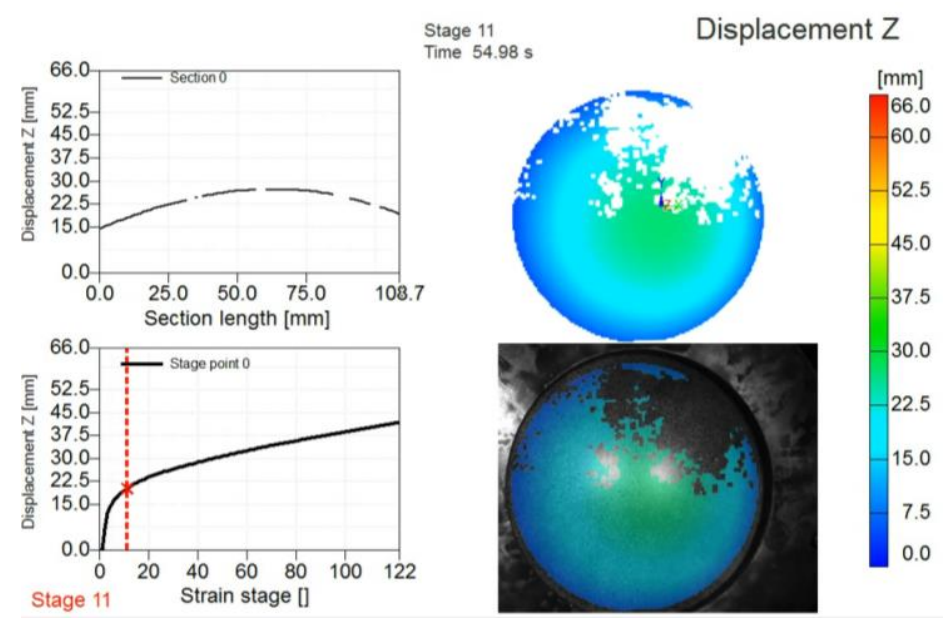

Figura 3.87 Exemplo da utilização do ARAMIS durante o início da expansão fluidoestática à temperatura ambiente utilizando o material $\mathrm{PbSn60.}$

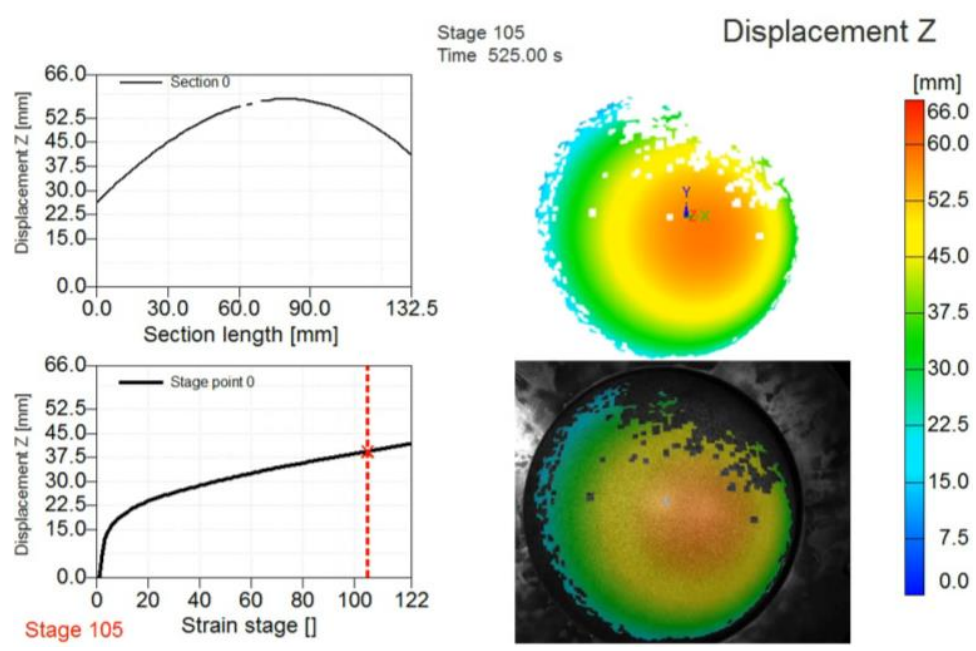

Figura 3.88 Exemplo da utilização do ARAMIS nos estágios finais da expansão fluidoestática à temperatura ambiente utilizando o material PbSn60. 
Devido o elevado volume de medição, em razão da superplasticidade resultar em grandes deformações, outra dúvida que foi esclarecida é até que ponto o sistema ótico acompanharia o pixel da imagem captada durante a conformação. As Figura 3.89, Figura 3.90, Figura 3.91 e Figura 3.92 respondem de maneira positiva, se for considerado que todos os pontos foram seguidos até o estágio 122, inclusive os pontos da região mais externa do blank, a inclinação gerada pela conformação, por mais acentuada que possa ser, não é o suficiente para desestabilizar o processo de medição.

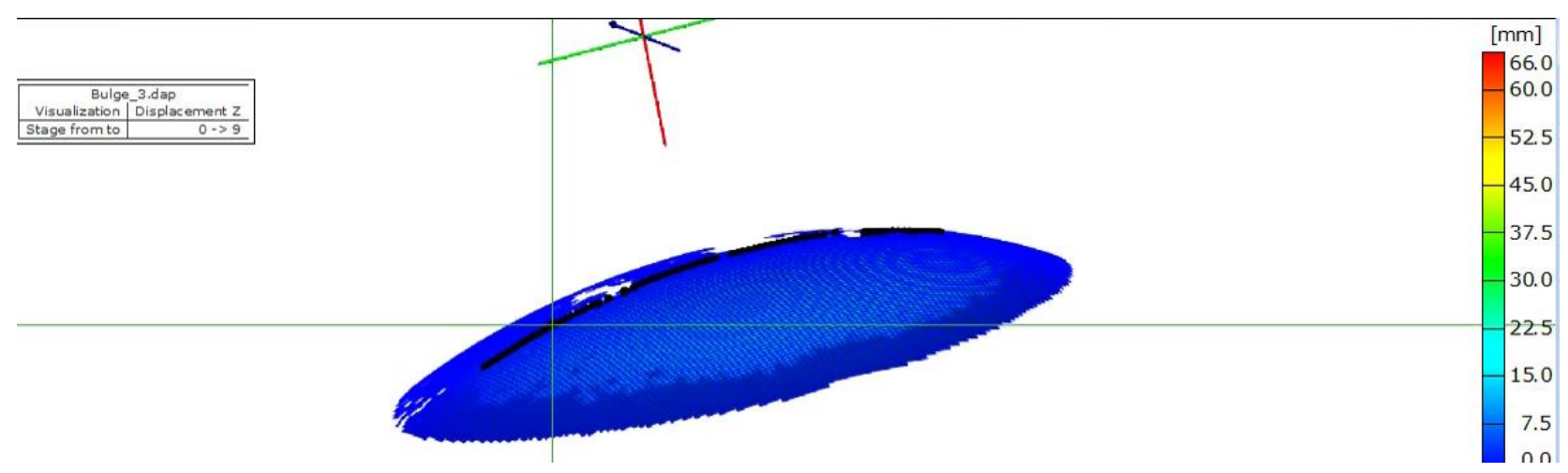

Figura 3.89 Estágio 9 de 122 de ensaio de verificação do acompanhamento do pixel durante a conformação.

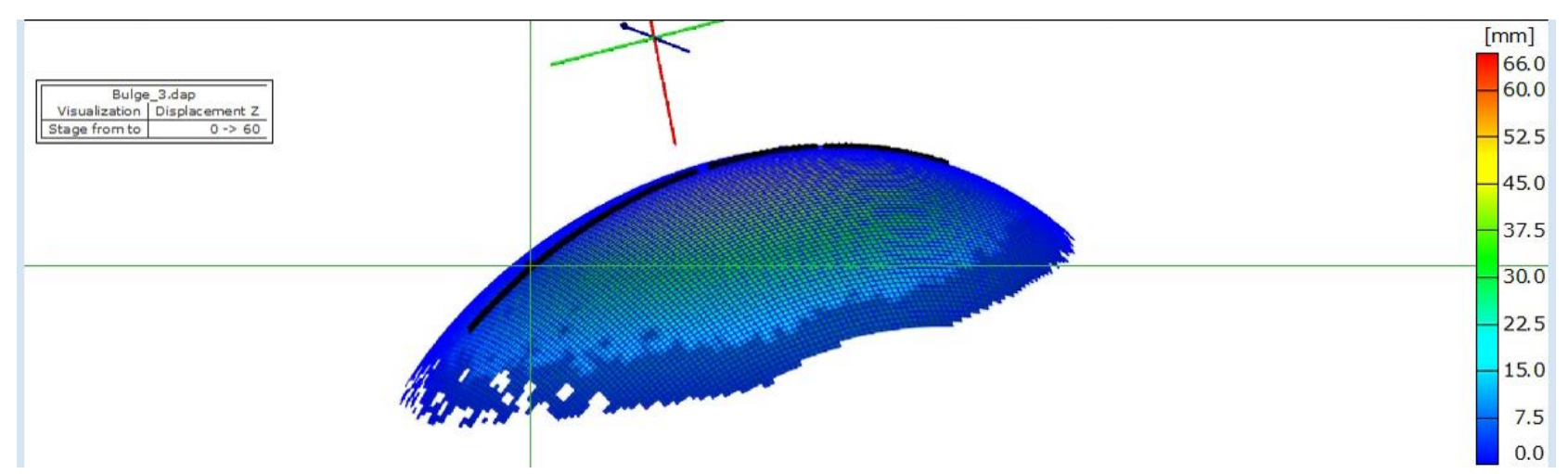

Figura 3.90 Estágio 40 de 122 de ensaio de verificação do acompanhamento do pixel durante a conformação. 


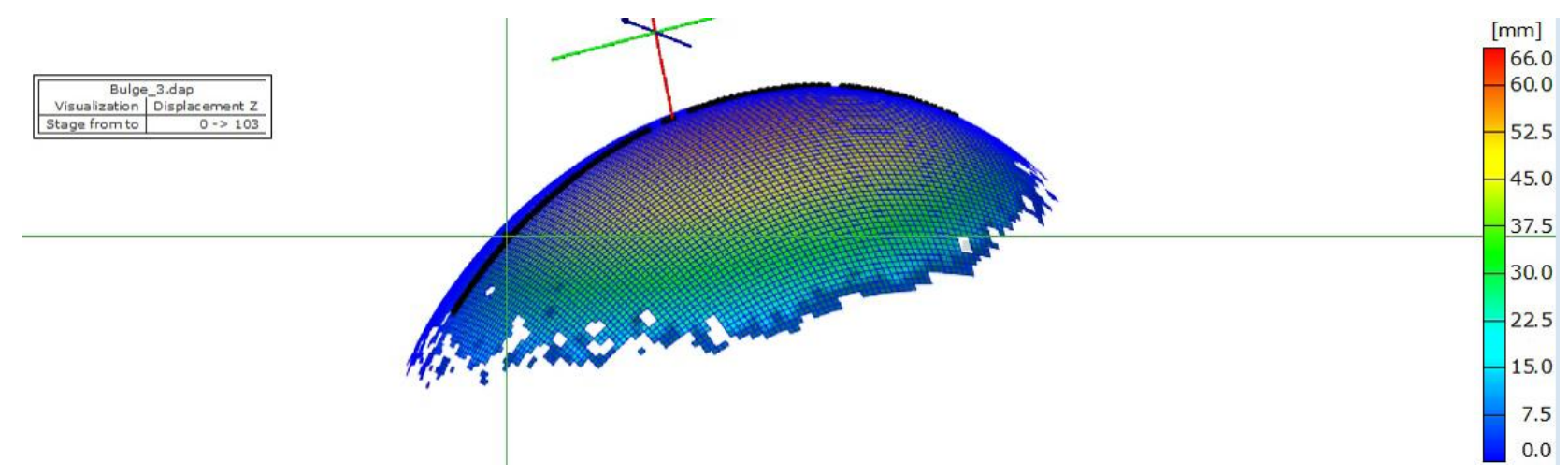

Figura 3.91 Estágio 103 de 122 de ensaio de verificação do acompanhamento do pixel durante a conformação.

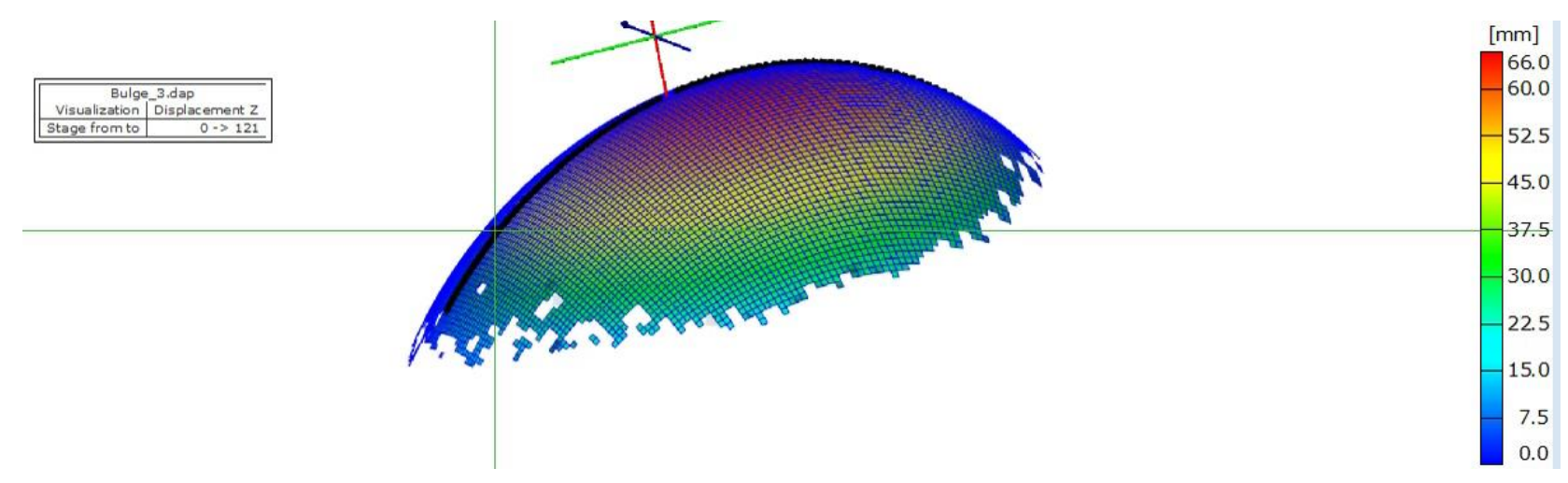

Figura 3.92 Estágio 121 de 122 de ensaio de verificação do acompanhamento do pixel durante a conformação.

Segue Figura 3.93 que mostra a evolução da calibração do sistema ARAMIS, utilizando a intensidade luminosa e abertura das lentes necessária para uma melhor medição.

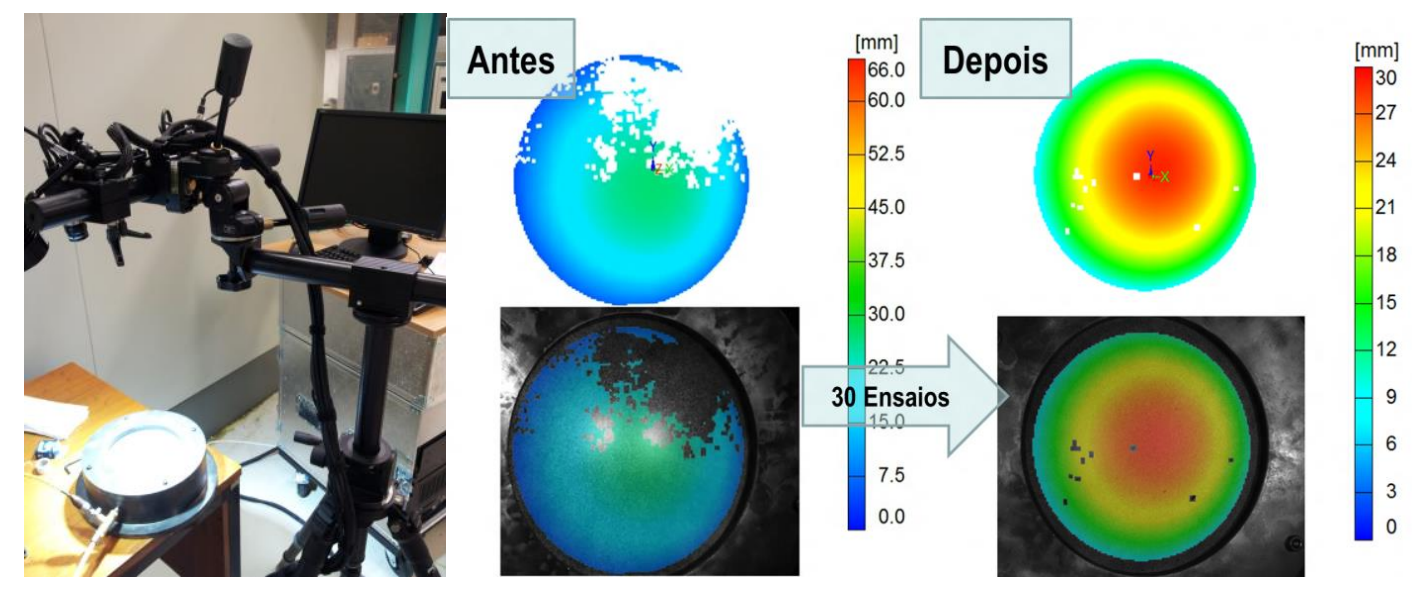

Figura 3.93 Instrumentação da ARAMIS para ensaio com sistema de medição ótica com a calibração definida e melhoria dos resultados pós-calibração. 
A melhoria da medição pode ser vista nos resultados do ensaio de medição ótica com a calibração definida, nas Figura 3.94 e Figura 3.95.
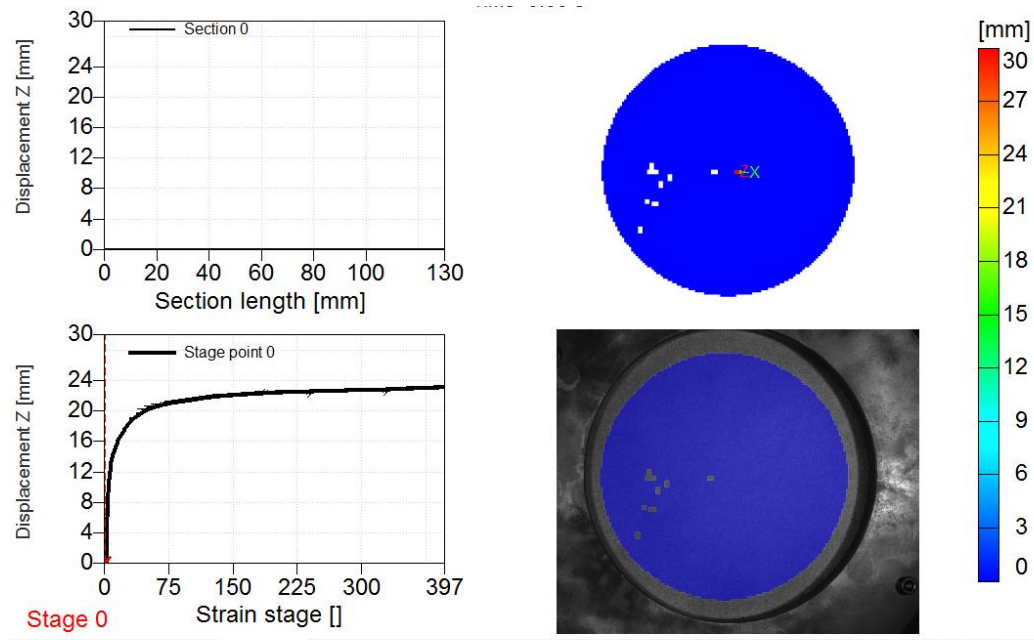

ARAMIS

Eng. Erick Petta Marinho Laboratory of Manufacturing Engineering

Figura 3.94 Exemplo da utilização do ARAMIS durante o início da expansão fluidoestática à temperatura ambiente utilizando o material PbSn60 com a calibração definida.
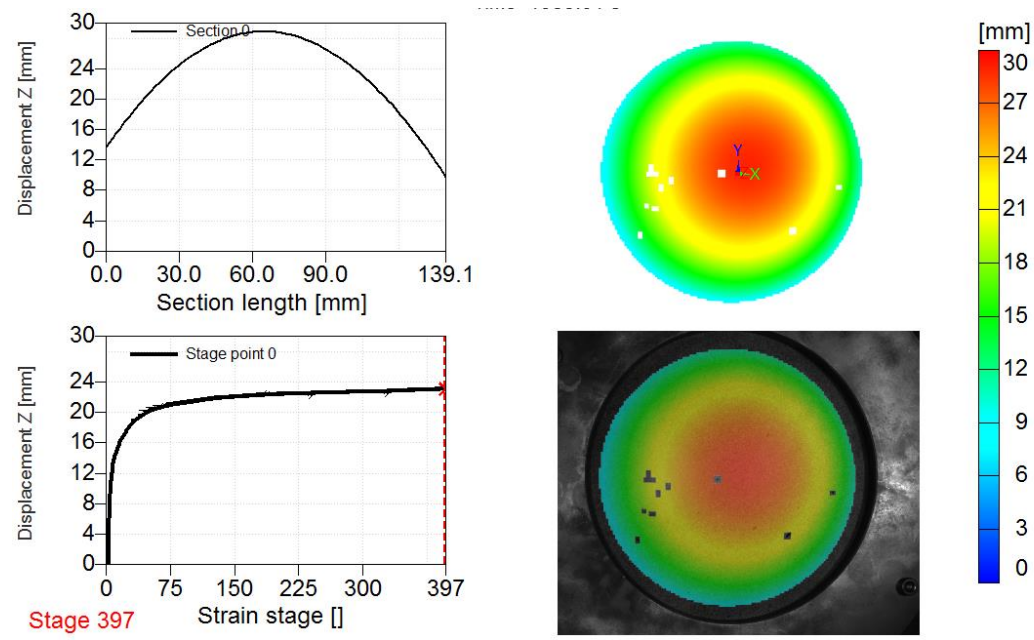

\section{ARAMIS}

Figura 3.95 Exemplo da utilização do ARAMIS durante o final da expansão fluidoestática à temperatura ambiente utilizando o material PbSn60 com a calibração definida. 


\subsubsection{Preparação do sistema de medição ótica}

Em linhas gerais seguem os passos padrões para realização de uma medição com o sistema ARAMIS:

- Determinação do volume de medição e preparação do objeto que será medido;

- Criação do padrão estocástico, através da aplicação do spray, necessário para que o sistema realize a medição.

- Calibração do sistema;

- Criação de um novo projeto de medição no software ARAMIS 3D

- Definição dos parâmetros de entrada do software (Tamanho das facetas, estágios, etc..)

- Ajuste do modo de gravação das imagens como "medições simples";

- Gravação das imagens durante a medição;

- Definição do ponto inicial necessário para os cálculos computacionais;

- Realização dos cálculos computacionais;

- Escolha dos resultados que se pretende analisar;

- Pós-processamento dos dados para eliminar ruídos de medição e realizar a interpolação dos dados 3D que estiverem faltando.

- Definição dos elementos de análise (Seções, planos, pontos, etc.);

- Documentação dos resultados.

Nas conformações superplásticas tem-se utilizado o sistema de medição ARAMIS $5 \mathrm{M}$ com a taxa de aquisição de 1 imagem/s, equipada com lentes de $23 \mathrm{~mm}$, que com o calibrador de dimensões $175 \times 140 \mathrm{~mm}$ teria o volume de medição esperado de $200 \times 170$ $\mathrm{mm}$. Contudo, durante a calibração, a distância de medição recomendada de $530 \mathrm{~mm}$ foi aumentada para $600 \mathrm{~mm}$, isso proporcionou uma área de medição final de $240 \times 240 \mathrm{~mm}$.

Toda essa etapa de calibrações foi realizada com ensaios de superplasticidade da liga de chumbo estanho. Ressalta-se a importância de ter desenvolvido toda uma instrumentação para realizar esses ensaios com chumbo estanho - Figura 3.96, haja vista que os corpos de prova do titânio seriam caros e iniciar a utilização da ARAMIS com ensaios a quente representaria assumir riscos não gerenciáveis, do ponto de vista de metodologia científica. Aproveitou-se do fato da liga de PbSn apresentar superplasticidade a temperatura ambiente. 


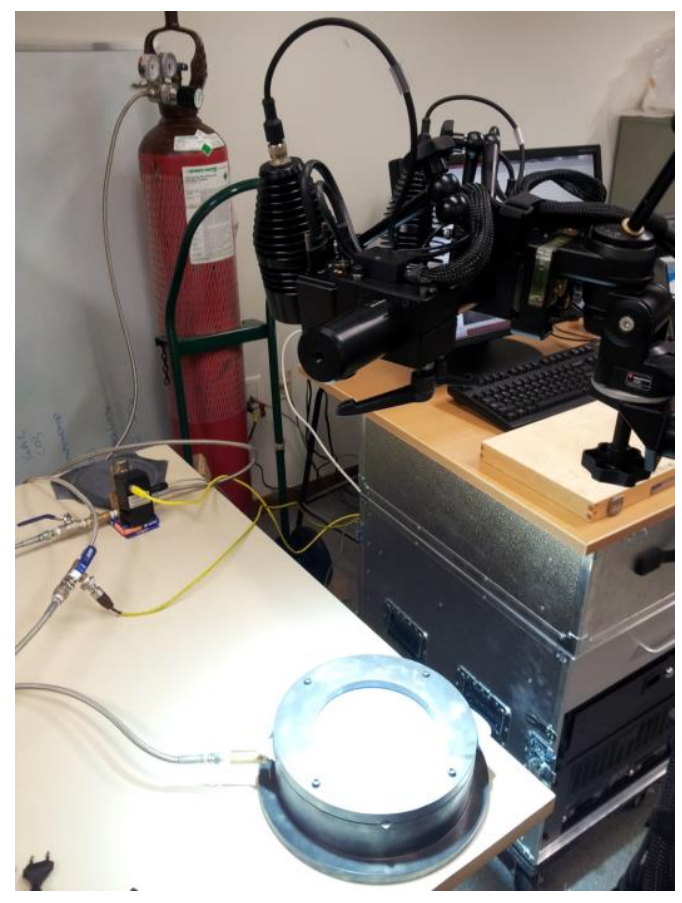

Figura 3.96 Montagem experimental e posicionamento do sistema de correlação de imagem digital nos ensaios de superplasticidade da liga de PbSn.

\subsubsection{Análise dos métodos de pós-processamento}

A evolução do sistema de medição de deformação está relacionada ao pósprocessamento; analisou-se duas maneiras de interpolação dos pontos medidos. A seguir será comentado cada uma delas separadamente.

\subsection{O modelo Plano}

Esse primeiro modelo assume que a vizinhança local do ponto pode ser bem aproximado por um plano tangente. Em razão da deformação arbitrária da superfície, o plano tangente precisa ser calculado separadamente, tanto para o estado deformado, quanto para o estado não deformado.

Os pontos na vizinhança local são então projetados perpendicularmente no plano tangencial. $O$ resultado é dois grupos de pontos no espaço bidimensional, no qual as deformações podem ser agora calculadas. 


\subsection{0 modelo Spline}

O modelo tangencial descrito acima produz bons resultados caso a premissa da linearização dos pontos vizinhos locais seja válida. Caso contrário é necessário ter mais informações que dois vizinhos.

$\mathrm{Na}$ faceta, Figura 3.97, os comprimentos dos lados são calculados usando formas splines. Os comprimentos resultantes podem ser usados para construir um quadrado no espaço bidimensional.

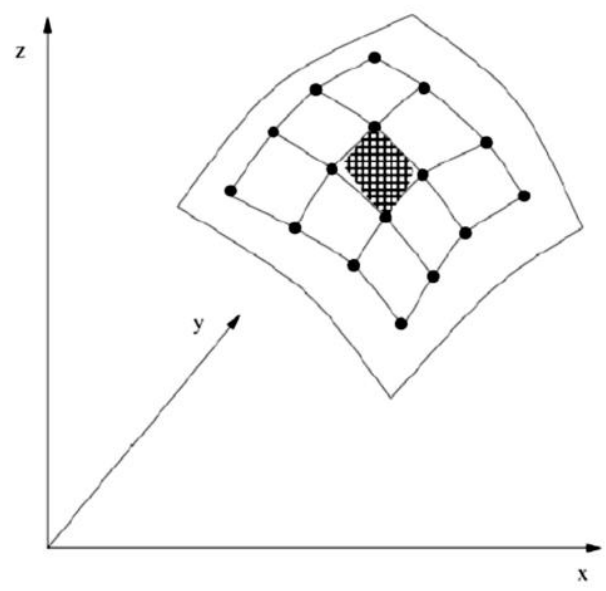

Figura 3.97 Faceta de lado 4 com pontos adjacentes

A comparação dos dois métodos de pós-processamento nos ensaios superplásticos da liga PbSn mostrou resultados muito semelhantes. Um desvio da ordem de $0,01 \%$, confundindo-se com o valor do erro de medição esperado pelo próprio sistema, da ordem de milésimo de milímetro.

Outro parâmetro analisado foi o modo como o software ARAMIS v 6.01 deve calcular os campos de deslocamento, há duas possibilidades; a primeira o software considera a comparação sempre com a imagem anterior (step-by-step) e a segunda realiza a comparação sempre com a primeira imagem. A segunda forma de cálculo apresentou melhores resultados.

\subsubsection{Análise da pigmentação branca e preta.}

À temperatura ambiente não há problemas quanto a utilização de spray de tinta comum, para realizar o padrão estocástico característico da medição, após alguns ensaios esse padrão pode ser conseguido com aplicação manual da tinta. 
A próxima etapa consiste em validar um conjunto de pigmentos que sirva de padrão para realizar a medição do ensaio de bulge da liga de titânio à temperatura de $925^{\circ} \mathrm{C}$ aproximadamente.

A primeira opção já testada, ainda sem o sistema ARAMIS, foi o conjunto de tintas ULFALUX® - Figura 3.101 - utilizada para pintura de caldeiras, tem como temperatura limite de trabalho $1200^{\circ} \mathrm{C}$.

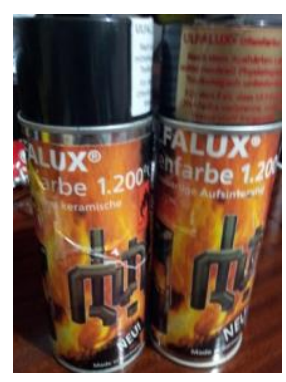

Figura 3.98 Tintas ULFALUX® utilizadas para produzir o padrão estocástico característica da medição do sistema de correlação digital de imagem ARAMIS.

A observação do padrão de cores resultante da chapa de titânio pintada com essas tintas na temperatura de $925^{\circ}$ apresenta, em primeira análise, um resultado satisfatório ao ser considerada a necessidade da busca por um filtro de radiação acoplado a um polarizador, somente com a análise da imagem através de um filtro polarizador e de um filtro de radiação que será possível alcançar o objetivo de utilizar o sistema ARAMIS na temperatura de $925^{\circ} \mathrm{C}$.

A Figura 3.99 fotografada com câmera comum sinaliza para a necessidade da utilização de um filtro de radiação e de um polarizador.

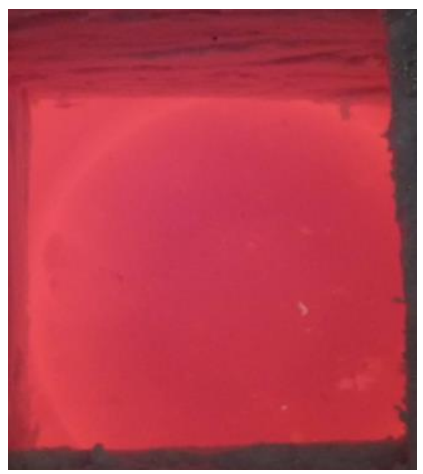

Figura 3.99 Luminosidade resultante do aquecimento do titânio na temperatura de $925^{\circ} \mathrm{C}$ observado pela janela do forno. 


\subsubsection{Aperfeiçoamento da medição óptica: Cristalinidade do Vidro}

Uma das etapas que merece destaque é a medição através da janela de vidro a altas temperaturas. Tal desafio foi sistematicamente segmentado durante o desenvolvimento da referida tese, seguem as etapas:

- Calibração do sistema de medição através da janela de vidro a temperatura ambiente.

- Teste de medição a temperatura ambiente através do vidro.

- Teste de medição em temperaturas elevadas.

Dividindo o desafio em pequenas etapas, busca-se a proteção do sistema de medição de deformação, não submetendo os sensores do sistema a situações de trabalho fora das condições estabelecidas, para isso será necessário a utilização de uma proteção contra radiação, como também contra condução do calor.

O primeiro vidro testado é o vidro comum cristal transparente e temperado, ele foi testado por 4 horas a $930^{\circ} \mathrm{C}$ e manteve a translucidez necessária para a medição com ARAMIS.

A Figura 3.100 mostra a cristalinidade da janela de vidro do forno a $930^{\circ} \mathrm{C}$, após 3 horas de aquecimento.

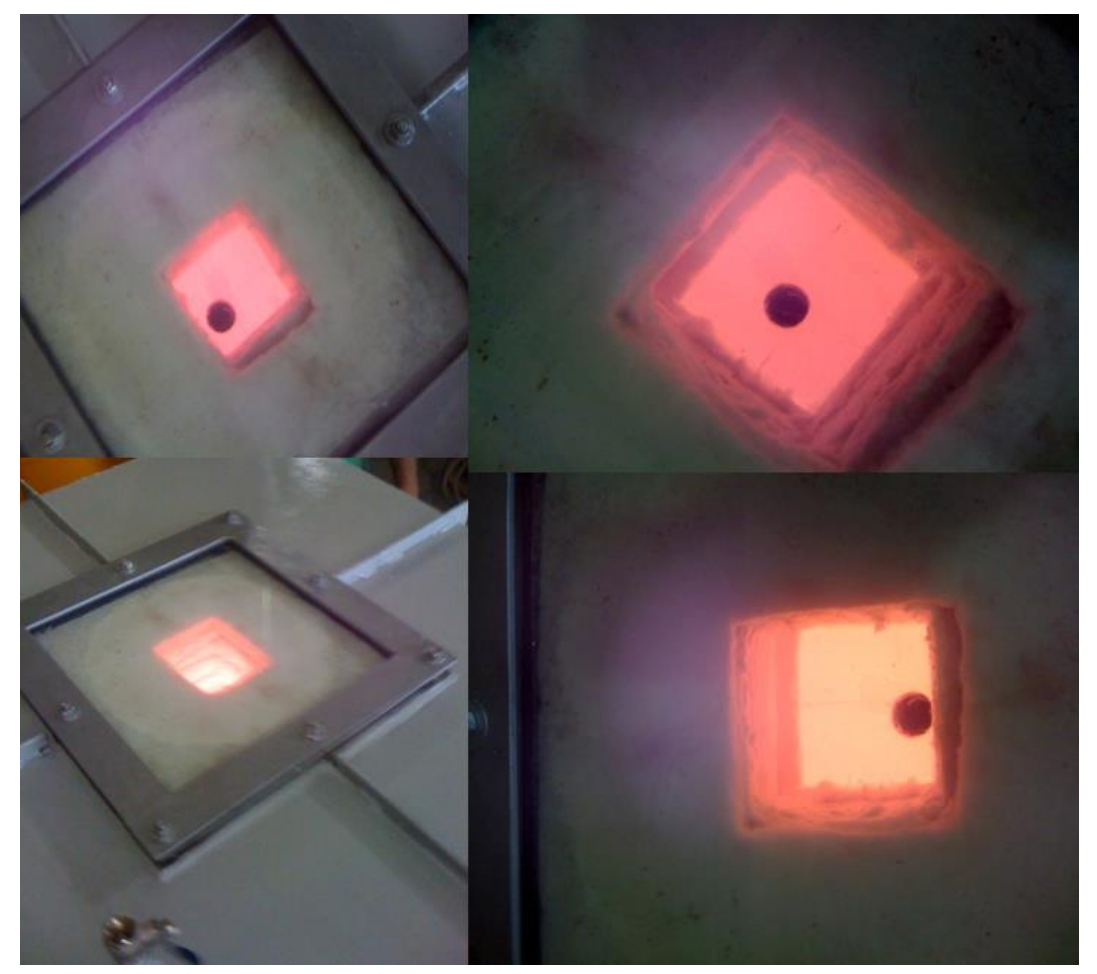

Figura 3.100 Cristalinidade da janela de vidro do forno a $930^{\circ} \mathrm{C}$. 


\subsubsection{Calibração do sistema de controle térmico}

Os primeiros testes foram realizados sem o ferramental dentro do forno, isso explica a ausência de inércia térmica nas primeiras análises.

O sistema de aquecimento já foi testado até $1050^{\circ} \mathrm{C}$, e foi possível obter curvas sem sobressinal, com rampas de aquecimento de até $8^{\circ} \mathrm{C} / \mathrm{min}$.

Sobre a estabilidade do processo, na temperatura objetivo a priori $-927^{\circ} \mathrm{C}$ - atingiuse resultados de $+-1^{\circ} \mathrm{C}$, conforme mostra Figura 3.101.

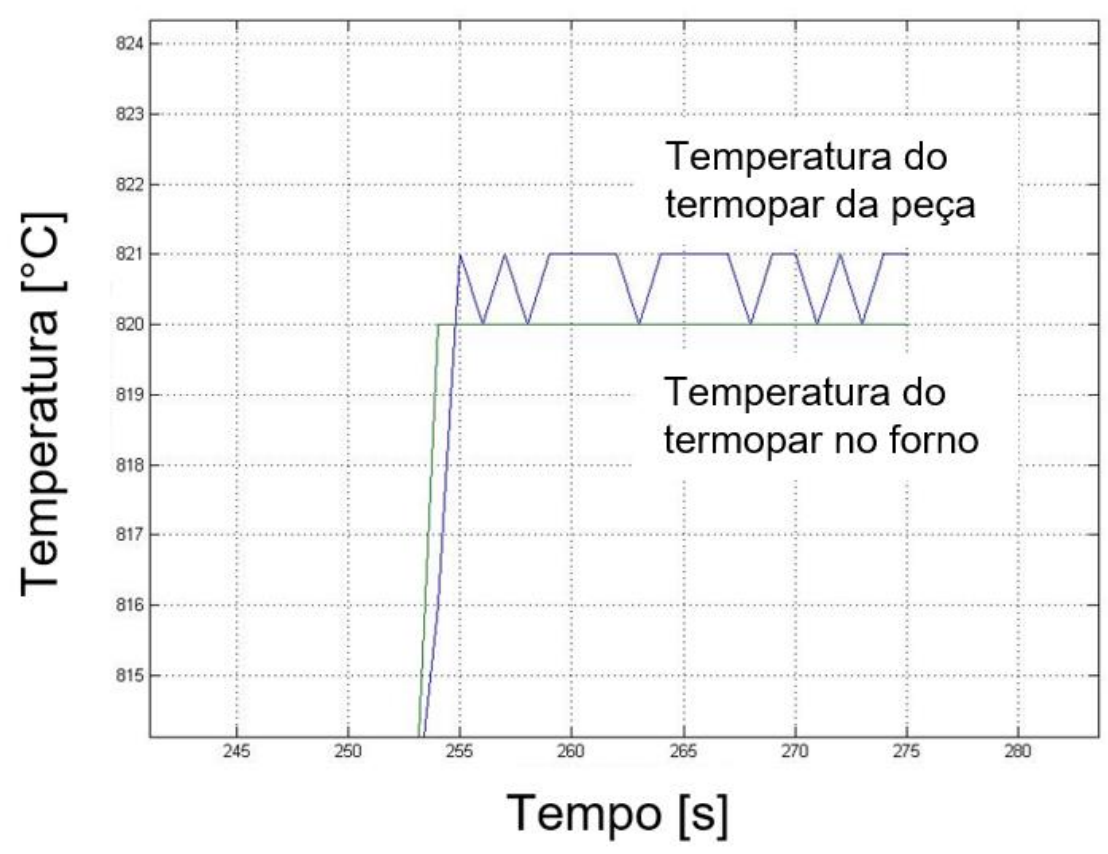

Figura 3.101 Curvas dos sinais de temperatura do termopar em contato com a peça (temperatura controlada, $820^{\circ} \mathrm{C}$, curva inferior flat) e do termopar junto ao meio próximo a uma das paredes do forno (curva superior oscilando em +/$\left.0.5^{\circ} \mathrm{C}\right)$. 


\subsection{Validação da instrumentação a frio: Superplasticidade da liga PbSn}

A importância dos ensaios a frio já foi discutida ao longo do texto dessa tese algumas vezes, de maneira resumida, a validação da instrumentação a frio possibilitou testes dos módulos de controle de deformação e de pressão de maneira isolada, os testes de integração desses módulos e o aperfeiçoamento dos mesmos.

Foi através desses ensaios a frio que se procurou a melhor abordagem analítica para o problema de medição de espessura, possibilitando que a instrumentação fosse testada e ajustada para se tornar robusta o suficiente para iniciar os ensaios a quente utilizando a liga de titânio.

\subsubsection{Material}

O material que é usado para treinamento do sistema de aquisição de imagens e controle da pressurização será a liga bifásica não ferrosa PbSn60 constituída por 60\% chumbo e 40\% estanho. A Figura 3.102 apresenta o diagrama de fases do sistema PbSn destacando a composição da liga.

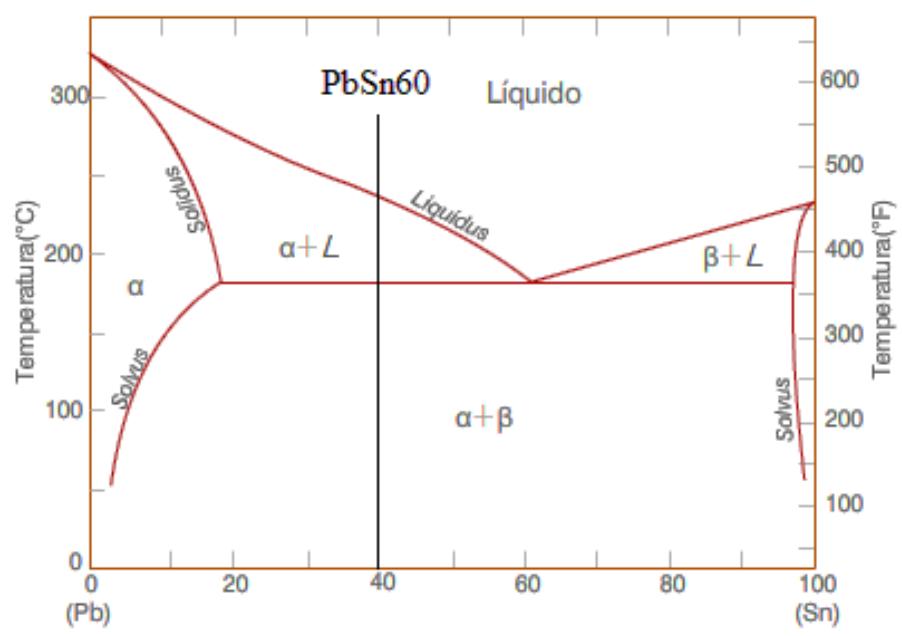

Figura 3.102 Diagrama de fases do sistema PbSn. (FRANCHITTI, 2006)

O material foi escolhido com base na tese de doutorado apresentada por Franchitti na Università degli Studi di Cassino em 2006 (FRANCHITTI, 2006). Nesse estudo a liga apresentou comportamento superplástico à temperatura ambiente após laminação a frio em várias etapas para obtenção de um tamanho de grão final de $\approx 0,7 \mu \mathrm{m}$. 
É importante ressaltar que além de apresentar comportamento superplástico a temperatura ambiente a liga PbSn60 é de baixo custo, o que justifica a aplicação desse material nos testes.

\subsubsection{Processamento}

A liga foi fundida em varetas de dimensões $25 \times 60 \times 8 \mathrm{~mm}$ e laminada até uma espessura de $\approx 0,6 \mathrm{~mm}$, o que corresponde a uma deformação equivalente de $\varepsilon \approx 3$, calculado a partir da equação $\varepsilon=1,15 \ln \left(\frac{t_{i}}{t_{f}}\right)$ sendo ti e tf a espessura inicial e final respectivamente. A Figura 3.103 apresenta uma fotografia da liga na condição inicial (fundida) e após laminação.

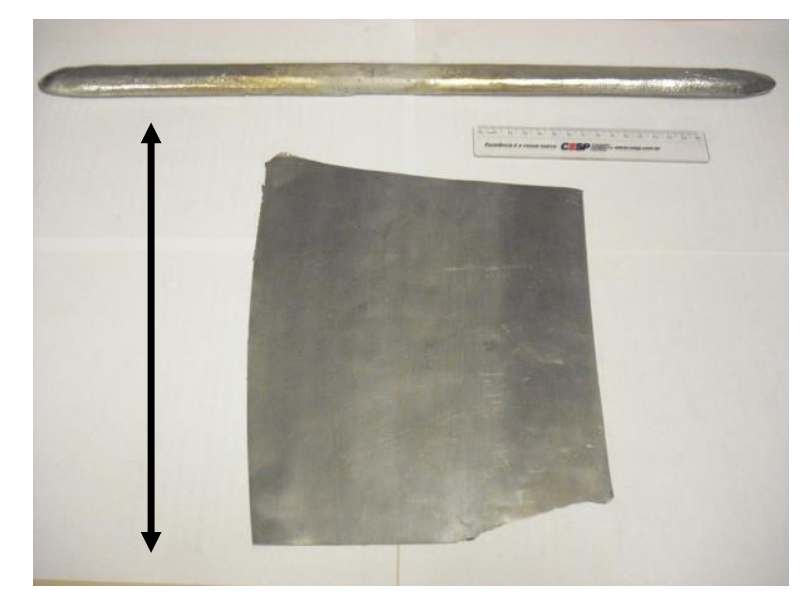

Figura 3.103 Liga PbSn60 fundida e laminada. A seta indica a direção laminação e a vareta tem dimensões $25 \times 60 \times 8 \mathrm{~mm}$

\subsubsection{Ferramenta}

O ensaio foi feito a temperatura ambiente utilizando ar comprimido, visto que a liga PbSn60 não apresenta problemas de oxidação. A Figura 3.104 apresenta uma fotografia da ferramenta construída em aço ABNT 1045 inicialmente construída para o processo de hidroconformação e adaptada para o ensaio de expansão fluidoestática biaxial. O material laminado é inserido entre a base e o anel. 


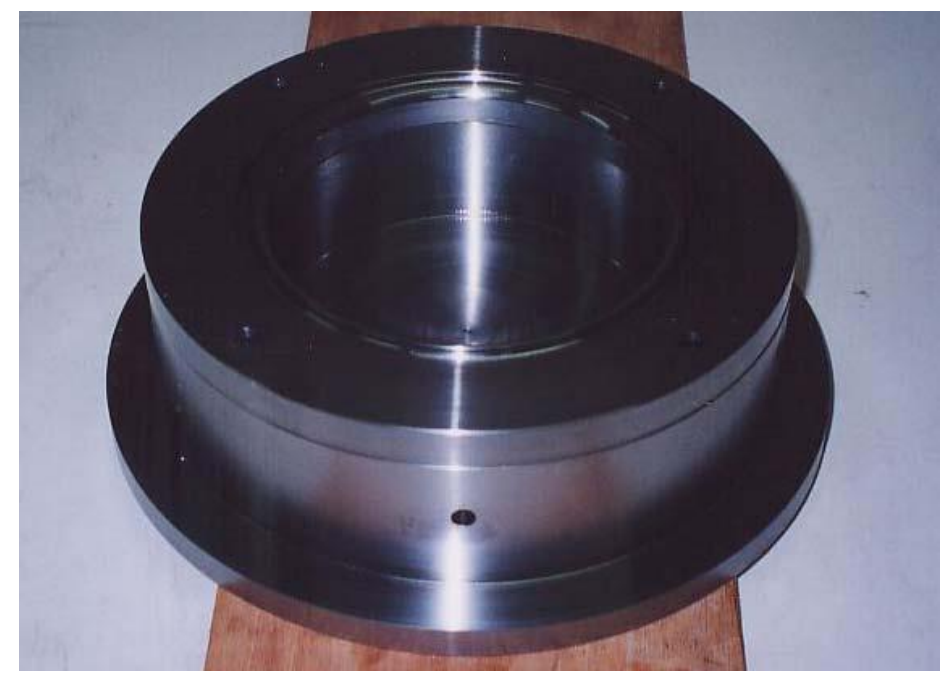

Figura 3.104 Fotografia da ferramenta utilizada no ensaio de expansão fluidoestática biaxial da liga PbSn60.

\subsubsection{Ensaios de ajuste da medição óptica.}

De forma resumida, o sistema de medição ARAMIS baseia-se em estabelecer uma correlação ótica entre as imagens de duas câmeras de alta definição, dessa forma a etapa de medição de deformação, no papel de uma das etapas de calibração do sistema de controle do processo de caracterização reológica, é uma das etapas mais desafiadoras do projeto. Assim, tem-se como um dos primeiros desafios avançar sobre a área útil de medição.

Mais uma vez é importante enfatizar a importância dos ensaios a temperatura ambiente com a liga de chumbo estanho para buscar passo a passo os desafios de instrumentação.

A Figura 3.105 apresenta o setup dos primeiros ensaios de bulge à pressão constante de 0,5 Bar. 


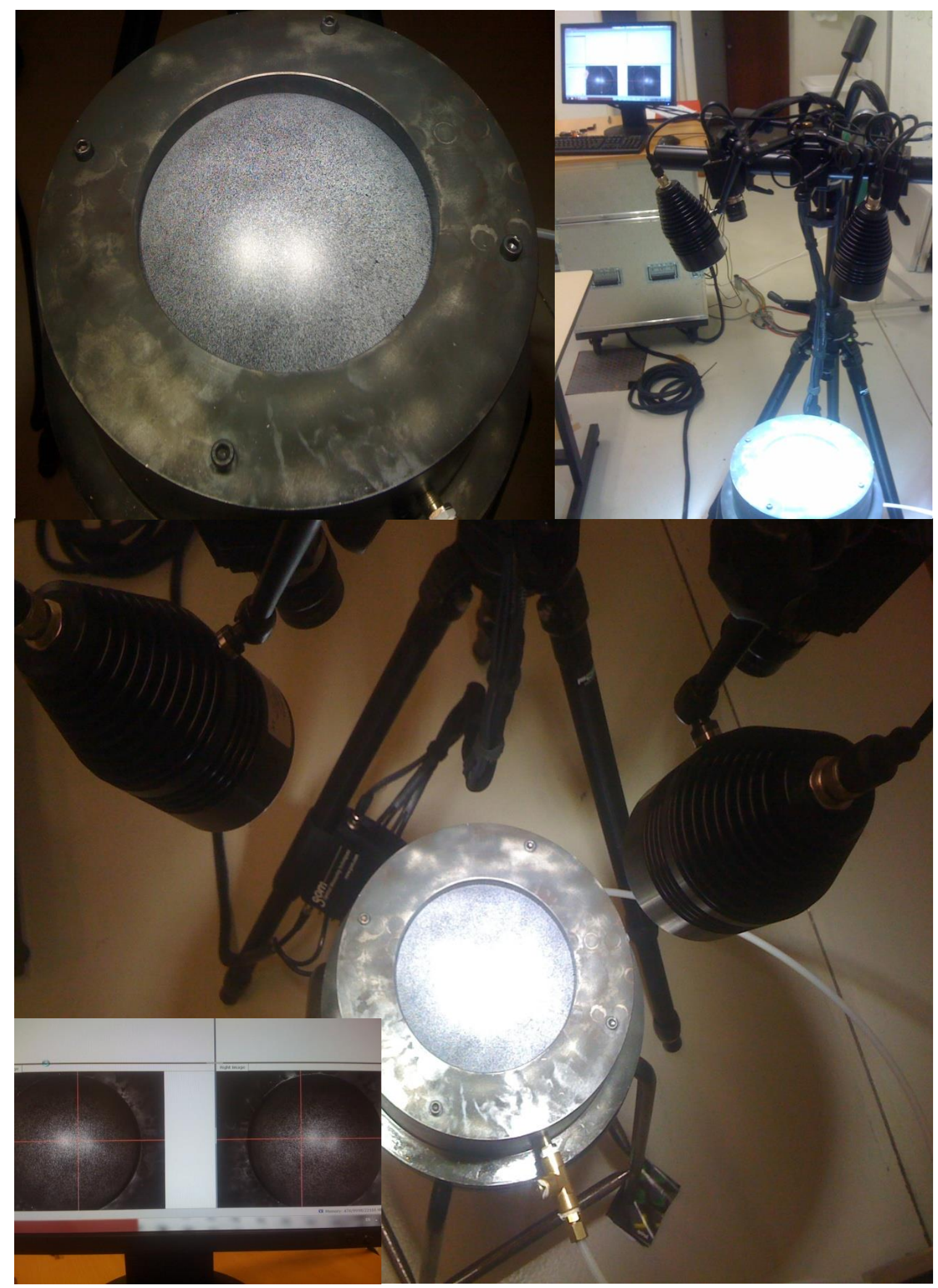

Figura 3.105 Setup dos primeiros ensaios de bulge à pressão de 0,5 Bar. Detalhe das câmeras e sua iluminação dedicada. 


\subsubsection{Vedação}

Duas tentativas de vedação da matriz foram realizadas. A primeira tentativa consistiu na utilização de chumbo estanho em fio; normalmente usado como insumo de solda, o fio de PbSn foi colocado entre a chapa laminada e a base da ferramenta. A ideia era que quando o fio sofresse deformação devido ao fechamento da matriz pudesse trabalhar a favor da vedação, após algumas tentativas, reduziu-se o vazamento, porém não o evitou.

A segunda tentativa e de sucesso, consistiu na utilização de adesivo termoplástico. A aplicação é feita entre a base e a lâmina, a força aplicada no fechamento e a boa deformação apresentada pelo adesivo termoplástico, comportando-se como uma borracha, garantiram a vedação.

\subsubsection{Definição da curva de pressurização}

Tendo como referência dois trabalhos que abordam o comportamento dessa liga escolheu-se a curva de pressão, Figura 3.106; O primeiro relaciona o tempo de conformação com a pressão de conformação e a taxa de deformação (KHRAISHEH, 2000), já o segundo gera resultados de elementos finitos para o ciclo de pressão. (FRANCHITTI,2007).

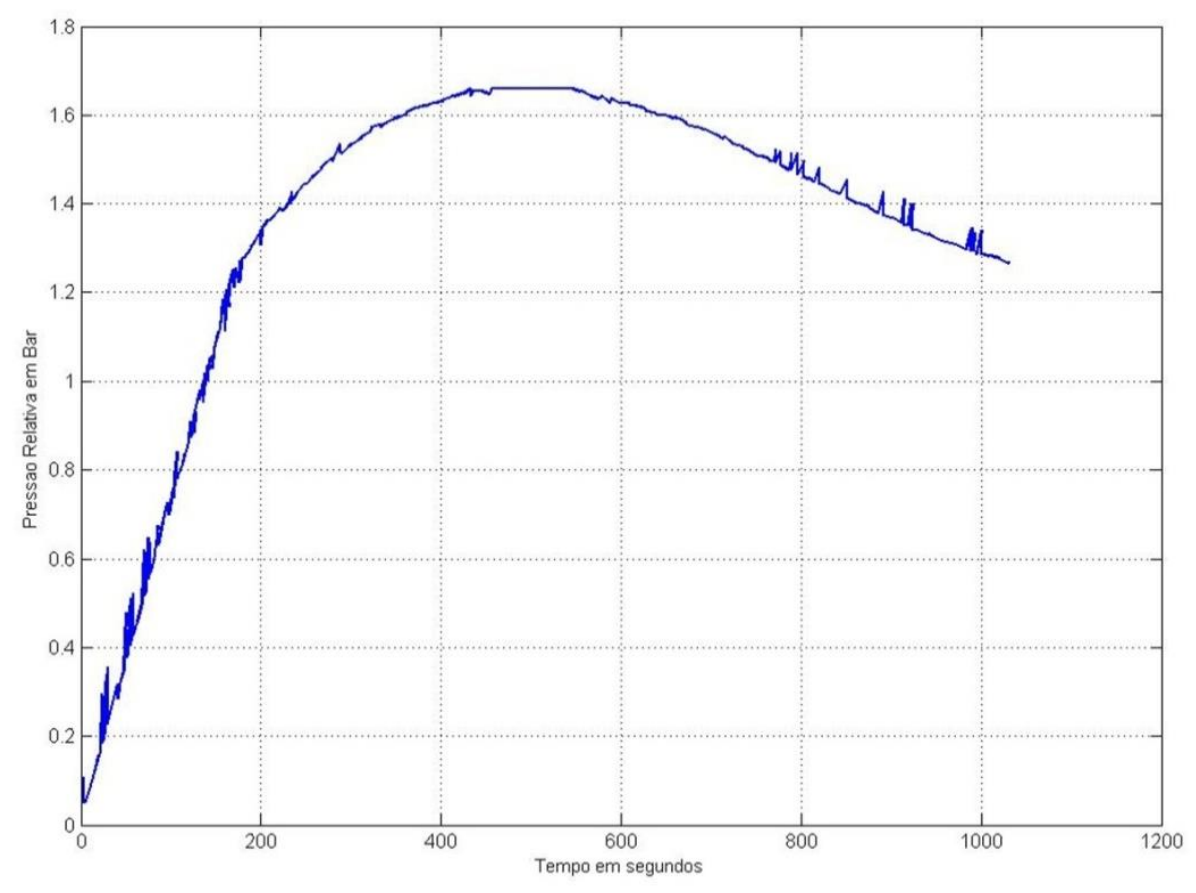

Figura 3.106 Curva de pressão exemplo utilizada para avaliar o ensaio a taxa de deformação constante. 


\subsection{Caracterização reológica em Conformação Superplástica}

Os dados levantados pela caracterização reológica ( $m, n$ e k) são importantes desde o processo de simulação numérica de uma conformação até o estudo comparativo das equações constitutivas, sendo utilizado também para uma melhor implementação do controle, conforme destaca Figura 3.107.

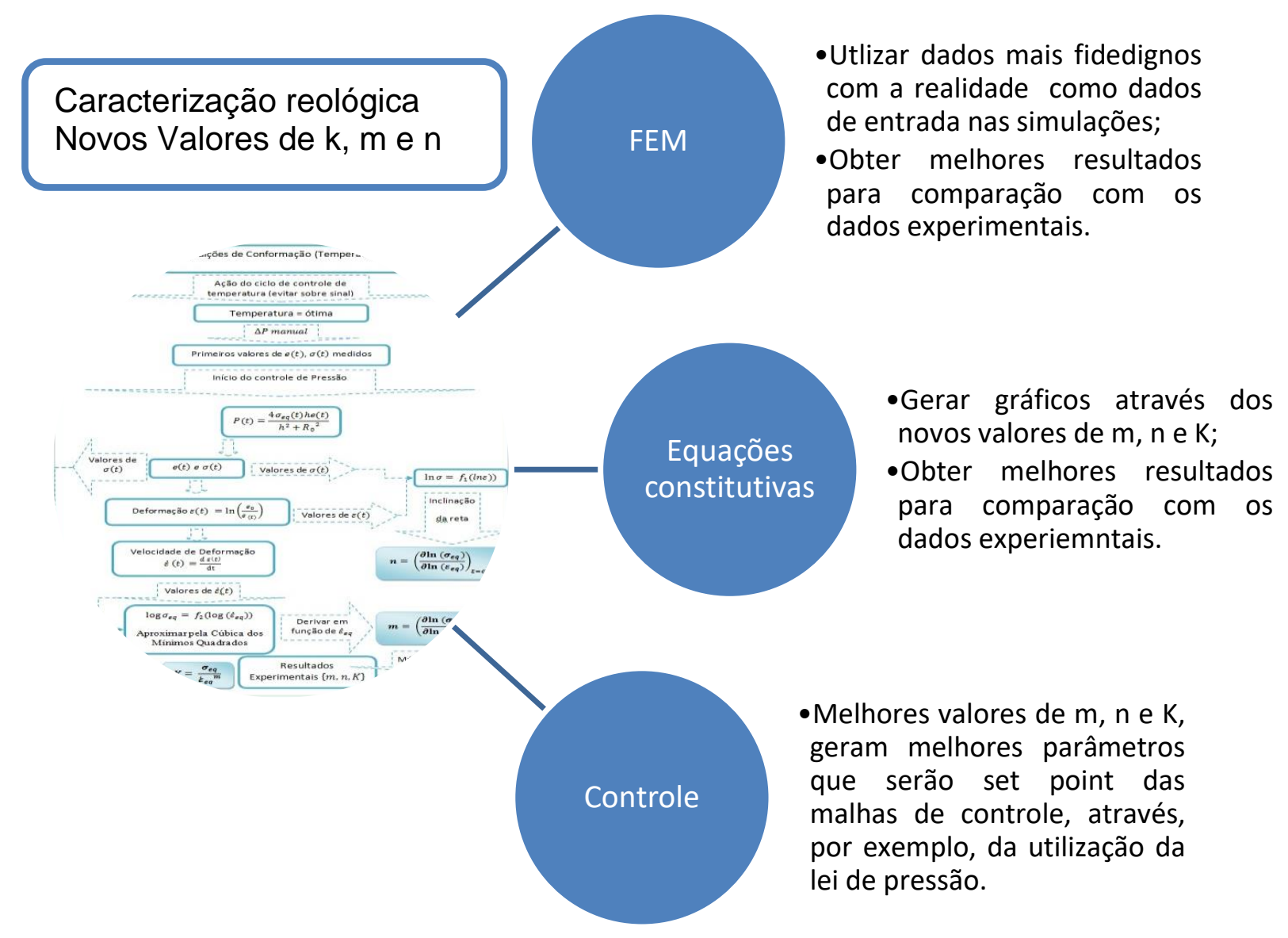

Figura 3.107 Importância da caracterização reológica

Os ensaios de tração, pela simplicidade e facilidade de realização, são os mais utilizados para identificar os modelos reológicos dos materiais no que cerne a superplasticidade, por mais que não sejam ensaios que traduzam a conformação real em alguns aspectos. Por exemplo, as tensões aplicadas nos ensaios de tração comuns são unidimensionais enquanto que numa expansão fluidoestática biaxial a tensão é resultado das tensões do estado plano de tensões. É devido a esse e outros problemas que se busca estudar maneiras de identificar as características reológicas mais próximas às condições reais da conformação fluidoestática biaxial. 
Inicialmente é interessante destacar quais são as características que são buscadas por esses ensaios. No caso da expansão fluidoestática biaxial são m (índice de sensibilidade a taxa de deformação), n (Expoente de encruamento) e $K$ (constante do material).

Nos anos 70 Jovane propôs o primeiro modelo analítico para estudar a expansão fluidoestática biaxial hemisférica em 1962. (JOVANE, 1968).

Em seguida, estudos experimentais e analíticos mostraram que a distribuição de espessura ao longo do corpo de prova depende do índice de sensibilidade a taxa de deformação. (HOLT,1970)

Outros trabalhos analíticos mostraram que a redução de espessura (thinning) da peça era mais importante que o coeficiente $m$ na distribuição não uniforme da mesma. Essa redução de espessura é devido ao gradiente de tensão entre o polo e a base do domo deformado. (GHOSH, 1982)

A caracterização do processo também foi estudada para a superfície cônica, conforme trabalho de Holt. (HOLT, 1970)

O procedimento apresentado por Jung-Hu (CHENG, 1996) é um dos primeiros estudos a propor uma metodologia de caracterização reológica a partir de ensaios de expansão fluidoestática biaxial livre. No entanto a identificação dos parâmetros reológicos teve como hipóteses a distribuição uniforme da espessura, e a utilização de ensaios a pressão constante, que também limitava o campo de aplicação desse procedimento.

Aoura realizou, em 2004, também uma proposta de caracterização reológica por ensaio biaxial (AOURA,2004). Nesse trabalho realiza-se ensaio a tensão constante, e possui um diferencial em relação a sua abordagem, a variação da espessura ao longe de um meridiano não é uniforme, como também ele realiza um estudo com a matriz cônica e uma matriz de geometria variável.

Os ensaios biaxiais para caracterização reológica dos materiais superplásticos são pouco citados na literatura. Geralmente o estudo é feito para expansão livre e para matriz cônica.

Seguem três protocolos que podem ser observados na literatura:

- Expansão fluidoestática biaxial à pressão constante;

- Expansão fluidoestática biaxial à velocidade de deformação constante;

- Expansão fluidoestática biaxial à tensão constante. 


\subsubsection{Expansão fluidoestática biaxial à pressão constante}

Esses ensaios foram os primeiros a serem utilizados para estudo de materiais em Conformação Superplástica (JOVANE, 1968). A lei de pressão é uma das grandes dificuldades do modelamento dos ensaios de caracterização reológica, como no teste de expansão fluidoestática biaxial à pressão constante não é necessário modelar uma lei de pressão, está justificada a facilidade de realização desse teste quando comparado aos outros dois que aparecem na literatura. Jovane mostrou que um ensaio a pressão constante provoca variações significativas na velocidade de deformação.

Os ensaios a pressão constante se adaptam melhor aos materiais que possuem o comportamento superplástico bem definido. (AOURA, 2004)

\subsubsection{Expansão fluidoestática biaxial à velocidade de deformação constante.}

Esse ensaio é o objetivo da instrumentação desenvolvida nessa tese, o ciclo de pressão garante a velocidade de deformação constante no topo do domo conformado através de modelos analíticos ou numéricos.

Nessa tese, através da aplicação de um ciclo de pressurização definido, verifica-se experimentalmente e durante o processo de conformação, a manutenção da taxa de deformação ótima do processo de conformação superplástico. Esse resultado, para a liga de PbSn, está detalhado no capítulo 4.3, através de uma curva de pressão pré-definida foi possível medir tanto a taxa de deformação ao longo do ensaio, quanto obter resultados de medição de espessura melhores que as aproximações analíticas comumente utilizadas.

No entanto, nesse tipo de ensaio, o conhecimento dos parâmetros reológicos é indispensável, o que se observa geralmente é que esses ensaios oferecem a possibilidade de verificação dos modelos mecânicos em expansão fluidoestática biaxial (JOVANE, 1968) e validação dos parâmetros reológicos obtidos a partir de ensaios de tração. (AOURA,2004).

No trabalho de Dutta e Mukherjee (DUTTA,1992), sobre o pressuposto de uma velocidade de deformação no domo da calota deformada constante, é desenvolvida uma lei, equação (114), para o ciclo de pressão que atuará no ensaio seguindo a equação de Norton-Hoff. 


$$
P_{h}(t)=4 \frac{e_{0}}{R_{0}}\left(1-e^{-\dot{\varepsilon} t}\right)^{\frac{1}{2}} e^{-\frac{3}{2} \dot{\varepsilon} t} K \dot{\varepsilon}^{m}
$$

Observa-se que no modelo de Dutta e Mukherjee (DUTTA, 1992) a altura da calota $\left(h_{p}\right)$ não é levada em consideração. Já no trabalho de Banabic (BANABIC, 1999), observase que a pressão já é uma função não só da variação da deformação, mas também da altura da calota. Conforme se observa pela equação (115):

$$
\begin{gathered}
P_{h}(t)=2 \frac{1+\alpha\left(\frac{b_{0}}{a_{0}}\right)^{2}}{\sqrt{1+\alpha+\alpha^{2}}} \frac{e_{0}}{R_{0}} h_{p}\left(1+\frac{h_{p}{ }^{2}}{b_{0}{ }^{2}}\right)^{\frac{3}{2-\alpha}} K \dot{\varepsilon}^{m} \\
\alpha=\frac{\sigma_{2}}{\sigma_{1}}=\frac{1}{2}\left(1+e^{1-\frac{a_{0}}{b_{0}}}\right)
\end{gathered}
$$

\subsubsection{Expansão fluidoestática biaxial à tensão constante}

Boulos (BOULOS, 1999) estudou a Conformação Superplástica de matrizes cônicas. Mostrou-se em seu trabalho que para realizar ensaios à pressão e tensão constantes, é necessário que o ângulo no topo do cone varie em função da altura.

Esses métodos que utilizam matrizes cônicas ou prismáticas apresentam limitações em relação ao modelo de contato entre a matriz e a peça de conformação. O coeficiente de atrito tem influência sobre a pressão de conformação e o tempo. (AOURA, 2004)

Aoura (AOURA, 2004) utilizou ensaios à tensão constante, para o estudo reológico de seu trabalho, no qual era preciso 4 ensaios à pressão constante, para que se calculassem os coeficientes $A_{0}, A_{1}, A_{2}$ e $A_{3}$; e de posse da equação de terceiro grau utilizada para modelar a curva tensão $\sigma$ versus velocidade de deformação $\dot{\varepsilon}$, a mesma pudesse ser derivada para que se gerasse a curva índice de sensibilidade a taxa de deformação $m$ versus velocidade de deformação $\dot{\varepsilon}$.

A Figura 3.108 resume a estratégia de ensaio de caracterização dos materiais proposta por Aoura (AOURA, 2004). 
Condições de Conformação

(Temperatura e Tensão)

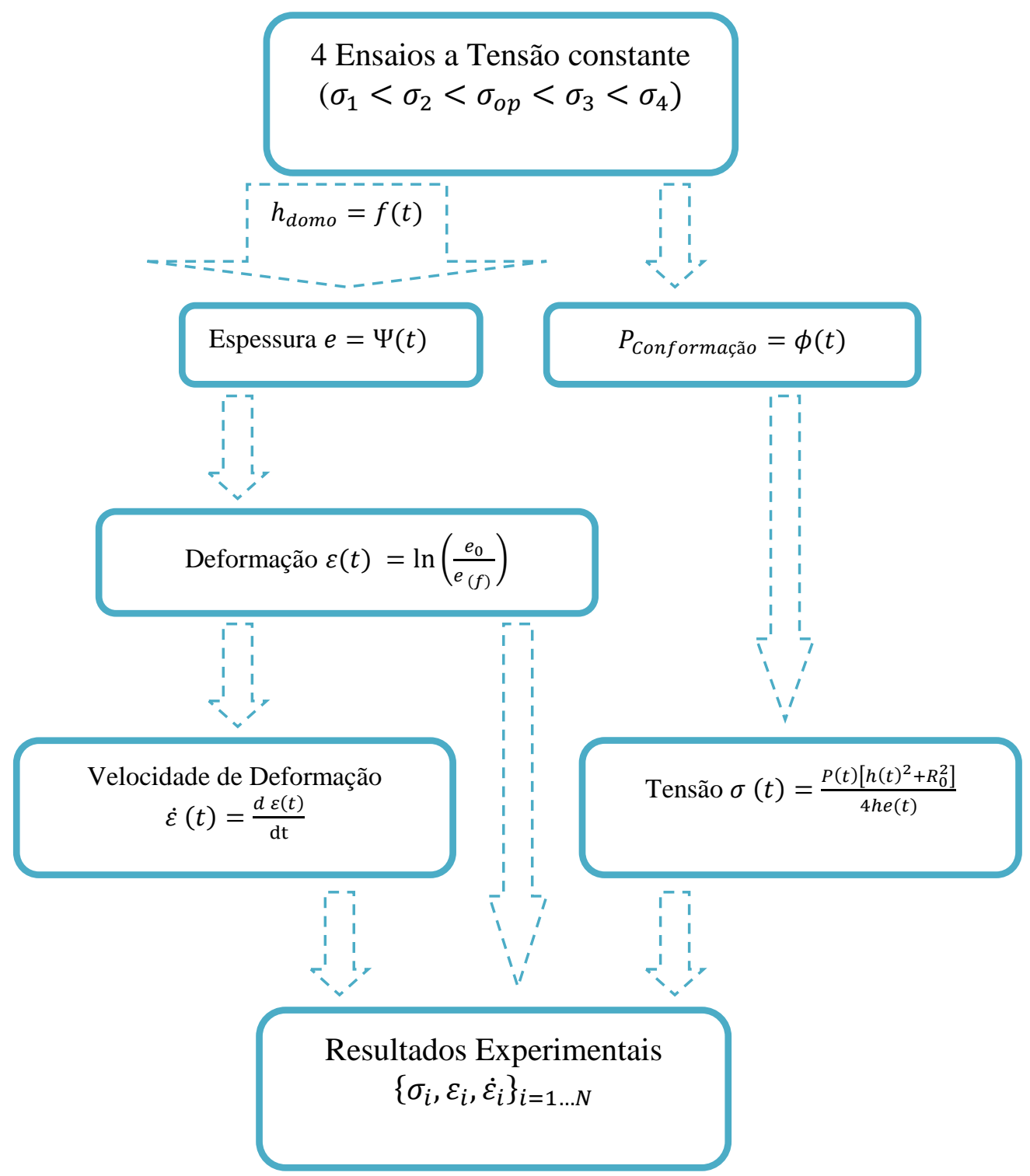

Figura 3.108 Estratégia de ensaio de caracterização dos materiais utilizado por AOURA. Adaptado (AOURA, 2004). 


\subsection{Proposta de estratégia de caracterização de expansão fluidoestática biaxial}

\subsubsection{Modelo analítico de expansão fluidoestática biaxial livre}

Apresentam-se as hipóteses tradicionalmente assumidas na abordagem analítica da expansão fluidoestática biaxial, em seguida será apresentada a função que relaciona as variáveis de interesse do ensaio de bulge teste superplástico, e, por fim, será apresentada a nova proposta de caracterização reológica que é possível ser aplicada com o desenvolvimento do ferramental da referida tese.

\subsubsection{Hipóteses}

As hipóteses aqui definidas seguem alguns trabalhos da literatura, como Jovane (JOVANE, 1968), e estão listadas a seguir:

- O material é isotrópico e incompressível;

- A forma da peça deformada é perfeitamente esférica;

- A variação de espessura ao longo de um meridiano não é uniforme;

- As deformações e as tensões são homogêneas por toda a espessura do material;

- Não há movimento entre a matriz e a parte presa da peça. 


\subsubsection{Modelo analítico aplicado}

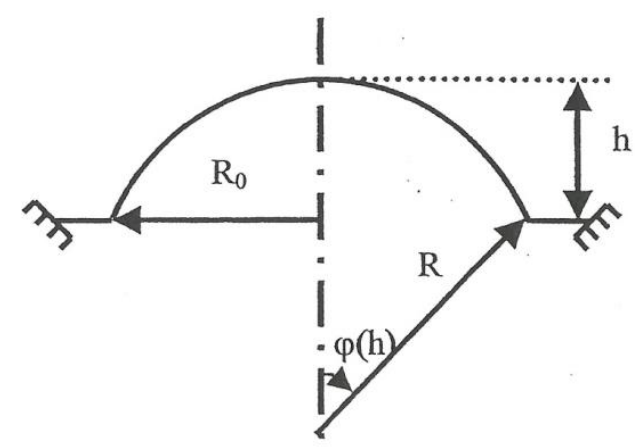

Figura 3.109 Esquema de ensaio de expansão fluidoestática biaxial para uma peça fina. (AOURA, 2004)

A equação (116) é retrabalhada nessa tese para gerar a função pressão de conformação em função do tempo, na sua forma original, em função da alutra, obteve bons resultados na literatura (AOURA, 2004)(JOVANE, 1968).

$$
P(h)=\frac{2 \sigma_{e q} s(h)}{\rho(h)}
$$

Tendo como relação para espessura a abordagem analítica a seguir:

$$
s(h)=\frac{s_{0}}{\left(1+\frac{h^{2}}{{R_{0}}^{2}}\right)}
$$

E para raio de curvatura:

$$
\rho(h)=\frac{h^{2}+R_{0}{ }^{2}}{2 h}
$$

Porém, ela foi usada para ensaios que se preocupavam em estabelecer uma condição de tensão constante no topo da peça durante a conformação, essa hipótese caracteriza um dos tipos clássicos de ensaios de expansão fluidoestática biaxial.

O novo modelo proposto consiste em medir, em cada amostragem do sistema de aquisição, valores referentes à tensão $\sigma$ e espessura e, e assim utilizar a equação (116) para gerar o ciclo de pressão da Conformação Superplástica resultante de um 
ensaio de expansão fluidoestática a taxa constante. O comportamento da variação da espessura deverá ser analisado ao longo do ensaio, não mais pela medição antes e depois do ensaio, devido a essa análise será possível melhor comparar os resultados da simulação por elementos finitos de um ensaio a taxa constante com os resultados experimentais gerados pela pressurização da curva de pressão da análise por elementos finitos a taxa constante.

A equação (116) seria usada ao longo do ensaio, tendo as variáveis tensão e espessura medidas ao longo do tempo. A tese propõe a aquisição da espessura em função do tempo, assim como aquisição do módulo do campo biaxial de tensão em função do tempo, realizando as medições com a ARAMIS.

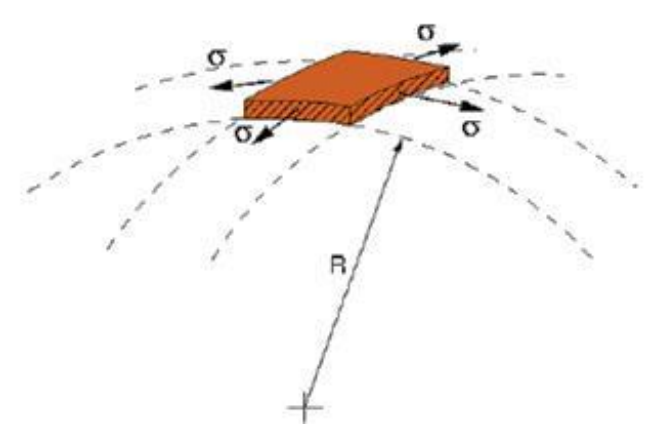

Figura 3.110 Representação esquemática do estado plano de tensão Biaxial usado pelo ARAMIS (GOM,2000)

Devido ao estado de tensão biaxial, a falha por estiramento local e seguido de ruptura ocorre consideravelmente para valores maiores quando comparado com testes de tensão uniaxiais, conforme analisado no capítulo 2.1.5.

Na expansão fluidoestática biaxial, o campo de tensões é calculado pela ARAMIS utilizando a forma da peça conformada, a deformação total equivalente no topo do domo e a pressão aplicada sobre a peça.

A equação (119) seria o resultado do retrabalho da equação (116) do ponto de vista de medição e aquisição das variáveis de interesse, o raio de curvatura continuaria a ser calculado analiticamente, equação (118), entretanto a tensão não seria considerada constante, seria medida, assim como a espessura também não seria resultado de uma análise analítica, ela também seria medida ao longo do ensaio.

$$
P(h)=\frac{2 \sigma_{e q}(t) s(t)}{\rho(h)}
$$




\subsubsection{Descrição do ensaio de caracterização reológica}

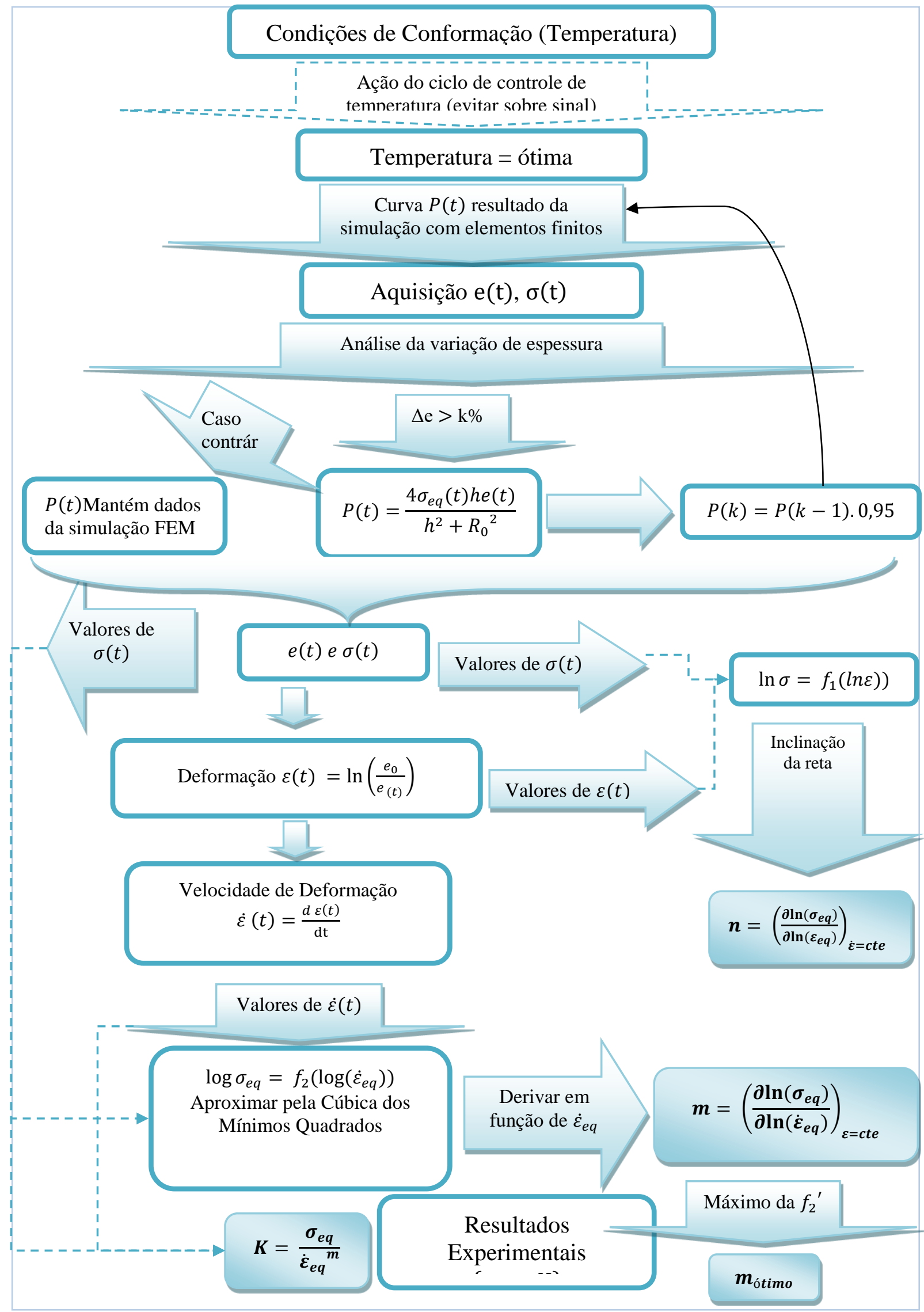

Figura 3.111 Esquemático descritivo da nova proposta de caracterização reológica de expansão fluidoestática biaxial livre. 
É interessante destacar que essa proposta de caracterização reológica necessita de um único ensaio para obter os valores esperados, entendam-se valores esperados por $\mathrm{m}, \mathrm{n}$ e k. Caso a variação de espessura, em comparação com o numérico resulte em grande diferença, o ensaio é refeito com um ajuste de pressão nos momentos de maior variação.

Em resumo, o ensaio é dividido em duas etapas, a primeira etapa consiste em aquecer a peça, sem sobre sinal, até a temperatura ótima superplástica, caso seja conhecida, caso contrário, é preciso realizar o ensaio para várias temperaturas e escolher aquela que resultar em uma maior deformação antes do rompimento.

A segunda etapa refere-se à conformação em si, através da aquisição de espessura em função do tempo e(t) e da tensão equivalente em função do tempo $\sigma(t)$, o ciclo de pressão é calculado pela equação (119), dependendo da variação de resultado entre a espessura medida da conformação e a resultante pelo método de elementos finitos, se erro for menor que $\mathrm{K} \%$ mantem-se os dados resultantes da simulação por elementos finitos $\mathrm{e}$ refaz-se a simulação com dados reológicos obtidos do próprio ensaio ou busca-se pressurizar seguindo o ciclo de pressurização da equação (119), realizando ajuste de pressão no momento que apresentou a falha.

Conforme mostra a Figura 3.111, há algumas etapas de tratamento dos valores aquisitados para que se calculem as variáveis resultantes do estudo reológico, entenda-se m, n e K.

\subsubsection{Método de determinação do coeficiente $\mathbf{m}$}

O método utilizado para determinação do coeficiente m para a proposta de estudo reológico de ensaio biaxial de Conformação Superplástica é conhecido como método direto, utilizado nos ensaios de tração. Esse método consiste em analisar e medir diretamente o gradiente, equação (120), da curva $\log \sigma_{\text {eq }}=\mathrm{f}_{2}\left(\log \left(\dot{\varepsilon}_{\text {eq }}\right)\right)$.

$$
m=\left(\frac{\partial \ln \left(\sigma_{e q}\right)}{\partial \ln \left(\dot{\varepsilon}_{e q}\right)}\right)_{\varepsilon=c t e}
$$

Para que se calcule o gradiente $m$, é necessário primeiro que seja conhecida a $f_{2}$ e para isso sugere-se o método de interpolação por mínimos quadrados.

Resumidamente, levantam-se os pares $\left(\log \dot{\varepsilon}_{e q}(t), \log \sigma_{e q}(t)\right)$. Escolhe-se a curva de cúbica para a interpolação. 
A ideia básica é tentar descobrir quais são os valores dos coeficientes $a_{o}, a_{1}, a_{2} e a_{3}$, de tal modo que a soma dos quadrados das distâncias (tomadas na vertical) da referida curva $\log \sigma_{\text {eq }}=\mathrm{f}_{2}\left(\log \left(\dot{\varepsilon}_{\text {eq }}\right)\right)$, a cada um dos pontos dados $\log \sigma_{\text {eq }}(\mathrm{t})$ seja a menor possível, daí o nome Método dos Mínimos Quadrados.

Para obter tais coeficientes, devem-se conhecer conceitos de Derivadas Parciais, a Teoria de Máximos e Mínimos de funções de várias variáveis e as características de formas quadráticas positivas definidas de funções de várias variáveis envolvidas com o Teorema de Sylvester.

De maneira esquemática e prática apresentam-se aqui as fórmulas para a obtenção da Regressão Linear para a curva de mínimos quadrados Cúbica. (PISKOUNOV, 1983)

Notações usadas na sequência:

$n=$ Número de pares ordenados

$S x=x_{1}+x_{2}+x_{3}+\ldots+x_{n}=$ Soma dos $x_{i}$

$\mathrm{S} Y=\mathrm{y}_{1}+\mathrm{y}_{2}+\mathrm{y}_{3}+\ldots+\mathrm{y}_{\mathrm{n}}=$ Soma dos $\mathrm{y}_{\mathrm{i}}$

$\mathrm{S} X \mathrm{XY}=\mathrm{x}_{1} \mathrm{y}_{1}+\mathrm{x}_{2} \mathrm{y}_{2}+\mathrm{x}_{3} \mathrm{y}_{3}+\ldots+\mathrm{x}_{\mathrm{n}} \mathrm{y}_{\mathrm{n}}=$ Soma dos $\mathrm{x}_{\mathrm{i}} \mathrm{y}_{\mathrm{i}}$

$S x^{2}=\left(x_{1}\right)^{2}+\left(x_{2}\right)^{2}+\left(x_{3}\right)^{2}+\ldots+\left(x_{n}\right)^{2}=$ Soma dos $x_{i}^{2}$

$S x^{3}=\left(x_{1}\right)^{3}+\left(x_{2}\right)^{3}+\left(x_{3}\right)^{3}+\ldots+\left(x_{n}\right)^{3}=$ Soma dos $x^{3}$

$S x^{4}=\left(x_{1}\right)^{4}+\left(x_{2}\right)^{4}+\left(x_{3}\right)^{4}+\ldots+\left(x_{n}\right)^{4}=$ Soma dos $x_{i}^{4}$

$S x^{5}=\left(x_{1}\right)^{5}+\left(x_{2}\right)^{5}+\left(x_{3}\right)^{5}+\ldots+\left(x_{n}\right)^{5}=$ Soma dos $x_{i}^{5}$

$S x^{6}=\left(x_{1}\right)^{6}+\left(x_{2}\right)^{6}+\left(x_{3}\right)^{6}+\ldots+\left(x_{n}\right)^{6}=$ Soma dos $x_{i}^{6}$

$S x^{2} y^{2}=\left(x_{1}\right)^{2} y_{1}+\left(x_{2}\right)^{2} y_{2}+\ldots+\left(x_{n}\right)^{2} y_{n}=$ Soma dos $x^{2} y_{i}$

$S x^{3} y=\left(x_{1}\right)^{3} y_{1}+\left(x_{2}\right)^{3} y_{2}+\ldots+\left(x_{n}\right)^{3} y_{n}=S o m a d o s x^{3} y_{i}$

Para obter a cúbica dos mínimos quadrados resolve-se o sistema de equações com 4 equações e 4 incógnitas $a_{o}, a_{1}, a_{2}$ e $a_{3}$, colocado na forma matricial:

$$
\left(\begin{array}{cccc}
n & S_{X} & S_{X^{2}} & S_{X^{3}} \\
S_{X} & S_{X^{2}} & S_{X^{3}} & S_{X^{4}} \\
S_{X^{2}} & S_{X^{3}} & S_{X^{4}} & S_{X^{5}} \\
S_{X^{3}} & S_{X^{4}} & S_{X^{5}} & S_{X^{6}}
\end{array}\right) \cdot\left(\begin{array}{c}
a_{o} \\
a_{1} \\
a_{2} \\
a_{3}
\end{array}\right)=\left(\begin{array}{c}
S_{Y} \\
S_{X Y} \\
S_{X^{2} Y} \\
S_{X^{3} Y}
\end{array}\right)
$$

Como os termos da primeira e última matriz são conhecidos, pode-se resolver o sistema invertendo a primeira matriz e multiplicando pela última. 


\subsubsection{Método de determinação do coeficiente n}

O método utilizado para determinação do coeficiente n para a proposta de estudo reológico de ensaio biaxial de Conformação Superplástica é a análise da inclinação da reta de equação $\left.\ln \sigma=\mathrm{f}_{1}(\ln \varepsilon)\right)$.

$$
n=\left(\frac{\partial \ln \left(\sigma_{e q}\right)}{\partial \ln \left(\varepsilon_{e q}\right)}\right)_{\dot{\varepsilon}=c t e}
$$

A literatura mostra resultados de ensaios que comprovam a teoria de negligenciar o coeficiente de encruamento no caso da Conformação Superplástica.

\subsubsection{Método de determinação da constante do material $\mathrm{K}$}

Para o cálculo da constante do material, deve-se utilizar a equação (123):

$$
K=\frac{\sigma_{e q}}{\dot{\varepsilon}_{e q}^{m}}
$$

Pela arquitetura de instrumentação desse trabalho, são conhecidos os valores de $\sigma_{\text {eq }}, \dot{\varepsilon}_{\text {eq }}$ e m em função do tempo.

Para o estudo da constante $\mathrm{K}$ são realizadas duas análises, a variação em função da deformação e do tempo de conformação. 


\section{Resultados Experimentais}

Após todo o detalhamento da metodologia utilizada no estudo da superplasticidade da liga de Ti6Al4V, seguindo as etapas propostas na abordagem apresentada na tese, seguem os resultados obtidos.

Inicialmente serão apresentados os resultados dos ensaios de tração uniaxial da liga de titânio superplástico. Em seguida, há o resultado preliminar da validação do sistema de medição ótica para grandes deformações, característica da superplasticidade e os resultados referentes às integrações dos sistemas de controle e aquisição.

Em seguida, há o detalhamento da realização da primeira conformação superplástica fluidoestática. As etapas realizadas são apresentadas e analisadas entre resultados positivos e negativos, cujos impactos negativos foram importantes para retrabalho do ferramental.

A concepção 2 do ferramental exigiu uma mudança no procedimento da montagem, cujas etapas estão detalhadas nos resultados. Utilizando a referida concepção, realizou-se com sucesso o bulge de titânio superplástico ainda sem o módulo de monitoramento da deformação.

Com intuito de confirmar e validar toda a metodologia e os sistemas de controle da prensa superplástica desenvolvida, realiza-se a conformação de uma peça modelo aeronáutica.

Finalmente, adotando todas as lições aprendidas dos outros módulos de monitoramento de deformação, realizou-se um bulge teste e o módulo de visualização foi validado.

Todos os resultados acima serão apresentados detalhadamente nesse capítulo. 


\subsection{Caracterização da Janela Superplástica}

Foram realizados um total de oito ensaios de saltos como descrito no item 3.2 em chapas de Ti6Al4V com espessura de 1 e $2 \mathrm{~mm}$. Os principais resultados são apresentados individualmente em fichas que constam no anexo 10.1 .

A Figura 4.1 apresenta as curvas comparativas dos ensaios de tração a quente em diferentes temperaturas, os resultados são coerentes aos apresentados na literatura para essa mesma liga como mostrado na Figura 4.2. É importante descartar que temperatura de $925^{\circ} \mathrm{C}$ é a que apresentou maiores valores de índice de sensibilidade a taxa de deformação próximo a taxa de deformação de $10^{-4} \mathrm{~s}^{-1}$.

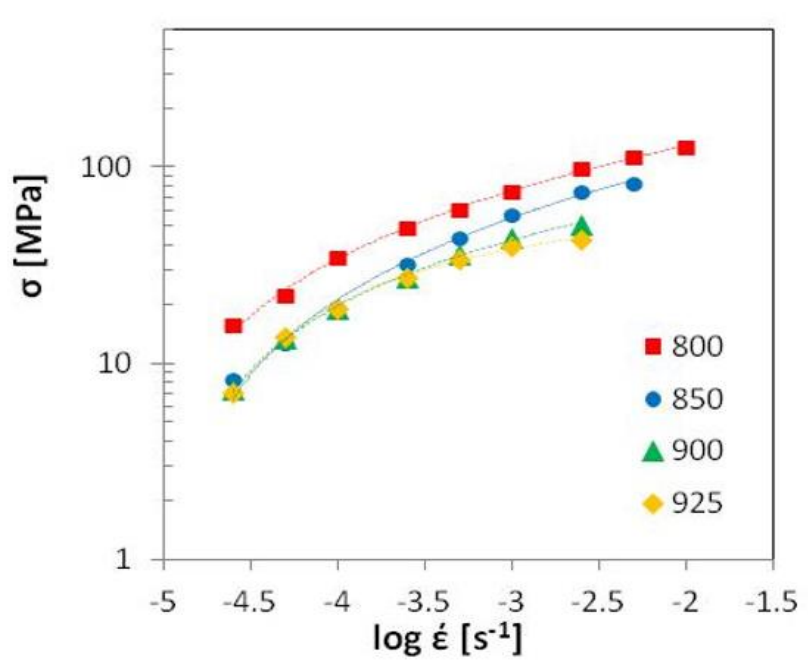

(a)

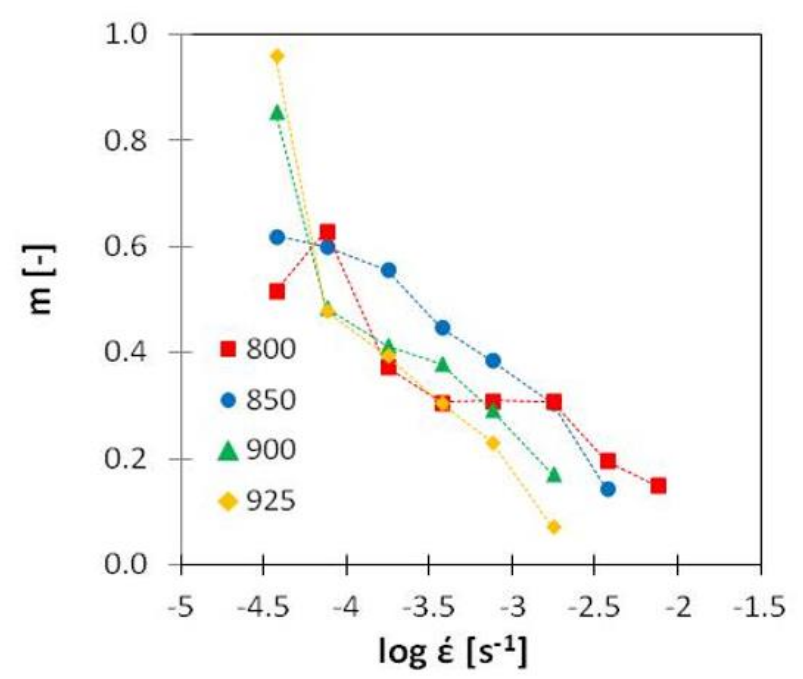

(b)

Figura 4.1 Curvas tensão versus taxa de deformação (a) e índice de sensibilidade à taxa de deformação $(\mathrm{m})$ versus taxa de deformação de chapas de Ti-6Al-4V de 2 $\mathrm{mm}$.

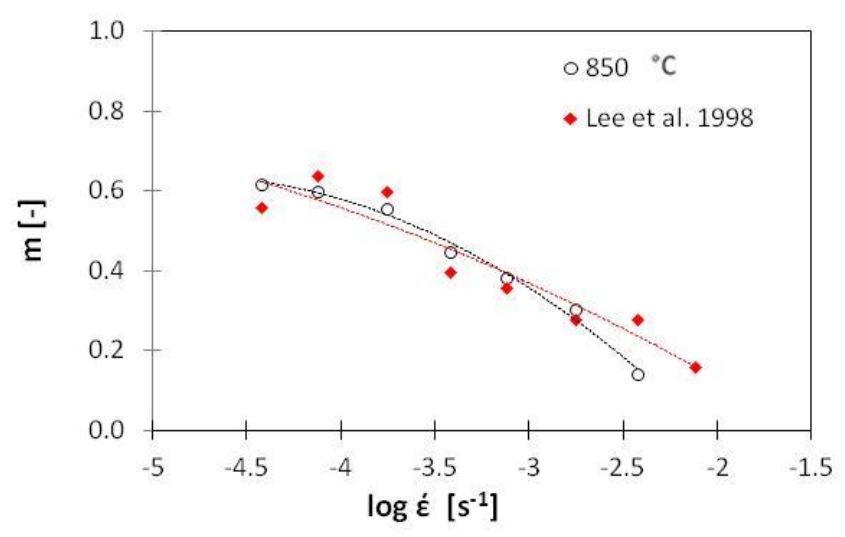

Figura 4.2 Curvas índice de sensibilidade à taxa de deformação $(\mathrm{m})$ versus log da taxa de deformação de chapas de Ti-6Al-4V de $2 \mathrm{~mm}$ a $850^{\circ} \mathrm{C}$ e dados da literatura obtidos nessa mesma condição (Lee et al., 1998). 
Foram repetidos todos os ensaios de tração uniaxial com a finalidade de verificar a repetibilidade dos resultados. As Figura 4.3, Figura 4.4, Figura 4.5 e Figura 4.6 apresentam as curvas sobrepostas para as diferentes temperaturas de ensaio.
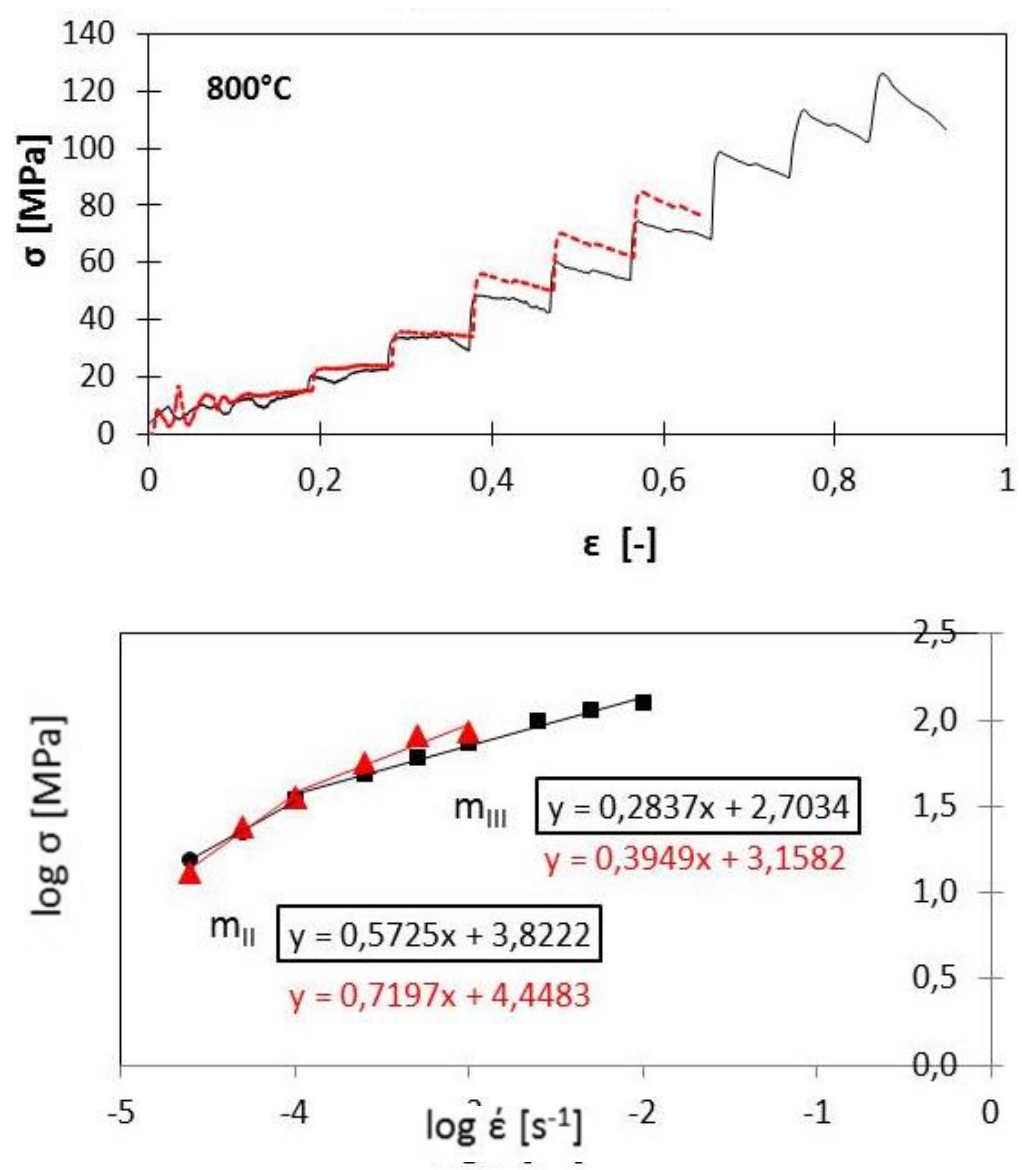

Figura 4.3 Curvas $\sigma \times \varepsilon$ e $\log \dot{\varepsilon} \times \log \sigma$ a $800^{\circ} \mathrm{C}$. As curvas em vermelho correspondem ao segundo ensaio realizado.
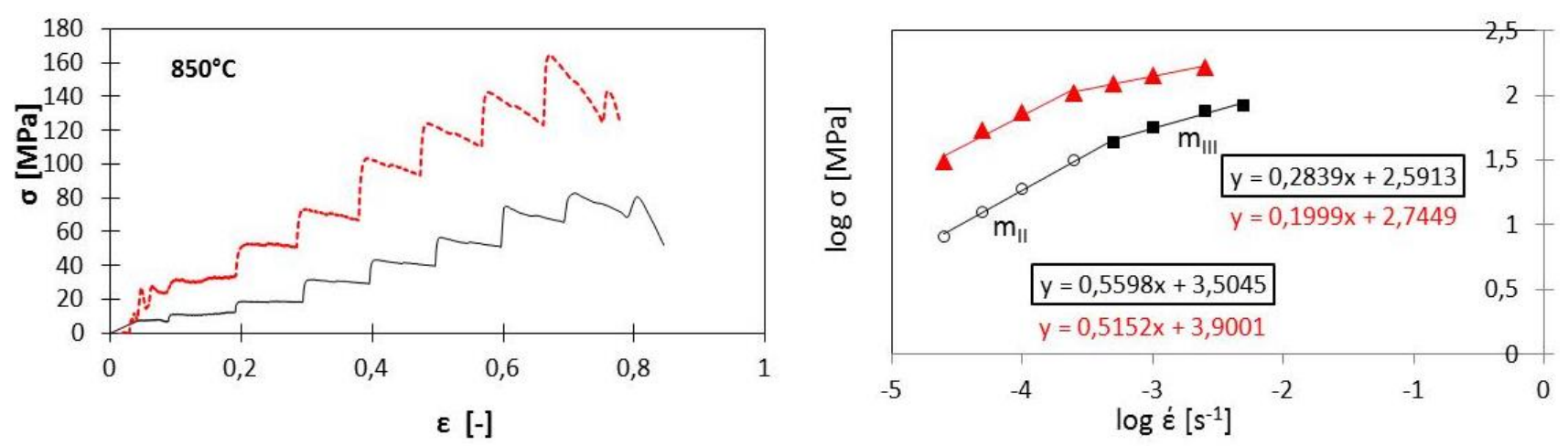

Figura 4.4 Curvas $\sigma \times \varepsilon$ e $\log \dot{\varepsilon} \times \log \sigma$ a $850^{\circ} \mathrm{C}$. As curvas em vermelho correspondem ao segundo ensaio realizado. 

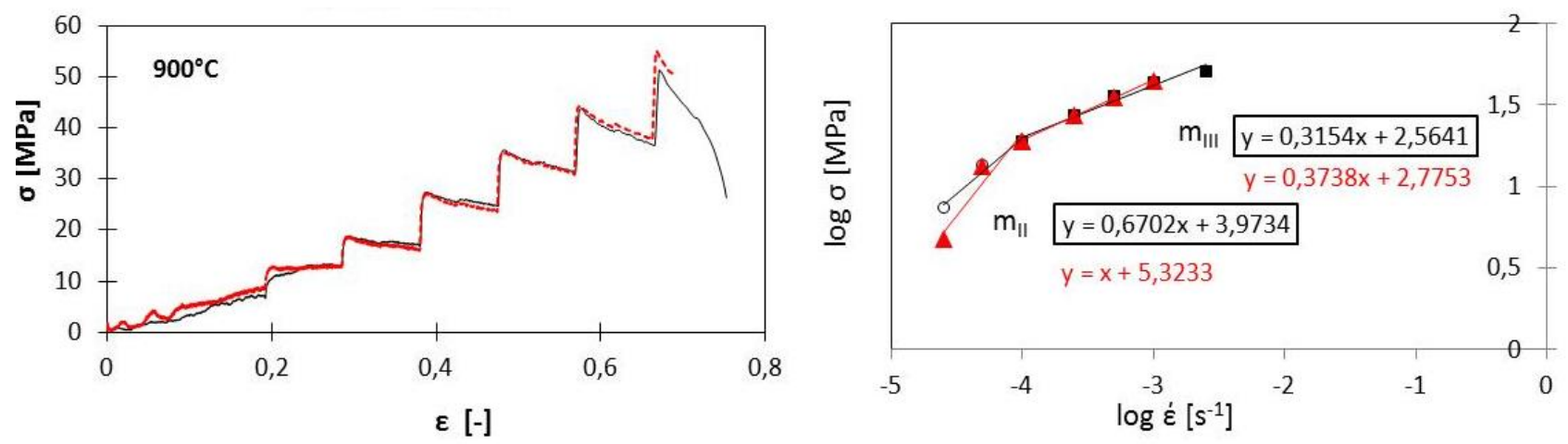

Figura 4.5 Curvas $\sigma \times \varepsilon$ e log $\dot{\varepsilon} \times \log \sigma$ a $900^{\circ} \mathrm{C}$. As curvas em vermelho correspondem ao segundo ensaio realizado.
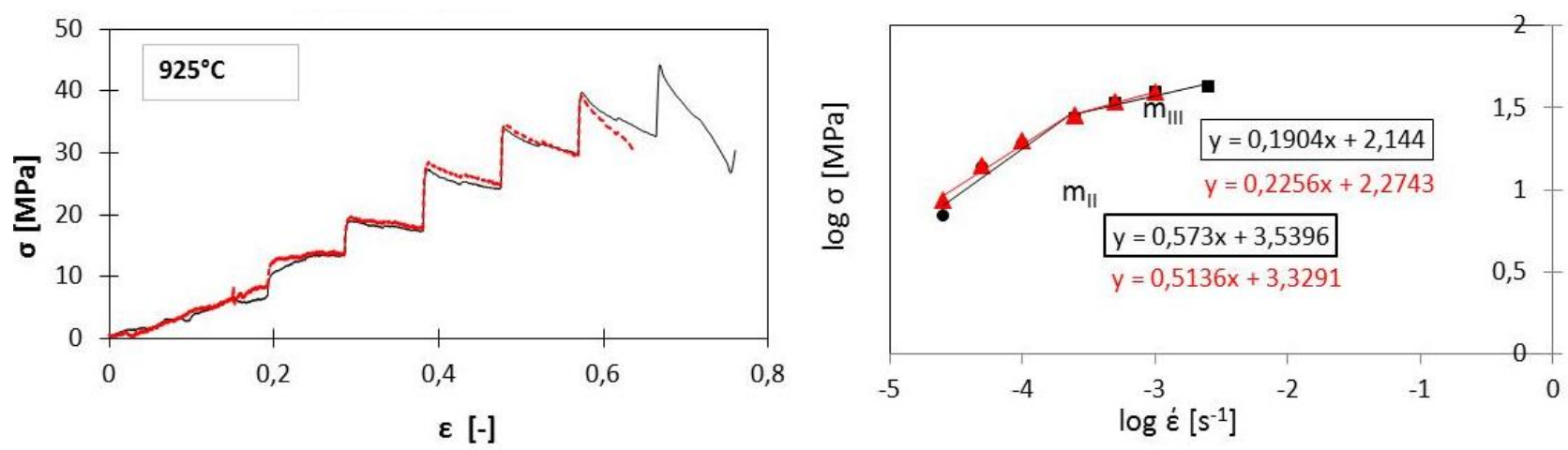

Figura 4.6 Curvas $\sigma \times \varepsilon$ e log $\dot{\varepsilon} \times \log \sigma$ a $900^{\circ} \mathrm{C}$. As curvas em vermelho correspondem ao segundo ensaio realizado. 


\subsection{Resultados da validação do sistema de medição ótica para grandes deformações}

O sistema de medição ARAMIS $5 \mathrm{M}$, conforme explicado no procedimento experimental, foi validado para grandes deformações através do ensaio de expansão fluidoestático biaxial a pressão constante com a liga de chumbo estanho.

Analisou-se, no pós-processamento, a redução de espessura na secção transversal diametral, o diagrama limite de conformação (FLD) - Figura 4.7 - e a variação da altura da secção transversal diametral. A baixa tolerância geométrica no controle da laminação foi responsável pela assimetria axial do processo de expansão fluidoestática, essa assimetria, que não pode ser observada nos dados pós-processado de variação de altura ficou visível quando os dados de variação percentual de espessura foram analisados - Figura $4.8 \mathrm{e}$ Figura 4.9.

E é através dos dados de variação percentual das cotas de altura do processo que é possível observar, desde as primeiras imagens, a localização da ruptura no final do processo de conformação.

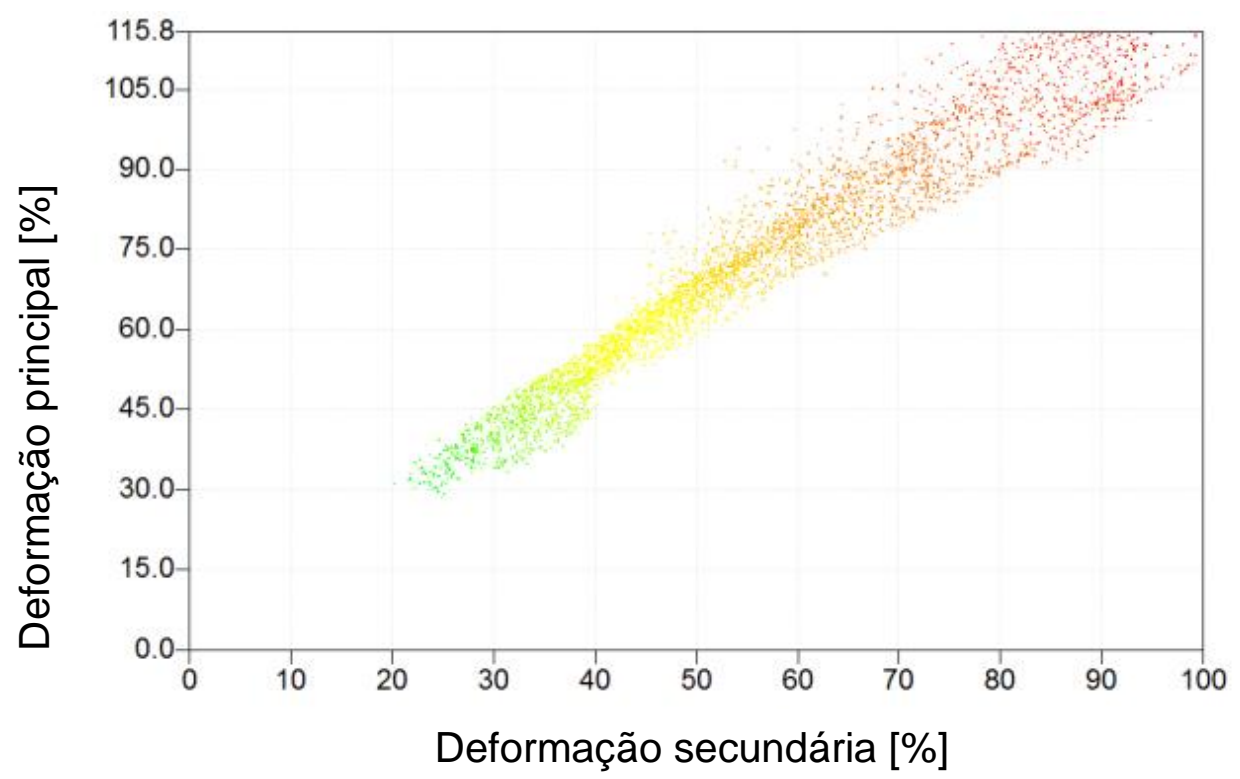

Figura 4.7 Diagrama limite de conformação para a última imagem antes da ruptura.

O sistema de correlação digital de imagem utilizado durante a Conformação Superplástica do PbSn, identificou o ponto de ruptura no estágio 210 de 1360, localização da ruptura nas Figura 4.8 e Figura 4.9.

. Caracterizando-se como um interessante sistema de predição de pontos de falha por ruptura. 
(a)

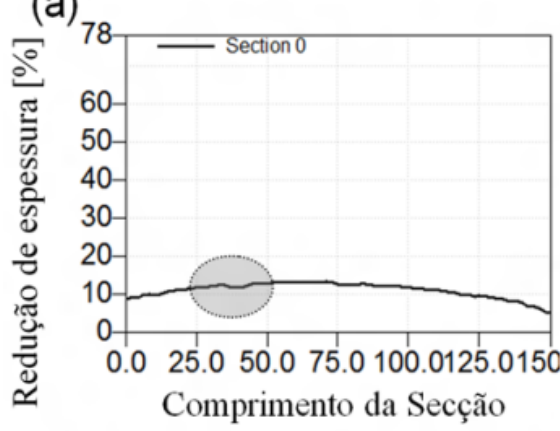

(c)

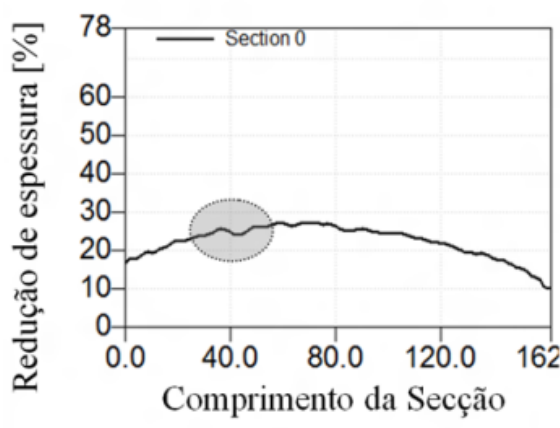

(b)

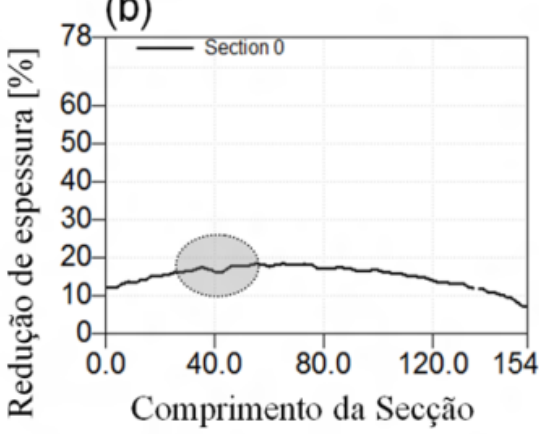

(d)

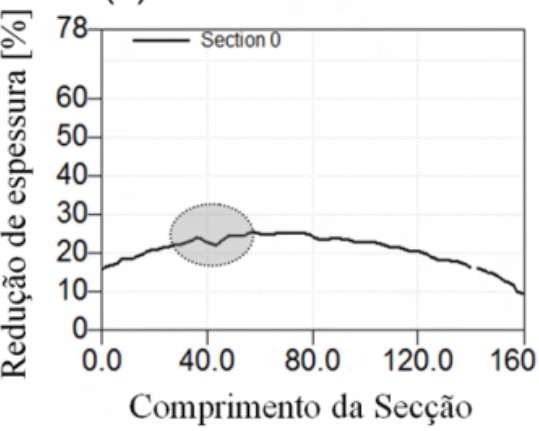

Figura 4.8 Variação de espessura percentual não uniforme monitorada nos estágios 310 (a), 470 (b), 750(c) e 820(d).

(a)

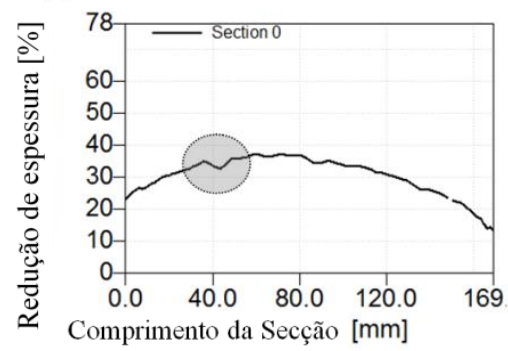

(b)

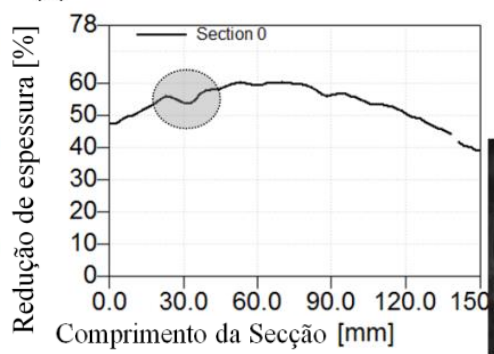

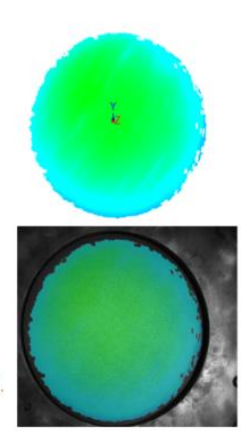

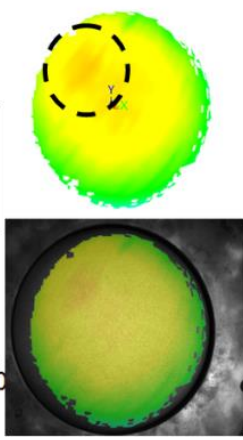

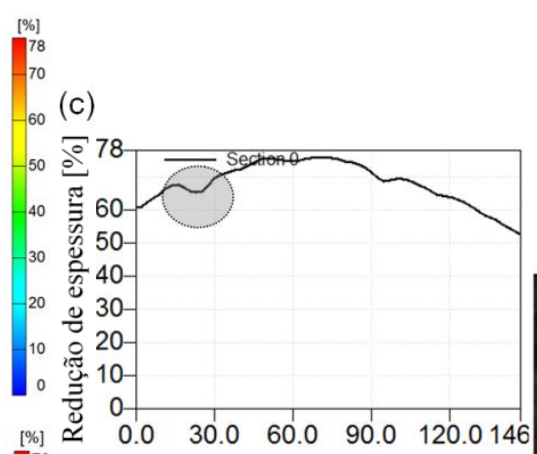

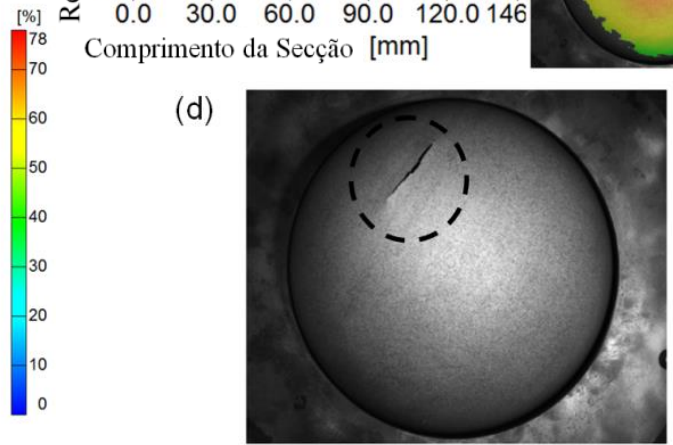

Figura 4.9 Monitoramento da falha nas últimas 260 imagens, imagem 1100 (a), 1303 (b), 1351(c) e 1360(d). 


\subsection{Resultado dos testes de Integração dos sistemas de pressão e de deformação realizado com a liga $\mathrm{PbSn}$}

Para realizar os testes de integração dos sistemas utilizou-se uma instrumentação de apoio e os testes foram realizados com $\mathrm{PbSn}$ a temperatura ambiente. Ao seguir a metodologia descrita no capítulo 3.7 validou-se a instrumentação (com excessão da parte de controle térmico) utilizada para caracterizar e realizar o ensaio superplástico controlado.

Após ajuste dos parâmetros da válvula descritos no procedimento experimental, obteve-se o ensaio de taxa de deformação controlado através da pressurização da curva de pressão obtida por análise de elementos finitos da literatura.

Segue na Figura 4.10 Curva de pressurização do bulge test de PbSn. (a) Resultado do controle de pressão, (b) curva pressurizada no ensaio de bulge a taxa constante e (c) resultado do controle da válvula reguladora de pressão proporcional.

(a)

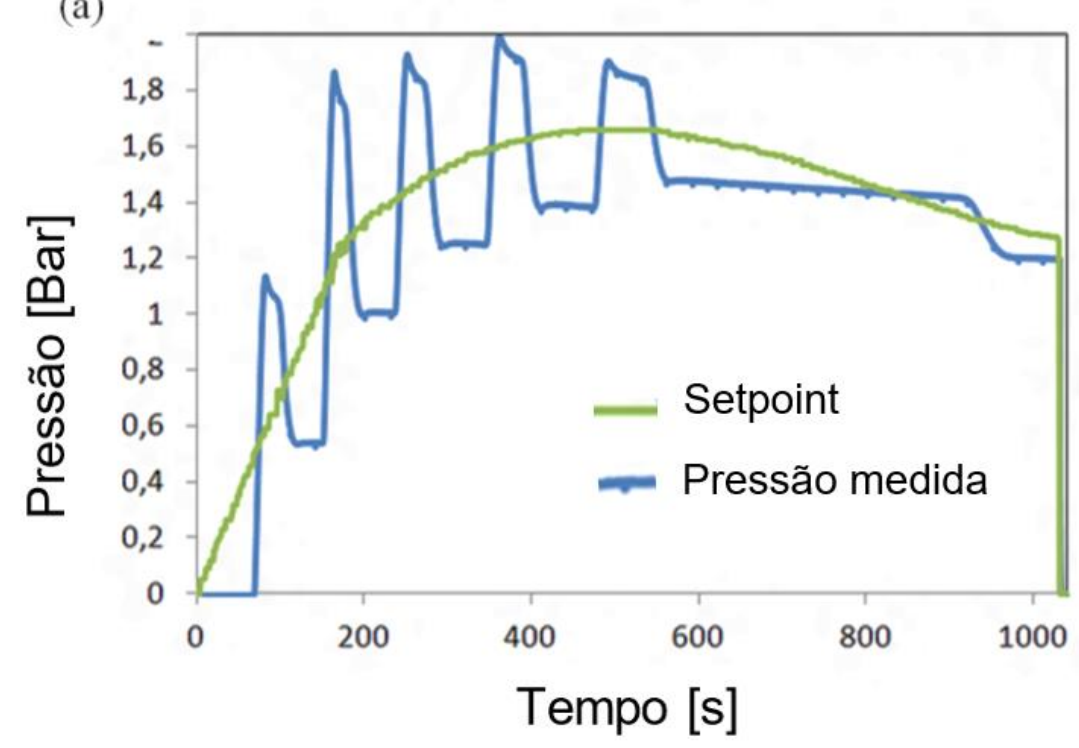

(b)

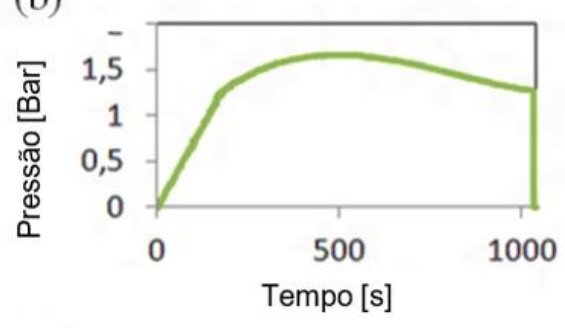

(c)

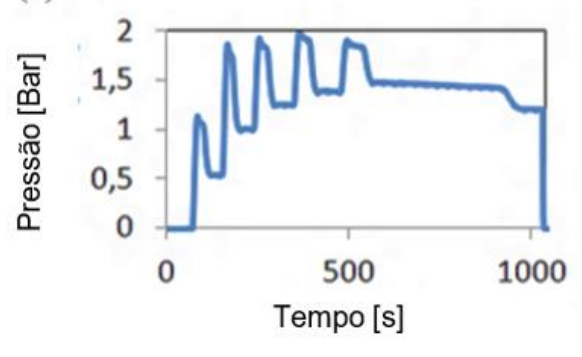

Figura 4.10 Curva de pressurização do bulge test de PbSn. (a) Resultado do controle de pressão, (b) curva pressurizada no ensaio de bulge a taxa constante e (c) resultado do controle da válvula reguladora de pressão proporcional.

Em conformidade com as características da Conformação Superplástica, o objetivo de produzir um ensaio com taxa de deformação constante através da pressurização de uma curva de pressão resultado da análise por elementos finitos foi alcançado. 
Conforme pode ser observado na Figura 4.11, a taxa de deformação obtida foi de $2 \times 10^{-4} \mathrm{~s}^{-1}$. Para o cálculo dessa taxa de deformação utilizou-se os valores de espessura ao longo do tempo do sistema ARAMIS junto as equações (124) e (125).

$$
\begin{gathered}
\varepsilon_{e q}(t)=\ln \left(\frac{s_{0}}{s(h)}\right) \\
\dot{\varepsilon}_{e q}(t)=\frac{d \varepsilon_{e q}}{d t}=\frac{\varepsilon_{e q}\left(t_{n+1}\right)-\varepsilon_{e q}\left(t_{n-1}\right)}{t_{n+1}-t_{n-1}}
\end{gathered}
$$

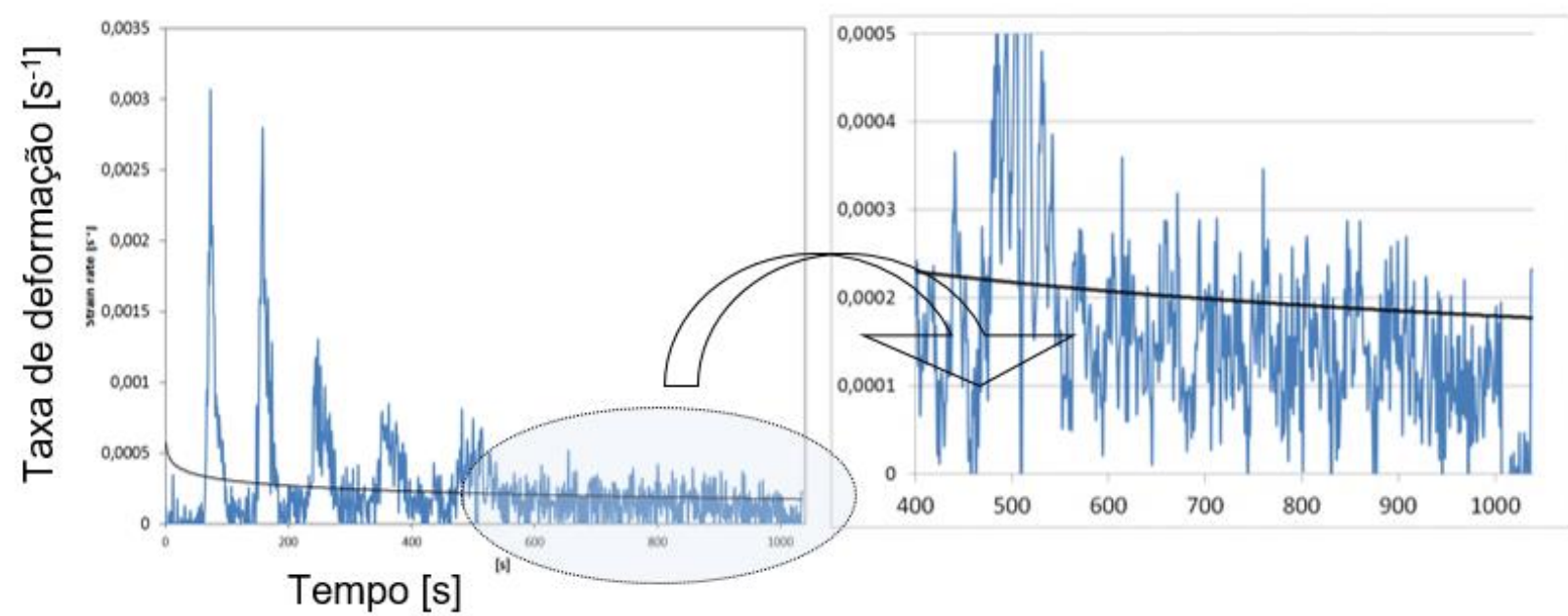

Figura 4.11 Resultado fornecido pelo sistema ARAMIS que afere 0 ensaio de Conformação Superplástica à taxa constante de $2 \times 10^{-4}\left[\mathrm{~s}^{-1}\right]$

O sistema de correlação de imagem digital da GOM ARAMIS foi calibrado com uma taxa de aquisição de 1 imagem/s, equipado com lentes de $23 \mathrm{~mm}$ e o calibrador de $175 \mathrm{~mm}$ x140mm de área atingiu uma área de medição de 200x170 mm, suficiente para o blank de $\mathrm{PbSn}$ de $160 \mathrm{~mm}$

1040 imagens foram aquisitadas no intuito de analisar a redução de espessura, o diagrama limite de deformação e a altura do domo; com essas informações foi possível observar o local de ruptura desde a imagem 200 de 1040 imagens, como pode ser observado na Figura 4.12. 


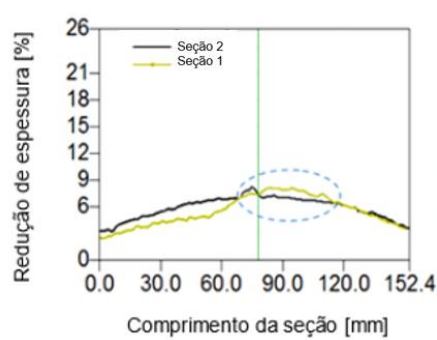

Imagem 200

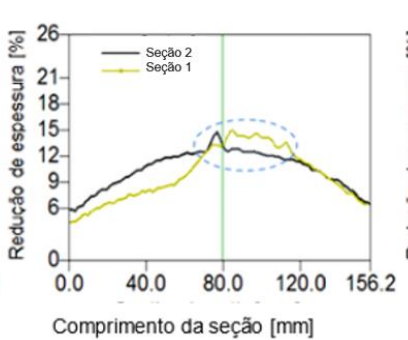

Imagem 400

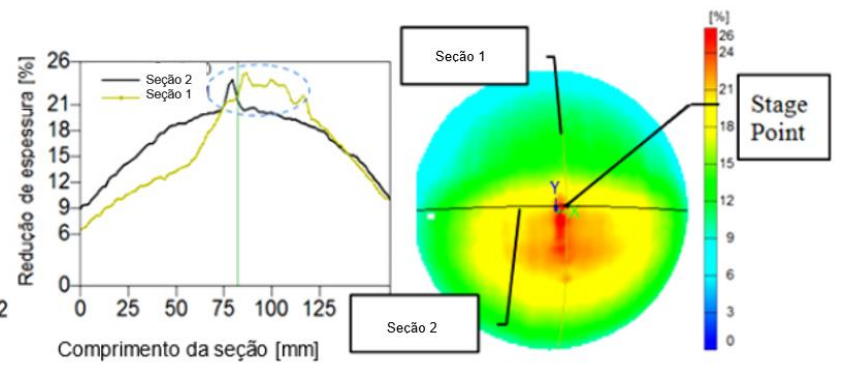

Imagem 1040

Figura 4.12 Monitoramento da região de deformação não uniforme de espessura nas imagens 200, 400 e na última imagem (1040) antes da ruptura.

Escolheram-se duas abordagens analíticas para cálculo da redução de espessura de um ensaio de bulge superplástico, a primeira relaciona o raio inicial do blank $\left(\mathrm{R}_{0}\right)$, a altura do domo $(\mathrm{h}(\mathrm{t}))$ e a espessura inicial (So) para determinar a espessura em função do tempo. Nessa tese a equação (126) (OLLIVIER, 2003) usa os dados medidos de altura do domo $(\mathrm{h}(\mathrm{t})$ ) através do ARAMIS, porém no trabalho de Ollivier ele usou um LVDT para realizar a medição.

$$
s(t)=\frac{s_{0}}{\left(1+\frac{h(t)^{2}}{R_{0}{ }^{2}}\right)}
$$

A segunda abordagem analítica utiliza o cálculo da media da taxa de deformação $(\dot{\varepsilon})$ para calcular a espessura em função do tempo através da equação (127). (KHRAISHEH, 2000)

$$
s(t)=s_{0} * e^{(-\dot{\varepsilon} t)}
$$

A Figura 4.13 traz a altura em função da coordenada da seção transversal (b) Altura em função do tempo (número de imagens = 1 imagem por segundo) para o ponto mais alto do bulge, tais informações são importantes para fornecer dados $(\mathrm{h}(\mathrm{t}))$ para os cálculos analíticos das fórmulas (126) e (127). 
(a)

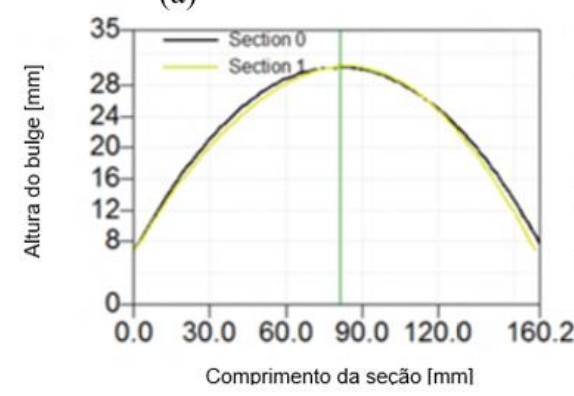

(b)

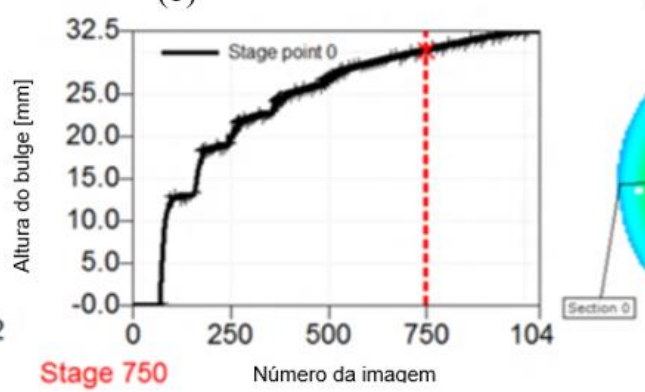

(c)

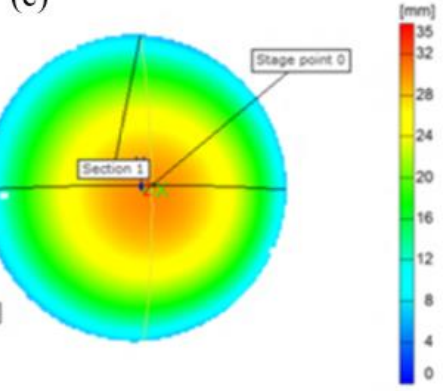

Figura 4.13 (a) Altura em função da coordenada da seção transversal (b) Altura em função do tempo (número de imagens = 1 imagem por segundo) para o ponto mais alto do bulge e (c) a análise da altura das duas seções transversais do bulge e indicação da localização do ponto escolhido (Stage point) no bulge.

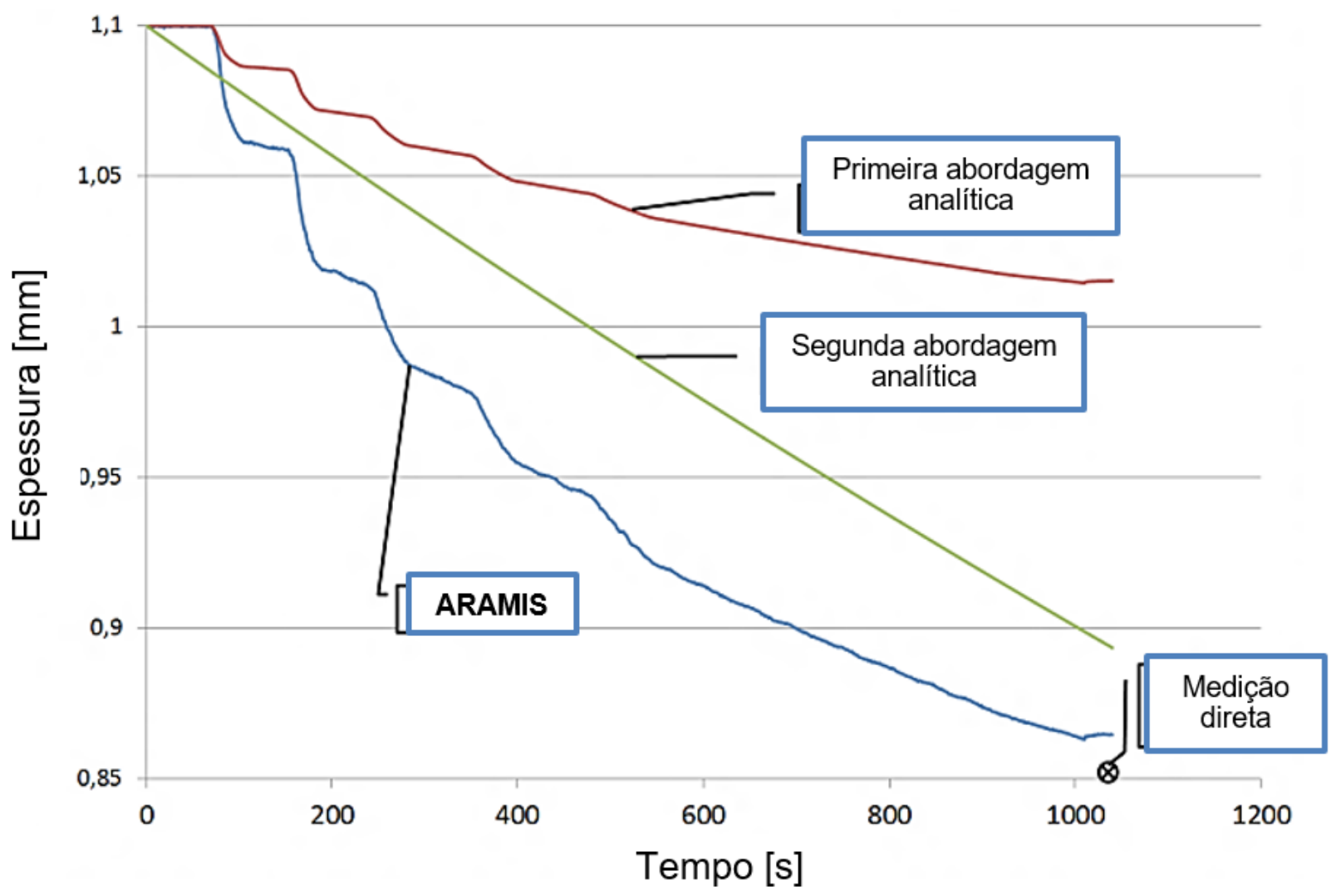

Figura 4.14 Comparação entre as medições experimentais da redução da espessura do domo e duas abordagens analíticas, equações (126) e (127)

A Figura 4.14 mostra a comparação entre as medições experimentais da redução da espessura do domo e duas abordagens analíticas, equações (126) e (127).

A análise da última imagem do ensaio possibilita a comparação de vários pontos entre a medição indireta do sistema de correlação digital de imagem (ARAMIS) e a medição direta com instrumentação mecânica (medição destrutiva por contato) - Figura 4.15. 
Escolheram-se 9 pontos, igualmente espaçados de $20 \mathrm{~mm}$, ao longo da seção transversal 1 (section 1) do bulge de PbSn para realizar a comparação entre as medições.

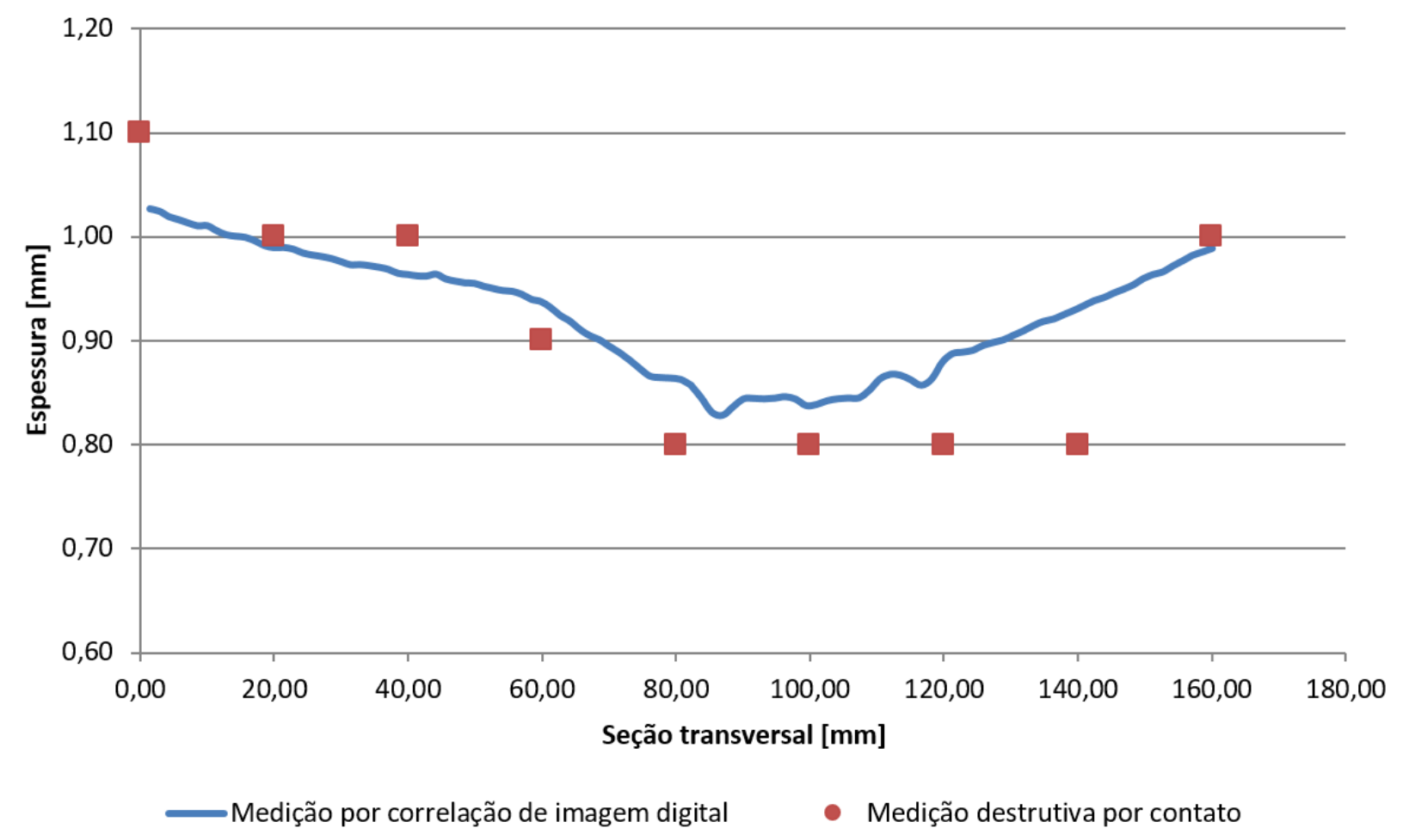

Figura 4.15 Comparação entre as medições experimentais e a medição direta destrutiva por contato da redução da espessura de nove pontos ao longo da seção transversal (section 1) do bulge de PbSn.

Obter o diagrama limite de conformação ao longo do ensaio mostra-se uma importante ferramenta para análise da instabilidade do processo. Segue evolução temporal do FLD na Figura 4.16. 


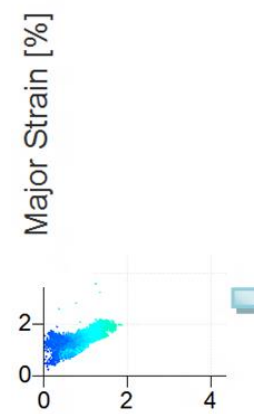

Stage 100

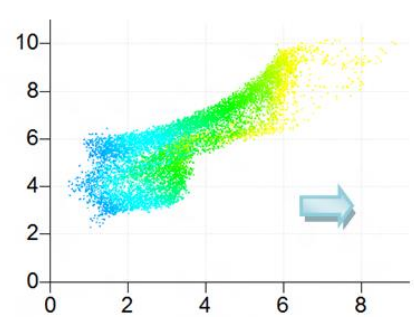

Stage 300

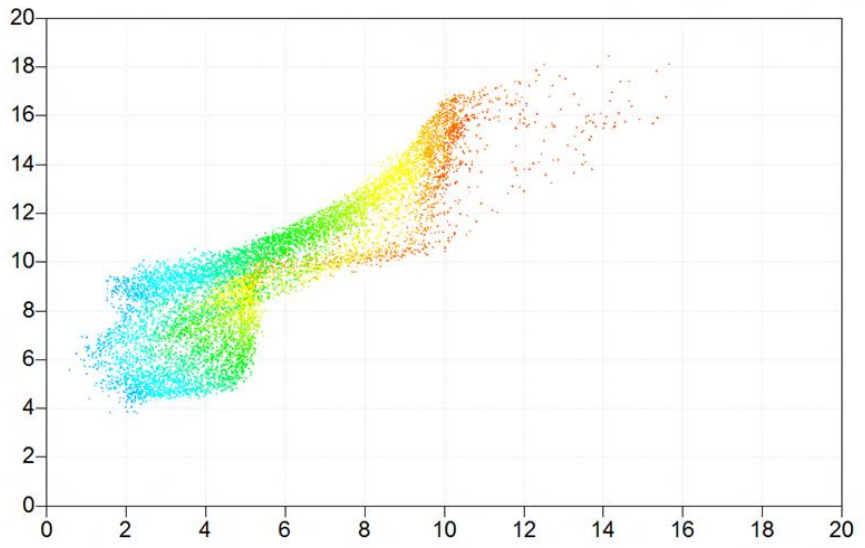

Stage 1040

Minor Strain [\%]

Figura 4.16 Exemplos dos diagramas limites de conformação para ilustrar a evolução temporal da trajetória de deformação.

Em suma, a instrumentação utilizada com PbSn mostra-se capaz de localizar e monitorar a provável localização do ponto de ruptura em um ensaio de expansão fluidoestática biaxial superplástico. O método usado para realizar um ensaio de bulge à taxa de deformação constante apresenta-se como validado para aplicação a quente na superplasticidade da liga de titânio (Ti6Al4V). E a comparação entre as abordagens do cálculo de espessura em ensaios de bulge mostra que a medição indireta que utiliza o sistema de correlação digital de imagem ARAMIS apresenta menor erro que as fórmulas analíticas, quando comparado com a medição mecânica direta. Assim, valida-se o método de correlação digital de imagem para estudar a conformação biaxial superplástica. 


\subsection{Resultados do primeiro ensaio de expansão fluidoestática biaxial superplástico}

Após todos os testes modulares apresentarem resultados positivos, realiza-se 0 primeiro ensaio fluidoestático biaxial superplástico da liga de Titânio (Ti6Al4V).

Os resultados serão apresentados seguindo as etapas de preparação do ensaio:

\subsubsection{Pintura do corpo de prova}

No primeiro ensaio utilizou-se o corpo de prova de titânio de $2 \mathrm{~mm}$. Inicialmente aplica-se uma camada de tinta branca, suficiente para inibir o fundo com brilho metálico do titânio, mas sem aplicar a quantidade que crie níveis diferentes de espessura da tinta. Após a secagem, aplica-se o padrão pulverizado de preto, utilizou-se o conjunto de tintas ULFALUX® - Figura 3.101 - utilizada para pintura de caldeiras que tem como temperatura limite de trabalho $1200^{\circ} \mathrm{C}$.

A Figura 4.17 apresenta um corpo de prova pintado e exemplo do padrão criado no titânio.

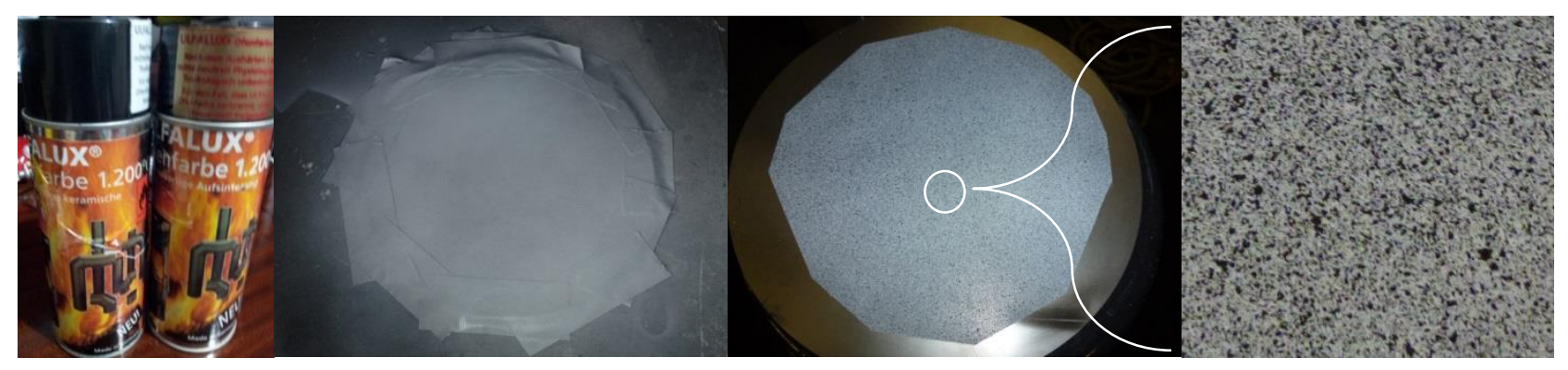

Figura 4.17 Tinta e corpo de prova de titânio pintado com o padrão estocástico característico do sistema de correlação digital de imagem ARAMIS.

Nesse primeiro ensaio não foi utilizado o módulo de controle de deformação, seguindo as etapas de planejamento, a primeira conformação a quente seria realizada sem o sistema ARAMIS. O principal motivo é a proteção ao sistema, conforme está especificado, esse primeiro ensaio visava validar vários pontos críticos do ensaio, na sua maioria relacionados a temperatura, dessa forma, decidiu-se realizar o ensaio com os sistemas de controle térmico e de pressurização. 
Era intenção do ensaio verificar as temperaturas resultantes da irradiação da matriz dentro do forno, haja vista que na etapa de testes de aquecimento do mesmo, ele estava vazio.

Durante o ensaio foi possível notar que a tinta realmente resiste a temperatura objetivo do ensaio, $925^{\circ} \mathrm{C}$. Porém, devido a problemas com entrada de oxigênio durante o ensaio, a excessiva oxidação da placa de titânio não permitiu analisar se o padrão estocástico se manteve durante todo o ensaio. O primeiro ensaio de bulge, não foi conclusivo se as tintas utilizadas serviriam de solução para o problema de medição a quente com ARAMIS, fato esse que seria validado juntamente com o módulo de monitoramento da deformação.

\subsubsection{Aplicação do nitreto de boro}

Conforme descrito no procedimento experimental, a aplicação do nitreto de boro visava garantir a desmontagem da matriz, o resultado da aplicação foi positivo. Após o ensaio toda a matriz foi desmontada.

\subsubsection{Aquecimento prévio do forno}

Com intuito de diminuir a umidade dos tijolos refratários, o forno foi aquecido por 5 horas a $400{ }^{\circ} \mathrm{C}$. Esse procedimento evita que a presença de umidade dentro do forno durante o aquecimento prejudique a visualização através do vidro, impedindo assim que o sistema de correlação digital de imagem realize as medições necessárias. Durante 0 primeiro ensaio o resultado desse procedimento foi positivo, o vidro não embaçou.

\subsubsection{Calibração da curva de pressão}

Essa etapa apresentou resultado positivo, a curva de pressurização foi seguida pelo sistema de controle de pressão de maneira eficiente, com erro máximo da ordem de 0,2 Bar. Todas as alterações necessárias para melhoria da atuação da válvula estão explicadas no procedimento experimental, capítulo 3.6.2 - Calibração do sistema de pressurização e fundamentadas no capítulo 3.5. 


\subsubsection{Montagem da ferramenta}

A ferramenta apresenta uma montagem bem simples, sequência apresentada na Figura 4.18.

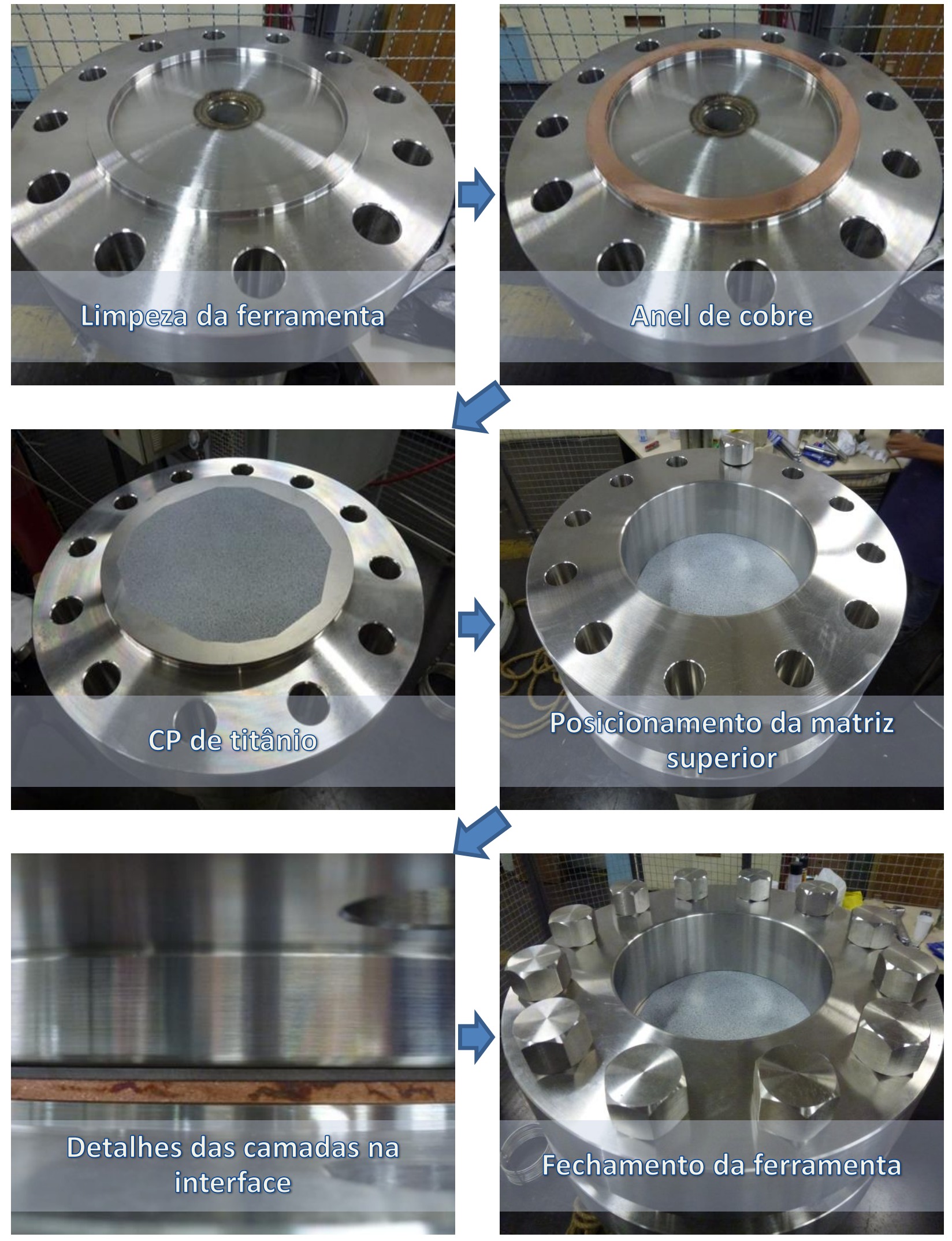

Figura 4.18. Sequência de montagem do ferramental para ensaio de bulge . 
Após montada a ferramenta, é necessário coloca-la dentro do forno, utiliza-se um guindaste hidráulico e cordas nessa etapa. A Figura 4.19 mostra o posicionamento do ferramental dentro do forno, é importante perceber que há uma altura certa de posicionamento, como também há uma folga planejada entre o tubo e o acesso inferior suficiente para que a vedação do prema gaxeta, logo após a jaqueta de resfriamento, funcione.

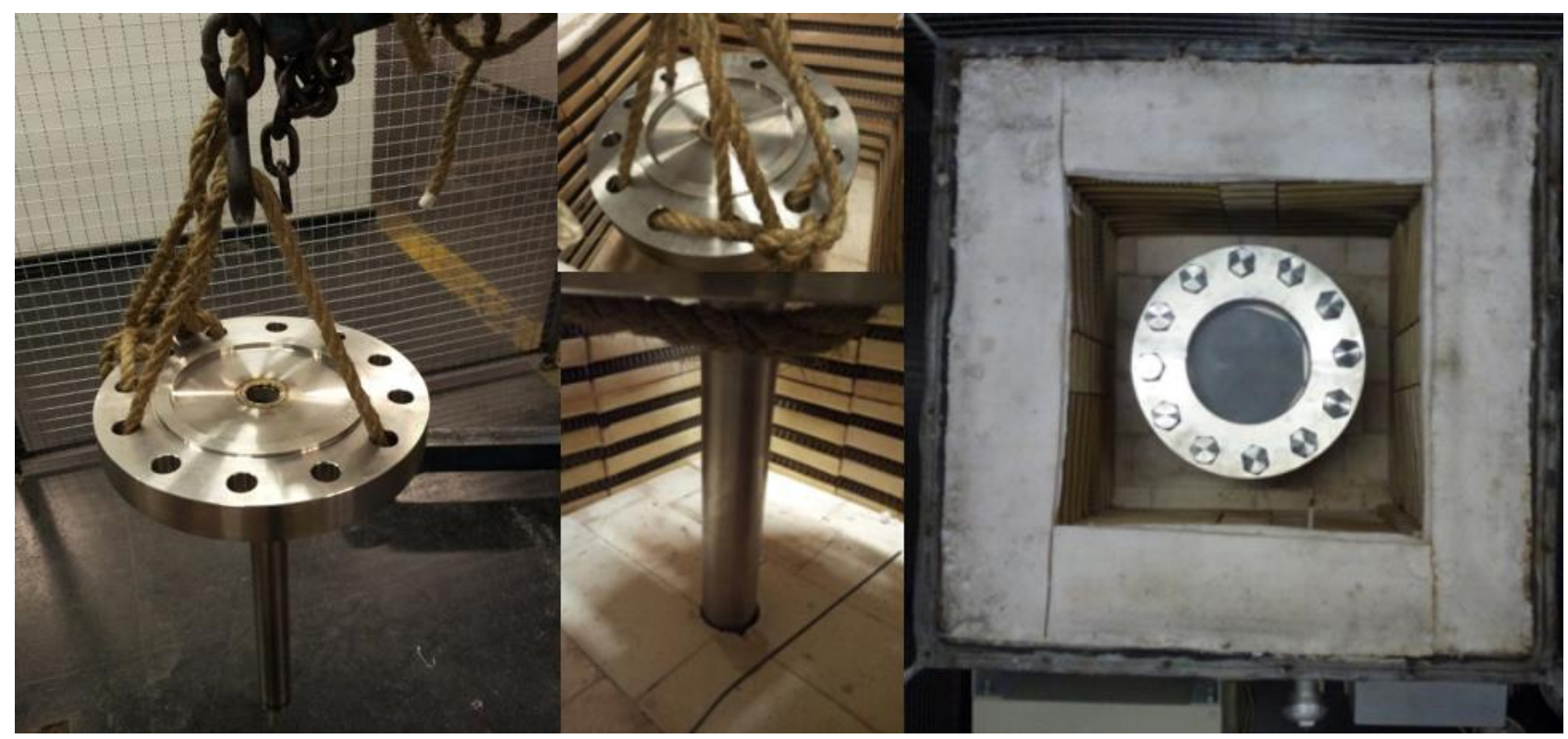

Figura 4.19. Sequência de posicionamento do ferramental para ensaio de expansão fluido estático biaxial.

\subsubsection{Ajuste da posição do termopar}

Para o sistema de controle da temperatura é fundamental que o termopar do controle de temperatura do titânio esteja em contato com a chapa de titânio, conforme Figura 4.20.
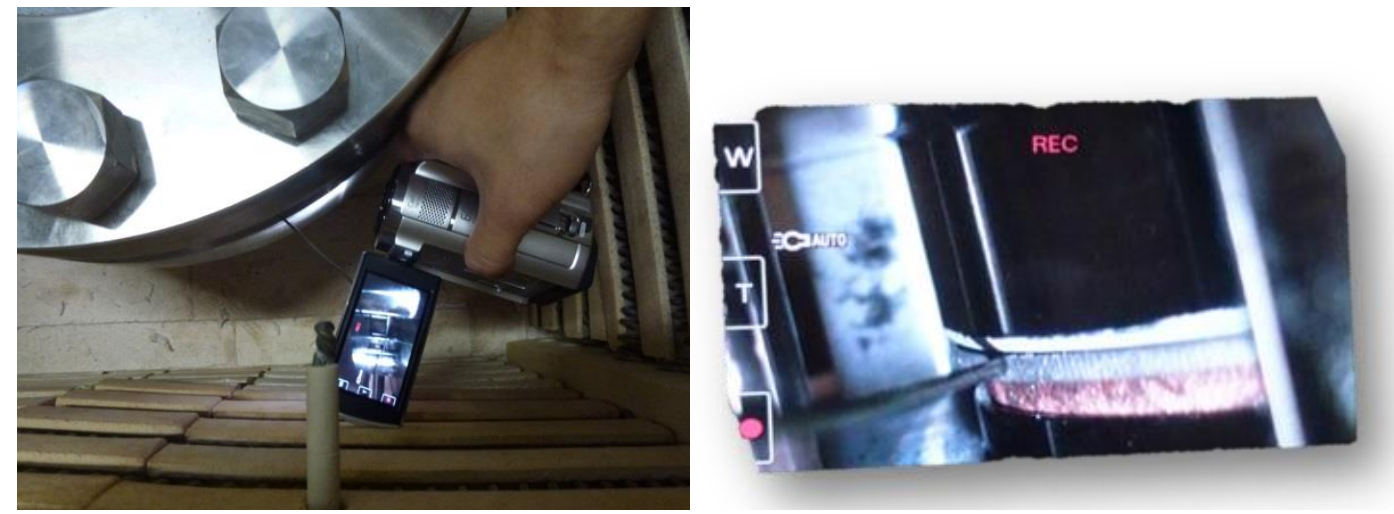

Figura 4.20. Posicionamento do termopar em contato com a chapa de titânio. 


\subsubsection{Fechamento da vedação da jaqueta}

A vedação da jaqueta de resfriamento - Figura 4.21 - através de "anel O" apresentou resultado positivo, o sistema preme gaxeta vedou o tubo de pressurização, e mesmo após o ensaio a desmontagem da vedação apresentou resultado positivo, que possibilitou a realização da purga do forno antes do ensaio de bulge.

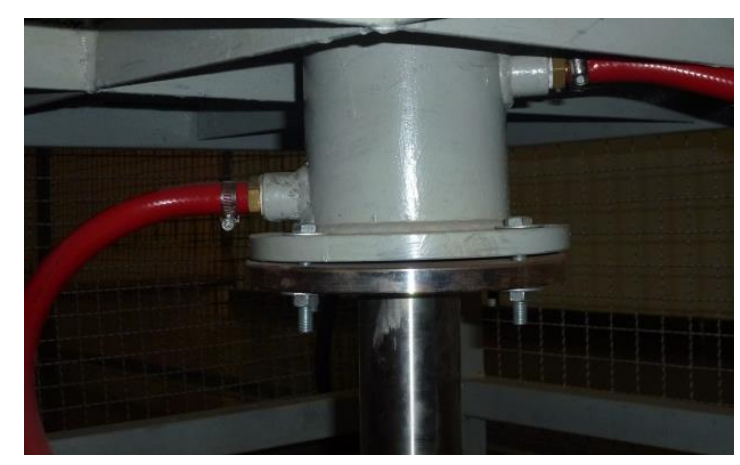

Figura 4.21. Tubo de pressurização vedado na jaqueta de resfriamento através do sistema de gaxeta.

\subsubsection{Purga do forno}

O sistema de purga do forno mostrou-se funcional, o procedimento foi realizado quatro vezes em seguida, após a purga, injeta-se argônio no forno e com a manutenção do fluxo de argônio mantém-se a atmosfera positiva evitando retorno de oxigênio para o interior do forno. Os problemas relacionados com o aparecimento da camada alfa na oxidação do titânio não puderam ser evitados, pois durante esse primeiro ensaio, uma quebra do vidro durante o aquecimento do forno prejudicou a atmosfera de proteção de argônio.

\subsubsection{Atmosfera positiva}

Antes do momento da quebra do vidro, o controle de fluxo de entrada de argônio permite a criação de uma atmosfera positiva dentro do forno. Não houveram problemas com essa etapa. 


\subsubsection{Aquecimento até o patamar de $900^{\circ} \mathrm{C}$}

Com a ferramenta dentro do forno, esperava-se que a temperatura do titânio tivesse uma maior inércia térmica, entretanto o sistema de controle conseguiu realizar o aquecimento do forno até o patamar necessário a soldagem por difusão $\left(900^{\circ} \mathrm{C}\right) \mathrm{em}$ aproximadamente 300 minutos com sobressinal de $25^{\circ} \mathrm{C}$ da temperatura do forno e sobressinal da temperatura do titânio de $5^{\circ} \mathrm{C}$ por 4 min, estabilizando em seguida.

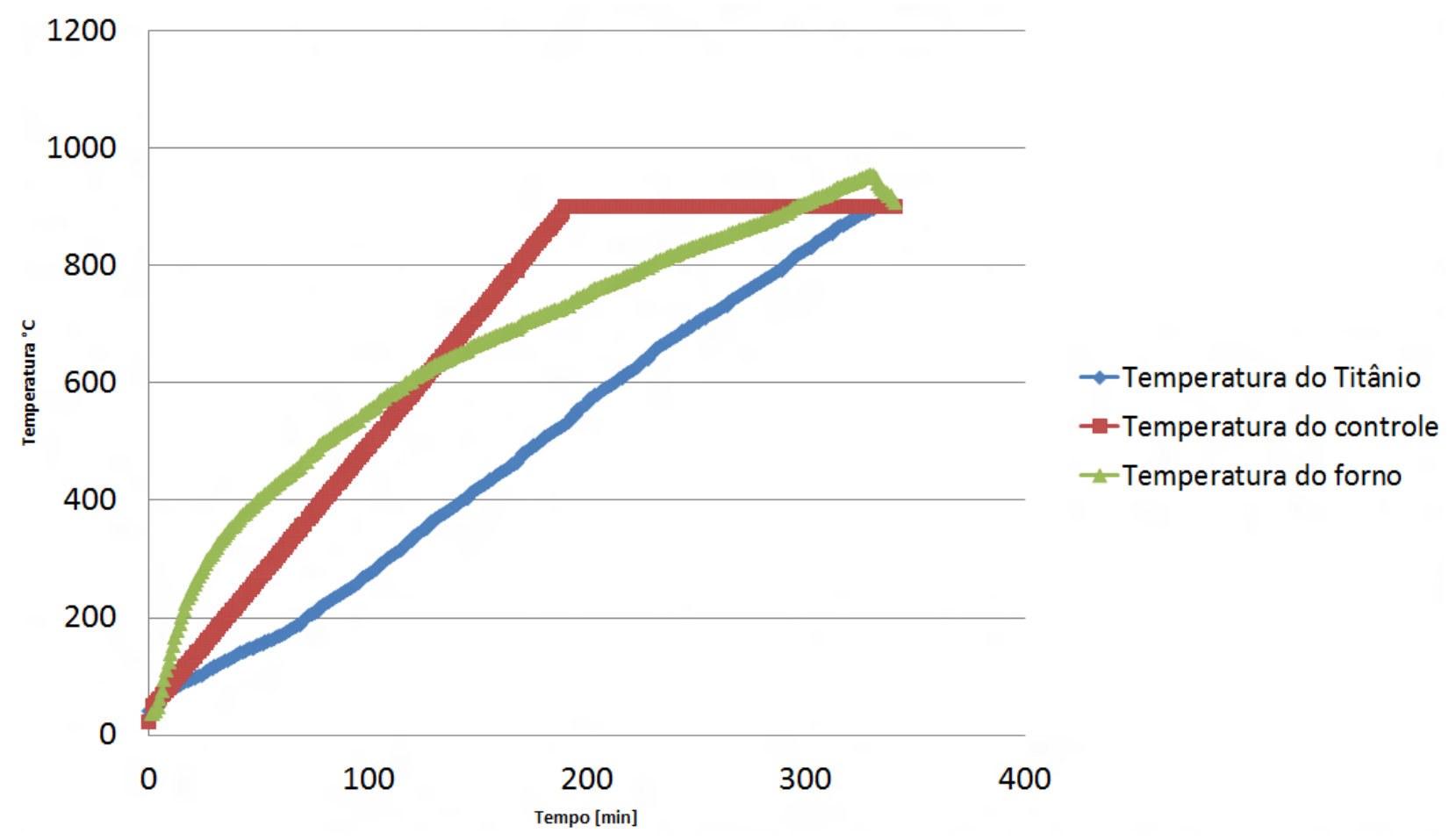

Figura 4.22. Atuação do sistema de controle térmico.

Após 90 minutos na temperatura de soldagem por difusão $\left(900^{\circ} \mathrm{C}\right)$ o forno realizou o aquecimento até o segundo patamar de $927^{\circ} \mathrm{C}$ e sem sobressinal manteve o aquecimento por mais 40 minutos nessa temperatura para que a curva de pressurização pudesse ser utilizada. Em resumo, o sistema de controle térmico apresentou um comportamento dentro do planejado.

\subsubsection{Quebra do vidro durante aquecimento}

Antes de alcançar a temperatura da soldagem por difusão, no momento que a ferramenta estava em $575^{\circ} \mathrm{C}$ e o forno em $757^{\circ} \mathrm{C}$, o vidro cristal temperado de $10 \mathrm{~mm}$ estilhaçou, conforme ilustra a Figura 4.23. 


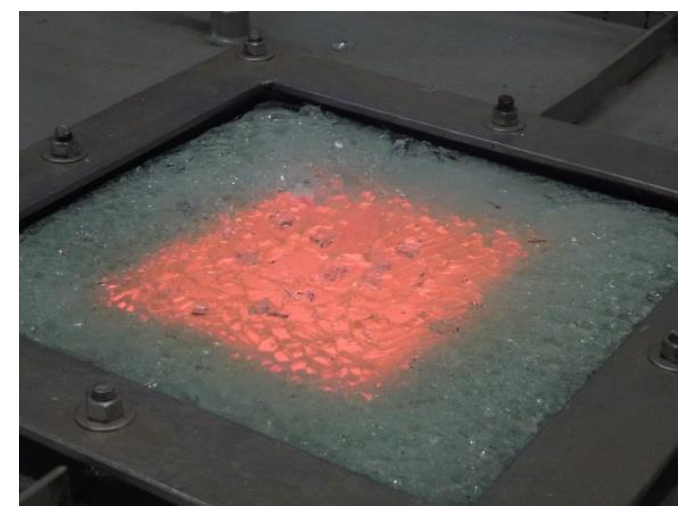

Figura 4.23. Detalhe do momento da quebra do vidro.

$\mathrm{Na}$ análise do problema concluiu-se que com o ferramental dentro do forno a radiação recebida pelo vidro foi maior que no momento dos testes de aquecimento sem o ferramental, isso resultou em uma maior deformação por dilatação do vidro, que resultou em contato com os parafusos que prendem o vidro sem vazamento - Figura 4.24.

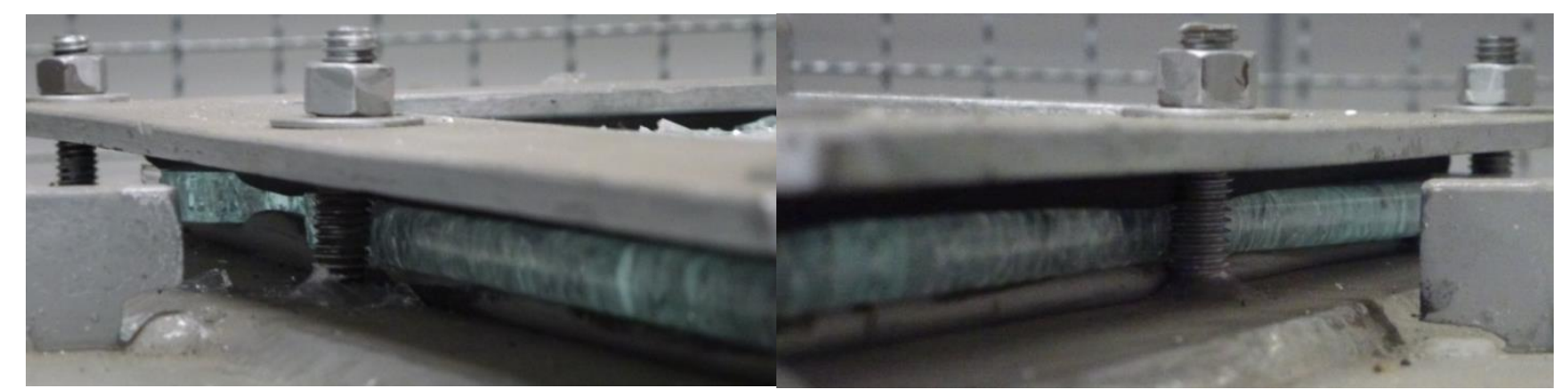

Figura 4.24. Detalhe do contato entre o parafuso e o vidro.

O dimensional do vidro que quebrou era de $350 \times 350 \mathrm{~mm}$, o novo vidro instalado para o próximo ensaio tem um dimensional menor, $335 \times 335 \mathrm{~mm}$. Em suma a interface entre o sistema de aquecimento e o sistema de correlação digital de imagem ARAMIS apresentara resultado negativo até aquele momento.

\subsubsection{Pressurização da curva resultado da análise por elementos finitos}

Apresentam-se a curva de entrada do sistema de controle de pressão e a curva lida pelo transdutor de pressão. 
(a)

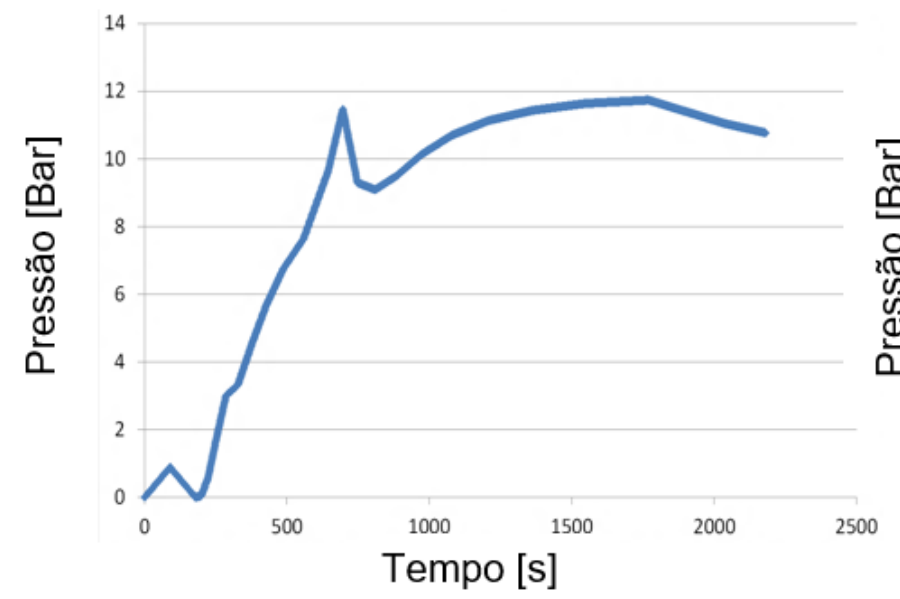

(b)

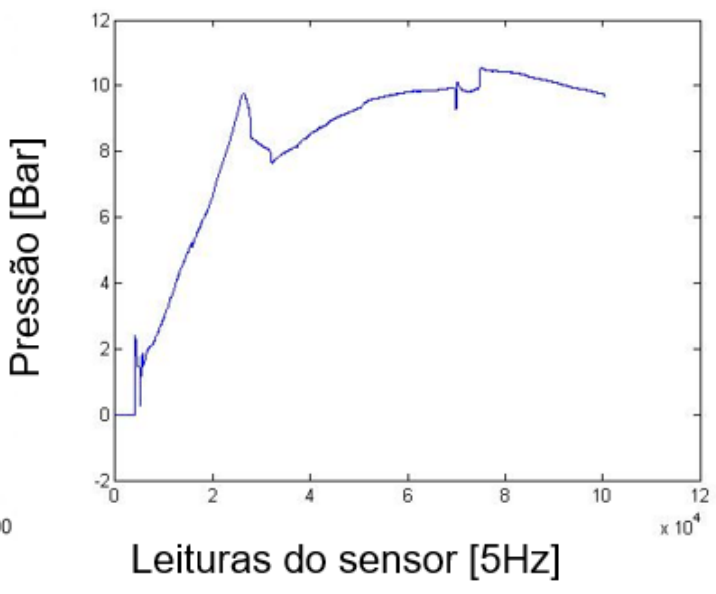

Figura 4.25. (a) Curva de entrada do sistema de controle de pressão, (b) Curva do sinal de pressão do ensaio aquisitado pelo transdutor de pressão.

A Figura 4.25 representa a validação do sistema de pressurização trabalhando a quente, as diferenças entre os valores máximos das curvas é resultado do vazamento que ocorreu durante a pressurização.

É importante ressaltar que o gráfico de entrada do sistema de pressurização possui um primeiro momento de elevação e queda de pressão (em destaque na figura) para que a válvula reguladora proporcional regule o seu sistema de atuação mecânico.

Apesar do vazamento, o sistema de pressurização apresentou comportamento conforme planejado.

\subsubsection{Vazamento no ferramental da primeira concepção}

Como resultado do primeiro ensaio de bulge de titânio superplástico, tem-se que o vazamento do ferramental se apresentou como o principal problema a ser retrabalhado.

Pela análise do ferramental pós ensaio verificou-se que a soldagem por difusão aconteceu em alguns pontos, mas garantir a soldagem na totalidade da superfície de contato mostrou-se uma tarefa que exigiria um estudo mais aprofundado do processo de soldagem por difusão. Na literatura a grande maioria dos estudos que trabalham com soldagem por difusão controlam a solda em área muito menores que a nossa necessidade.

Outro problema observado foi a maneira que aconteceu o vazamento, houve deslocamento por pressão do cobre, ele foi soprado da interface de contato entre a matriz inferior e a chapa de titânio. A dificuldade de controlar a pressão que a matriz superior 
exerce sobre o anel de cobre é um dos motivos que provoca escorregamento do cobre para fora da interface, a Figura 4.26 ilustra os problemas comentados.

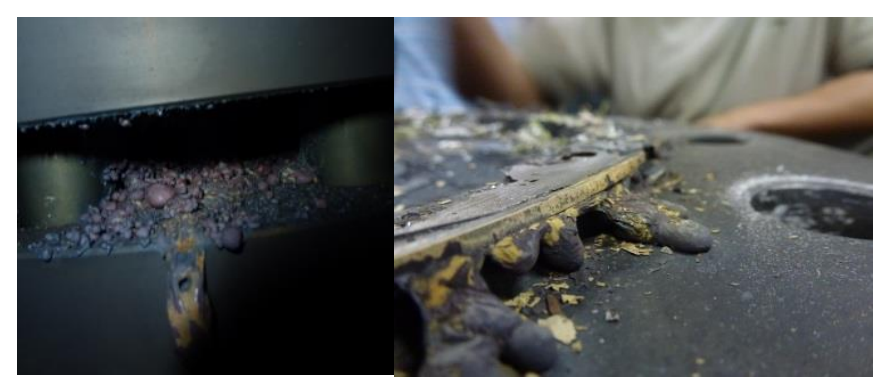

Figura 4.26. Resultado do vazamento do cobre da interface de vedação do bulge.

No momento do desmolde do bulge, verificou-se a necessidade de usinar um maior raio de arredondamento na matriz superior, devido a observação que o titânio estava cortado em alguns pontos. Segue Figura 4.27 do bulge formado no primeiro ensaio de bulge da liga de titânio (Ti6Al4V).
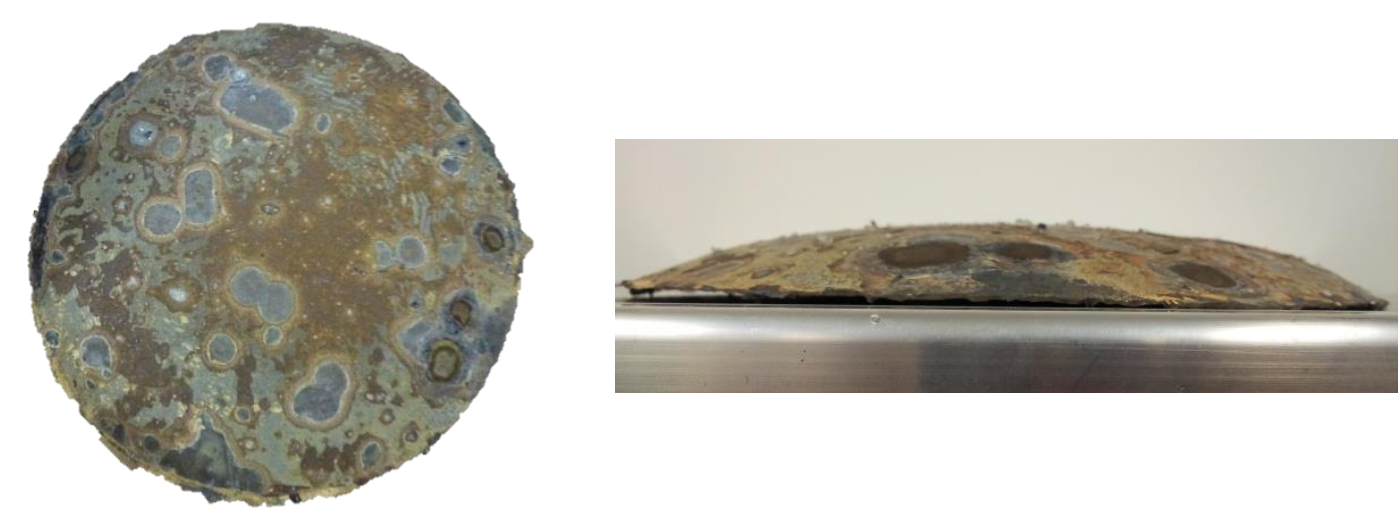

Figura 4.27. Blank conformado de titânio (Ti6Al4V) resultado do primeiro ensaio.

O aspecto não uniforme da superfície do bulge deve-se ao fato de que além da oxidação ocorrida pela entrada de oxigênio após a quebra do vidro, houve também pedaços de vidro que caíram e derreteram sobre a superfície do bulge.

Para resolver esse problema de vazamento, a ferramenta foi retrabalhada, conforme detalhado no capítulo 4.5 . 


\subsection{Retrabalho do ferramental superplástico}

Para melhor caracterizar cada etapa do retrabalho do ferramental, dividem-se as alterações nas respectivas partes do ferramental, matriz superior e matriz inferior.

\subsubsection{Retrabalho da matriz superior}

Para evitar a quebra do titânio no momento da conformação quando em contato com a superfície da matriz superior, usinou-se um raio de $6 \mathrm{~mm}$ conforme ilustrado Figura 4.28.
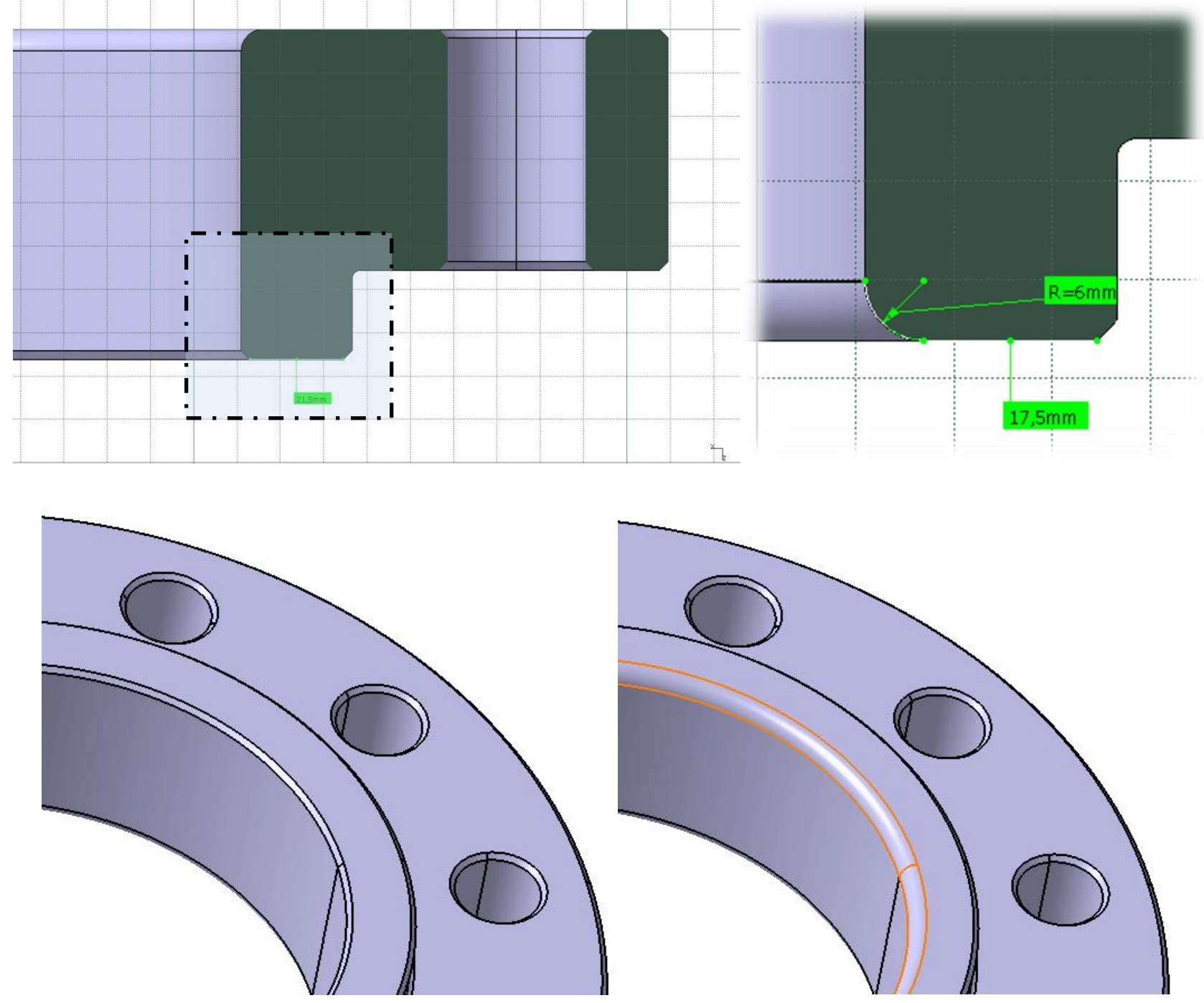

Figura 4.28. Usinagem do raio de $6 \mathrm{~mm}$ no local indicado. 


\subsubsection{Retrabalho da matriz inferior}

A matriz inferior foi retrabalhada com intuito de solucionar o problema do vazamento, as modificações realizadas alteram o procedimento de montagem do ferramental. Seguem as etapas de retrabalho na matriz inferior, Figura 4.29.

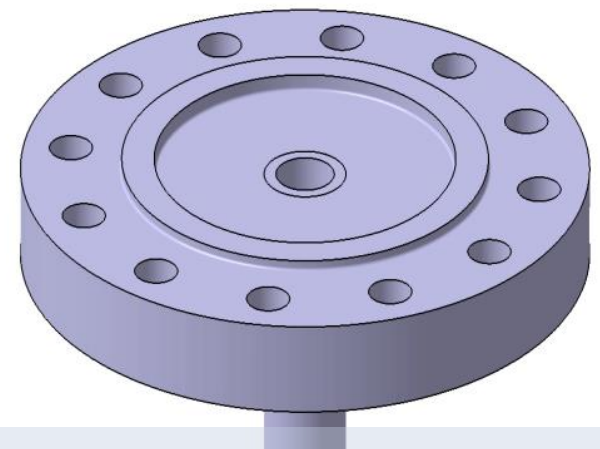

Concepção 1 do ferramental
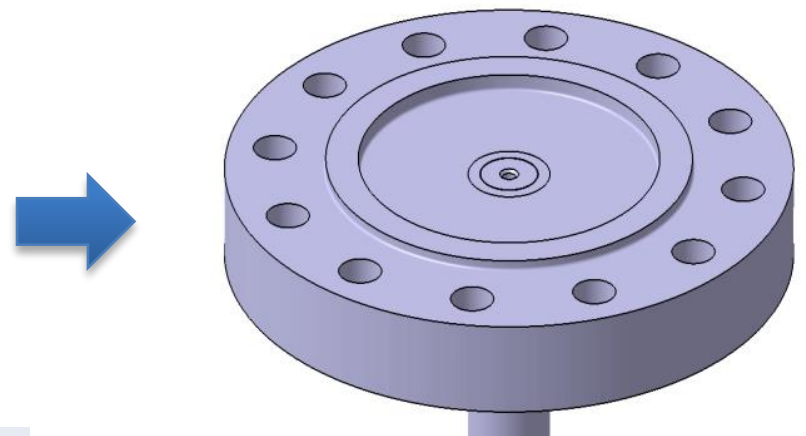

Redução do canal de pressurização

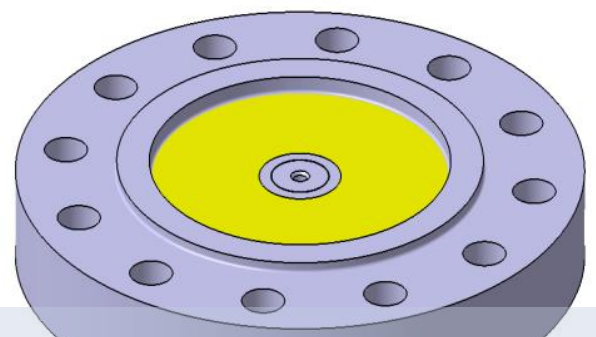

Aumento da area selecionada

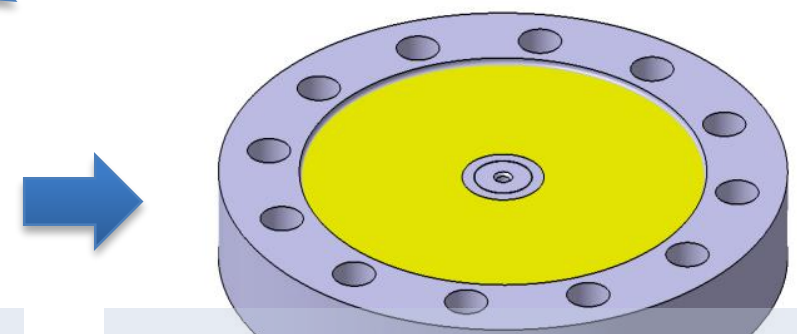

Concepção 2 do ferramental

Figura 4.29. Etapas de retrabalho da matriz inferior.

A primeira mudança diz respeito ao canal de pressurização, na concepção 2 do ferramental, a pressurização será realizada através de um tubo de argônio de diâmetro nominal de 1/4". Esse tubo é soldado em um acesso no centro de uma placa de titânio de 3/8" que por sua vez é soldada em toda sua lateral ao corpo de prova do bulge teste de titânio superplástico. A diminuição do canal de pressurização é necessária para que no momento da pressurização, a placa de $3 / 8$ " não conforme no sentido contrário ao do bulge superplástico. 
Para facilitar o entendimento da nova montagem do ferramental segue o esquema da solda para vedação da concepção 2 do ferramental.

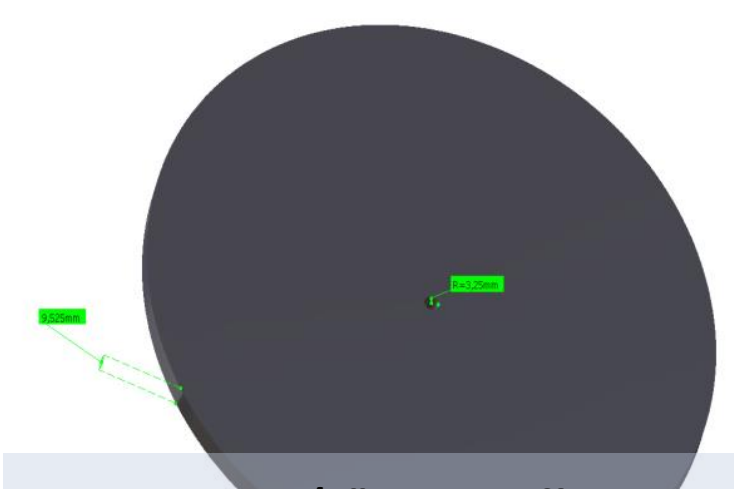

Chapa de 3/8" de sacrifício com orificio para soldagem com tubo

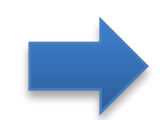

Tubo de titânio para pressurização

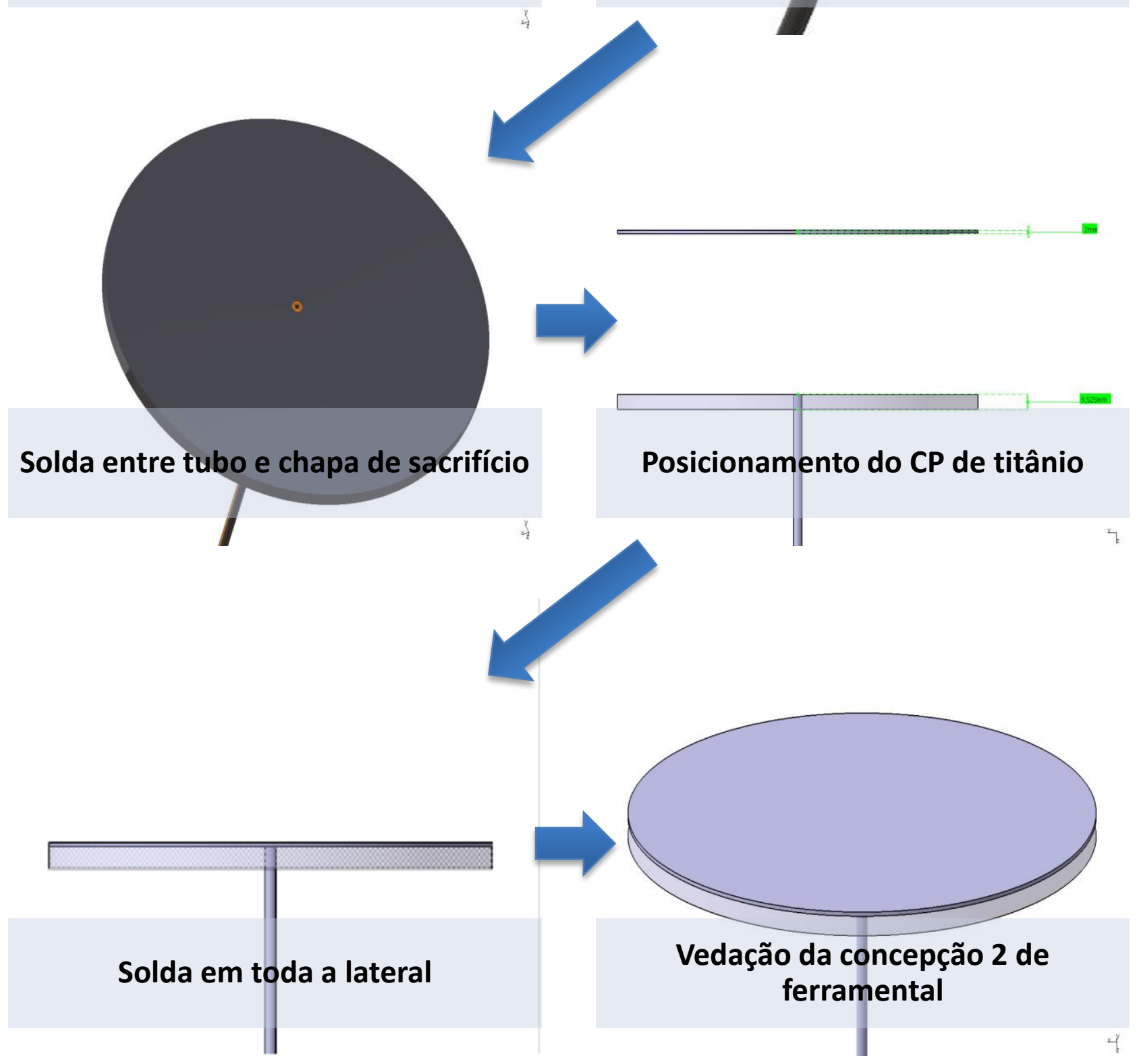

Figura 4.30. Etapas de soldagem da solução para vedação da concepção 2 de ferramental. 
Esse conjunto (tubo+chapa de sacrifício + CP de titânio) quando pressurizado na temperatura superplástica precisará da redução do canal de pressurização - Figura 4.31 para não ter conformação no sentido indesejado (para baixo).

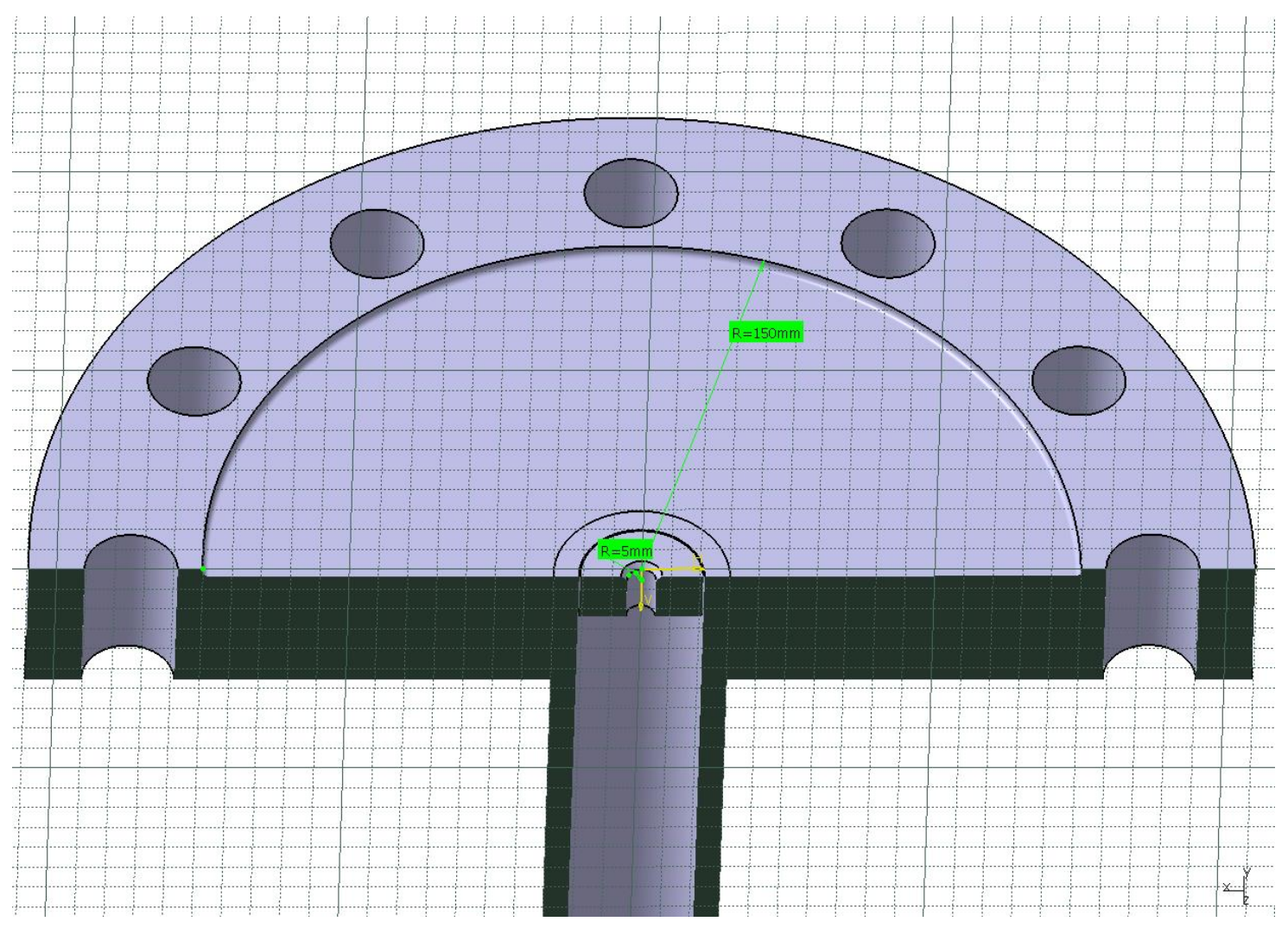

Figura 4.31. Detalhe de construção da redução do canal de pressurização.

A segunda mudança na matriz inferior é o aumento da area da base da matriz, que serve de apoio para a chapa de sacrifício, essa alteração é representada na Figura 4.29. 


\subsection{Alteração no procedimento de montagem do ferramental}

A concepção 2 de ferramental, além das alterações de retrabalho no ferramental, também utiliza uma nova abordagem de montagem, deixa de lado o anel de cobre, utilizase da solda lateral das chapas de titânio (chapa de sacrifício e corpo de prova de titânio superplástico) para realizar a vedação.

Observe a listrução do posicionamento do conjunto soldado (tubo+chapa de sacrifício + CP de titânio) na Figura 4.32.

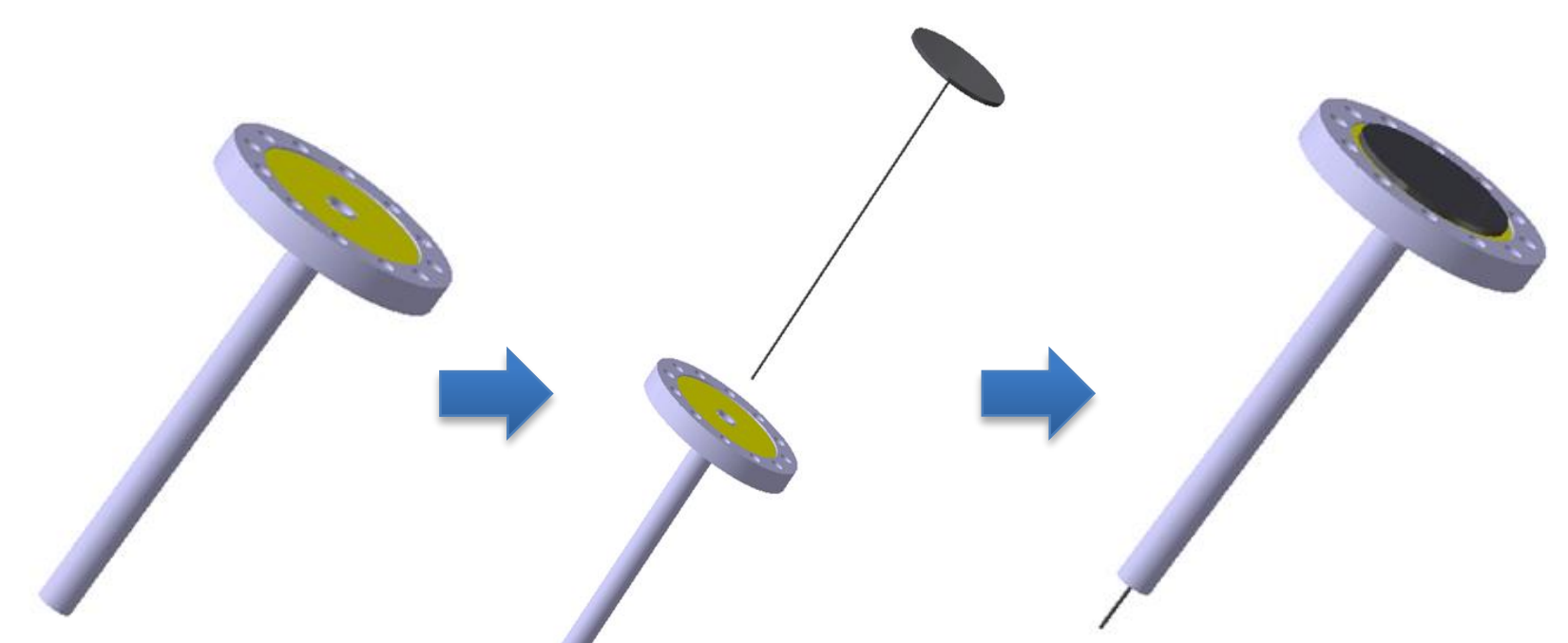

Matriz inferior

Posicionamento do conjunto soldado
Saida do tubo de titânio na matriz inferior

Figura 4.32. Posicionamento do conjunto soldado (tubo+chapa de sacrifício + CP de titânio) na matriz inferior e visualização da saida do tubo de titânio onde será conectado o sistema de pressurização.

Da mesma forma que foi apresentado o procedimento de montagem para a concepção 1 de ferramental, apresenta-se o procedimento de montagem da concepção 2 de ferramental na Figura 4.33. 

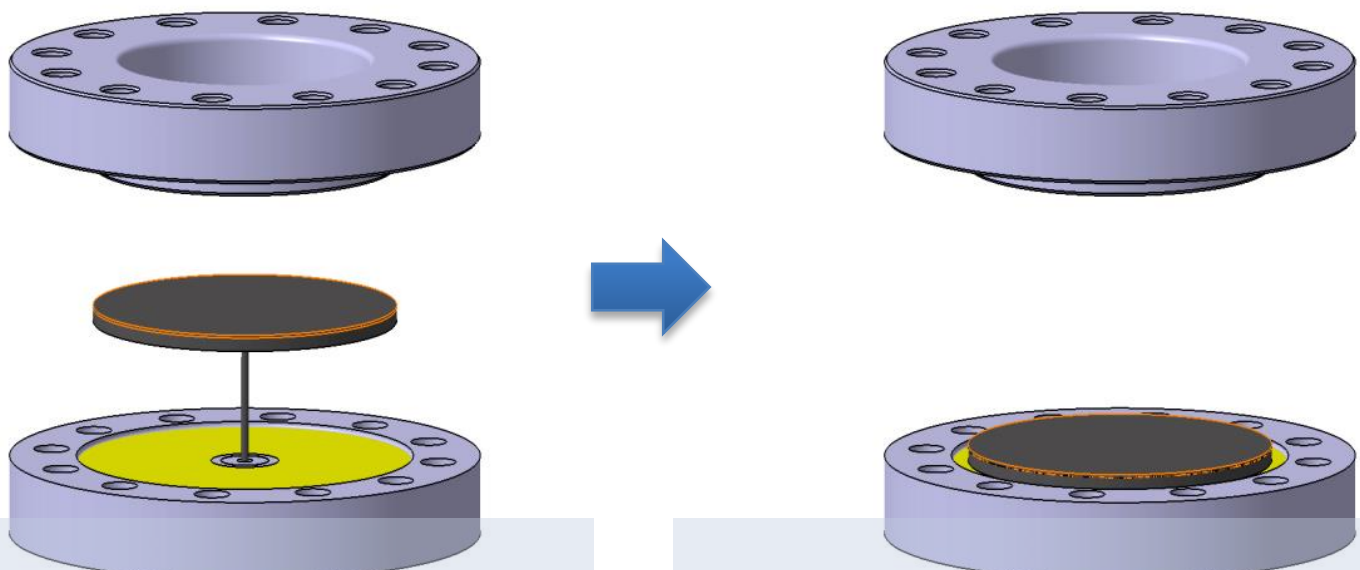

Posicionamento do conjunto soldado

Fechamento da matriz superior
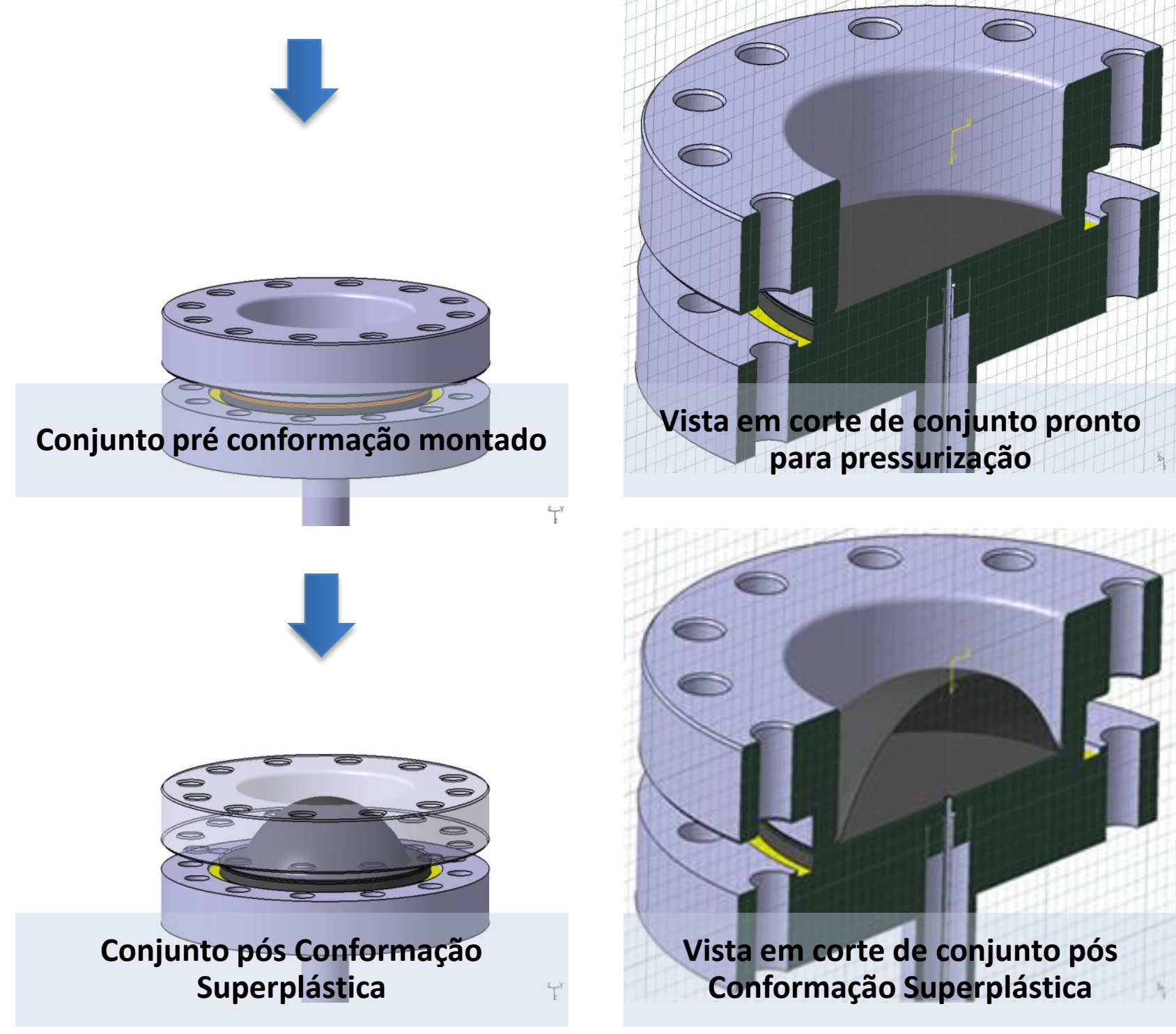

Figura 4.33. Procedimento de montagem da concepção dois do ferramental. 
O retrabalho no módulo de visualização buscou corrigir a quebra do vidro de borossilicato. Em suma, foi dividida a area de visualização em duas áreas menores e o borossilicato foi substituído por quartzo. Para definir a nova geometria do módulo de visualização e pela impossibilidade de calibrar a ARAMIS com quartzo localizado na própria janela do forno, foi construído um modelo icônico para representar o posicionamento geométrico necessário para medição através do quartzo. A Figura 4.34 traz o significado das variáveis geométricas, $A=600 \mathrm{~mm}$ e $B=280 \mathrm{~mm}$, o valor de "A" representa a distância da câmera para o bulge (600 mm), entretanto, esse valor é a composição de um par de posicionamentos que está definido em razão da localização das janelas, dessa forma é preciso respeitar a distância bulge janela de quartzo de $345 \mathrm{~mm}$ e a distância janela de quartzo câmera de $255 \mathrm{~mm}$. Na Figura 4.34 há também a ilustração que representa a utilização do modelo icônico durante a calibração do sistema GOM ARAMIS através do quartzo.

(a)

(b)

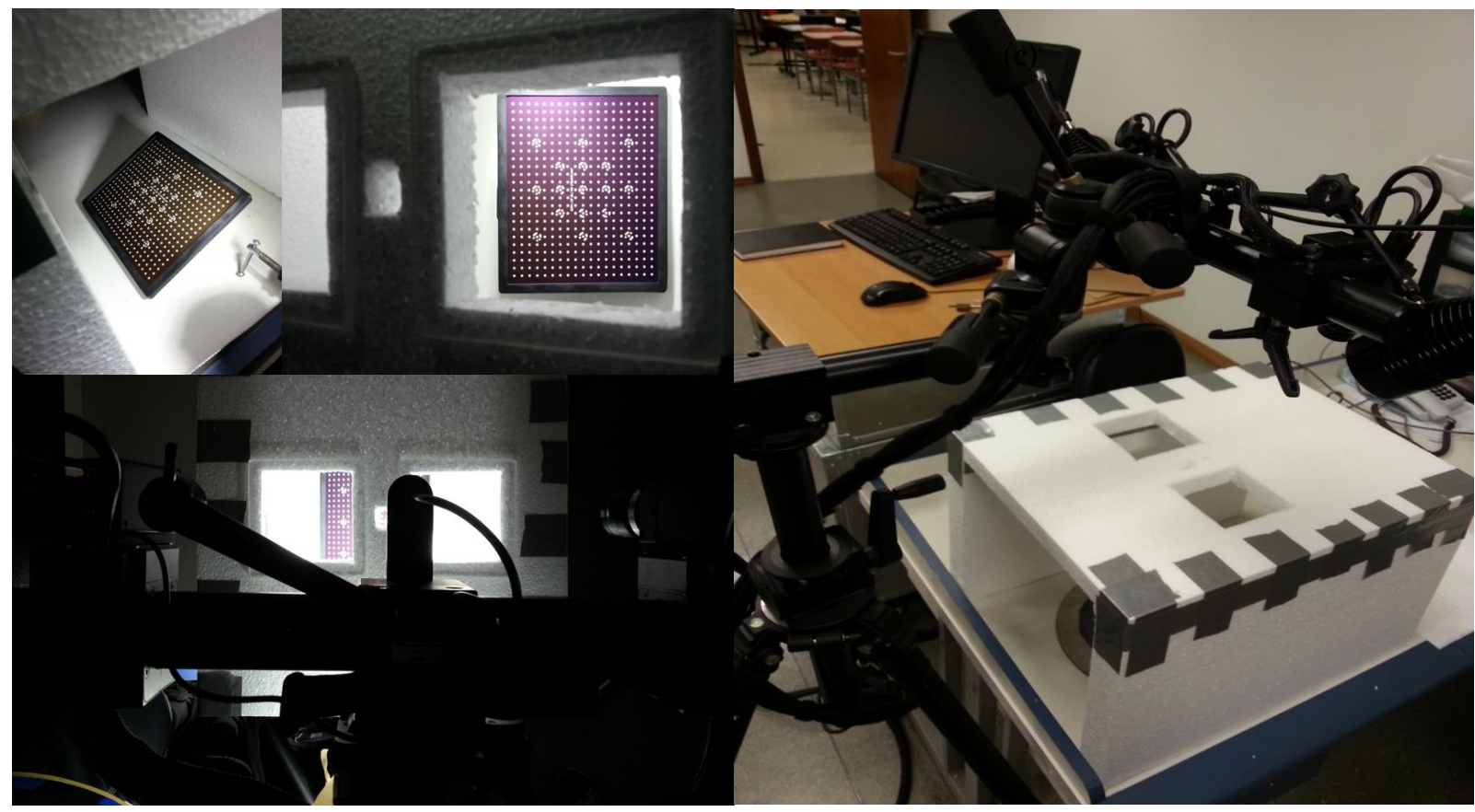


(c)

Distância entre

câmeras

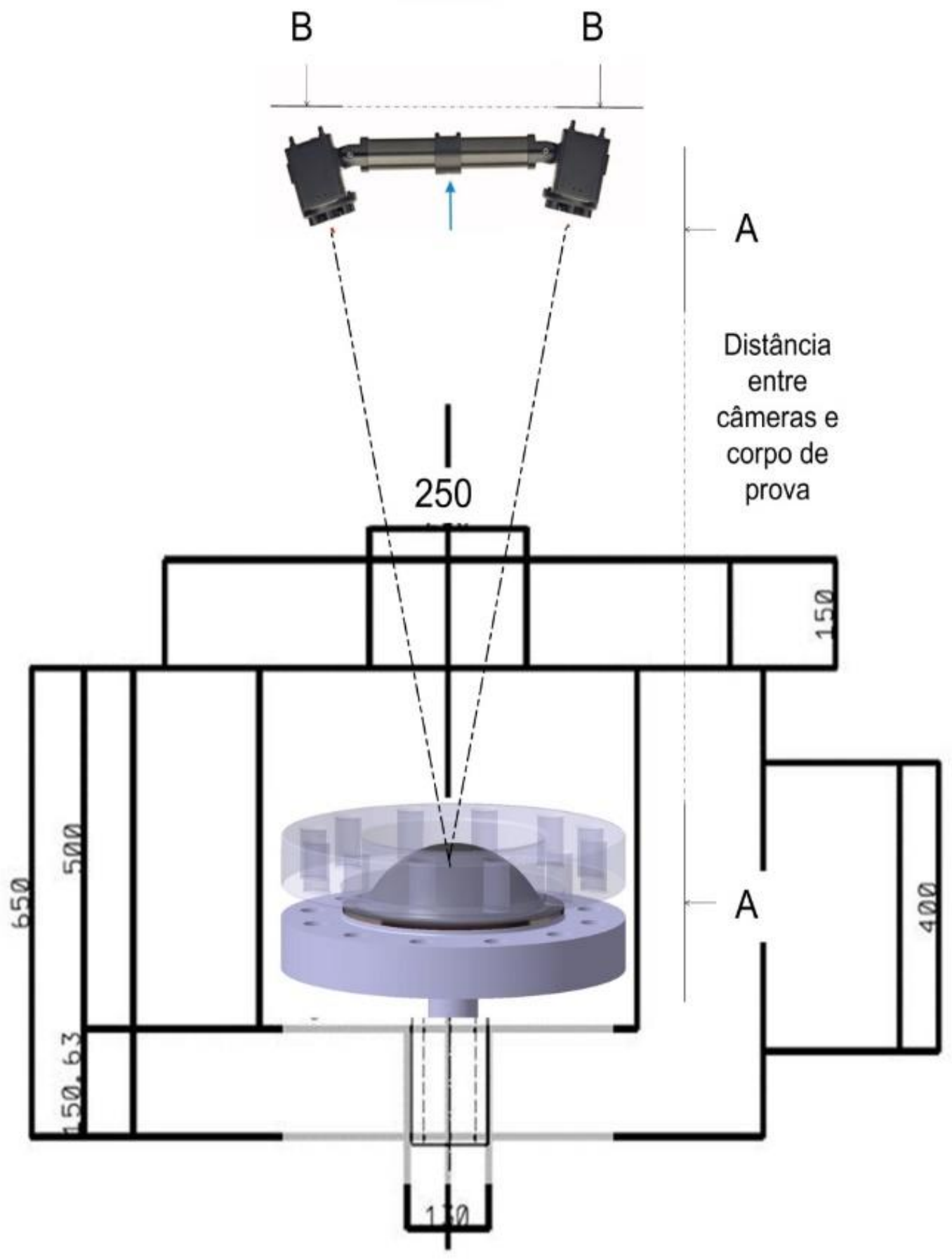

Figura 4.34. (a) Calibração da ARAMIS através do quartzo ao se utilizar o modelo icônico,

(b) Modelo Icônico nas mesmas dimensões da janela do forno e (c) Parâmetros de calibração

Com as placas inferior e superior usinadas nas geometrias definidas pela nova calibração, na Figura 4.35 há as etapas da montagem: 


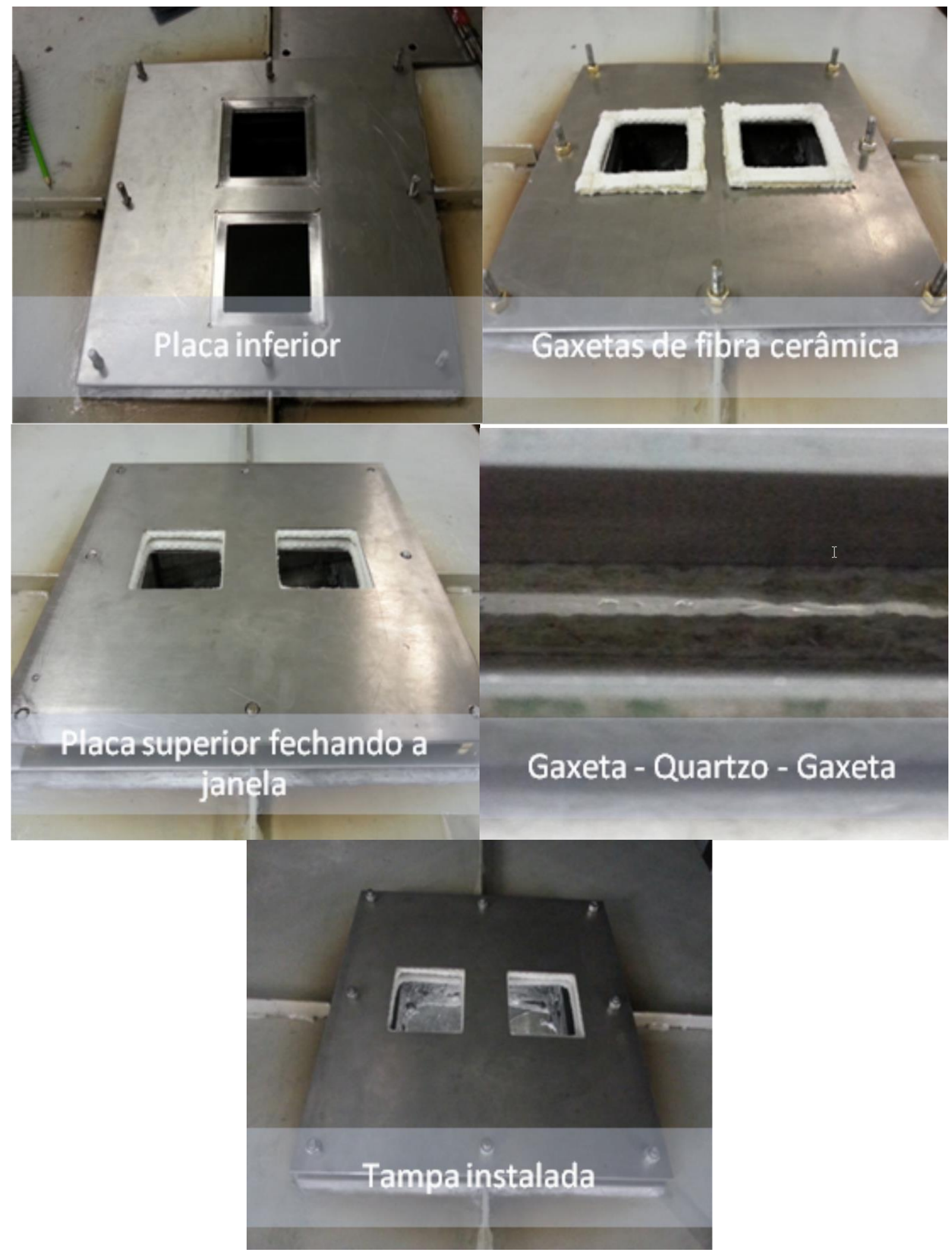

Figura 4.35. Montagem das placas de aço inox $304 \mathrm{com}$ janelas quadradas de área de visualização de $100 \mathrm{~mm} \times 100 \mathrm{~mm}$ com gaxetas de fibra cerâmica e quartzo. 
Mesmo com as modificações, o teste do módulo de visualização, que tinha como objetivo realizar uma medição com o ARAMIS através do módulo 2 de visualização, não obteve o resultado esperado, a configuração de montagem exigiu uma elevada força de compressão no fechamento que, por sua vez, impediu o movimento relativo das partes montadas, e pela alta diferença de dilatação (entre o inox e quartzo), resultou na quebra do quartzo do módulo de visualização, conforme Figura 4.36, entretanto a cristalinidade do quartzo na temperatura do ensaio $\left(900^{\circ} \mathrm{C}\right)$ foi aprovada e a estabilidade térmica nas condições do ensaio foi validada.

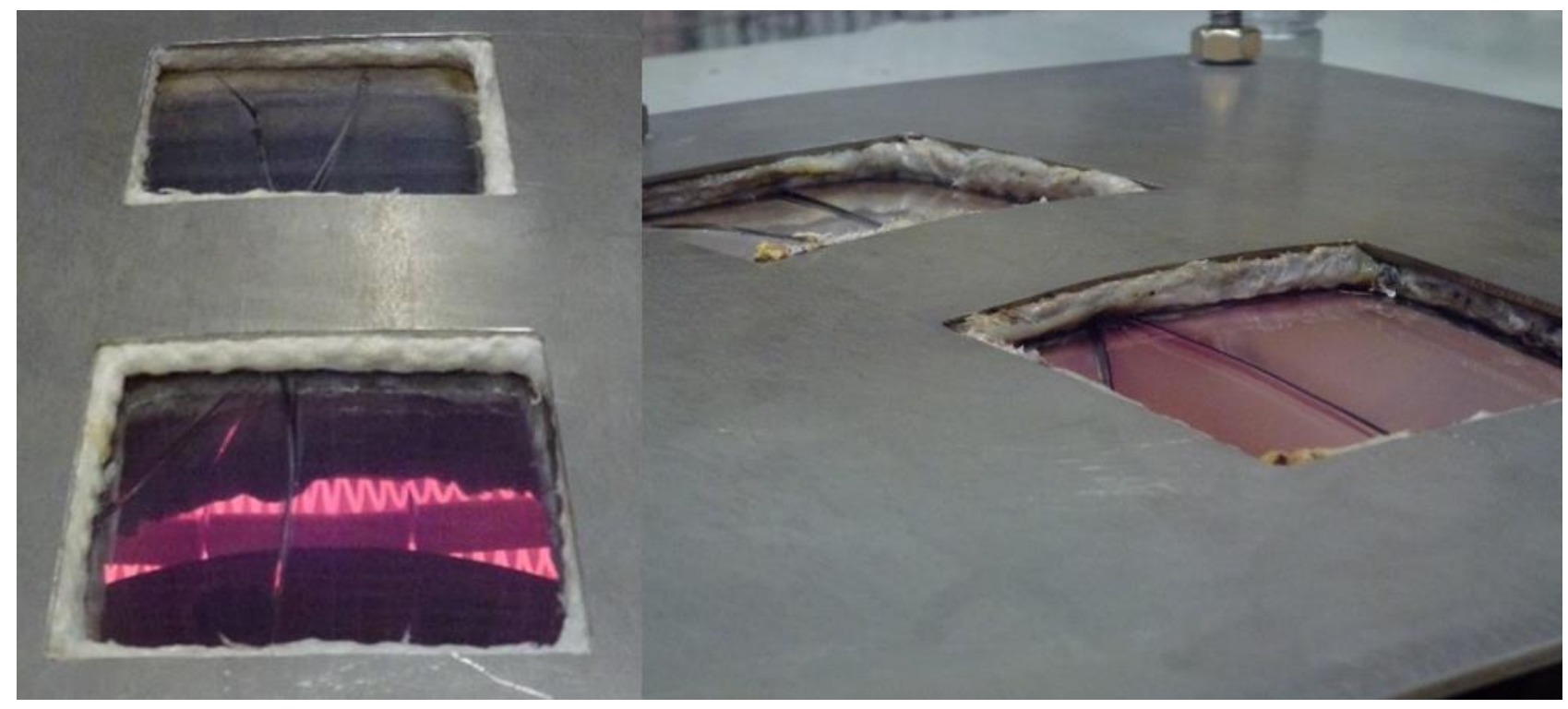

Figura 4.36. Detalhe da quebra do quartzo durante o aquecimento na temperatura interna do forno de $670^{\circ} \mathrm{C}$, com a ferramenta a $550^{\circ} \mathrm{C}$

Após apresentação do resultado do bulge cego, confome explicado esse ensaio não validou módulo de deformação, no próximo capítulo será apresentado o módulo de visualização de deformação final e validado para a referida prensa de Conformação Superplástica da tese. 


\subsection{Expansão fluidoestática biaxial cega da chapa de Ti6Al4V superplástico.}

Após os testes modulares (sistema de pressurização a frio, controle e estabilização térmica com o módulo de monitoramento de deformação fechado, teste de estanqueidade da concepção 2 de montagem do bulge e sistema de proteção térmica do sistema de pressurização) apresentarem resultados positivos, realiza-se o primeiro ensaio fluidoestática biaxial superplástico da liga de Titânio (Ti6Al4V) a quente com pressurização controlada. Nesse ensaio não foi utilizado o módulo de controle de deformação, foi necessário o desenvolvimento de um novo módulo de visualização, devido problema apresentado pela janela de visualização, o resultado final do referido módulo será apresentado na próxima sessão.

O principal objetivo é o teste integrado de todos os sistemas em conjunto com a concepção 2 de ferramental.

Utiliza-se o mesmo protocolo de ensaio, inicia-se com a aplicação do nitreto de boro, calibração da curva de pressão, realiza-se o procedimento de montagem da concepção 2 do ferramental com o fechamento da vedação da jaqueta para realizar a purga no forno, aplicação da atmosfera positiva de argônio, aquecimento até o patamar de $927^{\circ} \mathrm{C}$ sem sobressinal, após a estabilização térmica, realizou-se a primeira expansão fluido estática controlada da liga de Ti6AL4V.

O objetivo de validar o sistema de controle de pressão a quente foi alcançado no ensaio. Apresenta-se a curva de pressurização resultado do módulo de controle de pressão na Figura 4.37.

——Pressåo do transdutor de alta temperatura

— Curva de pressurização da análise de elementos finitos

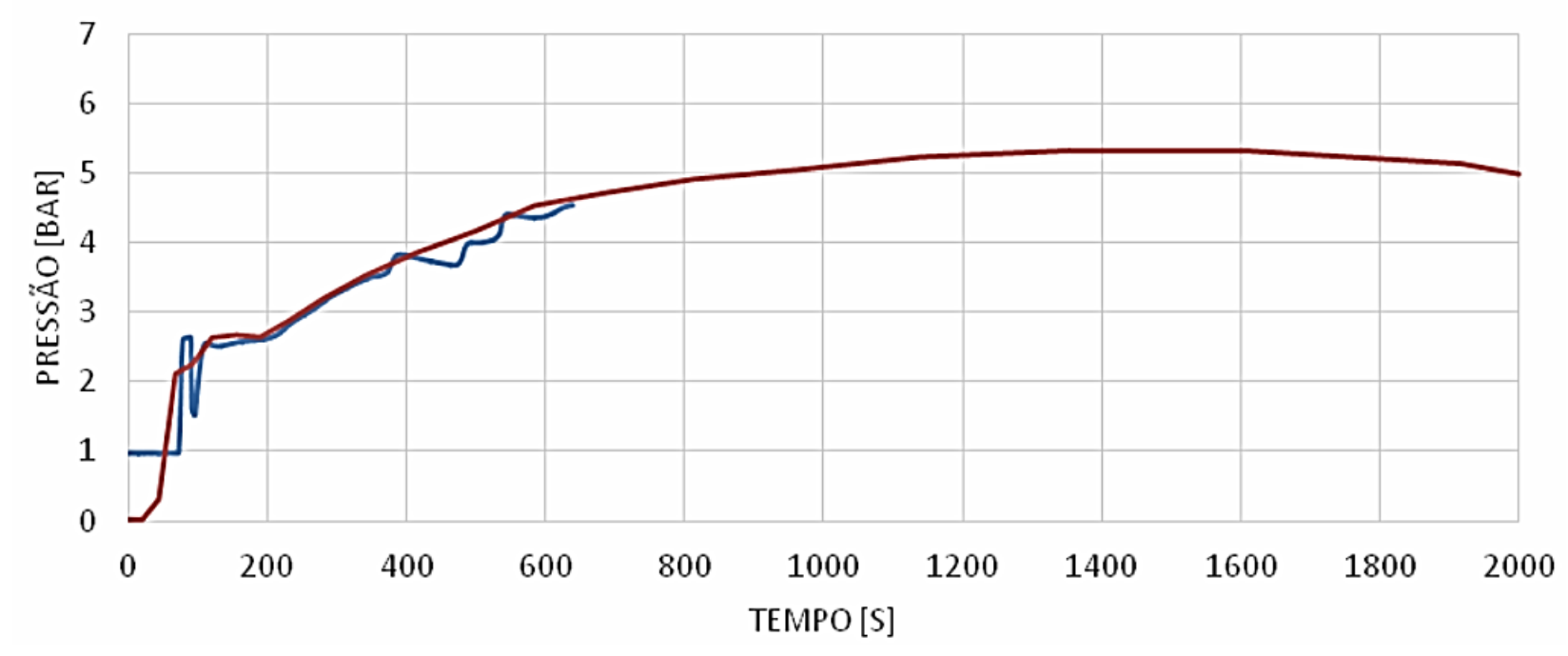

Figura 4.37. Curva de controle do módulo de pressurização. 
Segue imagem da chapa de Ti6AI4V conformada superplásticamente na Figura 4.38.
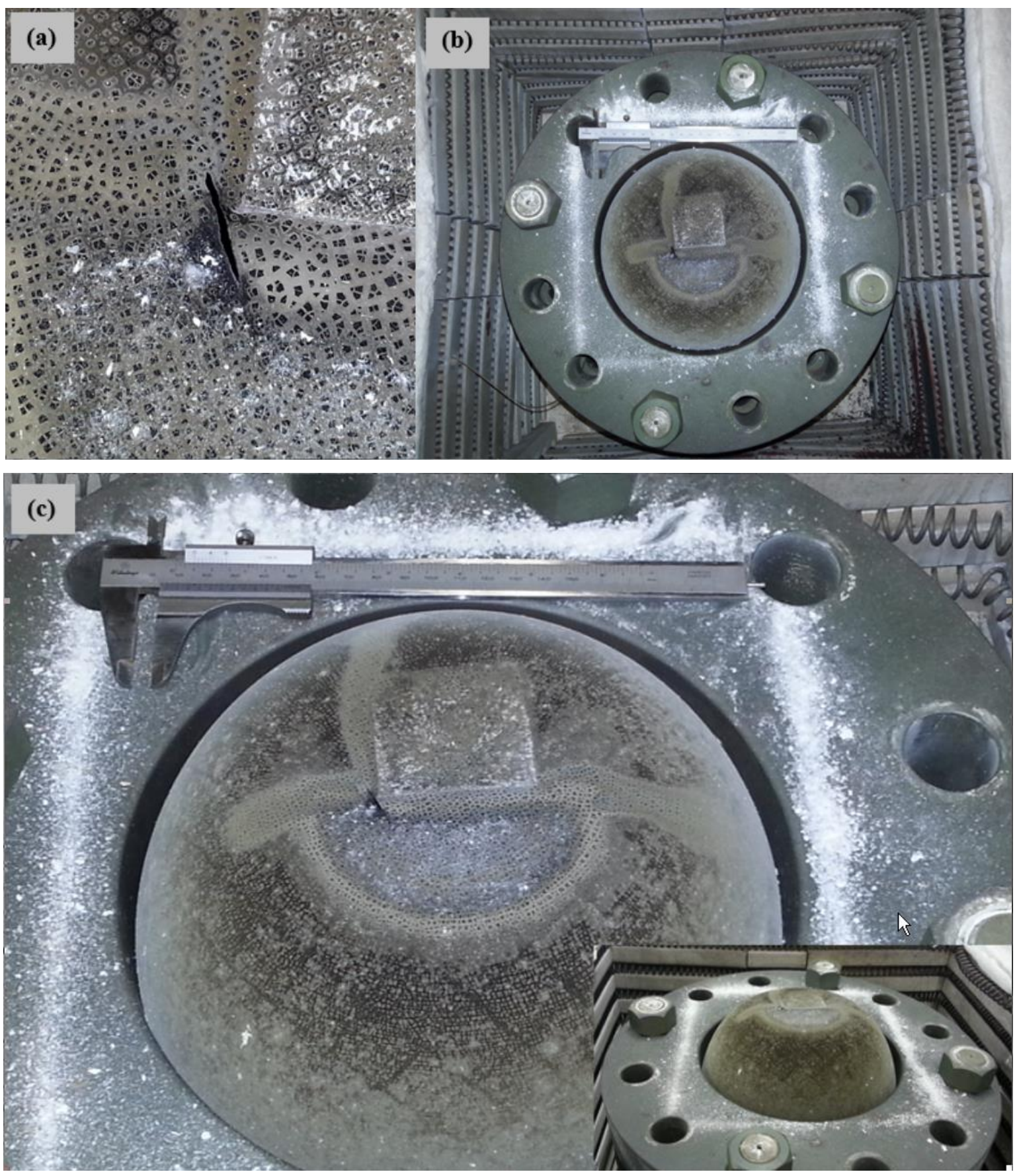

Figura 4.38. (a) Detalhe da ruptura, (b) vista superior e (c) lateral do bulge superplástico de Ti6Al4V. 


\subsection{Conformação Superplástica da peça modelo de Ti6Al4V}

Para a conformação da peça modelo, seria necessário retrabalhar a matriz superior, em uma primeira análise de reutilização do ferramental de bulge test para a usinagem da peça modelo aeronáutica no seu perfil maciço, o resultado foi positivo, entretanto, a utilização do ferramental para conformação de bulge test ficaria comprometida em razão do perfil da nova peça usinada. Por esse motivo foi escolhido a usinagem de uma nova parte superior do ferramental, segue a Figura $4.39 \mathrm{com}$ o desenho descartado da concepção 1 de ferramental para a peça aeronáutica reutilizando o ferramental de bulge test.
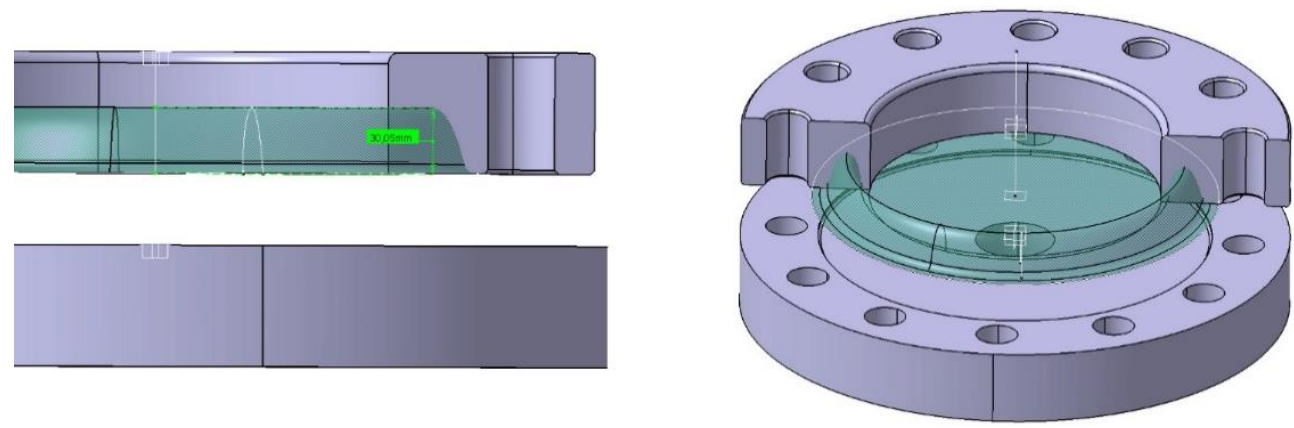

Figura 4.39. Concepção de ferramental para peça aeronáutica.

Segue Figura 4.40 da peça modelo, é um lipskin de um avião executivo.
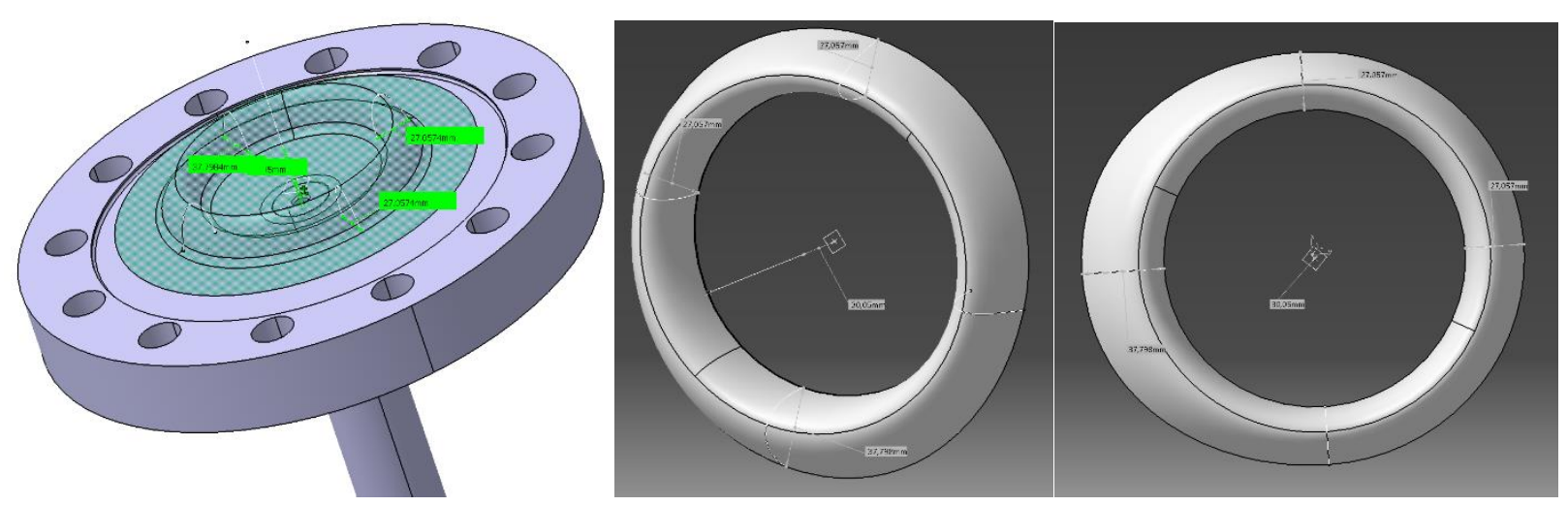

Figura 4.40. Peça modelo aeronáutica para ser conformada superplásticamente com a liga de Ti6Al4V. 
Segue a Figura 4.41 com as fotos do flange novo usinada para a concepção da peça modelo.

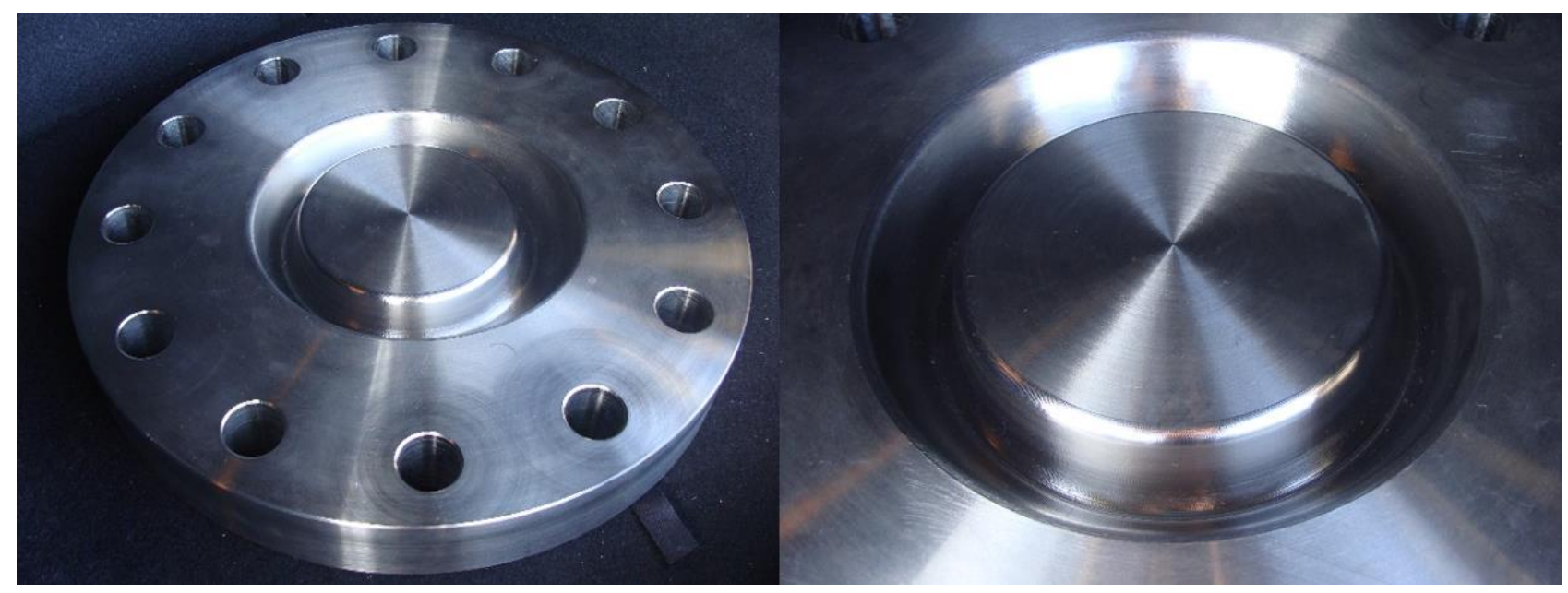

Figura 4.41. Matriz superior para conformação da peça aeronáutica superplástica de Ti6Al4V.

A mudança no perfil de pressão da conformação da peça modelo, em razão da etapa de contato com a matriz superior, motivou uma nova calibração do sistema de controle de pressão. Durante o ensaio, a curva de pressurização foi seguida pelo sistema de controle de pressão de maneira eficiente, com erro máximo da ordem de 0,2 Bar. Na Figura 4.42 há a evolução da calibração do sistema de pressurização.

Sem o módulo do controle de deformação, utilizando a tampa de fechamento da janela do forno (em substituição a janela de quartzo), realizou-se a conformação da peça modelo aeronáutica controlada com a liga de Ti6AL4V. Segue a curva de pressurização resultado do módulo de controle de pressão na Figura 4.43, observa-se a evolução do sistema de controle com a aplicação dos parâmteros de Ziegler-Nichols, detalhado no capítulo 3.5.

Segue imagem da chapa de Ti6Al4V conformada superplasticamente através da pressurização da peça modelo na Figura 37. 


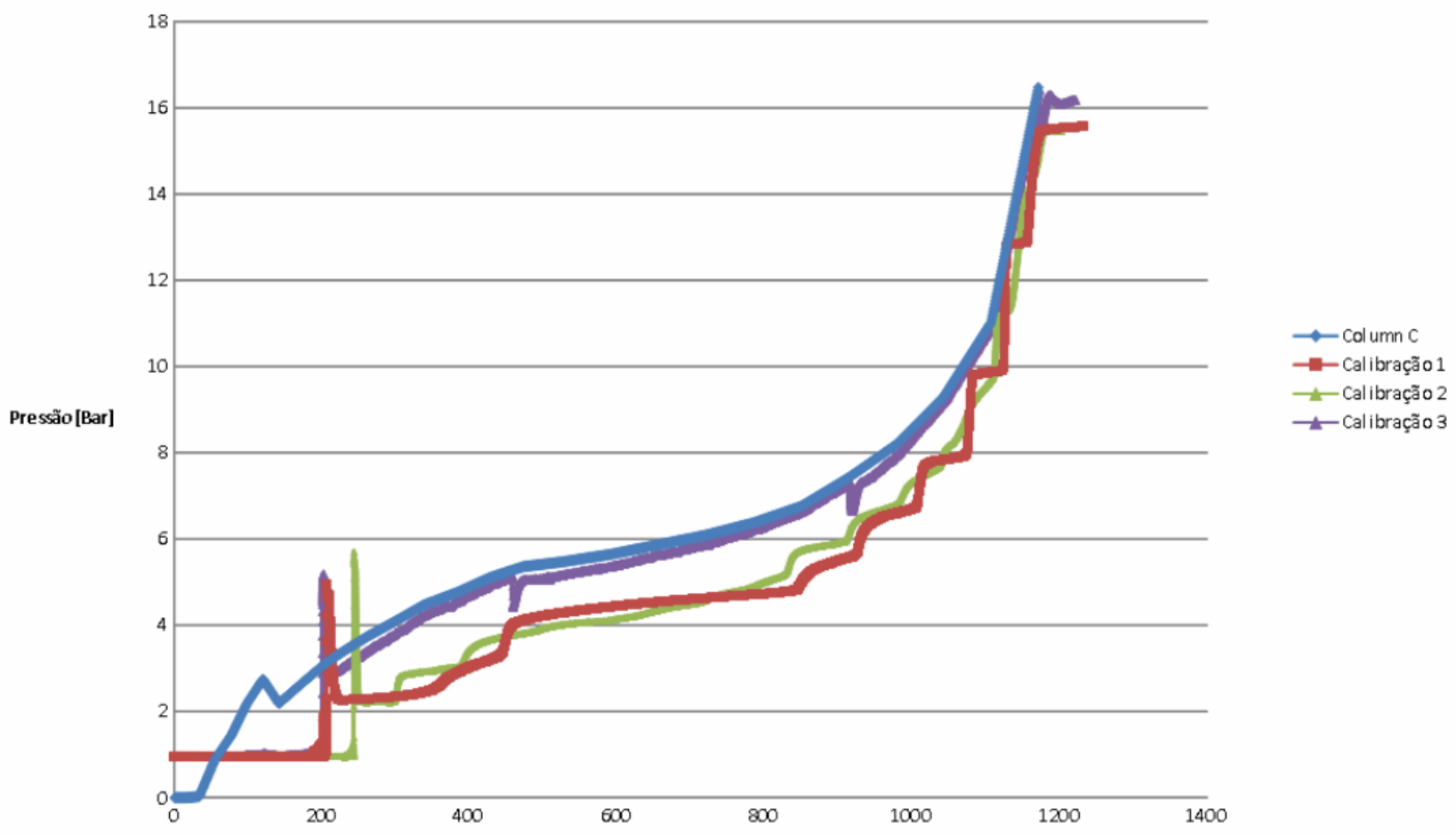

Figura 4.42. Evolução do sistema de controle devido alteração dos parâmetros do controlador do sistema de pressurização de alta pressão.

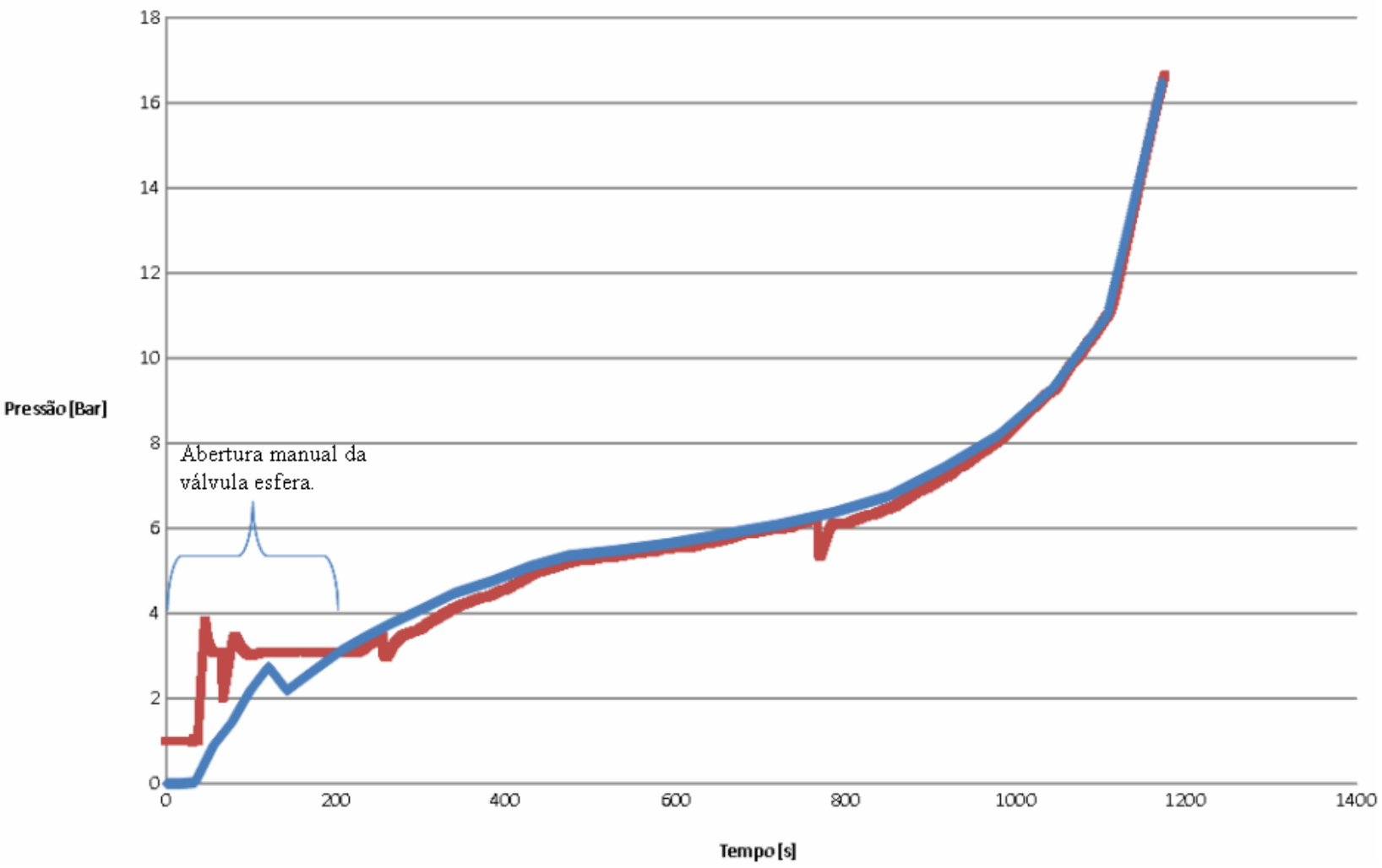

Figura 4.43. Curva de controle do módulo de pressurização após tuning do controlador proporcional integral com parâmetros de Ziegler-Nichols. 
(a)

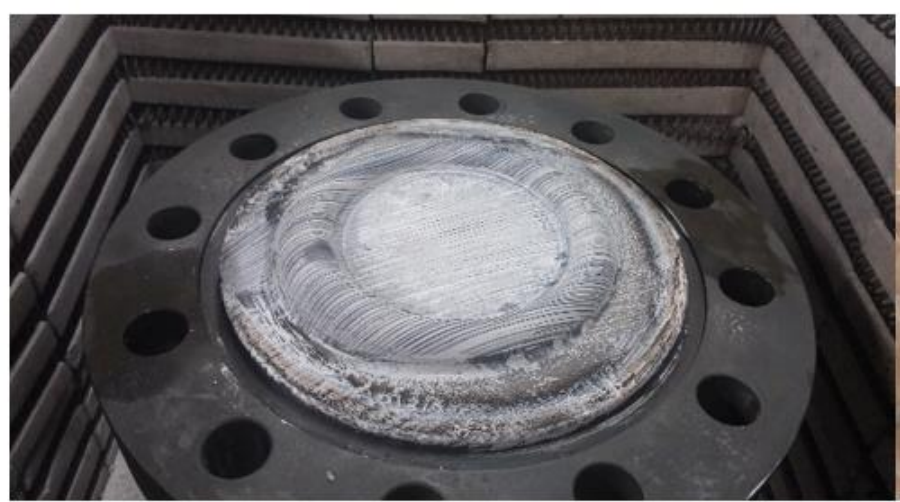

(b)

(c)

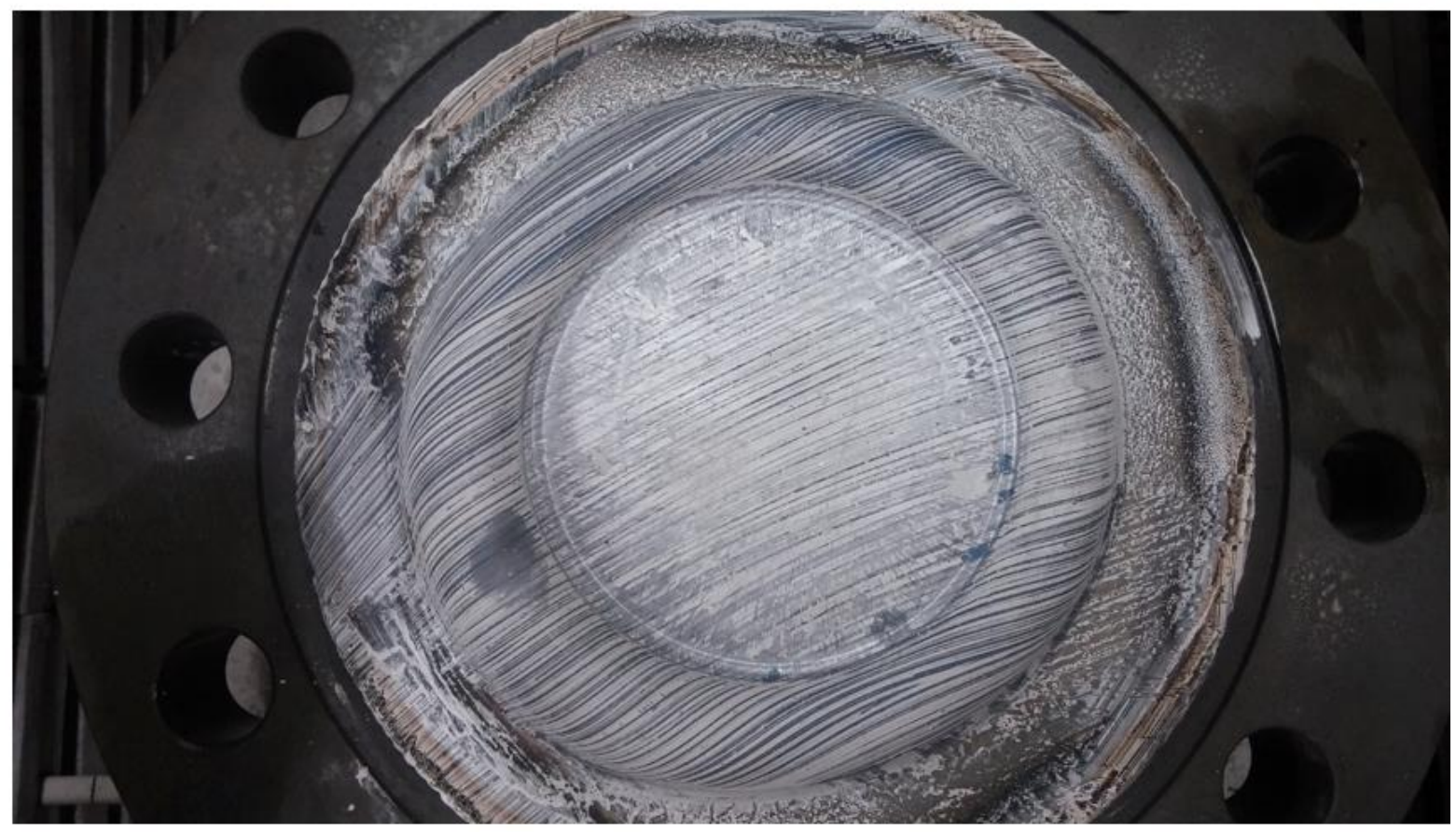

Figura 4.44. (a), (b) Vista em perspectiva da peça conformada, (c) vista superior. 


\subsection{Módulo de monitoramento da deformação final}

Após as lições aprendidas nos dois módulos de deformação anterior, segue a análise da concepção da janela final e detalhes do ensaio de validação que obteve sucesso. Segue evolução ilustrativa do módulo de visualização na Figura 4.45.

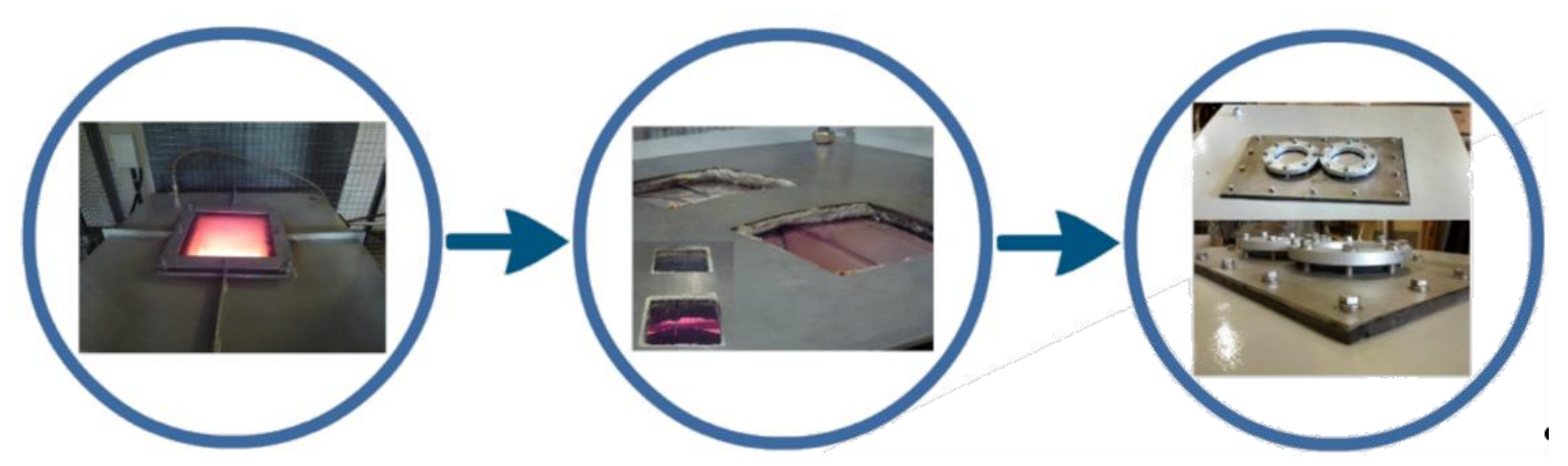

Figura 4.45. Evolução do módulo de monitoramento da deformação.

Alguns pontos merecem destaque na análise da nova janela, aumento da proteção térmica da janela, conforme Figura 4.46 .
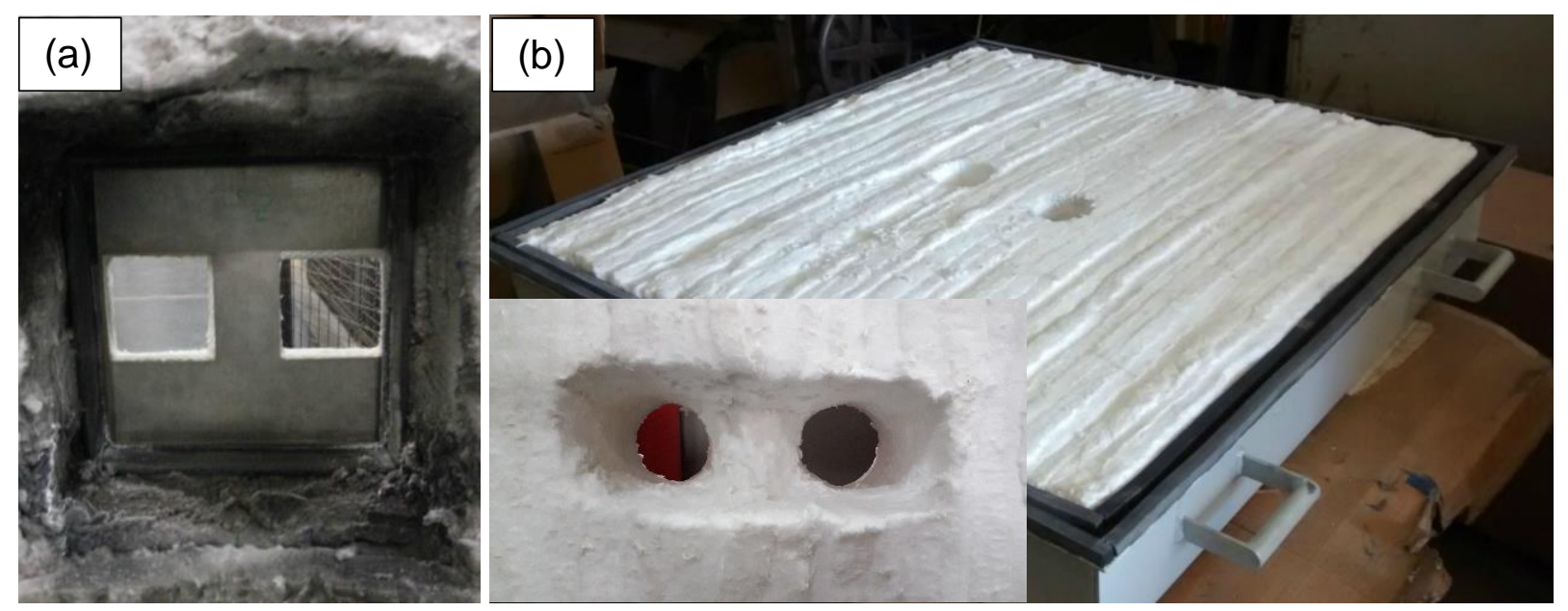

Figura 4.46. (a) Detalhe da proteção térmica do módulo antigo (b) detalhe do aumento da proteção térmica do módulo final.

Houve mudança na geometria e na estrutura do módulo de deformação; no que se refere a geometria, a janela redonda evita concentração de tensão nos cantos, no que diz 
respeito a mudança estrutural, utilizou-se um placa de inconel para evitar que a deformação devido ao aqueciemento.

O maior número de pontos de fixação, Figura 4.48, e o aumento na espessura do quartzo, Figura 4.49, melhoram a distribuição de carga no fechamento do módulo de visualização, segue Figura 4.47 do módulo de visualização que foi validado em um ensaio de bulge superplástico idêntico ao descrito no capítulo 4.7.

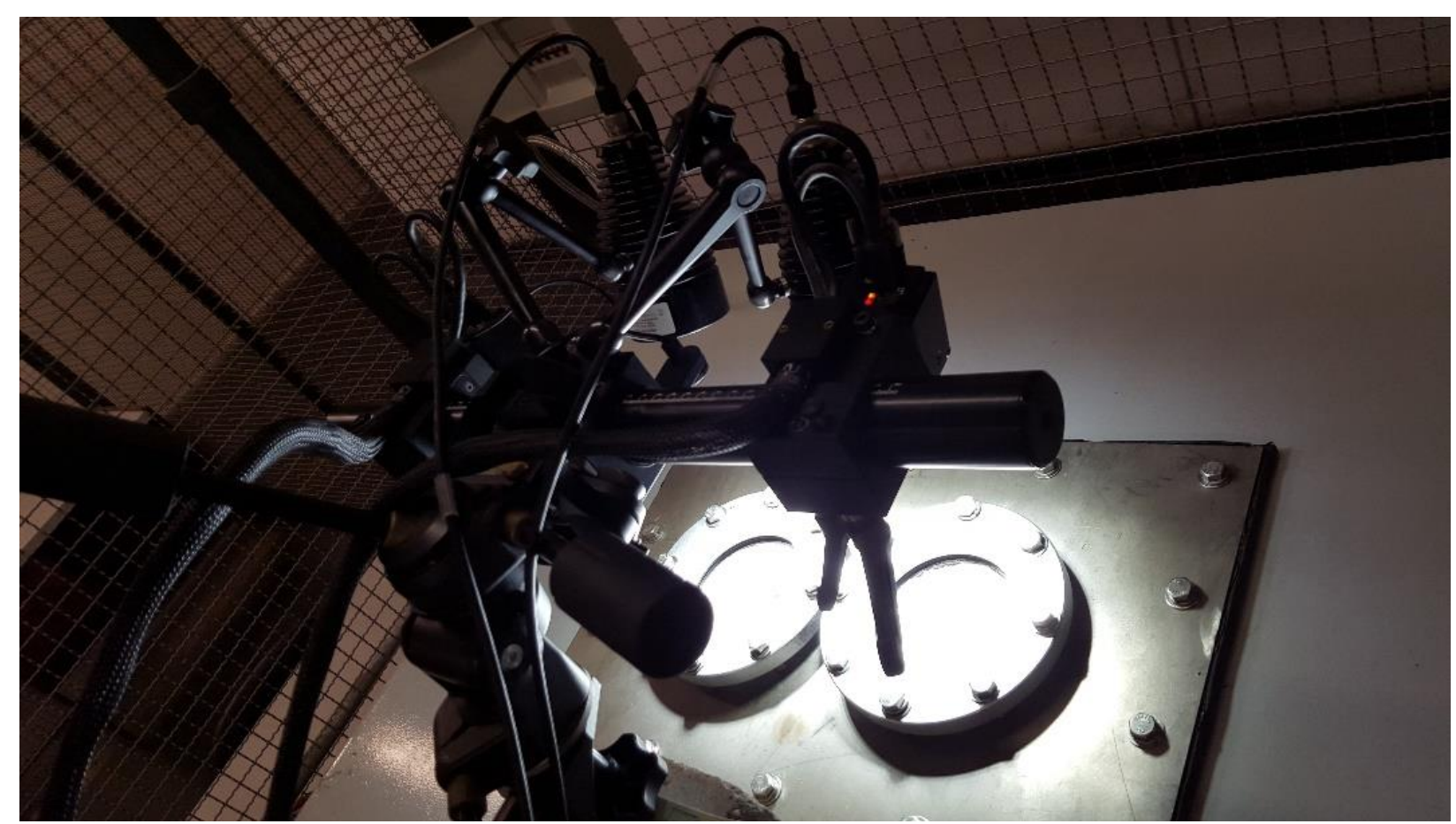

Figura 4.47. ARAMIS realizando a medição de deformação durante a Conformação Superplástica através do módulo de monitoramento de deformação.

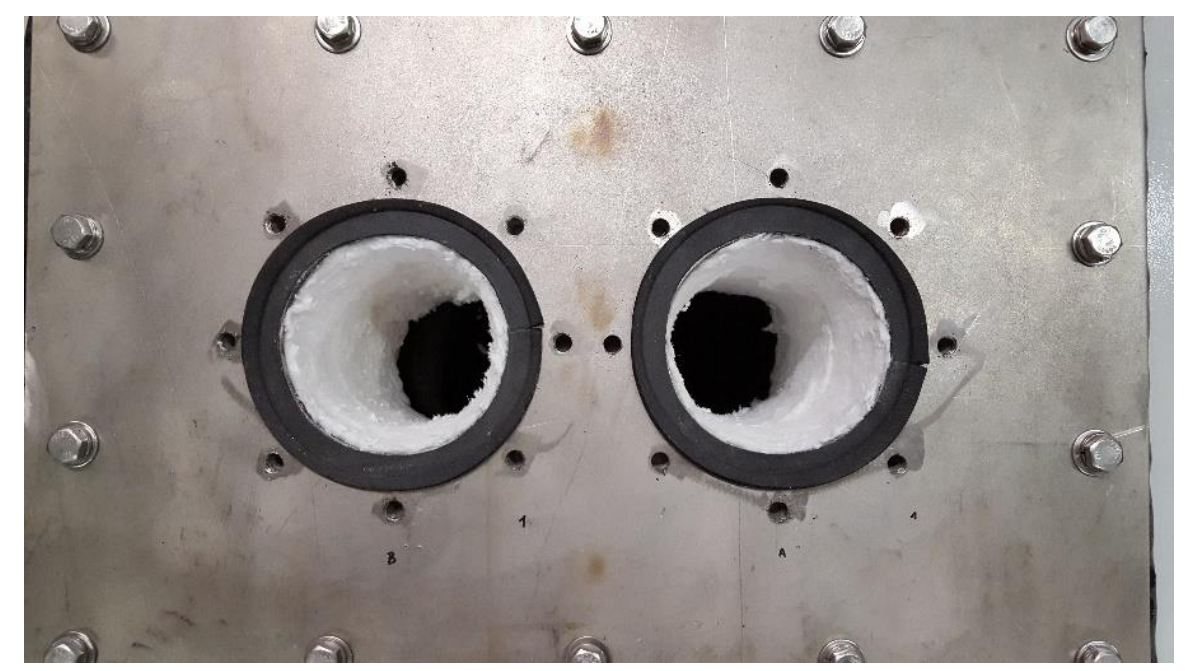

Figura 4.48. Detalhe do número de pontos de fixação. 


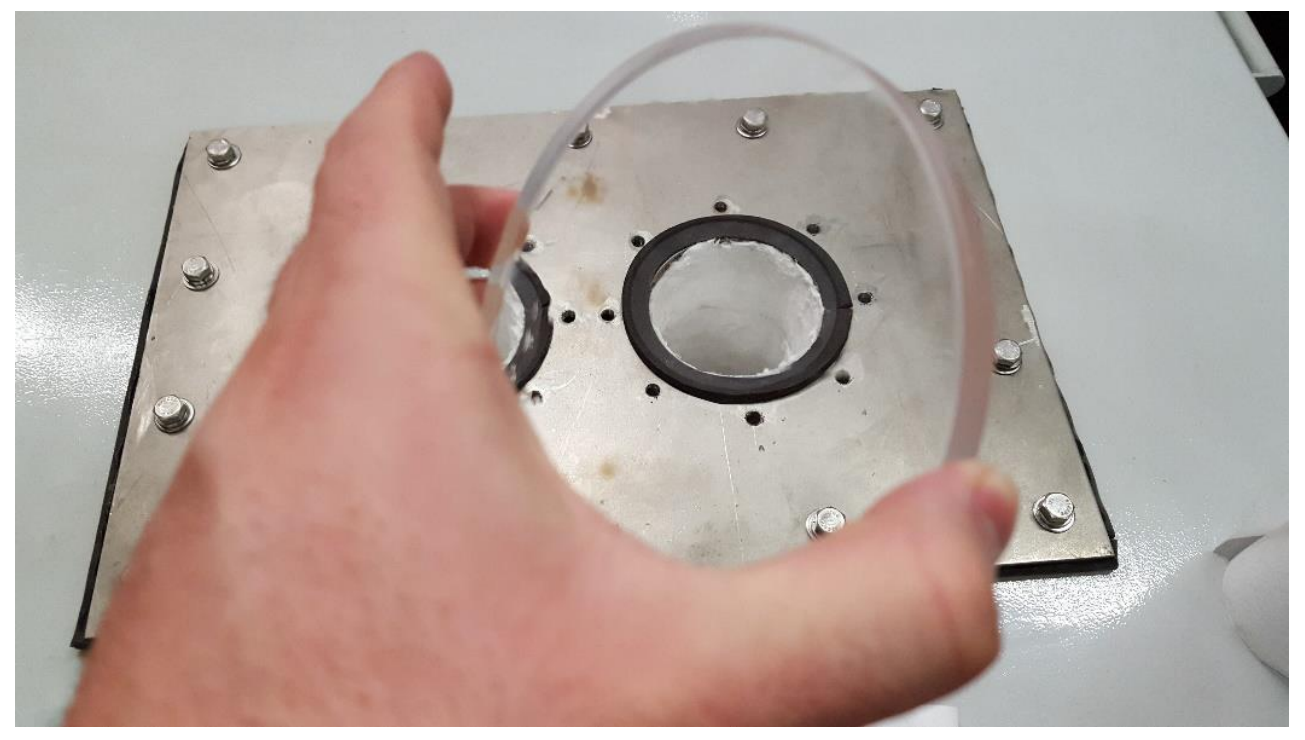

Figura 4.49. Detalhe do quartzo utilizado no módulo de monitoramento de deformação.

Segue Figura 4.50 que exemplifica o módulo de visualização na temperatura de $927^{\circ} \mathrm{C}$. Não há umidade condensada, como também não há distorção da imagem devido ao calor. A Figura 4.51 também exemplifica uma imagem monitorada pela ARAMIS através do módulo de monitoramento de deformação.

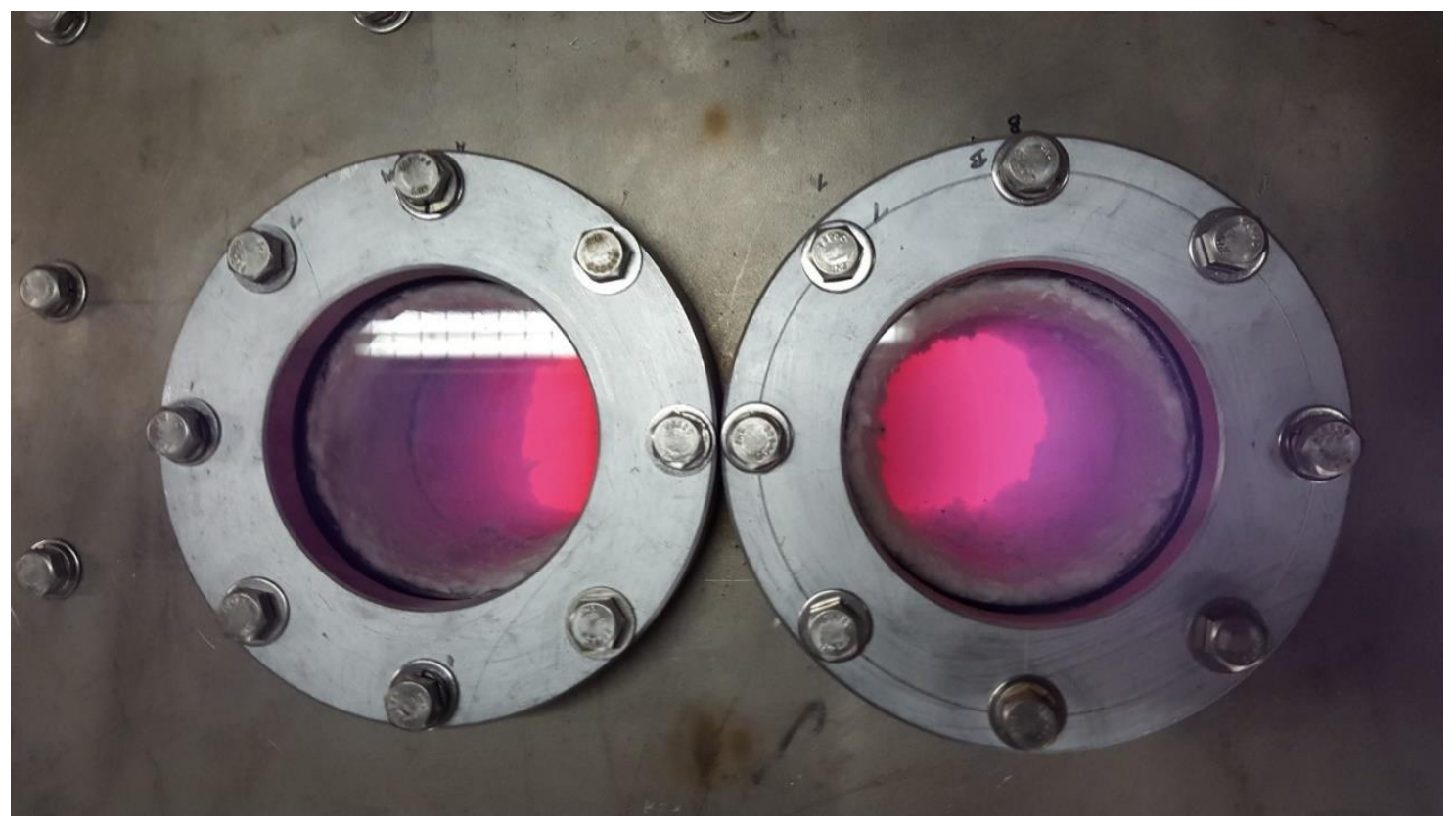

Figura 4.50. Módulo de monitoramento de deformação durante Conformação Superplástica na temperatura de $927^{\circ} \mathrm{C}$ 


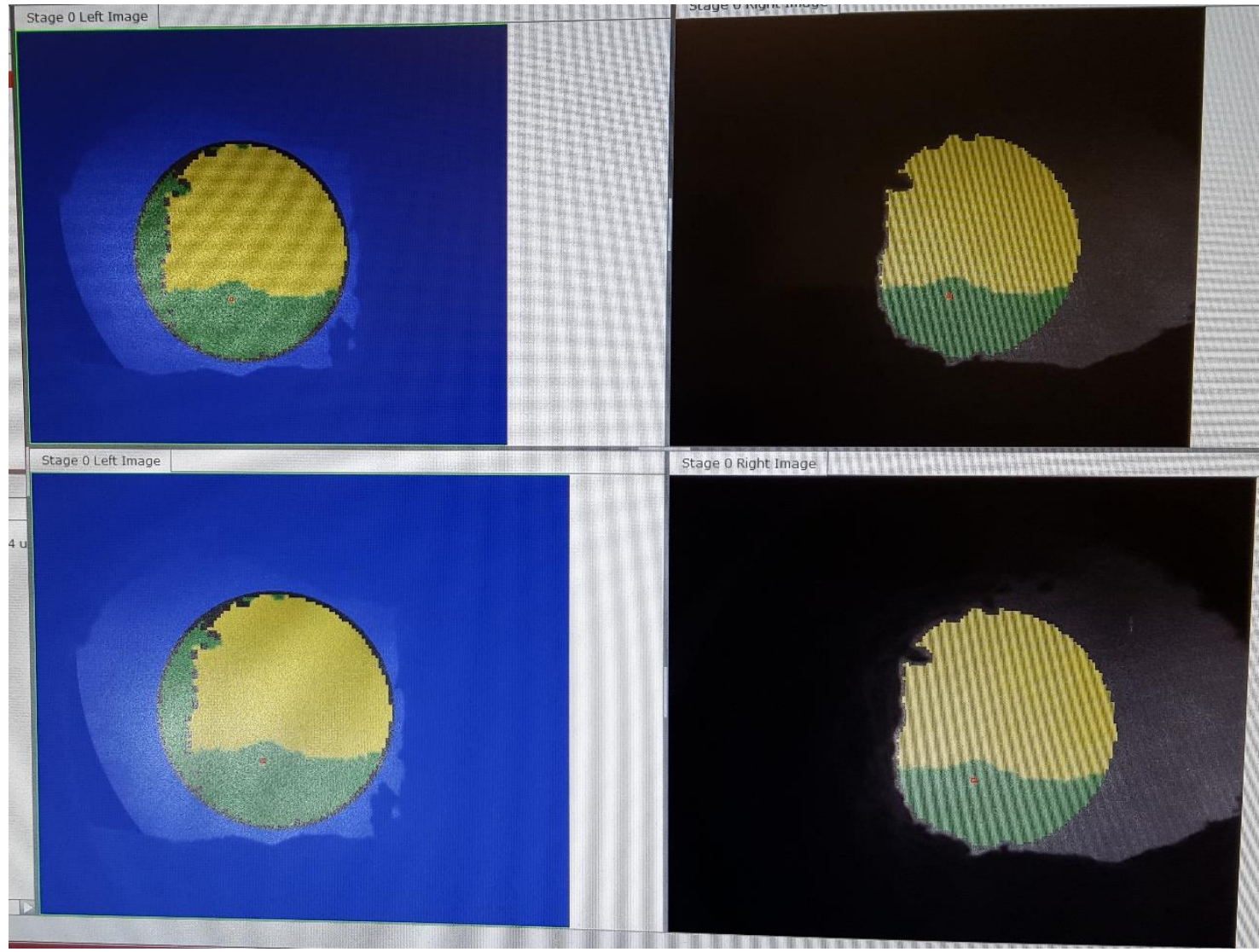

Figura 4.51. Exemplo de medição de deformação através do módulo de monitoramento de deformação, os pontos amarelos representam os pixeis que foram mapeados e acompanhados ao longo da deformação.

O ensaio de validação do novo módulo de deformação apresentou um resultado consistente no que diz respeito a estabilidade térmica do forno, obteve-se um bulge com uma deformação maior, menor espessura final e maior altura quando comparado ao anterior nas mesmas condições, Figura 4.52, características essas que evidenciam uma melhor homogeneidade térmica do forno com o novo módulo, que somado ao fato do controle de pressuriação calibrado manter a taxa de deformação próxima ao valor ótimo, propicia conformações superplásticas com elevado índice de sensibilidade a taxa de deformação. 


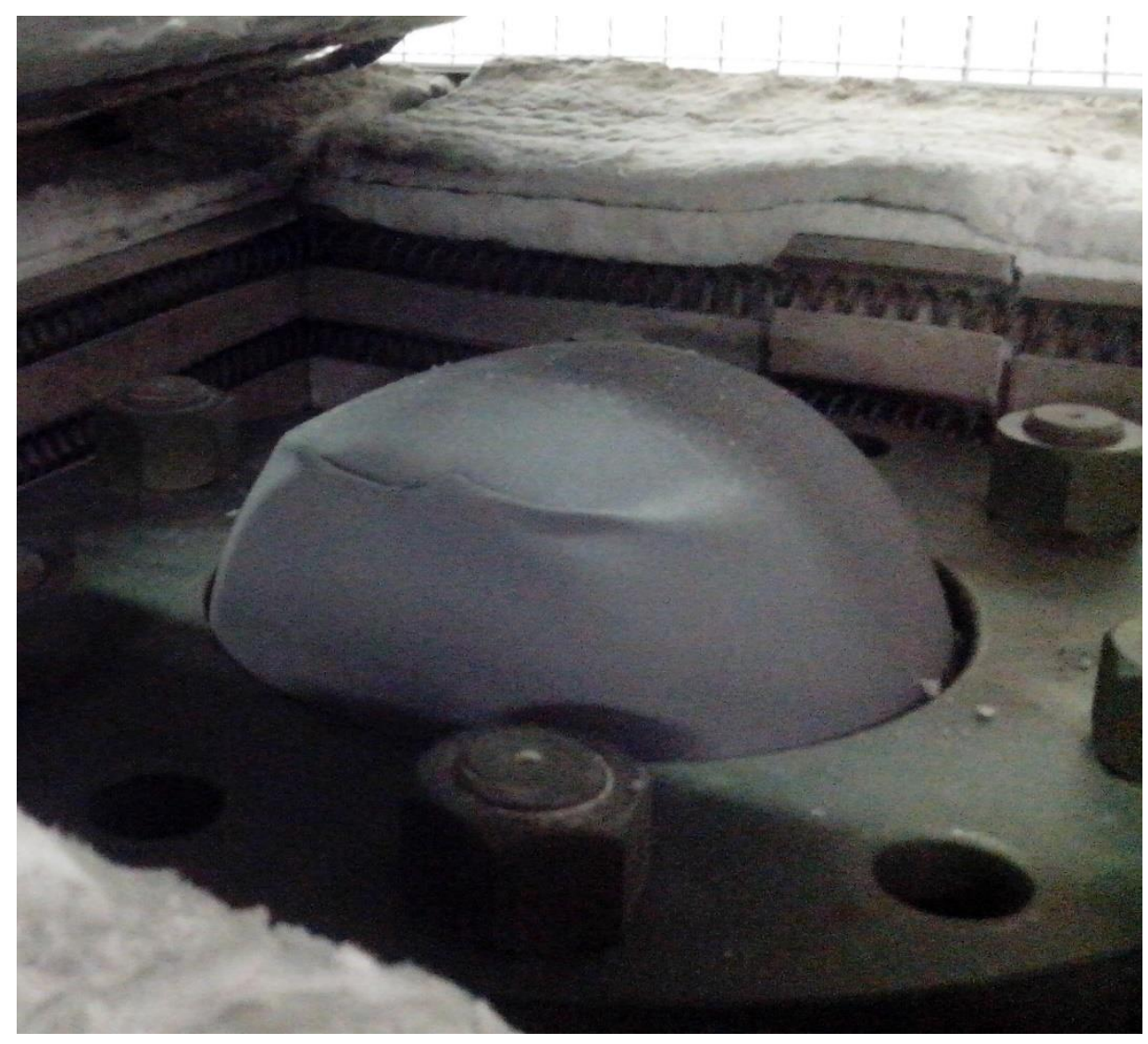

Figura 4.52. Bulge conformado superplásticamente no ensaio de validação do módulo de monitoramento de deformação. 


\section{Discussões}

Com intuito de se destacar os principais pontos desenvolvido na referida tese, seguem sumarizados:

- O ferramental de Conformação Superplástica objeto da tese encontra-se operacional, com volume de trabalho de $500 \mathrm{~mm}$ (A) X $600 \mathrm{~mm}$ (L) X $600 \mathrm{~mm}$ (P) é capaz de realizar conformações com atmosfera controlada e pressões de até 50 Bar e temperatura de até $1200^{\circ} \mathrm{C}$.

- O sistema de pressão é adaptável para aplicar ciclos de pressurização programados tanto para atender expansões livres quanto para expansões com calibração; o sistema de controle de temperatura é responsável por aperfeiçoar o aquecimento e a estabilidade do processo e por fim o sistema de medição de deformação confirma que a conformação ocorreu em torno do ponto ótimo do processo. Todos os 3 sistemas estão validados e testados de forma integrada em ensaios superplásticos.

- A caracterização da janela superplástica com um sistema de aquecimento desenvolvido exclusivamente para os corpos de prova de titânio da tese, possibilitou obter dados que foram usados como parâmetros do modelo de elementos finitos para gerar as curvas de pressurização, que no sistema de controle, tem o papel de set point durante a conformação.

- Durante a etapa da validação do sistema de medição ótica para grandes deformações, destaca-se o sistema de predição de pontos de falha por ruptura, que se mostra capaz de localizar e monitorar a provável localização do ponto de ruptura em um ensaio de expansão fluidoestática biaxial superplástico, nesse caso utilizou-se a liga de $\mathrm{PbSn}$.

- Apresenta-se na tese toda a documentação do método usado para realizar um ensaio de bulge à taxa de deformação constante, aplicado na superplasticidade da liga de titânio (Ti6Al4V).

- Escolheu-se o software MARC como modelo de geração de curvas de pressurização para servir de set point do sistema de controle.

- Após o bulge superplástico cego inicial com controle de pressão e temperatura, seguiu-se com a medição a quente através do modulo de monitoramento de deformação e finalizou-se com a conformação da peça modelo, essas etapas encadeiam o caminho percorrido na tese. 


\section{Conclusões}

Desenvolveu-se o Ferramental instrumentado e controlado para realização de conformação superplástica em atmosfera controlada e capaz de cumprir com os requisitos superplásticos da liga de Ti6Al4V, como também foram integrados validados e testados os sistemas de controle de temperatura, pressão e deformação.

Destaca-se do projeto de controle que os sistemas foram modularmente desenvolvidos, testados e validados, primeiramente em separado e integrado módulo a módulo; tal abordagem de integração apresentou resultado positivo. As etapas apresentadas na tese no capitulo de resultados evidenciam o sucesso na abordagem modular da instrumentação e dos testes.

Comprovou-se que a medição indireta com correlação digital de imagem apresenta menor erro tanto quando comparado com as fórmulas analíticas, como também quando comparado com a medição mecânica direta, ainda que para os casos de grandes áreas de medição e grandes profundidades de foco.

Através do ajuste dos parâmetros de controle proporcional-integral-derivativo (PID) pelo método de resposta em degrau com Ziegler Nichols para curva de pressurização durante a conformação superplástica, alcançou-se a sintonização necessária para que garantir que o sistema de pressurização realize a Conformação Superplástica na taxa de deformação esperada.

Por fim, conformou-se superplásticamente a peça modelo. 


\section{Sugestões de trabalhos futuros}

Para trabalhos futuros, utilizar o sistema de medição de deformação a quente, através do módulo de monitoramento da deformação, para aplicar o modelo de caracterização reológico proposto na tese ao titânio Ti6Al4V, tal modelo já foi validado para trabalhos a frio com a liga de PbSn.

Adaptar uma segunda válvula reguladora proporcional ao forno para realizar a conformação superplástica de ligas de alumínio, cuja contrapressão evitaria a cavitação da liga.

Utilizar o sistema de controle desenvolvido para realizar a conformação superplástica em diferentes ligas. 


\section{Publicações}

Durante o desenvolvimento dessa tese, foram 15 publicações, a mais importante dos trabalhos foi publicado na Revista Materials Science Forum na edição especial de Superplasticidade de 2012 e foi apresentado no ICSAM - 11th INTERNATIONAL CONFERENCE ON SUPERPLASTICITY IN ADVANCED MATERIALS - em Albi - França.

Trabalho completo publicado em Periódico:

1. MARINHO, E. P.; SAKATA, A.; PRADOS, E. F.; BATALHA, G.F. Instrumentation and Control of a Bulge Test on a Superplastic Pb-Sn Alloy. Trans Tech Publications, Switzerland. Materials Science Forum Vol. 735 pp 224-231. 2013. doi:10.4028/www.scientific.net/MSF.735.224.

2. MARINHO, E. P. ; SILVA JUNIOR, A. ; BATALHA, G.F . Comparison between direct and indirect measurement methods for bulge tests. Archives of Materials Science and Engineering, v. 61, p. 77, 2013.

3. RIBEIRO F.C.; MARINHO, E. P.; INFORZATO, D. J.; COSTA, P.R.; BATALHA, G.F. Creep age forming: a short review of fundaments and applications. Journal of Achievements in Materials and Manufacturing Engineering, v. 43, p. 353$361,2010$.

Trabalhos completos publicados em anais de congressos:

4. MARINHO, E. P.; SUPERPLASTIC FORMING OF TIGAL4V FOR AERO COMPONENTS. In: SETI - Seminário Embraer de Tecnologia e Inovação, 2015, São José dos Campos. SETI 2015, 2015.

5. MARINHO, E. P.; MULTIFACETS OF SUPERPLASTIC FORMING RESEARCH ON THE 'UNIVERSITY-INDUSTRY' DEVELOPMENT ENVIRONMENT. In: SETI 
- Seminário Embraer de Tecnologia e Inovação, 2015, São José dos Campos. SETI 2015, 2015.

6. FARIAS, A.; BATALHA, G.F; SANTOS, M. W.; MARINHO, E. P.; PRADOS, E. F.; DELIJAICOV, S. MECHANICAL PROPERTIES EVALUATION OF FRICTION STIR PROCESS OF TITANIUM TI-6AL-4V ALLOY. In: 22nd International Congress of Mechanical Engineering (COBEM 2013), 2013, Ribeirão Preto, SP, Brazil. 22nd International Congress of Mechanical Engineering (COBEM 2013), 2013. p. 8154-8162.

7. MARINHO, E. P.; PRADOS, E. F.; SAKATA, A.; BATALHA, G.F. Instrumentation and control of a bulge test on a Superplastic Ti-6AI-4V alloy. In: SBPMat 2012 XI Brazilian MRS Meeting, 2012, Florianópolis, 2012.

8. MARINHO, E.P.; BATALHA, G.F. Set up control of superplastic forming of aluminum alloys and strategy for rheological characterization of materials by bulge test. In: ABCM symposium series in mechatronics, v5, p 380-389, 2012.

9. PRADOS, E. F; MARINHO, E. P; SAKATA, A.; BATALHA, G.F. Superplastic behavior of a Ti-6AI-4V alloy. In: SBPMat 2012 - XI Brazilian MRS Meeting, 2012, Florianópolis, 2012.

10. MARINHO, E. P.; PRADOS, E. F.; BATALHA, G.F. Correlação digital de imagem de processo de expansão fluidoestática biaxial de ligas de PbSn. In: CONEM 2012 - VII Congresso Nacional de Engenharia Mecânica, 2012, São Luís. 'Engenharia em destaque', 2012. 
11.MARINHO, E. P.; F.C. RIBEIRO; BATALHA, G.F. Abordagem de controle do processo de fabricação de peças aeronáuticas por Conformação Superplástica de ligas de alumínio. In: 6o. Congresso Brasileiro De Engenharia De Fabricação, 2011, Caxias do Sul. Anais do Cobef 2011, 2011.

12.RIBEIRO F.C.; MARINHO, E. P.; INFORZATO, D. J.; COSTA, P.R.; BATALHA, G.F. Conformação por Fluência com Envelhecimento: Fundamentos e Aplicação em Conformação Cilíndrica. In: 6 Congresso Brasileiro de Engenharia de fabricação, 2011, Caxias do Sul. Anais do Cobef 2011, 2011.

13. MARINHO, E. P.; RIBEIRO, F.C.; BATALHA, G.F. Setup Control of Superplastic Forming of Aluminum Alloys and Strategy for Rheological Characterization of Materials by Bulge Test. In: 21st Brazilian Congress of Mechanical Engineering, 2011, Natal. Proceedings of COBEM 2011, 2011.

14. MARINHO, E. P.; PRADOS, E. F.; BATALHA, G.F. Conformação Superplástica em Ligas de Titânio. In: XXXI SENAFOR - 1st International Sheet Metal Forming Conference, 2011, Porto Alegre. Anais do 31 SENAFOR, 2011.

15.MARINHO, E. P.; BATALHA, G.F. Instrumentação e Controle do processo de Conformação Superplástica de Ligas de Alumínio. In: XXX SENAFOR - 13a Conferência nacional de Conformação de Chapas, 2010, Porto Alegre. Anais do 30 SENAFOR, 2010. 


\section{Referências Bibliográficas}

ABU-FARHA, F. K.; KHRAISHEH, M. K. An integrated approach to the Superplastic Forming of lightweight alloys: towards sustainable manufacturing. International Journal of Sustainable Manufacturing, v. 1, n. 1/2, p. 18-40, 2008.

ASHBY, M. F.; VERRAL, R. A. Diffusion-accommodated flow and superplasticity = Superplasticite et plasticite avec accommodation par diffusion $=$ Diffusionsakkomodiertes Fließen und superplastizitât. Acta Metallurgica, v. 21, n. 2, p. 149-163, 1973.

AIT - ASSOCIATION, INTERNATIONAL TITANIUM. (07/2007). Titanium Facts. (International Titanium Association, 2007) Fonte: www.titanium.org: http://www.titanium.org/chinese/English/PDF\%20Files/tifacts.html

ÅSTRÖM, K.; HÄGGLUND, T. PID controllers: Theory, Design, and Tuning, 2nd. Edition, Instrument Society of America. 1995. ISBN: 1-55617-516-7

ÅSTRÖM, K.; MURRAY, R. Feedback Systems: An Introduction for Scientists and Engineers. Princeton University Press. 2008. ISBN: 9780691135762

AOURA, Y. Contribution a la modélisation du comportement superplástique des alliages métalliques pour les procédés de mise em forme. 2004. 152p. Tese (Doutorado) - École Nationale Supérieure d'Arts et Métiers, Paris, França, 2004.

AUE-U-LAN, Y. Hydroforming of tubular materials at various temperatures. 2007. 244p. Tese (Doutorado). Graduate School of the Ohio State University, Ohio, Estados Unidos, 2007.

AKSENOV, S.; CHUMACHENKO, E.; LOGASHIMA, I. Experimental Investigation Of Ti-AIV Alloy Superplastic Behavior. 21st International Conference on Metallurgy and Materials Proceedings. May 23rd- 25th, Brno, Czech Republic, EU, 2012. 
BACKOFEN, W. A.; TURNER, I. R.; AVERY, D. H. Superplasticity in an Al-Zn Alloy, Transaction ASM, v. 57, n. 57, p. 914-919, 1962.

BANABIC, D., BĂLAN, T., COMSA, D.-S. Closed- Form Solutions for Bulging Through Elliptical Dies, Proc. of the SHEMET'99 Conf., M. Geiger et al (eds.), Bamberg, Meisenach, 623-628.(1999)

BARNES, A. J. Superplastic Forming 40 Years and Still Growing. Journal of Materials Engineering and Performance. v. 16, n. 4, p. 440-454, 2007.

BAUDELET, B.; LIAN, J. A composite model for superplasticity. Journal of Materials Science. v. 30, n. 8, p. 1977-1981, 1995.

BECK, W. Superplastic Forming and Diffusion Bonding of Titanium and Titanium Alloys. In. PETER, M; LEYENS, C. Titanium and Titanium Alloys. Fundamentals and Applications. Colônia, Alemanha, Centro Aeroespacial Alemão: Wiley-Vhc, Junho 2003. Cap. 10, p. 273-288.

BLANDIN, J. J.; SUERY, M.; Superplasticité. Mise en forme des métaux et fonderie. Ref. M613, Julho 1996. Disponível em: <http://www.techniquesingenieur.fr/book/m613/1/superplasticite.html>. Acesso em: 10 agosto 2010.

BOYER, R. R. An Overview on the use of titanium in aerospace industry. Materials Science and Engineering A, v. 213, p. 103-114, 1996.

BOCHVAR, A. A.; E SVIDERSKAYA, Z. A. Superplasticity in Zinc-Aluminum Alloys. 1946, Izvest. Akad. Nauk SSSR, Odtel. Tekh. Nauk. v.9, p. 821-827, 1945. . Apud NIEH, T. G.; WADSWOTH, J. E.; SHERBY, O. D.; Superplasticity in Metals and Ceramics. Nova Iorque, Estados Unidos: Cambrigde University Press, p. 1-16, 2007.

BOUDE, S. Maîtrise du procédé de formage superpalstique et realisation d'une installation pitole. 1994. 191 p. Doctor Thesis - Ecole Centrale de Nantes, France, 25 fevereiro 1994. 
BURKE, J.; MEHRABIAN, R.; WEISS, V. Advances in Metal Processing. Asagamore Army Materials Research Conference Proceedings. Plenum Press. New York. 1981.

CAPPETTI, N. et al. A method for setting variables in Super Plastic Forming procces. Journal of Achievements in Materials and Manufacturing Engineering. v. 38, n.2, p. 187-194, 2010.

CHANDRA, N. Constitutive behavior of superplastic materials. International Journal of Non-Linear Mechanics, v. 37, p. 461-484, 2000.

CHEN, Y. et al. Numerical analysis of superplastic blow forming of Ti-6Al-4V alloys. Materials and Design, v. 22,p. 679-685, 2001.

CHENG J. H. The determination of material parameters from superplastic inflation tests". Technology of Materials Processing Journal. Department of Mechanical Engineering, National Taiwan University, Taipei, Taiwan; Elsevier, v. 58, p.233-246, 1996.

CHOKSHI, A. H.; MUKHERJEE, A. K.; LANGDON, T. G. Superplasticity in Advanced Materiais. Materials Science and Engineering R , v. 10, p. 237-274, 1993.

CLINNING, N.; Thermomechanical Processing Of Blended Elemental Powder Ti-6al-4v Alloy, Masters Dissertation, University of Cape Town, África do Sul, 2012. http://open.uct.ac.za/handle/11427/4968?show=full

COURTNEY, T. H. Strengthening of Crystalline Materials. In: Mechanical behavior of materials. Illinois, EUA: Waveland press, INC, 2005. p. 175-243.

CORNFIELD, G. C.; JOHNSON, R. H. The forming of superplastic sheet metal, Int. J. Mech. Sci. 12 (1970) 479-490.

DOBRZAŃSKI , L. A. Metalowe materiały inżynierskie = Metal engineering materials. Ed. Wydawnictwa Naukowo-Techniczne, Varsovia, Polonia, 2004, pp. 888. 
DOLTSISNIS, J. St.; LUGINSLAND, J.; NOLTING, S. Some developments in the numerical simulation of metal forming processes, Proceedings of the International Conference on Computational Plasticity Models, Barcelona, Vol. 2, pp. 875-899, 1987

DUTTA, A.; MUKHERJEE, A. K. Superplastic forming: an analytical approach. Materials Science and Engineering A. v. 157, n. 1, p. 9-13, 1992.

ENIKEEV, F. U. An Analytical Model for Superplastic Bulge Forming of Domes. Materials Science Forum, v.170-172, p.681, 1994.

FANNING, J.; HARPER, M. Processing and Properties of Timetal 54M, a New Alpha-Beta Alloy with Improved Machinability Titanium Advances at Aeromat 2008 (Vol. Junho). Advanced Materials \& Processes. 2008.

FRANCHITTI, S., Analisi e modellazione dei processi di formatura superplastica. Doctor Thesis. Università Degli Studi Di Cassino, Cassino, Italy, 2007, 149 p.

GEIGER, M.; MERKLEIN, M. Sheet metal forming - a new kind of forge for the future. Key Engineering Materials, v. 344, p. 9-20, 2007.

GIULIANO, G. Superplastic forming of advanced metallic materials - Methods and applications. Woodhead Publishing in Materials. 2011 Cap. 6 p 115 - 119.

GHOSH, A. K.; HAMILTON, C. H. Influences of Material Parameters and Microstructure on Superplastic Forming. Metallurgical and Materials Transactions A. v. 13A, n. 5, p. 733743, 1982.

GHOSH, A. K., \& HAMILTON, C. N. Superplastic sheet forming: ASM Handbook. Vol. 14B. Metalworking: Sheet Forming. 2006

GOM mbH. ARAMIS user Manual - Software: ARAMIS v.6.1 and higher. Braunschweig, Alemanha. 2009. 
GONÇALVES, C. A. P. Simulação numérica de processos de Conformação Superplástica e corte de chapas metálicas. São Paulo, 2011. 94 p. Trabalho de Formatura - Escola Politécnica da Universidade de São Paulo. Departamento de Engenharia Mecânica.

GUANABARA, J. P.; BUENO, L. O.; BATALHA, G. F. Towards a Superplastic Forming of Fe-Mn-Al Alloys. In: International Conference on Advances in Materials and Processing Technologies (AMPT2010). Paris - France. AIP Conference Proc. Maryland, USA: American Institute of Physics, v. 1315. p.1683 - 1638, 2010. http://dx.doi.org/10.1063/1.3552435 - ISBN 9780735408715

HARTLEY, R.; ZISSERMAN, Multiple View Geometry in Computer Vision Second Edition. Cambridge University Press. 2003 Cap. 9 p 239-261.

HALE, J. Boing 787 from the Ground Up. Aeromagazine quarterly. 2006. Ed. 24. p. 16-23. HAWKINS R. B. Deep rawing of superplastic material. Met Technol Ed. 11, Vol 3,. 1976. HOLT, D. L. An Analysis of Bulging of a Superplastic Sheet by Lateral Pressure. International Journal of Mechanical Science. v. 12, n. 6, p. 491-497, 1970.

HWANG, Y. M.; LAY, H. S.; HUANG J. C. Study on superplastic blow-forming of 8090 Al-Li sheets in an ellip-cylindrical closed-die, International journal of machine tools \& manufacture, Vol. 42, No 12, pp. 1363-1372, 2002.

JAIN, M.; CHATURVEDI, M.C.; RICHARDS, N.L.; GOEL, N.C. Strain rate sensitivity effects with forming characteristics of superplastic Ti6Al4V. Materials Science and Engineering: A138, pp. 205-211, 1991.

JENKINS, C. H. Strength of Cd-Zn and Sn-Pb alloy solder. J. Inst. Metals. v. 40, p. 21-32, 1928. Apud NIEH, T. G.; WADSWOTH, J. E.; SHERBY, O. D.; Superplasticity in Metals and Ceramics. Nova Iorque, Estados Unidos: Cambrigde University Press, p. 1-16, 2007 
JOVANE, F. An Aproximate Analysis of the superplastic forming of a thin circular diaphragm: Theory and Experiments. International Journal of Mechanical Science. v. 10, n. 5, p. 403424, 1968.

KALPAKJIAN, S.; SCHMID, S. R. Manufacturing Engineering and Technology. Pearson Prentice Hall. 2006.

KELLER, S.; HOTZ, W.; FRIEBE, H. Yield curve determination using the Bulge Test combined with optical measurement. International Deep Drawing Research Group. IDDRG 2009 International Conference. 1-3 June, Golden, CO, USA. 2009

KHRAISHEH, M. K., On the failure characteristics of superplastic sheet materials subjected to gas pressure forming. Scripta materialia. V. 42, n. 3, p. 257-263, 2000.

LEE, J. H.; SONG, Y. J.; SHIN, D. H.; LEE, C. S. Microstructural evolution during superplastic bulge forming of Ti-6Al-4V alloy. Materials Science and Engineering A, V. 43, 1998.

LI, G. Y.; TAN, M. J.; LIEW, K. M. Three-dimensional modelling and simulation of superplastic forming. Journal of Materials Processing Technology, Vol. 150, pp. 76-83, 2004.

MAEHARA, Y. Superpalstic Deformation Mechanism of $\delta / \curlyvee$ Duplex Stainless Steels. Trans. ISIJ, 27, pp. 705-712, 1987.

LÜTJERING, G.; WILLIAMS, J. C.; Titanium. Springer-Verlag Berlin Heidelberg. 2003. DOI $10.1007 / 978-3-540-71398-2$

MAY, L. Mechanical properties of ultrafine-grained Ti-6Al-4V ELI alloy processed by severe plastic deformation (Mechanische Eigenschaften einer ultrafeinkörnigen TiAl6V4 ELI Legierung hergestellt mittels Hochverformung). Doctor Thesis. Universidade de Erlangen-Nuremberg, Alemanha, 2009, 13p. 
MARINHO, E. P. Instrumentação e Controle do processo de fabricação de Componentes Aeronáuticos por Conformação Superplástica. 2010. 164 p. Trabalho de Formatura - Escola Politécnica da Universidade de São Paulo. Departamento de Engenharia Mecatrônica e de Sistemas Mecânicos, São Paulo, Brazil, Dezembro de 2010. PEARSON, C. E. Viscous properties of extruded eutectic alloys of Pb-Sn and Bi-Sn. J. Inst. Metals. v. 54, p. 11-123, 1934. Apud NIEH, T. G.; WADSWOTH, J. E.; SHERBY, O. D.; Superplasticity in Metals and Ceramics. Nova lorque, Estados Unidos: Cambrigde University Press, p. 1-16, 2007.

MONZEN, R. ; FUTAKUCHI, M.; KITAGAWA, K.; MORI, T. Measurement of grain boundary sliding of [011] twist boundaries in copper by electron microscopy. Acta Metall. Mater. 41(6), pp. 1643-1646. 1993.

MOTYKA M., KUBIAK K., SIENIAWSKI J., ZIAJA W., Hot plasticity of alpha beta alloys, in: Nurul Amin A.K.M. (Ed.), Titanium alloys - Towards achieving enhanced properties for diversified applications, InTech, Rijeka, 2012, pp. 87-116.

OGATA, K. Modern Control Engineering. Pearson Prentice Hall, 4th Edition. 2003. Cap. 3, p. $45-84$.

OLLIVIER, D. Le formage superplastique associé au soudage par diffusion appliqué à l'alliage à base de titane Ti-6Al-4V pour la fabrication de nacelles aéronautiques. 2003. 235 p. Tese (Doutorado) - L’École Nationale Supérieure d'Arts et Métiers, Paris, França, 24 abril 2003.

PATERSON M. S. Superplasticity in Geological Materials. MRS Proceedings, V.196, 1990. doi:10.1557/PROC-196-303

PETER, M; LEYENS, C. Titanium and Titanium Alloys. Fundamentals and Applications. Colônia, Alemanha, Centro Aeroespacial Alemão: Wiley-Vhc, Junho 2003. Cap. 10 , p. $273-288$. 
PITT, F; RAMULU, M. Influence of Grain Size and Microstructure on Oxidation Rates in Titanium Alloy Ti-6Al-4V Under Superplastic Forming Conditions. Journal of Materials Engineering and Performance and Exposition, June 8-9, 2004, in Seattle, WA.. 04/2012; 13(6):727-734. DOI:10.1361/10599490421394.

RACHINGER, W. A. "Relative Grain Translations in the Plastic flow of Aluminium" Jour. Inst. Met. v.81, p.33-41.1952

RIDLEY, N. Metals for superplastic forming. Superplastic forming of advanced metallic materials - Methods and applications, Woodhead Publishing Limited Cambridge. p3-30. 2011.

RIDLEY, N. AGARD Lectures Series No. 168. Cavitation and Superplasticity. North Atlantic Treaty Organization Advisory Group For Aerospace Research And Development. Specialised Printing Services Limited. 1989. Chap. 4. Pp. 249.

ROBERT, C. Contrinbution a la Simulation des procedes de mise en forme, Application au Formage Incremental et au Formage Superplastique. 2009. 149p. Tese (Doutorado) - Laboratoire Arts et Métiers ParisTech d'Angers: l'École Nationale Supérieure d'Arts et Métiers, Paris, França. Dezembro de 2009.

ROSENHAIN, W; EWEN, D. Intercrystalline cohesion in metals. Journal Institute of Metals, v. 8. P. 149-185, 1912. Apud ROVER, C. F. S.; GUIMARÃES, P. R.; FERRANTE, M. A redução do TiCl4 pelo Mg na obtenção da esponja de titânio na usina piloto do CTA. Metalurgia e Materiais, v.27, n. 158, p. 11-18. 1971.

ROVER, C. F. S.; GUIMARÃES, P. R.; FERRANTE, M. A redução do TiCl4 pelo Mg na obtenção da esponja de titânio na usina piloto do CTA. Metalurgia e Materiais, v.27, n. 158, p. 11-18. 1971.

SATO, E. E KURIBAYASHI, K., Superplasticity and deformation induced grain growth. Iron Steel Institute Japan. 8 ed., v. 33. 1993. 
SAMEKTO, H. Finite Element Simulation des superplastischen Umformprozesses für Aluminiumlegierung 5083 = Simulação por elementos finitos do processo de Conformação Superplástica de ligas de alumínio 5083. 2005. 70 p. Tese (Doutorado) Universidade de Stuttgart, Stuttgart, Alemanha. 19 setembro 2005.

SAMEKTO, H.; ROLL, K. Finite Element Analysis of Superplastic Forming Process using LS-DYNA. 4th European LS-DYNA Users Conference, Ulm(Germany) on 22nd and 23rd of May 2003.

SANTOS, M.W.B; VELAY, V.; BERNHART, G.; BATALHA, G.F. The Influence of Low Strain Rate and High Temperature on Microstructural Evolution of Ti-6Al-4V Titanium Alloy. Advances in Materials \& Processing Technologies. Madrid, December 14-17, 2015.

SERRA, D. Superplastic forming applications on Aero engines. A review of itp Manufacturing processes. 6th EUROSPF Conference. Carcassonne : France. 2008.

SHERBY, O. D.; WADSWORTH, J. Advances and Futures Directions in Suerplastic Materias, in Superplasticity - AGARD Lectures Series, N. 168, NATO/AGARD, 1989.

SIEGERT, K.; WERLE, T. Manufacturing Examples and Fundamentals. U. S. Institut für Umformtechnik. Stuttgart:EAA-European Aluminium Association, v. 3081, p. 12.1994. SIENIAWSKI, J. MOTYKA, M. Superplasticity in titanium alloys. Journal of Achievements in Materials and Manufacturing Engineering. 1 ed., V. 24. 2007.

SNIPPE, Q.H.C. MEINDERS, T. A Constitutive Model For The Superplastic Material Alnovi1 Including Leak Risk Information, Mater. Sci. Eng. A (2010), doi:10.1016/j.msea.2010.09.075

SORGENTE, D.; TRICARICO, L. A numerical-experimental approach to material characterization and process analysis in the blow forming process, 6th EuroSPF conference, Carcassonne, França. 15 p., 2008. 
THIRUVARUDCHELVAN, S.; TAN, M. J.; ZHU, X. J. Effects of oxidization on the ductility of Ti-6AI-4V alloy during superplastic forming. Materials Forum. V. 29, 2005.

TOMÁNEK, S.; KAFKA, V. Non-contact Deformation Measurement by ARAMIS Photogrammetry System. Czech Aerospace Proceedings. Praga. República Chéca. v. 1, p. 13-17, Abril 2006.

UNDERWOOD, E. E. A Rewiew of superplasticity and Related Phenomena. Journal of Metals, v. 14, n. 12, pp. 914-919, Dec. 1962.

VANDERHASTEN, M.; RABET, L.; VERLINDEN, B. Ti-6Al-4V: Deformation map and modelisation of tensile behavior. Materials and Design, v. 29, p. 1090-1098, 2008.

VULCAN, M. Der pneumatische Tiefungsversuch und seine Anwendug in der superplastischen Aluminium-Blechumformung $=0$ ensaio de expansão fluidoestática biaxial e sua aplicação na Conformação Superplástica do alumínio. 2006. 108 p. Tese (Doutorado) - Universidade de Stuttgart, Stuttgart, Alemanha.

XIANG, Y; WU, S.; Numerical simulation of cavity damage evolution in superplastic bulging process, J. of Mat. Proc. Tech., Vol. 116, pp. 224-230, 2001 


\section{ANEXO}

\subsection{ANEXO I - Resultados dos Ensaios de Tração Uniaxial}

Seguem oito laudos com resultados preliminares, ensaios 3 a 10:

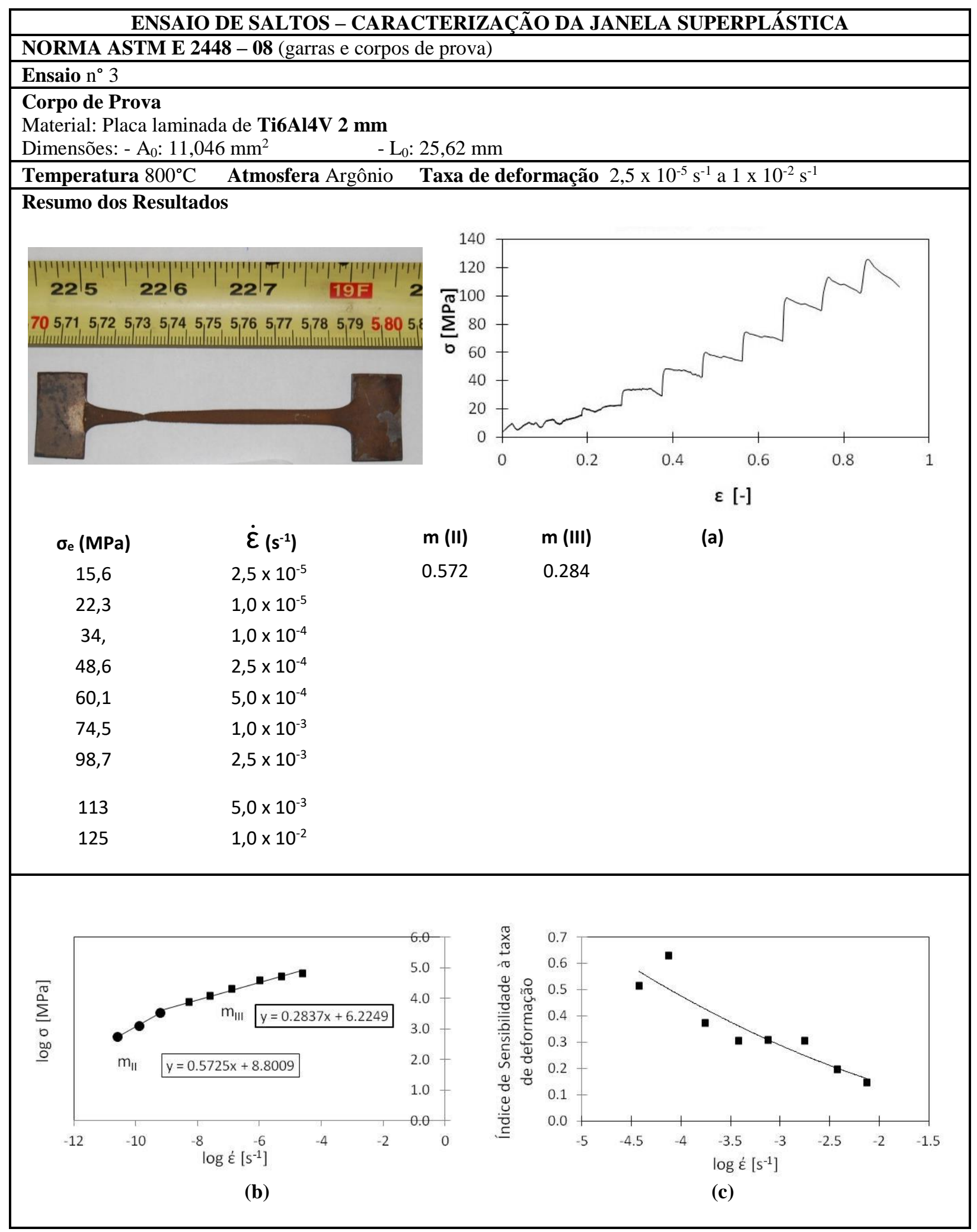




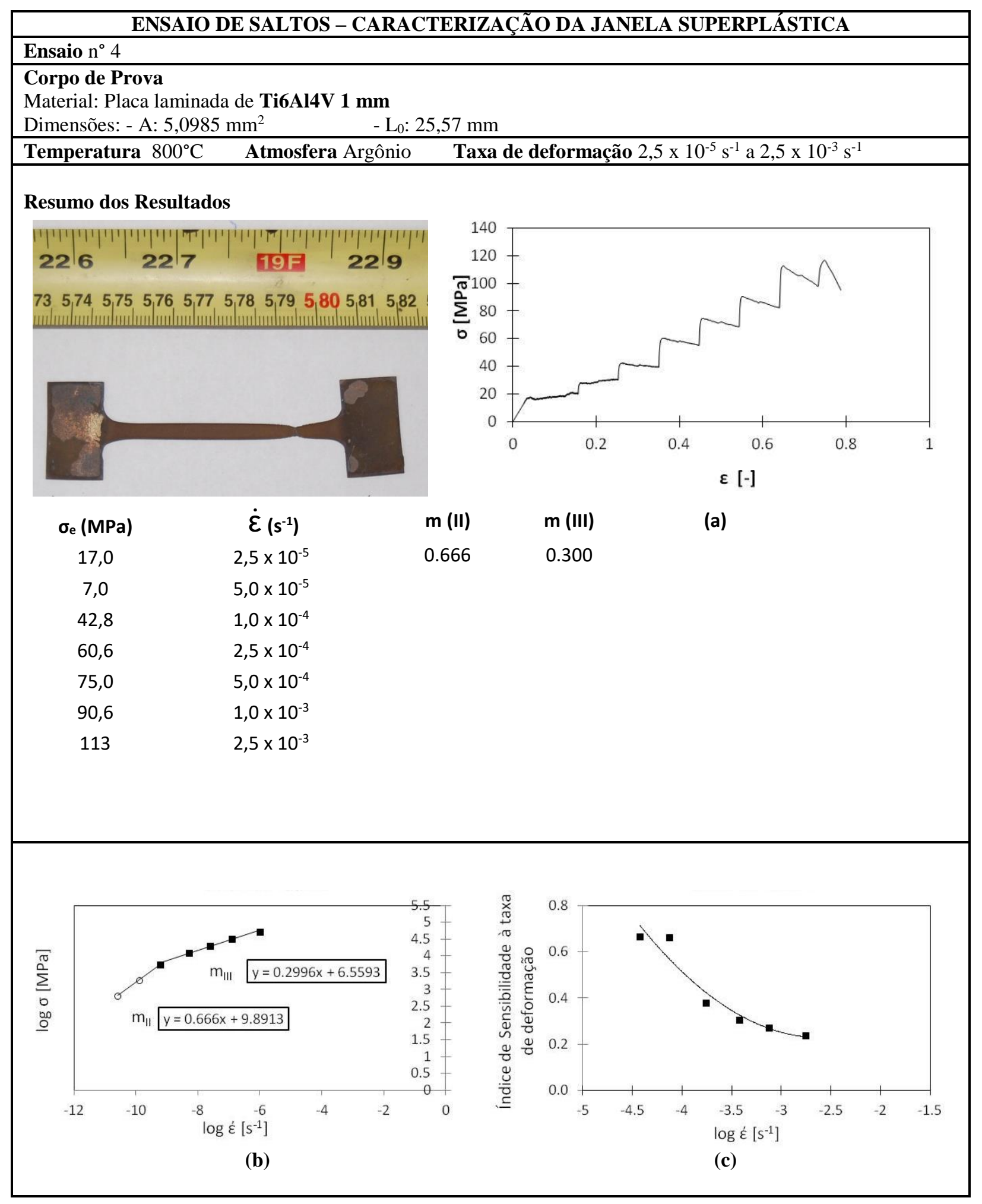




\begin{tabular}{|l|}
\hline \multicolumn{1}{|c|}{ ENSAIO DE SALTOS - CARACTERIZAÇÃO DA JANELA SUPERPLÁSTICA } \\
\hline Ensaio $\mathrm{n}^{\circ} 5$ \\
\hline Corpo de Prova \\
Material: Placa laminada de Ti6AI4V 2 mm \\
Dimensões: - A: $11,025 \mathrm{~mm}^{2} \quad-\mathrm{L}_{0}: 25,60 \mathrm{~mm}$ \\
\hline Temperatura $850^{\circ} \mathrm{C} \quad$ Atmosfera Argônio $\quad$ Taxa de deformação $2,5 \times 10^{-5} \mathrm{~s}^{-1}$ a $5,0 \times 10^{-3} \mathrm{~s}^{-1}$ \\
\hline Resumo dos Resultados
\end{tabular}
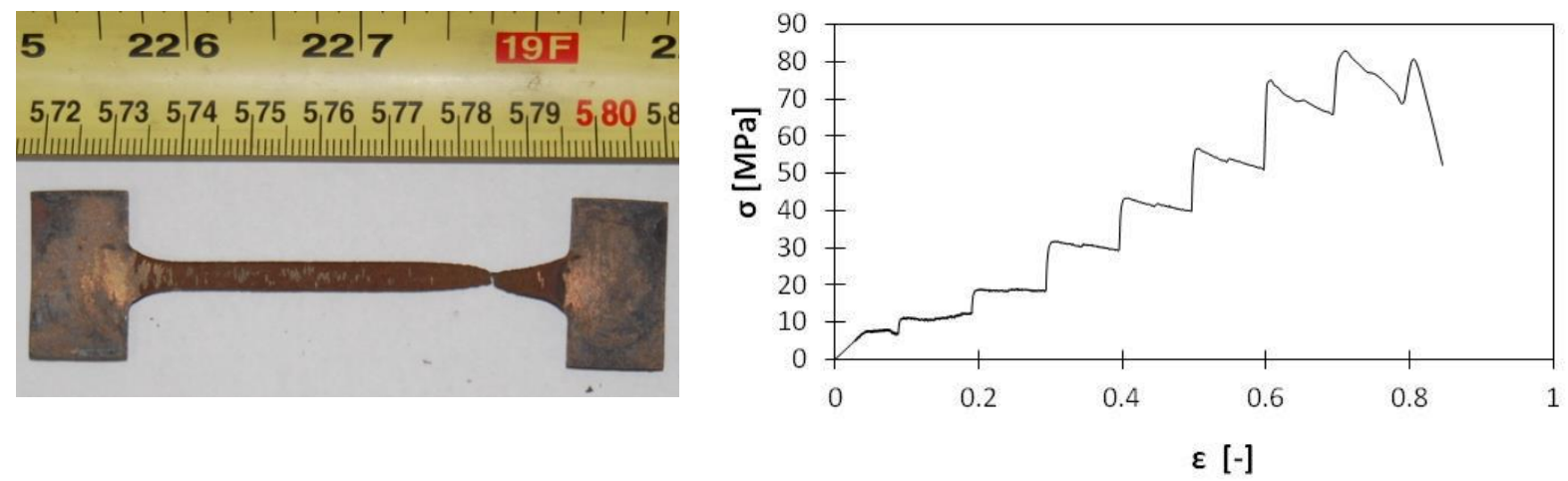

$\begin{array}{cc}\sigma_{\text {e }}(\mathrm{MPa}) & \dot{\varepsilon}\left(\mathrm{s}^{-1}\right) \\ 8,2 & 2,5 \times 10^{-5} \\ 12,6 & 5,0 \times 10^{-5} \\ 19,1 & 1,0 \times 10^{-4} \\ 31,8 & 2,5 \times 10^{-4} \\ 43,4 & 5,0 \times 10^{-4} \\ 56,7 & 1,0 \times 10^{-3} \\ 75,0 & 2,5 \times 10^{-3} \\ 82,8 & 5,0 \times 10^{-3}\end{array}$

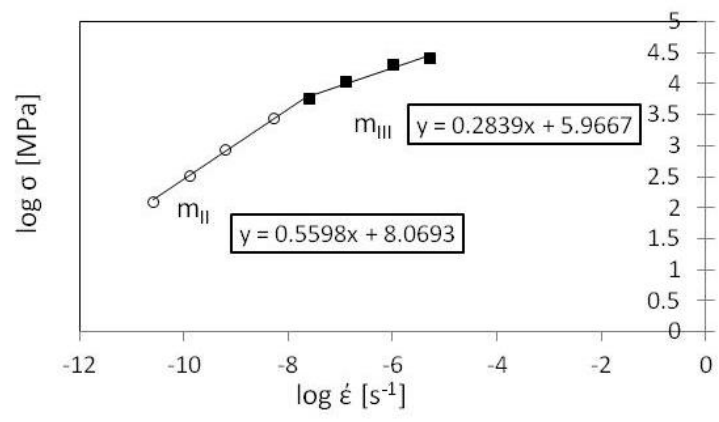

(b)

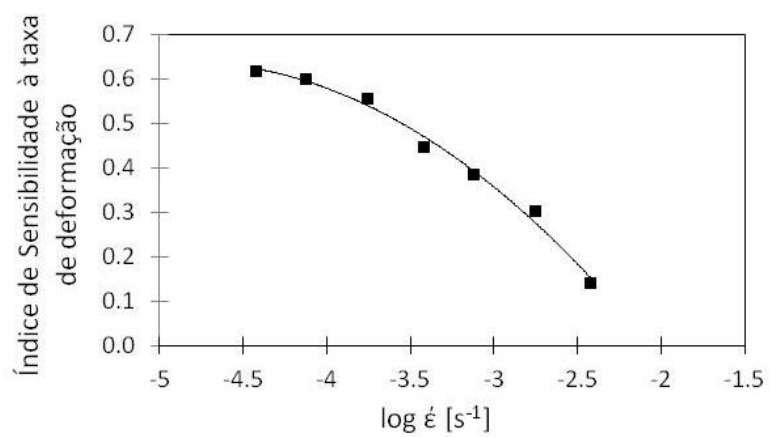

(c) 


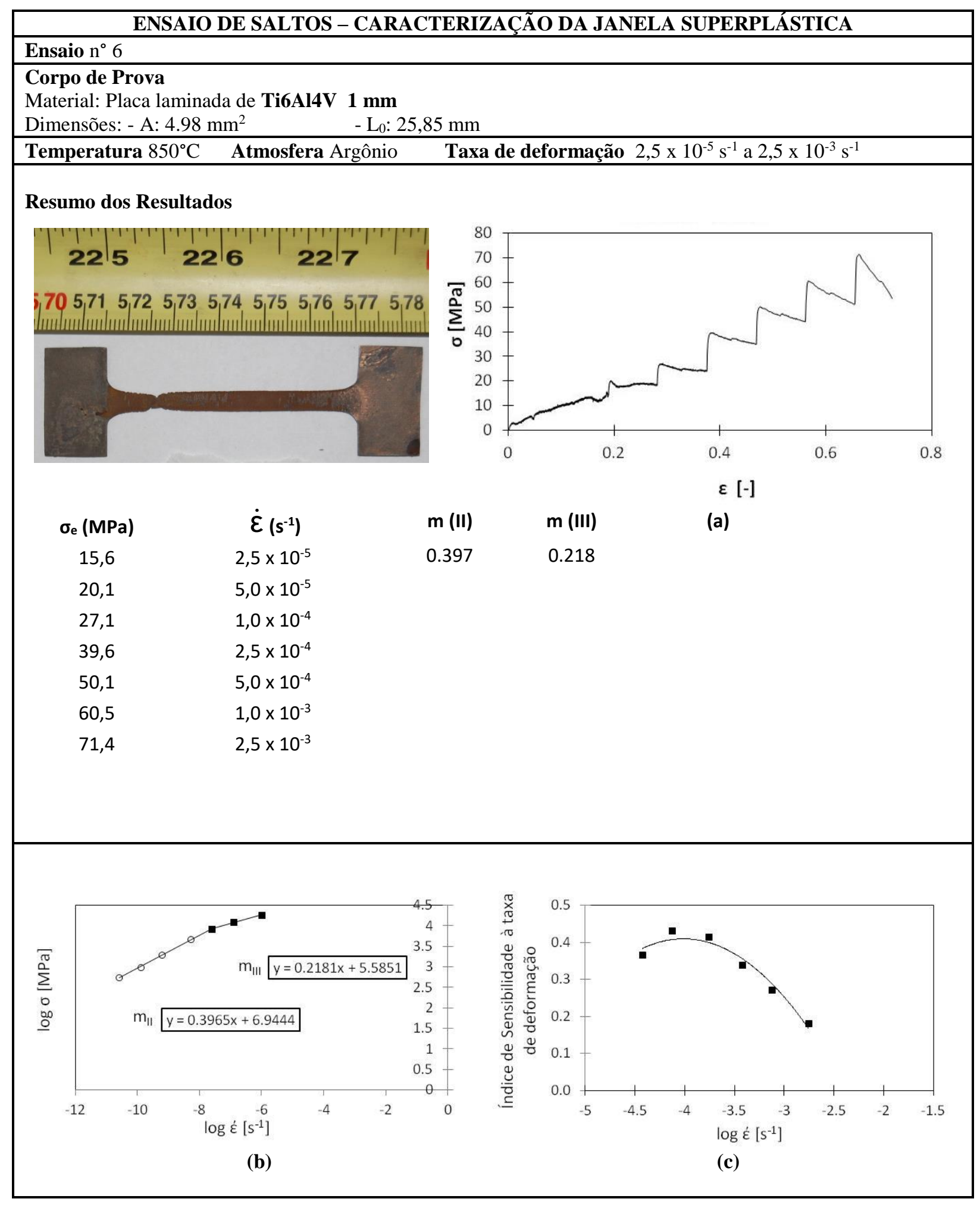




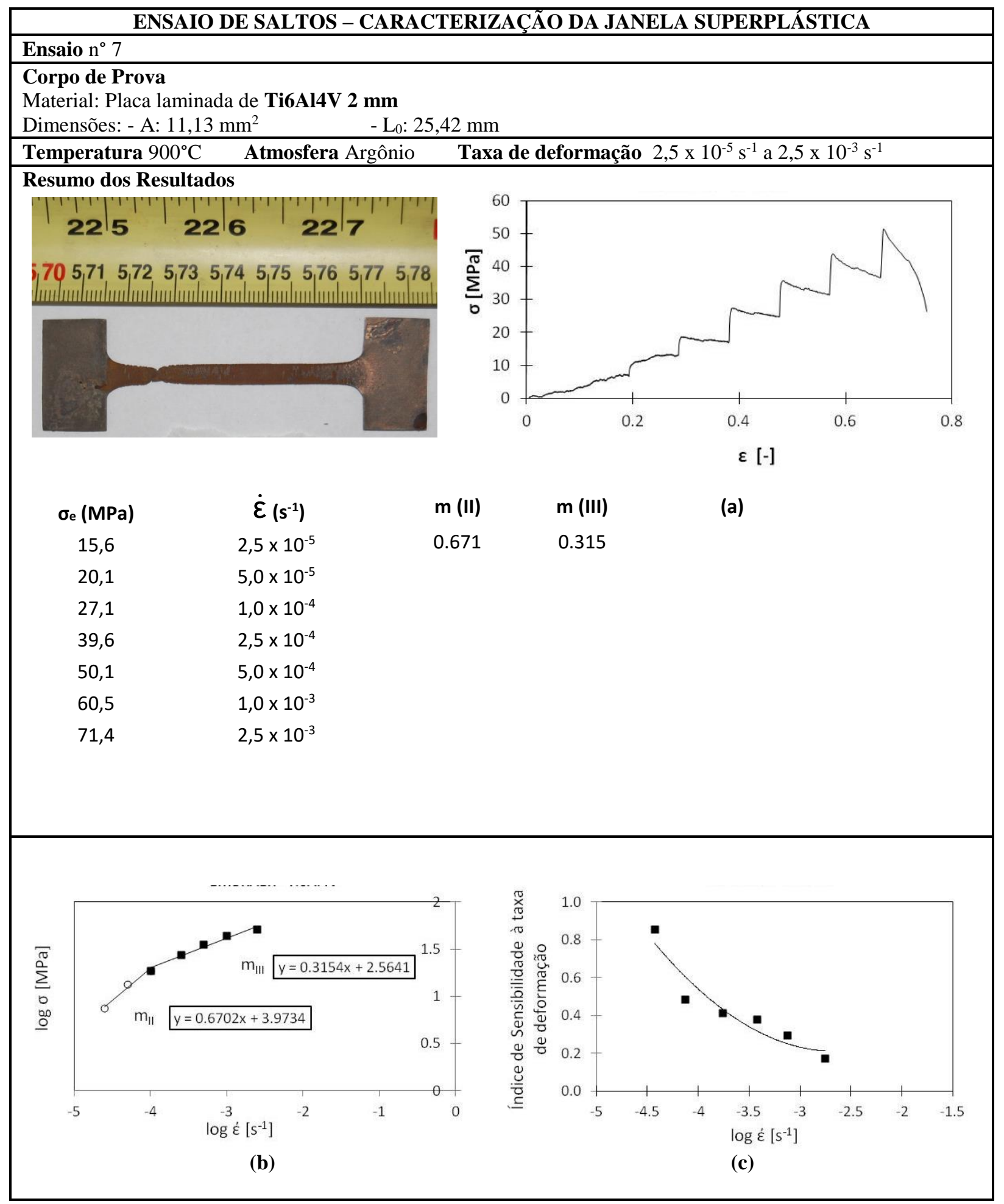




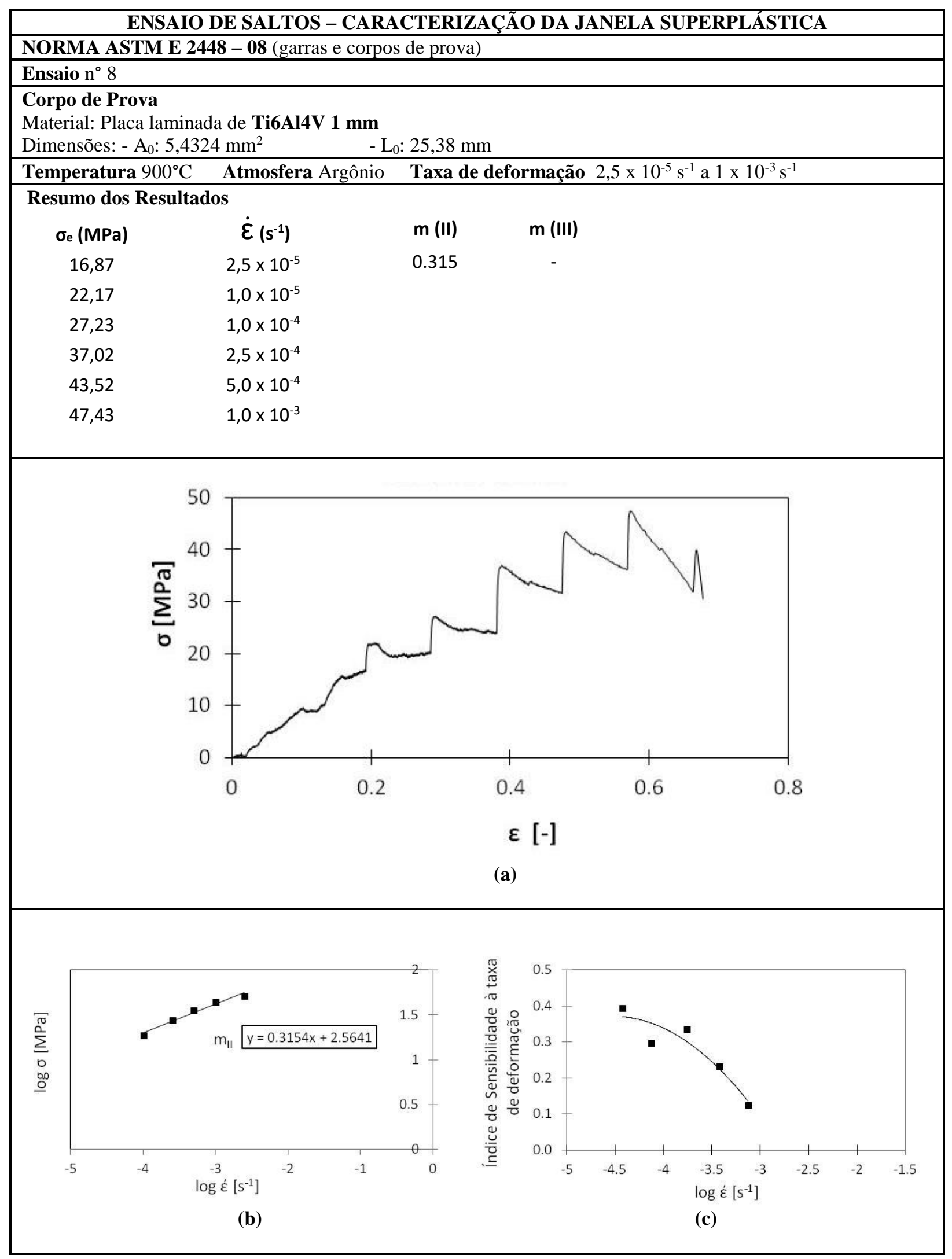




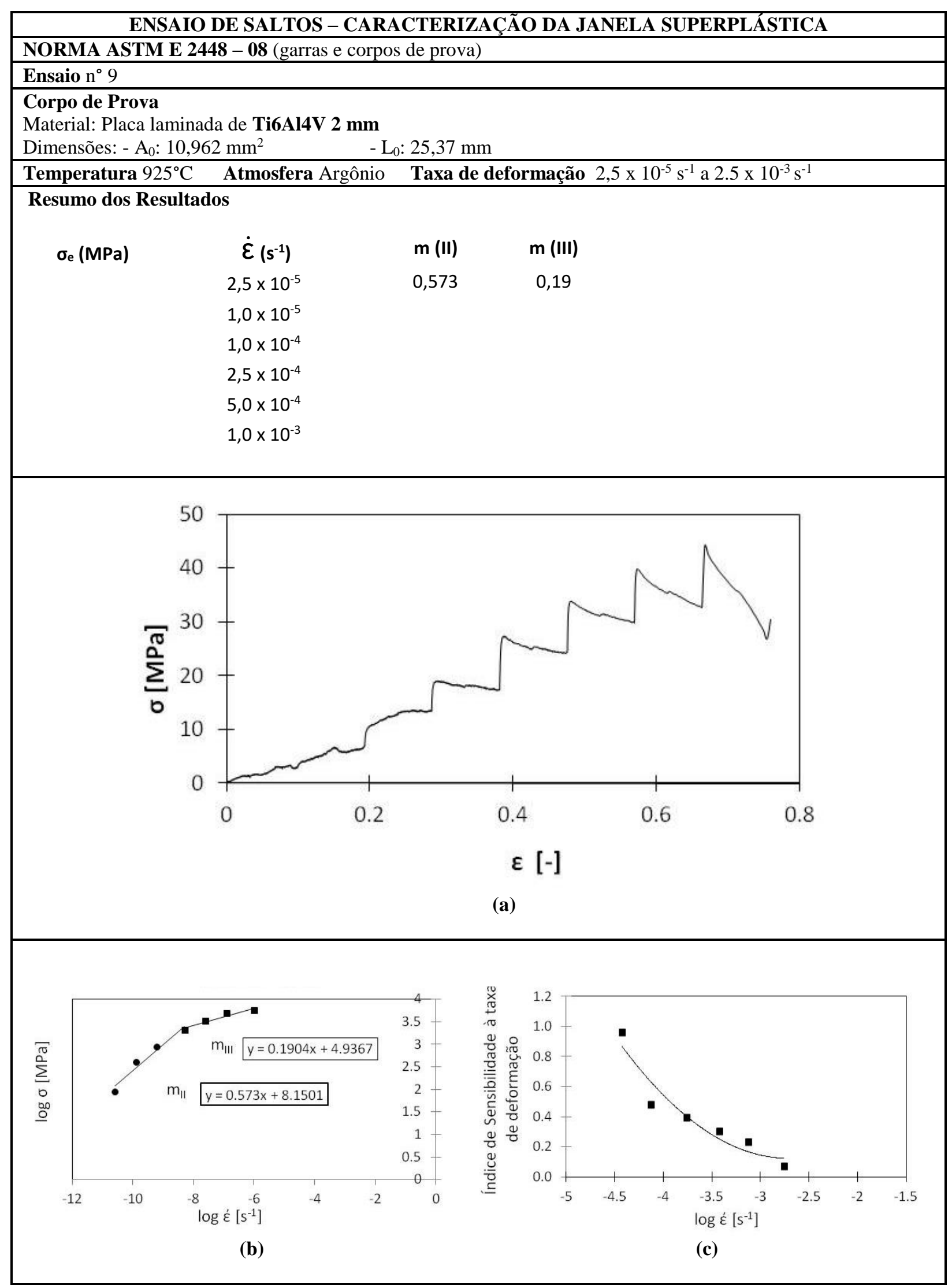


ENSAIO DE SALTOS - CARACTERIZAÇÃO DA JANELA SUPERPLÁSTICA

NORMA ASTM E 2448 - 08 (garras e corpos de prova)

Ensaio $\mathrm{n}^{\circ} 10$

Corpo de Prova

Material: Placa laminada de Ti6Al4V 1 mm

Dimensões: - $\mathrm{A}_{0}: 4,9894 \mathrm{~mm}^{2}$

$-\mathrm{L}_{0}: 25,6 \mathrm{~mm}$

Temperatura $925^{\circ} \mathrm{C} \quad$ Atmosfera Argônio Taxa de deformação $2,5 \times 10^{-5} \mathrm{~s}^{-1}$ a $2.5 \times 10^{-4} \mathrm{~s}^{-1}$

Resumo dos Resultados

$\begin{array}{cccc}\sigma_{\mathrm{e}}(\mathrm{MPa}) & \dot{\varepsilon}\left(\mathbf{s}^{-1}\right) & \mathbf{m} \text { (II) } & \mathbf{m} \text { (III) } \\ 17,8 & 2,5 \times 10^{-5} & 0,322 & - \\ 24,6 & 1,0 \times 10^{-5} & & \\ 29,5 & 1,0 \times 10^{-4} & & \\ 38,1 & 2,5 \times 10^{-4} & & \end{array}$

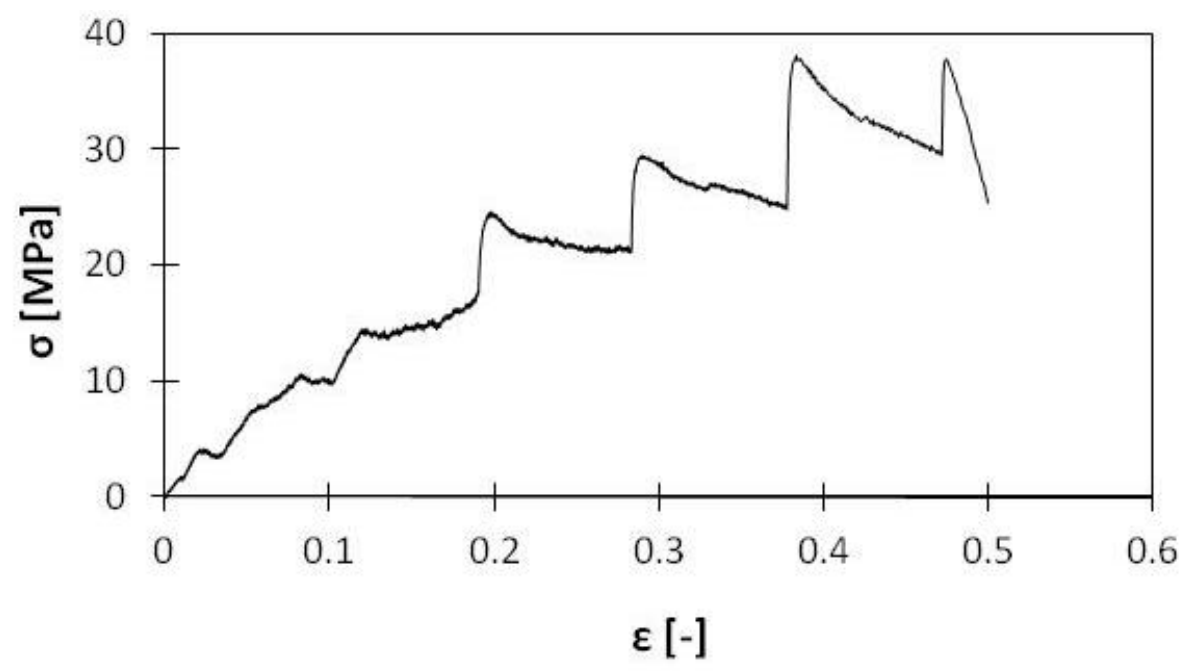

(a)

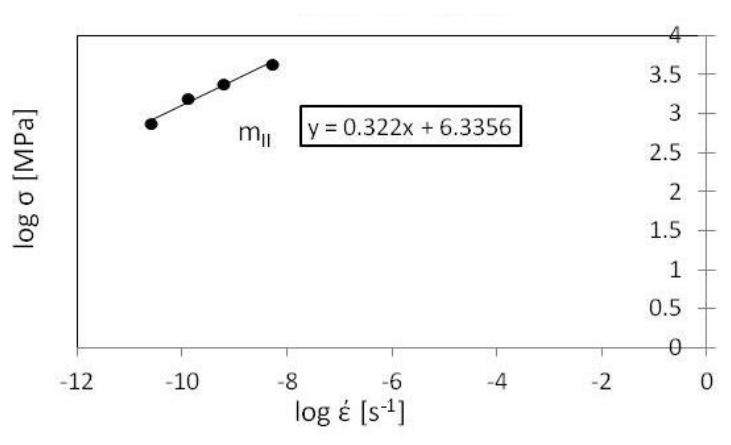

(b)

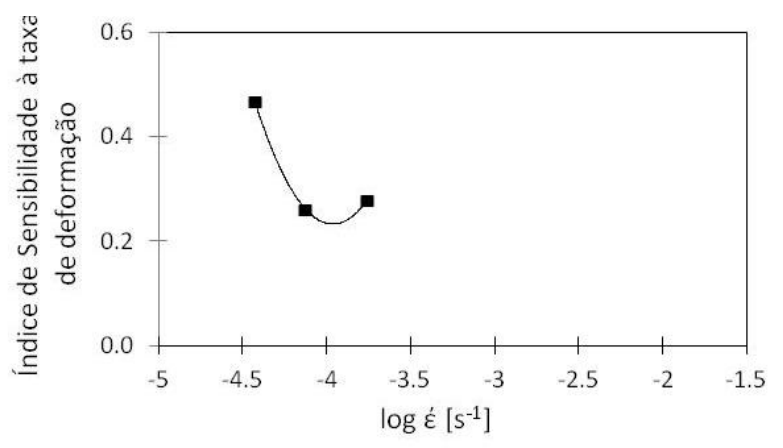

(c) 


\subsection{ANEXO II - As bases da deformação utilizada no ARAMIS}

No software da GOM - Empresa que produz o sistema de correlação digital de imagem ARAMIS, a nomenclatura utilizada para as variáveis seguem a convenção alemã e podem ser observadas no trabalho do Vulcan (VULCAN, 2006)

Deformação de engenharia: $\varepsilon$

Logaritmo da deformação verdadeira: $\varphi$

Com as técnicas de medição ótica, as coordenadas, deformações e tensões são determinadas somente na superfície dos objetos medidos, dessa forma não seria possível calcular o tensor de deformação 3D completo sem realizar o cálculo da variação de espessura, baseado na premissa de um modelo sem escorregamento da chapa em relação à matriz, que caracteriza um modelo de volume constante.

\subsubsection{Conceito básicos do cálculo de deformação 2D}

\subsubsection{O termo deformação}

Deformação é a medida de quanto um elemento linear se deforma. (TOMANEK, 2006)

$$
\lambda=\lim _{n \rightarrow 0}\left(\frac{l+\Delta l}{l}\right)^{n}
$$

A relação de estiramento $\lambda$ é a elongação relativa de um elemento de linha infinitesimal. E o valor da deformação de engenharia $(\varepsilon)$ pode ser definido em função de $\lambda$.

Deformação técnica:

$$
\varepsilon^{T}=f(\lambda)=\lambda-1
$$

Deformação logarítmica ou verdadeira:

$$
\varepsilon^{L}=\varphi=f(\lambda)=\ln (\lambda)
$$


Deformação de Green

$$
\varepsilon^{G}=f(\lambda)=\frac{1}{2}\left(\lambda^{2}-1\right)
$$

A relação de estiramento é usada para o caso unidimensional à descrição geral de medição de deformação. Essa ideia será estendida para o caso bidimensional.

\subsubsection{O tensor gradiente de deformação}

Com objetivo de representar quantitativamente a deformação de um elemento de superfície, o tensor gradiente de deformação $F$ é introduzido. O tensor gradiente de deformação transforma um elemento de linha $d X$ em um elemento de linha $d x$. Em ambos os casos, o elemento de linha conecta as mesmas coordenadas do material. Teoricamente, esse elemento deve ser um elemento de linha infinitesimal. A Figura 10.1 ilustra esse caso.

(a)

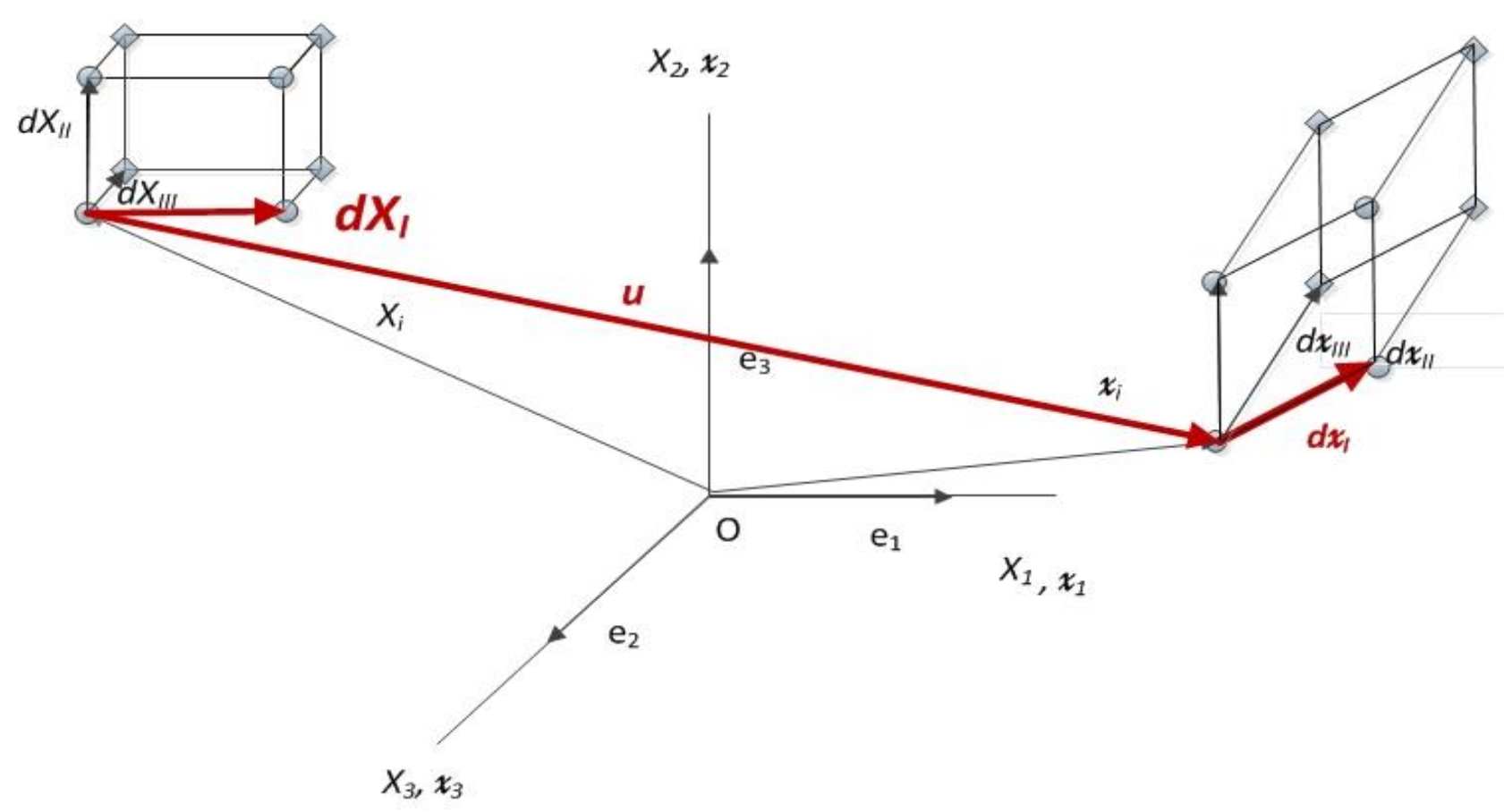

Figura 10.1. Translação (u) e deformação de um elemento de linha

Dessa forma, o tensor gradiente de deformação define-se como: 


$$
d x=F \cdot d X
$$

A desvantagem do tensor gradiente de deformação é que a Rotação e o estiramento são modelados usando uma única matriz. Esse fato pode ser contornado dividindo o gradiente de deformação em dois tensores, uma matriz de rotação pura e uma matriz de estiramento puro. A matriz pode ser decomposta de duas formas diferentes:

- Decomposição em Rotação R e tensor de estiramento a direita U.

$$
F=R \cdot U
$$

- Decomposição em tensor de estiramento à esquerda $\mathrm{V}$ e rotação $\mathrm{R}$.

$$
F=V \cdot R
$$

\subsubsection{Definição dos valores de deformação $X-Y$ em $2 D$}

Valores de $\varepsilon_{\mathrm{x}}$, $\varepsilon_{\mathrm{y}}$ e $\varepsilon_{\mathrm{xy}}$ podem ser lidos diretamente do tensor simétrico de estiramento $U$ que segue a forma:

$$
U=\left(\begin{array}{c}
U_{11} U_{12} \\
U_{21} U_{22}
\end{array}\right)=\left(\begin{array}{cc}
1+\varepsilon_{\mathrm{x}} & \varepsilon_{\mathrm{xy}} \\
\varepsilon_{\mathrm{xy}} & 1+\varepsilon_{\mathrm{y}}
\end{array}\right)
$$

Os valores de $\varepsilon_{\mathrm{x}}$, $\varepsilon_{\mathrm{y}}$ e $\varepsilon_{\mathrm{xy}}$ tem a desvantagem de serem definidos como dependentes das coordenadas do sistema.

Para melhor entendimento tem-se o esquema de análise da deformação representado pelo tensor de estiramento U. A

Figura 10.2 ilustra o estado deformado e o não deformado devido aos valores de $\varepsilon_{\mathrm{x}}$, $\varepsilon_{\mathrm{y}}$ e $\varepsilon_{\mathrm{xy}}$. A Figura 10.3 esquematiza a definição de ângulo de cisalhamento. 

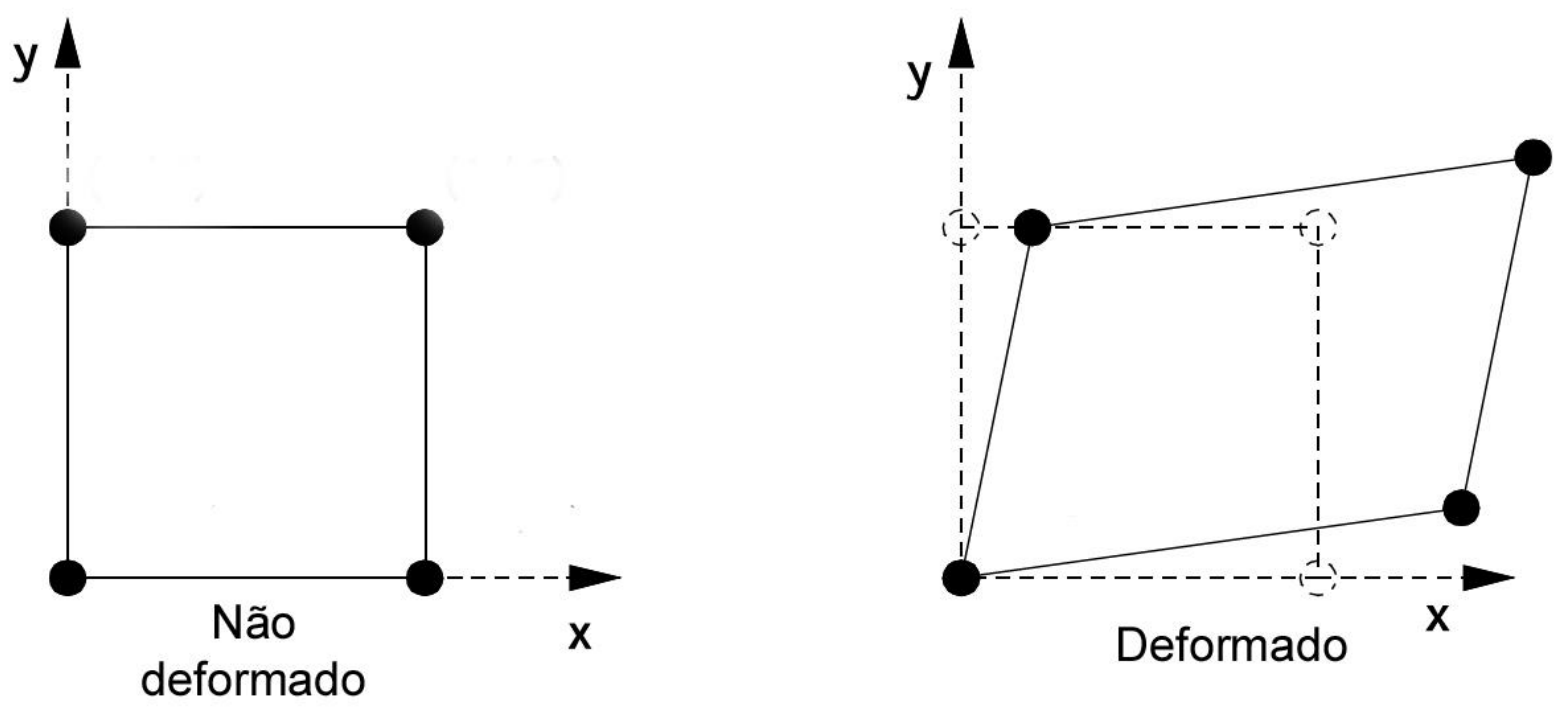

Figura 10.2 Deformação sofrida e representada pelo tensor $U$

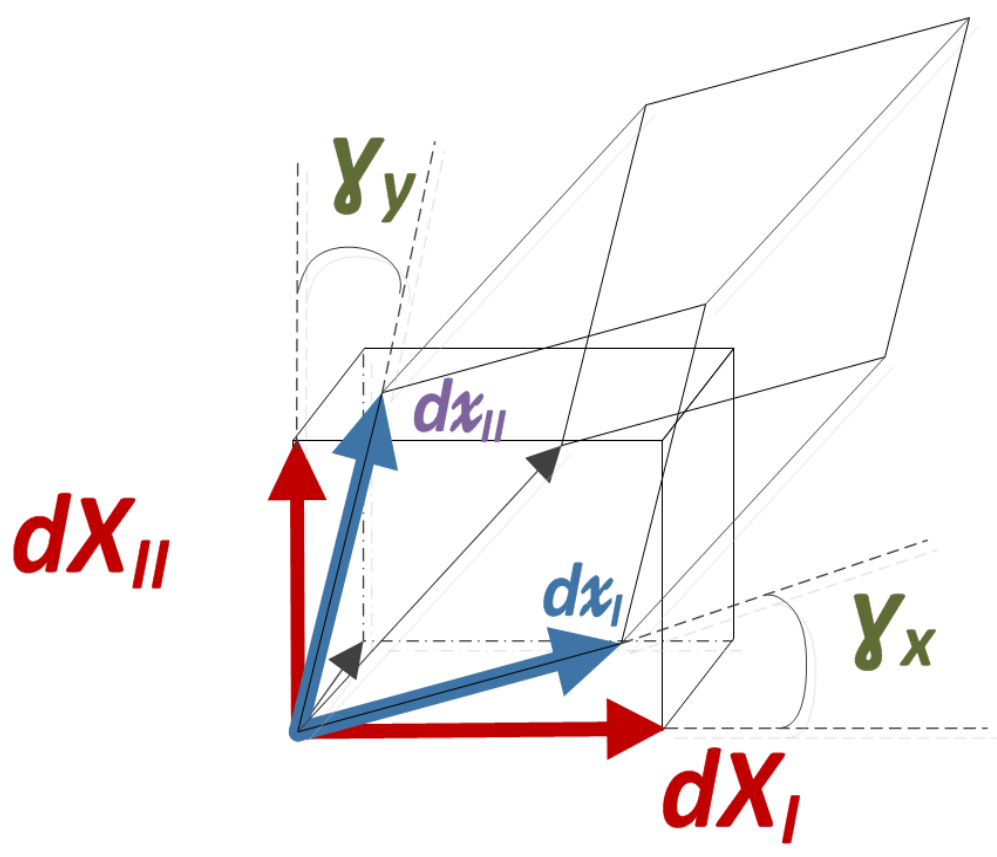

Figura 10.3 Definição de ângulo de cisalhamento

Tem-se que para pequenas deformações:

$$
\gamma_{x y}=2 . \varepsilon_{x y}
$$

Dessa forma: 


$$
\begin{gathered}
\gamma_{x y}=\gamma_{x}+\gamma_{y} \\
\gamma_{x}=\arctan \left(\frac{\varepsilon_{x y}}{1+\varepsilon_{\mathrm{x}}}\right) \\
\gamma_{y}=\arctan \left(\frac{\varepsilon_{x y}}{1+\varepsilon_{\mathrm{y}}}\right)
\end{gathered}
$$

\subsubsection{Definição do sistema de coordenada 2D e as direções de deformação}

O tensor gradiente de deformação $F$ cria uma conexão funcional entre as coordenadas dos pontos não deformados $P_{u, i}$ e as coordenadas do deformado $P_{v, i}$, sendo que $u_{i}$ é a translação do corpo rígido.

$$
P_{v, I}=u_{i}+F \cdot P_{u, I}
$$

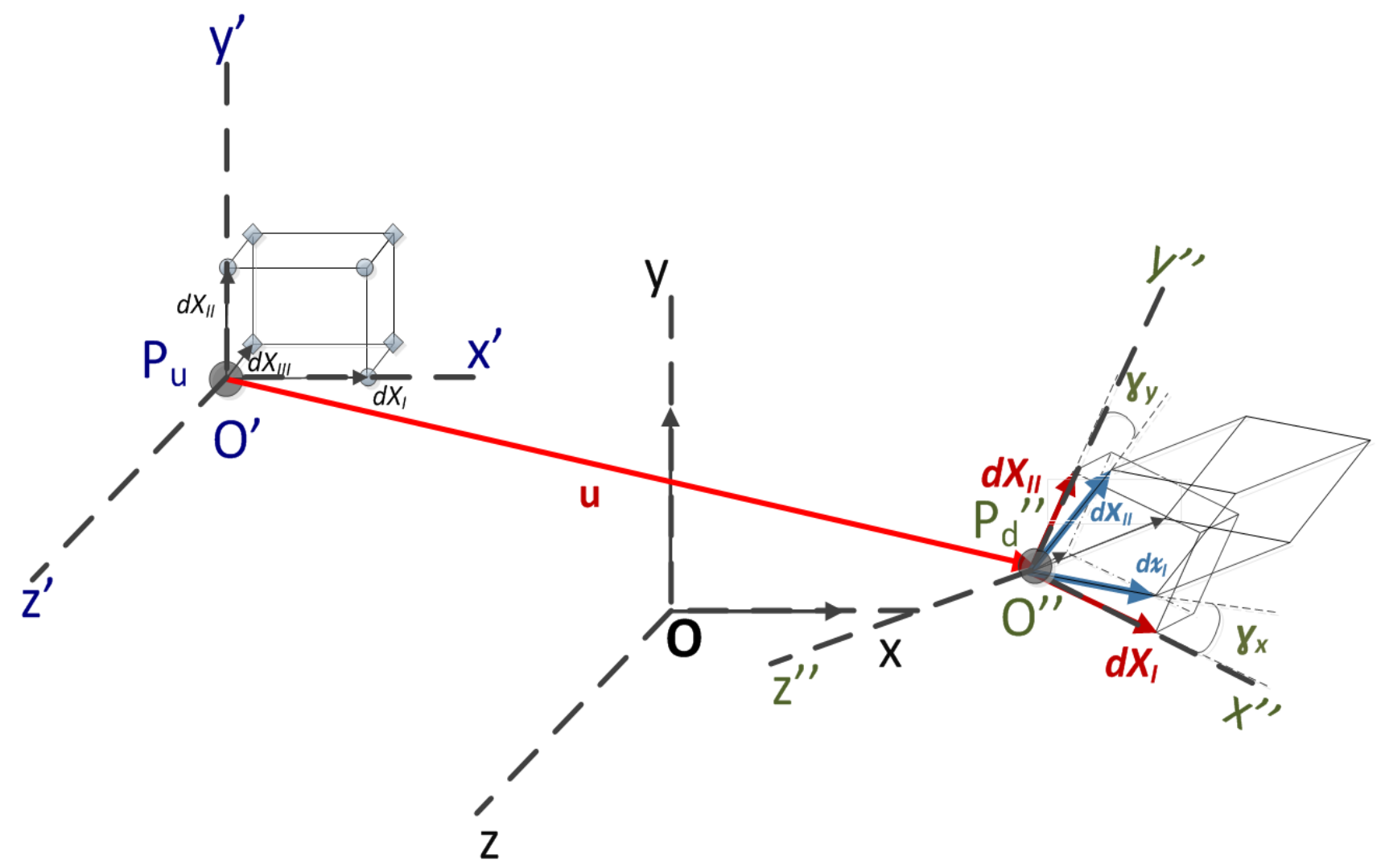

Figura 10.4 Definição do sistema de coordenadas, utilizando a deformação de uma área unitária (GOM, ARAMIS User Manual - Software - ARAMIS v6.1 and higher, 2007)

$x-y$ : Sistema de coordenadas global;

$x^{\prime}-y^{\prime}$ : Sistema de coordenada não deformada local; 
$x^{\prime \prime}-y^{\prime \prime}$ : Sistema de coordenada deformada local = direções de deformação.

As coordenadas do ponto $\mathrm{P}$ são calculadas no sistema de coordenadas global $\mathrm{x}-\mathrm{y}$. Para a discussão 2D, o sistema de coordenadas $x^{\prime}-y^{\prime}$ é paralelo ao $x-y$ e é localizado na posição não deformada do ponto do exemplo $P_{u, i}$.

A matriz de rotação $\mathrm{R}$ define a rotação do sistema $x^{\prime}-y^{\prime}$ no sistema $x^{\prime \prime}-y^{\prime \prime}$.

As coordenadas do sistema $x^{\prime \prime}-y^{\prime \prime}$ para o cálculo da deformação são independentes do movimento de corpo rígido e da rotação, representa a deformação introduzida pelo tensor de estiramento $U$ e define a direção da deformação.

\subsubsection{Deformações principais maior e menor derivadas do tensor gradiente de deformação}

As deformações $\varepsilon_{\mathrm{x}}$ e $\varepsilon_{\mathrm{y}}$ tem a desvantagem de serem definidas como dependentes das coordenadas do sistema, para eliminar esse problema, calculam-se as deformações principais maiores e menores. A matriz $U$ pode ser colocada na sua forma diagonal e teria como seus dois autovalores $\lambda_{1} e \lambda_{2}$.

$$
\lambda_{1,2}=1+\frac{\varepsilon_{\mathrm{x}}+\varepsilon_{\mathrm{y}}}{2} \mp \sqrt{\left(\frac{\varepsilon_{\mathrm{x}}+\varepsilon_{\mathrm{y}}}{2}\right)^{2}-\left(\varepsilon_{\mathrm{x}} \cdot \varepsilon_{\mathrm{y}}-\varepsilon_{\mathrm{xy}}{ }^{2}\right)}
$$

Os correspondentes autovetores determinam as direções das deformações principais maiores e menores. As deformações calculadas dessa forma são independentes das coordenadas do sistema.

Como as técnicas de medições óticas usadas não são capazes de obter dados na dimensão da espessura, a terceira deformação principal $\varepsilon_{3}$ pode ser calculada através das deformações maiores e menores principais $\left(\varepsilon_{1} e \varepsilon_{2}\right)$, caso seja assumido conservação de volume, relação (140) (TOMANEK, 2006)(VULCAN,2006)

$$
\lambda_{1} \cdot \lambda_{2} \cdot \lambda_{3}=1
$$

Frequentemente as deformações verdadeiras são necessárias. E de acordo com von Mises e von Tresca, segue: 


$$
\begin{gathered}
\varphi_{V}=\sqrt{\frac{2}{3}}\left(\varphi_{1}^{2}+\varphi_{2}^{2}+\varphi_{3}^{2}\right) \\
\varphi_{V}=|\varphi|_{\max }
\end{gathered}
$$

\subsubsection{Cálculo do tensor gradiente de deformação utilizando o campo de deslocamento 2D}

As coordenadas 2D de cada ponto devem ser conhecidas em ambos estados, deformado e não deformado.

A definição de tensor gradiente de deformação F explica como um elemento de linha não deformado é transformado em um deformado. Para calcular o tensor gradiente de deformação para um ponto, o conhecimento de certo número de pontos na vizinhança é necessário. Para esse modelo de cálculo, um estado homogêneo de deformação deve ser assumido para esse conjunto de pontos adjacentes.

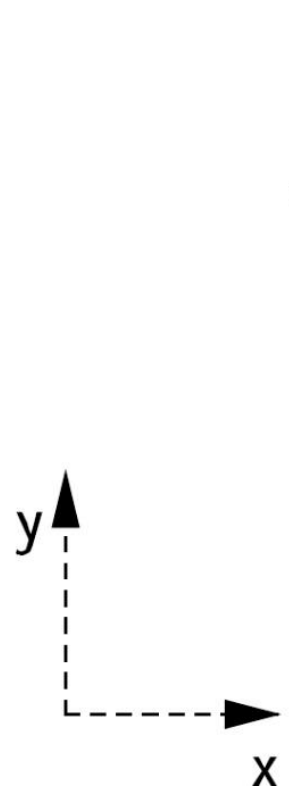

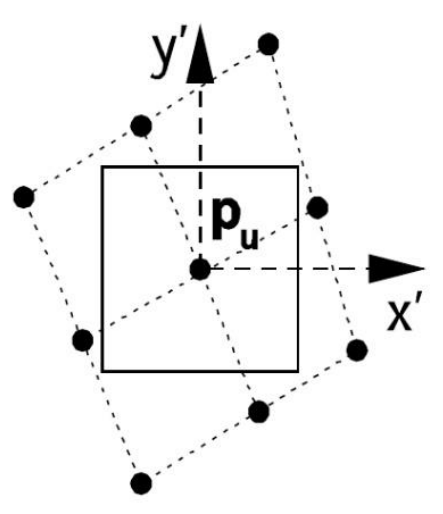

Estado não deformado

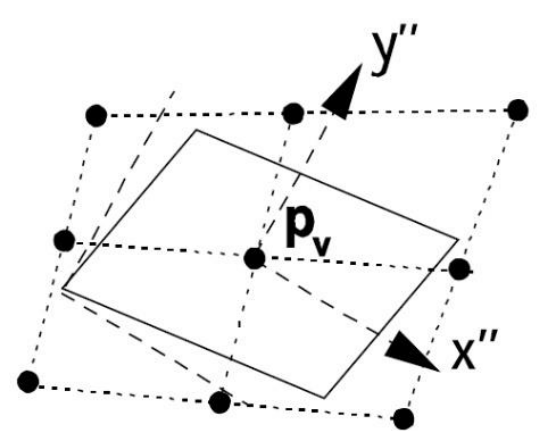

Estado deformado

Figura 10.5 Análise da vizinhança para cálculo da deformação 2D (GOM, 2007)

Para a Figura 10.5 Análise da vizinhança para cálculo da deformação 2D (GOM, 2007), valem as seguintes definições:

- Linhas tracejadas são as coordenadas do sistema: 
$x-y$ : Sistema de coordenadas global;

$x^{\prime}-y^{\prime}$ : Sistema de coordenada não deformada local;

$x^{\prime \prime}-y^{\prime \prime}$ : Sistema de coordenada deformada local = direções de deformação.

- Linhas pontilhadas formam a região dos pontos medidos;

- Linha cheia representa a unidade de área deformada e não deformada.

Para o cálculo de $F$, o sistema de coordenada $x^{\prime}-y^{\prime}$ é usado, e as coordenadas da região de pontos da vizinhança deformada devem ser trasladadas tal que o ponto $P_{V}$ (ponto de estudo deformado) coincida com a origem do sistema $x^{\prime}-y^{\prime}$ (não deformado, posição do ponto $P_{u}$ ).

\subsubsection{Definições dos valores de deformação X-y e das direções de deformação em} 3D

Para utilizar os modelos de cálculos definidos acima em 2D para os cálculos em 3D, uma definição estendida para as direções locais é necessária.

O sistema de coordenadas das deformações local deve ser tangencial a superfície local, e para o cálculo da deformação os dados em 3D devem ser transformados em um espaço 2D. 


\subsubsection{Definição das direções de deformação em 3D}

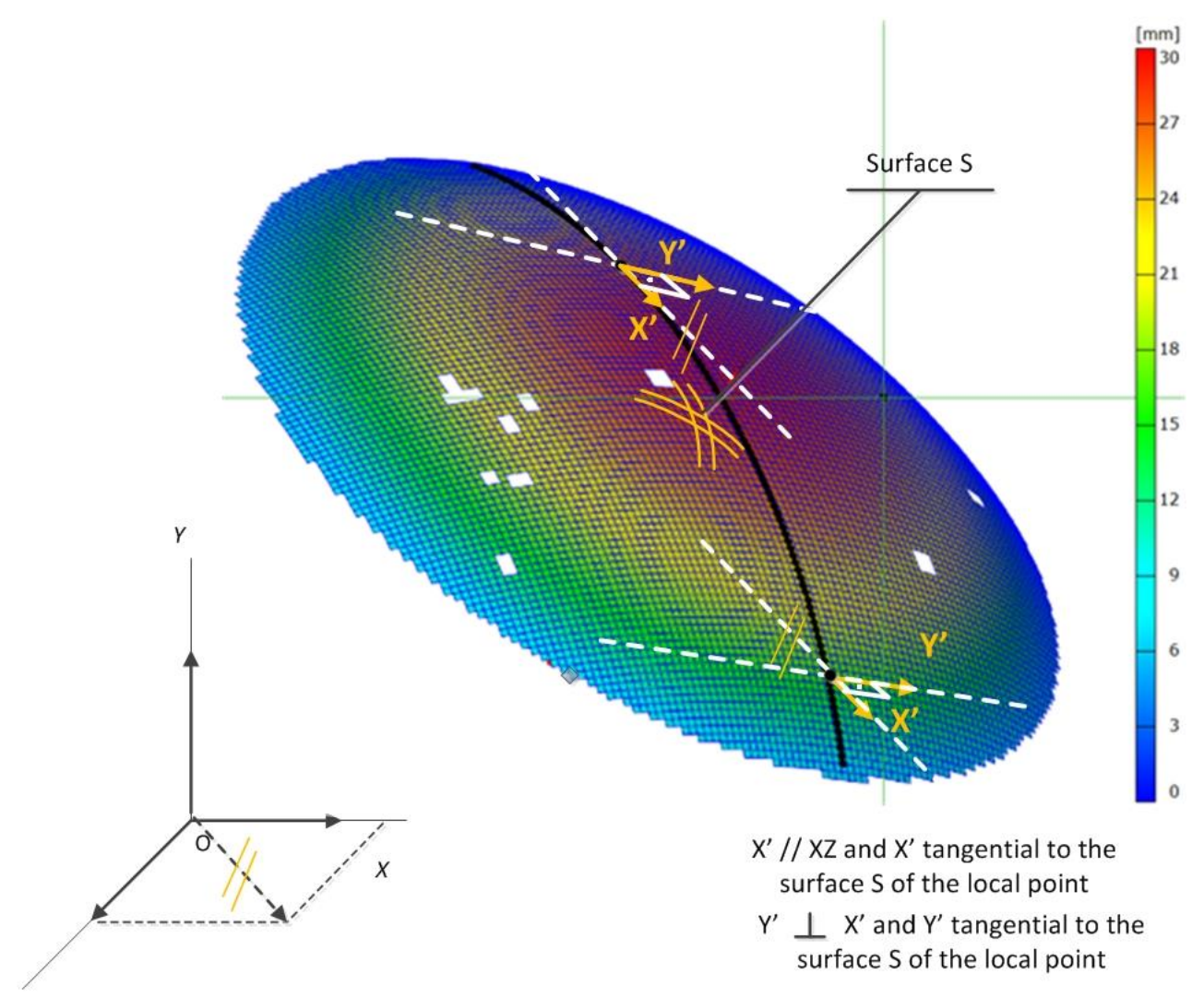

Figura 10.6 Definição do sistema 3D de coordenada de deformação da superfície local não deformada (GOM, ARAMIS User Manual - Software - ARAMIS v6.1 and higher, 2007)

O sistema de coordenadas global $x-y-z$ não pode ser usado para valores de deformações locais. $O$ sistema $x-y-z$ geralmente não é paralelo às direções tangenciais locais. Para o cálculo da deformação local no ARAMIS um sistema de coordenadas $x^{\prime}-y^{\prime}$ é definido para o estado não deformado da seguinte forma: Para cada ponto a direção $x^{\prime}$ é tangencial a superfície do ponto local e paralelo ao plano $x-z$, como também a direção $y^{\prime}$ é tangencial a superfície do ponto local e perpendicular ao $\mathrm{x}^{\prime}$ local, conforme pode ser observado na Figura 4. Para o estado deformado deve-se novamente ser introduzido um sistema de coordenadas $x^{\prime \prime}-y^{\prime \prime}$ como mostrado na Figura 10.6. No estado deformado, as direções de deformações $x^{\prime \prime}-y^{\prime \prime}$ ainda são tangentes a superfície nos pontos 3D locais e são definidas pelo tensor de cisalhamento do mesmo modo que na situação 2D. A área unitária é deformada em um paralelogramo. A geometria do paralelogramo juntamente com o tensor de cisalhamento $\left(\gamma_{1}\right.$ e $\left.\gamma_{2}\right)$ define as direções de deformações locais $x^{\prime \prime}$ e $y^{\prime \prime}$ no estado deformado. 


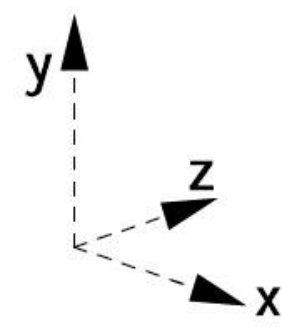

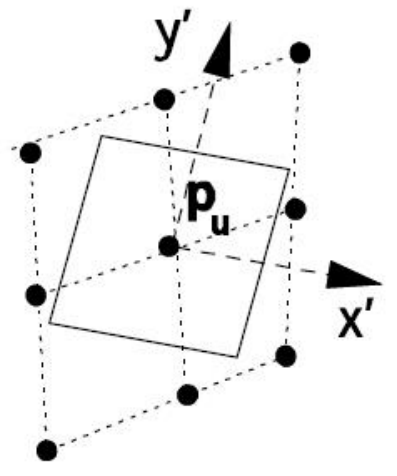

Estado não deformado

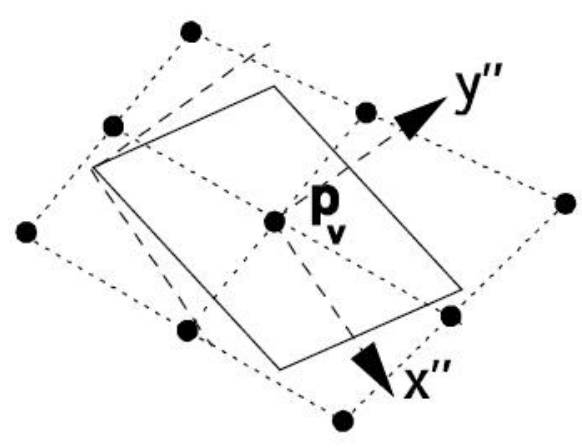

\section{Estado} deformado

Figura 10.7 Definição do sistema 3D de coordenada de deformação da superfície local (GOM, ARAMIS User Manual - Software - ARAMIS v6.1 and higher, 2007)

Os dados 3D devem ser transformados em um espaço 2D, e para isso, há dois diferentes modelos que podem ser usados. Esses modelos são baseados em planos e splines.

\subsubsection{O modelo Plano}

Esse primeiro modelo assume que a vizinhança local do ponto pode ser bem aproximado por um plano tangente. Em razão da deformação arbitrária da superfície, o plano tangente precisa ser calculado separadamente, tanto para o estado deformado, quanto para o estado não deformado.

Os pontos na vizinhança local são então projetados perpendicularmente no plano tangencial. O resultado são dois grupos de pontos no espaço bidimensional, no qual as deformações podem ser agora calculadas. 


\section{Cálculo do plano tangencial}

Transformação dos pontos vizinhos 3D no plano

tangente

Transformação de coordenada dos planos

tangentes no espaço 2D (sistemas de coordenadas

$x^{\prime}-y^{\prime}$ e $\left.x^{\prime \prime}-y^{\prime \prime}\right)$

Cálculo do tensor gradiente de deformação para o

grupo 2D de pontos

Figura 10.8 Etapas de cálculos necessários para cálculo das deformações

\subsubsection{O modelo Spline}

O modelo tangencial descrito acima produz bons resultados caso a premissa da linearização dos pontos vizinhos locais seja válida. Caso contrário é necessário ter mais informações que dois vizinhos, isso significa que pontos adjacentes de uma faceta de lado 4 deve ser incluída nos cálculos.

Na faceta - Figura 10.9, os comprimentos dos lados são calculados usando formas splines. Os comprimentos resultantes podem ser usados para construir um quadrado no espaço bidimensional.

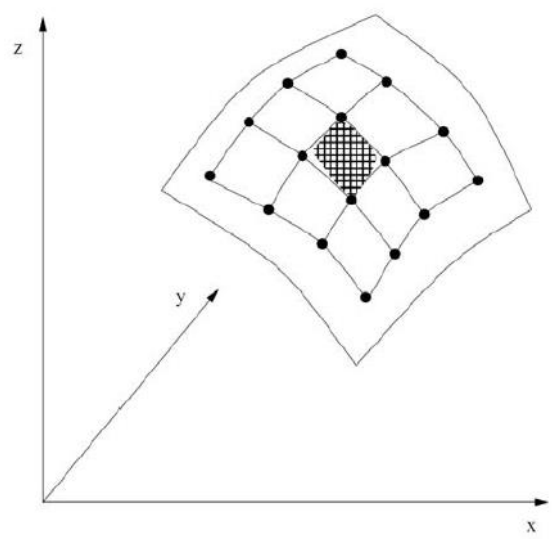

Figura 10.9 Faceta de lado 4 com pontos adjacentes 


\subsection{ANEXO III - Resumo das funcionalidades da biblioteca do drive da ADAM 6024}

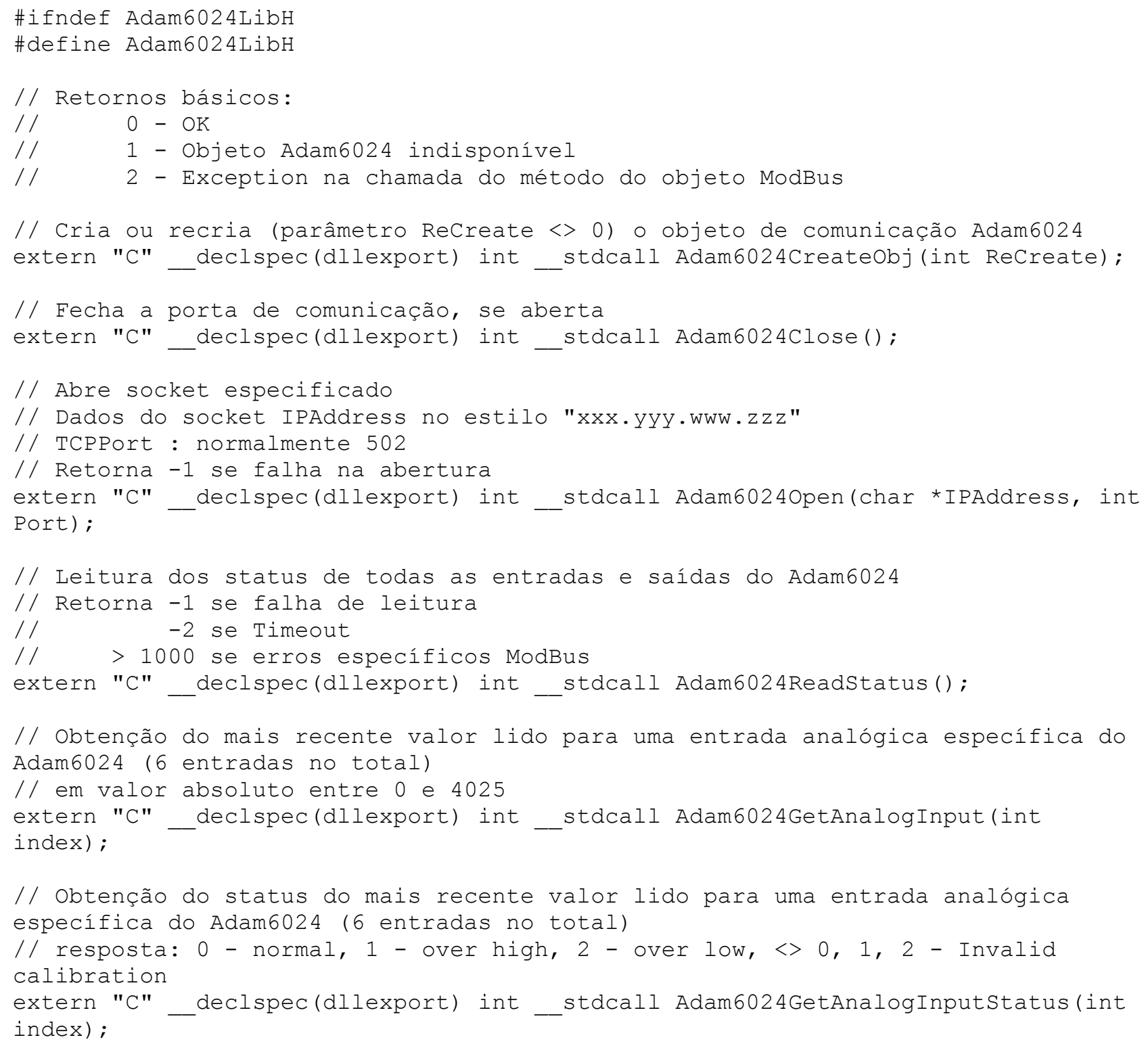


extern "C"__declspec(dllexport) int__stdcall Adam6024SetAnalogoutput (int index, int value);

// Ajuste do valor para uma saída digital específica do Adam6024 (2 saídas no total)

// em valor absoluto entre 0 (desligado) e $<>0$ (ligado)

extern "C" declspec(dllexport) int_stdcall Adam6024SetDigitaloutput(int

index, int value);

// Obtenção de um valor de registrador previamente lido

// dado o endereço do registrador (Register)

// Retorna -1 se registro indisponível

extern "C"__declspec(dllexport) int__stdcall Adam6024GetRegisterValue(int

Register);

// Obtenção da mais recente mensagem de erro disponível

// dada uma matriz de caracteres e seu tamanho máximo (a ser preenchida pela função)

extern "C"__declspec(dllexport) int__stdcall Adam6024GetLastErrorMessage (char *Message, int Size);

// Obtenção do número de erros ocorridos desde a abertura da porta de comunicação

extern "C" declspec(dllexport) int stdcall Adam6024GetErrorCounter();

\#endif 


\subsection{ANEXO IV - Programa de geração de curva teste de pressurização}

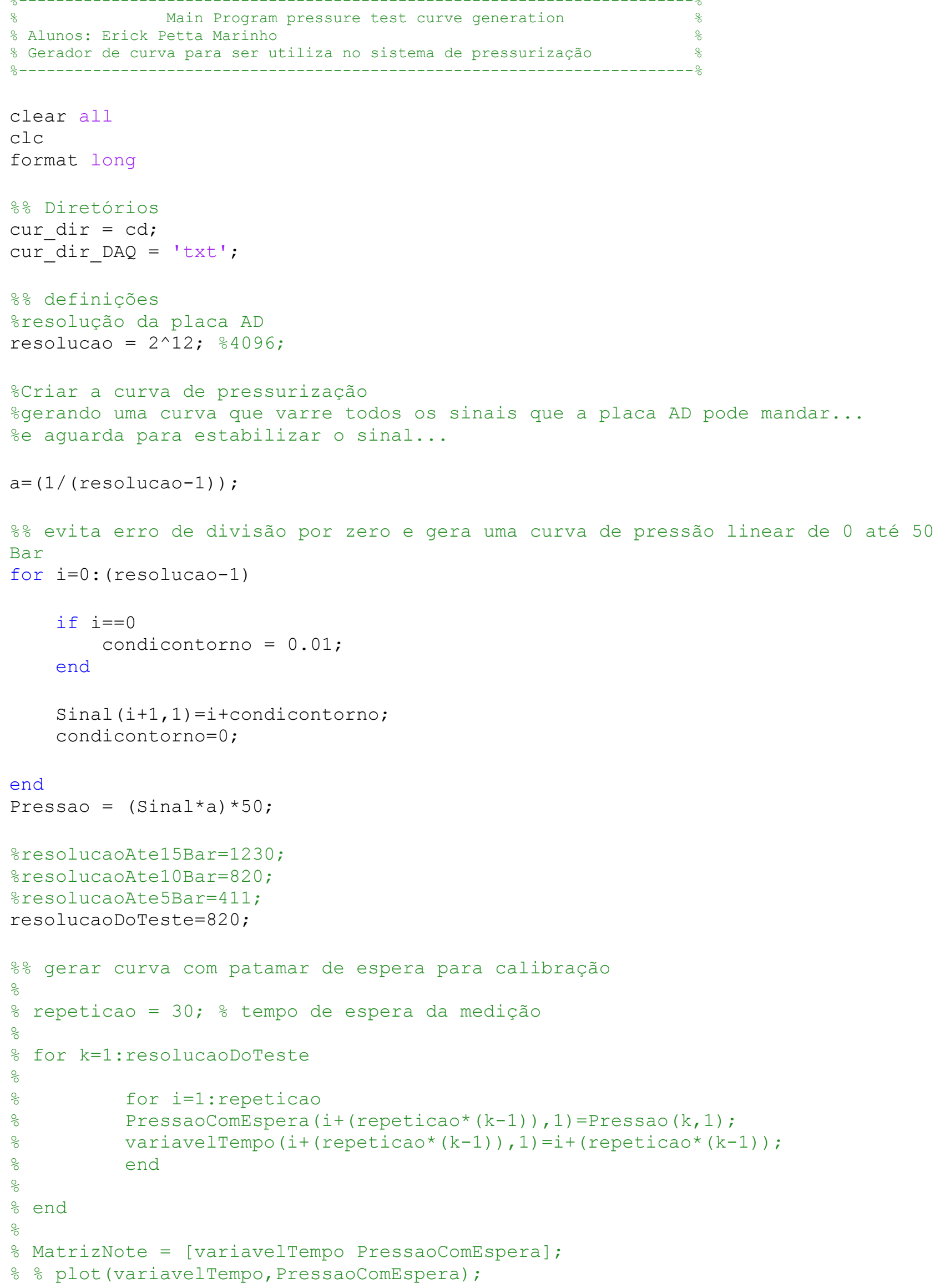


\% controle do tempo de cada ensaio

\% TempoDeEnsaioEmMinutos=repeticao*resolucaoDoTeste* $(1 / 60)$;

응 Leitura de dados txt (tempoxpressao Medidos)

cd (cur_dir_DAQ)

AUX.tempo = load (['tempo' '.txt']);

AUX.pressao $=\operatorname{load}([$ 'pressão' '.txt']);

$[i, j]=\operatorname{size}($ AUX.tempo);

$\mathrm{DAQ}$. resultado $=\operatorname{zeros}(i, 2)$;

$\mathrm{DAQ}$. resultado $(:, 1)=$ AUX.tempo;

DAQ.resultado $(:, 2)=$ AUX.pressao;

응 Ajuste da curva medida para a pressão absoluta.

ㅁ Diferenca $=1$; $\frac{\circ}{0}$ Entre pressão absoluta a relativa

ㅇ DAQ.resultado $(:, 2)=\mathrm{DAQ}$. resultado $(:, 2)+$ Diferenca;

응 Plot da curva que foi pressurizada e da aquisitada

LimitePressao=10; $\circ$ Bar

scrsz $=\operatorname{get}(0$, 'Screensize');

Fig = figure('name', ['plot da curva que foi pressurizada com o grafico do

PbSn'], 'Position', [scrsz(3)/4 scrsz(4)/5 $3 * \operatorname{scrsz}(3) / 53 * \operatorname{scrsz}(4) / 4])$;

$\mathrm{p} 1=$ plot $(\mathrm{DAQ}$.resultado $(:, 1), \operatorname{DAQ} \cdot$ resultado $(:, 2))$;

set (p1, 'Color', 'blue', 'LineWidth', 1.5)

hold

$\div \mathrm{p}=$ plot (variavelTempo, PressaoComEspera);

grid on

oset (p, 'Color', 'red', 'LineWidth', 1.5)

otitle('plot',12);

xlabel ('Tempo em segundos','FontSize',9);

ylabel ('Pressao Relativa em Bar ','FontSize',9);

oaxis equal;

saveas (Fig, ['C: \Users \erickfalcone \Dropbox \Dropbox \Catman VBA \PbSn' 'PbSn.jpg'] ); 


\subsection{ANEXO V - Script em VBA do sistema de atuação/aquisição}

\section{VARIAVEIS}

'Variáveis globais

Public gDblCurvaPressao() As Double

Public gDblCurvaTempo() As Double

'Matriz de elementos do programa de pressão (Pressão)

Public gDblUltimaPressaoEscrita As Double

'Matriz de elementos do programa de pressão (Tempo)

'Declaração das funções do Adam6024

Declare Function Adam6024Open Lib "Adam6024Lib.dll" (ByVal IPAddress As String, ByVal Port As Long) As Long Declare Function Adam6024Close Lib "Adam6024Lib.dll" As Long

Declare Function Adam6024SetAnalogOutput Lib "Adam6024Lib.dll" (ByVal index As Long, ByVal Value As Long) As Long

Declare Function Adam6024GetLastErrorMessage Lib "Adam6024Lib.dll" (ByVal Message As String, ByVal Size As Long) As Long

Sub Main

'EA_Panel.SetValue(ByVal Panel As Variant, ByVal ObjName as String, ByVal NewValue As Variant) As

Long

EA_Panel.SetValue 1, "txtMessages", "Inicialização do sistema de controle da pressão"

End Sub

Sub BeforeDAQStart

Dim ret As Long

Dim IPAddress As String

Debug.Clear

CarregarCurvaPressao

EA_Panel.SetValue 1, "txtMessages", "Curva de pressurização recebida"

IPAddress = "192.168.0.201"

ret = Adam6024Open(IPAddress, 502)

If ret $=0$ Then

Wait 0.5

gDblUltimaPressaoEscrita $=-1 \quad$ 'Invalidando para escrever o primeiro ZERO AjustaPressao 0

Else

End If

MostraMensagemErroAdam

End Sub

Sub AfterDAQStop

Erase CurvaPressao

Erase CurvaTempo

EA_Panel.SetValue 1, "txtAdamMsgs", "afterDAQStop"

AjustaPressao 0 
Wait 0.5

Call Adam6024Close

End Sub

Sub btnSetAnalogOut_OnClick

Dim Value As Variant

Dim iValue As Long

Dim ret As Long

Dim sErrorMessage As String

EA_Panel.GetValue 1, "txtAnalogOut", Value

iValue $=$ Value

ret $=$ Adam6024SetAnalogOutput $(0$, iValue $)$

If ret $<>0$ Then

sErrorMessage = "0123456789012345678901234567890123456789"

Adam6024GetLastErrorMessage sErrorMessage, 40

End If

EA_Panel.SetValue 1, "txtAdamMsgs", sErrorMessage

End Sub

Sub CarregarCurvaPressao

Dim Nomearquivo As String

Dim NumPontos As Long

Dim pos As Integer

Nomearquivo = "C:IUsersILEFA MOBILEIDropbox $\mid$ Dropbox $\backslash$ Catman VBA|Teste Adam $\backslash P b S n 1040 . t x t "$

'Nomearquivo = "C:IUsers\LEFA MOBILELDesktop\Dados_franchitttttttttttttttt|PbSn\txt|PbSn1040.txt"

NumPontos $=0$

Open Nomearquivo For Input As \#1

Do While Not EOF(1)

Line Input \#1,sLinha

NumPontos $=$ NumPontos +1

ReDim Preserve gDblCurvaPressao(NumPontos)

ReDim Preserve gDblCurvaTempo(NumPontos)

pos $=\operatorname{InStr}($ sLinha, $v b T a b)$

gDblCurvaTempo(NumPontos-1) $=$ CDbl(Mid(sLinha, 1, pos-1) $)$

gDblCurvaPressao $($ NumPontos-1) $=\operatorname{CDbl}(\operatorname{Mid}($ sLinha,pos+1, Len(sLinha $)-$ pos $))$

Loop

Close \#1

EA_Graph.PlotArrayXY(0, "GraficoCurvaPressao", 1, NumPontos, gDblCurvaTempo, gDblCurvaPressao)

GraficoCurvaPressao $=$ EA_Graph.PrintOut $(1$, GraficoCurvaPressao $)$

End Sub 
Sub AjustaPressao(Pressao As Double)

Dim iValue As Long

Dim iVoltagem As Long

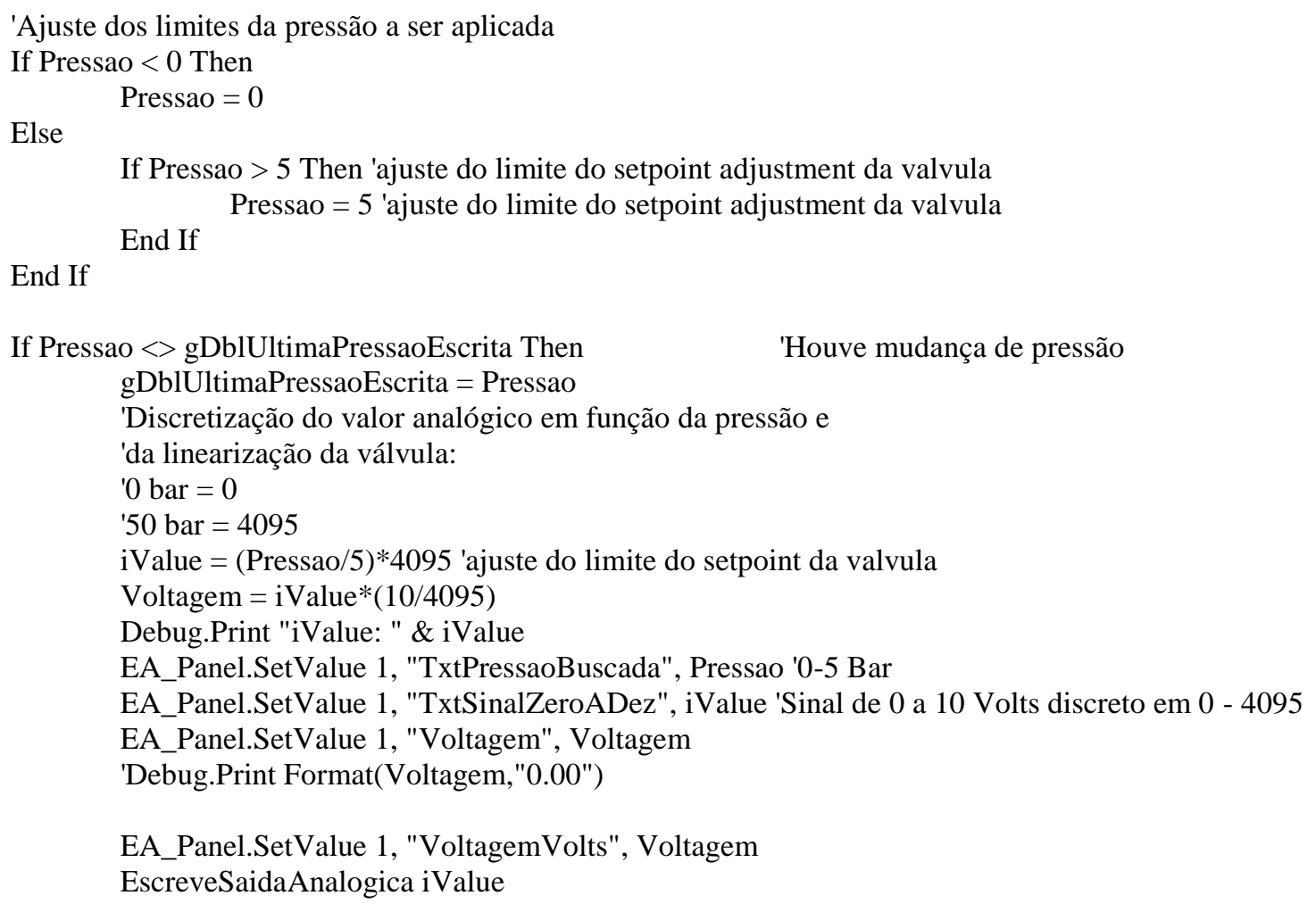

End If

End Sub

Sub EscreveSaidaAnalogica(Value As Long)

Dim ret As Long

ret = Adam6024SetAnalogOutput(1, Value)'AO1 é a usada para o controle de pressão

EA_Panel.SetValue 1, "txtAnalogOut", Value

If ret $<>0$ Then

MostraMensagemErroAdam

End If

End Sub

Sub MostraMensagemErroAdam

Dim sErrorMessage As String

sErrorMessage = "0123456789012345678901234567890123456789"

Adam6024GetLastErrorMessage sErrorMessage, 40

EA_Panel.SetValue 1, "txtMessages", sErrorMessage 
Sub AfterTransferDataBlock

Dim nPontos As Integer

Dim dTempoAtual As Double

Dim dPressao As Double

Dim ret As Integer

Dim i As Integer

Dim found As Boolean

EA_DAQ.CurrentBlockSize "Pressão", nPontos 'Obtem o número de pontos disponíveis no bloco mais recente

If nPontos > 0 Then

'obtenção do mais recente valor de tempo

ret = EA_DAQ.CurrentReading(1, dTempoAtual, DAQ_NEWEST)

'pesquisa na matriz de programa de pressão pela pressão

'adequada ao tempo decorrido

If ret $=0$ Then

nPontos $=$ UBound $(\mathrm{gDblCurvaTempo})$

$\mathrm{i}=1$ 'O primeiro elemento é o zero, começamos do segundo

found $=$ False

Do While Not found And $\mathrm{i}<\mathrm{nPontos}$

If dTempoAtual < gDblCurvaTempo(i) Then

found $=$ True

Else

End If

$$
\mathrm{i}=\mathrm{i}+1
$$

Loop

If found Then

Else

$$
\text { dPressao }=\text { gDblCurvaPressao }(\mathrm{i}-1)
$$

End If

$\mathrm{dPressao}=$ gDblCurvaPressao(nPontos-1) 'não encontrou, pega o último

Debug.Print "Tempo: " \& dTempoAtual \& " - Pressão " \& dPressao

AjustaPressao dPressao

End If

End If

End Sub 
10.6 ANEXO VII - itens utilizados na montagem da linha de alta pressão

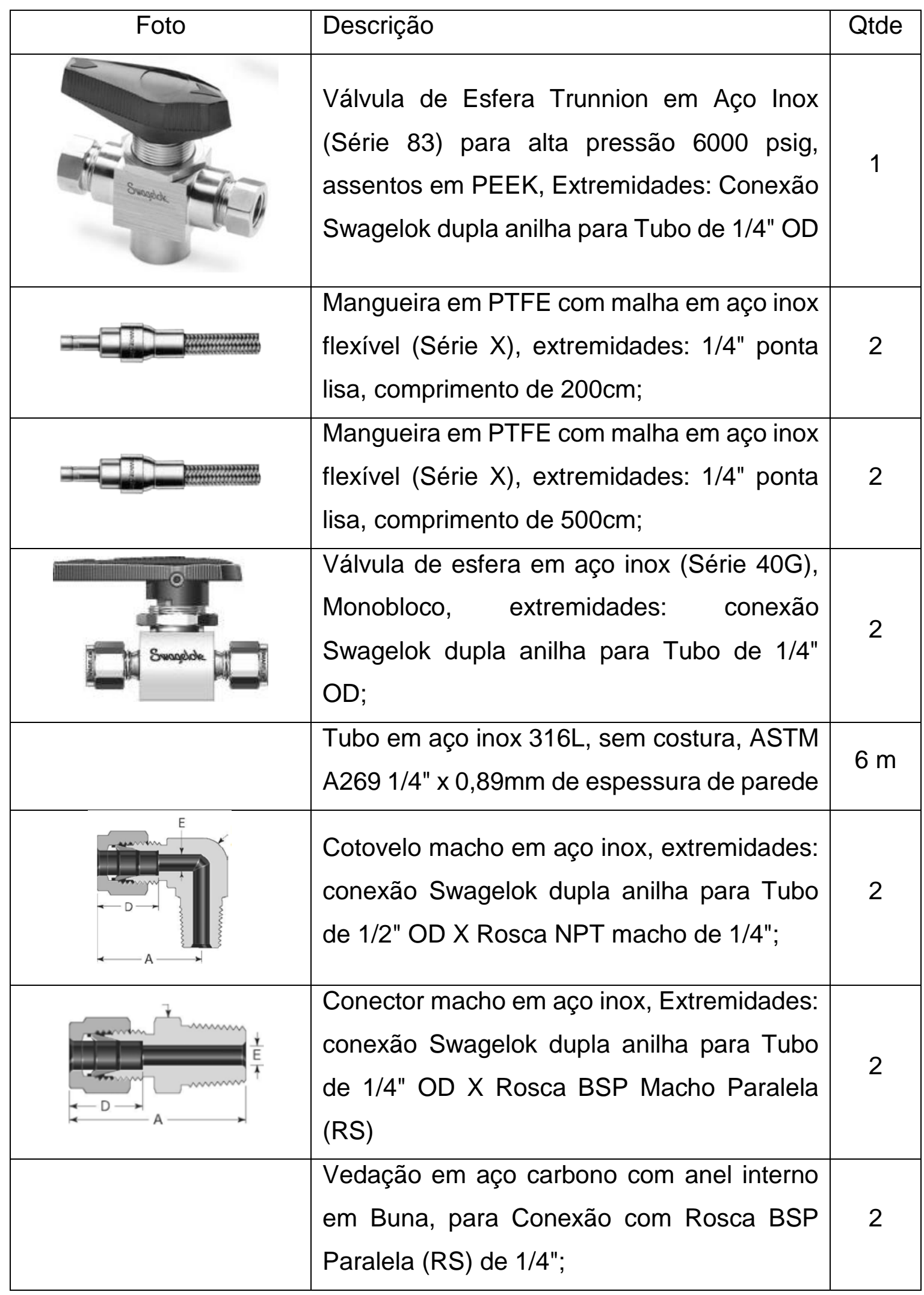




\begin{tabular}{|c|c|c|}
\hline 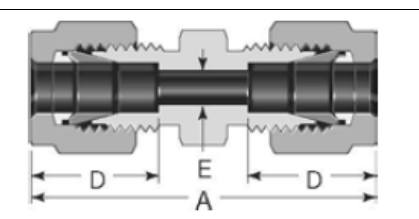 & $\begin{array}{l}\text { União em aço inox, Extremidades: conexão } \\
\text { Swagelok dupla anilha para Tubo de 1/4" } \\
\text { OD; }\end{array}$ & 2 \\
\hline . & $\begin{array}{l}\text { Tê fêmea central em aço inox, extremidades: } \\
\text { conexão Swagelok dupla anilha para Tubo } \\
\text { de 1/4" OD X conexão Swagelok dupla anilha } \\
\text { para Tubo de 1/4" OD X Rosca NPT fêmea } \\
\text { de 1/4"; }\end{array}$ & 2 \\
\hline & $\begin{array}{l}\text { Conector macho em aço inox, Extremidades: } \\
\text { conexão Swagelok dupla anilha para Tubo } \\
\text { de 1/4" OD X Rosca NPT Macho 1/4" }\end{array}$ & 1 \\
\hline & $\begin{array}{l}\text { Tê união em aço inox, Extremidades iguais: } \\
\text { Conexão Swagelok dupla anilha para Tubo } \\
\text { de } 1 / 4 \text { " OD; }\end{array}$ & 1 \\
\hline & $\begin{array}{l}\text { Port Connector em aço inox, Extremidades: } \\
\text { Port Connector de } 1 / 4 " \text { X Adaptador para } \\
\text { Tubo de } 1 / 4 \text { " OD; }\end{array}$ & 1 \\
\hline & $\begin{array}{l}\text { Válvula agulha em aço inox (Série 1) Castelo } \\
\text { Integral, Haste de Regulagem, } \\
\text { Extremidades: conexão Swagelok dupla } \\
\text { anilha para Tubo de 1/4" OD }\end{array}$ & 1 \\
\hline & $\begin{array}{l}\text { Corpo em aço inox do engate rápido (Série } \\
\text { QC), extremidade: conexão Swagelok dupla } \\
\text { anilha para Tubo de } 1 / 4 \text { " OD }\end{array}$ & 1 \\
\hline & $\begin{array}{l}\text { Espiga em Inox com retenção do engate } \\
\text { rápido (Série QC), extremidade: conexão } \\
\text { Swagelok dupla anilha para Tubo de } 1 / 4 \text { " OD }\end{array}$ & 1 \\
\hline & $\begin{array}{l}\text { Selante Anaeróbico SWAK(R) para Roscas, } \\
\text { Tubo de } 50 \mathrm{CM} 3 .\end{array}$ & 1 \\
\hline
\end{tabular}

